SANDIA REPORT

SAND96-0400 • UC-513

Unlimited Release

Printed August 1996
RECEIVED

SEP 051996

OSTI

\title{
Radiological Consequences of Ship Collisions That Might Occur in U.S. Ports During the Shipment of Foreign Research Reactor Spent Nuclear Fuel to the United States in Break-Bulk Freighters
}

Jeremy L. Sprung, Stephen J. Bespalko, Charles D. Massey, Richard Yoshimura, Jay D. Johnson, Philip C. Reardon, Martin W. Ebert, Daniel W. Gallagher

\section{Prepared by}

Sandia National Laboratories

Albuquerque, New Mexico 87185 and Livermore, California 94550

for the United States Department of Energy

under Contract DE-AC04-94AL85000

Approved for public release; distribution is unlimited.

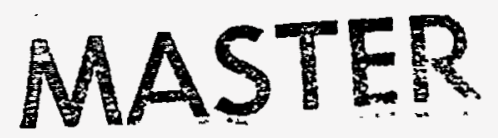


SANDIA REPORT

SAND96-0400 • UC-513

Unlimited Release

Printed August 1996
RECEIVED

SEP 051996

OSTI

\section{Radiological Consequences of Ship Collisions That Might Occur in U.S. Ports During the Shipment of Foreign Research Reactor Spent Nuclear Fuel to the United States in Break-Bulk Freighters}

Jeremy L. Sprung, Stephen J. Bespalko, Charles D. Massey, Richard Yoshimura, Jay D. Johnson, Philip C. Reardon, Martin W. Ebert, Daniel W. Gallagher

Prepared by

Sandia National Laboratories

Albuquerque, New Mexico 87185 and Livermore, California 94550

for the United States Department of Energy

under Contract DE-AC04-94AL85000

Approved for public release; distribution is unlimited.

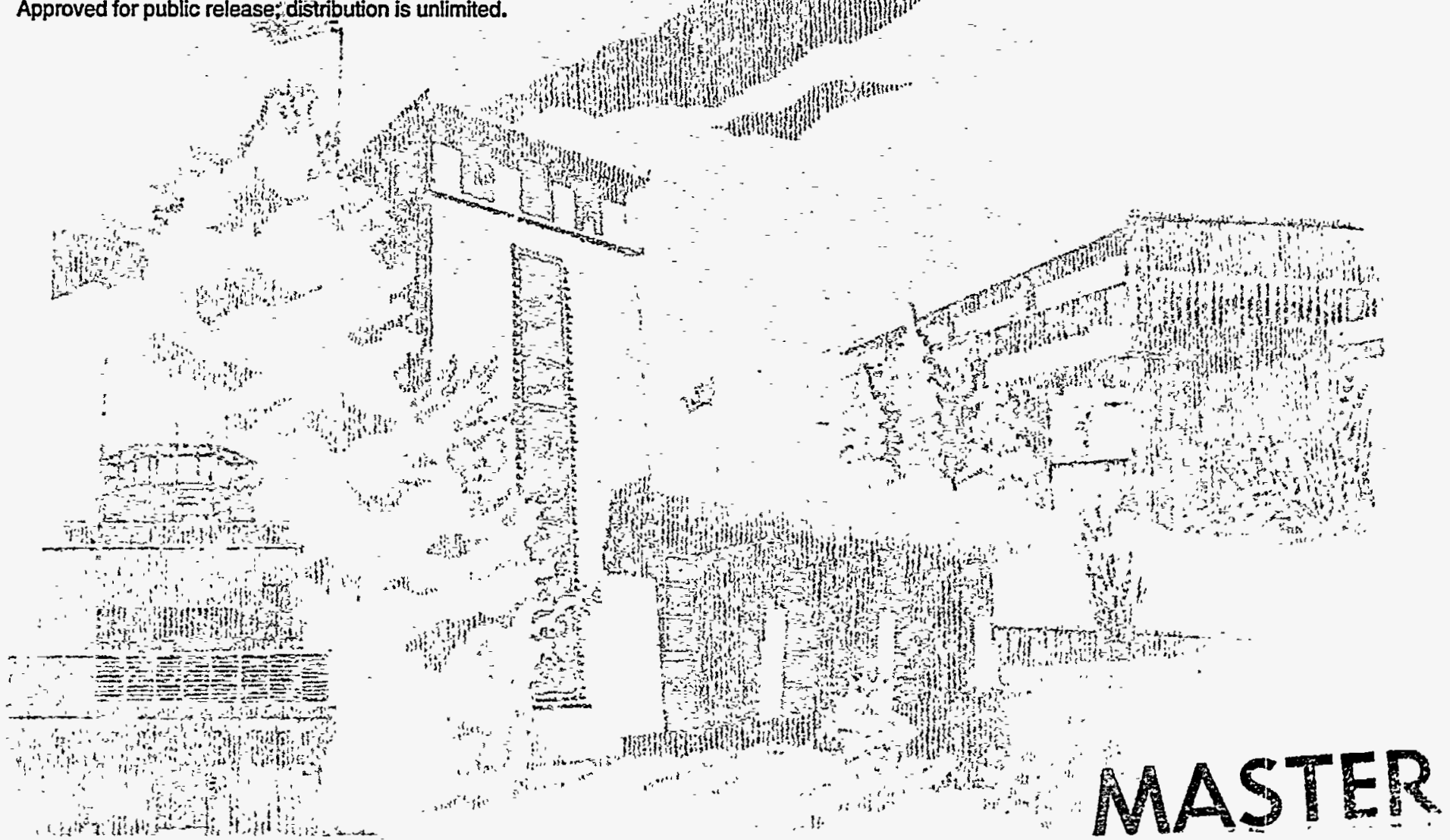


SANDIA REPORT

SAND96-0400 • UC-513

Unlimited Release

Printed August 1996
RECEIVEO

SEP 051996

OSTI

\section{Radiological Consequences of Ship Collisions That Might Occur in U.S. Ports During the Shipment of Foreign Research Reactor Spent Nuclear Fuel to the United States in Break-Bulk Freighters}

Jeremy L. Sprung, Stephen J. Bespalko, Charles D. Massey, Richard Yoshimura, Jay D. Johnson, Philip C. Reardon, Martin W. Ebert, Daniel W. Gallagher

Prepared by

Sandia National Laboratories

Albuquerque, New Mexico 87185 and Livermore, California 94550

for the United States Department of Energy

under Contract DE-AC04-94AL85000

Approved for public release; distribution is unlimited.

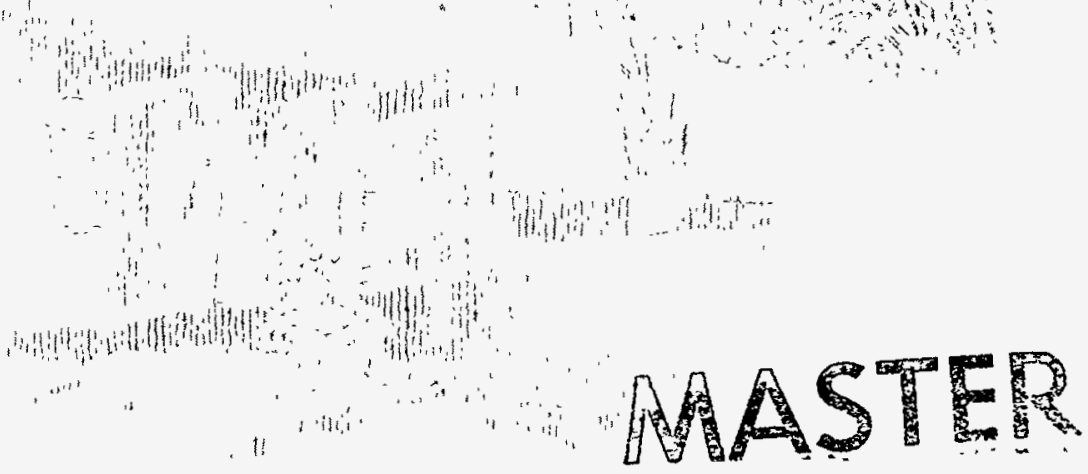


Issued by Sandia National Laboratories, operated for the United States Department of Energy by Sandia Corporation.

NOTICE: This report was prepared as an account of work sponsored by an agency of the United States Government. Neither the United States Government nor any agency thereof, nor any of their employees, nor any of their contractors, subcontractors, or their employees, makes any warranty, express or implied, or assumes any legal liability or responsibility for the accuracy, completeness, or usefulness of any information, apparatus, product, or process disclosed, or represents that its use would not infringe privately owned rights. Reference herein to any specific commercial product, process, or service by trade name, trademark, manufacturer, or otherwise, does not necessarily constitute or imply its endorsement, recommendation, or favoring by the United States Government, any agency thereof or any of their contractors or subcontractors. The views and opinions expressed herein do not necessarily state or reflect those of the United States Government, any agency thereof or any of their contractors.

Printed in the United States of America. This report has been reproduced directly from the best available copy.

Available to DOE and DOE contractors from Office of Scientific and Technical Information

PO Box 62

Oak Ridge, TN 37831

Prices available from (615) 576-8401, FTS 626-8401

Available to the public from

National Technical Information Service

US Department of Commerce

5285 Port Royal Rd

Springfield, VA 22161

NTIS price codes

Printed copy: A11

Microfiche copy: A01 


\section{DISCLAIMER}

Portions of this document may be illegible in electronic image products. Images are produced from the best available original document. 
SAND96-0400

Distribution

Unlimited Release

Printed August 1996

Category UC-513

TTC-1463

\title{
Radiological Consequences of Ship Collisions That Might Occur in U.S. Ports During the Shipment of Foreign Research Reactor Spent Nuclear Fuel to the United States in Break-Bulk Freighters
}

\author{
Jeremy L. Sprung, Stephen J. Bespalko, Charles D. Massey, and Richard Yoshimura \\ Transportation Systems Analysis Department \\ Sandia National Laboratories \\ P.O. Box 5800 \\ Albuquerque, NM 87185 \\ Jay D. Johnson \\ GRAM Incorporated \\ 8500 Menaul Boulevard NE, Suite B-370 \\ Albuquerque, NM 87111 \\ Philip C. Reardon \\ PCRT Technologies \\ 8416 Yeager Drive NE \\ Albuquerque, NM 87109 \\ Martin W. Ebert and Daniel W. Gallagher \\ Science Applications International Corporation \\ 11251 Roger Bacon Drive \\ Reston, VA 22090
}

\begin{abstract}
Accident source terms, source term probabilities, consequences, and risks are developed for ship collisions that might occur in U.S. ports during the shipment of spent fuel from foreign research reactors to the United States in break-bulk freighters.
\end{abstract}


Intentionally left blank. 


\section{CONTENTS}

Page

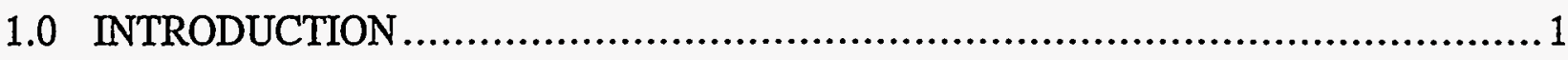

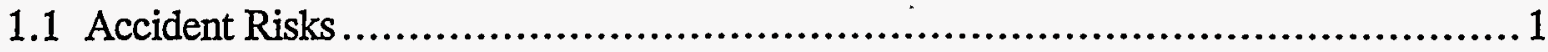

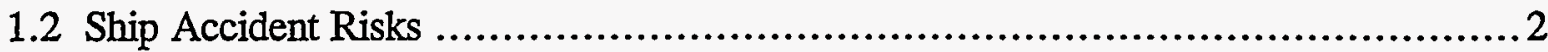

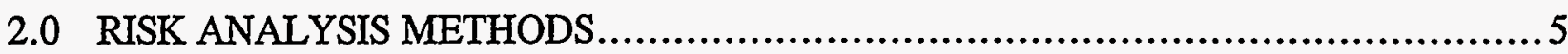

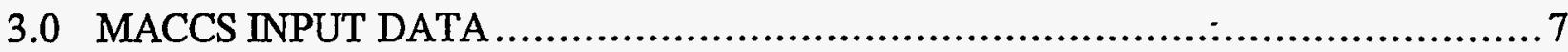

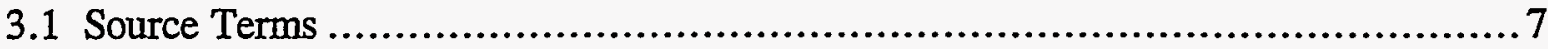

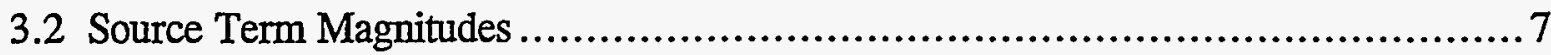

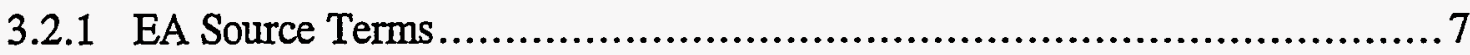

3.2.2 Fission Product Release at High Temperatures .................................. 9

3.2.3 Release Fractions for High-Temperature Events ............................. 12

3.2.3.1 Release Fraction Formulas ........................................ 12

3.2.3.2 Parameter Values for Release Fraction Formulas.................... 14

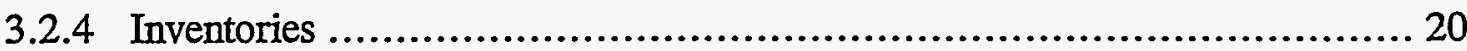

3.3 Source Term Timing and Sensible Heat ............................................. 20

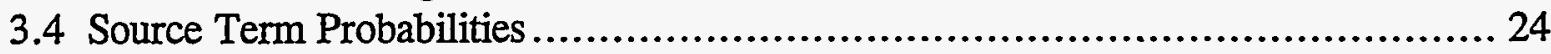

3.4.1 EA Source Term Probability Expressions ...................................... 25

3.4.2 Event Probabilities............................................................ 26

3.4.3 Probabilities Developed From Ship and Accident Data ...................... 26

3.4.3.1 Probability of Collisions in Ports ............................... 26

3.4.3.2 Probability That the RAM Hold is Struck......................... 28

3.4.3.3 Probability of Severe Fires......................................... 28

3.4.3.4 Probability That a Severe Fire Engulfs a RAM Cask ................ 29

3.4.4 Mechanical and Thermal Loads That Cause Damage........................... 30

3.4.4.1 Minorsky's Method.................................................. 31

3.4.4.2 Application to a Representative Break-Bulk Freighter ............... 32

3.4.4.3 Impact Forces.................................................... 41

3.4.4.4 Crush Forces ...................................................... 43

3.4.4.5 Probability of High-Temperature Events ......................... 51

3.4.4.6 Probability of Convective Flow Through the Failed Cask ........... 55

3.4.5 Accident Category Event Tree ................................................ 56

3.4.6 Revised Source Term Probabilities .............................................. 58

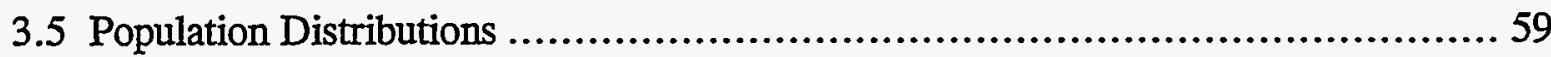

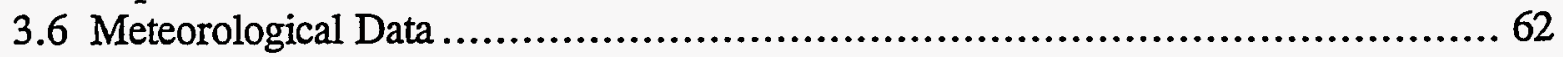




\section{CONTENTS (Continued)}

Page

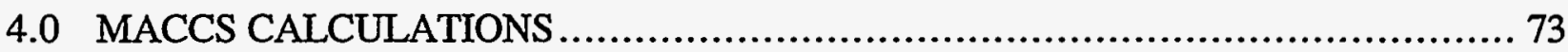

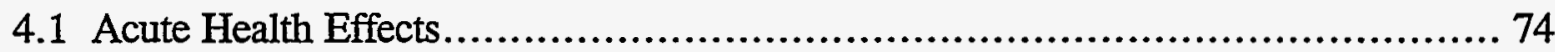

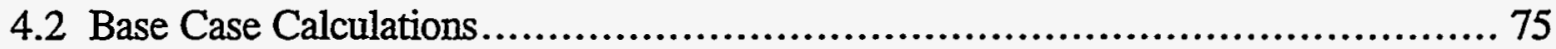

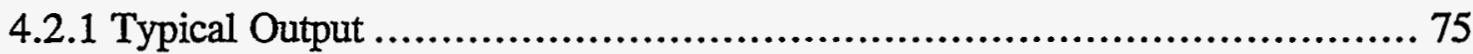

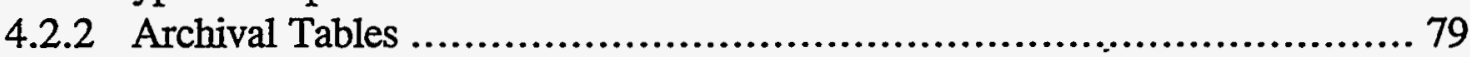

4.2.3 Principal Base Case Results................................................... 81

4.3 High-Temperature Calculations .................................................... 105

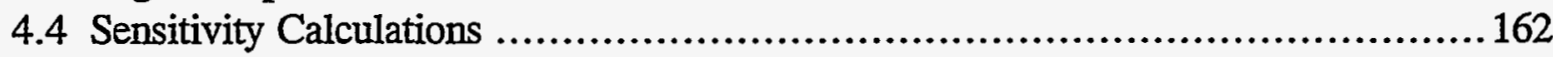

4.4.1 Variable Versus Constant Meteorology ......................................162

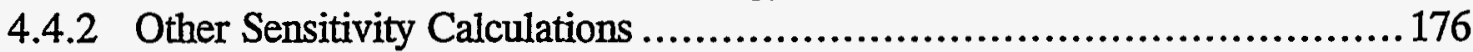

4.4.2.1 Plume Buoyancy ................................................ 185

4.4.2.2 Size of the Nuclide Set...........................................186

4.4.2.3 Alternative Release Fractions...................................... 187

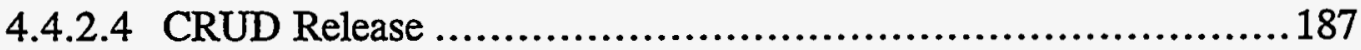

4.4.2.5 Workforce Population............................................... 188

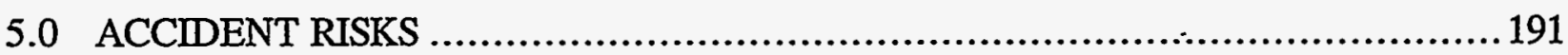

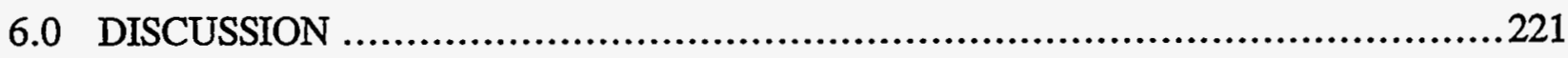

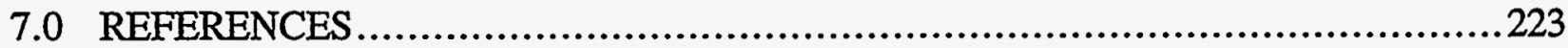

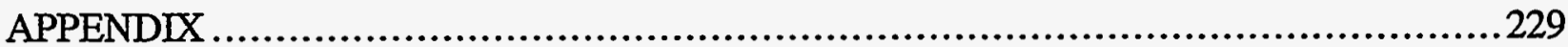




\section{FIGURES}

Figure

Page

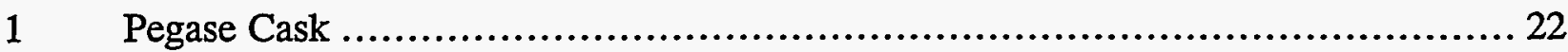

2 Energy Absorbed Versus Penetration in the No Cargo Case ........................... 35

3 Energy Absorbed Versus Penetration in the Light Cargo Case .......................... 35

4 Energy Absorbed Versus Penetration in the Medium Cargo Case ...................... 37

5 Energy Absorbed Versus Penetration in the Heavy Cargo Case.......................... 37

6 Maximum Penetration Distance in the No Cargo Case ................................. 40

7 Maximum Penetration Distance for the Light Cargo Case ............................ 40

8 Maximum Penetration Distance in the Medium Cargo Case ............................ 42

9 Maximum Penetration Distance in the Heavy Cargo Case ........................... 42

10 Average Accelerations for the No Cargo Case.......................................... 44

11 Average Accelerations for the Light Cargo Case ........................................ 44

12 Average Accelerations for the Medium Cargo Case ..................................... 45

13 Average Accelerations for the Heavy Cargo Case...................................... 45

14 Generic Truck Cask Force Displacement Characteristics .............................. 46

15 Distribution of Ship Penetration Distances for the No Cargo Case ..................... 49

16 Distribution of Ship Penetration Distances for the Light Cargo Case................... 49

17 Distribution of Ship Penetration Distances for the Medium Cargo Case ............... 50

18 Distribution of Ship Penetration Distances for the Heavy Cargo Case ................. 50

19 Cask Crush Probability for the Four Cargo Cases ..................................... 52

20 Cask Crush Probability for the Four Cargo Cases With the Striking Ship

Distribution Speed Truncated at $8.23 \mathrm{~m} / \mathrm{s}$............................................ 52

21 Event Tree for Oxygen Availability .............................................. 55

22 Event Tree for Category 4 Accidents .............................................. 57

23 Event Tree for Category 5 and 6 Accidents ....................................... 57

24 Total Cancer Fatalities, 0-1.6 km, Newark Port, Channel Location,

BR-2 Inventory, EA5 Release Fractions, Variable NY Meteorology ................... 78

25 Mean Effective Dose Equivalent Whole Body Centerline Dose vs Distance, Newark Port, Channel Location, BR-2 Inventory, EA5 Release Fractions, Variable NY Meteorology 


\section{FIGURES (Continued)}

Figure

Page

26 EDE Whole Body Population Dose, $0-80 \mathrm{~km}$, All Dock Locations, BR-2 Inventory, EA5 Release Fractions, Variable Meteorology 103

27 Total Cancer Fatalities, 0-80 km, All Channel Locations, BR-2 Inventory,

EA5 Release Fractions, Variable Meteorology

28 Total Cancer Fatalities and EDE Whole Body Population Dose, 0-80 km, Charleston Dock and Channel Locations, BR-2 Inventory,

EA5 Release Fractions, Variable Meteorology

29 Total Cancer Fatalities and EDE Whole Body Population Dose, 0-80 km, Concord Dock and Channel Locations, BR-2 Inventory,

EA5 Release Fractions, Variable Meteorology

30 Total Cancer Fatalities and EDE Whole Body Population Dose, 0-80 km, Galveston Dock and Channel Locations, BR-2 Inventory,

EA5 Release Fractions, Variable Meteorology 108

31 Total Cancer Fatalities and EDE Whole Body Population Dose, 0-80 km, Jacksonville Dock and Channel Locations, BR-2 Inventory, EA5 Release Fractions, Variable Meteorology

32 Total Cancer Fatalities and EDE Whole Body Population Dose, 0-80 km, Long Beach Dock and Channel Locations, BR-2 Inventory, EA5 Release Fractions, Variable Meteorology

33 Total Cancer Fatalities and EDE Whole Body Population Dose,

0-80 km, Newark Dock and Channel Locations, BR-2 Inventory,

EA5 Release Fractions, Variable Meteorology

34 Total Cancer Fatalities and EDE Whole Body Population Dose,

0-80 km, Norfolk Dock and Channel Locations, BR-2 Inventory,

EA5 Release Fractions, Variable Meteorology

35 Total Cancer Fatalities and EDE Whole Body Population Dose, 0-80 km, Philadelphia Dock and Channel Locations, BR-2 Inventory,

EA5 Release Fractions, Variable Meteorology

36 Total Cancer Fatalities and EDE Whole Body Population Dose, 0-80 km, Portland Dock and Channel Locations, BR-2 Inventory,

EA5 Release Fractions, Variable Meteorology

37 Total Cancer Fatalities and EDE Whole Body Population Dose, 0-80 km, Savannah Dock and Channel Locations, BR-2 Inventory, EA5 Release Fractions, Variable Meteorology 


\section{FIGURES (Continued)}

Figure

Page

38 Total Cancer Fatalities and EDE Whole Body Population Dose, 0-80 km, Tacoma Dock and Channel Locations, BR-2 Inventory, EA5 Release Fractions, Variable Meteorology

39 Total Cancer Fatalities and EDE Whole Body Population Dose, 0-80 km, Wilmington Dock and Channel and MOTSU Dock

Locations, BR-2 Inventory, EA5 Release Fractions, Variable Meteorology

40 EDE Whole Body Population Dose, 0-80 km, All Dock Locations, BR-2 Inventory, EIS6B Release Fractions, Variable Meteorology

41 Total Cancer Fatalities, 0-80 km, All Channel Locations, BR-2 Inventory, EIS6B Release Fractions, Variable Meteorology

42 Total Cancer Fatalities and EDE Whole Body Population Dose, 0-80 km, Charleston Dock and Channel Locations BR-2 Inventory, EIS6B Release Fractions, Variable Meteorology

43 Total Cancer Fatalities and EDE Whole Body Population Dose, 0-80 km, Concord Dock and Channel Locations, BR-2 Inventory, EIS6B Release Fractions, Variable Meteorology

44 Total Cancer Fatalities and EDE Whole Body Population Dose, 0-80 km, Galveston Dock and Channel Locations, BR-2 Inventory, EIS6B Release Fractions, Variable Meteorology

45 Total Cancer Fatalities and EDE Whole Body Population Dose, 0-80 km, Jacksonville Dock and Channel Locations, BR-2 Inventory, EIS6B Release Fractions, Variable Meteorology

46 Total Cancer Fatalities and EDE Whole Body Population Dose, 0-80 km, Los Angeles Dock and Channel Locations, BR-2 Inventory, EIS6B Release Fractions, Variable Meteorology

47 Total Cancer Fatalities and EDE Whole Body Population Dose, 0-80 km, Newark Dock and Channel Locations, BR-2 Inventory, EIS6B Release Fractions, Variable Meteorology 168

48 Total Cancer Fatalities and EDE Whole Body Population Dose, 0-80 km, Norfolk Dock and Channel Locations, BR-2 Inventory, EIS6B Release Fractions, Variable Meteorology

49 Total Cancer Fatalities and EDE Whole Body Population Dose, 0-80 km, Philadelphia Dock and Channel Locations, BR-2 Inventory, EIS6B Release Fractions, Variable Meteorology 


\section{FIGURES (Continued)}

Figure

Page

50 Total Cancer Fatalities and EDE Whole Body Population Dose, 0-80 km, Portland Dock and Channel Locations, BR-2 Inventory, EIS6B Release Fractions, Variable Meteorology

51 Total Cancer Fatalities and EDE Whole Body Population Dose, 0-80 km, Savannah Dock and Channel Locations, BR-2 Inventory; EIS6B Release Fractions, Variable Meteorology

52 Total Cancer Fatalities and EDE Whole Body Population Dose, 0-80 km, Tacoma Dock and Channel and Seattle Channel Locations, BR-2 Inventory, EIS6B Release Fractions, Variable Meteorology

53. Total Cancer Fatalities and EDE Whole Body Population Dose,

0-80 km, Wilmington Dock and Channel and MOTSU Dock Locations,

BR-2 Inventory, EIS6B Release Fractions, Variable Meteorology

54 Total Cancer Fatalities and EDE Whole Body Population Dose, 0-80 km, Charleston, Variable and Constant Meteorology,

BR-2 Inventory, EA5 Release Fractions

55 Total Cancer Fatalities and EDE Whole Body Population Dose, 0-80 km, Los Angeles, Variable and Constant Meteorology,

BR-2 Inventory, EA5 Release Fractions

56 Total Cancer Fatalities and EDE Whole Body Population Dose,

0-80 km, Newark, Variable and Constant Meteorology, BR-2

Inventory, EA5 Release Fractions

57 Total Cancer Fatalities and EDE Whole Body Population Dose,

0-80 km, Norfolk, Variable and Constant Meteorology, BR-2 Inventory,

EA5 Release Fractions.

58 Total Cancer Fatalities and EDE Whole Body Population Dose,

0-80 km, Philadelphia, Variable and Constant Meteorology,

BR-2 Inventory, EA5 Release Fractions

59 Total Cancer Fatalities and EDE Whole Body Population Dose,

0-80 km, Portland, Variable and Constant Meteorology, BR-2

Inventory, EA5 Release Fractions

60 Total Cancer Fatalities (Wilmington Channel) and EDE Whole Body

Population Dose (MOTSU Dock), 0-80 km, Variable and Constant

Meteorology, BR-2 Inventory, EA5 Release Fractions 


\section{FIGURES (Concluded)}

Figure

Page

61 EDE Whole Body Population Dose, 0-80 km, MOTSU Dock, BR-2

Inventory, All EA and EIS Source Terms, Variable Meteorology

62 EDE Whole Body Population Dose, $0-80 \mathrm{~km}$, Tacoma Dock,

BR-2 Inventory, All EA and EIS Source Terms, Variable Meteorology

63 EDE Whole Body Population Dose, 0-80 km, Newark Dock,

BR-2 Inventory, All EA and EIS Source Terms, Variable Meteorology ..............216

64 Total Cancer Fatalities, 0-80 km, MOTSU Dock,

BR-2 Inventory, All EA and EIS Source Terms, Variable Meteorology .............217

65 Total Cancer Fatalities, 0-80 km, Tacoma Dock,

BR-2 Inventory, All EA and EIS Source Terms, Variable Meteorology ...............218

66 Total Cancer Fatalities, 0-80 km, Newark Dock,

BR-2 Inventory, All EA and EIS Source Terms, Variable Meteorology 


\section{TABLES}

Table

1 Accident Severity Category Scheme Used in the EA...................................8

2 EA Release Category Scheme Attributes as Modified to Reflect the

High-Temperature Behavior of Research Reactor Fuels .............................. 13

3 Input Parameter Values Used to Calculate Release Fractions for High-

Temperature Fire Events ....................................................... 17

$4 \quad$ Release Fraction Values for Research Reactor Fuels................................. 18

5 Curie Content of Fully Loaded Shipping Casks for Four Representative

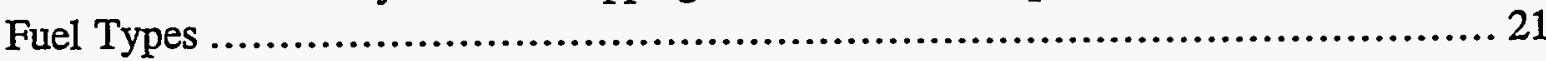

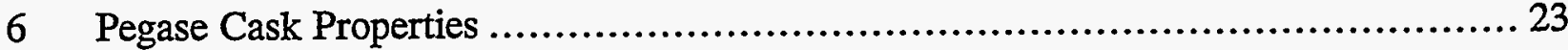

$7 \quad$ Release Timing Patterns .......................................................... 24

8 Event Sequence for a Severe Ship Accident ...................................... 25

9 Source Term Probability Expressions for EA Accident Categories 4 Through 6 ........ 25

10 Collisions per Port Call........................................................... 27

11 Quadratic Coefficients for Energy Absorbed by Ship Structures $(x<15 \mathrm{~m}) \ldots \ldots \ldots \ldots . . . .34$

12 Quadratic Coefficients for Energy Absorbed by Ship Structures $(x>15 \mathrm{~m})$............ 34

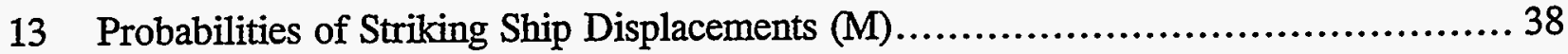

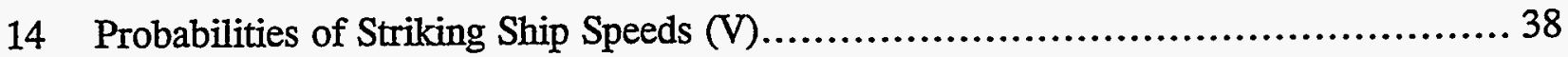

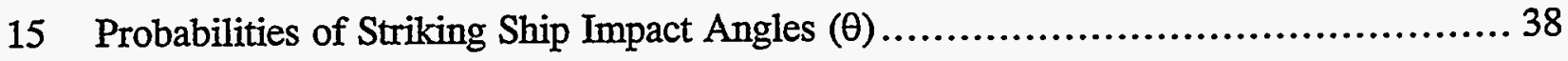

16 Relative Magnitudes of the New EIS Release Fractions Compared to the EA Release Fractions Used to Perform the Base Case Calculations..................... 58

17 Estimated Values for Event Probabilities, EA Source Term Probabilities, and EIS Source Term Probabilities ................................................ 59

18 Destination Ports and Ports-of-Call for Shipments of Foreign Research

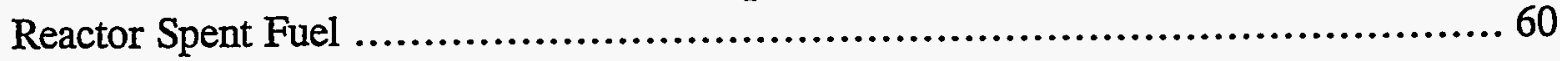

19 Accident Location Map Coordinates ............................................ 61

20 Site Wind Roses...........................................................6 63

21 Locations of National Weather Service Stations .................................. 64

22 Joint Frequency Weather Distribution for Charleston................................6 65

23 Joint Frequency Weather Distribution for Long Beach .............................66 66

24 Joint Frequency Weather Distribution for Newark ............................... 67 


\section{TABLES (Continued)}

Table

Page

25 Joint Frequency Weather Distribution for Norfolk ................................ 68

26 Joint Frequency Weather Distribution for Philadelphia................................ 69

27 Joint Frequency Weather Distribution for Portland ............................... 70

28 Joint Frequency Weather Distribution for Wilmington ................................ 71

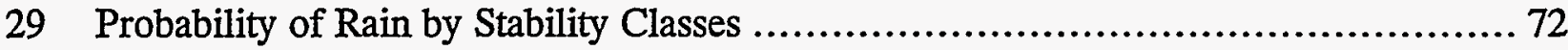

30 Typical Results: Newark Port, Channel Location, BR-2 Inventory,

EA5 Release Fractions, Variable NY Meteorology ................................... 76

31 Mean Values of Population Dose, Cancer Fatalities, Costs, Centerline Individual Dose and Centerline Individual Risk for EA Accident Categories .......... 82

32 99th Quantile Values of Population Dose, Cancer Fatalities, Costs, Centerline Individual Dose and Centerline Individual Risk for EA Accident Categories

33 Peak Values of Population Dose, Cancer Fatalities, Costs, Centerline Individual Dose and Centerline Individual Risk for EA Accident Categories...................... 92

34 Conditional Probabilities of Peak Values of Population Dose, Cancer Fatalities, Costs, Centerline Individual Dose and Centerline Individual Risk for EA Accident Categories

35 Mean Values of Population Dose, Cancer Fatalities, Costs, Centerline Individual Dose and Centerline Individual Risk for EIS Accident Categories

36 99th Quantile Values of Population Dose, Cancer Fatalities, Costs, Centerline Individual Dose and Centerline Individual Risk for EIS Accident Categories

37 Peak Values of Population Dose, Cancer Fatalities, Costs, Centerline Individual Dose and Centerline Individual Risk for EIS Accident Categories

38 Conditional Probability of Peak Values of Population Dose, Cancer

Fatalities, Costs, Centerline Individual Dose and Centerline Individual Risk for EIS Accident Categories

39 Mean and 99.9th Quantile Values for Population Dose and Cancer Fatalities

Calculated Using Variable and Constant Meteorology for Seven Ports...

40 Other Sensitivity Calculations . 184

41 Results for Other Sensitivity Studies 185

42 Modal Study Release Fractions. 


\section{TABLES (Concluded)}

Table

Page

43 Absolute Risks for EA Accident Categories ...................................... 192

44 Absolute Risks for EIS Accident Categories......................................... 199 


\section{Acronyms and Abbreviations}

CCDF Complementary Cumulative Distribution Function

CRUD Chalk River Unidentified Deposits

DOE U.S. Department of Energy

EA Environmental Assessment

EDE Effective Dose Equivalent

EIS Environmental Impact Statement

IMO International Maritime Organization

INEL Idaho National Engineering Laboratory

LLNL Lawrence Livermore National Laboratory

MACCS MELCOR Accident Consequence Code System

NRC U.S. Nuclear Regulatory Commission

PEIS DOE Programmatic Environmental Impact Statement

Part particulates

RAM radioactive material

SNF Spent Nuclear Fuel

SNL Sandia National Laboratories 
. 


\subsection{INTRODUCTION}

For four decades, under the Atoms for Peace program, the United States provided research reactor technology and fresh reactor fuel to foreign nations that agreed to return the spent fuel to the United States. Return of the spent fuel was sought to prevent its diversion to the production of nuclear weapons. Highly enriched and low-enriched uranium fuels were returned to the United States under programs that expired in 1988 and 1992, respectively. In 1991, an Environmental Assessment (EA) of the potential impacts of extending these two programs was issued by the U.S. Department of Energy (DOE) [DOE91]. In response to criticisms of that EA, the DOE published in 1993 a Notice of Intent to prepare an Environmental Impact Statement (EIS) that would examine in greater detail the impacts of reinstituting the two fuel-return programs. This report presents the results of an assessment of the radiological risks associated with accidents that might occur in U.S. ports to ships carrying foreign research reactor spent fuel from foreign nations back to the United States.

Port accident risks have been examined during other studies. In 1986 and 1988, DOE issued EAs of the impacts of shipping spent research reactor fuel from Taiwan to the United States [DOE86, DOE88a]. In 1994, DOE issued the Environmental Assessment of the Urgent-Relief Acceptance of Foreign Research Reactor Spent Nuclear Fuel [DOE94a], and pursuant to that EA, the United States accepted two shipments of spent fuel from research reactors located in six European nations. These EAs found that port accidents dominated the radiological risks associated with accidents that might occur during the shipment of spent research reactor fuel back to the United States.

Review of these EAs shows that port accident risks may have been overestimated for three reasons. First, the chance that a ship collision will fail the spent fuel transportation cask was assumed to be the same as the historic chance that a ship collision involves a large ship and also causes substantial damage to cargo (large dollar losses). Second, because descriptions of ship collisions that led to fires hardly ever specify the extent of structural damage due to thermal loads, the chance that a fire produces thermal loads that compromise cask integrity and oxidize fuel was assumed to be the same as the frequency of long duration fires (fires with durations of at least one hour). Third, the EA risk calculations used uniform population distributions that didn't reflect the fact that port channels and oceans are unpopulated, and thus overestimated the chance that, if an accident occurred, people would be present to be subjected to radiation exposures and radiation induced health effects. Accordingly, the primary objectives of this study were (1) to better estimate the chance that a port accident would lead to a release of radioactivity due to mechanical and/or thermal loads, and (2) to perform port accident risk calculations that could account for the absence of people from land covered by water.

\subsection{Accident Risks}

Risk $(R)$ is the product of the magnitude $(M)$ of an unfavorable consequence and the probability of occurrence $(\mathrm{P})$ of that consequence. Thus, $\mathrm{R}=\mathrm{P} \times \mathrm{M}$. 
For accidents that happen during the transportation of radioactive materials, the unfavorable consequences of the accident include (1) exposure of people to radiation emitted by the radioactive gases and particulates released to the atmosphere as a result of the accident, and (2) the occurrence of radiation induced health effects in the population exposed to radiation due to the downwind transport and deposition of these radioactive gases and particulates. The magnitudes of these consequences are determined by (1) the amount of radioactivity released to the atmosphere, (2) the degree to which the radioactive materials are diluted during downwind transport, and (3) the size of the population that is exposed to radiation emitted by materials in the passing plume or by materials deposited onto the ground from the plume. The amount of dilution experienced by a plume during downwind transport depends principally on atmospheric stability and windspeed. The size of the exposed population is determined by the direction the wind is blowing at the time of the accident. Thus, the probability that a given consequence occurs is given by the following product,

$$
\mathrm{P}=\mathrm{P}_{\mathrm{ST}} \mathrm{P}_{\mathrm{W}} \mathrm{P}_{\mathrm{P}}
$$

where $\mathrm{P}_{\mathrm{ST}}$ is the probability of the source term, $\mathrm{P}_{\mathrm{W}}$ is the probability of the prevailing weather conditions (atmospheric stability, windspeed), and $P_{P}$ is the probability that the wind is blowing toward a particular population group at the time of the accident.

Given the precision of the input data available to support the risk calculations performed for this study, when comparing study results, differences in risk, probabilities, or consequence magnitudes of a factor of ten or more are surely significant, differences of a factor of five are probably significant, and differences of a factor of three or less are probably not significant because, within uncertainties, both numbers are probably indistinguishable.

\subsection{Ship Accident Risks}

The total risk caused by transporting foreign research reactor spent fuel to and within the United States is the sum of the risks for transport on land by trains or trucks and at sea in ships. Thus,

$$
\mathrm{R}_{\text {Total }}=\mathrm{R}_{\text {Train }}+\mathrm{R}_{\text {Truck }}+\mathrm{R}_{\text {Ship }}
$$

where there is an incident free and an accident contribution to each of the terms in the sum. For ships, the risk due to accidents is given by,

$$
R_{\text {Ship }}=R_{\text {Sea }}+R_{\text {Coast }}+R_{\text {Port }}
$$

where $R_{\text {Sea }}, R_{\text {Coast }}$, and $R_{\text {Port }}$ are the risks due to ship accidents that occur at sea, in coastal waters, or in ports.

Research reactor spent fuel has always been stored for several years before being shipped. If this practice continues, when finally shipped, the fuel will be relatively cold since all rapidly 
decaying nuclides will have decayed away. Because the amount of fuel shipped in a transportation cask is small, at least when compared to the amount of fuel used in a commercial nuclear power plant, transportation accident source terms will always be much smaller than the source terms predicted for hypothetical large accidents at nuclear power plants.

Most of the radioactivity released due to a transportation accident will be contained in particulate materials. For ship accidents, unless the accident occurs near shore, most of these particulates will deposit on the ocean surface before the accident plume reaches land. Thus, accidents at sea will generate significant population dose only through the aquatic food pathway, and these doses should be negligible on a per person basis as they will be spread over a very large number of people (all of the people who consume some of the seafoods that become contaminated as a result of the accident). Therefore, because ship accident source terms will not be large, because the released radioactive materials will not be decaying rapidly, and because most of the released radioactivity will not reach land, population doses and health effects are not expected to be of concern if the accident occurs while the ship is sailing at sea.

When sailing coastal routes, commercial ships usually sail 30 to 50 miles offshore. Thus, ship accidents that occur while sailing in coastal waters will usually not produce significant accident consequences on land, because the quantity of radioactive particulates released due to an accident in coastal waters will be considerably diminished by deposition to the ocean surface before the accident plume reaches land. Therefore, individuals living onshore in the path of the plume are not expected to receive large exposures.

Sailing speeds in ports are much less than sailing speeds at sea for two reasons. First, harbor operational rules limit ship speeds in port channels, typically to speeds less than 15 knots. Second, when sailing near docks, to prevent collisions, ships normally sail at minimum steerage speeds ( 3 to $5 \mathrm{knots}$ ). Therefore, because collision damage decreases rapidly with decreasing collision speeds, port accidents are not likely to lead to large releases of radioactive materials. In addition, although this study takes no credit for administrative controls, such as safety and security zones, administrative controls in ports are also expected to limit the magnitudes of port accidient source terms.

Because only accidents that occur in ports are likely to produce significant consequences, consequence calculations were not performed for ocean or coastal accident locations. Moreover, the only port accidents considered were those where the ship carrying the spent fuel is struck by another ship. Accidents where the spent fuel transport ship rams a fixed structure (a bridge or a dock), rams another ship (a collision where the spent fuel ship is the striking ship), or runs aground were not examined for the following reasons:

- Ship accident data show that when a ship rams a fixed structure or collides with another ship, damage to the striking ship is confined to its prow and to the forwardmost hold. Therefore, because good shipping practice avoids the placement of hazardous cargo in forward holds, if the spent fuel transport ship rams a fixed structure or another ship, 
the spent fuel cask should not be damaged unless, contrary to normal practice, it has been loaded into the forwardmost hold.

- Because keel structures are massive and very sturdy, groundings rarely lead to significant damage to cargo, although monetary losses due to sinking of cargo or the ship can be substantial. Therefore, since immersion to the depths of harbor channels is unlikely to damage a spent fuel cask or pose a significant retrieval problem, groundings were not examined during this study. 


\subsection{RISK ANALYSIS METHODS}

The consequences of ship collisions that might occur in ports were estimated using the MELCOR Accident Consequence Code System (MACCS) [Ch90, Jo90, Sp90], originally developed by Sandia National Laboratories (SNL) for the U.S. Nuclear Regulatory Commission (NRC) for use in estimating the consequences of nuclear power plant accidents [NRC90]. The MACCS code was selected for these analyses because it can model an accident that takes place at a specific location and the actual population distribution around that location including space that is ocean and thus unpopulated.

If a ship transporting spent fuel is struck by another ship while making a port call and the collision leads to the failure of the spent fuel cask, the prevailing winds would transport the radioactive gases and aerosols in the plume released to the atmosphere during the accident away from the port. During transport by the prevailing winds, downwind populations would be exposed to radiation, and land, buildings, and crops located below the plume trajectory would be contaminated by the radioactive materials deposited from the plume. Estimation of the range and probability of the health effects induced by the radiation exposures, and of the economic costs and losses that would result from the contamination of land, buildings, and crops is the objective of a MACCS accident consequence analysis.

For each hypothetical accident examined, MACCS calculations require the following accident and site data:

The radioactive inventory of the cask at the time of the hypothetical accident for those radionuclides important for the calculation of accident consequences.

Release fractions and the probability of release for the radioactive source term caused by the accident.

Plume characteristics for each plume segment released to the atmosphere by the accident (number of segments, the sensible heat content of each segment, and the release time and duration of each segment).

Meteorological data characteristic of the region where the port is located, usually one year of hourly readings of windspeed, atmospheric stability, and rainfall, although MACCS calculations can be carried out using constant meteorological conditions such as those specified by a joint frequency distribution of windspeed by stability class and wind direction.

The population distribution about the port where the hypothetical accident is assumed to occur. 
Emergency response data, such as evacuation times and average evacuation speeds; and building shielding factors and the time when people take shelter, if nearby populations are instructed to take shelter.

Land usage (habital land fractions and farmland fractions) for the region surrounding the port.

Given these data, for each hypothetical accident examined, MACCS predicts:

The downwind transport, dispersion, and deposition of the radioactive materials released from the failed spent fuel cask.

The radiation doses received by the exposed populations via direct (cloudshine, inhalation, groundshine, resuspension) and indirect (ingestion) exposure pathways.

The mitigation of these doses by emergency response actions (evacuation, sheltering, and post-accident relocation of people).

The health effects that may occur in the individuals exposed to radiation as a result of the accident; for example, latent cancer fatalities, and acute injuries if short-term exposures are large.

The costs of emergency response, decontamination, temporary interdiction, and condemnation of milk, crops, land, and buildings located in the region around the port. 


\subsection{MACCS INPUT DATA}

\subsection{Source Terms}

MACCS source terms are specified by four input quantities: the probability $\left(\mathrm{P}_{\mathrm{ST}}\right)$ of the radioactive source term released as a result of the ship collision; the time (t) and duration $(\Delta t)$ of each segment of the release (for ship accidents there may be both a mechanical release at the time of the collision and a later thermal release if the accident progression leads to a fire); and the magnitude of the source term $\left(\mathrm{M}_{\mathrm{ST}}\right)$.

\subsection{Source Term Magnitudes}

In MACCS, the magnitude $\left(\mathrm{M}_{\mathrm{ST}}\right)$ of a source term is expressed in curies and is calculated as a sum of products where each term in the sum is the product of the inventory $\left(I_{i}\right)$ of radionuclide $i$ available for release and the fraction $\left(F_{R i}\right)$ of that inventory that is released during the accident being examined. Thus,

$$
\mathrm{M}_{\mathrm{ST}}=\sum_{\mathrm{i}} \mathrm{M}_{\mathrm{STi}}=\sum_{\mathrm{i}} \mathrm{I}_{\mathrm{i}} \mathrm{F}_{\mathrm{Ri}}
$$

\subsubsection{EA Source Terms}

In the EA titled "Environmental Assessment of Urgent-Relief Acceptance of Foreign Research Reactor Spent Nuclear Fuel" [DOE94a], hereafter referred to as the Urgent Relief EA or just the EA, accident risks were estimated using a six category accident severity scheme. To facilitate comparison of the risk estimates developed for this study to those developed for the EA, this study retained the six-category accident scheme used in the EA, modifying that scheme only as was necessary to reflect the unique physical and chemical properties of research reactor fuels that affect release of fission products from these fuels during hightemperature fire accident scenarios (see Section 3.2.2, Fission Product Release at High Temperatures).

Table 1 presents the six-category accident severity scheme used in the EA, and the values of the conditional release probabilities (conditional on the occurrence of the specified accident) used in the EA for each accident category. For each accident category, Table 1 also presents release fraction values for five chemical element groups: cobalt (Co), noble gases $(\mathrm{Kr})$, cesium $(\mathrm{Cs})$, ruthenium $(\mathrm{Ru})$, and radionuclides released as particulates (Part). Inspection of the accident conditions listed in Table 1 shows that no radioactive releases are expected for accidents that fall into Accident Categories EA1 or EA2. The conditions specified for EA3 accidents indicate that these accidents fail the cask seals but not the fuel elements contained within the cask. Thus, only radioactivity, formed by activation of chemical deposits (CRUD) located on fuel element outer walls, can be released by EA3 accidents [Sa88]. Since research 
Table 1. Accident Severity Category Scheme Used in the EA

\begin{tabular}{|c|c|c|c|c|}
\hline $\begin{array}{l}\text { Accident } \\
\text { Severity } \\
\text { Category }\end{array}$ & Accident Conditions & $\begin{array}{l}\text { Conditional } \\
\text { Probability }\end{array}$ & Specie & $\begin{array}{l}\text { Release } \\
\text { Fraction }\end{array}$ \\
\hline EA1 & $\begin{array}{l}\text { Conditions do not exceed those for a Type } \\
\text { A package; no release of contents }\end{array}$ & 0.603 & $\begin{array}{l}\mathrm{Co} \\
\mathrm{Kr} \\
\mathrm{Cs} \\
\mathrm{Ru} \\
\mathrm{Part}^{\mathrm{a}}\end{array}$ & $\begin{array}{l}0 \\
0 \\
0 \\
0 \\
0\end{array}$ \\
\hline $\mathrm{EA} 2$ & $\begin{array}{l}\text { Conditions equal to those for Type B } \\
\text { certification tests; no release of contents }\end{array}$ & 0.395 & $\begin{array}{l}\text { Co } \\
\mathrm{Kr} \\
\mathrm{Cs} \\
\mathrm{Ru} \\
\text { Part }\end{array}$ & $\begin{array}{l}0 \\
0 \\
0 \\
0 \\
0\end{array}$ \\
\hline EA3 & $\begin{array}{l}\text { Seal damage creates leak path, but fuel } \\
\text { undamaged; only CRUD if present } \\
\text { released from package }\end{array}$ & 0.002 & $\begin{array}{l}\mathrm{Co} \\
\mathrm{Kr} \\
\mathrm{Cs} \\
\mathrm{Ru} \\
\text { Part }\end{array}$ & $\begin{array}{l}1.2 \mathrm{E}-2^{\mathrm{b}} \\
0 \\
0 \\
0 \\
0\end{array}$ \\
\hline EA4 & $\begin{array}{l}\text { Impact damage great enough to cause } \\
\text { damage to spent fuel; fuel particulates and } \\
\text { fission gases may be released }\end{array}$ & $4.0 \mathrm{E}-4$ & $\begin{array}{l}\text { Co } \\
\mathrm{Kr} \\
\mathrm{Cs} \\
\mathrm{Ru} \\
\text { Part }\end{array}$ & $\begin{array}{l}1.2 \mathrm{E}-2 \\
1.0 \mathrm{E}-2 \\
1.0 \mathrm{E}-8 \\
1.0 \mathrm{E}-8 \\
1.0 \mathrm{E}-8\end{array}$ \\
\hline EA5 & $\begin{array}{l}\text { Impact damage to seals plus fire severe } \\
\text { enough to cause thermal burst with release } \\
\text { of fission gases, volatiles, and particulates }\end{array}$ & $4.0 \mathrm{E}-4$ & $\begin{array}{l}\text { Co } \\
\mathrm{Kr} \\
\mathrm{Cs} \\
\mathrm{Ru} \\
\text { Part }\end{array}$ & $\begin{array}{l}1.2 \mathrm{E}-2 \\
1.0 \mathrm{E}-1 \\
9.0 \mathrm{E}-4 \\
1.0 \mathrm{E}-6 \\
5.0 \mathrm{E}-8\end{array}$ \\
\hline EA6 & $\begin{array}{l}\text { Severe impact damage plus fire severe } \\
\text { enough to oxidize fuel with release of } \\
\text { greater amounts of volatiles than } \\
\text { Category } 5\end{array}$ & $4.0 \mathrm{E}-4$ & $\begin{array}{l}\mathrm{Co} \\
\mathrm{Kr} \\
\mathrm{Cs} \\
\mathrm{Ru} \\
\text { Part }\end{array}$ & $\begin{array}{l}1.2 \mathrm{E}-2 \\
1.1 \mathrm{E}-1 \\
9.8 \mathrm{E}-4 \\
4.2 \mathrm{E}-5 \\
5.0 \mathrm{E}-8\end{array}$ \\
\hline
\end{tabular}

${ }^{\mathrm{a}} \mathrm{Part}=$ Particulates.

${ }^{b} 1.2 \mathrm{E}-2=1.2 \times 10^{-2}$. 
reactor fuels are not significantly subject to deposit formation, formation of radionuclides by activation of CRUD deposits is not significant. Thus, none of the four inventories used in this study (see Table 5) contain radiocobalt, the principal radionuclide formed by activation of CRUD deposits.

The accident conditions specified in Table 1 for EA4, EA5, and EA6 accidents indicate that all of these accidents involve seal failure and fuel damage, while only EA5 and EA6 accidents lead to severe fires. Because by definition, EA6 accidents lead to oxidization of fuel, these accidents must also lead to more severe cask failures than those assumed for EA4 and EA5 accidents. Specifically, EA6 accidents must lead to cask failures that allow the ensuing severe fire to induce a convective flow of air through the failed cask. Otherwise fuel oxidation could not occur.

Finally, although the accident phenomenology specified for EA accident Category 6 is more severe than that specified for Category 5 , and that for Category 5 is more severe than that for Category 4 , in the EA all three of these categories were conservatively assigned a Conditional Probability of Occurrence of 4.0E-4 (i.e., $4 \times 10^{-4}$ ). Since increasing accident severity should mean decreasing accident probability, the conditional probabilities assigned to these categories should not be identical. Therefore, a way to develop new estimates of the conditional probabilities of occurrence for EA Accident Categories 4, 5, and 6 was formulated (see Section 3.4, Source Term Probabilities).

\subsubsection{Fission Product Release at High Temperatures}

Table 1 shows that the principal difference between Severity Category 5 and Severity Category 4 release fractions is a five order of magnitude increase (from 1.0E-8 to $9.0 \mathrm{E}-4$ ) in the release fraction for Cs; and that the principal difference between Severity Category 6 and Severity Category 5 release fractions is a 42 fold increase (from 1.0E-6 to $4.2 \mathrm{E}-5$ ) in the release fraction for $\mathrm{Ru}$.

Cs release is dramatically increased during Category 5 accidents because, in contrast to Category 4 accidents, these accidents lead to a severe fire, which heats the spent fuel to temperatures where $\mathrm{Cs}$ volatility is greatly increased. $\mathrm{Ru}$ release is increased during Category 6 accidents because these accidents involve cask failures that allow significant convective flow of air through the cask to occur, which causes involatile $\mathrm{Ru}$ species in the spent fuel to be oxidized to volatile $\mathrm{RuO}_{4}$.

The release fractions listed in Table 1 were constructed from release estimates developed by Wilmot [Wi81, Wi84] for power reactor fuel ( $\mathrm{UO}_{2}$ pellets clad in zircaloy). The fuels used in research reactors are not zircaloy clad $\mathrm{UO}_{2}$ pellets. TRIGA reactors use large pellets formed from a mixture of uranium, zirconium, and zirconium hydride $\left(\mathrm{ZrH}_{2}\right)$ that are clad in stainless steel. All of the other reactors considered in this study use aluminum clad metallic fuels where the metal is an alloy of aluminum and uranium. At elevated temperatures ( $\mathrm{T}>900 \mathrm{~K}$ ), Al-U alloy fuels melt [E193] and, if exposed to air, TRIGA fuel burns [Be81]. Therefore, if a ship collision leads to a fire that heats these fuels to temperatures much above $900 \mathrm{~K}$, fission 
product release from these fuels is likely to be much greater than that predicted for $\mathrm{UO}_{2}$ power reactor fuels. Therefore, the properties of metallic Al-U alloy fuels and of TRIGA fuel were reviewed to identify any significant differences between release of fission products at elevated temperatures from research reactor fuels and power reactor fuel.

The BR-2, RHF, and Osiris fuels considered by this study are fabricated as stacks of aluminum clad Al-U alloy cylinders or plates. Release of fission products from Al-U alloy fuels has been reviewed by Ellison et al. [E193]. They conclude that release is minor below about $923 \mathrm{~K}$, the melting point of the Al-U alloy from which these fuels are fabricated. Once the Al-U alloy has melted, fission products volatile at melt temperatures are rapidly released from the molten alloy. Although molten aluminum can dissolve both the stainless steel spacers that support individual fuel bundles and the alloy fuel plates, melting of the aluminum cladding that surrounds these alloy fuels does not significantly affect release. The melting temperature of the clad, $933 \mathrm{~K}$, is slightly higher than the melting temperature of the alloy fuel, which means that clad melting will follow but not influence fuel melting.

The effects of air ingression on release of fission products from commercial reactor fuel have been reviewed by Powers et al. [P094]. Their review indicates that $\mathrm{Ru}$ release fractions from $\mathrm{UO}_{2}$ fuel will equal or exceed 4.2E-5, the release fraction for Ru used in the EA for Category 6 accidents, if the fuel is exposed to air for 15 to 30 minutes while heated to $700 \mathrm{~K}$. Their review also indicates that release increases rapidly as temperature rises or exposure times lengthen, and that for temperatures less than $1200 \mathrm{~K}, \mathrm{Ru}$ is released principally as $\mathrm{RuO}_{4}$.

TRIGA fuel is a uranium-zirconium-hydrogen (U-Zr-H) alloy with atomic proportions 0.03:1:1 that burns spontaneously in air at temperatures above $925 \mathrm{~K}$ [Be81]. Because this combustion process is highly exothermic, if a severe fire heats a failed cask to temperatures above $925 \mathrm{~K}$, air ingression due to convection or due to contraction of cask gases upon cask cooling might be expected to initiate spontaneous combustion of the $\mathrm{U}-\mathrm{Zr}-\mathrm{H}$ alloy, which could lead to substantially increased release from fuel of $\mathrm{Kr}, \mathrm{Cs}$, most likely as $\mathrm{Cs}_{2} \mathrm{O}$, and of $\mathrm{Ru}$ by conversion to volatile $\mathrm{RuO}_{4}$ to the cask interior.

Theoretical [US88, SNL89, GNS93, Sh94] and experimental [Ba86a, Ne86, Gr87, Gr89, Sc89, Ke94] studies of the thermal loads on casks produced by engulfing fires indicate that only engulfing fires with durations of an hour or more that are not oxygen-starved and are supported by the combustion of some high-grade fuel (gasoline, jet fuel, diesel fuel) can raise the spent fuel contained in the casks to temperatures that approach $1000 \mathrm{~K}$. These studies also indicate that cask temperatures this high are not attained for fires of similar duration caused by lower-grade fuels (e.g., crude oil, wood). Thus, short duration fires involving low-grade fuels or mixtures of low- and high-grade fuels, and fires involving high-grade fuels that are oxygenstarved, because hold covers are closed, or are suppressed by the operation of fire fighting systems, are unlikely to raise cask temperatures high enough to significantly increase Cs vaporization or to cause substantial conversion of $\mathrm{Ru}$ to volatile $\mathrm{RuO}_{4}$. Conversely, engulfing fires of about one hour duration that involve high-grade fuels could for some accidents heat cask interiors to temperatures where (1) Al-U alloy fuels melt, (2) $\mathrm{Kr}, \mathrm{Cs}_{2} \mathrm{O}$, and $\mathrm{RuO}_{4}$ are 
easily vaporized both from TRIGA fuel pellets and from melted Al-U alloy fuels, and (3) conversion of $\mathrm{Ru}$ to $\mathrm{RuO}_{4}$ is substantial if either fuel is exposed to air.

By definition, Category 5 and 6 accidents are caused by or lead to fires. Thus, for Category 5 and 6 accidents, fission product release depends strongly on the temperature to which the spent fuel is heated by the fire. For Category 5 accidents, where fuel temperatures remain below $900 \mathrm{~K}$ (i.e., remain below the ignition point of TRIGA fuel in air and the melting point of Al-U alloy fuels), release from TRIGA U-Zr-H pellets should be similar to that from $\mathrm{UO}_{2}$ pellets, and release from Al-U alloy fuels should be very small, perhaps negligible, since diffusion in the metal plates from which the fuel is fabricated will be too slow to cause significant release to the cask, much less to the environment.

Above $900 \mathrm{~K}, \mathrm{Cs}_{2} \mathrm{O}$, the expected chemical form of $\mathrm{Cs}$ in spent fuel, and $\mathrm{RuO}_{4}$, become quite volatile [Cu84, Co90]. Thus, for Category 5 accidents during which fuel is heated to temperatures that significantly exceed $900 \mathrm{~K}$, release of $\mathrm{Kr}$ and of $\mathrm{Cs}$ as $\mathrm{Cs}_{2} \mathrm{O}$ from TRIGA fuel pellets or from melted Al-U alloy fuels to the cask interior should be substantial. Release of $\mathrm{Ru}$ will also be substantial if exposure of the fuel to air converts $\mathrm{Ru}$ to volatile $\mathrm{RuO}_{4}$. After release to the cask interior, transport of these fission products from the cask to the environment past a failed cask seal will only be efficient if the gases in the cask expand significantly due to heating of the cask to temperatures well above $900 \mathrm{~K}$. For example, if melting of an Al-U alloy fuel at $923 \mathrm{~K}$ causes almost all of the $\mathrm{Kr}$ trapped in the fuel to be released to the cask interior, then further heating of cask gases to $1023 \mathrm{~K}$ will cause 10 percent of the $\mathrm{Kr}$ and of all other gaseous species in the cask interior to be lost to the environment due to expansion of the cask gases past the failed cask seal.

After the fire dies out, cooling of the hot cask will cause air to be drawn into the cask as the gases in the cask cool and contract. Thus, almost any hot fire of substantial duration will lead to substantial air ingression into a failed cask. Enhanced $\mathrm{Ru}$ release could then occur, but only if large amounts of fuel are exposed to the air, if this exposure occurs when the fuel is still hot enough to allow $\mathrm{Ru}$ to be oxidized to a volatile species such as $\mathrm{RuO}_{4}$, and if there is a transport process operating that causes the volatile $\mathrm{Ru}$ species to be released from the failed cask.

If air is drawn into the cask by cooling while an Al-U alloy fuel is still molten, substantial exposure of fuel to air will occur, and therefore oxidation of $\mathrm{Ru}$ to $\mathrm{RuO}_{4}$ should take place. However, after the $\mathrm{RuO}_{4}$ is released to the cask interior, release to the environment can only occur by an inefficient transport mechanism, diffusion against the inflow of air into the cooling cask. Thus, Category 5 accident conditions, even those that reach unusually high temperatures, are not expected to significantly increase $\mathrm{Ru}$ release from $\mathrm{Al}-\mathrm{U}$ alloy fuels. Significant $\mathrm{Ru}$ release might occur during a Category 5 accident, if, after the fire dies down and air is drawn into the cask, the fire flares up anew and again heats the cask to elevated temperatures, whereupon gas expansion would transport some of the $\mathrm{RuO}_{4}$ vapors from the cask to the environment. 
If cask cooling draws air into a cask that contains TRIGA fuel while the fuel is still at temperatures above $900 \mathrm{~K}$, the fuel will burn spontaneously and exothermically, causing $\mathrm{Ru}$ to be converted to $\mathrm{RuO}_{4}$. Heating of the fuel and the cask gases by the highly exothermic oxidation of the hydride fuel will then cause the $\mathrm{RuO}_{4}$ to vaporize, the cask gases to expand, and some of the volatilized $\mathrm{RuO}_{4}$ to be transported from the cask to the environment. Cyclic repetition of this sequence could further increase $\mathrm{Ru}$ release.

During Category 6 accidents, release from fuel to the cask interior of $\mathrm{Kr}, \mathrm{Cs}$, and $\mathrm{Ru}$, after conversion to $\mathrm{RuO}_{4}$ by exposure to air, would occur by the processes just described for Category 5 accidents. Because gas convection through a failed cask is by definition substantial during Category 6 accidents, exposure of hot fuel to air would always cause conversion of $\mathrm{Ru}$ to $\mathrm{RuO}_{4}$ to be substantial, and all vapors released from the fuel to the cask would be transported from the cask to the environment by the convective flow of gases.

\subsubsection{Release Fractions for High-Temperature Events}

The discussion presented in Section 3.2.2 indicates that at elevated temperatures release fractions for Al-U alloy and TRIGA fuels will differ substantially from those used in the EA for Category 6 events and also for Category 5 events that reach unusually high temperatures. To allow the consequences of such high-temperature events to be examined, the EA severity category scheme was modified by subdividing Categories 5 and 6 into low (Categories 5A and $6 \mathrm{~A})$ and high (Categories 5B and 6B) temperature categories.

Fire events that do not heat cask contents above $900 \mathrm{~K}$ are placed in Categories $5 \mathrm{~A}$ and $6 \mathrm{~A}$. Fire events that heat cask contents above $900 \mathrm{~K}$ are placed in Categories $5 \mathrm{~B}$ and $6 \mathrm{~B}$. Events that lead to seal failure are placed in Category 5. Events that lead to catastrophic cask failures (e.g., one medium hole, two or more small holes), failures that permit significant convective flow of gases through the failed cask, are placed in Category 6. Thus, for Category 5 events, transport from the cask interior to the environment of fission products released from fuel to the cask interior must be driven by expansion of cask gases caused by heating of the cask by the fire; whereas for Category 6 events, transport from the cask to the environment can be efficiently driven by convective flow of gases through the cask. Table 2 summarizes the attributes of the modified EA Accident Categories (from now on, these modified accident categories will be designated EIS4, EIS5A, EIS5B, EIS6A, and EIS6B to distinguish them from the original EA Accident Categories EA4, EA5, and EA6).

\subsubsection{Release Fraction Formulas}

In order to develop release fraction formulas for the modified Accident Categories EIS4, EIS5A, EIS5B, EIS6A, and EIS6B, let

$$
F_{B 1}=\text { the fraction of fuel elements failed by mechanical forces caused by the ship collision }
$$


Table 2. EA Release Category Scheme Attributes as Modified to Reflect the High-Temperature Behavior of Research Reactor Fuels

\begin{tabular}{|c|c|c|c|}
\hline Category & Cask Failure Mode & $\begin{array}{l}\text { Transport Process } \\
\text { From Cask }\end{array}$ & $\begin{array}{l}\text { Temperature of } \\
\text { Cask Contents }\end{array}$ \\
\hline EIS4 & Seal Failure & Diffusion & Ambient \\
\hline EIS5A & Seal Failure & Gas Expansion & $\mathrm{T}<900 \mathrm{~K}$ \\
\hline EIS5B & Seal Failure & Gas Expansion & $\mathrm{T}>900 \mathrm{~K}$ \\
\hline EIS6A & $\begin{array}{l}\text { One medium hole or } \\
\text { two small holes }\end{array}$ & Convection & $\mathrm{T}<900 \mathrm{~K}$ \\
\hline EIS6B & $\begin{array}{l}\text { One medium hole or } \\
\text { two small holes }\end{array}$ & Convection & $\mathrm{T}>900 \mathrm{~K}$ \\
\hline
\end{tabular}

$\mathrm{F}_{\mathrm{FCl}}=$ the release fraction for fission products from the fuel to the cask cavity caused by the mechanical effects of the ship collision

$\mathrm{F}_{\mathrm{CE1}}=$ the fraction of the fission products released to the cask cavity that escape from the cask in the absence of a fire

Then, the release fraction $\left(\mathrm{F}_{\mathrm{R} 4}\right)$ for Category 4 events is given by

$$
\mathrm{F}_{\mathrm{R} 4}=\mathrm{F}_{\mathrm{B} 1} \mathrm{~F}_{\mathrm{FCl}} \mathrm{F}_{\mathrm{CE} 1}
$$

If the collision leads to a fire that heats the cask to elevated temperatures that do not exceed $900 \mathrm{~K}$, heating of the fuel may cause more fission products to be released from the fuel to the cask cavity, and expansion of cask gases due to heating by the fire will cause some fraction of the gas-borne fission products to be transported from the cask interior through the failed cask seal to the environment. Thus, the release fraction for Category $5 \mathrm{~A}$ events is given by

$$
\mathrm{F}_{\mathrm{R} 5 \mathrm{~A}}=\mathrm{F}_{\mathrm{R} 4}+\mathrm{F}_{\mathrm{B} 1} \mathrm{~F}_{\mathrm{FC1}}\left(1-\mathrm{F}_{\mathrm{CE} 1}\right) \mathrm{F}_{\mathrm{CE} 2}+\left[\mathrm{F}_{\mathrm{B} 1}+\left(1-\mathrm{F}_{\mathrm{B} 1}\right) \mathrm{F}_{\mathrm{B} 2}\right] \mathrm{F}_{\mathrm{FC} 2} \mathrm{~F}_{\mathrm{CE} 2}
$$

where

$\mathrm{F}_{\mathrm{FC} 2}=$ the fraction of fission products released from the fuel to the cask cavity due to heating of the fuel from ambient temperature $\left(\mathrm{T}_{\mathrm{a}}\right)$ to some elevated final temperature $\left(T_{f}\right)$ less than $900 \mathrm{~K}$ for Category $5 \mathrm{~A}$ and $6 \mathrm{~A}$ accidents and greater than $900 \mathrm{~K}$ for Category $5 \mathrm{~B}$ and $6 \mathrm{~B}$ accidents

$F_{B 2}=$ the fraction of the fuel elements failed by burst rupture due to heating from $T_{a}$ to $\mathrm{T}_{\mathrm{f}}=0.0$ as all rods are assumed to fail mechanically due to crush 
$\mathrm{F}_{\mathrm{CE2}}=1-\left(\mathrm{T}_{\mathrm{a}} / \mathrm{T}_{\mathrm{f}}\right)=$ the fraction of fission products that escape from the cask to the environment due to heating of cask gases from ambient temperature $\left(T_{a}\right)$ to some elevated temperature $\left(T_{f}\right)$, where $T_{a} / T_{f}=$ the fraction of the gases in the cask at ambient temperature that remain in the cask after heating to $T_{f}$

and $\mathrm{F}_{\mathrm{R} 4}, \mathrm{~F}_{\mathrm{B} 1}, \mathrm{~F}_{\mathrm{FC} 1}$, and $\mathrm{F}_{\mathrm{CE} 1}$ are as previously defined.

If the collision has led to cask failures (a single medium hole or two smaller holes) that allow substantial convective flow through the cask, then all fission products released to the cask interior will be transported from the cask to the environment. Thus, the release fraction for Category $6 \mathrm{~A}$ events is given by

$$
\mathrm{F}_{\mathrm{R} 6 \mathrm{~A}}=\mathrm{F}_{\mathrm{R} 4}+\mathrm{F}_{\mathrm{B} 1} \mathrm{~F}_{\mathrm{FC} 1}\left(1-\mathrm{F}_{\mathrm{CE} 1}\right)+\left[\mathrm{F}_{\mathrm{B} 1}+\left(1-\mathrm{F}_{\mathrm{B} 1}\right) \mathrm{F}_{\mathrm{B} 2}\right] \mathrm{F}_{\mathrm{FC} 2}
$$

as by definition $\mathrm{F}_{\mathrm{CE2}}=1.0$ for Category 6 events.

The release fraction for fire events that heat a failed cask to temperatures above $900 \mathrm{~K}$, where Al-U alloy fuels melt and TRIGA fuel burns if exposed to oxygen, is given by

$$
F_{R S B}=F_{R S A}+\left[F_{B 1}+\left(1-F_{B 1}\right)\left(F_{B 2}+F_{B 3}\right)\right] F_{F C 3} F_{C E 3}
$$

where

$\mathrm{F}_{\mathrm{FC} 3}=$ the fraction of fission products released from the fuel to the cask cavity after the fuel has been heated to $\mathrm{T}_{\mathrm{FC} 3}$, the temperature where Al-U alloy fuels melt, and TRIGA fuel burns if exposed to air

$F_{B 3}=$ the fraction of the fuel elements failed by burst rupture due to heating from $T_{\mathrm{FC3}}$ to $\mathrm{T}_{\mathrm{f}}$ where now $\mathrm{T}_{\mathrm{f}}>\mathrm{T}_{\mathrm{FC} 3}=0.0$ as all rods are assumed to fail mechanically due to crush

$\mathrm{F}_{\mathrm{CE} 3}=1-\left(\mathrm{T}_{\mathrm{FC} 3} / \mathrm{T}_{\mathrm{f}}\right)=$ the fraction of fission products in the cask at $\mathrm{T}_{\mathrm{FC} 3}$ that escape to the environment due to heating of cask gases from $T_{F C 3}$ to some temperature $T_{f}>T_{F C 3}$, where $T_{\mathrm{FC} 3} / \mathrm{T}_{\mathrm{f}}=$ the fraction of the gases in the cask after heating to $\mathrm{T}_{\mathrm{FC} 3}$ that remain in the cask after further heating to $T_{f}$

and all other parameters are as previously defined. Again, if a Category 6 event has occurred,

$$
\mathrm{F}_{\mathrm{R} 6 \mathrm{~B}}=\mathrm{F}_{\mathrm{R} 6 \mathrm{~A}}+\left[\mathrm{F}_{\mathrm{B} 1}+\left(1-\mathrm{F}_{\mathrm{B} 1}\right)\left(\mathrm{F}_{\mathrm{B} 2}+\mathrm{F}_{\mathrm{B} 3}\right)\right] \mathrm{F}_{\mathrm{FC} 3}
$$

since by definition $\mathrm{F}_{\mathrm{CE} 3}=1.0$ for Category 6 events.

\subsubsection{Parameter Values for Release Fraction Formulas}

The release fractions used in the EA are the same as those used in the Taiwan EA [DOE86, DOE88a], which cites Wilmot [Wi84] as its source for release fractions. Wilmot developed 
release fractions for air-cooled casks for release of fission products from spent commercial $\mathrm{UO}_{2}$ fuel for three processes: impact, burst, and oxidation. EA Category 4 release fractions are the same as those developed by Wilmot for impact events involving air-cooled casks. Except for Cs, EA Category 5 release fractions are equal to the sum of Wilmot's release fractions for impact and burst, and EA Category 6 release fractions are equal to the sum of Wilmot's release fractions for impact, burst, and oxidation. For Cs, the EA used release fractions that were adjusted to reflect the effect of metallic fuel properties on Cs release.

For impact events, Wilmot used $\mathrm{F}_{\mathrm{B} 1}=0.1, \mathrm{~F}_{\mathrm{FC} 1}=0.2$ and $\mathrm{F}_{\mathrm{CE} 1}=0.5$ for $\mathrm{Kr}$; and $\mathrm{F}_{\mathrm{FC} 1}=$ $2 \times 10^{-6}$ and $F_{C E 1}=0.05$ for $\mathrm{Cs}, \mathrm{Ru}$, and $\mathrm{Pu}$ (i.e., for release of fuel fines and thus also for the fission products trapped in the fines). For burst events, Wilmot assumed that $F_{B 2}=0.9$. Table 1 shows that the EA used values of $0.1,9 \times 10^{-4}, 1 \times 10^{-6}$, and $5 \times 10^{-8}$, respectively, for the release fractions for $\mathrm{Kr}, \mathrm{Cs}, \mathrm{Ru}$, and Particulate for Category 5 events. If Equation 2 is solved for $F_{\mathrm{FC} 2}$ using the $E A$ values for Category 5 events for $F_{R 5 A}$, Wilmot's values for $F_{B 1}$, $F_{B 2}, F_{F C 1}$, and $F_{C E 1}$, and values of 300 and $800 \mathrm{~K}$ for $T_{2}$ and $T_{f}$, then the following values are obtained for $\mathrm{F}_{\mathrm{FC} 2}$ : 0.15 for $\mathrm{Kr}, 1.6 \times 10^{-3}$ for $\mathrm{Cs}, 1.6 \times 10^{-6}$ for $\mathrm{Ru}$, and 0 for Particulate.

Cask damage caused by impact and crush forces is analyzed below in Section 3.4.4. That analysis suggests (1) that cask damage will not result from the impact forces experienced by casks during ship collisions, and (2) that, if a cask is subjected-to crush forces, the resulting cask damage will always fail most of the fuel elements in the cask. Therefore, to be conservative, $F_{B 1}=F_{B 2}=F_{B 3}=1.0$.

To facilitate comparison of the release fraction values developed here to the values used in the $\mathrm{EA}$, the release fraction values for the $\mathrm{Cs}, \mathrm{Ru}$, and Particulate chemical element groups for Category 4 events were forced to be the same as the values used in the EA. Although Al-U alloy fuels should have very little (if any) fuel fines associated with the metal plates from which the fuel bundles are fabricated, to regenerate the EA Category 4 release fraction for Particulate, it was arbitrarily assumed that Al-U alloy fuels have amounts of fuel fines onetenth of the amount assumed by Wilmot for $\mathrm{UO}_{2}$ fuels. Thus, for Al-U alloy fuels, $\mathrm{F}_{\mathrm{FC1}}=$ $2 \times 10^{-7}$ and therefore, because $\mathrm{F}_{\mathrm{B} 1}=1.0, \mathrm{~F}_{\mathrm{R} 4}=2 \times 10^{-8}$, which is the value used in the EA for the release fraction for $\mathrm{Cs}, \mathrm{Ru}$, and Particulate for Category 4 events.

The parameter $\mathrm{F}_{\mathrm{FC} 3}$ specifies the fraction of fission products that are released to the cask cavity from spent research reactor fuel when Al-U alloy fuels melt or TRIGA fuel burns. Literature values for this parameter could not be found. Reasonable values for $\mathrm{F}_{\mathrm{FC} 3}$ for $\mathrm{Al}-\mathrm{U}$ alloy fuels are 1.0 for $\mathrm{Kr}, 0.1$ for $\mathrm{Cs}, 1.6 \times 10^{-5}$ for $\mathrm{Ru}$, and $1.6 \times 10^{-6}$ for Particulate, where Ru release from alloy fuel upon melting has been assumed to be ten times the Ru release estimated for commercial $\mathrm{UO}_{2}$ fuel during Category $5 \mathrm{~A}$ events (the value of $\mathrm{F}_{\mathrm{FC2}}$ for $\mathrm{Ru}$ release from $\mathrm{UO}_{2}$ fuel for Category 5A events), and Particulate release has been assumed to be about the same as $\mathrm{Ru}$ release from $\mathrm{UO}_{2}$ fuel for Category $5 \mathrm{~A}$ events and about ten times larger than Particulate release from Al-U alloy fuels for Category. 4 events (the value of $\mathrm{F}_{\mathrm{FCl}}$ for Particulate release from Al-U alloy fuels for Category 4 events), as the melting of Al-U alloy fuels due to heating of the cask by a fire is not likely to be violent. 
Category 6B accidents involve cask failures that allow convective flow of combustion gases and air through the failed cask. During Category 6B accidents, TRIGA fuel will burn exothermically, if convection causes air to flow through the cask. Accordingly, reasonable values for $\mathrm{F}_{\mathrm{FC} 3}$ for TRIGA fuel for Category $6 \mathrm{~B}$ accidents are 1.0 for $\mathrm{Kr} ; 0.3$ for $\mathrm{Cs} ; 0.3$ for $\mathrm{Ru}$, since burning of the fuel means that $\mathrm{Ru}$ will be converted to volatile $\mathrm{RuO}_{4}$ by exposure to air; and 0.01 for Particulate, on the assumption that the high exothermicity of the combustion process will cause one percent of the fuel mass to be aerosolized.

Air can enter a failed cask during Category 5B accidents only when cask gases contract upon cask cooling. But entry of air will not always lead to increased release of fission products from TRIGA fuel. Increased release will not occur if the air cools the TRIGA fuel below $900 \mathrm{~K}$, the temperature at which TRIGA fuel burns spontaneously in air. Even if burning does occur, the fission products released by burning of fuel can be efficiently transported from the cask to the environment only by expansion of cask gases during the burning of the TRIGA fuel. But expansion of cask gases will stop air flow into the cask and consequently the burning will also cease. Thus, substantial release of fission products during Category $5 \mathrm{~B}$ accidents can occur from TRIGA fuel only if the cask passes through several cooling/burning cycles. As this is unlikely, Category $6 \mathrm{~B}$ values for $\mathrm{F}_{\mathrm{FC} 3}$ for TRIGA fuel are not suitable for Category $5 \mathrm{~B}$ accidents. Accordingly, when applied to Category $5 \mathrm{~B}$ accidents, the TRIGA fuel $\mathrm{F}_{\mathrm{FC} 3}$ values for Category $6 \mathrm{~B}$ accidents were decreased by a factor of three.

Table 3 lists the parameters used in Equations 1 through 5, and presents the values used for each input parameter to calculate the release fractions $F_{R 4}, F_{R 5 A}, F_{R 6 A} ; F_{R 5 B}$, and $F_{R 6 B}$. In the table, a check mark $(\sqrt{ })$ indicates the chemical element group ( $\mathrm{Kr}, \mathrm{Cs}, \mathrm{Ru}, \mathrm{P}=$ Particulate) that the values in the row apply to and quotation marks mean that the previous value listed in the column was used to calculate the indicated $F_{R}$ value. For the four EA5 results for $\mathrm{UO}_{2}$ fuel, the result calculated is the $F_{\mathrm{FC} 2}$ value, not the $\mathrm{F}_{\mathrm{R} 5}$ value, which here is an input parameter whose value was set equal to the release fraction value used in the EA for the indicated chemical element group for Category 5 accidents.

Table 4 presents the release fraction values developed using the construct just described, and compares the values to the release fraction values used in the EA for Accident Categories 4, 5, and 6 by presenting the ratio (EIS value/EA value) of the EIS values for Al-U and TRIGA $(\mathrm{U}-\mathrm{Zr}-\mathrm{H})$ fuels to the value used in the EA that was developed from Wilmot's results [Wi81, Wi84].

Table 4 shows that EA4 and EIS4 release fractions for $\mathrm{Cs}, \mathrm{Ru}$, and Particulate from Al-U alloy and $\mathrm{UO}_{2}$ fuels are the same. They are the same because the parameter values used to calculate the EIS4 release fractions for these three chemical element classes were deliberately given values that would reproduce the EA4 value of $1 \mathrm{E}-8$. The EIS4 release fraction for $\mathrm{Kr}$ also has a value of $1 \mathrm{E}-8$ because, below the melting point of the Al-U alloy, $\mathrm{Kr}$ can only be released as a constituent of small particles that become gasborne as a result of the collision. Therefore the release fraction for $\mathrm{Kr}$ is the same as that for Particulate. U-Zr-H (TRIGA) fuel EIS4 release fractions all have values that are ten times larger than the EA4 release fraction values because the EIS release construct assumes that the crush forces that characterize a ship 
Table 3. Input Parameter Values Used to Calculate Release Fractions for High-Temperature Fire Events

\begin{tabular}{|c|c|c|c|c|c|c|c|c|c|c|c|c|c|c|c|c|}
\hline \multirow{2}{*}{$\begin{array}{l}\text { Accident } \\
\text { Category }\end{array}$} & \multirow[b]{2}{*}{ Fuel } & \multicolumn{4}{|c|}{ Element } & \multicolumn{11}{|c|}{ Parameter } \\
\hline & & $\mathrm{Kr}$ & Cs & $\mathrm{Ru}$ & $\mathrm{P}$ & $\mathrm{F}_{\mathrm{B} 1}$ & $\mathrm{~F}_{\mathrm{FC} 1}$ & $\mathrm{~F}_{\mathrm{CE1} 1}$ & $\mathrm{~F}_{\mathrm{B} 2}$ & $\mathrm{~F}_{\mathrm{FC} 2}$ & $\mathrm{~F}_{\mathrm{B} 3}$ & $\mathrm{~T}_{\mathrm{a}}(\mathrm{K})$ & $\mathrm{T}_{\mathrm{FC3}}$ & $T_{\mathrm{f}}(\mathrm{K})$ & $\mathrm{F}_{\mathrm{FC3}}$ & $\mathrm{F}_{\mathrm{R}}$ \\
\hline EA4 & $\mathrm{UO}_{2}$ & $\sqrt{ }$ & & & 1 & 0.1 & 0.2 & 0.5 & & & & & & & & 0.01 \\
\hline EA5 & & $\sqrt{ }$ & v & $\sqrt{ }$ & $v$ & " & $\begin{array}{l}2 \mathrm{E}-6 \\
0.2\end{array}$ & $\begin{array}{l}0.05 \\
0.5\end{array}$ & 09 & 0.15 & & 300 & & 800 & & $\mid \begin{array}{l}1 \mathrm{E}-8 \\
1 \mathrm{E}-1\end{array}$ \\
\hline & & & $\sqrt{ }$ & & & $"$ & $2 \mathrm{E}-6$ & 0.05 & $"$ & $1.6 \mathrm{E}-3$ & & & & & & $9 \mathrm{E}-4$ \\
\hline & & & & $\sqrt{ }$ & $\sqrt{ }$ & " & $"$ & $"$ & " " & $1.6 \mathrm{E}-6$ & & $"$ & & $"$ & & $1 \mathrm{E}-6$ \\
\hline EIS4 & U-Zr-H & $\sqrt{ }$ & & & & 1.0 & 0.2 & 0.5 & & & & & & & & 0.1 \\
\hline & $\mathrm{x}$ & & $\sqrt{ }$ & $\sqrt{ }$ & $\sqrt{ }$ & $"$ & $2 \mathrm{E}-6$ & 0.05 & & & & & & & & $1 \mathrm{E}-7$ \\
\hline & Al-U & $\sqrt{ }$ & $\sqrt{ }$ & $\sqrt{ }$ & $\sqrt{ }$ & $"$ & $2 \mathrm{E}-7$ & " & & & & & & & & | $1 \mathrm{E}-8$ \\
\hline EIS5A & $\mathrm{U}-\mathrm{Zr}-\mathrm{H}$ & $\sqrt{ }$ & 1 & & & $"$ & 0.2 & 0.5 & 0.0 & 0.15 & & 300 & & 800 & & 0.26 \\
\hline & $\begin{array}{l}x \\
x\end{array}$ & & v & $\sqrt{ }$ & & $"$ & $\begin{array}{c}2 \mathrm{E}-6 \\
11\end{array}$ & $\begin{array}{c}0.05 \\
.1\end{array}$ & $"$ & $\begin{array}{l}1.6 \mathrm{E}-3 \\
1.6 \mathrm{E}-6\end{array}$ & & $"$ & & $"$ & & $\mid \begin{array}{l}1 \mathrm{E}-3 \\
2.3 \mathrm{E}-6\end{array}$ \\
\hline & $\hat{x}$ & & & & $\sqrt{ }$ & " & $"$ & $"$ & " & 0.0 & & " & & $"$ & & $1.3 \mathrm{E}-6$ \\
\hline & $\mathrm{Al}-\mathrm{U}$ & $\sqrt{ }$ & $\sqrt{ }$ & $\sqrt{ }$ & $\sqrt{ }$ & " & $2 \mathrm{E}-7$ & " & $"$ & & & " & & $"$ & & $1.3 \mathrm{E}-7$ \\
\hline EIS5B & $\mathrm{U}-\mathrm{Zr}-\mathrm{H}$ & $\sqrt{ }$ & & & & $"$ & 0.2 & 0.5 & " & 0.15 & 0.0 & $"$ & 923 & 1023 & & 0.31 \\
\hline & $\mathrm{x}$ & & $\sqrt{ }$ & $\sqrt{1}$ & & $"$ & $2 \mathrm{E}-6$ & 0.05 & " & $1.6 \mathrm{E}-3$ & $"$ & " & " & " & 0.1 & $1.1 \mathrm{E}-2$ \\
\hline & $\begin{array}{l}x \\
x\end{array}$ & & & & $\sqrt{ }$ & $"$ & " & 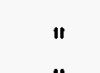 & $"$ & $\left\{\begin{array}{l}.0 \mathrm{D}-0 \\
0.0\end{array}\right.$ & $"$ & $"$ & $"$ & $"$ & $\begin{array}{l}0.1 \\
3.3 \mathrm{E}-3\end{array}$ & 3.3E-4 \\
\hline & Al-U & $\sqrt{ }$ & & & & " & 2E-7 & " & " & & " & $"$ & " & $"$ & 1.0 & $9.8 \mathrm{E}-2$ \\
\hline & $\mathrm{x}$ & & $\sqrt{ }$ & $\sqrt{1}$ & & $"$ & $"$ & $"$ " & $"$ & " & " & " & " & " & 0.1 & $\mid \begin{array}{l}9.8 \mathrm{E}-3 \\
175-6\end{array}$ \\
\hline & & & & $v$ & $\sqrt{ }$ & " & $"$ & $"$ & $"$ & $"$ & " & $"$ & $"$ & $"$ & $\begin{array}{l}1.0 \mathrm{E}-3 \\
1.6 \mathrm{E}-6\end{array}$ & $\begin{array}{l}1.7 \mathrm{E}-6 \\
3.0 \mathrm{E}-7\end{array}$ \\
\hline EIS6A & $\mathrm{U}-\mathrm{Zr}-\mathrm{H}$ & $\sqrt{ }$ & & & & " & 0.2 & 0.5 & " & 0.15 & & $"$ & & 800 & & 0.35 \\
\hline & $x$ & & $\sqrt{ }$ & $\sqrt{ }$ & & " & $\underset{\text { I"-6 }}{2 \mathrm{E}}$ & 0.05 & " & $\begin{array}{l}1.6 \mathrm{E}-3 \\
1.6 \mathrm{E}-6\end{array}$ & & $"$ & & " & & $\begin{array}{l}1.6 \mathrm{E}-3 \\
36 \mathrm{E}-6\end{array}$ \\
\hline & $\begin{array}{l}x \\
x\end{array}$ & & & $\checkmark$ & $\sqrt{ }$ & " & $"$ & 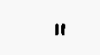 & $"$ & $\begin{array}{l}0.0 \\
0.0\end{array}$ & & $"$ & & $"$ & & $2 \mathrm{E}-6$ \\
\hline & $\mathrm{Al}-\mathrm{U}$ & $\sqrt{ }$ & $\sqrt{ }$ & $\sqrt{ }$ & $\sqrt{ }$ & 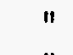 & 2E-7 & " & $"$ & " & & " & & $"$ & & 2E-7 \\
\hline EIS6B & $\mathrm{U}-\mathrm{Zr}-\mathrm{H}$ & $\sqrt{ }$ & & & & 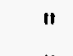 & 0.2 & 0.5 & $"$ & 0.15 & 0.0 & $"$ & 923 & 1023 & 1.0 & 1.0 \\
\hline & $\mathrm{x}$ & & $\sqrt{ }$ & $\sqrt{1}$ & & " " & $2 \mathrm{E}-6$ & 0.05 & " & $1.6 \mathrm{E}-3$ & $"$ & " & " & " & 0.3 & 0.3 \\
\hline & $\begin{array}{l}x \\
x \\
x\end{array}$ & & & & $\sqrt{ }$ & $"$ & " & 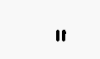 & 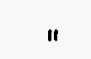 & $\mid \begin{array}{l}1.0 \mathrm{E}-0 \\
0.0\end{array}$ & " & $"$ & $"$ & $"$ & $\begin{array}{l}0.3 \\
0.01\end{array}$ & $\begin{array}{l}0.3 \\
0.01\end{array}$ \\
\hline & $\hat{\mathrm{Al}}-\mathrm{U}$ & $\sqrt{ }$ & & & & 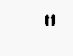 & $2 \mathrm{E}-7$ & " & $"$ & & " & " & " & $"$ & 1.0 & 1.0 \\
\hline & & & $\sqrt{ }$ & & & 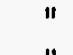 & $"$ & 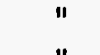 & " & $"$ & $"$ & " & $"$ & $"$ & 0.1 & 0.1 \\
\hline & & & & v & $\sqrt{ }$ & " & & $\pi$ & 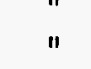 & 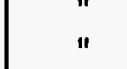 & " & $"$ & $"$ & $"$ & $\begin{array}{l}1.6 \mathrm{E}-5 \\
1.6 \mathrm{E}-6\end{array}$ & $\begin{array}{l}1.6 \mathrm{E}-5 \\
1.8 \mathrm{E}-6\end{array}$ \\
\hline
\end{tabular}


Table 4. Release Fraction Values for Research Reactor Fuels

\begin{tabular}{|c|c|c|c|c|c|}
\hline \multirow{2}{*}{$\begin{array}{l}\text { Accident } \\
\text { Category }\end{array}$} & \multirow[b]{2}{*}{ Fuel } & \multicolumn{4}{|c|}{ Element Group } \\
\hline & & $\mathrm{Kr}$ & Cs & $\mathrm{Ru}$ & Particulate \\
\hline EA4 & $\mathrm{UO}_{2}$ & 0.01 & $1 \mathrm{E}-8$ & $1 \mathrm{E}-8$ & $1 \mathrm{E}-8$ \\
\hline EIS4 & $\mathrm{Al}-\mathrm{U}$ & $1 \mathrm{E}-8$ & $1 \mathrm{E}-8$ & $1 \mathrm{E}-8$ & $1 \mathrm{E}-8$ \\
\hline Ratio & & $1 \mathrm{E}-6$ & 1 & 1 & 1 \\
\hline EA5 & $\mathrm{UO}_{2}$ & 0.1 & $9 E-4$ & $1 \mathrm{E}-6$ & $5 \mathrm{E}-8$ \\
\hline EIS5A & $\mathrm{Al}-\mathrm{U}$ & $1.3 \mathrm{E}-7$ & $1.3 \mathrm{E}-7$ & $1.3 \mathrm{E}-7$ & $1.3 \mathrm{E}-7$ \\
\hline Ratio & & $1.3 \mathrm{E}-6$ & $1.4 \mathrm{E}-4$ & 0.13 & 2.6 \\
\hline EA5 & $\mathrm{UO}_{2}$ & 0.1 & $9 \mathrm{E}-4$ & $1 \mathrm{E}-6$ & $5 \mathrm{E}-8$ \\
\hline EIS5B & $\mathrm{Al}-\mathrm{U}$ & $9.8 \mathrm{E}-2$ & $9.8 \mathrm{E}-3$ & $1.7 \mathrm{E}-6$ & $3 \mathrm{E}-7$ \\
\hline Ratio & & 0.098 & 11 & 1.7 & 0.6 \\
\hline EA6 & $\mathrm{UO}_{2}$ & 0.11 & $9.8 \mathrm{E}-4$ & $4.2 \mathrm{E}-5$ & $5 \mathrm{E}-8$ \\
\hline EIS6A & $\mathrm{Al}-\mathrm{U}$ & $2 \mathrm{E}-7$ & $2 \mathrm{E}-7$ & $2 \mathrm{E}-7$ & $2 E-7$ \\
\hline Ratio & & $1.8 \mathrm{E}-6$ & $2.0 \mathrm{E}-4$ & $4.6 \mathrm{E}-3$ & 4.0 \\
\hline EA6 & $\mathrm{UO}_{2}$ & $1.1 \mathrm{E}-1$ & $9.8 \mathrm{E}-4$ & $4.2 E-5$ & $5 \mathrm{E}-8$ \\
\hline EIS6B & $A L-U$ & 1.0 & 0.1 & $1.6 \mathrm{E}-5$ & $1.6 \mathrm{E}-6$ \\
\hline Ratio & & 9.1 & 100 & 0.4 & 32 \\
\hline EA4 & $\mathrm{UO}_{2}$ & 0.01 & $1 \mathrm{E}-8$ & $1 \mathrm{E}-8$ & $1 \mathrm{E}-8$ \\
\hline EIS4 & $\mathrm{U}-\mathrm{Zr}-\mathrm{H}$ & 0.1 & $1 \mathrm{E}-7$ & $1 \mathrm{E}-7$ & $1 \mathrm{E}-7$ \\
\hline Ratio & & 10 & 10 & 10 & 10 \\
\hline EA5 & $\mathrm{UO}_{2}$ & 0.1 & $9 \mathrm{E}-4$ & $1 \mathrm{E}-6$ & $5 \mathrm{E}-8$ \\
\hline EIS5A & $\mathrm{U}-\mathrm{Zr}-\mathrm{H}$ & 0.26 & $1 \mathrm{E}-3$ & $2.3 \mathrm{E}-6$ & $1.3 \mathrm{E}-6$ \\
\hline Ratio & & 2.6 & 1.1 & 2.3 & 26 \\
\hline EA5 & $\mathrm{UO}_{2}$ & 0.1 & $9 \mathrm{E}-4$ & $1 \mathrm{E}-6$ & $5 \mathrm{E}-8$ \\
\hline EIS5B & $\mathrm{U}-\mathrm{Zr}-\mathrm{H}$ & 0.31 & $1.1 \mathrm{E}-2$ & $9.8 \mathrm{E}-3$ & $3.3 \mathrm{E}-4$ \\
\hline Ratio & & 3.1 & 12 & $9.8 \mathrm{E}+3$ & $6.6 \mathrm{E}+3$ \\
\hline EA6 & $\mathrm{UO}_{2}$ & 0.11 & $9.8 \mathrm{E}-4$ & $4.2 \mathrm{E}-5$ & $5 \mathrm{E}-8$ \\
\hline EIS6A & $\mathrm{U}-\mathrm{Zr}-\mathrm{H}$ & 0.35 & $1.6 \mathrm{E}-3$ & $3.6 \mathrm{E}-6$ & $2 \mathrm{E}-6$ \\
\hline Ratio & & 3.2 & 1.6 & 0.086 & 40 \\
\hline EA6 & $\mathrm{UO}_{2}$ & 0.11 & $9.8 \mathrm{E}-4$ & $4.2 \mathrm{E}-5$ & $5 \mathrm{E}-8$ \\
\hline EIS6B & $\mathrm{U}-\mathrm{Zr}-\mathrm{H}$ & 1.0 & 0.3 & 0.3 & 0.01 \\
\hline Ratio & & 0.91 & 310 & $7.1 \mathrm{E}+3$ & $2 E+5$ \\
\hline
\end{tabular}


collision will fail all of the rods in the transportation cask, whereas Wilmot assumed that the impact forces that characterize truck and train collisions would fail only ten percent of the spent $\mathrm{UO}_{2}$ fuel rods in the cask.

Differences between EA and EIS release fraction values for Accident Categories 5, 5A, 5B, 6, $6 \mathrm{~A}$, and $6 \mathrm{~B}$ cannot be quantitatively explained. In general, EIS5A release fractions for Al-U alloy fuels are smaller than EA5 release fractions while EIS5B release fractions are larger than EA5 release fractions. The same pattern is observed for EIS6A and 6B release fractions when compared to EA6 release fractions. This pattern is expected for Al-U alloy fuels where release will be inhibited in comparison to pelletized fuels until the alloy melts, whereupon release will be greatly enhanced. For U-Zr-H (TRIGA) fuel, EIS5A release fractions are larger and EIS5B release fractions are much larger than EA5 release fractions. EIS5A release fractions are larger than EA5 release fractions because the EIS construct assumes that all rods fail while the EA construct assumes that only ten percent of the rods fail. Thus, although fission product transport in TRIGA and $\mathrm{UO}_{2}$ fuel pellets should be similar, because the EIS construct assumes that more rods fail, release from the rods to the cask is always greater for the EIS construct than for the EA construct. Conversely, because the EIS construct assumes that TRIGA fuel burns spontaneously at elevated temperatures, release from TRIGA fuel pellets is much larger than release from $\mathrm{UO}_{2}$ fuel pellets once the TRIGA fuel pellets begin to burn.

Although not quantitatively explicable, the trends in release fraction values generated by the EIS release construct are consistent with the behavior expected for Al-U alloy fuels and TRIGA fuel pellets during ship accidents. Therefore, the release fraction values generated by the new EIS release construct are wholly suitable for use in the ship accident consequence calculations performed for this study.

As is described in detail in Section 4.0, three sets of consequence calculations were performed for this study: base case calculations, high-temperature calculations, and sensitivity calculations. Base case calculations use EA release fraction values $\left(\mathrm{F}_{\mathrm{Ri}}\right.$ values) taken from Table 1. High-temperature calculations use release fraction values taken from Table 3. During the sensitivity stidies described below, MACCS calculations were performed that used release fractions that were developed for truck and rail accidents by Lawrence Livermore National Laboratory (LLNL) for the NRC's Modal Study [Fi87]. Although the EA presents release fractions for six severity categories, MACCS calculations were not performed for the first two categories, because cask failure does not occur for either category, or for Category 3 , because only CRUD is released in a Category 3 accident, and only minor amounts of CRUD deposits form on research reactor spent fuel. To examine the possible impacts of CRUD release, during the sensitivity studies, one Category 3 accident calculation was performed during which $350 \mathrm{Ci}$ of ${ }^{60} \mathrm{Co}$ was the only nuclide released, and one calculation was performed that added the same amount of ${ }^{60} \mathrm{Co}$ to the base case calculation. 


\subsubsection{Inventories}

About 100 research reactors may ship spent fuel to the United States. The fuels used in these reactors are fabricated as rods or stacks of flat, curved, or cylindrical plates. Radionuclide inventories for four representative research reactors, Osiris (flat plate design), RHF (curved plates arranged in an annular design), BR-2 (cylindrical plate design), and TRIGA (rod design), were examined during this study. Table 5 presents these inventories. Cask inventories were constructed for these four reactor fuels by SAIC [DOE95] using the ORIGEN 2 code [Cr80]. The constructions assumed transport in fully loaded Pegase casks [FR88]. Transport in Pegase casks was assumed as this maximized inventory size. Figure 1 and Table 6 depict the construction of the Pegase cask.

\subsection{Source Term Timing and Sensible Heat}

Ship accident source terms may be released as a puff (a short-duration release) and/or a tail (a long, slow release). Usually the puff release will follow the failure of the cask due to collision forces as the radioactive materials transferred to the cask atmosphere by the collision forces are transported from the cask by diffusion, or by gas expansion if the fuel is pressurized. A puff release may also occur if an ensuing fire leads to near-simultaneous cask and rod failure due to thermal loads. After cask failure due to collision forces, a tail release may occur, if an ensuing fire drives volatile fission products from the fuel over an extended heating period.

Ship collisions are short duration events. Therefore, if collision forces produce a puff release, the effective duration of the puff should be relatively short (10 to 30 minutes) as deposition to surfaces inside the failed cask will steadily decrease the amount of gas-borne aerosols available for release from the cask to the environment. Moreover, the release should be comprised of materials that are cold (no significant sensible heat content) and because cold should not be subject to plume rise.

If the puff release is caused by the near-simultaneous failure of cask seals and fuel elements due to fire-driven thermal loads, then the puff will be delayed in time and subject to plume rise, as the materials in the puff will be hot. The delay time will usually be about an hour, as a substantial engulfing fire must burn for about an hour to heat a cask and its contents to temperatures where cask seals and fuel elements may fail and vaporization rates [Cu84, $\mathrm{Co90]}$ for nongaseous fission products (e.g., $\mathrm{Cs}_{2} \mathrm{O}$ ) become significant. Puff releases caused by burst rupture of fuel elements should have relatively short durations (about ten minutes) as relief of cask pressure through the failed cask seal will be fairly rapid. Conversely, if cask failure was caused by collision forces, then thermal releases will take place over a long time period (of duration about an hour) as both vaporization of fission products and expansion of cask gases will take place throughout the entire heating period caused by the long-duration engulfing fire. 
Table 5. Curie Content of Fully Loaded Shipping Casks for Four Representative Fuel Types

\begin{tabular}{|c|c|c|c|c|}
\hline \multirow[b]{2}{*}{ Nuclide } & \multicolumn{4}{|c|}{ Fuel } \\
\hline & BR-2 & RHF & OSIRIS & TRIGA \\
\hline $\mathrm{H}-3$ & $8.64 \mathrm{E}+1$ & $3.70 \mathrm{E}+1$ & $1.03 E+2$ & $1.31 E+1$ \\
\hline $\mathrm{Kr}-85$ & $2.47 E+3$ & $1.07 \mathrm{E}+3$ & $2.76 E+3$ & $3.63 E+2$ \\
\hline $\mathrm{Sr}-89$ & $4.08 E+4$ & $1.76 \mathrm{E}+4$ & $6.68 \mathrm{E}+4$ & $2.75 \mathrm{E}+3$ \\
\hline$S r-Y-90$ & $2.08 \mathrm{E}+4$ & $8.93 E+3$ & $2.29 E+4$ & $3.16 \mathrm{E}+3$ \\
\hline$Y-91$ & $7.30 \mathrm{E}+4$ & $3.14 \mathrm{E}+4$ & $1.14 \mathrm{E}+5$ & $4.56 \mathrm{E}+3$ \\
\hline $\mathrm{Zr}-95$ & $1.07 E+5$ & $4.63 E+4$ & $1.63 E+5$ & $6.48 \mathrm{E}+3$ \\
\hline $\mathrm{Nb}-95$ & $2.20 \mathrm{E}+5$ & $9.49 E+4$ & $3.28 \mathrm{E}+5$ & $1.28 \mathrm{E}+4$ \\
\hline Ru-103; Rh-103m & $8.90 E+3$ & $3.77 E+3$ & $2.02 E+4$ & $8.44 \mathrm{E}+2$ \\
\hline Ru-106; Rh-106m & $2.15 E+4$ & $9.16 \mathrm{E}+3$ & $4.05 E+4$ & $2.54 \mathrm{E}+3$ \\
\hline $\mathrm{Sn}-123$ & $4.27 E+2$ & $1.84 \mathrm{E}+2$ & $6.16 E+2$ & $2.71 E+1$ \\
\hline $\mathrm{Sb}-125$ & $8.90 E+2$ & $3.81 E+2$ & $1.22 \mathrm{E}+3$ & $1.19 E+2$ \\
\hline $\mathrm{Te}-125 \mathrm{~m}$ & $2.12 \mathrm{E}+2$ & $9.06 \mathrm{E}+1$ & $2.86 \mathrm{E}+2$ & $2.87 \mathrm{E}+1$ \\
\hline $\mathrm{Te}-127 \mathrm{~m}$ & $8.87 \mathrm{E}+2$ & $3.82 E+2$ & $1.40 \mathrm{E}+3$ & $5.57 \mathrm{E}+1$ \\
\hline $\mathrm{Te}-129 \mathrm{~m}$ & $1.89 \mathrm{E}+2$ & $7.98 \mathrm{E}+1$ & $4.98 E+2$ & $2.31 E+1$ \\
\hline Cs-134 & $1.64 \mathrm{E}+4$ & $4.00 \mathrm{E}+3$ & $2.60 E+3$ & $1.16 \mathrm{E}+3$ \\
\hline Cs-137 & $2.06 \mathrm{E}+4$ & $8.87 E+3$ & $2.38 \mathrm{E}+4$ & $3.19 E+3$ \\
\hline Ce-141 & $5.74 \mathrm{E}+3$ & $2.44 \mathrm{E}+3$ & $1.39 E+4$ & $6.97 \mathrm{E}+2$ \\
\hline Ce-Pr-144 & $3.12 E+5$ & $1.35 E+5$ & $3.73 E+5$ & $2.55 E+4$ \\
\hline Pm-147 & $4.83 E+4$ & $2.46 E+4$ & $4.80 E+4$ & $7.02 E+3$ \\
\hline $\mathrm{Pm}-148 \mathrm{~m}$ & $7.56 \mathrm{E}+1$ & $2.92 \mathrm{E}+1$ & $2.59 \mathrm{E}+2$ & $4.68 E+1$ \\
\hline Eu-154 & $6.20 \mathrm{E}+2$ & $1.63 E+2$ & $9.33 E+2$ & $4.18 \mathrm{E}+1$ \\
\hline Eu-155 & $1.30 \mathrm{E}+2$ & $4.56 E+1$ & $2.04 E+2$ & $2.27 E+1$ \\
\hline U-234 & $9.14 \mathrm{E}-4$ & $3.74 \mathrm{E}-4$ & $1.28 \mathrm{E}-3$ & $1.81 \mathrm{E}-4$ \\
\hline U-235 & $1.38 \mathrm{E}-2$ & $1.09 \mathrm{E}-2$ & $1.47 \mathrm{E}-2$ & 7.91E-3 \\
\hline U-238 & $3.41 \mathrm{E}-4$ & $2.06 \mathrm{E}-4$ & $2.01 \mathrm{E}-2$ & $6.51 \mathrm{E}-3$ \\
\hline $\mathrm{Pu}-238$ & $6.42 E+1$ & $1.03 E+1$ & $1.16 \mathrm{E}+2$ & $3.03 E+0$ \\
\hline $\mathrm{Pu}-239$ & $1.84 \mathrm{E}+0$ & $8.89 \mathrm{E}-2$ & $3.05 E+1$ & 5.50E-1 \\
\hline $\mathrm{Pu}-240$ & $1.20 \mathrm{E}+0$ & $4.21 \mathrm{E}-1$ & $2.38 \mathrm{E}+1$ & $2.09 E+0$ \\
\hline $\mathrm{Pu}-241$ & $2.84 \mathrm{E}+2$ & $6.77 \mathrm{E}+1$ & $6.06 \mathrm{E}+3$ & $2.13 E+2$ \\
\hline Am-241 & $3.96 \mathrm{E}-1$ & $9.67 \mathrm{E}-2$ & $7.20 \mathrm{E}+0$ & $4.07 \mathrm{E}-1$ \\
\hline Am-242m & $1.05 \mathrm{E}-3$ & $1.55 \mathrm{E}-4$ & $5.22 \mathrm{E}-2$ & $9.00 \mathrm{E}-3$ \\
\hline Am-243 & 4.33E-3 & $3.76 \mathrm{E}-3$ & $1.11 \mathrm{E}-1$ & $4.38 \mathrm{E}-4$ \\
\hline $\mathrm{Cm}-244$ & $1.33 \mathrm{E}+0$ & $9.26 \mathrm{E}-3$ & $5.51 E+0$ & $7.14 \mathrm{E}-3$ \\
\hline $\mathrm{Cm}-242$ & $1.75 \mathrm{E}+0$ & $1.27 \mathrm{E}-1$ & $8.37 E+1$ & $5.25 \mathrm{E}+0$ \\
\hline
\end{tabular}




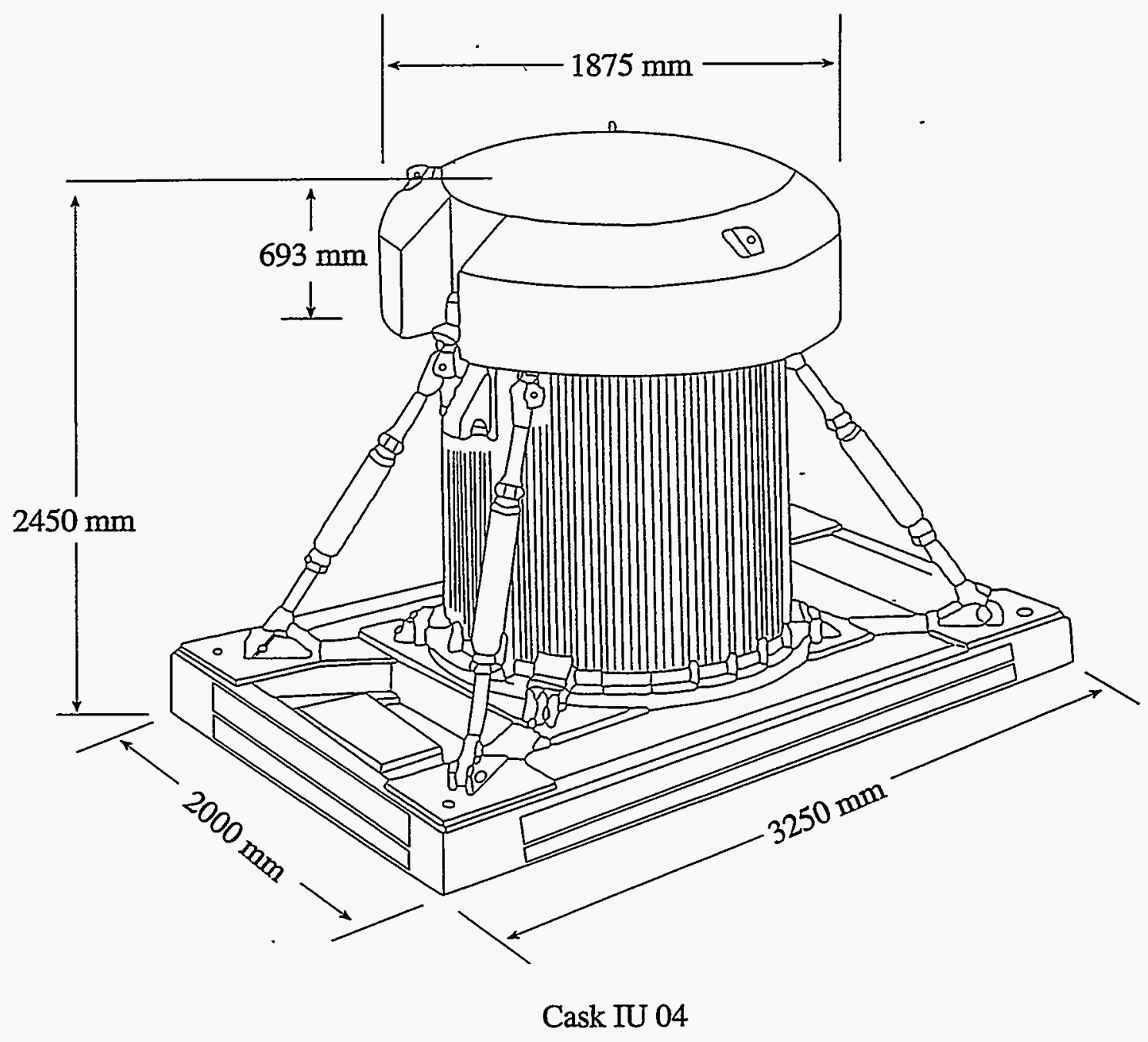

Figure 1. Pegase Cask 
Table 6. Pegase Cask Properties

\begin{tabular}{|c|c|}
\hline \multicolumn{2}{|r|}{ Description } \\
\hline Body & $\begin{array}{l}\text { Two stainless steel shells that enclose a lead shield. } \\
\text { The outer shell is fitted with cooling fins and attaches } \\
\text { to a base plate that is filled with asbestos. }\end{array}$ \\
\hline Lid & Steel filled with lead and plaster. \\
\hline Base & $\begin{array}{l}\text { Steel fitted with four turnbuckles that attach the cask } \\
\text { to the base during transport. }\end{array}$ \\
\hline Baskets & $\begin{array}{l}\text { Various designs that allow different research reactor } \\
\text { fuels (e.g., BR-2, RHF, Osiris) to be transported. }\end{array}$ \\
\hline \multicolumn{2}{|r|}{ Weight } \\
\hline Body & $15500 \mathrm{~kg}$ \\
\hline Lid & $2000 \mathrm{~kg}$ \\
\hline Cover & $1400 \mathrm{~kg}$ \\
\hline Total & $18900 \mathrm{~kg}$ \\
\hline \multicolumn{2}{|r|}{ Dimensions } \\
\hline Body - External & \\
\hline Diameter & $1600 \mathrm{~mm}$ \\
\hline Height & $1760 \mathrm{~mm}$ \\
\hline Body - Internal & \\
\hline Diameter & $800 \mathrm{~mm}$ \\
\hline Height & $1040 \mathrm{~mm}$ \\
\hline Lid & \\
\hline Diameter & $1875 \mathrm{~mm}$ \\
\hline Thickness & $693 \mathrm{~mm}$ \\
\hline Base & \\
\hline Length & $3250 \mathrm{~mm}$ \\
\hline Width & $2000 \mathrm{~mm}$ \\
\hline Cask & \\
\hline Total Height & $2450 \mathrm{~mm}$ \\
\hline Maximum Diameter & $1875 \mathrm{~mm}$ \\
\hline
\end{tabular}


The preceding discussion suggests that ship accident source terms could follow any of four release timing patterns: (1) a single short-duration (10 minute) release, synchronous with and caused only by mechanical collision loads; (2) a single short-duration (10 minute) release caused by mechanical collision loads, followed by a longer ( 60 minute) thermal release driven by an ensuing fire that begins about 60 minutes after the collision takes place; (3) a single long-duration (60 minute) thermally driven release that begins about 60 minutes after the collision, when fuel elements are failed by collision forces but cask seals are failed by thermal loads; and (4) a single, much delayed (90 minute delay) short-duration (10 minute) release, if cask failure and burst rupture of fuel elements occur nearly simultaneously due to thermal loads.

Because only a substantial long-duration engulfing fire can cause a thermal release, radioactive materials released due to thermal loads were assumed to be released directly into the fire plume. Because plumes from freely burning fires will have bulk gas temperatures of about $1200 \mathrm{~K}$, the rate of release of sensible heat in fire plumes was taken to be $1.0 \times 10^{5}$ watts for Category 5 releases and $1.5 \times 10^{5}$ watts for Category 6 releases.

The start time and duration of the four hypothetical release patterns are presented in Table 7. For base case calculations, the first release pattern was assumed for Severity Category 4 accidents and the third pattern for Severity Category 5 and 6 accidents. The second release pattern was examined during the workforce sensitivity study described in Section 4.4.2.5. The fourth pattern was not examined, because both prompt and delayed short-duration releases should lead to very similar consequences, when emergency response actions are not undertaken, and the consequences of delayed short-duration releases will usually be diminished by emergency response actions.

Table 7. Release Timing Patterns

\begin{tabular}{|c|c|c|c|c|}
\hline \multirow{2}{*}{} & \multicolumn{2}{|c|}{ Puff } & \multicolumn{2}{c|}{ Tail } \\
\cline { 2 - 5 } Pattern & $\begin{array}{c}\text { Release } \\
\text { Start } \\
\text { (min) }\end{array}$ & $\begin{array}{c}\text { Release } \\
\text { Duration } \\
\text { (min) }\end{array}$ & $\begin{array}{c}\text { Release } \\
\text { Start } \\
(\mathrm{min})\end{array}$ & $\begin{array}{c}\text { Release } \\
\text { Duration } \\
\text { (min) }\end{array}$ \\
\hline 1 & 0 & 10 & & \\
2 & 0 & 10 & 60 & 60 \\
3 & & & 60 & 60 \\
4 & & & 90 & 10 \\
\hline
\end{tabular}

\subsection{Source Term Probabilities}

In this section, probability expressions for each EA and EIS source term are formulated and values are estimated for each probability that enters the expressions. New expressions and values are developed in order to remove the conservatism inherent in the EA of using a single value $\left(4.0 \times 10^{-4}\right)$ for the conditional probability (severity fraction) of EA Accident 
Categories 4, 5, and 6 despite the considerable difference in the severity of the ship accidents represented by each category (see Section 3.2.1, EA Source Terms).

\subsubsection{EA Source Term Probability Expressions}

Table 8 presents a sequence of events that encompasses all of the accident conditions set forth in Table 1. Thus, this sequence of events provides a reasonable description of a severe collision between two large ships that leads both to a severe fire and to a release of radioactivity from the failed spent fuel cask. This event sequence allows source term probabilities $\left(\mathrm{P}_{\mathrm{ST}}\right)$ to be estimated as the product of some or all of the probabilities of occurrence of the seven events. Table 9 shows how values for $P_{S T}$ were calculated in this study for EA Accident Categories 4 through 6. Although event trees were not used to develop the expressions for $\mathrm{P}_{\mathrm{ST}}$ presented in Table 9, they are used in Section 3.4.4.5 below to develop values of $\mathrm{P}_{\mathrm{ST}}$ that reflect the unique physical and chemical behavior of research reactor fuels during high-temperature, long-duration fire events.

Table 8. Event Sequence for a Severe Ship Accident

\begin{tabular}{|l|l|}
\hline \multicolumn{1}{|c|}{ Event } & \multicolumn{1}{|c|}{$\begin{array}{c}\text { Event } \\
\text { Probability }\end{array}$} \\
\hline Collisions between large ships & $\mathrm{P}_{\text {Collision }}$ \\
RAM hold struck & $\mathrm{P}_{\text {Hold }}$ \\
$\begin{array}{l}\text { Collision subjects cask to impact forces large enough to damage cask } \\
\text { contents }\end{array}$ & $\mathrm{P}_{\text {Impact }}$ \\
$\begin{array}{l}\text { Cask subjected to crush forces because bow of striking ship contacts the } \\
\text { cask or cargo compression causes the hold to go material solid }\end{array}$ & $\mathrm{P}_{\text {Crush }}$ \\
Severe fire ensues & $\mathrm{P}_{\text {Severe Fire }}$ \\
$\begin{array}{l}\text { The fire engulfs the cask (cask heat loads are sufficient to vaporize CsI) } \\
\text { Convective flow of air through the cask causes Ru to be oxidized to } \mathrm{RuO}_{4}\end{array}$ & $\mathrm{P}_{\text {Engulfing Fire }}$ \\
\hline
\end{tabular}

Table 9. Source Term Probability Expressions for EA Accident Categories 4 Through 6

\begin{tabular}{|c|cc|}
\hline $\begin{array}{c}\text { Accident } \\
\text { Category }\end{array}$ & Probability Expression \\
\hline EA4 & $\mathrm{P}_{\mathrm{ST}}=\mathrm{P}_{\text {Collision }} \times \mathrm{P}_{\text {Hold }} \times\left(\mathrm{P}_{\text {Irmact }}+\mathrm{P}_{\text {Crush }}\right)$ \\
EA5 & $\mathrm{P}_{\mathrm{ST}}=\mathrm{P}_{\text {Collision }} \times \mathrm{P}_{\text {Hold }} \times\left(\mathrm{P}_{\text {Impact }}+\mathrm{P}_{\text {Crush }}\right) \times \mathrm{P}_{\text {Severe Fire }} \times \mathrm{P}_{\text {Engulfing Fire }}$ \\
EA6 & $\mathrm{P}_{\mathrm{ST}}=\mathrm{P}_{\text {Collision }} \times \mathrm{P}_{\text {Hold }} \times\left(\mathrm{P}_{\text {Impact }}+\mathrm{P}_{\text {Crush }}\right) \times \mathrm{P}_{\text {Severe Fire }} \times \mathrm{P}_{\text {Engulfing Fire }} \times \mathrm{P}_{\text {Convection }}$ \\
\hline
\end{tabular}




\subsubsection{Event Probabilities}

Values for $\mathrm{P}_{\text {Collision }}$ and $\mathrm{P}_{\text {Severe Fire }}$ were estimated from ship accident data. Because data were sparse for some of the ports studied, these probabilities were not developed separately for each port (i.e., dependencies on port traffic were neglected). Values for $P_{\text {Hold }}$ and $P_{\text {Engulfing Fire }}$ were derived from ship specifications (number of cargo holds and the dimensions of these holds for the prototypic break-bulk freighter used in the impact and crush analyses). Values for $P_{\text {Impact }}$ and $\mathrm{P}_{\mathrm{Cnsh}}$ were estimated, as is described below, using the methods of Minorsky [Mi59] and results from previous studies of ship accidents [ORI81]. A value for $\mathrm{P}_{\text {Convection }}$ was estimated by review of data on fires and on the temperatures required to oxidize $\mathrm{Ru}$ to $\mathrm{RuO}_{4}$. Finally, because they were reestimated, the accident probabilities

$\mathrm{P}_{\text {Collision }}$

and the severity category probabilities

$\mathrm{P}_{\text {Severity Category }}=\mathrm{P}_{\text {Hold }} \times\left(\mathrm{P}_{\text {Impact }}+\mathrm{P}_{\text {Crush }}\right) \times \mathrm{P}_{\text {Severe Fire }} \times \mathrm{P}_{\text {Engulfing Fire }} \times \mathrm{P}_{\text {Convection }}$

used in the EA source term calculations described below have values that differ from those used in the original EA.

\subsubsection{Probabilities Developed From Ship and Accident Data}

\subsubsection{Probability of Collisions in Ports}

Fifteen years of Lloyd's casualty data [LMIS91] and previous studies of ship accidents [Wa76, SRI78, ORI80, Ab85] were reviewed to develop (1) the probability of a severe collision $\left(\mathrm{P}_{\text {Collision }}\right)$ between large ships that occurs dockside in ports or while sailing in port channels, and (2) the probability that such a collision leads to a severe fire $\left(\mathrm{P}_{\text {Severe Fire }}\right)$.

Ship accident casualty data for the years 1978 through 1993 and U.S. port call data for the years 1992 and 1993 were obtained from Lloyd's Maritime Information Services, Inc. Searches of the port call data for the two-year period 1992 through 1993 identified the number of port calls made in U.S. ports by all ships, all dry cargo ships, and all dry cargo ships of deadweight 10 to 20 thousand long tons. The searches were performed twice, once restricting the results to collisions that occurred in port waters only and once adding collisions that occurred in restricted approaches (e.g., rivers) that lead to some of the ports. The addition of restricted approach waters was done to permit comparison to results from the literature that included or seemed to include collisions in the rivers that lead to ports. Table 10 compares the results developed by searches of the Lloyd's databases (the first five entries in the table) to results from previous studies.

The values for collisions per port call in Table 10 range from $3.7 \times 10^{-5}$ to $1.5 \times 10^{-3}$. The geometric mean of this range is $2.4 \times 10^{-4}$. Table 10 contains three values of collisions per 
Table 10. Collisions per Port Call

\begin{tabular}{|c|c|c|c|c|c|}
\hline \multirow[b]{2}{*}{ Port, Region, or Study } & \multirow[b]{2}{*}{ Ref. } & \multirow[b]{2}{*}{ Ship Type } & \multirow[b]{2}{*}{$\begin{array}{l}\text { Dead Weight } \\
\text { (long tons) }\end{array}$} & \multicolumn{2}{|c|}{ Collisions per Port Call } \\
\hline & & & & Port Only & $\begin{array}{c}\text { Port plus } \\
\text { Restricted } \\
\text { Waters }\end{array}$ \\
\hline \multirow[t]{3}{*}{ All U.S. } & Lloyds & All & All & $4.8 \mathrm{E}-5$ & $7.7 \mathrm{E}-5$ \\
\hline & " & Dry cargo & All & $6.1 E-5$ & $9.7 \mathrm{E}-5$ \\
\hline & " & Dry cargo & $10-20$ & $3.7 \mathrm{E}-5$ & $3.7 \mathrm{E}-5$ \\
\hline New York & $"$ & Dry cargo & All & $3.0 \mathrm{E}-4$ & $3.6 \mathrm{E}-4$ \\
\hline Galveston/Houston & $"$ & Dry cargo & All & $2.0 \mathrm{E}-4$ & $3.8 \mathrm{E}-4$ \\
\hline All U.S. & ORI80 & All & All & & $1.2 \mathrm{E}-3$ \\
\hline All U.S. & Wa76 & All & All & & $5.8 \mathrm{E}-4$ \\
\hline New York & $"$ & All & All & & $8.6 \mathrm{E}-4$ \\
\hline Galveston/Houston & $"$ & All & All & & $8.3 \mathrm{E}-4$ \\
\hline Houston Ship Channel & Ab85 & Tanker & All & & $1.5 \mathrm{E}-3$ \\
\hline Mobile & $"$ & $"$ & All & & $1.5 \mathrm{E}-3$ \\
\hline Corpus Christi & $"$ & $"$ & All & & $1.3 \mathrm{E}-3$ \\
\hline Delaware Bay & $"$ & $"$ & All & 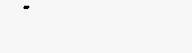 & $7.2 \mathrm{E}-4$ \\
\hline Providence & $"$ & $"$ & All & & $3.1 \mathrm{E}-4$ \\
\hline Thames & $"$ & $"$ & All & & $4.6 \mathrm{E}-5$ \\
\hline Holland & $"$ & $"$ & All & & $5.0 \mathrm{E}-5$ \\
\hline North Sea & $"$ & $"$ & All & & $6.7 \mathrm{E}-5$ \\
\hline J.J. Henry Study & $"$ & $"$ & All & & $4.6 \mathrm{E}-5$ \\
\hline IMCO Study & $"$ & $"$ & All & & 7.1E-5 \\
\hline Washington State Study & $"$ & $"$ & All & & $6.2 \mathrm{E}-4$ \\
\hline Tanker Fleet Analysis & $"$ & $"$ & All & & 4.7E-4 \\
\hline
\end{tabular}

port call for "All U.S." ports, $7.7 \times 10^{-5}, 1.2 \times 10^{-3}$, and $5.8 \times 10^{-4}$, based respectively on collision and port call data developed by Lloyd's, ORI [ORI80], and Warrick and Anderson [Wa76]. A fourth value of $1.2 \times 10^{-3}$ collisions per port call can be developed from the data of Abkowitz and Galarraga [Ab85]. The average of these four values is $7.6 \times 10^{-4}$.

The Lloyd's data contains 69 collisions in U.S. ports during the fifteen-year period 1978 through 1993, and 60,000 U.S. port calls per year during the two-year period 1992 through 1993. Review by ORI of U.S. Coast Guard data identified 94 collisions in U.S. ports and 39,000 U.S. port calls per year during the two-year period 1974 through 1975. Review of U.S. Coast Guard data for the five-year period 1970 through 1974 by Warrick and Anderson identified 83 collisions and 64,000 port calls per year that occurred in seven U.S. ports (New 
York, Baltimore, Hampton Roads, New Orleans, Galveston/Houston, Los Angeles/Long Beach, and Oakland/San Francisco). Abkowitz and Galarraga identified 391 collisions involving tankers that occurred during the years 1976 through 1980 in five U.S. ports (Houston Ship Channel, Mobile, Corpus Christi, Delaware, and Providence). For this fiveyear period, 64,000 port calls per year were made to these ports.

Three of the four values for collisions per port call for "All U.S." ports are based on about 60,000 port calls per year, while the fourth, the ORI result, is based on only 39,000 port calls per year. If the ORI value for port calls per year is low, then the ORI value for collisions per port call may be high. Because 228 of the 391 collisions that enter the value of Abkowitz and Galarraga occurred in the Houston Ship Channel, the Abkowitz and Galarraga value may be more characteristic of a high-traffic port than an average port. Thus, the true value for collisions per port call for an average U.S. port may lie nearer to the mean of the range of values presented in Table 10 than to the average of the four values for "All U.S." ports. In any event, the range $\left(10^{-3}\right.$ to $\left.10^{-5}\right)$ and variability of the results presented in Table 10 are too large to support the use of a single value for collisions per port call for all ports. Since the data is somewhat sparse, use of order-of-magnitude estimates is indicated. Therefore, use of values of $10^{-3}, 10^{-4}$, and $10^{-5}$ collisions per port call for high, medium, and low traffic ports seems appropriate. Finally, because research reactor spent fuel is not likely to be shipped to high traffic ports, the $10^{-4}$ collisions per port call value was used in all of the MACCS consequence calculations performed for this study.

\subsubsection{Probability That the RAM Hold is Struck}

If foreign research reactor spent-fuel casks are shipped one at a time, as is assumed here, then $\mathrm{P}_{\text {Hold }}$, the probability that the hold that contains the cask is the hold that is struck, equals $1 / N_{\text {Hold }}$, where $N_{\text {Hold }}$ is the number of holds in the ship transporting the spent fuel cask. The prototypic break-bulk freighter [ORI81] used in the impact and crush analyses described below has seven holds. Therefore, for this prototypic ship, $\mathrm{P}_{\text {Hold }}=1 / 7$.

\subsubsection{Probability of Severe Fires}

The fifteen years of Lloyd's casualty data contains 1073 ship collisions in ports located anywhere in the world. Eleven of these collisions led to fires, five caused extensive fire damage, and one involved buckling of structures due to thermal loads. Therefore, the Lloyd's data suggest that the chance that a ship collision leads to a severe fire is about $5 / 1073=4.5 \times 10^{-3}$. Only one of the 83 collisions identified by Warick and Anderson led to a fire. However, that fire consumed one of the ships involved in that collision, the Sea Witch. Thus, the Warick and Anderson data suggest that the chance that a collision will lead to a severe fire is about $1 / 83=1.2 \times 10^{-2}$. Only 17 of the 391 collisions in the Abkowitz and Galarraga study led to fires of any severity. Thus, the probability that a collision leads to a fire of any severity is about $17 / 391=4.4 \times 10^{-2}$. SRI data [SRI78] suggest that about nine percent of all fires on break-bulk freighters involve at least an entire deck in one cargo hold, when the fire occurs while the ship is in port (docked or sailing in port waters). Thus, the chance that a ship fire on a break-bulk freighter will fully involve at least one cargo hold is 
about 0.12 , when the ship is in port. Combining these last two results allows the probability that a cargo ship collision leads to a severe fire (one that fully involves at least one hold) to be estimated as follows:

$$
\begin{aligned}
\text { (fires per collision) } \mathrm{x} \text { (full hold fires per fire) } & =\left(4.4 \times 10^{-2}\right) \times(0.09) \\
& =4.0 \times 10^{-3} \text { severe fires per collision }
\end{aligned}
$$

Fires on cargo ships were reviewed by several nations for the International Maritime Organization (IMO). The French submission [IMO92] to the IMO developed data for 599 cargo ship fires that took place during the eleven-year period 1978 through 1988. Only 2 of the 599 fires were caused by ship collisions, but Lloyd's data indicate that ship fires occur with about the same frequency as ship collisions (2000 collisions and 2547 fires during the 15 years from 1978 through 1992). Thus, the probability that a collision leads to a fire of any severity is $\sim(2 / 599)(2547 / 2000)=4.3 \times 10^{-3}$. Of the 599 fires, 122 led to immediate total loss, and 195 led to damage first thought to be repairable but later was determined to be beyond repair. Thus, given that a fire has occurred, the chance that a fire is severe is greater than $122 / 599=0.20$ and less than $(122+195) / 599=0.53$. If the average of these two estimates is used, then the probability that a collision leads to a severe fire can again be calculated as was just done above:

$$
\begin{aligned}
\text { (fires per collision) } \mathrm{x} \text { (severe fires per fire) } & =\left(4.3 \times 10^{-3}\right) \times(1 / 2)(0.20+0.53) \\
& =1.6 \times 10^{-3} \text { severe fires per collision }
\end{aligned}
$$

If these four estimates for severe fires per collision are averaged, a value of $5.5 \times 10^{-3}$ results. Rounding to the nearest order-of-magnitude suggests that $P_{\text {Severe Fire }}=10^{-2}$ is a reasonable estimate for the chance that a severe fire will be caused by a ship collision.

\subsubsection{Probability That a Severe Fire Engulfs a RAM Cask}

$\mathrm{P}_{\text {Engulfing Fire }}$ is the probability that a severe fire starts on or spreads to the cargo deck where a RAM cask is stowed, and then completely engulfs the cask. For fires that occur on break-bulk freighters while the ship is in port, SRI data [SRI78] show (1) that 3.7 percent of such fires fully involve one deck in a single hold, (2) that 2.3 percent fully involve all of the decks in a single hold, and (3) that 3.0 percent involve the entire ship. The prototypical break-bulk freighter examined by this study has 21 cargo decks in 7 holds, that each contain 2,3 , or 4 cargo decks. Thus, if a fire starts on one deck in a given hold, fully involves that deck, but does not spread to other decks or holds, then the chance that that fire fully engulfs the RAM cask is $1 / 21$. If a fire starts on a deck in a hold and spreads to all decks above that deck but not to lower decks or to neighboring holds, then the chance that the fire spreads to the deck where the RAM cask is stowed and engulfs the cask is $(1 / 2)(2 / 21+1 / 21)=0.07$ for a hold with two decks, $(1 / 3)(3 / 21+2 / 21+1 / 21)=0.1$ for a hold with three decks, and $(1 / 4)(4 / 21$ $+3 / 21+2 / 21+1 / 21)=0.12$ for a hold with four decks. Thus, the chance that fire spread within a hold subjects a RAM cask stowed in that hold to an engulfing fire is about 0.1. Of course, if the fire involves the entire ship, then the chance that the RAM cask is subjected to 
an engulfing fire is 1.0. Using the SRI data to construct a weighted sum for these three results gives

$$
P_{\text {Engulfing Fire }}=(0.037)(1 / 21)+(0.023)(1 / 7)+(0.030)(1.0)=0.035
$$

Rounding to the next order of magnitude yields $\mathrm{P}_{\text {Engulfing Fire }}=10^{-1}$ as a reasonable, though most likely conservative, estimate of the chance that a severe fire will start on or spread to the deck of a break-bulk freighter where a RAM cask is stowed, and then fully engulf the cask.

The prototypical break-bulk freighter examined by this study has about $1.1 \times 10^{5} \mathrm{ft}^{2}$ of space for dry bulk cargo, or about $5000 \mathrm{ft}^{2}$ per cargo deck. The Pegase RAM transport cask examined by this study has a 7 -ft by $10-\mathrm{ft}$ base. This cask should be completely engulfed by a pool fire that has a diameter of $20 \mathrm{ft}$ and an area of $314 \mathrm{ft}^{2}$, provided that the fire occurs in the same hold and on the same deck where the cask is stowed and is centered on the cask. Because the area of an engulfing fire is much smaller than the area of an average deck, it might seem that a severe fire of a size that could engulf a cask can occur on the deck where the cask is stowed without engulfing the cask. But severe fires usually involve flammable liquids (e.g., ship bunker fuel) or loosely packed combustible cargo that easily supports rapid combustion. Therefore, if it is assumed that severe fires involve rapid combustion, then it seems unlikely that a severe fire will be confined to a portion of any deck on which it starts or to which it spreads. Accordingly, although slowly burning fires may be able to coexist on a deck with a RAM cask without engulfing the cask, it is here assumed that the severe fires of interest are those that involve rapidly burning materials and thus fully involve any deck to which they spread. Therefore, the value of $\mathrm{P}_{\text {Engulfing Fire }}=10^{-1}$ was not decreased to reflect the possibility that a severe fire might occur on a deck where a RAM cask was stowed without engulfing the cask.

\subsubsection{Mechanical and Thermal Loads That Cause Damage}

A severe ship collision may damage a spent fuel shipping cask, and the spent fuel elements contained in the cask, by subjecting the cask to impact forces, crush forces, and/or thermal loads. Because ship collisions are essentially inelastic events (after a severe collision, ships usually stick together), energy lost during a collision can be equated to the work done damaging ship structures or compressing cargo. By relating the work done during the collision to the masses and initial velocities of the ships involved in the collision, expressions for the dependence of striking ship velocity on penetration distance and for the average accelerations experienced by a cask and its contents during the collision can be derived. In Section 3.4.4.1, an expression for the kinetic energy consumed damaging ship structures during a collision is derived following the method of Minorsky [Mi59]. In Section 3.4.4.2, this expression is used to determine the dependence of penetration distance on collision energy for several types of cargo. In Section 3.4.4.3, the accelerations experienced by the cask and its contents during a ship collision and the probability of damage due to impact forces are estimated for the same set of cargo scenarios. In Section 3.4.4.4, the probability that the cask will be subjected to crush forces is estimated. Section 3.4.4.5 discusses the probability of high-temperature, long duration fires and the temperatures and durations required to cause 
burst rupture of intact fuel elements, fail cask seals, or oxidize research reactor spent fuel. Finally, Section 3.4.4.6 estimates the probability of cask failures that would allow convective flow of air through the failed cask and thus enhanced release of $\mathrm{Ru}$ due to oxidation to volatile $\mathrm{RuO}_{4}$.

\subsubsection{Minorsky's Method}

A way to estimate the kinetic energy available to tear or crush ship structures during a collision between ships has been developed by Minorsky [Mi59]. Because penetration of the striking ship into the hull of the struck ship was the result of interest, Minorsky developed his equations by examining the components of force and momentum oriented along the normal to the course of the struck ship.

Let $M_{A}$ and $M_{B}$ be the masses of the struck (A) and striking (B) ships; $v_{A}$ and $v_{B}$ be the initial velocities of the struck and striking ships; $\theta_{A}$ and $\theta_{B}$ be the angles between the paths of the struck and striking ships and the normal to the path of the struck ship (in his paper, Minorsky used the complements of these angles); $\mathrm{dm}$ be the mass of water entrained by the ships after they have collided; $U$ be the component of the final velocity of the two ships and the entrained water, which together are treated as a single mass after the collision has occurred, normal to the path of the struck ship; $E_{k}$ be the kinetic energy expended tearing or crushing ship structures during the collision; $\mathrm{E}_{\mathrm{w}}$ be the kinetic energy required to penetrate the hull of the struck ship; $E_{d}(d)$ be the kinetic energy required to penetrate a distance $d$ into the hull after the hull has been breached by the bow of the striking ship; and $\mathrm{E}_{\mathrm{r}}(\mathrm{d})$ be the kinetic energy that remains to be dissipated after penetration to a distance $\mathrm{d}$. Then, energy balance requires that

$$
E_{r}(d)=E_{k}-E_{w}-E_{d}(d)
$$

and conservation of momentum along the normal to the path of the struck ship requires that

$$
\mathrm{M}_{\mathrm{A}} \mathrm{v}_{\mathrm{A}} \cos \theta_{\mathrm{A}}+\mathrm{M}_{\mathrm{B}} \mathrm{v}_{\mathrm{B}} \cos \theta_{\mathrm{B}}=\left(\mathrm{M}_{\mathrm{A}}+\mathrm{M}_{\mathrm{B}}+\mathrm{dm}\right) \mathrm{U}
$$

In addition, along the normal to the path of the struck ship,

$$
E_{k}=(1 / 2) M_{A}\left(v_{A} \cos \theta_{A}\right)^{2}+(1 / 2) M_{B}\left(v_{B} \cos \theta_{B}\right)^{2}-(1 / 2)\left(M_{A}+M_{B}+d m\right) U^{2}
$$

Since $\theta_{\mathrm{A}}=90^{\circ}$ and $\mathrm{dm}$ is approximately $0.4 \mathrm{M}_{\mathrm{A}}$ [Mo71], combining Equations 7 and 8 yields the following expression for $\mathrm{E}_{\mathrm{k}}$ :

$$
E_{k}=\frac{M_{A} M_{B}}{1.43 M_{B}+2.0 M_{A}}\left(v_{B} \cos \theta_{B}\right)^{2}
$$

By analysis of a set of severe ship collisions, Minorsky showed [Mi59] that

$$
E_{\mathrm{w}}=121,900 \text { ton } \text { knots }^{2}
$$


and

$$
\mathrm{E}_{\mathrm{d}}(\mathrm{d})=414.5 \mathrm{R}_{\mathrm{T}}
$$

where $R_{t}$ is a resistance factor that represents the amount of damage done to decks, flats, and double bottoms in both ships, to transverse bulkheads in the struck ship, and to longitudinal bulkheads in and the shell of the striking ship, expressed as the volume of the tears in the damaged structures. Thus,

$$
R_{t}=\sum_{i} d_{i} w_{i} t_{i}
$$

where $t_{i}$ is the thickness of the damaged structure $i$ and $d_{i}$ and $w_{i}$ are the depth and width of the tear that damaged the structure.

\subsubsection{Application to a Representative Break-Bulk Freighter}

Kirkland and Baranano of ORI used Minorsky's method to develop correlations between penetration depth and the energy absorbed in ship collisions [ORI81] where the struck ship is a seven-hold break-bulk freighter with a displacement of 22.6 kilotons. By considering empirical probability distributions for displacement, speed, and the angle of impact of the striking ship, bounding curves were developed for the probability of occurrence of force levels at selected penetration depths, where force is the negative of the gradient of absorbed energy, here denoted by $W$. The force value referred to is the collision force acting between the two ships.

Only a fraction of the collision force would be absorbed by a spent fuel shipping cask on board the struck break-bulk freighter. ORI gave a qualitative discussion of this aspect of the collision, together with values for some limiting cases based on assumptions about stowage and the presence and type of other cargo.

The present analysis closely follows the Minorsky and ORI analyses. An approximate treatment of the accelerations experienced by a spent fuel package during a ship collision is added to the ORI adaptation of Minorsky's method.

The dynamics of inelastic ship collisions are treated through conservation laws for momentum and energy. Following Minorsky, the transverse hydrodynamic forces on the hull of the struck ship are accounted for by a virtual increase in mass (the mass of water entrained behind the hull of the struck ship), hence kinetic energy. This is a conventional method used by naval architects, but has limitations when applied to collisions. M. J. Petersen [Pe82] pointed out that experiments and calculations performed by Motora et al. [Mo71] have shown that the added mass treatment is not always a good approximation. Here the limitations imposed by the added mass method are accepted, because a more rigorous treatment of the collision is not warranted due to other uncertainties in the analysis, particularly in the modeling of cargo effects. 
Following ORI, energy expended compressing cargo is calculated using the following equation:

$$
\mathrm{W}_{\text {cargo }}=A \sigma(\mathrm{x}-\mathrm{fB})
$$

where

$A=$ the area of the surface that is compressing the cargo (i.e., the effective surface area of the deformed bow of the striking ship);

$\sigma=$ the crush strength of the cargo;

$\mathrm{x}=$ the penetration distance into the struck ship by the bow of the striking ship;

$\mathrm{f}=$ the one-dimensional fraction of the width (beam) of the struck ship that is empty (i.e., the fraction of the space along the beam of the struck ship both between and within cargo that is not occupied by material); and

$B=$ the beam of the struck ship.

Thus, $\mathrm{fB}$ is the penetration distance that will consume all of the empty space along the beam of the struck ship, Ao is the compressive force that is applied to the cargo as soon as this empty space has been consumed, and $\mathrm{x}-\mathrm{fB}$ is the distance over which that force acts. Now, following ORI, the compression surface area $A$ is assumed to increase linearly with penetration distance, the maximum compression surface area is assumed to equal one-third of the cross-sectional area of the striking ship at a distance back from its bow equal to one-tenth its length, and this maximum compressive surface area is assumed to be attained when penetration distance becomes equal to the beam of the struck ship. Thus,

$$
A=(x / B)(1 / 3) H(L / 10) 2 \tan (\phi / 2)
$$

where $H, L$, and $\phi$ are the height, length, and bow angle of the striking ship. Because cargo compression takes place over a small distance $(x-f B)$, in the expression for $A, x$ is set equal to $\mathrm{fB}$, the penetration distance at which compression begins.

For the analyses performed here, following ORI, the height, length, and bow angle of the striking ship were taken to be $7.62 \mathrm{~m}, 165.8 \mathrm{~m}$, and $26^{\circ}$ for all analyses. Thus,

$$
\mathrm{W}_{\text {cargo }}=19.44 \mathrm{f} \sigma(\mathrm{x}-\mathrm{fB})
$$

where $\sigma$ is in $\mathrm{MPa}$, and $\mathrm{x}$ and $\mathrm{B}$ are in meters.

Parameters and Assumptions. The target break-bulk freighter in the following calculations has a beam of 24.99 meters and a displacement, $\mathrm{m}$, of 25.31 tonnes. The virtual mass, $\mathrm{dm}$, due to hydrodynamic forces is $0.4 \mathrm{~m}=10.12$ tonnes. Eight cases are considered for the 
displacement, $M$, of the striking ship: $5600,16800,28000,39200,50400,61600,72800$ and 84000 kilotonnes, while the normal component of the striking ship's speed at impact ranges from 1 to $10 \mathrm{~m} / \mathrm{s}$.

Prior to the initiation of cargo compression, energy is absorbed solely by the deformation of ship structures. This effect is modeled using the Minorsky value of $32 \mathrm{MJ}$ for the energy expended penetrating the hull of the struck ship, together with the semi-empirical curves in Figure 6.2 of the ORI report [ORI81] that give the dependence of energy absorbed $\left(\mathrm{W}_{\text {ship }}\right.$ ) upon penetration depth $(\mathrm{x})$ for a set of eight striking ship displacements. Table 11 gives coefficients for a quadratic fit used to represent the ORI curves for penetration distances less than $15 \mathrm{~m}$; a second fit for penetration distances greater than $15 \mathrm{~m}$ is given in Table 12 .

Table 11. Quadratic Coefficients for Energy Absorbed by Ship Structures $(x<15 \mathrm{~m})$

\begin{tabular}{|r|c|c|c|}
\hline \multicolumn{4}{|c|}{$\mathrm{W}_{\text {ship }}=\mathrm{a}+\mathrm{bx}+\mathrm{cx}^{2}$} \\
\hline Tonnes & $\mathrm{a}(\mathrm{MJ})$ & $\mathrm{b}(\mathrm{MJ} / \mathrm{m})$ & $\mathrm{c}\left(\mathrm{MJ} / \mathrm{m}^{2}\right)$ \\
\hline 5600 & 9.551 & 0.6836 & 0.0405 \\
16800 & 8.709 & 0.8118 & 0.2984 \\
28000 & 8.056 & 1.2030 & 0.4558 \\
39200 & 8.121 & 1.0850 & 0.5296 \\
50400 & 9.234 & 0.6555 & 0.6217 \\
61600 & 8.956 & 0.8639 & 0.6698 \\
72800 & 8.574 & 1.1790 & 0.6906 \\
84000 & 8.204 & 1.5290 & 0.7154 \\
\hline
\end{tabular}

Table 12. Quadratic Coefficients for Energy Absorbed by Ship Structures $(x>15 \mathrm{~m})$

\begin{tabular}{|c|c|c|c|}
\hline \multicolumn{4}{|c|}{$\mathrm{W}_{\text {ship }}=\mathrm{a}+\mathrm{bx}+\mathrm{cx}^{2}$} \\
\hline Tonnes & $\mathrm{a}(\mathrm{MJ})$ & $\mathrm{b}(\mathrm{MJ} / \mathrm{m})$ & $\mathrm{c}\left(\mathrm{MJ} / \mathrm{m}^{2}\right)$ \\
\hline 5600 & 58.13 & -4.837 & 0.1919 \\
16800 & 14.72 & -0.057 & 0.3337 \\
28000 & 15.76 & -0.304 & 0.5179 \\
39200 & 64.87 & -5.622 & 0.7306 \\
50400 & 189.5 & -19.21 & 1.162 \\
61600 & 264.4 & -29.02 & 1.531 \\
72800 & 303.8 & -36.36 & 1.878 \\
84000 & 412.2 & -50.50 & 2.393 \\
\hline
\end{tabular}

The first series of figures below show the energy absorbed as a result of deformation of ship structures and compression of cargo. Figure 2 is the no cargo case. The light cargo case, Figure 3 , has a one-dimensional empty space fraction (f) of 0.6 and a crush strength $(\sigma)$ of 


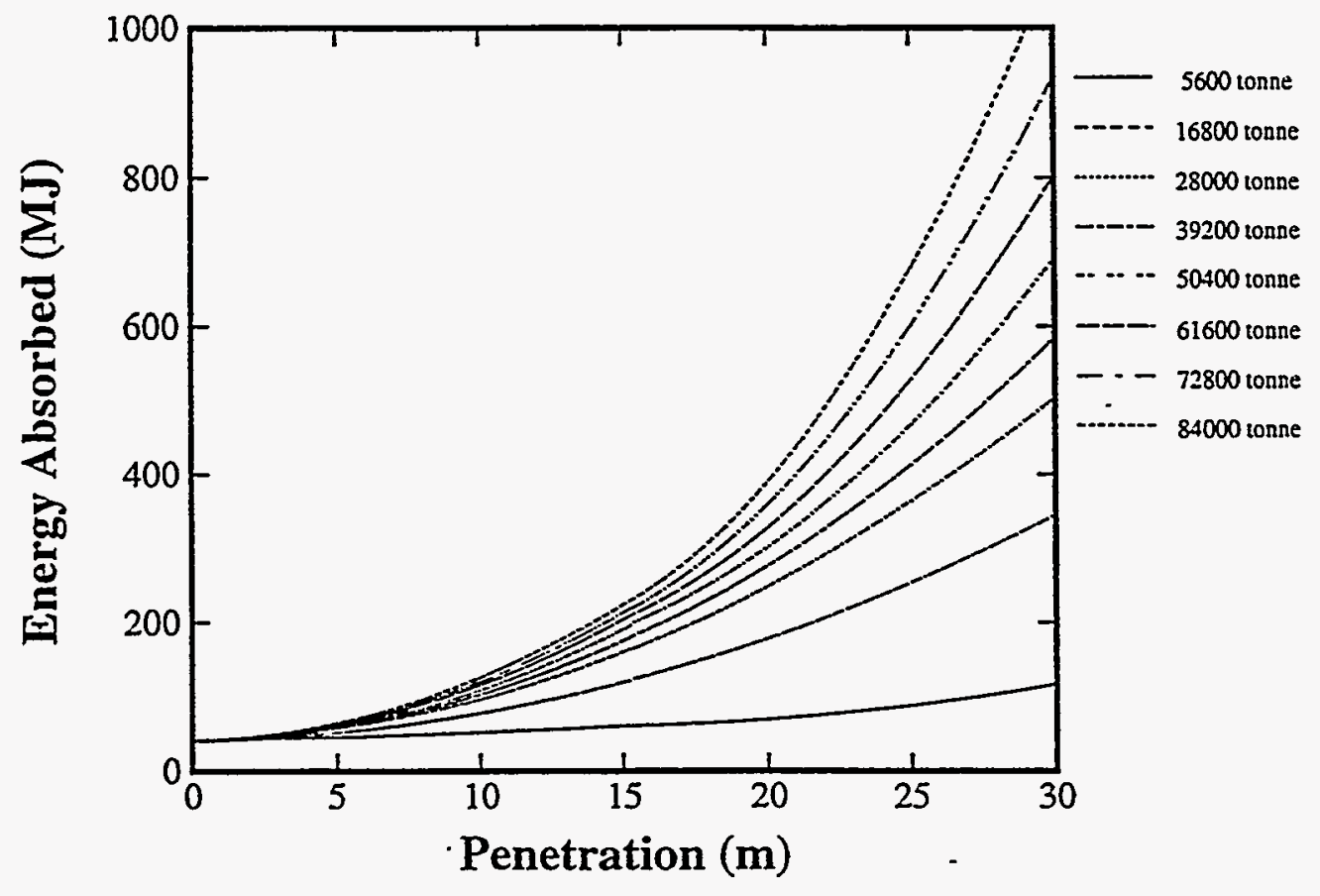

Figure 2. Energy Absorbed Versus Penetration in the No Cargo Case

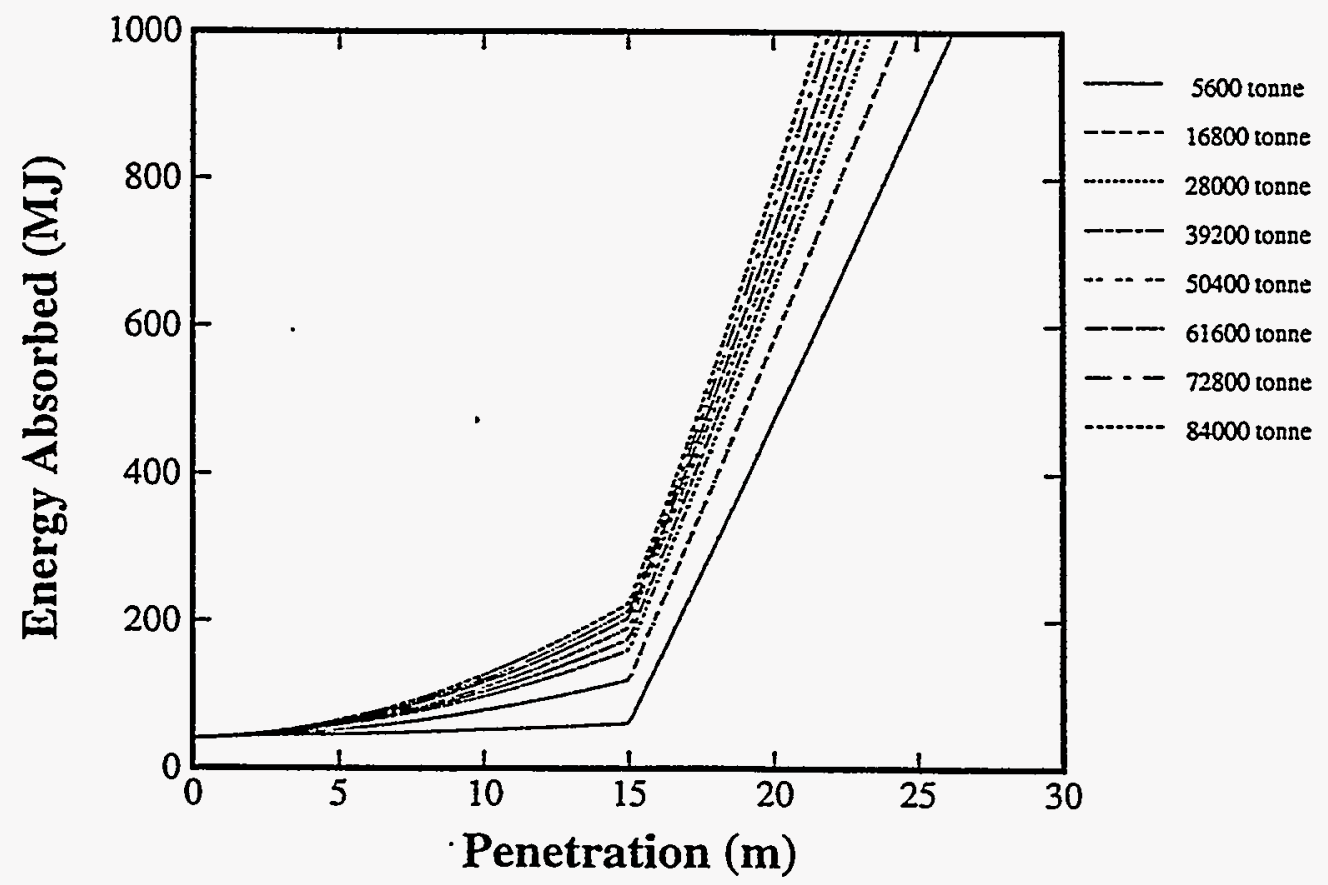

Figure 3. Energy Absorbed Versus Penetration in the Light Cargo Case ( $f=0.6, \sigma=6.89 \mathrm{MPa})$ 
6.89 $\mathrm{MPa}$; this cargo closes up and begins compression, i.e., "goes material solid," after a penetration of 15 meters. A medium cargo case, representing a shipment of wood, is shown in Figure 4; it has an empty space fraction of 0.2 and a crush strength of $34.5 \mathrm{MPa}$; it closes up after a 5 -meter penetration. The heavy cargo case shown in Figure 5 represents a cargo of structural steel or heavy equipment. It has an empty space fraction of 0.5 and a crush strength of $1500 \mathrm{MPa}$; it closes up after 12.5 meters of penetration.

\section{Distribution of Ship Displacements, Speeds, and Angles}

From an analysis of two years of ship accident data, ORI developed probability distributions for the displacement $(M)$, velocity $(V)$, and impact angle $(\theta)$ of the striking ship. These distributions are presented in Tables 13 through 15 . The ORI tables originally contained 11 intervals for the displacement of the striking ship. For this analysis, the two lowest intervals were combined, as were the three highest, which reduced the 11 intervals to 8 intervals that matched the 8 ORI curves for absorbed energy (W). The ORI tables also contain 11 values of $\mathrm{V}$, with speeds ranging up to $11.3 \mathrm{~m} / \mathrm{s}$, and 9 values of impact angle $\theta$. Finally, the 968 different combinations of these values were all examined to estimate the probability of cask failure.

Speed During a Collision. Let $\mathrm{m}$ and $\mathrm{v}$ be the mass and transverse speed of the struck ship, $M$ and $V$ be the mass and transverse speed of the striking ship, $V_{0}$ and $E_{0}$ be the initial transverse speed and initial transverse kinetic energy of the striking ship, $\mathrm{dm}$ be the mass of water entrained behind the struck ship during the collision, $x$ be the penetration distance of the striking ship into the hull of the struck ship, $d$ be the final (maximum) penetration distance, $\mathrm{W}(\mathrm{x})$ and $\mathrm{W}(\mathrm{d})$ respectively be the work done deforming ship structures and compressing cargo during the collision for penetration to the distance $x$ and to the final penetration distance $\mathrm{d}$, and $\theta$ be the angle of impact measured from the normal to the initial direction of the struck ship (accordingly, $\mathrm{V}=\mathrm{v}_{\mathrm{b}} \cos \theta$ where $\mathrm{v}_{\mathrm{b}}$ is the initial velocity of the striking ship as defined in Section 3.4.4.1, above).

From Minorsky's derivation (see Section 3.4.4.1), we have that

$$
\mathrm{W}(\mathrm{d})=\frac{\mathrm{M}(\mathrm{m}+\mathrm{dm})}{2(\mathrm{M}+\mathrm{m}+\mathrm{dm})} \mathrm{V}_{0}^{2}=\frac{(\mathrm{m}+\mathrm{dm})}{2 \mathrm{~A}} \mathrm{~V}_{0}^{2}
$$

where $A=\left(\frac{M+m+d m}{M}\right)$, and

$$
\mathrm{E}_{0}=\frac{1}{2} \mathrm{MV} \mathrm{V}_{0}^{2}
$$

While the striking ship is penetrating the hull of the struck ship, $v$ and $V$ are not the same. Thus, during the collision, 


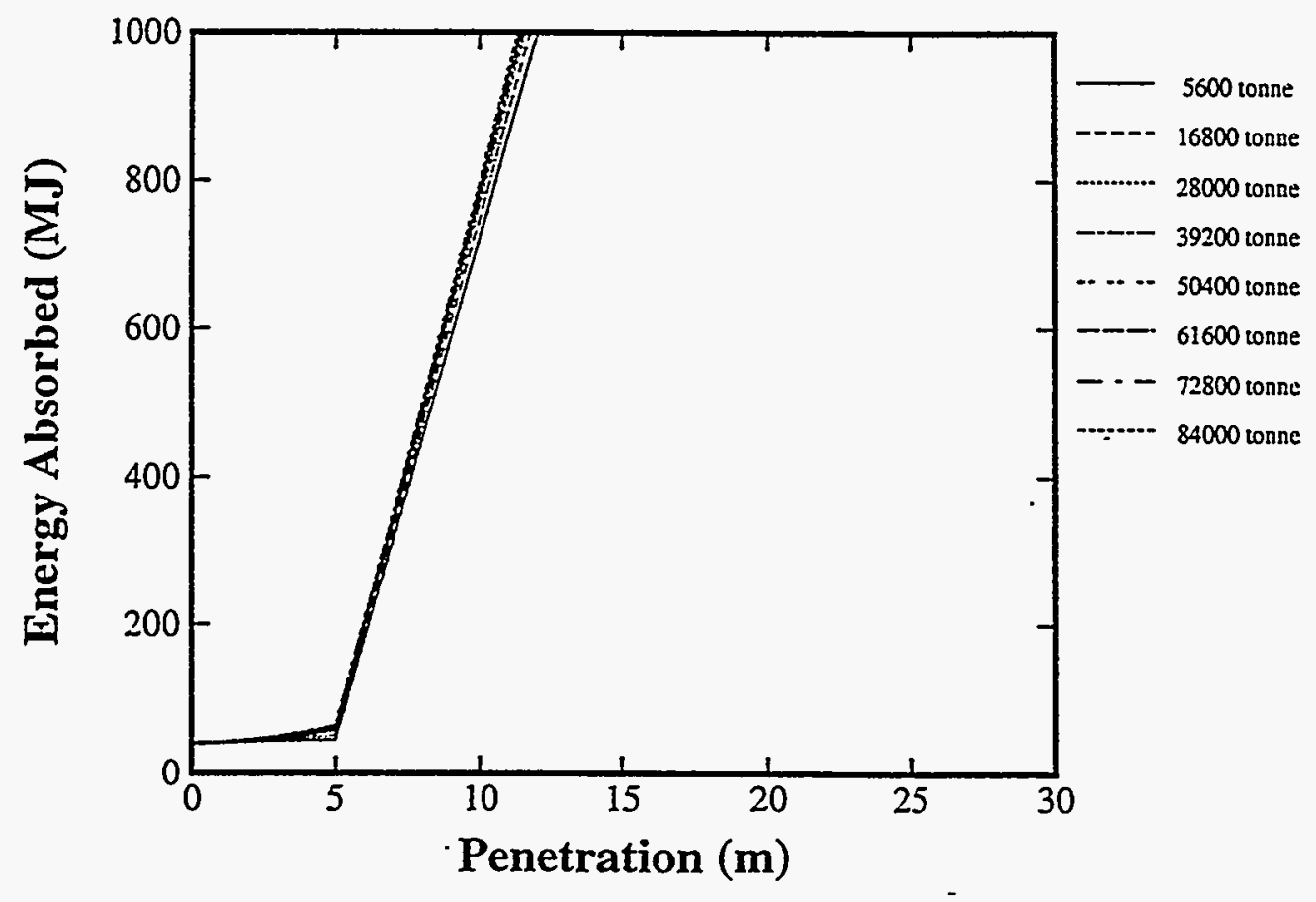

Figure 4. Energy Absorbed Versus Penetration in the Medium Cargo Case $(f=0.2, \sigma=34.5 \mathrm{MPa})$

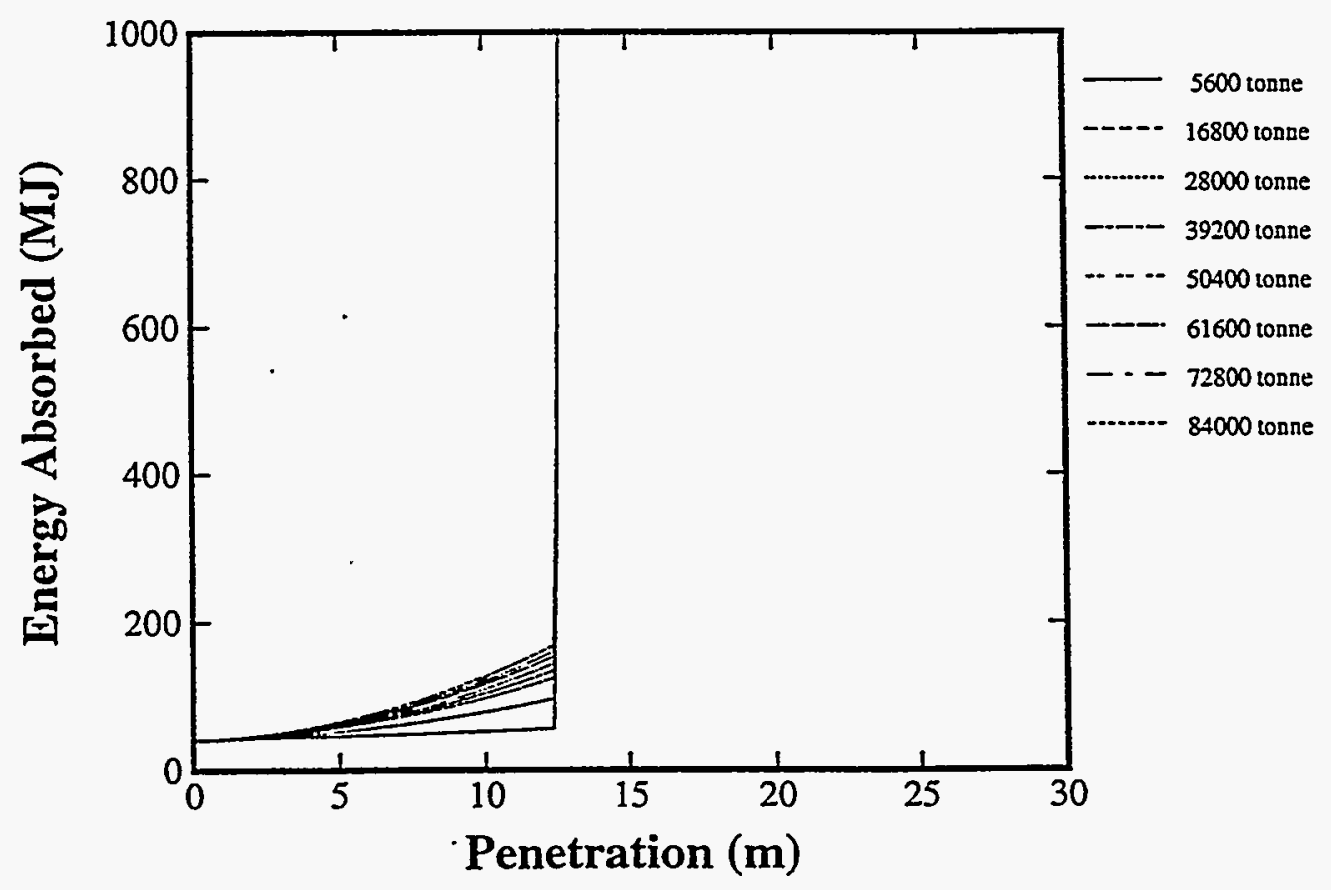

Figure 5. Energy Absorbed Versus Penetration in the Heavy Cargo Case

$$
(\mathrm{f}=0.5, \sigma=1500 \mathrm{MPa})
$$


Table 13. Probabilities of Striking Ship Displacements (M)

\begin{tabular}{|c|c|}
\hline Displacement (tonnes) & Probability of Occurrence \\
\hline $0-10160$ & 0.15 \\
$10161-20321$ & 0.25 \\
$20322-30481$ & 0.25 \\
$30482-40642$ & 0.05 \\
$40643-50802$ & 0.05 \\
$50803-60963$ & 0.05 \\
$60964-71123$ & 0.10 \\
$71124-152407+$ & 0.1 \\
\hline
\end{tabular}

Table 14. Probabilities of Striking Ship Speeds (V)

\begin{tabular}{|r|c|}
\hline Speed $(\mathrm{m} / \mathrm{s})$ & Probability of Occurrence \\
\hline $0-1.028$ & 0.0448 \\
$1.028-2.058$ & 0.2538 \\
$2.058-3.087$ & 0.1045 \\
$3.087-4.115$ & 0.1343 \\
$4.115-5.144$ & 0.1343 \\
$5.144-6.173$ & 0.0896 \\
$6.173-7.202$ & 0.0746 \\
$7.202-8.231$ & 0.0597 \\
$8.231-9.260$ & 0.0746 \\
$9.260-10.29$ & 0.0149 \\
$10.29-11.32$ & 0.0149 \\
\hline
\end{tabular}

Table 15. Probabilities of Striking Ship Impact Angles ( $\theta)$

\begin{tabular}{|c|c|}
\hline Angle From the Normal (degrees) & Probability of Occurrence \\
\hline $0-10$ & 0.2754 \\
$10-20$ & 0.1305 \\
$20-30$ & 0.0725 \\
$30-40$ & 0.1305 \\
$40-50$ & 0.1015 \\
$50-60$ & 0.0724 \\
$60-70$ & 0.1303 \\
$70-80$ & 0.0435 \\
$80-90$ & 0.0434 \\
\hline
\end{tabular}




$$
E_{0}=\frac{1}{2} M V^{2}+\frac{1}{2}(m+d m) v^{2}+W(x)
$$

Because momentum is conserved during the course of the collision,

$$
M V_{0}=M V+(m+d m) v
$$

Combining Equations 14,15 , and 16 by replacing $E_{0}$ and $V^{2}$ in Equation 15 yields the following quadratic expression for the velocity of the struck ship during the course of the collision,

$$
\frac{1}{2} A v^{2}-V_{0} v+\frac{W(x)}{m+d m}=0
$$

Thus, the value of the struck ship's transverse speed during the collision is

$$
\mathrm{v}=\frac{1}{\mathrm{~A}} \mathrm{~V}_{0}-\frac{1}{\mathrm{~A}} \sqrt{\mathrm{V}_{0}^{2}-\frac{2 \mathrm{AW}(\mathrm{x})}{\mathrm{m}+\mathrm{dm}}}
$$

as the other root yields a non-zero value for $\mathrm{v}$ when $\mathrm{x}=0$. Inspection of Equation 13 shows that the argument of the square root in Equation 13 equals zero when $x=d$ (i.e., at maximum penetration). Thus, the terminal transverse velocity of both ships is $\mathrm{V}=\mathrm{v}=\frac{1}{\mathrm{~A}} \mathrm{~V}_{0}$.

Maximum Penetration Distance. The maximum penetration of the bow of the striking ship into the target ship was computed by finding the position at which the ships reached their terminal transverse speed using Newton's method. From conservation of energy and momentum, terminal speed is reached when

$$
\mathrm{W}(\mathrm{x})=\frac{1}{2} \mu \mathrm{V}_{0}^{2}
$$

where $\mu=M(m+d m) /(M+m+d m)$, and $V_{0}$ is the initial transverse speed of the striking ship.

For the no cargo case, Figure 6 shows that, for each of the striking ship displacements considered, initial normal speeds of $8 \mathrm{~m} / \mathrm{s}$ and $10 \mathrm{~m} / \mathrm{s}$ were sufficient to cut completely through the struck ship, resulting in a probable sinking. On the other hand, at $2 \mathrm{~m} / \mathrm{s}$ only the four heaviest ships penetrated the hull of the struck ship, and at or below $1 \mathrm{~m} / \mathrm{s}$ the hull was not penetrated for striking ships of any displacement.

Figure 7 shows the corresponding information for the light cargo case. Because the empty space fraction for this case is 0.6 , the cargo effect does not begin until penetration has reached $15 \mathrm{~m}$. The figure shows the results as a function of the displacement of the striking ship, for normal impact speeds from $2 \mathrm{~m} / \mathrm{s}$ to $10 \mathrm{~m} / \mathrm{s}$. There were no cases where the struck ship was 


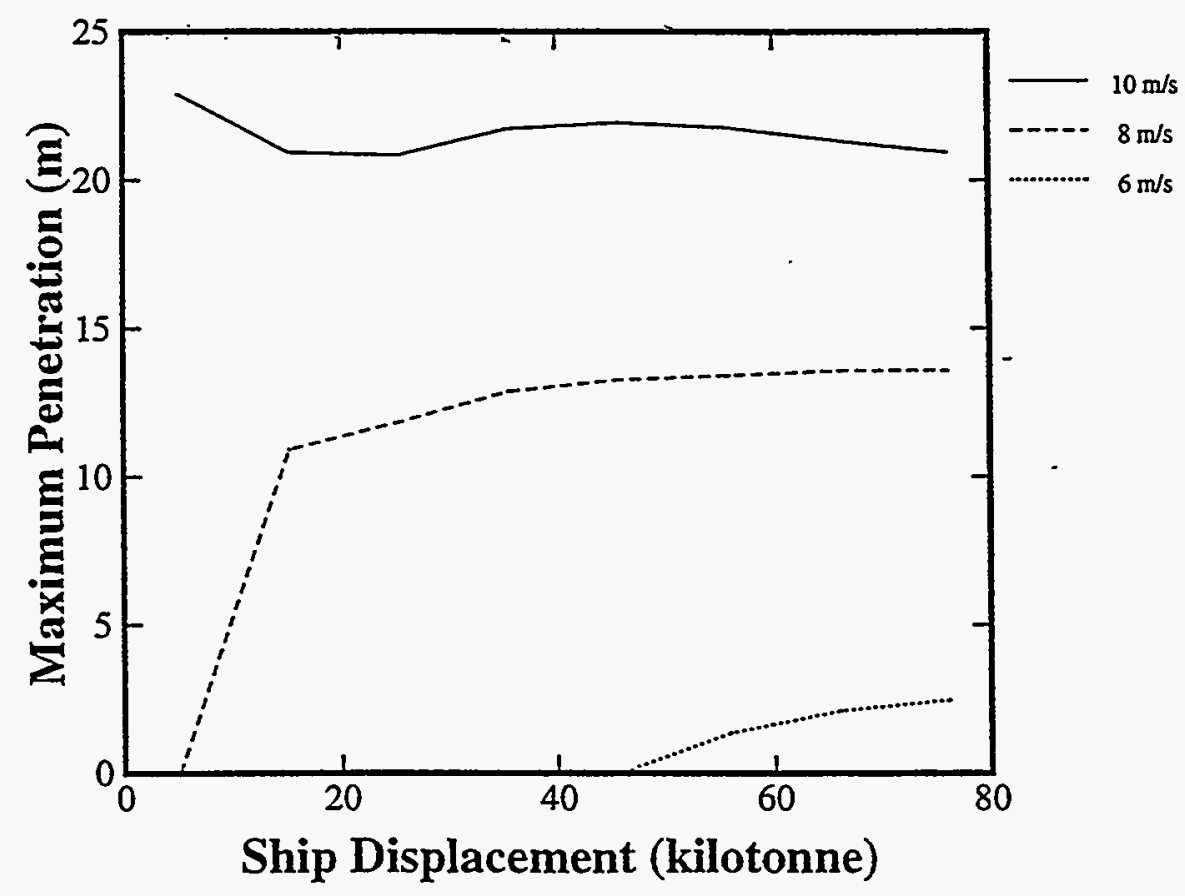

Figure 6. Maximum Penetration Distance in the No Cargo Case

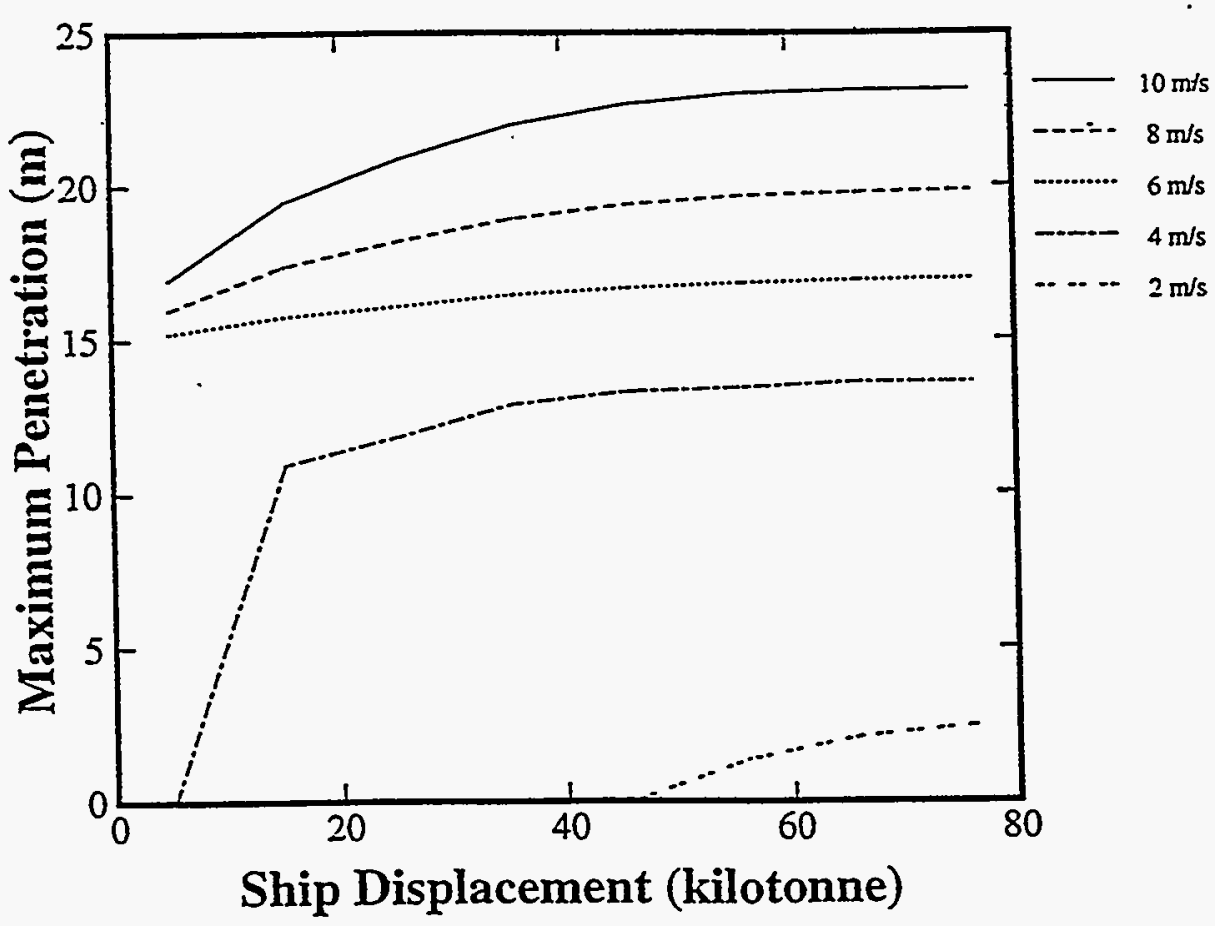

Figure 7. Maximum Penetration Distance for the Light Cargo Case $(f=0.6, \sigma=6.89 \mathrm{MPa})$ 
completely cut through. At the two lowest speeds, the cargo did not close up, and thus was not a factor in absorbing impact energy. There was no penetration at $1 \mathrm{~m} / \mathrm{s}$ for any of the eight striking ship displacements considered.

The medium and heavy cargo cases are shown in Figures 8 and 9, respectively. Figure 8 shows that the cargo effect begins at $5 \mathrm{~m}$ of penetration and is important down to impact speeds of $4 \mathrm{~m} / \mathrm{s}$. At lower speeds, the cargo did not close up, and thus was not a factor in determining the penetration depth. A similar result was obtained for heavy cargo. In both cases there was a strong influence by the cargo on the maximum penetration depth.

\subsubsection{Impact Forces}

Fuel rods experience impact forces if, during a strong acceleration event, they are driven against the inside of the cask or basket, or come into hard rod-to-rod contact. It is shown in Sanders et al. that accelerations of $100 \mathrm{~g}$ (where $\mathrm{g}$ is the acceleration due to gravity, $9.8 \mathrm{~m} / \mathrm{sec}^{2}$ ) can be produced during hypothetical accidents that involve 9-meter drops onto unyielding targets [Sa92, US90]. Sanders et al. also showed that the probability of cladding breach can be as large as $2 \times 10^{-4}$. Here, the average accelerations experienced during ship collisions are shown to be much smaller than $100 \mathrm{~g}$, usually below $1 \mathrm{~g}$, and, therefore, that inertial effects on the fuel are not likely to be significant during ship collisions.

The acceleration (experienced by the cask during a ship collision) is the time derivative of the transverse speed of the struck ship,

$$
a=\frac{d v}{d t}=\frac{d v}{d x} \frac{d x}{d t}=v \frac{d v}{d x}
$$

Differentiating Equation 18 with respect to $\mathrm{x}$ and substituting the derivative into Equation 19 yields,

$$
a(x)=v(x) \frac{\left[\frac{1}{m+d m}\right] \frac{d W(x)}{d x}}{\sqrt{v_{0}^{2}-\frac{2 A W(x)}{m+d m}}}
$$

Because the argument of the square root equals zero at the maximum penetration distance $d$, acceleration $\mathrm{a}(\mathrm{x})$ increases rapidly as maximum penetration is approached and has a vertical asymptote at the maximum penetration distance $d$.

The average acceleration during the collision is

$$
\bar{a}=\frac{1}{d} \int_{0}^{d} a(x) d x=\frac{1}{d} \int_{0}^{d} v(x) \frac{d v(x)}{d x} d x
$$




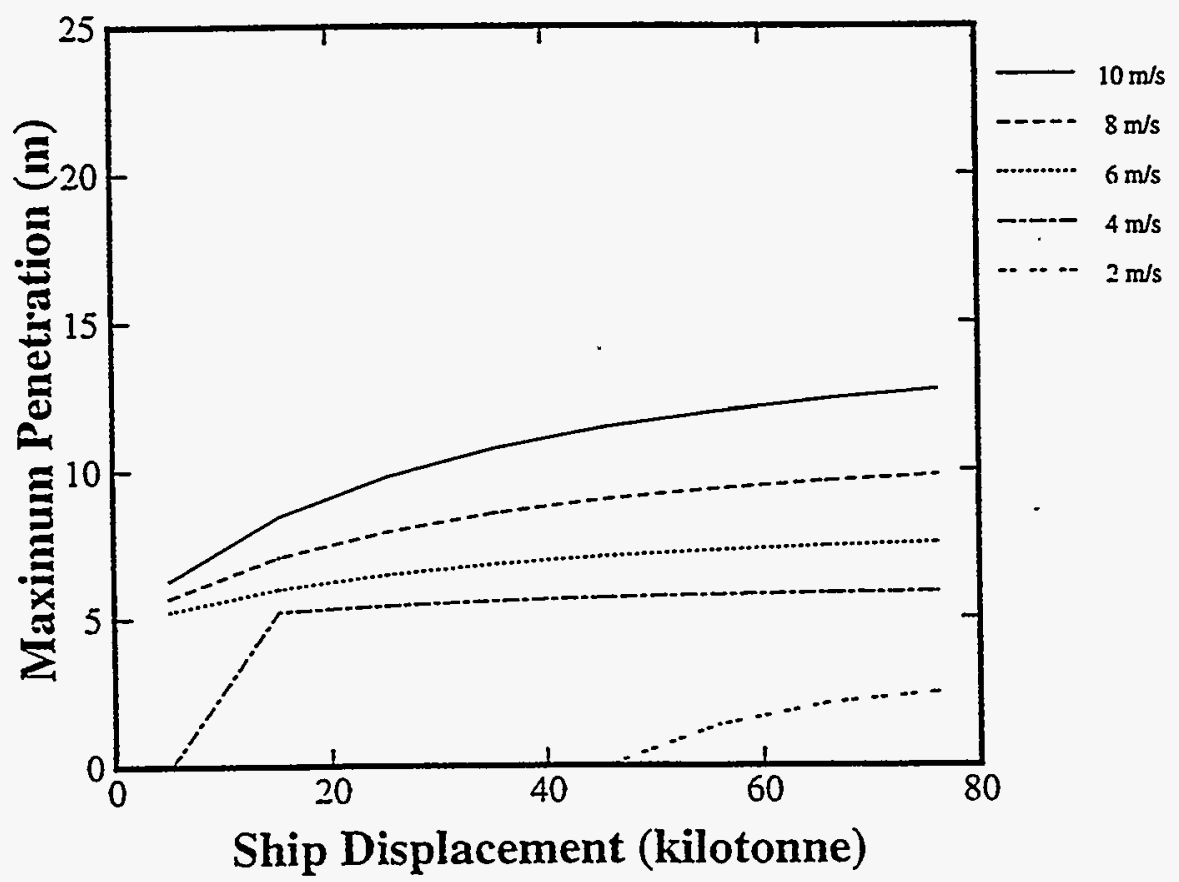

Figure 8. Maximum Penetration Distance in the Medium Cargo Case ( $f=0.2, \sigma=34.5 \mathrm{MPa}$ )

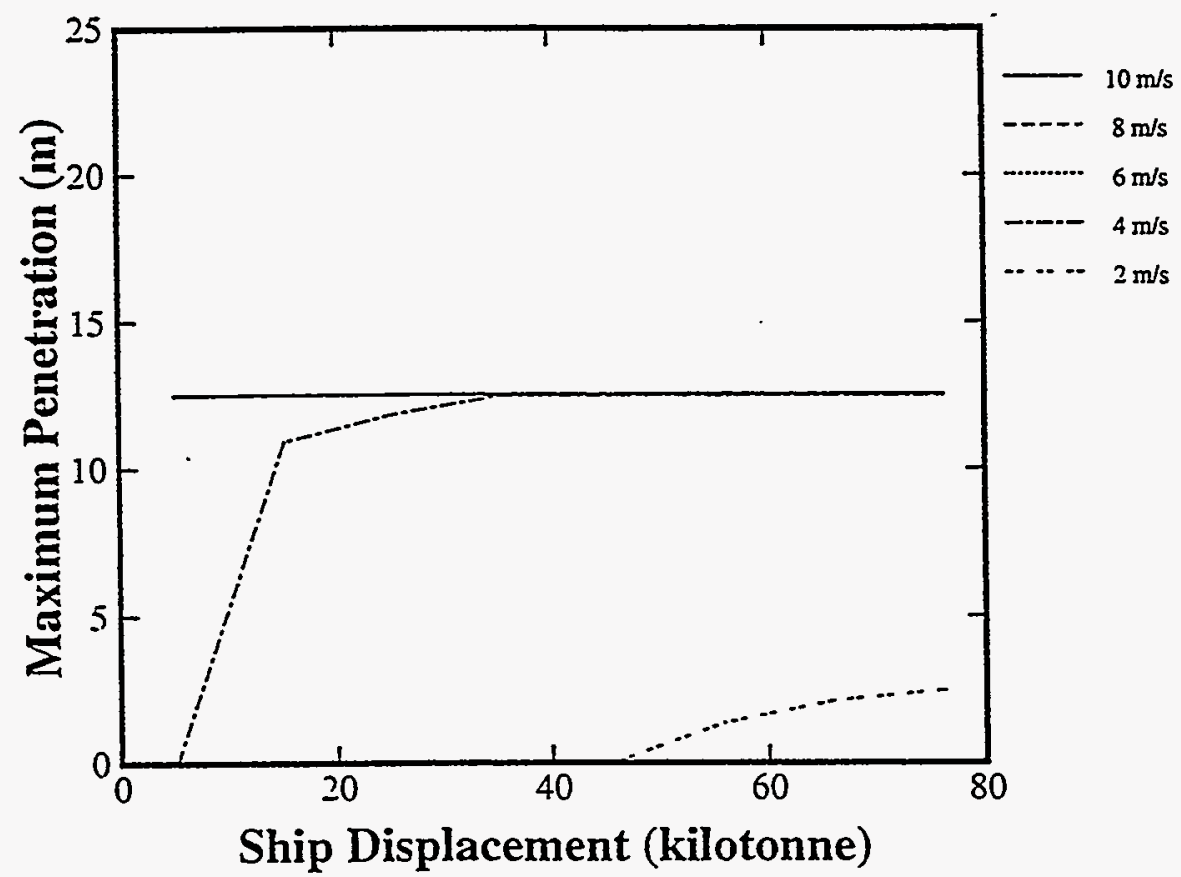

Figure 9. Maximum Penetration Distance in the Heavy Cargo Case ( $f=0.5, \sigma=1500 \mathrm{MPa}$ ) 
where $d$ is the maximum penetration distance. Because $a(x)$ has a singularity at $d$, this is an improper integral. Nevertheless, the integral converges, because the integrand increases slowly, like $(\mathrm{d}-\mathrm{x})^{-1 / 2}$, as $\mathrm{x} \rightarrow \mathrm{d}$.

An analytic solution for the integral in Equation 21 was obtained by transformation of variables.

Let

$$
g(x)=V_{0}^{2}-\frac{2 A W(x)}{m+d m}
$$

Then,

$$
g(0)=V_{0}^{2}, \quad g(d)=0, \quad v(x)=\frac{1}{A}\left[V_{0}-g(x)^{1 / 2}\right], \quad \text { and } \frac{d v(x)}{d x}=-\frac{1}{2 A} g(x)^{-1 / 2} \frac{d g}{d x}
$$

Transformation of the variables in Equation 21 then yields

$$
\bar{a}=\frac{1}{2 A^{2} d} \int_{g(d)}^{g(0)} \frac{V_{0}-g(x)^{1 / 2}}{g(x)^{1 / 2}} d g=\frac{V_{0}^{2}}{2 A^{2} d}
$$

When there is no other cargo in the hold with the spent fuel cask, the average acceleration is only a fraction of $1 \mathrm{~g}\left(9.8 \mathrm{~m} / \mathrm{s}^{2}\right)$ in all cases. Figure 10 shows that the average acceleration with no other cargo is always less than $1 \mathrm{~m} / \mathrm{s}^{2}$. Similar results are obtained for the light cargo case, as shown in Figure 11. In the medium and even in the extreme case of heavy cargo, the average accelerations found were less than $2 \mathrm{~m} / \mathrm{s}^{2}$, as shown in Figures 12 and 13; here the highest acceleration, corresponding to a 75-kilotonne ship striking with a normal speed of $10 \mathrm{~m} / \mathrm{s}$, was about $2 \mathrm{~m} / \mathrm{s}^{2}$.

Because of these low average accelerations, generally on the order 1 percent relative to the accelerations expected in the NRC regulatory accident conditions, impact of fuel rods inside the cask is not expected to do any damage to the fuel as a result of collisions either in port or on the high seas. Therefore, we conclude $P_{\text {Impact }}=0.0$.

\subsubsection{Crush Forces}

The spent fuel package examined by this study is the Pegase shipping cask, a transport cask of French design [FR88]. It is a lead-shielded truck cask, with a mass of 18.9 tonnes, a diameter of $1.875 \mathrm{~m}$, and a height of $2.239 \mathrm{~m}$. The cask body consists of two stainless-steel shells that surround a lead shield. The cask is designed to carry fuel or other radioactive materials in baskets which fit into the cylindrical cavity of the cask. 


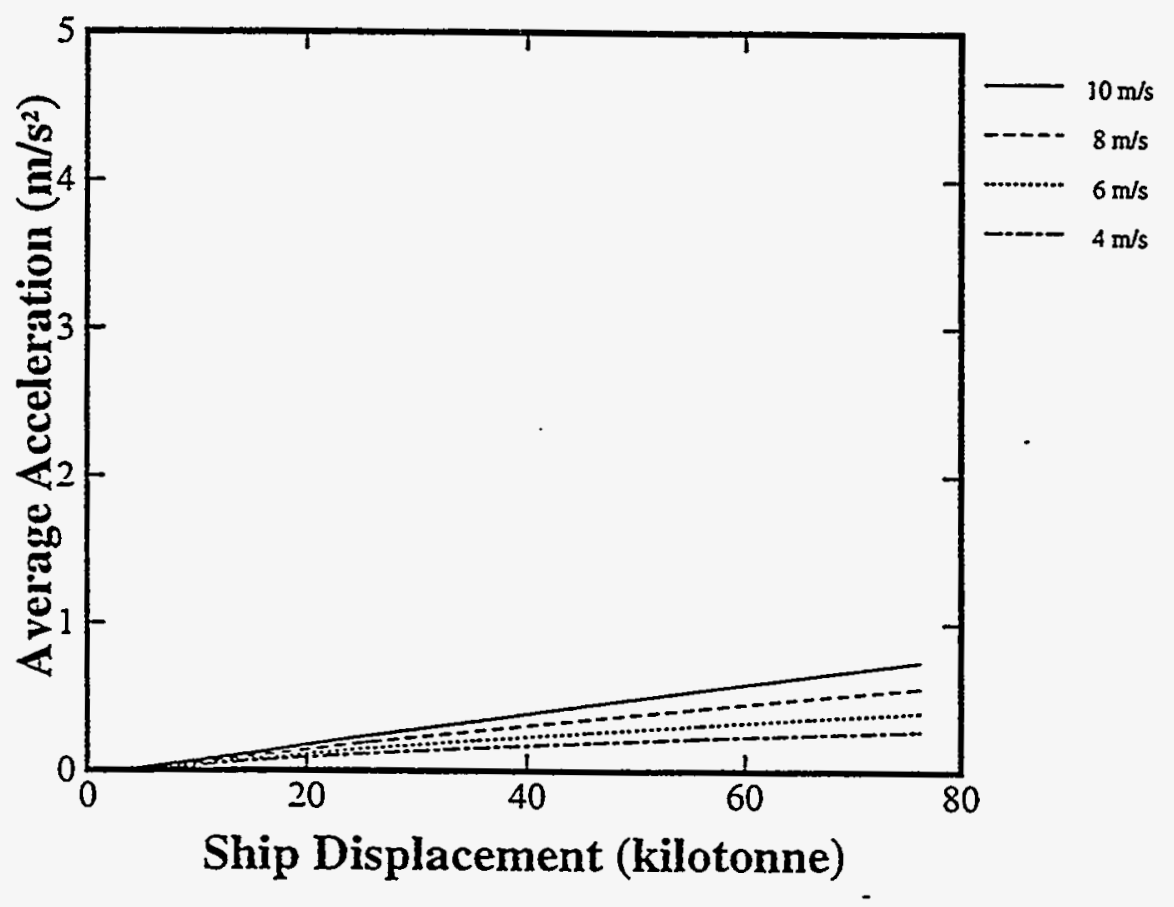

Figure 10. Average Accelerations for the No Cargo Case

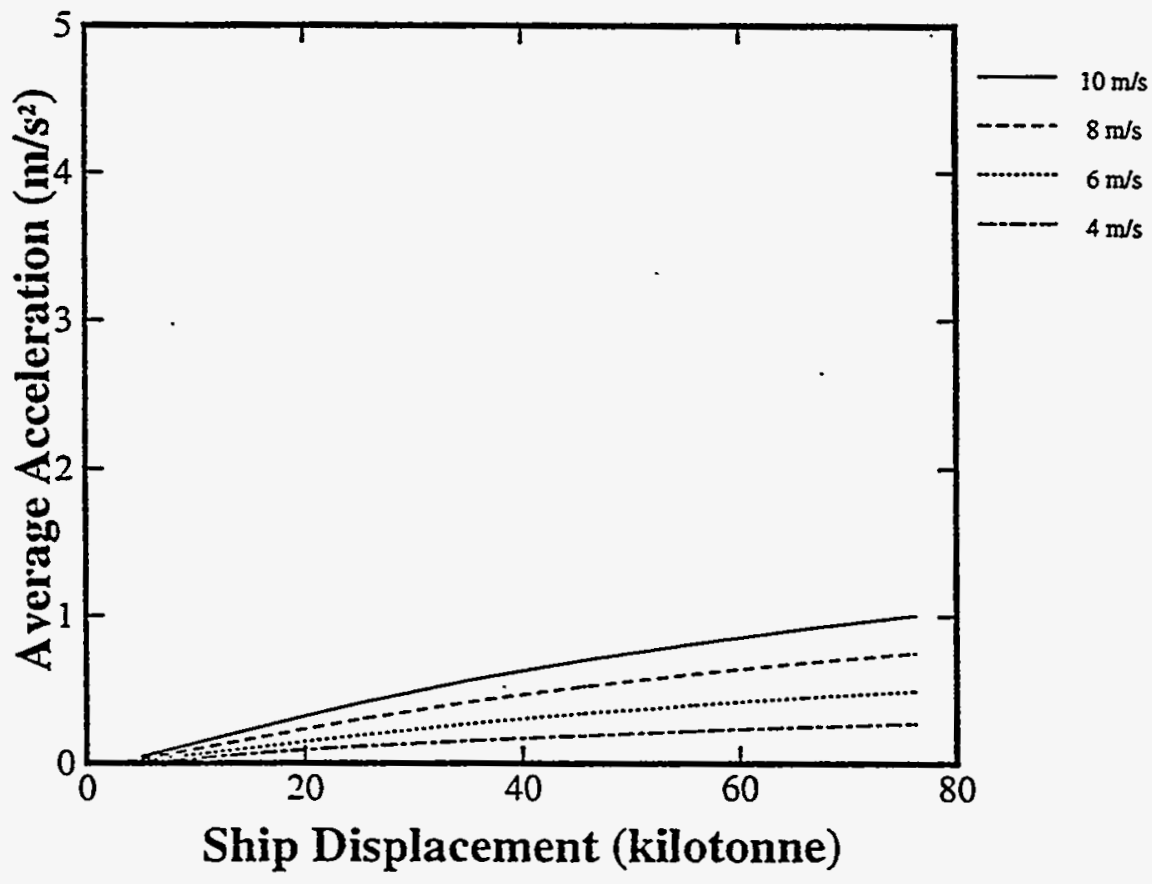

Figure 11. Average Accelerations for the Light Cargo Case ( $f=0.6, \sigma=6.89 \mathrm{MPa}$ ) 


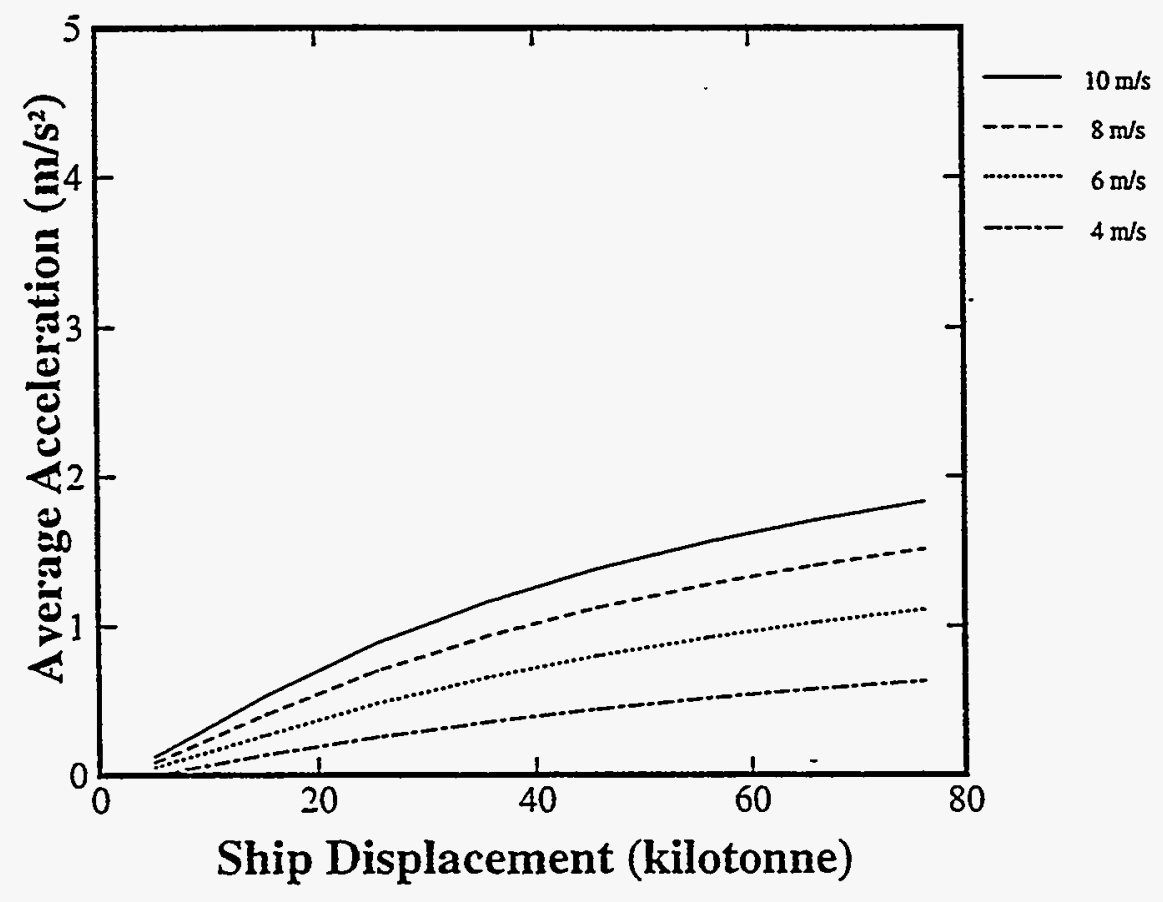

Figure 12. Average Accelerations for the Medium Cargo Case $(f=0.2, \sigma=34.5 \mathrm{MPa})$

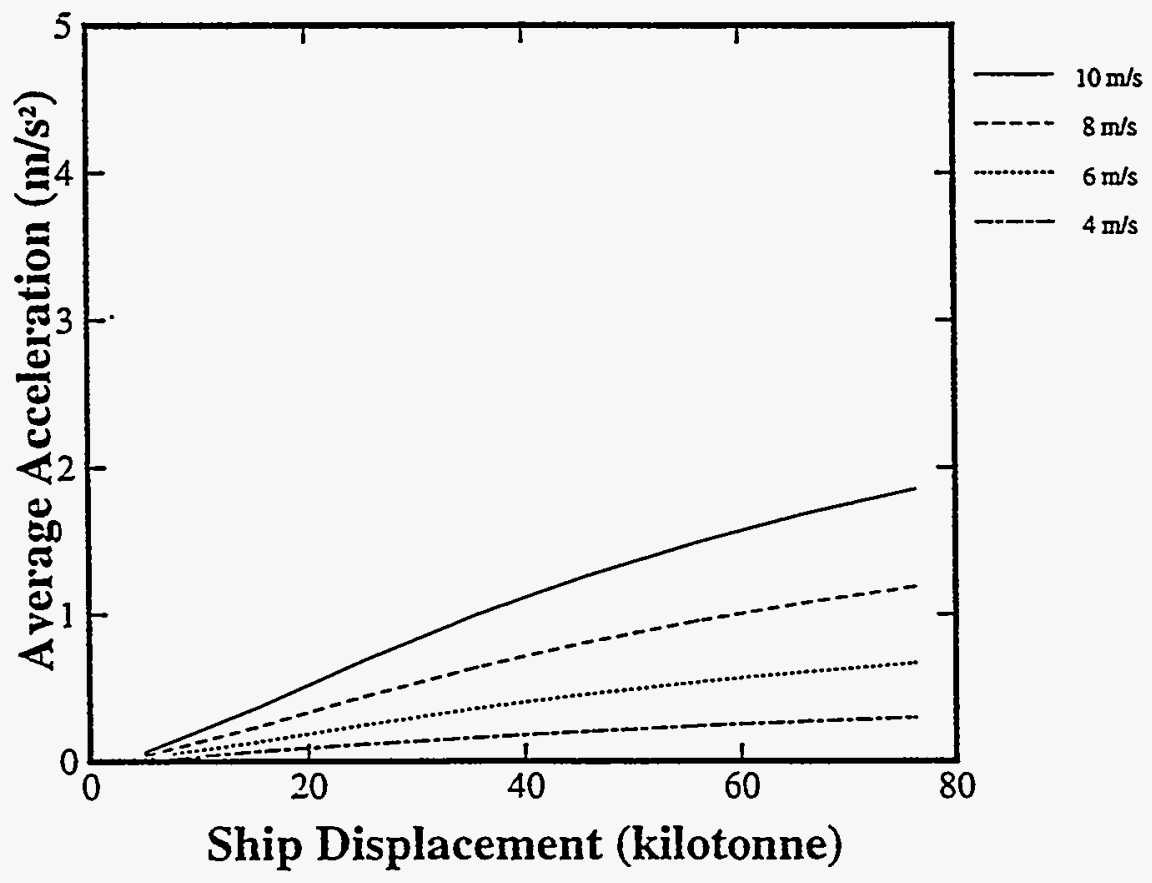

Figure 13. Average Accelerations for the Heavy Cargo Case ( $f=0.5, \sigma=1500 \mathrm{MPa})$ 
The design and construction of the Pegase cask are similar to thiat of a generic lead-shielded truck cask analyzed by Fisher et al. [Fi87]. Therefore, although an analysis of the mechanical response of the Pegase cask to crush forces is not available, that response should be similar to the response predicted by Fisher et al. for the generic truck cask. The generic cask analyzed by Fisher et al. is $4.9 \mathrm{~m}$ long and has a body that consists of a lead shield $0.133 \mathrm{~m}$ thick surrounded by outer and inner stainless-steel shells with respective thicknesses of 0.0318 and $0.0127 \mathrm{~m}$. Fisher et al. analyzed the response of their generic truck cask to mechanical loads (i.e., crush forces). Figure 14 presents the results of that analysis for sidewise loadings. The figure shows that a loading of about $8.9 \times 10^{6}$ newtons produces a radial (that is inward) deflection of the cask body of about $0.0254 \mathrm{~m}(1.0 \mathrm{in}$.). The figure also shows that the negative slope of the displacement-force curve is much larger for deflections greater than about $0.0254 \mathrm{~m}$ than it is for smaller deflections, which suggests that the cask response changes from elastic to plastic in this region.

Because the Pegase cask is of similar construction but much shorter than the generic truck cask analyzed by Fisher et al., it probably is more resistant than the generic cask to inward deflections due to sidewise loadings. Although most likely conservative for this analysis, it was assumed that sidewise loadings that exceed $8.9 \times 10^{6}$ newtons would also produce substantial inward deflections of the body of a Pegase cask. Accordingly, the chance that a Pegase cask would be subjected to loadings of this magnitude was examined.

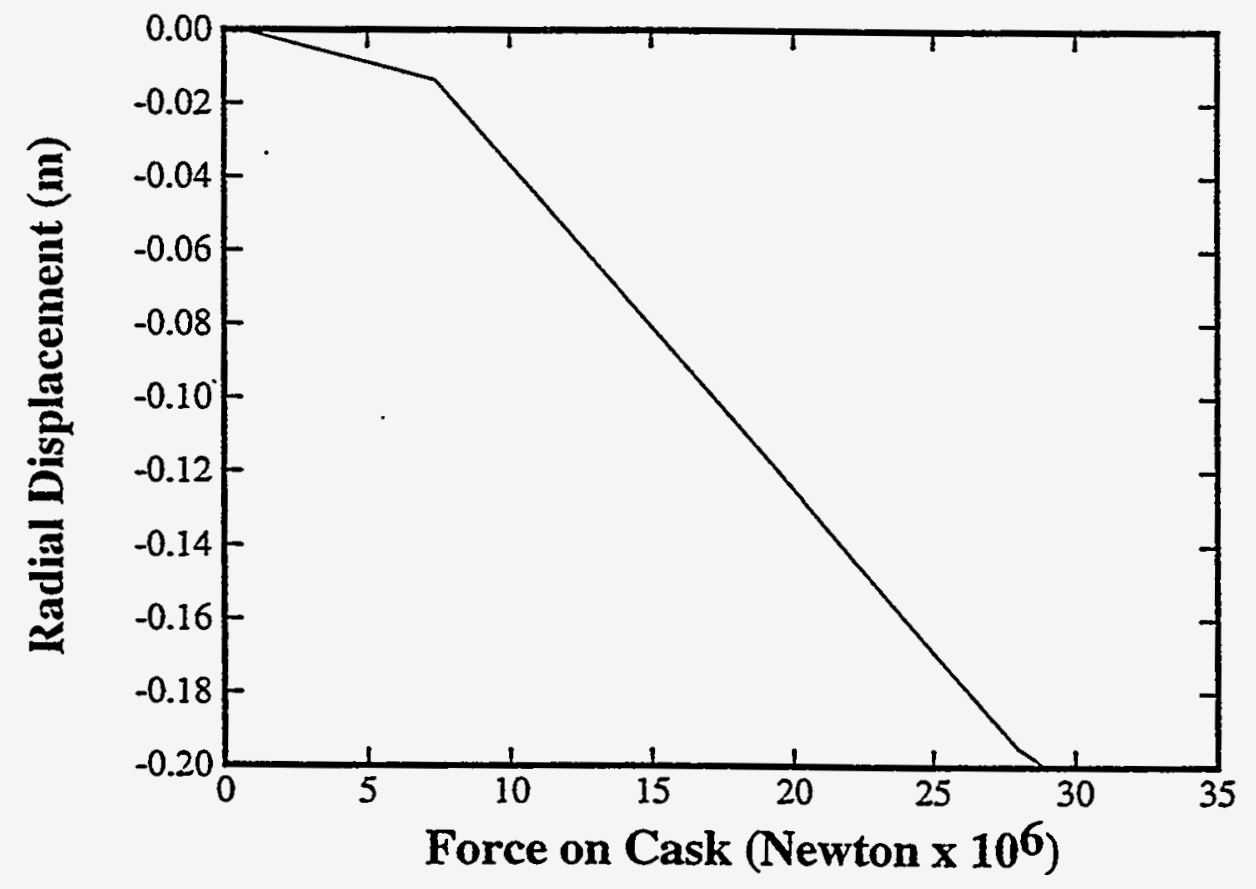

Figure 14. Generic Truck Cask Force Displacement Characteristics 
A RAM cask will experience crush forces during a ship collision if the bow of the striking ship overruns the RAM cask due to penetration of the RAM hold, or if penetration compresses other cargo stowed in that hold about the cask, thus transmitting force to the cask through the compressed cargo. After cargo closeup, that is, after all space between and within the cargo has been consumed by compression of that cargo, the one-dimensional force transmitted through the cargo to the RAM cask can be approximated as

$$
\mathrm{F}_{\text {cask }}=\sigma_{\text {cargo }} \mathrm{A}
$$

where $\sigma_{\text {cargo }}$ is the crush strength of the cargo and A is the area to which the force is applied. Here, the area to which the force is applied is taken to be the cross-sectional area of the Pegase cask (i.e., $A=h_{\text {cask }} d_{\text {cask }}$, where $h_{\text {cask }}$ is the height and $d_{\text {cask }}$ the diameter of the Pegase cask). Thus, for the Pegase cask, $A=4.198 \mathrm{~m}^{2}$. In actuality, after the cargo has closed about the cask, the force transmitted through the cargo to the cask will first cause further compression of cargo materials until they become so compressed that their crush strength is greater than that of the cask, whereupon inward collapse of cask walls will begin. The forces experienced by the cask during crush events will thus be larger than the forces estimated using Equation 23.

Forces transmitted through cargo that has closed about the RAM cask were estimated using Equation 23 for each of the three cargo cases defined previously in Section 3.4.4.2. For the light cargo case, the force is 28.0 million newtons, and for the medium and heavy cargo cases, it is many times larger. Thus, if they occur, crush events caused by compression of cargo about the RAM cask are expected to subject the RAM cask to forces substantially larger than 8.9 million newtons. But the analysis of Fisher et al. showed that inward collapse of the walls of a generic truck cask should become substantial when that cask is subjected to crush forces significantly greater than 8.9 million newtons. Therefore, if this threshold also applies to the Pegase cask as is assumed here, then most cargo crush events will cause substantial inward collapse of Pegase cask walls, and consequently will cause a large fraction of the fuel elements in the Pegase cask to fail. As the available data do not allow this failure fraction to be estimated, it was assumed to have a value of 1.0 (in Section 3.2.3, above, where estimates of source term release fractions were developed).

If the RAM hold contains no other cargo, or if cargo closeup does not take place because striking ship penetration into the hold is shallow, then the RAM cask can experience crush forces only if it is overrun by the bow of the striking ship as it penetrates the RAM hold (i.e., was stowed at a distance from the struck side of the RAM transport ship that is significantly less than the maximum penetration distance into the RAM hold by the bow of the striking ship). When stowed within this penetration region, the RAM cask could be crushed, provided that, if overrun, it is unable to move and therefore is subjected to crush forces.

If overrun, the RAM cask would not be able to move if cask tie-downs do not break or if the collapse of ship structures prevents the cask from sliding when tie-downs do break. Cask tiedowns are designed, under United States regulatory practice, to withstand about 5 million newtons of transverse force [US90]. The difference between this value and the 8.9 million 
newtons required to produce a $0.025-\mathrm{m}$ deflection in the cask wall of the generic cask is not considered to be large enough to assure that tie-downs break. Moreover, in ORI's opinion "the RAM package could conceivably be restrained from sliding, even in an empty hold, after the fittings failed. A buckled deck for example could do this and in effect act as an infinitely strong fitting" [ORI81].

Thus there are two cases to consider for failure due to crush forces. In the first the penetration depth exceeds the cargo closeup distance, whereas in the second it exceeds the cask stowage location. We expect fuel damage and closure failure in both types of events.

Since there are two different scenarios, the total probability of cask failure due to crush is the sum of two terms, one for cargo going solid, the other for the bow of the striking ship overrunning the cask location.

$$
\mathrm{P}_{\text {Crush }}=\mathrm{P}_{\text {Solid }}+\mathrm{P}_{\text {Contact }}
$$

$\mathrm{P}_{\text {Solid }}$ and $\mathrm{P}_{\text {Contact }}$ were evaluated by comparing the maximum penetration distance against the cargo closeup distance and the stowage position of the cask, which was assumed to be on the centerline of the hull. All possible combinations of the values of striking ship displacement, speed, and angle given in Tables 13 through 15 of Section 3.4.4.2 of this report were evaluated. Each individual case was counted as either causing or not causing cask and fuel failure (meaning the fuel is damaged and the cask seal is broken). The sum of $\mathrm{P}_{\text {Solid }}+\mathrm{P}_{\text {Contact }}$ for all failure cases is $\mathrm{P}_{\text {Crush }}$.

Histograms of penetration distance were constructed for each of the four cargo cases examined (no cargo, and light, medium, and heavy cargo). Figure 15 presents the penetration distance histogram for the no cargo case. The figure shows that the most probable result of a collision is failure to penetrate the hull of the struck ship, and that this result occurs almost 50 percent of the time. When the cask is stowed on the centerline of the RAM transport ship, penetration to a distance of at least $15 \mathrm{~m}$ means that cask overrun has occurred. Thus, the last five bars in the histogram contribute to $\mathrm{P}_{\text {Contact }}$. Because the prototypical break-bulk freighter has a $25-\mathrm{m}$ beam, the last bar in the histogram represents penetration to distances greater than the beam of the struck ship, which probably means that the ship would sink.

Figures 16 through 18 present penetration distance histograms for the light, medium, and heavy cargo cases. In these figures, the bar in the middle of the distribution (that is much taller than its neighbors) represents the onset of cargo compression sufficient to cause the RAM hold to go material solid. For this bar and all bars to its right, penetration distance is greater than the product $f B$, where $f$ is the one-dimensional fraction of empty space along the beam of the RAM hold and $B$ is the width of the beam of that hold, here $25 \mathrm{~m}$. For the light, medium, and heavy cargo cases, the product $\mathrm{fB}$ has values of 15,5 , and $12.5 \mathrm{~m}$, respectively. Thus, the tall bar in the middle of each distribution and all bars to its right contribute to $P_{\text {solid, }}$, the probability that the RAM cask is subjected to crush forces because the RAM hold goes material solid due to compression of cargo. Also of note is the fact that the beam of the RAM ship is not fully penetrated for any of these three cargo cases. 


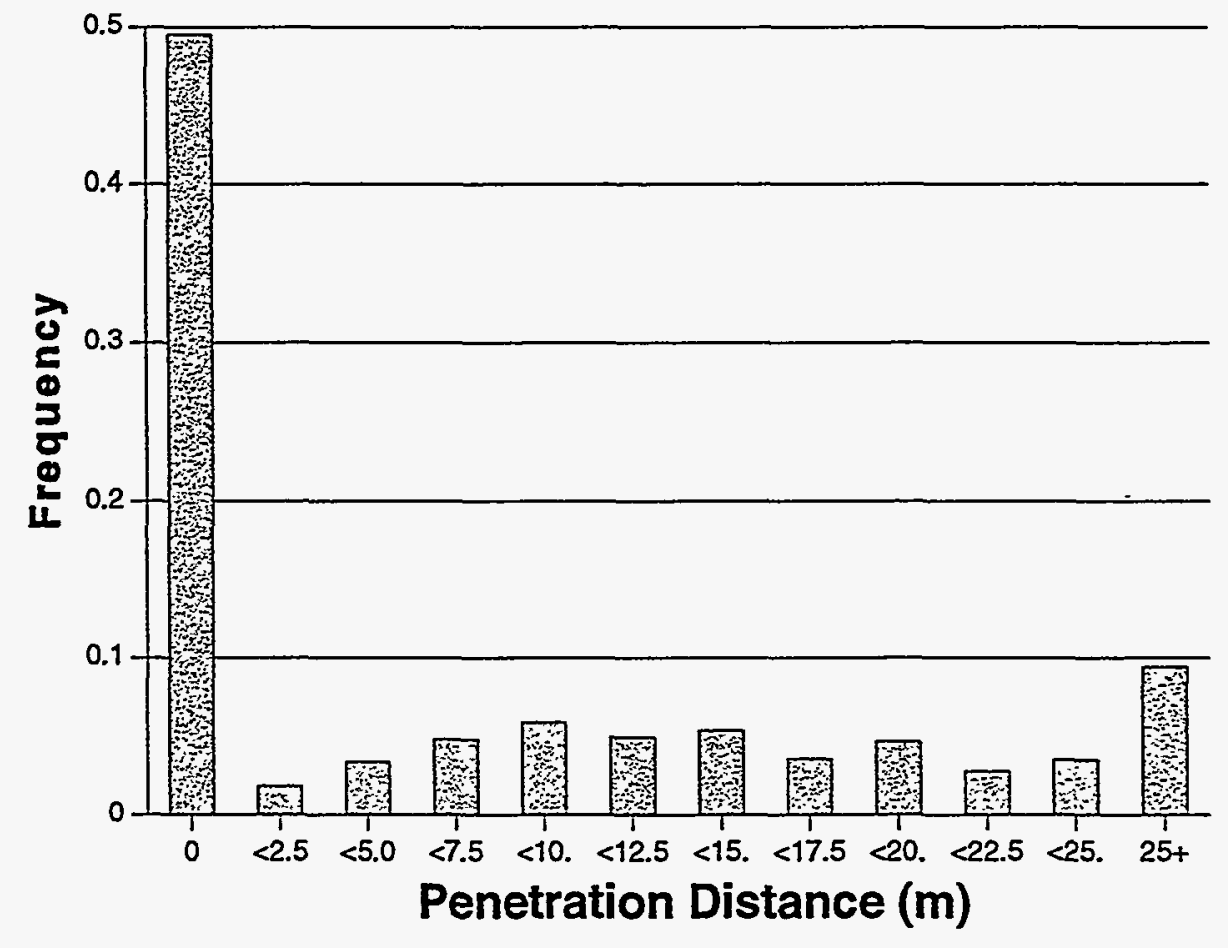

Figure 15. Distribution of Ship Penetration Distances for the No Cargo Case

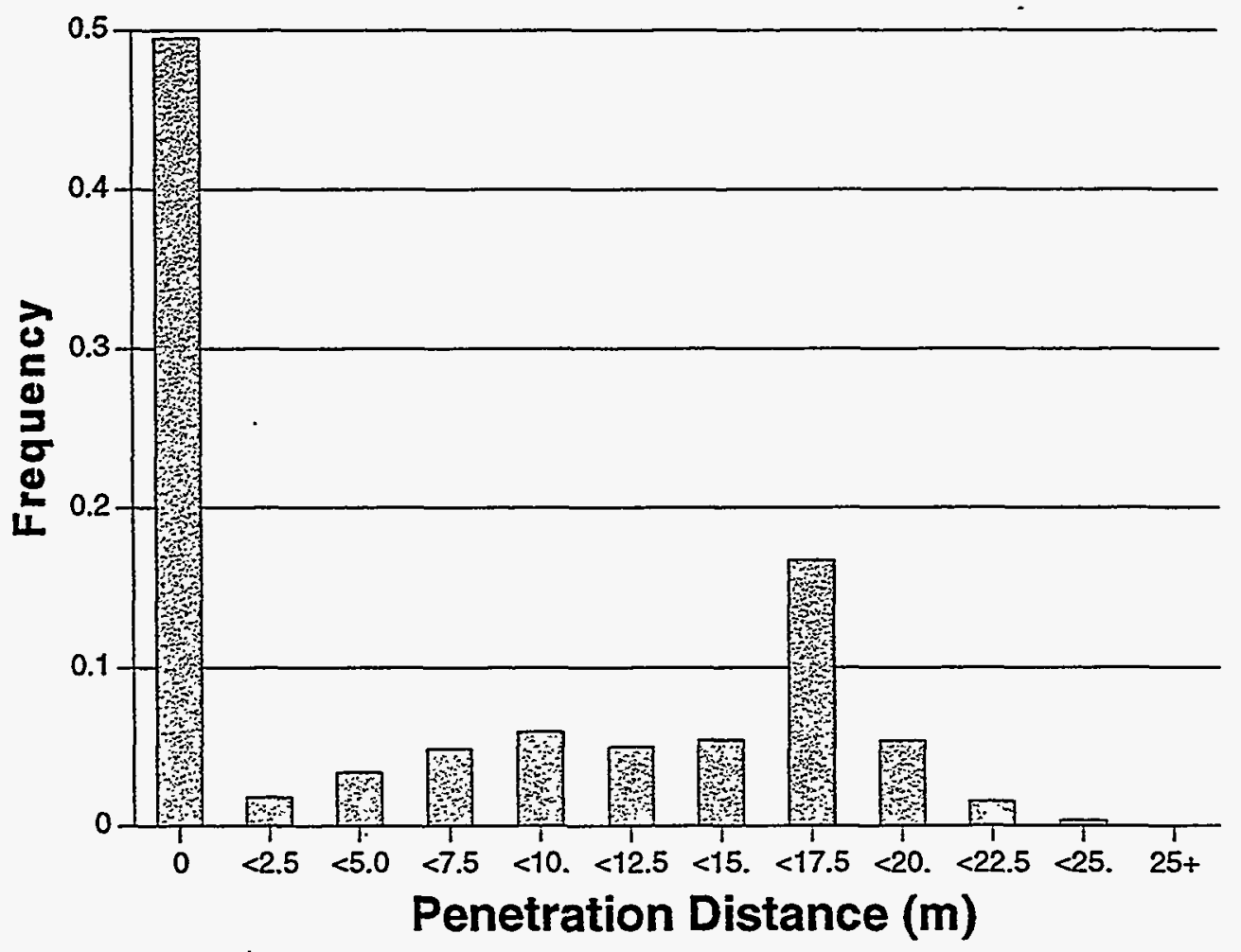

Figure 16. Distribution of Ship Penetration Distances for the Light Cargo Case ( $f=0.6, \sigma=6.89 \mathrm{MPa})$ 


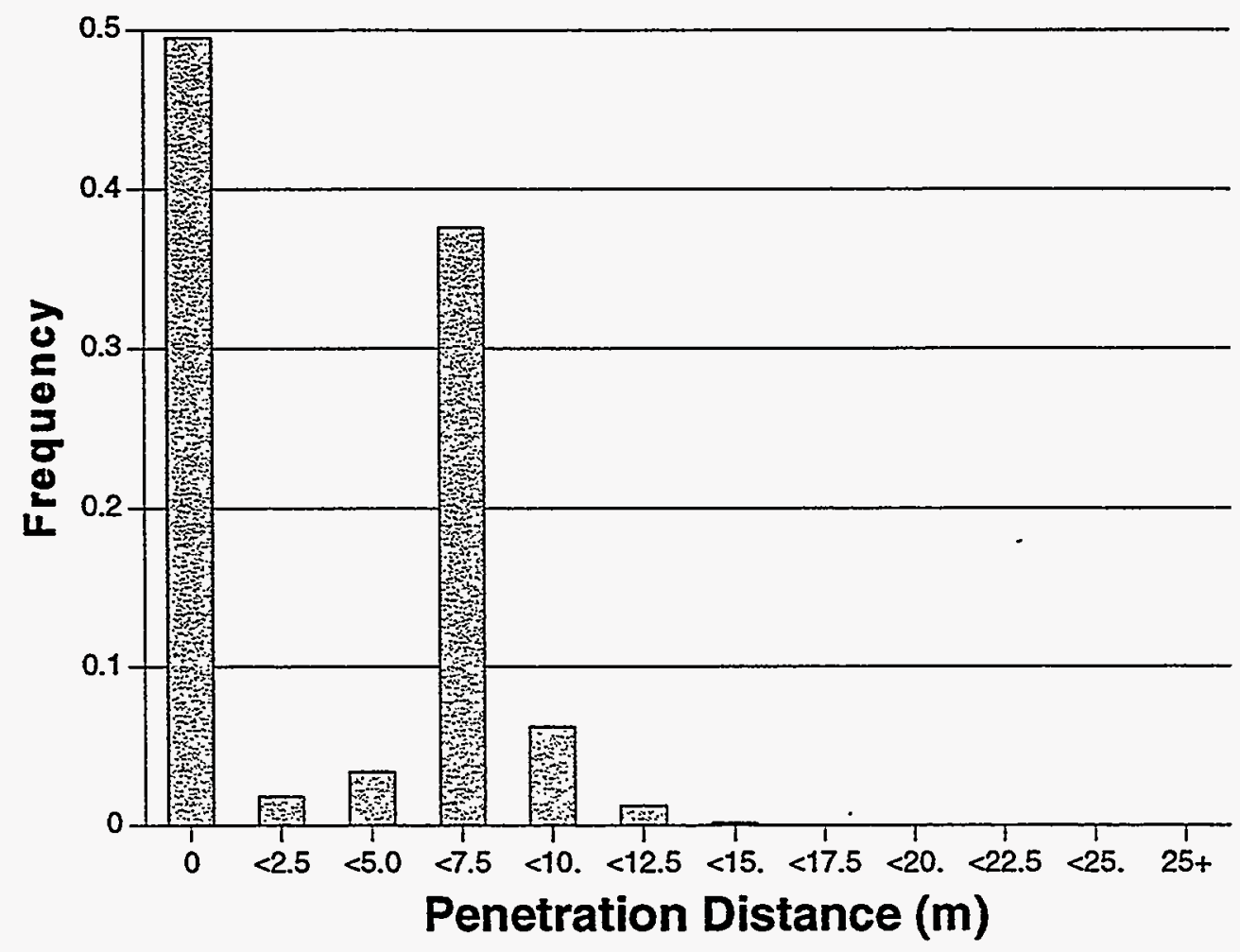

Figure 17. Distribution of Ship Penetration Distances for the Medium Cargo Case ( $f=0.2, \sigma=34.5 \mathrm{MPa})$

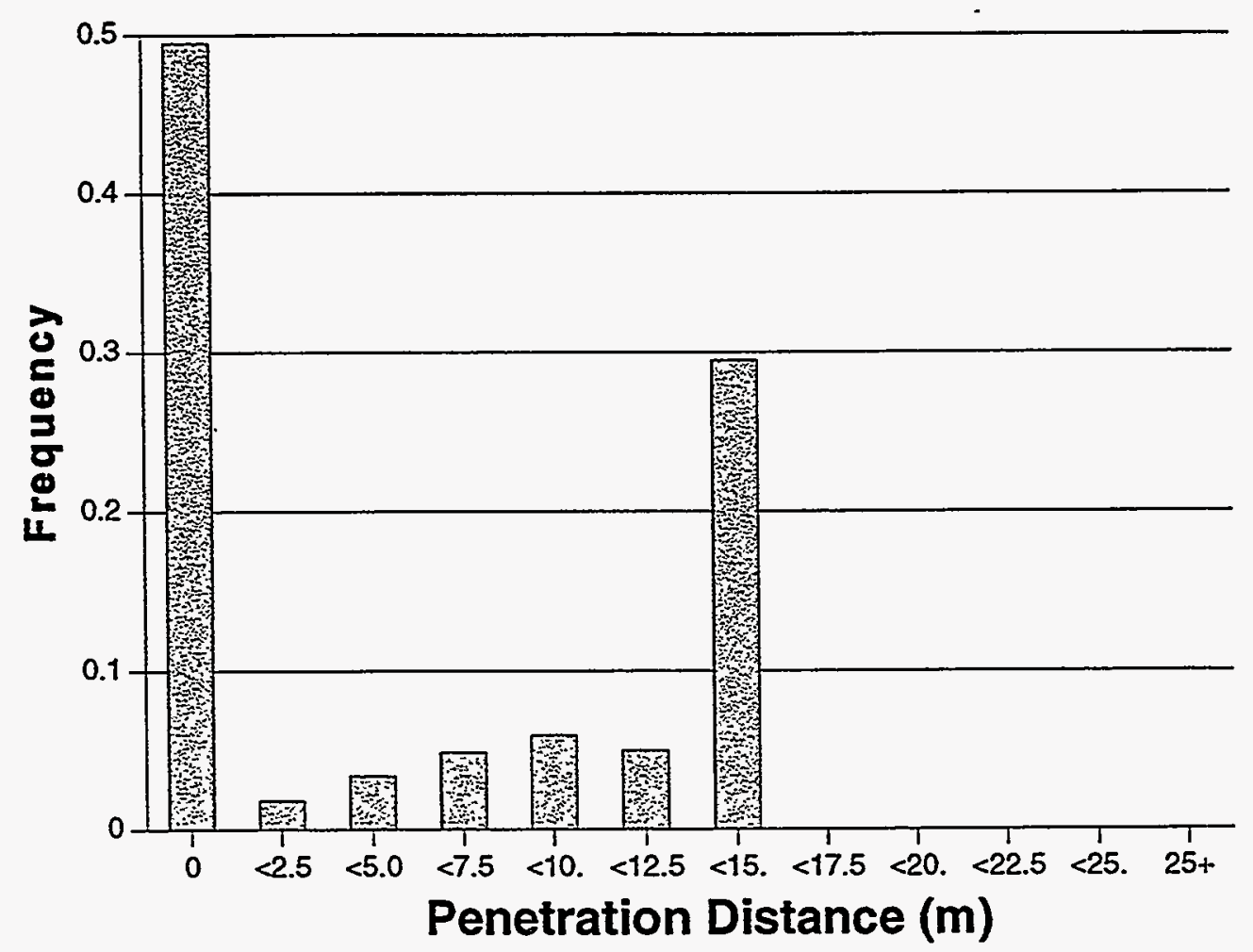

Figure 18. Distribution of Ship Penetration Distances for the Heavy Cargo Case

$$
\text { ( } f=0.5, \sigma=1500 \mathrm{MPa} \text { ) }
$$


Comparison of maximum penetration distances to cargo closeup distances and to the distance to the centerline of the RAM transport ship, where the RAM cask is assumed to be stowed, allow values for $\mathrm{P}_{\text {Solid }}, \mathrm{P}_{\text {Contact }}$, and their sum $\mathrm{P}_{\text {Crush }}$ to be developed. Figure 19 presents a histogram of these values. The four bars of the histogram present the results for the four cargo cases examined. For all but the medium cargo case, the crush probability is about 0.29 , although the portion of that probability caused by the hold going material solid (i.e., $\mathrm{P}_{\text {Solid }} / \mathrm{P}_{\text {Crush }}$ ) varies considerably, being zero for the no cargo case, about 0.8 for the light cargo case, and identically one for the heavy cargo case. For the medium cargo case, $P_{\text {Solid }} / P_{\text {Crush }}$ is almost exactly one and thus crush is almost entirely caused by the RAM hold going material solid. Because the cargo closeup distance for the medium cargo case $(5 \mathrm{~m})$ is only about onefourth of the beam of the ship, more collisions lead to crush conditions as lower striking ship speeds are able to produce cargo closeup. Consequently, the medium cargo case yields the largest value, 0.45 , for $\mathrm{P}_{\text {Crush }}$.

Because the top speed in a harbor is controlled, the ORI open sea speed distribution was truncated to a top speed of $8.23 \mathrm{~m} / \mathrm{s}$. This reduced the number of speed intervals to 8 , and eliminated the three highest speed categories in Table 14. The total number of combinations of striking ship displacement, speed, and angle was therefore reduced from 968 to 704 . Figure 20 presents the cask probabilities that were obtained for the four cargo cases when penetration distances were calculated using the truncated speed distribution. The crush probabilities decrease for each case reexamined. The decrease is smaller for the medium cargo case, which again yields the largest value for $\mathrm{P}_{\text {Crush }}, 0.4$. Larger decreases are obtained for the other three cases because these cases require penetration to the centerline of the RAM transport ship in order to produce crush by contact or by cargo compression. Therefore, these cases are more sensitive to truncation of the speed distribution than the medium cargo case.

If the four values for $\mathrm{P}_{\text {Crush }}$ that were obtained using the full speed distribution are averaged, a value of 0.33 results. Since this value is bounded by the maximum value of 0.4 obtained using the truncated speed distribution, $\mathrm{P}_{\mathrm{Crush}}$ is set equal to 0.4 . This value is probably conservative because it was obtained assuming (1) that when the cask is overrun, either tie-downs hold or deformed ship structures prevent the cask from sliding, if tie-downs break; and (2) that if cargo compression causes the hold to go material solid, compression forces are not relieved by buckling of hold bulkheads or of the back wall of the ship or by upward displacement of cargo. As these assumptions are likely to be incorrect, a significant fraction of the time, the value of $P_{\text {Crush }}=0.4$ is surely quite conservative.

\subsubsection{Probability of High-Temperature Events}

A severe, engulfing (thus, collocated) shipboard fire can heat the contents of a transportation cask to temperatures above $900 \mathrm{~K}$ only if three conditions are met: (1) the fire must consume a good fuel, (2) enough fuel must be available to cause the fire to burn for an hour or more, and (3) the fire cannot be smothered by lack of air or the operation of fire suppression systems. Thus, $\mathrm{P}_{\mathrm{T}>900 \mathrm{~K}}$, the chance that a ship fire can heat the contents of a transportation cask to temperatures above $900 \mathrm{~K}$, can be estimated as follows: 


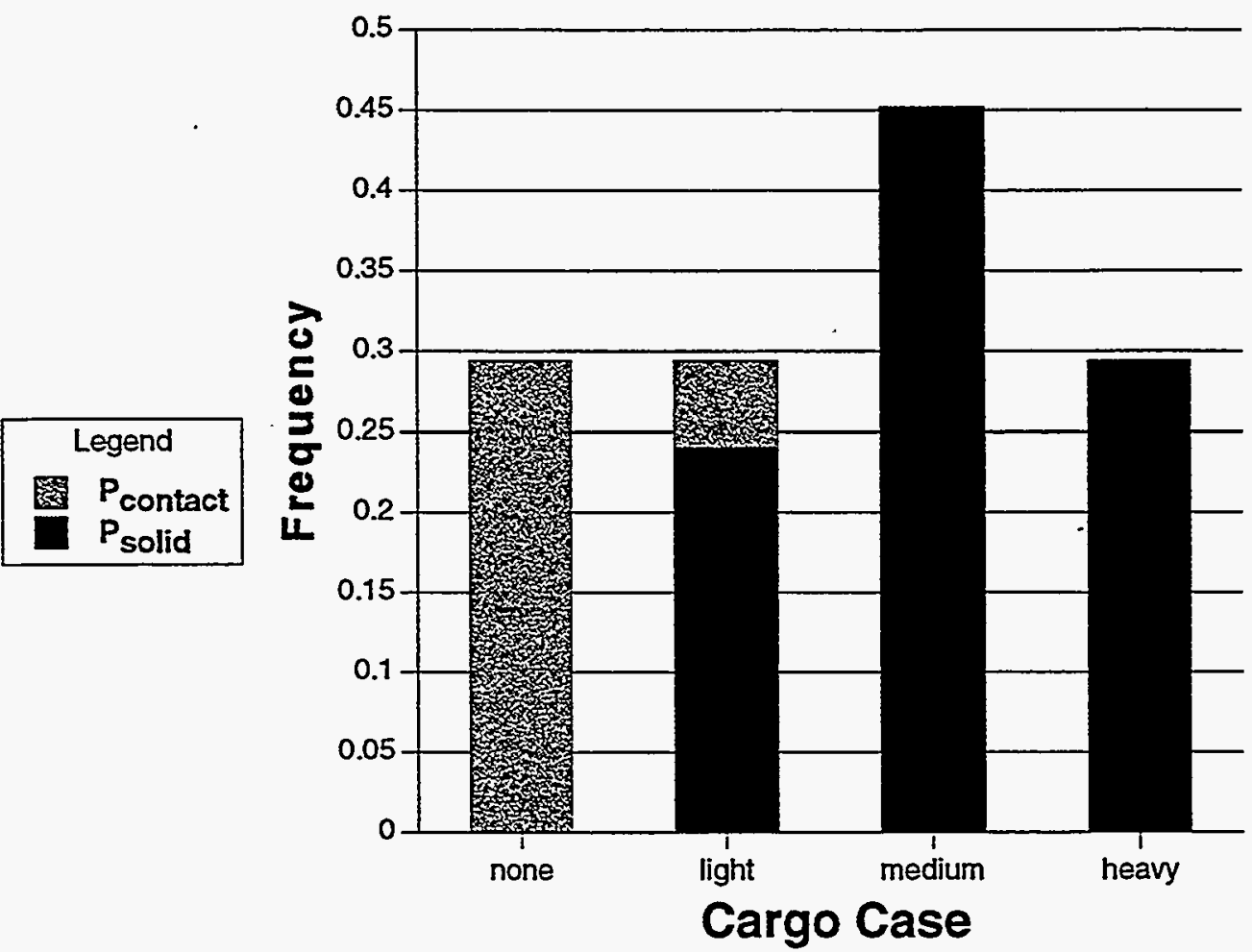

Figure 19. Cask Crush Probability for the Four Cargo Cases

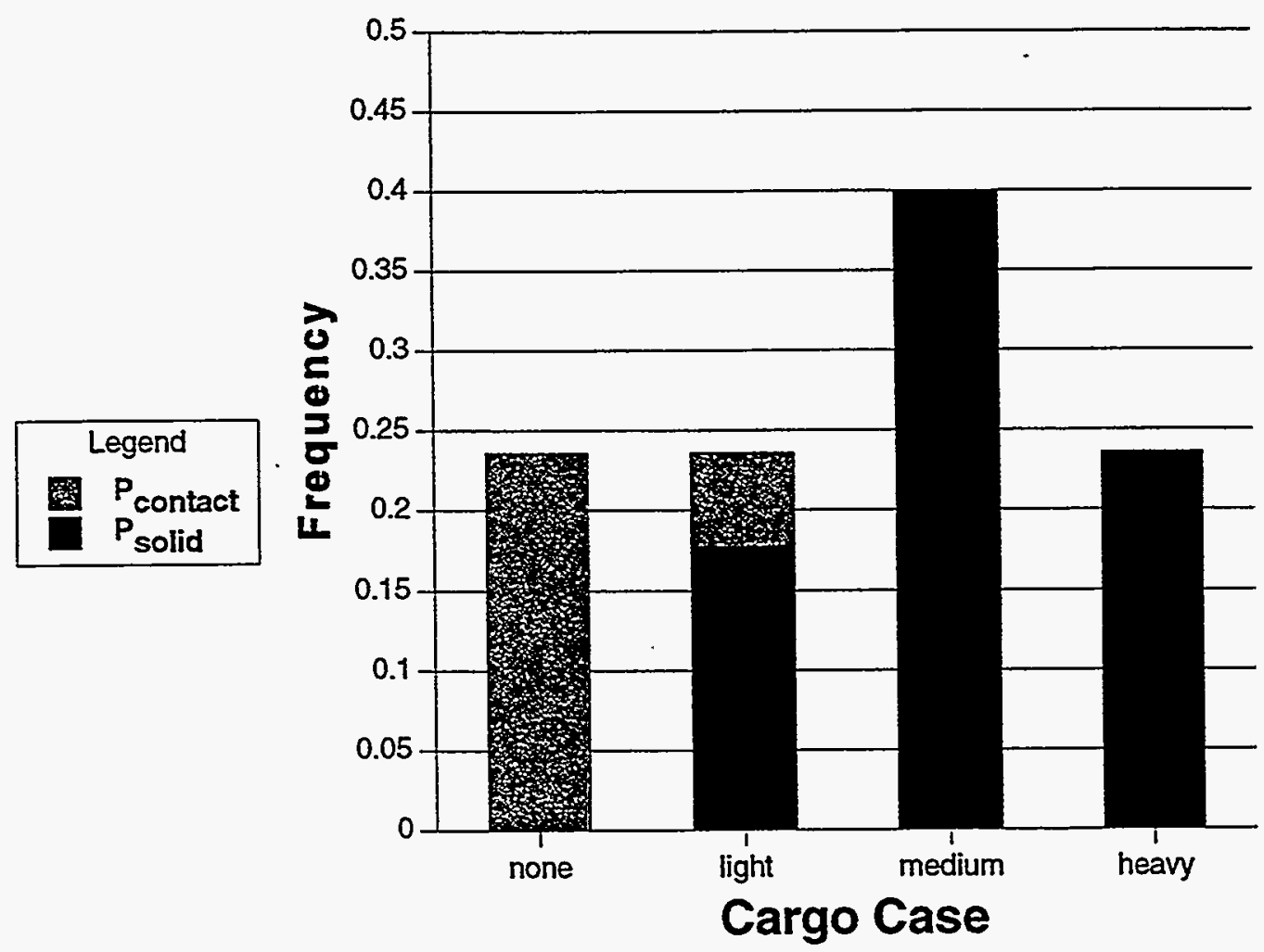

Figure 20. Cask Crush Probability for the Four Cargo Cases With the Striking Ship Distribution Speed Truncated at $8.23 \mathrm{~m} / \mathrm{s}$ 


$$
\mathrm{P}_{\mathrm{T}>900 \mathrm{~K}}=\mathrm{P}_{\text {Good Fuel }} \times \mathrm{P}_{\text {Enough Fuel }} \times \mathrm{P}_{\text {Enough Oxygen }}
$$

Most severe ship fires are supported primarily by the combustion of either the struck ship's own fuel (diesel or bunker fuel), crude oil (when the collision that leads to the fire involves an oil tanker), or easily combustible cargo (wood or plastics). Diesel fuel, bunker fuel, and crude oil all have peak flame temperatures that exceed $900 \mathrm{~K}$ [Mu88]. Most polymeric materials (e.g., plastics, wood) have peak flame temperatures of about $1200 \mathrm{~K}$ [Ba86a]. Fires in cargo holds should behave like enclosure fires. Enclosure fires that burn wood attain peak temperatures of about $1200 \mathrm{~K}$, if post-flashover conditions are attained [Ba86b]. Thus, the fuels and solid materials that are likely to be involved in shipboard fires in cargo holds should be able to heat cask contents to temperatures significantly above $900 \mathrm{~K}$, provided the fire burns long enough and is not suppressed by lack of oxygen or the operation of fire suppression systems. Thus, $\mathrm{P}_{\mathrm{Good} \text { Fuel }}$, the chance that a long burning hold fire is supported by the burning of a good fuel, is not likely to be small and is here assumed to be 0.9 .

Data on the temperatures of real ship fires are sparse. Only one of the five severe fires identified by searching Lloyd's data attained temperatures where steel beams buckled due to thermal stress. Carbon steels begin to soften at about $475 \mathrm{~K}$ and lose 90 percent of their strength at about $925 \mathrm{~K}$. Thus, buckling of ship structures due to thermal stress might be expected to occur at about $700 \mathrm{~K}$, the midpoint of this temperature range, which suggests that one severe fire in five attains temperatures of about $700 \mathrm{~K}$ and also that $\mathrm{P}_{\mathrm{T}>900 \mathrm{~K}}<0.2$.

The review of ship fires prepared by the French Bureau Veritas for the International Maritime Organization [IMO92] contains data on ship fire durations. Most ship fires (70 to 80 percent) do not burn for an hour. However, most severe ship fires (95 percent) burn for more than an hour. Therefore, the chance that a severe fire involves enough fuel to burn for an hour or more, $\mathrm{P}_{\text {Enough Fuel }}$, is assumed to be 0.95 .

Cargo hold covers are normally closed except during loading or unloading of cargo. Thus, if a typical port call takes approximately three days, half a day (twelve hours) entering the port and docking at the pier, two days pier-side with two-thirds of that time (two eight-hour shifts per day) spent loading and unloading cargo, and half a day casting off and leaving the port, then $\mathrm{P}_{\mathrm{All}}$ Closed, the probability that all of the holds are closed while in port, is given by

$$
\mathrm{P}_{\text {All Closed }}=[1 /(3 \times 24)](12+8+8+12)=0.554
$$

The prototypic break-bulk freighter used in these analyses has seven holds. Five of these holds contain three cargo decks, one contains four cargo decks, and one contains only two cargo decks. Thus, there are $21=(5 \times 3)+(1 \times 4)+(1 \times 2)$ possible locations for a spent fuel cask in this prototypic ship. Thus, $\mathrm{P}_{\text {Location, the chance that a spent fuel cask has been }}$ loaded onto a given deck in one of the seven holds, is $1 / 21$.

When a break-bulk freighter like the prototypic seven-hold ship used in these analyses is being loaded or unloaded, usually at most four holds are being worked at any given time. Thus, 
when the ship is being loaded or unloaded, $\mathrm{P}_{\text {Worked }}$, the probability that a given hold is being worked, is $4 / 7$.

All hold openings have covers, not just the opening in the main deck through which the hold is loaded and unloaded but also the openings in the cargo decks within each hold. When a deck in a cargo hold is being loaded or unloaded, all openings above that deck must be open and the opening in the deck and all openings in lower decks are normally closed. Thus, while a hold is being worked, upper decks in that hold will be open to outside air more often than lower decks. For example, for a three-deck hold, while the hold is being worked, the upper deck will always be open to outside air, the second deck will be open about two-thirds of the time, and the bottom deck will be open about one-third of the time. Thus, if $\mathrm{N}_{\mathrm{i}}$ is the number of holds with two, three, or four decks, and $\mathrm{P}_{\text {Deck,i }}$ is the probability that a given deck in the $\mathrm{N}_{\mathrm{i}}$ holds that have either two, three, or four decks is open to the outside air, then $\mathrm{P}_{\text {Open }}$, the chance that an engulfing fire is not partially starved for oxygen because there is a cargo deck or a main deck hold cover in place between the fire and the outside air, is given by:

$$
\begin{aligned}
\mathrm{P}_{\text {Open }}= & \left(1-\mathrm{P}_{\text {All Closed }}\right) \times \mathrm{P}_{\text {Worked }} \times \mathrm{P}_{\text {Location }} \times \sum_{\mathrm{i}} \mathrm{N}_{\mathrm{i}} \times \mathrm{P}_{\text {Deck } \mathrm{i}} \\
= & (1-0.554)(4 / 7)(1 / 21) \\
& \times\{[(5)(1+2 / 3+1 / 3)]+[(1)(1+3 / 4+2 / 4+1 / 4)]+[\dot{(1)}(1+1 / 2)]\} \\
= & 0.17
\end{aligned}
$$

The ORI study [ORI80] found that about half ( 60 percent) of all cargo ships are equipped with fire detectors and fire suppression systems. Because $\mathrm{CO}_{2}$ and halon fire suppression systems are not complicated, they should operate reliably on demand most of the time. To be conservative, successful operation during four of five fire events is assumed.

Figure 21 presents an event tree for oxygen availability during fires in cargo holds. The tree shows that most cargo hold fires will be partially starved for oxygen for two reasons, because fire suppression systems are installed in the hold and operate successfully; or because hold covers will be closed when the fire starts, or will be deliberately closed after it starts in order to smother the fire. Two branches of the oxygen availability tree lead to the outcome "enough air." The probabilities of these two branches sum to 0.088 . Thus, 0.09 is a reasonable estimate for $\mathrm{P}_{\text {Enough } \mathrm{Oxygen}}$, the chance that a fire has adequate oxygen available to burn freely and generate maximum heat loads.

Combining the probability estimates for $P_{\text {Good Fuel }}, P_{\text {Enough Fuel, and }} P_{\text {Enough Oxygen }}$ allows $P_{T>900 \mathrm{~K}}$ to be estimated as follows:

$$
\begin{aligned}
P_{T}>900 \mathrm{~K} & =P_{\text {Good Fuel }} \times P_{\text {Enough Fuel }} \times P_{\text {Enough Oxygen }} \\
& =0.9 \times 0.95 \times 0.09=0.077
\end{aligned}
$$


Sequence Enough

Probability Oxygen

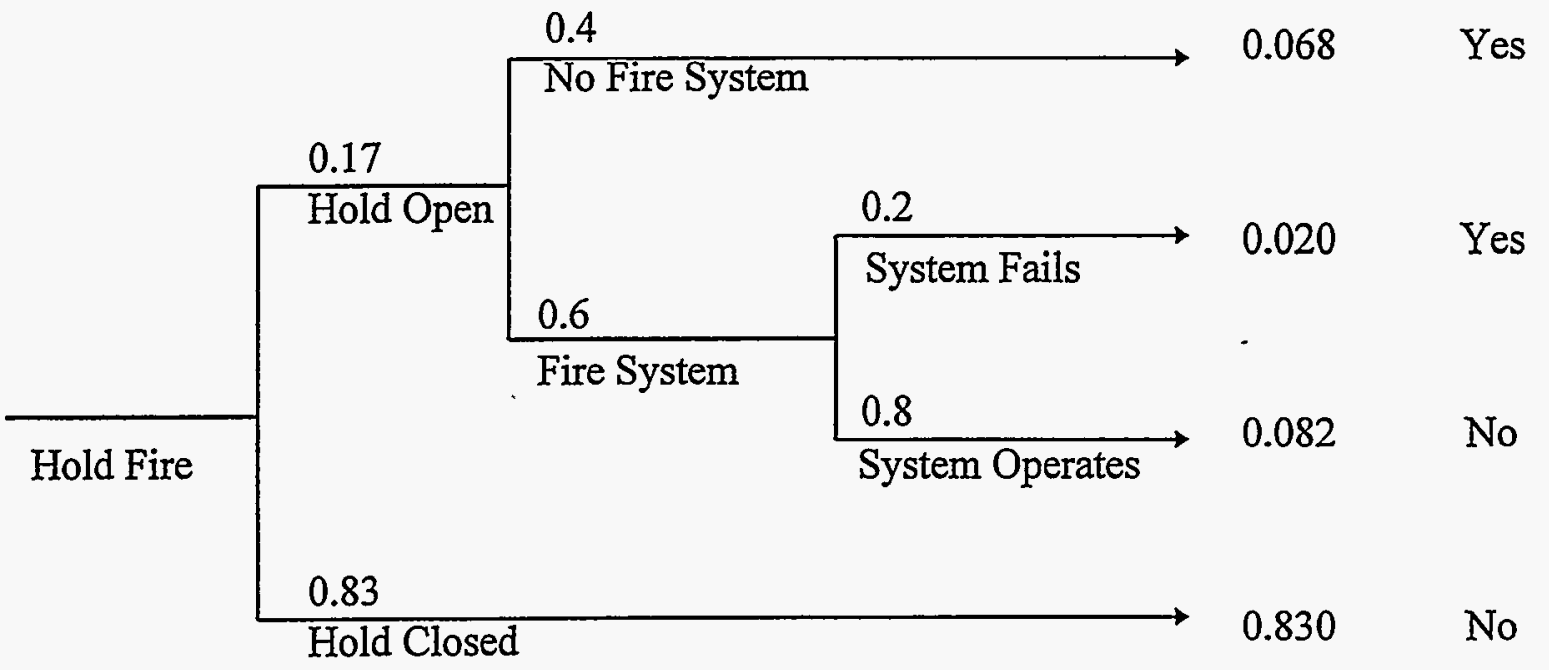

Figure 21. Event Tree for Oxygen Availability

Rounding to the next order of magnitude yields a conservative estimate of $10^{-1}$ for the chance that a severe engulfing fire with a duration of at least an hour will heat the contents of a transportation cask engulfed by the fire to temperatures significantly higher than $900 \mathrm{~K}$.

\subsubsection{Probability of Convective Flow Through the Failed Cask}

Non-uniform heating of the cask during engulfing fires could produce substantial flow of gases through the cask if two or more small holes or one medium hole have been produced in the cask by the ship collision. Because transportation cask bottoms and lid seats are welded to the cylindrical shell of the cask using full-penetration welds that are as strong or stronger than the parent material, if the cask shell is subjected to a severe stress (e.g., high impact or crush forces), the cask shell should yield before the welds fail. In fact, extra-regulatory $60-\mathrm{mph}$ drop tests produced large plastic strains in the cylindrical shell of the test cask without failing its welds [Am95]. Thus, during a ship collision, crush forces should collapse the cask walls inward without producing catastrophic failure of the lid, its seat, or the welds that attach the seat or the bottom of the cask to the cask walls. Therefore, an unusual configuration of cargo and/or deformed ship structures must be produced during the ship collision in order to subject the cask to forces that will produce failures substantially worse than simple failure of the lid seal. Thus, for gases to convectively flow through a damaged cask, either the lid seat must be bent significantly (one large hole), or at least two cask penetrations must break (two medium holes), or the cask walls must be sheared or punctured (one large hole, the shear or puncture, and one small hole, the seal failure). Although data for such failures is lacking, because casks normally do not fail by these mechanisms, the probability that a failure substantially worse than seal failure occurs is conservatively assumed to be no larger than 0.1 . 


\subsubsection{Accident Category Event Tree}

In Section 3.2.2, the high-temperature behavior of research reactor fuels was reviewed. The review concluded that, if heated to temperatures above $900 \mathrm{~K}$, Al-U alloy fuels melt and TRIGA fuel, if exposed to air, burns. In Section 3.2.3, EA Accident Categories 5 and 6 were each divided into a low and a high temperature category (EIS Categories 5A and 6A, $\mathrm{T}<$ $900 \mathrm{~K}$; EIS Categories 5B and 6B, $\mathrm{T}>900 \mathrm{~K}$ ), and release fractions were developed for each of the new categories in order to address the consequences of fire events that might heat research reactor fuels to temperatures that exceed $900 \mathrm{~K}$.

Figures 22 and 23 present an event tree that depicts the sequences of events that lead to EIS Category 4, 5A, 5B, 6A, and $6 \mathrm{~B}$ releases from transportation casks due to ship collisions. In preceding sections, values were developed for the following probabilities: (1) the probability that a severe collision will occur in a port $\left(\mathrm{P}_{\text {Collision }}=1.0 \times 10^{-4}\right.$ per port call, see Section 3.4.3.1); (2) the probability that the RAM hold of the prototypical seven-hold break-bulk freighter will be struck $\left(P_{\text {Hold }}=1 / 7=0.143\right.$, see Section 3.4.3.2); (3) the probability that the RAM cask will be subjected to impact $\left(\mathrm{P}_{\text {Impact }}=0.0\right.$, see Section 3.4.4.3) or crush $\left(\mathrm{P}_{\text {Crush }}=\right.$ 0.4, see Section 3.4.4.4) forces that are large enough to damage the RAM cask or its contents; (4) the probability that a collision will lead to a severe fire $\left(P_{\text {Severe Fire }}=10^{-2}\right.$, see Section 3.4.3.3); (5) the probability that a severe fire is collocated with the cask and thus is an engulfing fire $\left(\mathrm{P}_{\text {Engulfing Fire }}=10^{-1}\right.$, see Section 3.4.3.3); and (6) the probability that a severe fire can heat a RAM cask to temperatures that exceed $900 \mathrm{~K}\left(\mathrm{P}_{\mathrm{T}>900 \mathrm{~K}}=10^{-1}\right.$, see Section 3.4.4.5). With one exception, all of the branch point probabilities on the event tree depicted in Figures 22 and 23 are either one of these seven probabilities, or the complement of one of these probabilities. The exception is the probability of a severe engulfing fire which is the product of $P_{\text {Severe Fire }}$ and $P_{\text {Engulfing Fire }}$ and which thus has a value of $10^{-3}$.

After rounding to the nearest integer, Figures 22 and 23 show that EIS Accident Categories 4, $5 \mathrm{~A}, 5 \mathrm{~B}, 6 \mathrm{~A}$, and $6 \mathrm{~B}$ have the following release probabilities per port call:

$\begin{array}{lccccc}\text { Category } & \text { EIS4 } & \text { EIS5A } & \text { EIS5B } & \text { EIS6A } & \text { EIS6B } \\ \text { Probability } & 6 \mathrm{E}-6 & 5 \mathrm{E}-9 & 5 \mathrm{E}-10 & 5 \mathrm{E}-10 & 6 \mathrm{E}-11\end{array}$

Table 4 in Section 3.2.3 presents the release fraction values that were developed for this modified accident category scheme, and compares these new release fraction values to the values that were used for Accident Categories 4, 5, and 6 in the EA. Table 16 compares the magnitudes of the new EIS release fractions to the magnitudes of the old EA release fractions.

Because risk is the product of the consequences of an accident and its probability of occurrence, in order to estimate the risks associated with EA Category accidents, the probabilities of EA source terms need to be reestimated by combining EIS Accident Categories and summing their probabilities. Inspection of Table 16 allows accidents that fall into EIS Accident Categories 5A, 5B, 6A, and 6B to be assigned either to EA Accident Category 5 or EA Accident Category 6. For Al-U alloy fuels, EIS Category 5A and 6A accidents should be 
Sequence Severity

Probability Category

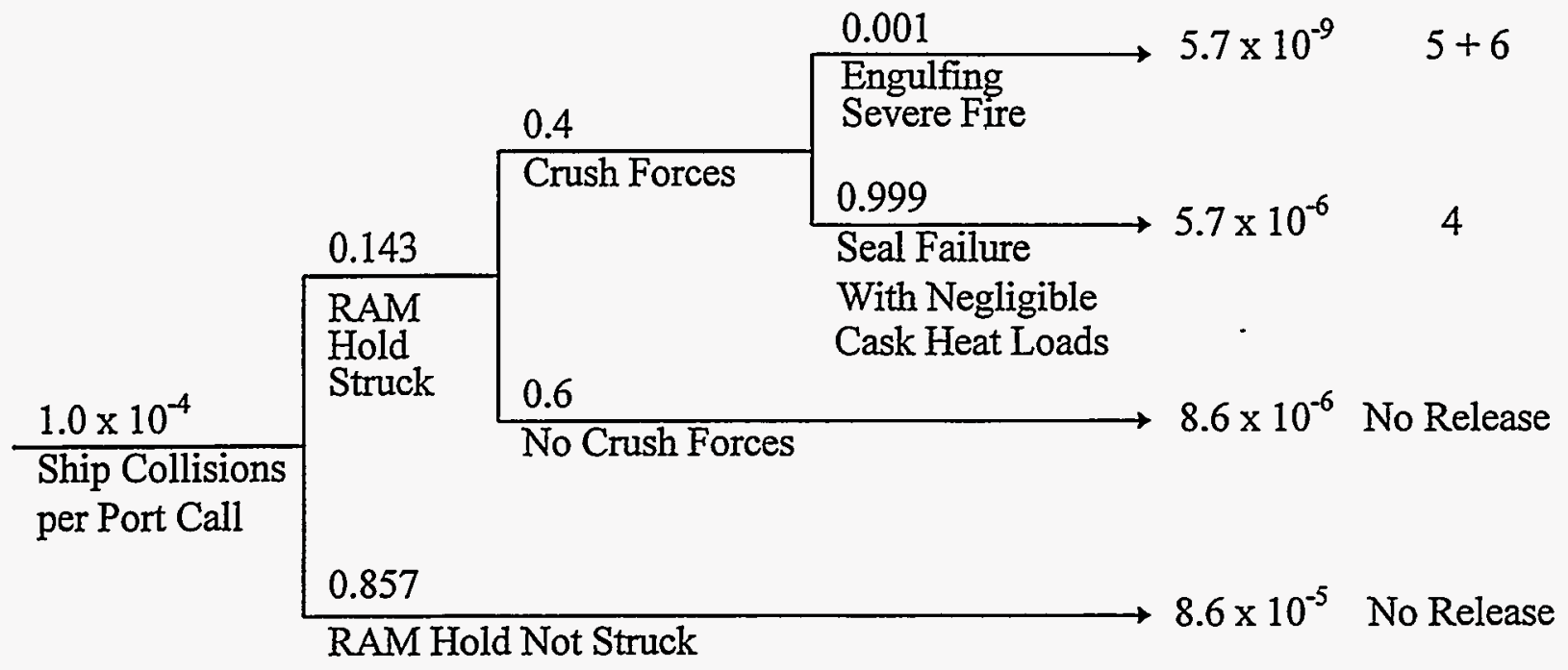

Figure 22. Event Tree for Category 4 Accidents

Sequence Severity

Probability Category

$5.7 \times 10^{-9}$

Ship Collisions per Port Call That Lead to Crush Forces on the Cask and an Engulfing Severe Fire

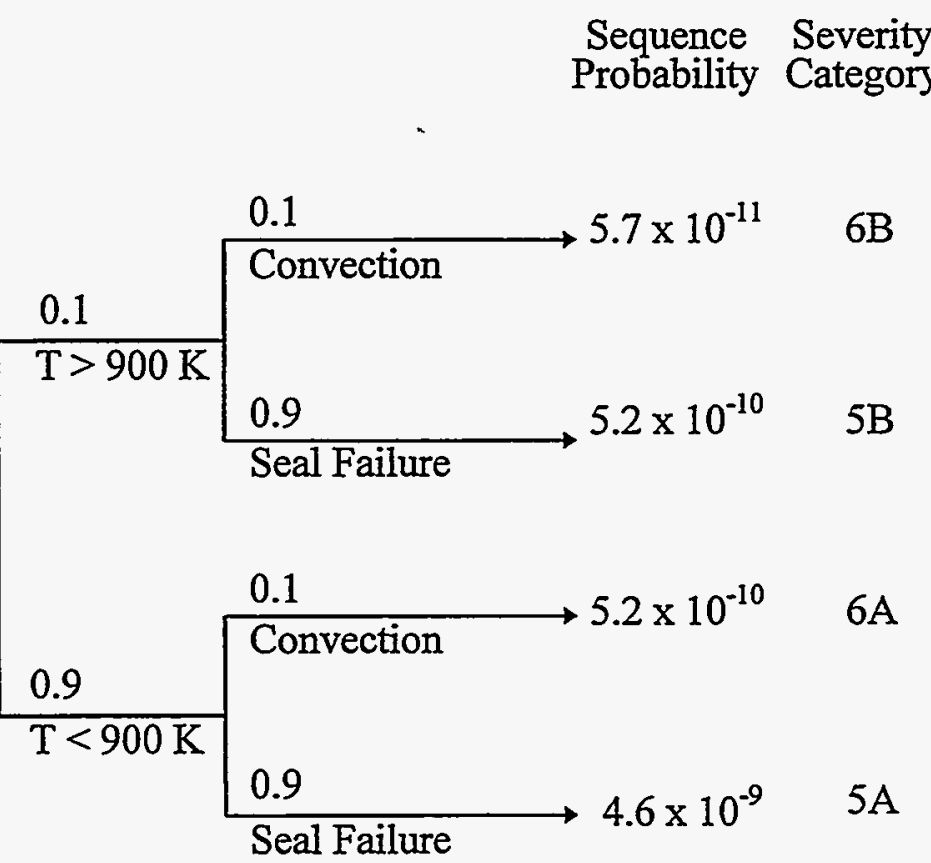

Figure 23. Event Tree for Category 5 and 6 Accidents 
Table 16. Relative Magnitudes of the New EIS Release Fractions Compared to the EA Release Fractions Used to Perform the Base Case Calculations

\begin{tabular}{|c|c|c|c|}
\hline \multirow[b]{2}{*}{ Fuel } & \multicolumn{2}{|c|}{$\begin{array}{l}\text { Accident } \\
\text { Category }\end{array}$} & \multirow{2}{*}{$\begin{array}{l}\text { Size of New EIS Release Fractions } \\
\text { Compared to EA Release Fractions }\end{array}$} \\
\hline & EA & EIS & \\
\hline \multirow{5}{*}{ Al-U Alloy } & 4 & 4 & About the same ( $\mathrm{Kr}$ much smaller) \\
\hline & 5 & $5 \mathrm{~A}$ & Much smaller (Cs 7000 times smaller) \\
\hline & 5 & $5 \mathrm{~B}$ & Somewhat larger (Cs 11 times larger) \\
\hline & 6 & $6 \mathrm{~A}$ & Much smaller (Cs 5000 times smaller) \\
\hline & 6 & $6 \mathrm{~B}$ & Much larger (Cs 100 times larger) \\
\hline \multirow{5}{*}{ TRIGA (U-Zr-H) } & 4 & 4 & Ten times larger \\
\hline & 5 & $5 \mathrm{~A}$ & Somewhat larger (Cs 1.1 times larger) \\
\hline & 5 & $5 B$ & Much larger (Cs 12 times larger) \\
\hline & 6 & $6 \mathrm{~A}$ & Somewhat larger (Cs 1.6 times larger) \\
\hline & 6 & $6 \mathrm{~B}$ & Very much larger (Cs 310 times larger) \\
\hline
\end{tabular}

assigned to EA Category 5, because these accidents have release fractions smaller than those used in the EA for Category 5 accidents. EIS Category 5B and $6 \mathrm{~B}$ accidents should be assigned to EA Category 6, because these accidents have release fractions larger than those used in the EA for Category 6 accidents. For TRIGA fuel, EIS Category 5A and 6A accidents should be assigned to EA Category 5, because they have release fractions about the same size as those used in the EA for Category 5 accidents. EIS Category $5 B$ and $6 \mathrm{~B}$ accidents should be assigned to EA Category 6 because they have release fractions that are larger or much larger than those used in the EA for Category 6 accidents. Therefore, the probability of EA Category 5 accidents is $4.6 \times 10^{-9}+5.2 \times 10^{-10}=5 \times 10^{-9}$, and the probability of EA Category 6 accidents is $5.2 \times 10^{-10}+5.7 \times 10^{-11}=6 \times 10^{-10}$ for both Al-U alloy and TRIGA fuels.

\subsubsection{Revised Source Term Probabilities}

Table 17 summarizes the estimates developed for event probabilities and for the source term probabilities constructed from those event probabilities. Probabilities are presented in Table 17 both for EA source terms 4 through 6, and also for the new set of source terms derived for research reactor fuels subjected to high-temperature events, hereafter termed EIS source terms $4,5 \mathrm{~A}, 5 \mathrm{~B}, 6 \mathrm{~A}$, and $6 \mathrm{~B}$.

In Table 17, the "units" for $\mathrm{P}_{\text {Collision }}$ and all of the source term probabilities are "per port call." All of the other event probabilities $\left(\mathrm{P}_{\text {Hold }}, \ldots, \mathrm{P}_{\text {Convection }}\right)$ are dimensionless but conditional on the occurrence of preceding events. 
Table 17. Estimated Values for Event Probabilities, EA Source Term Probabilities, and EIS Source Term Probabilities

\begin{tabular}{|l|l|l|}
\hline $\begin{array}{c}\text { Accident } \\
\text { Category }\end{array}$ & \multicolumn{1}{|c|}{ Event } & \multicolumn{1}{|c|}{ Estimated Value } \\
\hline & $\mathrm{P}_{\text {Collision }}$ & $10^{-4}$ per port call \\
& $\mathrm{P}_{\text {Hold }}$ & 0.143 \\
& $\mathrm{P}_{\text {Impact }}$ & 0.0 \\
& $\mathrm{P}_{\text {Crush }}$ & 0.4 \\
& $\mathrm{P}_{\text {Severe Fire }}$ & $10^{-2}$ \\
& $\mathrm{P}_{\text {Engulfing Fire }}$ & $10^{-1}$ \\
& $\mathrm{P}_{\text {Convection }}$ & $10^{-1}$ \\
EA4 & $\mathrm{P}_{\text {ST }}=\mathrm{P}_{\text {Collision }} \times \mathrm{P}_{\text {Hold }} \times\left(\mathrm{P}_{\text {Impact }}+\mathrm{P}_{\text {Crush }}\right)$ & $6 \times 10^{-6}$ per port call \\
EA5 & $\mathrm{P}_{\text {ST }}=\mathrm{P}_{\text {Collision }} \times \mathrm{P}_{\text {Hold }} \times\left(\mathrm{P}_{\text {Impact }}+\mathrm{P}_{\text {Crush }}\right)$ & $5 \times 10^{-9}$ per port call \\
& \multicolumn{1}{|c|}{$\times \mathrm{P}_{\text {Severe Fire }} \times \mathrm{P}_{\text {Engulfing Fire }}$} & \\
EA6 & $\mathrm{P}_{\mathrm{ST}}=\mathrm{P}_{\text {Collision }} \times \mathrm{P}_{\text {Hold }} \times\left(\mathrm{P}_{\text {Impact }}+\mathrm{P}_{\text {Crush }}\right)$ & $6 \times 10^{-10}$ per port call \\
& $\mathrm{x} \mathrm{P}_{\text {Severe Fire }} \times \mathrm{P}_{\text {Engulfing Fire }}$ & \\
EIS4 & $\mathrm{x} \mathrm{P}_{\text {Convection }}$ & $6 \times 10^{-6}$ per port call \\
EIS5A & & $5 \times 10^{-9}$ per port call \\
EIS5B & & $5 \times 10^{-10}$ per port call \\
EIS6A & & $5 \times 10^{-10}$ per port call \\
EIS6B & & $6 \times 10^{-11}$ per port call \\
\hline
\end{tabular}

\subsection{Population Distributions}

Table 18 lists the thirteen ports that were examined by this study. Eight of the ports are East Coast ports, one is a Gulf Coast port, and four are West Coast ports. Three of the ports are high population ports (population to 10 miles exceeds 1,000,000); five are medium population ports (10 mile population is less than 700,000 but greater than 300,000 ); and five are low population ports (10 mile population is less than 250,000$)$. Ten of the ports are possible unloading sites for research reactor spent fuel, while three (the three high population ports) are possible intermediate ports-of-call. 
Table 18. Destination Ports and Ports-of-Call for Shipments of Foreign Research Reactor Spent Fuel

\begin{tabular}{|c|l|l|l|l|}
\hline \multirow{2}{*}{ Coast } & \multicolumn{4}{|c|}{ Port Characteristics } \\
\cline { 2 - 5 } & \multicolumn{1}{|c|}{ Name } & \multicolumn{1}{|c|}{ Location } & \multicolumn{1}{c|}{ Type } & Population \\
\hline East & Elizabeth & Newark, NJ & Port-of-Call & High \\
& Philadelphia & Philadelphia, PA & Port-of-Call & High \\
& Hampton Roads & Norfolk, VA & Destination & Medium \\
& Wilmington & Wilmington, NC & Destination & Low \\
& MOTSU & Wilmington, NC & Destination & Low \\
& Charleston & Charleston, SC & Destination & Low \\
& Savannah & Savannah, GA & Destination & Low \\
& Jacksonville & Jacksonville, FL & Destination & Medium \\
Gulf & Galveston & Galveston, TX & Destination & Low \\
West & Los Angeles & Long Beach, CA & Port-of-Call & High \\
& Concord NWS & San Francisco, CA & Destination & Medium \\
& Portland & Portland, OR & Destination & Medium \\
& Tacoma & Tacoma, WA & Destination & Medium \\
\hline
\end{tabular}

For ten of the thirteen ports, two accident locations were considered, a channel location where a major ship collision appeared to be plausible and a dockside location. For the port of Tacoma, two channel locations, one near Seattle and one at the entrance to Puget Sound, were selected. Because the MOTSU and Wilmington NC ports are both reached by the same channel, the same channel accident location was used for both ports.

For each of the 26 hypothetical accident locations, population distributions were constructed on a compass-sector polar coordinate grid that had ten radial intervals $(1,2,3,4,5,10,20$, 30,40 , and 50 miles). The distributions were constructed from 1990 block census data using Sandia's POPSEC90 code [Hu94]. The coordinates of the midpoint of the compass-sector polar coordinate grid were selected by inspection of navigational maps for the 13 ports examined by this study. Table 19 gives the coordinates of the 26 hypothetical accident locations.

The 26 population distributions constructed using POPSEC90 were entered into the site data file for the dockside or channel accident locations for each of the thirteen ports. Part A of the Appendix presents these site data files. Examination of these files shows that many of the cells in the twenty-six population distributions are unpopulated because they are covered by water (ocean, rivers, bays, harbor channels).

At many ports, the work force population is probably much larger than the residential population, at least in the commercial area near to the port. Therefore, the work force population was estimated for one port, the port of Elizabeth, and added to the residential population distribution that had been constructed for that port using POPSEC90. Then, during 
Table 19. Accident Location Map Coordinates

\begin{tabular}{|c|c|c|c|c|}
\hline \multirow[b]{2}{*}{ Port } & \multirow[b]{2}{*}{ Location } & \multirow[b]{2}{*}{ Description } & \multicolumn{2}{|c|}{ Coordinates } \\
\hline & & & Latitude & Longitude \\
\hline Newark & $\begin{array}{l}\text { Dock } \\
\text { Channel }\end{array}$ & $\begin{array}{l}\text { Marine terminal, Sealand pier } \\
\text { Narrows }\end{array}$ & $\begin{array}{l}40^{\circ} 39^{\prime} 35^{\prime \prime} \mathrm{N} \\
40^{\circ} 36^{\prime} 29^{\prime \prime} \mathrm{N}\end{array}$ & $\begin{array}{l}74^{\circ} 08^{\prime} 52^{\prime \prime} W \\
74^{\circ} 02^{\prime} 21^{\prime \prime} W\end{array}$ \\
\hline Philadelphia & Dock & $\begin{array}{l}\text { Packer Avenue marine terminal } \\
\text { container births }\end{array}$ & $39^{\circ} 53^{\prime} 55^{\prime \prime} \mathrm{N}$ & $75^{\circ} 08^{\prime} 09^{\prime \prime} \mathrm{W}$ \\
\hline & Channel & Commodore Berry fixed bridge & $\begin{array}{l}39^{\circ} 49^{\prime} 43^{\prime \prime N} \\
36^{\circ} 51^{\prime} 25^{\prime \prime} \mathrm{N}\end{array}$ & $\begin{array}{l}75^{\circ} 22^{\prime} 18^{\prime \prime W} \\
76^{\circ} 19^{\prime} 45^{\prime \prime W}\end{array}$ \\
\hline Norfolk & $\begin{array}{l}\text { Dock } \\
\text { Channel }\end{array}$ & $\begin{array}{l}\text { Portsmouth marine terminal } \\
\text { Willoughby Bank, north side }\end{array}$ & $\begin{array}{l}36^{\circ} 51^{\prime} 25^{\prime \prime N} \\
36^{\circ} 59^{\prime} 57^{\prime \prime} \mathrm{N}\end{array}$ & $\begin{array}{l}76^{\circ} 19^{\circ} 45^{\prime \prime} \mathrm{W} \\
76^{\circ} 18^{\prime} 43^{\prime \prime} \mathrm{W}\end{array}$ \\
\hline Wilmington & Dock & Main dock, Wilmington port & $34^{\circ} 13^{\prime} 03^{\prime \prime N}$ & $77^{\circ} 57^{\prime} 09^{\prime \prime} \mathrm{W}$ \\
\hline MOTSU & $\begin{array}{l}\text { Dock } \\
\text { Channel }\end{array}$ & $\begin{array}{l}\text { Sunny Point, Wharf } 1 \\
\text { Lower Swash channel }\end{array}$ & $\begin{array}{l}33^{\circ} 59^{\prime} 39^{\prime \prime} \mathrm{N} \\
33^{\circ} 54^{\prime} 39^{\prime \prime} \mathrm{N}\end{array}$ & $\begin{array}{l}77^{\circ} 51^{\prime} 21^{\prime \prime} \mathrm{W} \\
78^{\circ} 01^{\prime} 12^{\prime \prime} \mathrm{W}\end{array}$ \\
\hline Charleston & $\begin{array}{l}\text { Dock } \\
\text { Channel }\end{array}$ & $\begin{array}{l}\text { Pier at Wando terminal } \\
\text { Commercial anchorage area D }\end{array}$ & $\begin{array}{l}32^{\circ} 49^{\prime} 51^{\prime \prime} \mathrm{N} \\
32^{\circ} 47^{\prime} 05^{\prime \prime N}\end{array}$ & $\begin{array}{l}79^{\circ} 53^{\prime} 34^{\prime \prime} \mathrm{W} \\
79^{\circ} 55^{\prime} 10^{\prime \prime} \mathrm{W}\end{array}$ \\
\hline Savannah & $\begin{array}{l}\text { Dock } \\
\text { Channel }\end{array}$ & $\begin{array}{l}\text { Savannah Ocean Terminal } \\
\text { Intersection of Savannah River } \\
\text { and Intercoastal Waterway at } \\
\text { Elba Island Cut }\end{array}$ & $\begin{array}{l}32^{\circ} 05^{\prime} 00^{\prime \prime} \mathrm{N} \\
32^{\circ} 04^{\prime} 26^{\prime \prime} \mathrm{N}\end{array}$ & $\begin{array}{l}81^{\circ} 05^{\prime} 18^{\prime \prime} \mathrm{W} \\
80^{\circ} 58^{\prime} 17^{\prime \prime} \mathrm{W}\end{array}$ \\
\hline Jacksonville & Dock & $\begin{array}{l}\text { Blount Island Terminal } \\
\text { St. John's River ferry crossing to } \\
\text { Mayport }\end{array}$ & $\begin{array}{l}30^{\circ} 23^{\prime} 16^{\prime \prime N} \\
30^{\circ} 23^{\prime} 40^{\prime \prime} \mathrm{N}\end{array}$ & $\begin{array}{l}81^{\circ} 33^{\prime} 00^{\prime \prime} \mathrm{W} \\
81^{\circ} 26^{\prime} 00^{\prime \prime} \mathrm{W}\end{array}$ \\
\hline Galveston & $\begin{array}{l}\text { Dock } \\
\text { Channel }\end{array}$ & $\begin{array}{l}\text { Container Terminal, Pier } 9 \\
\text { Intersection of Bolivar Roads and } \\
\text { Galveston Channels }\end{array}$ & $\begin{array}{l}29^{\circ} 19^{\prime} 00^{\prime \prime N} \\
29^{\circ} 20^{\prime} 27^{\prime \prime} \mathrm{N}\end{array}$ & $\begin{array}{l}94^{\circ} 46^{\prime} 53^{\prime \prime} \mathrm{W} \\
94^{\circ} 46^{\prime} 12^{\prime \prime} \mathrm{W}\end{array}$ \\
\hline Los Angeles & $\begin{array}{l}\text { Dock } \\
\text { Channel }\end{array}$ & $\begin{array}{l}\text { Pier } \mathrm{E} \\
\text { East side breakwater }\end{array}$ & $\begin{array}{l}33^{\circ} 45^{\prime} 43^{\prime \prime} \mathrm{N} \\
33^{\circ} 43^{\prime} 23^{\prime \prime} \mathrm{N}\end{array}$ & $\begin{array}{l}118^{\circ} 12^{\prime} 31^{\prime \prime} \mathrm{W} \\
118^{\circ} 10^{\prime} 53^{\prime \prime} \mathrm{W}\end{array}$ \\
\hline Concord NWS & $\begin{array}{l}\text { Dock } \\
\text { Channel }\end{array}$ & $\begin{array}{l}\text { Naval Weapons Station } \\
\text { San Francisco Bay Temporary } \\
\text { Anchorage No. 7, Shipping Lane } \\
\text { Route W of Treasure Island }\end{array}$ & $\begin{array}{l}38^{\circ} 03^{\prime} 32^{\prime \prime} \mathrm{N} \\
37^{\circ} 49^{\prime} 24^{\prime \prime} \mathrm{N}\end{array}$ & $\begin{array}{l}122^{\circ} 00^{\prime} 49^{\prime \prime} \mathrm{W} \\
122^{\circ} 23^{\prime} 47^{\prime \prime} \mathrm{W}\end{array}$ \\
\hline Portland & $\begin{array}{l}\text { Dock } \\
\text { Channel }\end{array}$ & $\begin{array}{l}\text { Terminal No. } 2 \\
\text { St. Johns bridge }\end{array}$ & $\begin{array}{l}45^{\circ} 32^{\prime} 54^{\prime \prime N} \\
45^{\circ} 35^{\prime} 04^{\prime \prime N}\end{array}$ & $\begin{array}{l}122^{\circ} 41^{\prime} 56^{\prime \prime} \mathrm{W} \\
122^{\circ} 45^{\prime} 58^{\prime \prime} \mathrm{W}\end{array}$ \\
\hline Tacoma & $\begin{array}{l}\text { Dock } \\
\text { Channel }\end{array}$ & $\begin{array}{l}\text { Port of Tacoma, Pier No. } 7 \\
\text { Elliot Bay shipping lane near } \\
\text { entrance to Port of Seattle }\end{array}$ & $\begin{array}{l}47^{\circ} 16^{\prime} 03^{\prime \prime} \mathrm{N} \\
47^{\circ} 36^{\prime} 42^{\prime \prime N}\end{array}$ & $\begin{array}{l}122^{\circ} 24^{\prime} 49^{\prime \prime} \mathrm{W} \\
122^{\circ} 26^{\prime} 30^{\prime \prime} \mathrm{W}\end{array}$ \\
\hline & Channel & $\begin{array}{l}\text { Intersection of } 4 \text { shipping lanes } \\
\text { in Puget Sound } \mathrm{N} \text { of Port } \\
\text { Townsend }\end{array}$ & $48^{\circ} 11^{\prime} 24^{\prime \prime} \mathrm{N}$ & $122^{\circ} 49^{\prime} 48^{\prime \prime} \mathrm{W}$ \\
\hline
\end{tabular}


the sensitivity studies, the effect of the work force population on consequences of accidents at the port of Elizabeth was examined.

\subsection{Meteorological Data}

MACCS calculations examine all possible combinations of a representative set of weather sequences and a representative set of population distributions (the populations of the sixteen compass sectors at each site studied; the populations in neighboring sectors are used if the plume becomes wider than one compass sector at any time during its downwind transport). Thus, MACCS calculations require a site wind rose, which after inversion gives the exposure probabilities of the compass sector population distributions, and one year of hourly readings of wind speed, atmospheric stability, and rainfall rate, recorded either at the accident site or at some not too distant meteorological station that is located in the same meteorological and topological regime as the accident site, to use in determining dispersion as a function of downwind transport distance. Annual wind roses were available for each of the 13 sites examined during this study. Table 20 presents these wind roses. One year of hourly meteorological data was available from National Weather Service stations located in the port city for only two of the thirteen ports studied (Newark and Charleston). For the other eleven ports, hourly meteorological data recorded at a nearby National Weather Service station was used during the base case calculations. Table 21 lists the ports examined during this study and gives the location of the National Weather Station where the hourly meteorological data, that was used to analyze the consequences of accidents at that port, were recorded.

Although MACCS calculations can use constant meteorology, one year of hourly meteorological data is preferred because adverse results are often the result of meteorological sequences that involve changing meteorological conditions. MACCS uses an importance sampling scheme to find these less probable sequences that may yield adverse results. The sampling scheme examines all of the 8760 weather sequences in one year of hourly data and selects the start times of the approximately one hundred weather sequences that are used during a variable meteorology calculation. Accordingly, because less probable weather conditions are not used, constant meteorology calculations usually underestimate higher quantiles in the Complementary Cumulative Distribution Functions (CCDFs) generated by variable meteorology MACCS calculations that use representative sets of weather sequences selected by importance sampling.

Although the use of meteorological data from a nearby weather station has been shown to be more than satisfactory [A182], this substitution was reexamined during this study by performing for seven of the thirteen ports studied a large number of constant meteorology calculations using the meteorological conditions and probabilities of occurrence specified in the Joint Frequency Distributions that were available for each of the seven ports. Since Joint Frequency Distributions specify for each compass sector the probability of occurrence of each of the six Pasquil-Gifford atmospheric stability classes with each of six windspeed ranges, $16 \mathrm{x}$ $6 \times 6=576$ constant meteorology calculations could each be performed twice, once assuming that it was raining and once assuming that it was not raining. Then, by cumulating the results 
1988-92 Summary Wind Rose Table For Charleston, SC Port Wind Directions (Blowing Toward)

N NNE NE ENE E ESE SE SSE S SSW SW WSW W WNW NW NNW $\begin{array}{lllllllllllllllllllll}.0974 & .0796 & .0892 & .0650 & .0712 & .0530 & .0380 & .0436 & .0790 & .0817 & .0882 & .0549 & .0479 & .0389 & .0341 & .0385\end{array}$

1988-92 Summary Wind Rose Table For Concord, CA port

N NNE NE ENE $\quad$ E ESE SE SSE S SSW SW WSW W WNW NW NNW

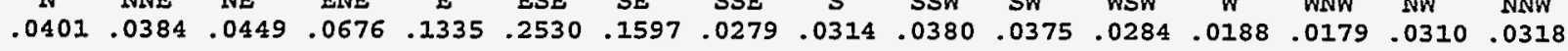

1988-92 Summary Wind Rose Table For Galveston, TX port

N NNE NE ENE $E$ ESE SE SSE S SSW SW WSW W WNW NW NNW $\begin{array}{llllllllllllllll}.1205 & .0630 & .0396 & .0280 & .0259 & .0339 & .0461 & .0497 & .08805 & .0683 & .0683 & .0569 & .0582 & .0763 & .0849 & .0997\end{array}$

1988-92 Summary Wind Rose Table For Jacksonville, FL Port Wind Directions (Blowing Toward)

N NNE NE ENE E ESE SE SSE S SSW SW WSW W WNW NW NW $\begin{array}{lllllllllllllllll}.0587 & .0504 & .0718 & .0677 & .0706 & .0700 & .0774 & .0533 & .0627 & .0528 & .0805 & .0637 & .0518 & .0480 & .0707 & .0498\end{array}$

1988-92 Summary Wind Rose Table For Long Beach, CA Port Wind Directions (Blowing Toward)

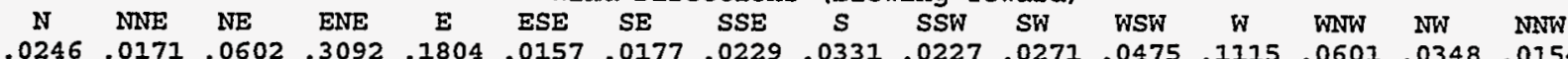

1988-92 Summary Wind Rose Table For MOTSU, NC Port

Wind Directions (Blowing Toward)

N NNE NE ENE $E$ ESE SE SSE S SSW SW WSW W WW NW NW W $\begin{array}{llllllllllllllllll}.0744 & .0804 & .0994 & .0798 & .0747 & .0378 & .0417 & .0435 & .0955 & .0780 & .0699 & .0488 & .0549 & .0351 & .0411 & .0451\end{array}$

1988-92 Summary Wind Rose Table For Newark, NJ Port wind Directions (Blowing Toward)

N NNE NE ENE $E$ ESE SE SSE S SSW SW WSW W WNW NW NW $\begin{array}{lllllllllllllllllllllllll}.0784 & .0725 & .1015 & .0871 & .0854 & .0639 & .0788 & .0559 & .0832 & .0786 & .0442 & .0273 & .0231 & .0304 & .0452 & .04447\end{array}$

1988-92 Summary Wind Rose Table For Norfolk, VA Port wind Directions (Blowing Toward)

N NNE NE ENE E ESE SE SSE S SSW SW WSW W WNW NW NNW $\begin{array}{llllllllllllllllllllll}.1078 & .0963 & .1021 & .0647 & .0562 & .0456 & .0344 & .0285 & .0940 & .0665 & .04860 & .0573 & .0470 & .0321 & .0358 & .04458\end{array}$

1988-92 Summary wind Rose Table For Philadelphia, PA Port Wind Directions (Blowing Toward)

N NNE NE ENE E ESE SE SSE S SSW SW WSW W WNW NW NNW $\begin{array}{llllllllllllllllll}0.0682 & .0440 & .0950 & .1118 & .1281 & .0913 & .0715 & .0568 & .0669 & .0266 & .0275 & .0639 & .0545 & .0284 & .02278 & .0378\end{array}$

1988-92 Summary wind Rose Table For Portland, OR Port Wind Dixections (Blowing Towara)

$N$ NNE NE ENE $E$ ESE SE SSE S SSW SW WSW W WNW NW $\begin{array}{llllllllllllllllllllll}.0936 & .0551 & .0337 & .0315 & .0756 & .0956 & .1163 & .03054 & .0704 & .0187 & .0171 & .0225 & .0638 & .01126 & .0576 & .0304\end{array}$

1988-92 Summary Wind Rose Table For Savannah, GA Port wind Directions (Blowing Toward)

N NNE NE ENE $E$ ESE SE SSE S SSW SW WWW W WNW NW NNW $\begin{array}{llllllllllllllllllllll}.0905 & .0616 & .0757 & .0748 & .0685 & .0674 & .0652 & .0567 & .0582 & .0545 & .0664 & .0570 & .0388 & .0358 & .0558 & .0732\end{array}$

1988-92 Summary Wind Rose Table For Seattle, wA Port wind Directions (Blowing Toward)

N NNE NE ENE $E$ ESE SE $S S E$ S SSW SW WSW W WNW NW

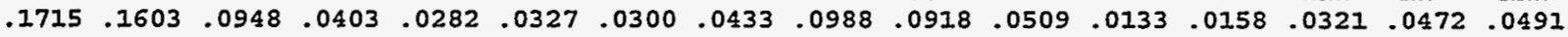

1988-92 Summary Wind Rose Table For Tacoma, WA Port wind Directions (Blowing Toward)

N NNE NE ENE E NSE SE SSE S SSW SW WSW W WNW NW NNW $\begin{array}{lllllllllllllllllllll} & 1715 & .1603 & .0948 & .0403 & .0282 & .0327 & .0300 & .0433 & .0988 & .0918 & .0509 & .0133 & .0158 & .0321 & .0472 & .0491\end{array}$

1988-92 Summary Wind Rose Table For Wilmington, NC Port Wind Directions (Blowing Toward)

N NWE NE ENE $E$ ESE SE SSE S SNW SW WSW W WN

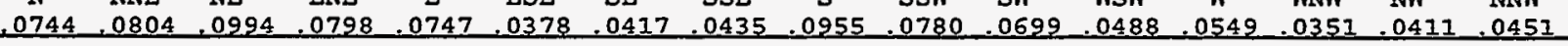


Table 21. Locations of National Weather Service Stations

\begin{tabular}{|l|c|}
\hline \multicolumn{1}{|c|}{ Port } & National Weather Service Station \\
\hline Newark (Port of Elizabeth) & New York City, NY \\
Philadelphia & New York City, NY \\
Norfolk (Hampton Roads) & Cape Hatteras, NC \\
Wilmington & Cape Hatteras, NC \\
MOTSU (Wilmington, NC) & Cape Hatteras, NC \\
Charleston & Charleston, SC \\
Savannah & Charleston, SC \\
Jacksonville & Charleston, SC \\
Galveston & Lake Charles, LA \\
Los Angeles (Long Beach, CA) & Santa Maria, CA \\
Concord NWS (San Francisco, CA) & Santa Maria, CA \\
Portland & Seattle, WA \\
Tacoma & Seattle, WA \\
\hline
\end{tabular}

of each set of approximately 1150 constant meteorology single-weather-trial calculations (rain does not occur for all of the sets of conditions in the Joint Frequency Distribution), a CCDF could be constructed to compare with the CCDF obtained using variable meteorology recorded at the nearest National Weather Service Station.

Tables 22 through 28 present Joint Frequency Distributions for the seven ports examined during this study. Table 29 presents the probability of rain by stability class for the same seven ports. 
Table 22. Joint Frequency Weather Distribution for Charleston

1988-92 Summary Joint Frequency Table For Charleston, SC Port

\begin{tabular}{|c|c|c|c|c|c|c|c|c|c|c|c|c|c|c|c|c|}
\hline \multirow{2}{*}{$\begin{array}{l}\text { Wind speed } \\
\text { (mph) }\end{array}$} & \multicolumn{16}{|c|}{ A stability } \\
\hline & N & NNE & NE & ENE & $E$ & ESE & SE & SSE & $s$ & SSW & SW & WSW & $w$ & WNW & $N W$ & $\mathrm{NNW}$ \\
\hline $1-3$ & .0003 & .0002 & .0002 & .0002 & .0002 & .0002 & .0002 & .0002 & .0003 & .0003 & .0002 & .0003 & .0001 & .0002 & .0001 & .0001 \\
\hline $4-7$ & .0005 & .0003 & .0005 & .0004 & .0004 & .0006 & .0003 & .0003 & .0006 & .0004 & .0004 & .0002 & .0002 & .0001 & .0002 & .0003 \\
\hline $8-12$ & .0000 & .0000 & .0000 & .0000 & .0000 & .0000 & .0000 & .0000 & .0000 & .0000 & .0000 & .0000 & .0000 & .0000 & .0000 & .0000 \\
\hline $13-18$ & .0000 & .0000 & .0000 & .0000 & .0000 & .0000 & .0000 & .0000 & .0000 & .0000 & .0000 & .0000 & .0000 & .0000 & .0000 & .0000 \\
\hline $19-24$ & .0000 & .0000 & .0000 & .0000 & .0000 & .0000 & .0000 & .0000 & .0000 & .0000 & .0000 & .0000 & .0000 & .0000 & .0000 & .0000 \\
\hline$>24$ & .0000 & .0000 & .0000 & .0000 & .0000 & .0000 & .0000 & .0000 & .0000 & .0000 & .0000 & .0000 & .0000 & .0000 & .0000 & .0000 \\
\hline
\end{tabular}

B Stability

\begin{tabular}{|c|c|c|c|c|c|c|c|c|c|c|c|c|c|c|c|c|}
\hline \multicolumn{2}{|c|}{ Wind speed } & \multicolumn{15}{|c|}{ Wind Directions (Blowing Toward) } \\
\hline (mph) & $\mathbf{N}$ & NNE & NE & ENE & $E$ & ESE & $S E$ & SSE & $s$ & ssW & sw & WSW & W & WNW & NW & NNW \\
\hline $1-3$ & .0008 & .0003 & .0006 & 007 & 0005 & 007 & .0008 & .0005 & .0011 & .0006 & .0010 & .0007 & .0007 & .0006 & .0004 & .0005 \\
\hline 4- 7 & .0018 & .0013 & .0017 & 0019 & .0023 & .0020 & .0017 & .0013 & .0031 & .0016 & .0023 & .0017 & .0018 & .0011 & .0013 & .0007 \\
\hline $8-12$ & .0021 & .0013 & .0021 & .0025 & .0025 & .0014 & .0013 & .0008 & .0016 & .0013 & .0013 & .0010 & .0013 & .0012 & .0016 & .0012 \\
\hline $13-18$ & .0000 & .0000 & .0000 & .0000 & .0000 & .0000 & .0000 & .0000 & .0000 & .0000 & .0000 & .0000 & .0000 & .0000 & .0000 & .0000 \\
\hline $9-24$ & .0000 & .0000 & .0000 & .0000 & .0000 & .0000 & .0000 & .0000 & .0000 & .0000 & .0000 & .0000 & .0000 & .0000 & .0000 & .0000 \\
\hline$>24$ & .0000 & .0000 & .0000 & .0000 & .0000 & .0000 & .0000 & .0000 & .0000 & .0000 & .0000 & .0000 & .0000 & .0000 & .0000 & .000 \\
\hline
\end{tabular}

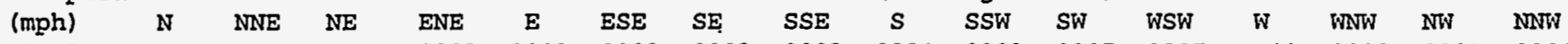

$\begin{array}{lllllllllllllllllll}1-3 & .0002 & .0002 & .0003 & .0003 & .0003 & .0003 & .0003 & .0003 & .0004 & .0003 & .0005 & .0005 & .0003 & .0002 & .0001 & .0001\end{array}$

$\begin{array}{lllllllllllllllllll}4-7 & .0015 & .0014 & .0016 & .0022 & .0026 & .0021 & .0019 & .0020 & .0026 & .0021 & .0035 & .0021 & .0014 & .0010 & .0014 & .0012\end{array}$

$\begin{array}{llllllllllllllllllll}8-12 & .0081 & .0038 & .0061 & .0072 & .0090 & .0049 & .0037 & .0031 & .0057 & .0051 & .0062 & .0042 & .0034 & .0043 & .0042 & .0049\end{array}$

$\begin{array}{llllllllllllllllllllll}13-18 & .0017 & .0012 & .0021 & .0020 & .0021 & .0014 & .0006 & .0005 & .0006 & .0005 & .0005 & .0004 & .0008 & .0005 & .0008 & .0007\end{array}$

$\begin{array}{lllllllllllllllll}19-24 & .0000 & .0000 & .0000 & .0001 & .0000 & .0000 & .0000 & .0000 & .0000 & .0000 & .0000 & .0000 & .0000 & .0000 & .0000 & .0000\end{array}$

$\begin{array}{llllllllllllllllll}>24 & .0000 & .0000 & .0000 & .0000 & .0000 & .0000 & .0000 & .0000 & .0000 & .0000 & .0000 & .0000 & .0000 & .0000 & .0000 & .0000\end{array}$

Wind speed

(mph) $N$ NNE NE ENE $\quad$ N ESE SE SSE S SSW SW WSW W WNW NW NNW

$\begin{array}{lllllllllllllllll}1-3 & .0009 & .0005 & .0005 & .0007 & .0006 & .0005 & .0004 & .0008 & .0013 & .0012 & .0013 & .0012 & .0007 & .0007 & .0004 & .0004\end{array}$

$\begin{array}{lllllllllllllllll}4-7 & .0045 & .0030 & .0037 & .0027 & .0028 & .0026 & .0022 & .0044 & .0094 & .0079 & .0093 & .0056 & .0042 & .0039 & .0026 & .0022\end{array}$

$\begin{array}{lllllllllllllllllll}8-12 & .0196 & .0151 & .0165 & .0112 & .0108 & .0070 & .0047 & .0061 & .0168 & .0216 & .0201 & .0124 & .0108 & .0075 & .0066 & .0083\end{array}$

$\begin{array}{lllllllllllllllllll}13-18 & .0140 & .0179 & .0145 & .0082 & .0133 & .0096 & .0058 & .0058 & .0084 & .0080 & .0057 & .0047 & .0051 & .0035 & .0034 & .0036\end{array}$

$\begin{array}{lllllllllllllllll}19-24 & .0009 & .0019 & .0020 & .0007 & .0020 & .0023 & .0010 & .0004 & .0003 & .0000 & .0000 & .0001 & .0001 & .0001 & .0001 & .0000\end{array}$

$\begin{array}{llllllllllllllllllllll}>24 & .0002 & .0005 & .0002 & .0001 & .0003 & .0003 & .0001 & .0000 & .0000 & .0001 & .0000 & .0000 & .0000 & .0000 & 0.0000 & .0000\end{array}$

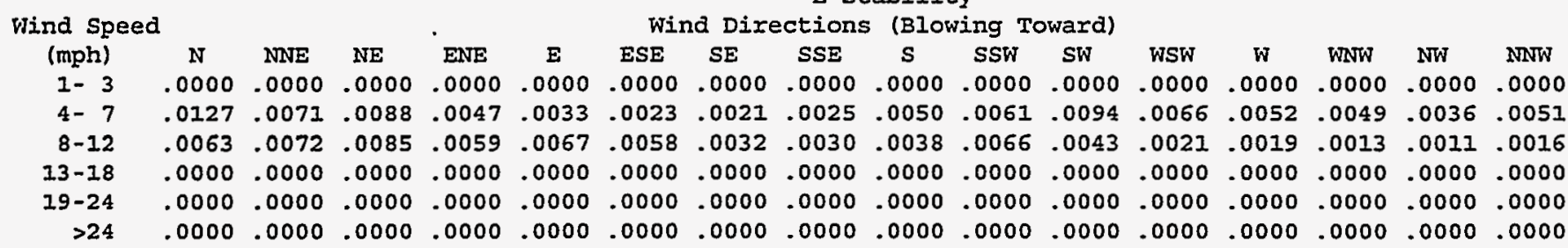

\begin{tabular}{|c|c|c|c|c|c|c|c|c|c|c|c|c|c|c|c|c|}
\hline \multirow{2}{*}{$\begin{array}{l}\text { Wind Speed } \\
\text { (mph) }\end{array}$} & \\
\hline & $\mathrm{N}$ & NE & $\mathrm{N}$ & ENE & $E$ & ESE & SE & SSE & $s$ & SSW & SW & WS & $w$ & WNW & $w$ & NNW \\
\hline $1-3$ & 090 & 76 & 1 & 9 & 2 & 39 & .0035 & .0057 & 086 & .0076 & & & & & 2 & 3 \\
\hline $4-7$ & .0122 & 088 & 0112 & 074 & 0063 & .0051 & .0044 & .0059 & .0095 & .0104 & .0122 & & & & 29 & .0039 \\
\hline $8-12$ & .0000 & 0000 & 0000 & 0000 & .0000 & .0000 & .0000 & .0000 & .0000 & .0000 & .0000 & & 00 & & 00 & .0000 \\
\hline $13-18$ & .0000 & .0000 & .0000 & .0000 & .0000 & .0000 & .0000 & .0000 & .0000 & .0000 & .0000 & Do & .0000 & 00 & .0000 & .0000 \\
\hline $19-24$ & .0000 & .0000 & .0000 & .0000 & .0000 & .0000 & .0000 & .0000 & .0000 & .0000 & .0000 & .0000 & .0000 & .0000 & .0000 & .0000 \\
\hline$>24$ & .0000 & .0000 & .0000 & .0000 & .0000 & .0000 & .0000 & .0000 & .0000 & .0000 & .0000 & .0000 & .0000 & .0000 & .0000 & .0000 \\
\hline
\end{tabular}


Table 23. Joint Frequency Weather Distribution for Long Beach

1988-92 Summary Joint Frequency Table For Long Beach, CA Port

\begin{tabular}{|c|c|c|c|c|c|c|c|c|c|c|c|c|c|c|c|c|}
\hline \multicolumn{2}{|c|}{ Wind Speed } & \multicolumn{15}{|c|}{ A stability } \\
\hline (mph) & N & NNNE & $\mathrm{NE}$ & ENE & $E$ & ESE & $S E$ & SSE & $\mathbf{s}$ & SSW & SW & WSW & W & WNW & NW & NNTW \\
\hline $1-3$ & .0002 & 003 & .0005 & 0011 & .0001 & .0002 & .0000 & .0000 & .0003 & .0000 & .0002 & .0000 & .0000 & .0002 & .0001 & .0001 \\
\hline $4-7$ & .0001 & .0000 & .0001 & .0002 & .0000 & .0000 & .0000 & .0000 & .0000 & .0000 & .0000 & .0000 & .0000 & .0000 & .0000 & .0000 \\
\hline $8-12$ & .0000 & .0000 & .0000 & .0000 & .0000 & .0000 & .0000 & .0000 & .0000 & .0000 & .0000 & .0000 & .0000 & .0000 & .0000 & .0000 \\
\hline $13-18$ & .0000 & .0000 & .0000 & .0000 & .0000 & .0000 & .0000 & .0000 & .0000 & .0000 & .0000 & .0000 & .0000 & .0000 & .0000 & .0000 \\
\hline $19-24$ & .0000 & .0000 & .0000 & .0000 & .0000 & .0000 & .0000 & .0000 & .0000 & .0000 & .0000 & .0000 & .0000 & .0000 & .0000 & .0000 \\
\hline$>24$ & .0000 & .0000 & .0000 & .0000 & .0000 & .0000 & .0000 & .0000 & .0000 & .0000 & .0000 & .0000 & .0000 & .0000 & .0000 & .0000 \\
\hline ind $S p$ & & & & & & WiI & d Dire & $\begin{array}{l}\text { B S } \\
\text { ction }\end{array}$ & (B) & ing & ward) & & & & & \\
\hline (mph) & $\mathrm{N}$ & NNE & NE & ENE & $\mathbf{E}$ & ESE & SE & SSE & $s$ & SSW & SW & WSW & W & WNW & $\mathrm{NW}$ & NNW \\
\hline $1-3$ & .0010 & .0009 & .0013 & .0016 & .0008 & .0002 & .0003 & .0003 & .0007 & .0006 & .0005 & .0006 & .0018 & .0026 & .0019 & .0011 \\
\hline $4-7$ & .0011 & .0009 & .0019 & .0056 & .0023 & .0004 & .0003 & .0003 & .0006 & .0005 & .0004 & .0006 & .0019 & .0022 & .0018 & .0011 \\
\hline $8-12$ & .0003 & .0001 & .0018 & .0127 & .0052 & .0002 & .0001 & .0000 & .0001 & .0000 & .0001 & .0001 & .0005 & .0007 & .0003 & .0003 \\
\hline $13-18$ & .0000 & .0000 & .0000 & .0000 & .0000 & .0000 & .0000 & .0000 & .0000 & .0000 & .0000 & .0000 & .0000 & .0000 & .0000 & .0000 \\
\hline $19-24$ & .0000 & .0000 & .0000 & .0000 & .0000 & .0000 & .0000 & .0000 & .0000 & .0000 & .0000 & .0000 & .0000 & .0000 & .0000 & .0000 \\
\hline$>24$ & .0000 & 0000 & 0000 & 0000 & .0000 & .0000 & 0000 & 0000 & .0000 & .0000 & .0000 & .0000 & .0000 & .0000 & .0000 & 0000 \\
\hline
\end{tabular}

C stability

wind Speed

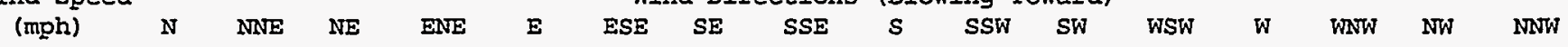

$\begin{array}{llllllllllllllllll}1-3 & .0004 & .0001 & .0004 & .0005 & .0004 & .0001 & .0001 & .0002 & .0005 & .0003 & .0004 & .0006 & .0013 & .0010 & .0005 & .0002\end{array}$

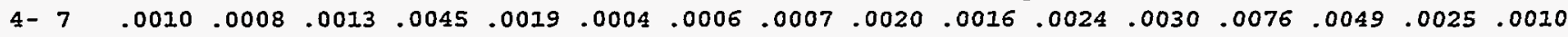

$\begin{array}{lllllllllllllllllll}8-12 & .0005 & .0007 & .0048 & .0404 & .0195 & .0006 & .0006 & .0004 & .0008 & .0011 & .0011 & .0019 & .0026 & .0015 & .0008 & .0002\end{array}$

$\begin{array}{lllllllllllllllll}13-18 & .0000 & .0001 & .0021 & .0237 & .0093 & .0001 & .0000 & .0001 & .0000 & .0000 & .0000 & .0000 & .0000 & .0001 & .0002 & .0000\end{array}$

$\begin{array}{lllllllllllllllllll}19-24 & .0000 & .0000 & .0000 & .0003 & .0003 & .0000 & .0000 & .0000 & .0000 & .0000 & .0000 & .0000 & .0000 & .0000 & .0000 & .0000\end{array}$

$\begin{array}{lllllllllllllllll}>24 & .0000 & .0000 & .0000 & .0000 & .0002 & .0000 & .0000 & .0000 & .0000 & .0000 & .0000 & .0000 & .0000 & .0000 & .0000 & .0000\end{array}$

Wind Directions (Blowing Toward)

\begin{tabular}{|c|c|c|c|c|c|c|c|c|c|c|c|c|c|c|c|c|}
\hline & & & & & & & & & & & & & & & & \\
\hline$(\mathrm{mph})$ & N & NNE & NE & ENE & $\mathbf{E}$ & ESE & SE & SSE & $\mathbf{s}$ & SSW & SW & ws & W & WN & W & NNW \\
\hline $1-3$ & .0014 & .0010 & .0021 & 0052 & 041 & 2008 & 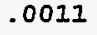 & .0010 & .0012 & .0007 & .0010 & .0015 & 0047 & .0035 & 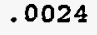 & .0015 \\
\hline & .0039 & 26 & 74 & 0247 & 10 & 28 & & & & & & & & & & .0029 \\
\hline$\varepsilon$ & 22 & .0015 & 77 & 3 & 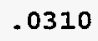 & 18 & 10 & & & 18 & & & & iz & 14 & 13 \\
\hline & 99 & .0013 & 38 & 85 & 17 & 3 & 19 & & & 9 & .0 & & 20 & .0016 & 15 & 0006 \\
\hline & & 01 & 02 & 22 & & 01 & 02 & & & 01 & 01 & 00 & 00 & 100 & 100 & .0000 \\
\hline$?$ & 00 & 000 & 200 & 003 & 018 & 000 & 001 & 001 & 000 & 200 & .0000 & 000 & 0000 & 000 & 0000 & .0000 \\
\hline
\end{tabular}

$\begin{array}{lllllllllllllllllll}>24 & .0000 & .0000 & .0000 & .0003 & .0018 & .0000 & .0001 & .0001 & .0000 & .0000 & .0000 & .0000 & .0000 & .0000 & .0000 & .0000\end{array}$

\begin{tabular}{|c|c|c|c|c|c|c|c|c|c|c|c|c|c|c|c|c|}
\hline \multirow{3}{*}{$\begin{array}{l}\text { Wind Speed } \\
\text { (mph) }\end{array}$} & \multicolumn{16}{|c|}{ Stability } \\
\hline & & & & & & & $\mathrm{Di}$ & & סל & 19 & (ard) & & & & & \\
\hline & $N$ & NE & NE & ENE & E & SE & SE & SSE & $s$ & SSW & SW & WSW & $W$ & WNW & & NNW \\
\hline $1-3$ & .0000 & 000 & 000 & 1000 & 0000 & 000 & .0000 & .0000 & .0000 & .0000 & .0000 & 0000 & 0000 & 0000 & 0000 & 0000 \\
\hline $4-7$ & .0019 & 1009 & .0041 & 0125 & 073 & .0013 & .0017 & .0015 & .0033 & .0017 & .0023 & .0049 & .0105 & .0039 & .0024 & 0010 \\
\hline $8-12$ & .0010 & .0005 & .0045 & .0285 & .0176 & .0017 & .0018 & .0022 & .0036 & .0022 & .0 & .0016 & .0032 & .0012 & .0003 & 0001 \\
\hline $13-18$ & .0000 & .0000 & .0000 & .0000 & .0000 & .0000 & .0000 & .0000 & .0000 & .0000 & .0000 & .0000 & .0000 & .0000 & .0000 & .0000 \\
\hline $19-24$ & .0000 & .0000 & .0000 & .0000 & .0000 & .0000 & .0000 & .0000 & .0000 & .0000 & .0000 & .0000 & .0000 & .0000 & .0000 & .0000 \\
\hline$>24$ & .0000 & .0000 & .0000 & .0000 & .0000 & .0000 & .0000 & .0000 & .0000 & .0000 & .0000 & .0000 & .0000 & .0000 & .0000 & .0000 \\
\hline
\end{tabular}

\begin{tabular}{|c|c|c|c|c|c|c|c|c|c|c|c|c|c|c|c|c|}
\hline \multirow{2}{*}{$\begin{array}{l}\text { Wind Speed } \\
\text { (mph) }\end{array}$} & \multicolumn{16}{|c|}{ Wind Directions (Blowing Toward) } \\
\hline & $\mathrm{N}$ & INE & NE & ENE & $E$ & SE & SE & SSE & $s$ & SSW & SW & WSW & W & WNW & NW & NNW \\
\hline $1-3$ & 2040 & 25 & 64 & 29 & 060 & 16 & .0026 & .0031 & 057 & .0037 & & 97 & 0205 & .0097 & .0039 & .0022 \\
\hline $4-7$ & .0045 & 0028 & 0097 & 0253 & .0107 & .0023 & .0029 & .0042 & .0063 & .0055 & .0075 & 33 & .0275 & .0098 & .0043 & .0019 \\
\hline $8-12$ & .0000 & .0000 & .0000 & .0000 & .0000 & .0000 & .0000 & .0000 & .0000 & .0000 & .0000 & .0000 & .0000 & .0000 & .0000 & .0000 \\
\hline $13-18$ & .0000 & .0000 & .0000 & .0000 & .0000 & .0000 & .0000 & .0000 & .0000 & .0000 & .0000 & .0000 & .0000 & .0000 & .0000 & .0000 \\
\hline $19-24$ & .0000 & .0000 & .0000 & .0000 & .0000 & .0000 & .0000 & .0000 & .0000 & .0000 & .0000 & .0000 & .0000 & .0000 & .0000 & .0000 \\
\hline$>24$ & .0000 & .0000 & .0000 & 0000 & .0000 & 0000 & .0000 & .0000 & .0000 & .0000 & .0000 & .0000 & .0000 & 0000 & .0000 & .0000 \\
\hline
\end{tabular}


Table 24. Joint Frequency Weather Distribution for Newark

1988-92 Summary Joint Frequency Table For Newark, NJ Port

\begin{tabular}{|c|c|c|c|c|c|c|c|c|c|c|c|c|c|c|c|c|}
\hline \multicolumn{2}{|c|}{ Wind Speed } & \multicolumn{15}{|c|}{ A stability } \\
\hline (mph) & $\mathrm{N}$ & NNE & NE & ENE & $E$ & ESE & SE & SSE & $s$ & ssw & sw & SW & W & WNW & W & NNW \\
\hline $1-3$ & .0001 & 001 & .0000 & .0001 & 0001 & 000 & .0001 & .0001 & 0001 & .0001 & .0001 & 000 & .0002 & $.000 z$ & .0000 & 0001 \\
\hline 7 & .0003 & .0002 & .0001 & .0001 & .0002 & .0000 & .0001 & .0001 & .0001 & .0002 & .0001 & .0000 & .0001 & .0001 & .0001 & .0002 \\
\hline $8-12$ & .0000 & .0000 & .0000 & .0000 & .0000 & .0000 & .0000 & .0000 & .0000 & .0000 & .0000 & .0000 & .0000 & .0000 & .0000 & .0000 \\
\hline $13-18$ & .0000 & .0000 & .0000 & .0000 & .0000 & .0000 & .0000 & .0000 & .0000 & .0000 & .0000 & .0000 & .0000 & .0000 & .0000 & .0000 \\
\hline $19-24$ & .0000 & .0000 & .0000 & .0000 & .0000 & .0000 & .0000 & .0000 & .0000 & .0000 & .0000 & .0000 & .0000 & .0000 & .0000 & 1000 \\
\hline$>24$ & .0000 & .0000 & .0000 & .0000 & .0000 & .0000 & .0000 & .0000 & .0000 & .0000 & 0000 & 0000 & 0000 & 000 & 000 & 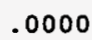 \\
\hline
\end{tabular}

Wind speed

(mph) IN NNE NE ENE $\quad$ E ESE SE SSE S SSW SW NSW W WNW NW NNW

$\begin{array}{llllllllllllllllllll}1-3 & .0007 & .0005 & .0005 & .0003 & .0003 & .0001 & .0002 & .0003 & .0005 & .0005 & .0003 & .0003 & .0003 & .0002 & .0005 & .0004\end{array}$

$\begin{array}{lllllllllllllllllll}4-7 & .0017 & .0012 & .0012 & .0016 & .0012 & .0006 & .0008 & .0007 & .0016 & .0010 & .0009 & .0008 & .0008 & .0011 & .0017 & .0018\end{array}$

$\begin{array}{lllllllllllllllllll}8-12 & .0009 & .0008 & .0013 & .0013 & .0010 & .0007 & .0005 & .0005 & .0011 & .0009 & .0006 & .0004 & .0005 & .0009 & .0014 & .0016\end{array}$

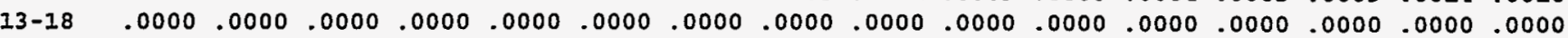

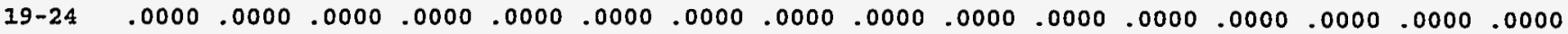

$\begin{array}{lllllllllllllllllllllllll}>24 & .0000 & .0000 & .0000 & .0000 & .0000 & .0000 & .0000 & .0000 & .0000 & .0000 & .0000 & .0000 & .0000 & .0000 & .0000 & .0000\end{array}$

Wind speed

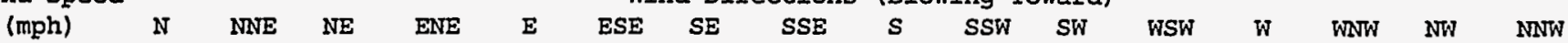

$\begin{array}{lllllllllllllllllll}1-3 & .0004 & .0002 & .0003 & .0002 & .0003 & .0001 & .0001 & .0001 & .0003 & .0002 & .0002 & .0002 & .0000 & .0001 & .0002 & .0002\end{array}$

$\begin{array}{llllllllllllllllll}4-7 & .0021 & .0018 & .0020 & .0015 & .0014 & .0007 & .0011 & .0009 & .0026 & .0017 & .0012 & .0009 & .0007 & .0012 & .0013 & .0017\end{array}$

$\begin{array}{lllllllllllllllll}8-12 & .0038 & .0037 & .0058 & .0060 & .0056 & .0034 & .0038 & .0029 & .0052 & .0039 & .0021 & .0012 & .0007 & .0019 & .0054 & .0048\end{array}$

$\begin{array}{llllllllllllllllllll}13-18 & .0005 & .0005 & .0012 & .0017 & .0016 & .0010 & .0012 & .0009 & .0008 & .0004 & .0005 & .0001 & .0000 & .0003 & .0007 & .0002\end{array}$

$\begin{array}{lllllllllllllllll}19-24 & .0000 & .0000 & .0001 & .0001 & .0000 & .0001 & .0003 & .0000 & .0000 & .0000 & .0000 & .0000 & .0000 & .0000 & .0000 & .0000\end{array}$

$\begin{array}{lllllllllllllllllllll}>24 & .0000 & .0000 & .0000 & .0000 & .0000 & .0000 & .0000 & .0000 & .0000 & .0000 & .0000 & .0000 & .0000 & .0000 & .0000 & .0000\end{array}$

Wind speed

(mph) Wind Directions (Blowing Toward)

$\begin{array}{llllllllllllllllllll}.0000 & .0006 & .0005 & .0002 & .0003 & .0006 & .0010 & .0013 & .0010 & .0015 & .0011 & .0011 & .0017 & .0012 & \end{array}$

$\begin{array}{llllllllllllllllll}4-7 & .0107 & .0050 & .0049 & .0041 & .0038 & .0016 & .0022 & .0020 & .0071 & .0085 & .0057 & .0064 & .0065 & .0075 & .0093 & .0075\end{array}$

$\begin{array}{lllllllllllllllllllll}8-12 & .0182 & .0148 & .0241 & .0196 & .0152 & .0080 & .0094 & .0088 & .0205 & .0242 & .0144 & .0071 & .0054 & .0084 & .0107 & .0105\end{array}$

$\begin{array}{lllllllllllllllllllll}13-18 & .0071 & .0112 & .0233 & .0236 & .0224 & .0230 & .0310 & .0223 & .0183 & .0179 & .0083 & .0028 & .0018 & .0018 & .0033 & .0029\end{array}$

$\begin{array}{lllllllllllllllllll}19-24 & .0007 & .0015 & .0020 & .0023 & .0045 & .0079 & .0086 & .0034 & .0020 & .0013 & .0006 & .0003 & .0001 & .0001 & .0001 & .0002\end{array}$

$\begin{array}{llllllllllllllllllllll}>24 & .0000 & .0001 & .0002 & .0004 & .0009 & .0027 & .0022 & .0006 & .0003 & .0001 & .0003 & .0001 & .0000 & .0000 & .0000 & .0000\end{array}$

(mph) $N$ NNE NE ENE $E$ ESE SE SSE S SSW SW WSW W WNW NW NNW

$\begin{array}{lllllllllllllllll}1-3 & .0000 & .0000 & .0000 & .0000 & .0000 & .0000 & .0000 & .0000 & .0000 & .0000 & .0000 & .0000 & .0000 & .0000 & .0000 & .0000\end{array}$

$\begin{array}{lllllllllllllllll}4-7 & .0101 & .0077 & .0066 & .0038 & .0049 & .0016 & .0019 & .0013 & .0048 & .0041 & .0024 & .0021 & .0019 & .0024 & .0033 & .0045\end{array}$

$\begin{array}{llllllllllllllllllllll}8-12 & .0054 & .0062 & .0116 & .0115 & .0100 & .0069 & .0091 & .0068 & .0077 & .0045 & .0012 & .0004 & .0003 & .0005 & .0009 & .0018\end{array}$

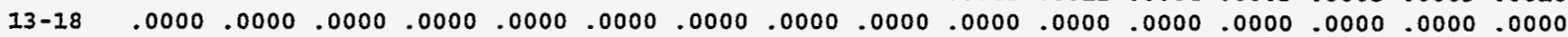

$\begin{array}{lllllllllllllllll}19-24 & .0000 & .0000 & .0000 & .0000 & .0000 & .0000 & .0000 & .0000 & .0000 & .0000 & .0000 & .0000 & .0000 & .0000 & .0000 & .0000\end{array}$

$\begin{array}{lllllllllllllllll}>24 & .0000 & .0000 & .0000 & .0000 & .0000 & .0000 & .0000 & .0000 & .0000 & .0000 & .0000 & .0000 & .0000 & .0000 & .0000 & .0000\end{array}$

F stability

wind Speed

(mph) N NNE NE ENE $\mathrm{N}$ ESE SE SSE S SSW SW WSW W WNW NW NNW

$\begin{array}{llllllllllllllllll}1-3 & .0043 & .0040 & .0044 & .0025 & .0027 & .0015 & .0014 & .0010 & .0024 & .0021 & .0018 & .0013 & .0013 & .0011 & .0023 & .0019\end{array}$

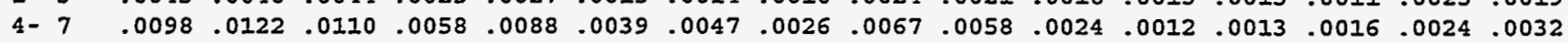

$\begin{array}{lllllllllllllllll}8-12 & .0000 & .0000 & .0000 & .0000 & .0000 & .0000 & .0000 & .0000 & .0000 & .0000 & .0000 & .0000 & .0000 & .0000 & .0000 & .0000\end{array}$

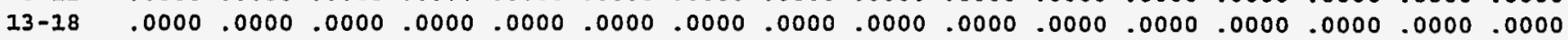

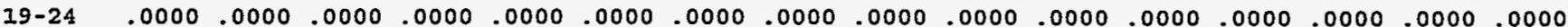

$\begin{array}{lllllllllllllllll}>24 & .0000 & .0000 & .0000 & .0000 & .0000 & .0000 & .0000 & .0000 & .0000 & .0000 & .0000 & .0000 & .0000 & .0000 & .0000 & .0000\end{array}$ 
Table 25. Joint Frequency Weather Distribution for Norfolk

1988-92 Summary Joint Frequency Table For Norfolk, VA Port

\begin{tabular}{|c|c|c|c|c|c|c|c|c|c|c|c|c|c|c|c|c|}
\hline \multirow{2}{*}{$\begin{array}{l}\text { Wind Speed } \\
\text { (mph) }\end{array}$} & & \multicolumn{15}{|c|}{ A stability } \\
\hline & $\mathrm{N}$ & NNE & NE & ENE & $\mathbf{E}$ & ESE & SE & SSE & $S$ & SSW & SW & WSW & w & WNT & $N W$ & NNW \\
\hline $1-3$ & .0001 & .0001 & .0000 & .0002 & .0003 & .0001 & .0000 & .0000 & .0002 & .0001 & .0001 & .0002 & .0001 & .0001 & .0000 & .0001 \\
\hline $4-7$ & .0001 & .0002 & .0000 & .0002 & .0003 & .0001 & .0000 & .0000 & .0001 & .0002 & .0001 & .0003 & .0001 & .0001 & .0000 & .0001 \\
\hline $8-12$ & .0000 & .0000 & .0000 & .0000 & .0000 & .0000 & .0000 & .0000 & .0000 & .0000 & .0000 & .0000 & .0000 & .0000 & .0000 & .0000 \\
\hline $13-18$ & .0000 & .0000 & .0000 & .0000 & .0000 & .0000 & .0000 & .0000 & .0000 & .0000 & .0000 & .0000 & .0000 & .0000 & .0000 & .0000 \\
\hline $19-24$ & .0000 & .0000 & .0000 & .0000 & .0000 & .0000 & .0000 & .0000 & .0000 & .0000 & .0000 & .0000 & .0000 & .0000 & .0000 & .0000 \\
\hline$>24$ & .0000 & .0000 & .0000 & .0000 & .0000 & .0000 & .0000 & .0000 & .0000 & .0000 & .0000 & .0000 & .0000 & .0000 & .0000 & .0000 \\
\hline ind Speed & & & & & & wix & d Dire & $\begin{array}{r}\text { B St } \\
\text { ctions }\end{array}$ & (BI) & ng & & & & & & \\
\hline (mph) & $\mathrm{N}$ & NNE & NE & ENE & $\mathbf{E}$ & ESE & SE & SSE & $\mathbf{S}$ & SSW & SW & WSW & w & WNIN & NW & 2NNW \\
\hline $1-3$ & .0002 & .0002 & .0002 & .0004 & .0004 & .0004 & .0002 & .0001 & .0004 & .0004 & .0003 & .0003 & .0004 & .0002 & .0002 & .0003 \\
\hline $4-7$ & .0008 & .0006 & .0006 & .0010 & .0010 & .0011 & .0005 & .0005 & .0013 & .0015 & .0013 & .0007 & .0009 & .0004 & .0005 & .0006 \\
\hline $8-12$ & .0008 & .0008 & .0010 & .0013 & .0015 & .0009 & .0006 & .0003 & .0020 & .0030 & .0022 & .0017 & .0012 & .0007 & .0006 & .0005 \\
\hline $13-18$ & .0000 & .0000 & .0000 & .0000 & .0000 & .0000 & .0000 & .0000 & .0000 & .0000 & .0000 & .0000 & .0000 & .0000 & .0000 & .0000 \\
\hline $19-24$ & .0000 & .0000 & .0000 & .0000 & .0000 & .0000 & .0000 & .0000 & .0000 & .0000 & .0000 & .0000 & .0000 & .0000 & .0000 & .0000 \\
\hline$>24$ & .0000 & .0000 & .0000 & .0000 & .0000 & .0000 & .0000 & .0000 & .0000 & .0000 & .0000 & .0000 & .0000 & .0000 & .0000 & .0000 \\
\hline
\end{tabular}

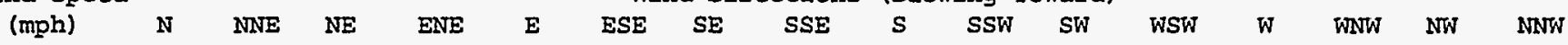

$\begin{array}{lllllllllllllllllll}1-3 & .0002 & .0001 & .0003 & .0002 & .0003 & .0002 & .0001 & .0001 & .0002 & .0003 & .0002 & .0001 & .0003 & .0002 & .0001 & .0001\end{array}$

$\begin{array}{lllllllllllllllll}4-7 & .0011 & .0008 & .0015 & .0014 & .0014 & .0012 & .0005 & .0005 & .0013 & .0017 & .0013 & .0010 & .0012 & .0010 & .0005 & .0003\end{array}$

$\begin{array}{llllllllllllllllll}8-12 & .0043 & .0038 & .0062 & .0048 & .0054 & .0034 & .0021 & .0013 & .0057 & .0080 & .0102 & .0043 & .0042 & .0029 & .0023 & .0017\end{array}$

$\begin{array}{lllllllllllllllllll}13-18 & .0012 & .0012 & .0025 & .0021 & .0015 & .0011 & .0003 & .0005 & .0021 & .0015 & .0024 & .0015 & .0008 & .0004 & .0004 & .0003\end{array}$

$\begin{array}{llllllllllllllllll}19-24 & .0000 & .0001 & .0004 & .0002 & .0000 & .0000 & .0000 & .0000 & .0001 & .0000 & .0002 & .0001 & .0000 & .0000 & .0000 & .0000\end{array}$ $\begin{array}{llllllllllllllllll}>24 & .0000 & .0000 & .0000 & .0000 & .0000 & .0000 & .0000 & .0000 & .0000 & .0000 & .0000 & .0000 & .0000 & .0000 & .0000 & .0000\end{array}$

wind speed

(mph) N NNE NE ENE $E$ ESE SE SSE S SSW SW WSW W WNW NW NNW

$\begin{array}{llllllllllllllllllllll}1-3 & .0008 & .0005 & .0007 & .0007 & .0005 & .0006 & .0004 & .0002 & .0007 & .0006 & .0007 & .0007 & .0008 & .0006 & .0007 & .0008\end{array}$

$\begin{array}{llllllllllllllllll}4-7 & .0043 & .0026 & .0026 & .0027 & .0028 & .0021 & .0018 & .0011 & .0032 & .0032 & .0038 & .0036 & .0042 & .0031 & .0025 & .0026\end{array}$

$\begin{array}{llllllllllllllllllll}8-12 & .0243 & .0197 & .0186 & .0126 & .0096 & .0064 & .0056 & .0052 & .0145 & .0115 & .0148 & .0126 & .0106 & .0074 & .0091 & .0109\end{array}$

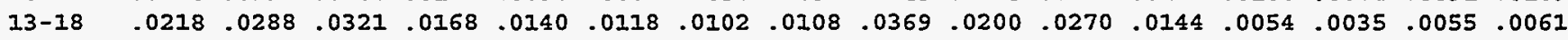

$\begin{array}{lllllllllllllllllll}19-24 & .0039 & .0036 & .0060 & .0027 & .0026 & .0034 & .0023 & .0021 & .0105 & .0056 & .0069 & .0028 & .0003 & .0002 & .0002 & .0003\end{array}$

$\begin{array}{lllllllllllllllllllllll}>24 & .0008 & .0005 & .0004 & .0002 & .0003 & .0007 & .0003 & .0004 & .0027 & .0015 & .0021 & .0002 & .0000 & .0000 & .0000 & .0000\end{array}$

Wind speed

E Stability

\begin{tabular}{|c|c|c|c|c|c|c|c|c|c|c|c|c|c|c|c|c|}
\hline \multicolumn{2}{|l|}{ Wind Speed } & \multicolumn{15}{|c|}{ Wind Directions (Blowing Toward) } \\
\hline (mph) & N & NNE & $\mathrm{NE}$ & ENE & E & ESE & SE & SSE & $\mathrm{s}$ & SSW & SW & WSW & 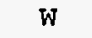 & $m$ & 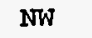 & NNW \\
\hline $1-3$ & .0000 & 1000 & 1000 & 0000 & 0000 & 1000 & 1000 & .0000 & .0000 & 000 & .0000 & 000 & 00 & 1000 & 000 & 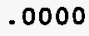 \\
\hline $4-7$ & .0078 & .0048 & .0043 & .0027 & .0023 & .0018 & .0012 & .0006 & .0015 & .0013 & .0026 & .0028 & .0052 & .0036 & .0032 & .0054 \\
\hline $8-12$ & .0124 & .0122 & .0120 & .0069 & .0048 & .0046 & .0049 & .0028 & .0060 & .0034 & .0055 & .0040 & .0017 & .0013 & .0028 & .0047 \\
\hline $13-18$ & .0000 & .0000 & .0000 & .0000 & .0000 & .0000 & .0000 & .0000 & .0000 & .0000 & .0000 & .0000 & .0000 & .0000 & .0000 & .0000 \\
\hline $19-24$ & .0000 & .0000 & .0000 & .0000 & .0000 & .0000 & .0000 & .0000 & .0000 & .0000 & .0000 & .0000 & .0000 & .0000 & .0000 & .0000 \\
\hline$>24$ & .0000 & .0000 & .0000 & .0000 & .0000 & .0000 & .0000 & .0000 & .0000 & .0000 & .0000 & .0000 & .0000 & .0000 & .0000 & .0000 \\
\hline 114 spe & & & & & & Wir & DI. & $\begin{array}{r}\text { F S } \\
\text { tion }\end{array}$ & & s & & & & & & \\
\hline (mph) & $\mathbf{N}$ & NNE & NE & ENE & E & ESE & SE & SSE & 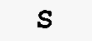 & SSW & SW & WSW & W & WNW & NW & NNW \\
\hline $1-3$ & .0097 & .0066 & .0056 & .0033 & 0031 & .0025 & .0013 & .0008 & .0015 & .0013 & .0021 & .0026 & .0047 & .0035 & .0033 & .0052 \\
\hline $4-7$ & .0130 & .0090 & .0070 & .0043 & .0042 & .0033 & .0020 & .0012 & .0021 & .0016 & .0023 & .0 & .0050 & .0030 & .0038 & .0057 \\
\hline $8-12$ & .0000 & .0000 & .0000 & .0000 & .0000 & .0000 & .0000 & .0000 & .0000 & .0000 & .0000 & .0000 & .0000 & .0000 & .0000 & .0000 \\
\hline $13-18$ & .0000 & .0000 & .0000 & .0000 & .0000 & .0000 & .0000 & .0000 & .0000 & .0000 & .0000 & .0000 & .0000 & .0000 & .0000 & .0000 \\
\hline-24 & .0000 & .0000 & .0000 & .0000 & .0000 & .0000 & .0000 & .0000 & .0000 & .0000 & .0000 & .0000 & .0 & .0000 & .0000 & .0000 \\
\hline$>24$ & .0000 & .0000 & .0000 & .0000 & .0000 & .0000 & .0000 & .0000 & .0000 & .0000 & .0000 & .0000 & .0000 & .0000 & .0000 & .0000 \\
\hline
\end{tabular}


Table 26. Joint Frequency Weather Distribution for Philadelphia

1988-92 Summary Joint Frequency Table For Philadelphia, PA Port

Wind speed

(mph) $N$ NNE NE ENE $E$ ESE SE SSE S SSW SW WSW W WNW NW NNW

$\begin{array}{llllllllllllllllllll}1-3 & .0000 & .0000 & .0000 & .0000 & .0000 & .0000 & .0000 & .0000 & .0001 & .0000 & .0000 & .0000 & .0000 & .0000 & .0000 & .0000\end{array}$

$\begin{array}{lllllllllllllllllll}4-7 & .0003 & .0002 & .0001 & .0002 & .0003 & .0003 & .0001 & .0001 & .0002 & .0000 & .0000 & .0000 & .0002 & .0001 & .0001 & .0002\end{array}$

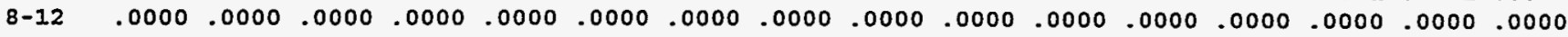

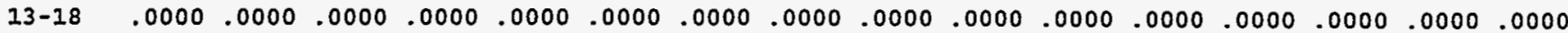

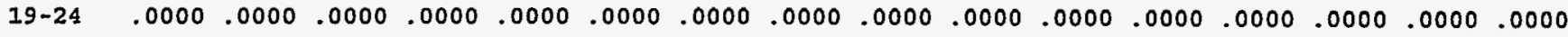

$\begin{array}{lllllllllllllllllllllllllll}>24 & .0000 & .0000 & .0000 & .0000 & .0000 & .0000 & .0000 & .0000 & .0000 & .0000 & .0000 & .0000 & .0000 & .0000 & .0000 & .0000\end{array}$

\begin{tabular}{|c|c|c|c|c|c|c|c|c|c|c|c|c|c|c|c|c|}
\hline \multicolumn{2}{|c|}{ Wind Speed } & \multicolumn{15}{|c|}{ Wind Directions (BIowing Toward) } \\
\hline (mph & $\mathrm{N}$ & NNE & NE & ENE & $E$ & ESE & SE & SSE & $s$ & sSw & SW & WSW & พ & WNW & NW & NN \\
\hline $1-3$ & 007 & 004 & 005 & 007 & 09 & .0005 & .0003 & .0003 & 0005 & 0002 & .0002 & 0003 & .0003 & .0003 & .0005 & .00 \\
\hline $4-7$ & .0017 & .0016 & 026 & 0034 & .0026 & .0014 & .0011 & .0010 & .0014 & .0005 & .0006 & .0005 & 16 & .0014 & .0013 & . \\
\hline $8-12$ & .0008 & .0014 & 0035 & .0046 & 025 & .0010 & .0009 & .0008 & .0012 & .0004 & .0004 & 205 & 110 & 008 & 03 & .00 \\
\hline $13-18$ & .0000 & .0000 & .0000 & .0000 & .0000 & .0000 & .0000 & .0000 & .0000 & .0000 & .0000 & 0000 & 00 & .0000 & .0000 & .000 \\
\hline $9-24$ & .0000 & .0000 & .0000 & .0000 & .0000 & .0000 & .0000 & .0000 & .0000 & .0000 & .0000 & .0000 & .0000 & .0000 & .0000 & .000 \\
\hline$>24$ & .0000 & .0000 & .0000 & .0000 & .0000 & .0000 & .0000 & .0000 & .0000 & .0000 & .0000 & .0000 & .0000 & .0000 & .0000 & .000 \\
\hline
\end{tabular}

Wind Speed

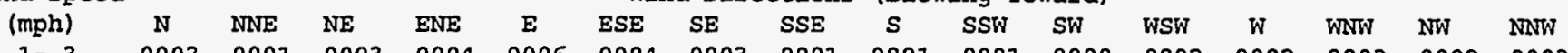

$\begin{array}{llllllllllllllllll}1-3 & .0003 & .0001 & .0003 & .0004 & .0006 & .0004 & .0003 & .0001 & .0001 & .0001 & .0000 & .0002 & .0002 & .0003 & .0002 & .0003\end{array}$

$\begin{array}{lllllllllllllllll}4-7 & .0018 & .0010 & .0025 & .0037 & .0035 & .0014 & .0015 & .0014 & .0014 & .0005 & .0004 & .0008 & .0020 & .0010 & .0009 & .0012\end{array}$

$\begin{array}{llllllllllllllllllll}8-12 & .0025 & .0026 & .0086 & .0119 & .0071 & .0049 & .0047 & .0043 & .0049 & .0018 & .0013 & .0025 & .0025 & .0012 & .0010 & .0011\end{array}$

$\begin{array}{lllllllllllllllllllll}13-18 & .0006 & .0007 & .0016 & .0021 & .0017 & .0016 & .0014 & .0011 & .0009 & .0003 & .0001 & .0005 & .0004 & .0001 & .0001 & .0001\end{array}$

$\begin{array}{lllllllllllllllllll}19-24 & .0000 & .0000 & .0000 & .0000 & .0001 & .0001 & .0001 & .0000 & .0000 & .0000 & .0000 & .0000 & .0000 & .0000 & .0000 & .0000\end{array}$

$\begin{array}{lllllllllllllllllllllllll}>24 & .0000 & .0000 & .0000 & .0000 & .0000 & .0000 & .0000 & .0000 & .0000 & .0000 & .0000 & .0000 & .0000 & .0000 & .0000 & .0000\end{array}$

Wind speed

(mph) N NNE NE ENE E ESE SE SSE S SSW SW WSW W WNW NW NNW

$\begin{array}{llllllllllllllllllll}1-3 & .0010 & .0003 & .0006 & .0011 & .0012 & .0006 & .0005 & .0005 & .0006 & .0003 & .0003 & .0011 & .0017 & .0012 & .0011 & .0010\end{array}$

$\begin{array}{lllllllllllllllllllll}4-7 & .0052 & .0021 & .0050 & .0087 & .0076 & .0031 & .0034 & .0031 & .0046 & .0019 & .0017 & .0049 & .0086 & .0050 & .0045 & .0046\end{array}$

$\begin{array}{llllllllllllllllll}8-12 & .0172 & .0105 & .0232 & .0221 & .0181 & .0106 & .0095 & .0093 & .0145 & .0068 & .0067 & .0224 & .0168 & .0074 & .0075 & .0094\end{array}$

$\begin{array}{llllllllllllllllll}13-18 & .0137 & .0117 & .0195 & .0115 & .0229 & .0314 & .0204 & .0141 & .0152 & .0092 & .0105 & .0197 & .0092 & .0023 & .0019 & .0040\end{array}$

$\begin{array}{llllllllllllllllll}19-24 & .0017 & .0010 & .0012 & .0005 & .0051 & .0090 & .0035 & .0019 & .0010 & .0005 & .0016 & .0028 & .0005 & .0000 & .0000 & .0007\end{array}$

$\begin{array}{llllllllllllllllll}>24 & .0004 & .0000 & .0001 & .0001 & .0014 & .0023 & .0013 & .0003 & .0000 & .0000 & .0003 & .0007 & .0004 & .0001 & .0000 & .0001\end{array}$

(mph) N NNE NE ENE E $\quad$ ESE SE SSE S SSW SW WSW $W$ WNW NW NNW

$\begin{array}{lllllllllllllllll}1-3 & .0000 & .0000 & .0000 & .0000 & .0000 & .0000 & .0000 & .0000 & .0000 & .0000 & .0000 & .0000 & .0000 & .0000 & .0000 & .0000\end{array}$

$\begin{array}{lllllllllllllllll}4-7 & .0060 & .0022 & .0048 & .0097 & .0099 & .0033 & .0041 & .0032 & .0028 & .0004 & .0007 & .0020 & .0032 & .0025 & .0029 & .0050\end{array}$

$\begin{array}{llllllllllllllllllll}8-12 & .0057 & .0044 & .0105 & .0088 & .0182 & .0103 & .0079 & .0058 & .0083 & .0024 & .0012 & .0026 & .0019 & .0009 & .0008 & .0021\end{array}$

$\begin{array}{llllllllllllllllll}13-18 & .0000 & .0000 & .0000 & .0000 & .0000 & .0000 & .0000 & .0000 & .0000 & .0000 & .0000 & .0000 & .0000 & .0000 & .0000 & .0000\end{array}$

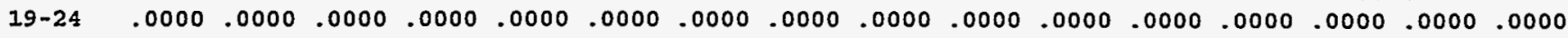

$\begin{array}{llllllllllllllllll}>24 & .0000 & .0000 & .0000 & .0000 & .0000 & .0000 & .0000 & .0000 & .0000 & .0000 & .0000 & .0000 & .0000 & .0000 & .0000 & .0000\end{array}$

\begin{tabular}{|c|c|c|c|c|c|c|c|c|c|c|c|c|c|c|c|c|}
\hline \multicolumn{2}{|c|}{ Wind Speed } & \multicolumn{15}{|c|}{ Wind Directions (Blowing Toward) } \\
\hline (mph) & $\mathrm{N}$ & NNE & NE & ENE & $E$ & ESE & $S E$ & SSE & $\mathbf{s}$ & SSW & SW & WSW & $w$ & WNW & NW & NNW \\
\hline $1-3$ & .0035 & .0013 & .0025 & .0061 & .0068 & .0029 & .0030 & .0026 & .0020 & .0005 & .0005 & .0010 & .0014 & .0015 & .0019 & .0024 \\
\hline $4-7$ & .0050 & .0022 & .0078 & .0161 & .0175 & .0062 & .0074 & .0066 & .0072 & .0007 & .0007 & .0015 & .0027 & .0021 & .0027 & .0035 \\
\hline $8-12$ & .0000 & .0000 & .0000 & .0000 & .0000 & .0000 & .0000 & .0000 & .0000 & .0000 & .0000 & .0000 & .0000 & .0000 & .0000 & .0000 \\
\hline $13-18$ & .0000 & .0000 & .0000 & .0000 & .0000 & .0000 & .0000 & .0000 & .0000 & .0000 & .0000 & .0000 & .0000 & .0000 & .0000 & .0000 \\
\hline $19-24$ & .0000 & .0000 & .0000 & .0000 & .0000 & .0000 & .0000 & .0000 & .0000 & .0000 & .0000 & .0000 & .0000 & .0000 & .0000 & .0000 \\
\hline$>24$ & .0000 & .0000 & .0000 & .0000 & .0000 & .0000 & .0000 & .0000 & .0000 & .0000 & .0000 & .0000 & .0000 & .0000 & .0000 & .0000 \\
\hline
\end{tabular}


Table 27. Joint Frequency Weather Distribution for Portland

1988-92 Summaxy Joint Frequency Table For Portland, OR Port

\begin{tabular}{|c|c|c|c|c|c|c|c|c|c|c|c|c|c|c|c|c|}
\hline \multirow{3}{*}{$\begin{array}{l}\text { Wind Speed } \\
\text { (mph) }\end{array}$} & \multicolumn{16}{|c|}{ A stability } \\
\hline & & & & & & Wir & ad Dire & ections & (Blor & sing $T$ & sward) & & & & & \\
\hline & $\mathrm{N}$ & NNE & $\mathrm{NE}$ & ENE & E & ESE & SE & SSE & $s$ & SSW & SW & WSW & W & WNW & NW & NNW \\
\hline $1-3$ & .0001 & .0001 & .0001 & .0002 & .0004 & .0005 & .0005 & .0004 & .0005 & .0003 & .0001 & .0001 & .0000 & .0000 & .0000 & .0000 \\
\hline $4-7$ & .0000 & .0000 & .0000 & .0001 & .0003 & .0004 & .0006 & .0005 & .0006 & .0003 & .0001 & .0002 & .0000 & .0000 & .0000 & .0000 \\
\hline $8-12$ & .0000 & .0000 & .0000 & .0000 & .0000 & .0000 & .0000 & .0000 & .0000 & .0000 & .0000 & .0000 & .0000 & .0000 & .0000 & .0000 \\
\hline $13-18$ & .0000 & .0000 & .0000 & .0000 & .0000 & .0000 & .0000 & .0000 & .0000 & .0000 & .0000 & .0000 & .0000 & .0000 & .0000 & .0000 \\
\hline $19-24$ & .0000 & .0000 & .0000 & .0000 & .0000 & .0000 & .0000 & .0000 & .0000 & .0000 & .0000 & .0000 & .0000 & .0000 & .0000 & .0000 \\
\hline$>24$ & .0000 & .0000 & .0000 & .0000 & .0000 & .0000 & .0000 & .0000 & .0000 & .0000 & .0000 & .0000 & .0000 & .0000 & .0000 & .0000 \\
\hline
\end{tabular}

B Stability

Wind speed

(mph) $N$ NNE NE ENE E ESE SE SSE S SSW SW WSW W WNW NW NNW

$\begin{array}{lllllllllllllllllll}1-3 & .0005 & .0002 & .0004 & .0006 & .0020 & .0027 & .0025 & .0026 & .0033 & .0009 & .0007 & .0006 & .0003 & .0003 & .0002 & .0002\end{array}$

$\begin{array}{llllllllllllllllll}4-7 & .0003 & .0003 & .0005 & .0012 & .0047 & .0059 & .0051 & .0049 & .0053 & .0021 & .0013 & .0008 & .0007 & .0003 & .0003 & .0002\end{array}$

$\begin{array}{lllllllllllllllllll}8-12 & .0002 & .0002 & .0003 & .0002 & .0026 & .0038 & .0027 & .0020 & .0010 & .0001 & .0001 & .0002 & .0002 & .0001 & .0000 & .0001\end{array}$

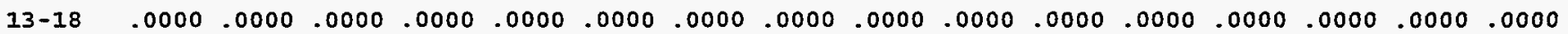

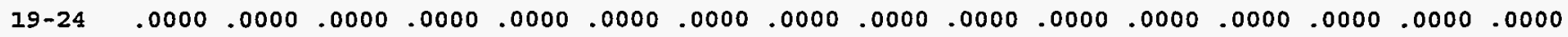

$\begin{array}{llllllllllllllllll}>24 & .0000 & .0000 & .0000 & .0000 & .0000 & .0000 & .0000 & .0000 & .0000 & .0000 & .0000 & .0000 & .0000 & .0000 & .0000 & .0000\end{array}$

\begin{tabular}{|c|c|c|c|c|c|c|c|c|c|c|c|c|c|c|c|c|}
\hline & \multirow{2}{*}{\multicolumn{15}{|c|}{ Wind Directions (Blowing Toward) }} \\
\hline & & & & & & & & & & & & & & & & \\
\hline \multicolumn{2}{|c|}{$\begin{array}{l}\text { Wind Speed } \\
\text { (mph) }\end{array}$} & $\mathrm{NNE}$ & NE & $\mathrm{NE}$ & $E$ & ESE & $\mathrm{SE}$ & SSE & $\mathrm{s}$ & SSW & SW & WSW & W & NNW & W & NNW \\
\hline $1-3$ & 0008 & 03 & 0004 & 06 & 14 & 017 & 16 & 24 & 19 & 30 & 07 & 08 & 08 & 05 & 22 & 1003 \\
\hline $4-7$ & .0009 & .0005 & .0005 & 010 & 030 & 0058 & .0052 & .0041 & .0043 & .0011 & .0013 & 0016 & .0013 & .0010 & .0004 & .0005 \\
\hline $8-12$ & .0010 & .0007 & .0005 & 0005 & 0054 & 0097 & .0083 & .0053 & .0020 & .0002 & .0003 & .0005 & .0013 & .0008 & .0004 & .0003 \\
\hline $13-18$ & .0001 & .0000 & .0001 & .0000 & .0005 & .0008 & .0009 & .0008 & .0003 & .0000 & .0000 & .0000 & .0003 & .0000 & .0000 & .0000 \\
\hline $9-24$ & .0000 & .0000 & .0000 & .0000 & .0000 & .0000 & .0000 & .0000 & .0000 & .0000 & .0000 & .0000 & .0000 & .0000 & .0000 & .0000 \\
\hline$>24$ & .0000 & .0000 & .0000 & .0000 & .0000 & .0000 & .0000 & .0000 & .0000 & .0000 & .0000 & .0000 & .0000 & .0000 & .0000 & .0000 \\
\hline
\end{tabular}

\begin{tabular}{|c|c|c|c|c|c|c|c|c|c|c|c|c|c|c|c|c|}
\hline & \multicolumn{15}{|c|}{ 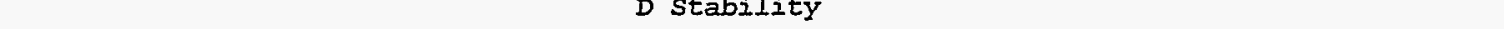 } \\
\hline & & \multicolumn{15}{|c|}{ Wind Directions (Blowing Toward) } \\
\hline \multicolumn{2}{|c|}{$\begin{array}{c}\text { Wind speed } \\
\text { (mph) }\end{array}$} & NNE & NE & ENE & $\mathbf{E}$ & ESE & SE & SSE & $s$ & sSW & SW & พSพ & W & WNW & $N W$ & NNW \\
\hline $1-3$ & .0065 & .0030 & 0025 & 1028 & 48 & 044 & 11 & .0042 & 48 & .0022 & 2 & 24 & 6 & 0045 & 0031 & .0029 \\
\hline $4-7$ & .0183 & .0072 & 2059 & 1069 & 129 & 0125 & .0129 & .0124 & 28 & .0038 & .0041 & 51 & 2 & .0152 & .0085 & .0090 \\
\hline $8-12$ & .0269 & .0153 & 0993 & 0056 & 080 & .0107 & .0174 & .0158 & 075 & .0004 & .0005 & 0009 & .0081 & .0282 & .0172 & .0068 \\
\hline $13-18$ & .0208 & .0173 & .0065 & .0026 & .0028 & .0041 & .0128 & .0166 & .0033 & .0001 & .0002 & 0014 & .0105 & .0329 & .0153 & .0026 \\
\hline-24 & .0032 & .0037 & 2008 & .0002 & .0003 & .0001 & .0007 & .0006 & .0001 & .0000 & .0000 & .0003 & .0054 & .0056 & .0015 & .0001 \\
\hline$>24$ & .0010 & .0010 & 0003 & .0000 & .0000 & .0000 & .0000 & .0000 & .0000 & .0000 & .0000 & .0000 & .0024 & .0021 & .0001 & .0000 \\
\hline
\end{tabular}

$\begin{array}{llllllllllllll}\text { (mph) } N \text { NNE NE ENE } & \text { E } & \text { ESE SE SSE S SNW }\end{array}$

$\begin{array}{lllllllllllllllllllll}1-3 & .0000 & .0000 & .0000 & .0000 & .0000 & .0000 & .0000 & .0000 & .0000 & .0000 & .0000 & .0000 & .0000 & .0000 & .0000 & .0000\end{array}$

$\begin{array}{llllllllllllllllll}4-7 & .0062 & .0022 & .0016 & .0029 & .0058 & .0072 & .0067 & .0048 & .0047 & .0013 & .0013 & .0019 & .0043 & .0074 & .0040 & .0031\end{array}$

$\begin{array}{llllllllllllllllllll}8-12 & .0007 & .0003 & .0001 & .0003 & .0020 & .0041 & .0130 & .0109 & .0029 & .0001 & .0001 & .0003 & .0017 & .0031 & .0013 & .0003\end{array}$

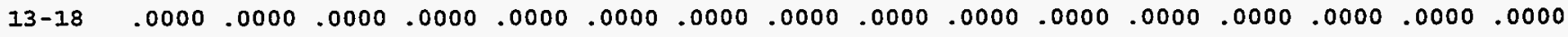

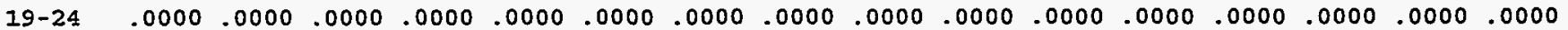

$\begin{array}{llllllllllllllllll}>24 & .0000 & .0000 & .0000 & .0000 & .0000 & .0000 & .0000 & .0000 & .0000 & .0000 & .0000 & .0000 & .0000 & .0000 & .0000 & .0000\end{array}$

\begin{tabular}{|c|c|c|c|c|c|c|c|c|c|c|c|c|c|c|c|c|}
\hline \multirow{2}{*}{\multicolumn{2}{|c|}{ Wind Speed }} & \multicolumn{15}{|c|}{ F stability } \\
\hline & & & & & & & 1 & & & & & & & & & \\
\hline 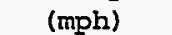 & $\mathrm{N}$ & NE & NE & ENE & $\mathbf{E}$ & ESE & SE & SSE & $\mathbf{s}$ & SSW & SW & WSW & $\mathrm{W}$ & WNW & NW & NNW \\
\hline 3 & .0046 & 019 & 028 & 037 & 04 & & 8 & 85 & 0080 & 34 & & 5 & 77 & 56 & .0032 & .0026 \\
\hline 7 & .00 & 008 & .0012 & .0029 & .0 & 8 & 15 & .0093 & .0070 & .0016 & .0 & .0018 & .08 & .0052 & .0019 & .0015 \\
\hline $8-12$ & .0 & 1000 & 0000 & 1000 & .00 & .0 & .0000 & .0000 & .0000 & .0000 & .0000 & .0000 & .0000 & .0000 & .0000 & .0000 \\
\hline 18 & .0000 & 1000 & 0000 & 000 & .0000 & .0000 & .0000 & .0000 & .0000 & .0000 & .0000 & .0000 & .0000 & .0000 & .0000 & .0000 \\
\hline $9-24$ & .0000 & 1000 & 2000 & 0000 & .0000 & .0000 & .0000 & .0000 & .0000 & .0000 & .0000 & .0000 & .0000 & .0000 & .0000 & .0000 \\
\hline$>24$ & .0000 & 0000 & .0000 & 000 & .0000 & .0000 & .0000 & .0000 & .0000 & .0000 & .0000 & .0000 & .0000 & .0000 & .0000 & .0000 \\
\hline
\end{tabular}


Table 28. Joint Frequency Weather Distribution for Wilmington

1988-92 Summary Joint Erequency Table For wilmington, NC Port

\begin{tabular}{|c|c|c|c|c|c|c|c|c|c|c|c|c|c|c|c|c|}
\hline \multicolumn{2}{|c|}{ Wind Speed } & \multicolumn{15}{|c|}{ Wind Directions (Blowing Toward) } \\
\hline (mph) & $\mathbf{N}$ & NNE & NE & ENE & $\mathbf{E}$ & ESE & SE & SSE & $\mathbf{S}$ & SSW & SW & WSW & $\mathrm{W}$ & WNW & NW & NNW \\
\hline $1-3$ & .0001 & .0002 & .0001 & .0001 & .0001 & .0001 & .0001 & .0001 & .0002 & .0001 & .0001 & .0001 & .0001 & .0001 & .0001 & 0002 \\
\hline $4-7$ & .0004 & .0006 & .0007 & .0007 & .0007 & .0004 & .0003 & .0003 & .0005 & .0004 & .0001 & .0003 & .0003 & .0002 & .0002 & .0001 \\
\hline $8-12$ & .0000 & .0000 & .0000 & .0000 & .0000 & .0000 & .0000 & .0000 & .0000 & .0000 & .0000 & .0000 & .0000 & .0000 & .0000 & .0000 \\
\hline $13-18$ & .0000 & .0000 & .0000 & .0000 & .0000 & .0000 & .0000 & .0000 & .0000 & .0000 & .0000 & .0000 & .0000 & .0000 & .0000 & .0000 \\
\hline $19-24$ & .0000 & .0000 & .0000 & .0000 & .0000 & .0000 & .0000 & .0000 & .0000 & .0000 & .0000 & .0000 & .0000 & .0000 & .0000 & .0000 \\
\hline$>24$ & .0000 & .0000 & .0000 & .0000 & .0000 & .0000 & .0000 & .0000 & .0000 & .0000 & .0000 & .0000 & .0000 & .0000 & .0000 & .0000 \\
\hline
\end{tabular}

wind speed

(mph) N NNE NE ENE $E$ ESE SE SSE S SSW SW WSW W WNW NW NNW

$\begin{array}{llllllllllllllllllll}1-3 & .0008 & .0006 & .0011 & .0012 & .0012 & .0009 & .0009 & .0008 & .0017 & .0007 & .0009 & .0007 & .0012 & .0006 & .0006 & .0006\end{array}$

$\begin{array}{llllllllllllllllll}4-7 & .0014 & .0011 & .0020 & .0029 & .0028 & .0017 & .0018 & .0014 & .0023 & .0015 & .0013 & .0010 & .0015 & .0008 & .0012 & .0010\end{array}$

$\begin{array}{llllllllllllllllll}8-12 & .0013 & .0014 & .0024 & .0032 & .0033 & .0018 & .0010 & .0011 & .0015 & .0012 & .0010 & .0007 & .0016 & .0020 & .0018 & .0015\end{array}$

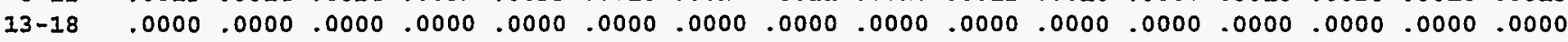

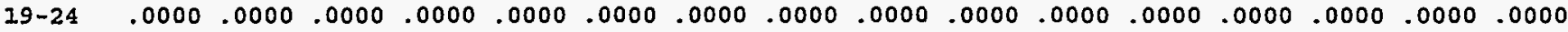

$\begin{array}{llllllllllllllllll}>24 & .0000 & .0000 & .0000 & .0000 & .0000 & .0000 & .0000 & .0000 & .0000 & .0000 & .0000 & .0000 & .0000 & .0000 & .0000 & .0000\end{array}$

\begin{tabular}{|c|c|c|c|c|c|c|c|c|c|c|c|c|c|c|c|c|}
\hline \multirow{3}{*}{$\begin{array}{l}\text { Wind speed } \\
\text { (mph) }\end{array}$} & \multirow{2}{*}{\multicolumn{16}{|c|}{ Wind Directions (Blowing Toward) }} \\
\hline & & & & & & & & & & & & & & & & \\
\hline & $\mathbf{N}$ & NNE & NE & ONE & E & SE & SE & SSE & $\mathbf{s}$ & SSW & SW & WS & $w$ & WN & NW & NNW \\
\hline $1-3$ & 0005 & 003 & 006 & 106 & 07 & 04 & 1003 & 04 & 1007 & 0004 & 0006 & 5 & 15 & \pm & 15 & 5 \\
\hline $4-7$ & .0016 & 3012 & .0018 & .0034 & .0033 & .0018 & .0015 & .0019 & .0033 & 0024 & .0019 & .00 & .0015 & .0013 & .0014 & .0014 \\
\hline $8-12$ & .0057 & 0044 & .0066 & .0079 & .0075 & .0032 & .0025 & .0028 & .0060 & .0045 & .0049 & .0035 & .0044 & .0052 & .0067 & .0066 \\
\hline $13-18$ & .0012 & .0014 & .0019 & .0012 & .0015 & .0006 & .0005 & .0004 & .0007 & .0007 & .0005 & .0005 & .0014 & .0009 & .0009 & .0010 \\
\hline $9-24$ & .0000 & .0000 & .0001 & .0000 & .0000 & .0000 & .0000 & .0000 & .0000 & .0000 & .0000 & .0000 & .0000 & .0000 & .0000 & .0000 \\
\hline$>24$ & .0000 & .0000 & .0000 & .0000 & .0000 & .0000 & .0000 & .0000 & .0000 & .0000 & .0000 & .0000 & .0000 & .0000 & .0000 & .0000 \\
\hline
\end{tabular}

D Stability

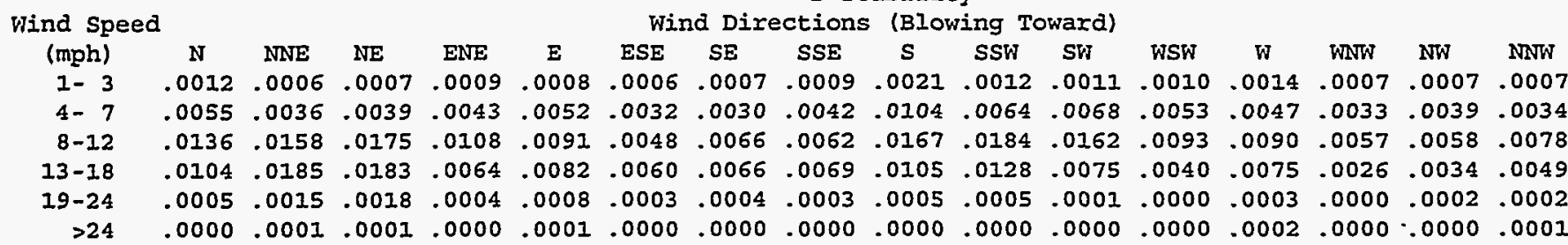

E Stability

Wind speed . Wind Directions (Blowing Toward)

(mph) N NNE NE ENE E ESE SE SSE S SSW SW WSW W WNW NW NNW

$\begin{array}{llllllllllllllllllll}1-3 & .0000 & .0000 & .0000 & .0000 & .0000 & .0000 & .0000 & .0000 & .0000 & .0000 & .0000 & .0000 & .0000 & .0000 & .0000 & .0000\end{array}$

$\begin{array}{llllllllllllllllll}4-7 & .0088 & .0068 & .0076 & .0066 & .0045 & .0017 & .0018 & .0016 & .0056 & .0048 & .0049 & .0043 & .0042 & .0027 & .0037 & .0043\end{array}$

$\begin{array}{lllllllllllllllll}8-12 & .0027 & .0066 & .0110 & .0070 & .0046 & .0029 & .0047 & .0028 & .0050 & .0061 & .0050 & .0016 & .0019 & .0006 & .0008 & .0012\end{array}$

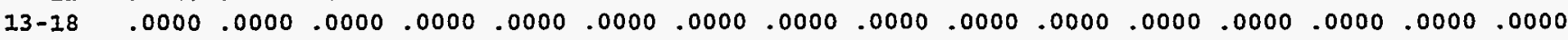

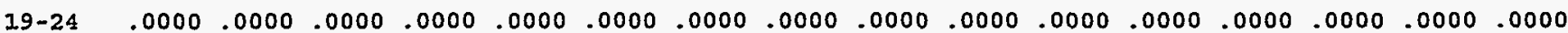

$\begin{array}{lllllllllllllllll}>24 & .0000 & .0000 & .0000 & .0000 & .0000 & .0000 & .0000 & .0000 & .0000 & .0000 & .0000 & .0000 & .0000 & .0000 & .0000 & .0000\end{array}$

Wind speed

F Stability

\begin{tabular}{|c|c|c|c|c|c|c|c|c|c|c|c|c|c|c|c|c|}
\hline \multicolumn{2}{|c|}{ Spe } & \multicolumn{15}{|c|}{ Wind Directions (Blowing Toward) } \\
\hline $\mathrm{mp}$ & $\mathrm{N}$ & INE & NE & ENE & $\mathbf{E}$ & SE & SE & SSE & $\mathbf{s}$ & SSW & SW & & $\mathrm{W}$ & . & NW & NNW \\
\hline & & & & & & 042 & & & 71 & & & & & & & \\
\hline & & & & & & & & & & & & & & & & \\
\hline & & & & & & & & & & & & & & & & \\
\hline & & 0 & 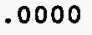 & 0 & & & 0 & & & & & & & & & 100 \\
\hline & & 50 & 1000 & 100 & 00 & & 0 & 0 & 0 & 0 & 0 & & 00 & 00 & Do & .0000 \\
\hline & 000 & 000 & 0000 & 000 & 000 & .0000 & .0000 & .0000 & 3000 & 0000 & .0000 & .0000 & 0000 & .0000 & 0000 & .0000 \\
\hline
\end{tabular}


Table 29. Probability of Rain by Stability Classes

$\begin{array}{ccc}\text { Rainfall Data for the Charleston, } & \text { SC Port } & 1988-1992 \text { Data } \\ \text { Stab Class } & \text { Avg Rate (in/hr) } & \text { Fraction Time } \\ \text { A } & 0.05000 & 0.00264 \\ \text { B } & 0.22400 & 0.00371 \\ \text { C } & 0.16322 & 0.00771 \\ \text { D } & 0.13860 & 0.11099 \\ \text { E } & 0.14740 & 0.00125 \\ \text { F } & 0.07941 & 0.00125\end{array}$

Rainfall Data for the Iong Beach, CA Port 1988-1992 Data Stab Class Avg Rate (in/hr)

Fraction Time

$\begin{array}{ll}\text { A } & 0.00000 \\ \text { B } & 0.00000 \\ \text { C } & 0.14375 \\ \text { D } & 0.07837 \\ \text { E } & 0.06596 \\ \text { F } & 0.07083\end{array}$

0.00000

0.00000

0.00233

0.03648

0.00809

0.00115

Rainfall Data for the Newark, NJ Port Stab Class Avg Rate $(\mathrm{in} / \mathrm{h} x)$

A
B
C
D
F

0.00000

0.05000

0.08571

0.08577

0.08968

0.05000

1988-1992 Data

Fraction Time

0.00000

0.00059

0.00648

0.12139

0.00971

0.00153

Rainfall Data for the Norfolk, VA Port Stab Class Avg Rate $(\mathrm{in} / \mathrm{hr})$

$\begin{array}{ll}\text { A } & 0.00000 \\ B & 0.09167 \\ C & 0.10921 \\ D & 0.47136 \\ E & 0.12574 \\ \text { E } & 0.05000\end{array}$

1988-1992 Data

Fraction Time
0.00000
0.00371
0.00771
0.11099
0.01099
0.00125

Rainfall Data for the Philadelphia, PA Port 1988-1992 Data Stab Class Avg Rate (in/hr)

Exaction Time

$\begin{array}{lll}\text { A } & 0.00000 & 0.00000 \\ \text { B } & 0.17500 & 0.00089 \\ \text { C } & 0.11250 & 0.00431 \\ \text { D } & 0.07520 & 0.12101 \\ \text { E } & 0.10682 & 0.00649 \\ \text { F. } & 0.17500 & 0.00035\end{array}$

Rainfall Data for the Portland, OR Port Stab Class Avg Rate $(\mathrm{in} / \mathrm{hr})$

1988-1992 Data

A
B
C
D
E
F
0.00000
0.11250
0.08125
0.06172
0.06493
0.05000

Fraction Time
0.00000
0.00139
0.01245
0.15220
0.01428
0.00087

Rainfall Data for the Wilmington, NC Port 1988-1992 Data

$\begin{array}{ccc}\text { Stab Class } & \text { Avg Rate }(\text { in } / \mathrm{hr}) & \text { Fraction Time } \\ \text { A } & 0.00000 & 0.00000 \\ \text { B } & 0.18235 & 0.00718 \\ \text { C } & 0.17500 & 0.01937 \\ \text { D } & 0.15048 & 0.12490 \\ \text { E } & 0.16295 & 0.02310 \\ \text { F } & 0.08571 & 0.00244\end{array}$




\subsection{MACCS CALCULATIONS}

All of the MACCS calculations performed during this study used a source term probability of one. Thus, the consequence estimates generated and the probabilities associated with those estimates are conditional on the release of the source term (i.e., the consequence estimates generated by any specific MACCS calculation assume the occurrence of both the event that initiates the accident and also of all subsequent events that contribute to the release of the source term used in that MACCS calculation).

For any source term, a MACCS calculation generates results for all possible combinations of a representative set of weather sequences and a representative set of exposed downwind populations. Since the probability of occurrence of each weather sequence and the exposure probability of each population distribution are known, the variability of consequences due to weather and population, conditional on the accident having occurred, can be displayed by plotting the probability that a consequence magnitude will be equaled or exceeded against consequence magnitude. Such a plot is called a Complementary Cumulative Distribution Functions (CCDF).

Three types of MACCS accident consequence calculations - were performed, base case calculations, high-temperature calculations, and sensitivity calculations. Base case calculations used

- the inventories given in Table 5,

- the release fractions presented in Table 1 for EA Accident Categories 4, 5, and 6,

- the release timings specified in Table 7 (pattern 1 was used for Accident Category 4 releases and pattern 3 for Category 5 and 6 releases),

- one year of hourly meteorological data recorded at the National Weather Service station listed in Table 21, and

- population distributions calculated using POPSEC90 for the dockside and channel locations presented in Table 19.

Population distributions and other site specific data are input to MACCS via a site data file. The site data files constructed for this study and the input data that was the same for all base case calculations are presented in Appendix A.

Input for the high-temperature calculations was identical to that used in the base case calculations except that the EA release fractions for Accident Categories 4, 5, and 6 were replaced by the modified release fractions developed for EIS Accident Categories 4, 5A, 5B, $6 \mathrm{~A}$, and $6 \mathrm{~B}$. The release fraction values used for these EIS Accident Categories are presented in Table 4. 
Sensitivity calculations modified the input used in the base case calculations as required to identify the influence on consequences

- of using variable meteorology recorded offsite at a nearby National Weather Service station rather than constant meteorology recorded onsite at the harbor,

- of using source terms that contained 17 nuclides for which acute health-effect dose conversion factors were not available,

- of neglecting the enhanced shielding likely to be afforded to the population near the harbor by the masonry buildings that typify construction in urban commercial neighborhoods,

- of using release fractions developed for the Modal Study [Fi87] for truck and rail accidents,

- of adding the harbor workforce population to the residential population distribution,

- of modeling accidents that lead to severe fires using a puff and a tail (two segment release) rather than only a puff, and

- of adding ${ }^{60} \mathrm{Co}$ to the inventory so that CRUD release can be calculated.

Both the variable meteorology and the constant meteorology MACCS calculations performed for this study consist of a large number of individual trials (about 1750 trials for each variable meteorology calculation; about 1150 trials for each constant meteorology calculation). By accumulating the results of the individual trials, an expected (mean) result and a CCDF are generated for each output quantity (result) calculated. In addition, for each output calculated, the value of the largest result obtained for any individual trial, the probability of occurrence of that trial, and the weather sequence used in that trial are saved.

\subsection{Acute Health Effects}

The MACCS code can estimate the numbers of fatalities and injuries that might be caused by acute exposures that occur over time periods of a few days (due to a dose to the stomach or the intestines) to one year (due to an internal dose to the lungs). Of the seven acute injuries that MACCS can examine, prodromal vomiting is the acute injury most likely to appear at low doses and dose rates. Because the occurrence of acute health effects would be cause for considerable concern, acute fatalities and cases of prodromal vomiting were calculated for every MACCS run made during this study; and the output of every run was inspected to determine whether either acute effect had occurred. Inspection of all of the MACCS output generated showed that no acute fatalities and no cases of prodromal vomiting were ever predicted to occur for any output quantile (i.e., the mean result, all quantile values on the 
$\mathrm{CCDF}$, and the result obtained for the least favorable weather sequence were all zero for acute fatalities and cases of prodromal vomiting).

\subsection{Base Case Calculations}

The base case calculations estimated the consequences that might result if any one of twelve ship accidents ( 4 inventories, each run with 3 sets of release fractions, the release fractions for accident categories EA4, EA5, and EA6) occurred at any of the twenty-six accident locations examined. Thus, $4 \times 3 \times 26=312$ base case MACCS calculations were performed.

\subsubsection{Typical Output}

Table 30 presents MACCS output for one base case calculation, the calculation for the channel accident location at Newark, NJ (the port of Elizabeth) performed with the BR-2 source term and accident category EA5 release fractions. The first group of results in this table are Health Effect Cases. The first health effect considered is the number of cancer fatalities expected to occur among the population located within one mile $(0-1.6 \mathrm{~km})$ of the accident location. For this population group, the table shows

- that the conditional probability of getting a non-zero result is 0.6818 which means that no cancer fatalities were predicted to occur in this population group for 31.82 percent of the some 1750 trials run during this calculation (conversely, at least a fractional cancer death was predicted to occur in 68.18 percent of the trials);

- that the expected (mean) number of cancer fatalities for this population group is 0.0985 ;

- that the 90th and 99th quantiles of the CCDF of cancer fatalities for this population group have values of 0.0271 and 2.60 ; and

- that the largest number of cancer fatalities predicted for this population group for any weather trial was 17.5 , that this result had a probability of occurrence of $7.65 \times 10^{-5}$, and that the 45 th weather sequence selected by the importance sampling scheme led to this result.

In Table 30, the probability of getting a non-zero result, the mean, 50th, 90th, 95th, 99th, and 99.9th quantile probabilities, and the probability of the peak result are all conditional probabilities. Thus, each of these probabilities assumes that the accident has occurred and has progressed to the source term that generated the results given in the table. To obtain the absolute probability of any of the results presented in Table 30 (the probability per port call of that result), the conditional probability must be multiplied by the probability of occurrence per port call of the source term that produced the specific result. These source term probabilities of occurrence per port call are given in Table 17. Thus, the probability of occurrence per port call of any mean consequence presented in Table 30 is simply the source term probability 

Table 30. Typical Results: Newark Port, Channel Location, BR-2 Inventory, EA5 Release
Fractions, Variable NY Meteorology

\begin{tabular}{|c|c|c|c|c|c|c|c|c|c|c|c|c|}
\hline \multirow[t]{3}{*}{ SITE=NEW } & \multirow[t]{3}{*}{ IOCDCHANNEL } & \multirow[t]{3}{*}{$I N V=B R-2$} & \multicolumn{3}{|c|}{ ST=EA5 $\quad$ VAR MET $=$ NYC } & & & & & & & \\
\hline & & & \multirow{2}{*}{$\begin{array}{c}\text { PROB } \\
\text { NON-ZERO }\end{array}$} & & & QUANT & ILES & & & PEAK & PEAK 8 & EAK \\
\hline & & & & MEAN & $50 \mathrm{TH}$ & $90 \mathrm{TH}$ & $.95 \mathrm{TH}$ & $99 \mathrm{TH}$ & $99.9 \mathrm{TH}$ & cons & PROB I & RIAL \\
\hline HEALTH EFE & ECTS CASES & & & & & & & & & & & \\
\hline CAN FAT/T & TAL & $0-1.6 \mathrm{kM}$ & 0.6818 & $9.85 \mathrm{E}-02$ & $2.32 E-06$ & $2.71 E-02$ & $2.60 \Sigma-01$ & $2.60 E+00$ & $6.86 E+00$ & $1.75 \mathrm{E}+01$ & $7.65 \mathrm{E}-05$ & 45 \\
\hline CAN FAT/T & DTAL & $0-8.1 \mathrm{kM}$ & 0.8854 & $6.55 \mathrm{E}-01$ & $8.02 E-03$ & $1.34 E+00$ & $2.64 E+00$ & $1.18 E+01$ & $2.07 E+01$ & $3.86 \mathrm{E}+01$ & $7.65 E-05$ & 45 \\
\hline CAN FAT/T & DTAL & $0-16.1 \mathrm{kM}$ & 0.9686 & $1.38 \mathrm{E}+00$ & $1.23 E-01$ & $3.69 \mathrm{E}+00$ & $6.058+00$ & $2.29 E+01$ & $3.51 \mathrm{E}+01$ & $5.23 E+01$ & $1.16 \mathrm{E}-05$ & 44 \\
\hline CAN FAT/T & DTAL & $0-80.5 \mathrm{kM}$ & 1.0000 & $2.90 \mathrm{E}+00$ & $1.22 \mathrm{E}+00$ & $7.38 \mathrm{E}+00$ & $1.178+01$ & $2.91 E+01$ & $3.89 \mathrm{E}+01$ & $5.53 E+01$ & $7.65 \mathrm{E}-05$ & 45 \\
\hline POPULATION & DOSE (SV) & & & & & & & & & & & \\
\hline EDEKBODY & TOT IIF & $0-1.6 \mathrm{kM}$ & 0.6818 & $2.36 E+00$ & $5.22 \mathrm{E}-05$ & $6.05 E-01$ & $6.11 E+00$ & $6.21 E+01$ & $1.74 E+02$ & $4.21 E+02$ & $7.65 \mathrm{E}-05$ & 45 \\
\hline EDEKBODY & TOT IIF & $0-3.2 \mathrm{kM}$ & 0.8032 & $4.92 E+00$ & $6.63 E-04$ & $2.99 E+00$ & $2.03 E+01$ & $1.178+02$ & $2.82 E+02$ & $6.968+02$ & $7.65 \mathrm{E}-05$ & 45 \\
\hline EDEKBODY & TOT IIF & $0.4 .8 \mathrm{kM}$ & 0.8750 & $8.61 E+00$ & $2.58 E-02$ & $8.94 E+00$ & $4.43 E+01$ & $1.84 E+02$ & $3.96 \mathrm{E}+02$ & $8.57 \mathrm{E}+02$ & $7.65 \mathrm{E}-05$ & 45 \\
\hline EDEKBODY & TOT IIF & $0-6.4 \mathrm{KM}$ & 0.8750 & $1.20 \mathrm{E}+01$ & $1.27 E-01$ & $1.65 E+01$ & $5.36 E+01$ & $2.62 \mathrm{E}+02$ & $4.55 E+02$ & $8.99 \mathrm{E}+02$ & $7.65 \mathrm{E}-05$ & 45 \\
\hline EDEKBODY & TOT IIE & $0.8 .1 \mathrm{kM}$ & 0.8854 & $1.57 E+02$ & $2.08 E-01$ & $3.35 E+01$ & $6.23 E+01$ & $3.23 E+02$ & $5.13 E+02$ & $9.27 \Sigma+02$ & $9.81 \mathrm{E}-05$ & 45 \\
\hline EDEWBODY & TOT LIF & $0-16.1 \mathrm{kM}$ & 0.9686 & $3.30 \mathrm{~B}+02$ & $3.13 E+00$ & $9.40 \mathrm{E}+01$ & $1.48 \mathrm{E}+02$ & $5.48 E+02$ & $8.50 \mathrm{E}+02$ & $1.25 \mathrm{E}+03$ & $1.16 \mathrm{E}-05$ & 44 \\
\hline EDEKBODY & TOT IIE & $0-32.2 \mathrm{kM}$ & 1.0000 & $5.033+01$ & $8.79 E+00$ & $1.31 E+02$ & $2.34 E+02$ & $7.05 E+02$ & $9.38 \mathrm{E}+02$ & $1.32 \mathrm{E}+03$ & $7.65 \mathrm{E}-05$ & 45 \\
\hline EDEWBODY & TOT LIF & $0-48.3 \mathrm{kM}$ & 1.0000 & $5.56 \mathrm{E}+01$ & $1.34 E+01$ & $1.43 E+02$ & $2.45 E+02$ & $7.09 E+02$ & $9.41 E+02$ & $1.33 E+03$ & $7.65 \mathrm{E}-05$ & 45 \\
\hline EDEWBODY & TOT IIF & $0-64.4 \mathrm{kM}$ & 1.0000 & $5.75 \mathrm{E}+01$ & $2.46 E+01$ & $1.47 E+02$ & $2.47 \mathrm{~B}+02$ & $7.09 E+02$ & $9.41 E+02$ & $1.33 \mathrm{E}+03$ & $7.65 E-05$ & 45 \\
\hline EDENBODY & TOT LIF & $0-80.5 \mathrm{kM}$ & 2.0000 & $6.93 \mathrm{E}+01$ & $2.84 \mathrm{E}+01$ & $1.80 \mathrm{E}+02$ & $2.61 E+02$ & $7.09 \mathrm{E}+02$ & $9.41 E+02$ & $1.33 \mathrm{E}+03$ & $7.65 E-05$ & 45 \\
\hline CENTERLINE & DOSE AT SOME I & DISTANCES (SV) & & & & & & & & & & \\
\hline EDENBODY & TOT LIF & $0.1 .6 \mathrm{kM}$ & 1.0000 & $1.17 \mathrm{E}-03$ & $1.60 \mathrm{E}-06$ & $5.29 E-03$ & $6.69 \mathrm{E}-03$ & $1.52 E-02$ & NOT-FOUND & 4.12E-02 & $1.06 \mathrm{E}-03$ & 45 \\
\hline EDEसBODY & TOT LIF & $1.6-3.2 \mathrm{kM}$ & 1.0000 & $3.02 \mathrm{E}-04$ & $2.23 E-06$ & $7.78 E-04$ & $2.39 \mathrm{E}-03$ & $4.68 \mathrm{E}-03$ & NOT-FOUND & $9.71 \mathrm{E}-03$ & $1.06 \mathrm{E}-03$ & 45 \\
\hline EDEWBODY & TOT LIF & $3.2-4.8 \mathrm{gM}$ & 1.0000 & $1.88 \mathrm{E}-04$ & $2.08 E-05$ & $3.57 E-04$ & $1.44 \mathrm{E}-03$ & $2.49 \mathrm{E}-03$ & $3.43 E-03$ & $4.40 \mathrm{E}-02$ & $1.14 E-04$ & 44 \\
\hline EDEFBODY & TOT LIF & $4.8-6.4 \mathrm{kM}$ & 1.0000 & $1.49 \mathrm{E}-04$ & $1.59 E-05$ & $2.33 E-04$ & $9.04 \mathrm{E}-04$ & $2.34 \mathrm{E}-03$ & $2.09 \mathrm{E}-03$ & $3.67 \mathrm{E}-03$ & $1.14 \mathrm{E}-04$ & 44 \\
\hline EDEWBODY & TOT LIF & $6.4-8.1 \mathrm{xM}$ & 1.0000 & $1.298-04$ & $2.42 E-05$ & $2.48 E-04$ & $7.86 \mathrm{E}-04$ & $1.19 \mathrm{E}-03$ & $1.63 \mathrm{E}-03$ & $2.87 \mathrm{E}-03$ & $1.14 \mathrm{E}-04$ & 44 \\
\hline EDEWBODY & TOT LIF & $8.1-16.1 \mathrm{kM}$ & 1.0000 & $9.12 \mathrm{E}-05$ & $3.92 E-05$ & $2.31 E-04$ & $3.60 \mathrm{E}-04$ & $5.58 \mathrm{E}-04$ & $6.90 \mathrm{E}-04$ & $1.19 \mathrm{E}-03$ & $2.008-04$ & 43 \\
\hline EDEKTBODY & TOT IIP & $16.1-32.2 \mathrm{kM}$ & 1.0000 & $3.74 E-05$ & $1.99 E-05$ & $9.87 \mathrm{~B}-05$ & $1.14 \mathrm{E}-04$ & $1.59 \mathrm{E}-04$ & $2.67 E-04$ & $5.32 E-04$ & $2.00 E-04$ & 97 \\
\hline EDEWBODY & TOT LIE & $32.2-48.3 \mathrm{kM}$ & 1.0000 & $2.35 \mathrm{E}-05$ & $3.205-05$ & $5.46 E-05$ & $7.708-05$ & NOT-FOUND & NOT-FOUND & $1.54 \mathrm{E}-04$ & $4.05 \mathrm{z}-02$ & 96 \\
\hline EDEWBODY & TOT LIF & $48.3-64.4 \mathrm{kM}$ & 1.0000 & $1.37 E-05$ & $6.15 E-06$ & $2.34 \mathrm{E}-05$ & $4.86 \mathrm{E}-05$ & NOT-FOUND & NOT-FOUND & $1.21 \mathrm{E}-04$ & $4.05 \mathrm{E}-02$ & 96 \\
\hline EDEWBODY & TOT LIF & $64.4-80.5 \mathrm{kM}$ & 1.0000 & $9.88 \mathrm{E}-05$ & $1.02 E-04$ & $1.138-04$ & $3.18 E-04$ & $-1.31 E-04$ & NOT-FOUND & $1.31 \mathrm{E}-04$ & $9.39 E-03$ & 17 \\
\hline EDEWBODY & POP. DOSE (SV) & $0-8.1 x$ & KM & & & & & & & & & \\
\hline TOTAL LON & 5-TERM PATHWAY: & S DOSE & 0.8043 & $1.57 E+01$ & $2.08 E-01$ & $3.348+01$ & $6.23 E+01$ & $3.23 \mathrm{E}+02$ & $5.13 E+02$ & $9.26 E+02$ & $9.81 E-05$ & 45 \\
\hline LONG-TERM & DIRECT EXPOSU & RE PATHWAYS & 0.7941 & $1.57 E+01$ & $2.00 E-01$ & $3.33 E+01$ & $6.22 \mathrm{~B}+01$ & $3.23 E+02$ & $5.13 E+02$ & $9.26 \mathrm{E}+02$ & $9.81 z-05$ & 45 \\
\hline TOTAL ING & ESTION PATHWAY & S DOSE & 0.8043 & $3.22 E-02$ & $1.55 E-03$ & $6.70 \mathrm{E}-02$ & $1.42 \mathrm{E}-01$ & $3.00 \mathrm{E}-01$ & $3.02 E+00$ & $4.93 \mathrm{E}+00$ & $9.20 E-05$ & 10 \\
\hline LOXG-TERM & GROUNDSEINE D & OSE & 0.7941 & $1.56 \mathrm{E}+01$ & $2.008-01$ & $3.33 E+01$ & $6.21 E+01$ & $3.23 E+02$ & $5.13 \mathrm{E}+02$ & $9.22 \mathrm{E}+02$ & $9.81 E-05$ & 45 \\
\hline LONG-TERM & RESUSPENSION & DOSE & 0.7941 & $6.46 \mathrm{E}-02$ & $8.008-04$ & $1.34 \mathrm{E}-01$ & $2.62 E-02$ & $1.18 \mathrm{E}+00$ & $2.06 E+00$ & $3.82 E+00$ & $7.65 E-05$ & 45 \\
\hline POP. DEPE & DDENT DECONTAM & IINATION DOSE & 0.0000 & $0.00 E+00$ & $0.00 E+00$ & $0.00 E+00$ & $0.00 \mathrm{E}+00$ & $0.00 \mathrm{E}+00$ & $0.00 \mathrm{E}+00$ & $0.00 \mathrm{E}+00$ & $0.00 \mathrm{E}+00$ & 0 \\
\hline AREA DEPE & NDENT DECONTAM & IINATION DOSE & 0.0000 & $0.00 E+00$ & $0.00 E+00$ & $0.00 \mathrm{~B}+00$ & $0.00 \mathrm{E}+00$ & $0.00 \mathrm{E}+00$ & $0.00 \mathrm{E}+00$ & $0.00 E+00$ & $0.00 \mathrm{E}+00$ & 0 \\
\hline MILK DIRE & CT-DEPOSITION & DOSE & 0.4319 & $5.13 E-03$ & $0.00 E+00$ & $1.08 \mathrm{E}-02$ & $2.66 \pm-02$ & $4.79 \mathrm{E}-02$ & $5.05 E-01$ & $6.88 \mathrm{E}-01$ & $9.20 \mathrm{E}-05$ & 10 \\
\hline CROP DIRE & CT-DEPOSITION & DOSE & 0.4319 & $2.08 \mathrm{E}-02$ & $0.00 \mathrm{E}+00$ & $4.22 E-02$ & $8.60 \Xi-02$ & $2.49 E-02$ & $2.26 \mathrm{E}+00$ & $4.21 E+00$ & $9.20 E-05$ & 10 \\
\hline MILK ROOT & -UETAKE DOSE & & 0.8043 & $1.80 \mathrm{E}-03$ & $7.56 \mathrm{E}-05$ & $2.72 E-03$ & $8.46 \Xi-03$ & $3.22 \mathrm{E}-02$ & $5.11 E-02$ & $7.75 E-02$ & $1.99 \mathrm{E}-04$ & 45 \\
\hline CROP ROOT & -UPTAKE DOSE & & 0.8043 & $3.97 \mathrm{E}-03$ & $1.91 E-04$ & $6.32 E-03$ & $1.61 \mathrm{E}-02$ & $7.43 \mathrm{E}-02$ & $1.12 \mathrm{E}-01$ & $1.71 E-01$ & $9.20 \mathrm{E}-05$ & 45 \\
\hline WATER ING & ESTION DOSE & & 0.8018 & $5.02 E-04$ & $1.46 \mathrm{E}-05$ & $9.26 E-04$ & $2.33 E-03$ & $9.82 \mathrm{E}-03$ & $2.19 \mathrm{E}-02$ & $4.22 E-02$ & $8.95 \mathrm{E}-06$ & 44 \\
\hline EDEWBODY & POP. DOSE (SV & $0-80.5 \mathrm{~K}$ & EM & & & & & & & & & \\
\hline TOTAL LON & G-TERM PATHWAY & S DOSE & 0.9943 & $6.92 \mathrm{E}+01$ & $2.84 E+02$ & $1.808+02$ & $2.61 E+02$ & $7.09 \mathrm{E}+02$ & $9.41 E+02$ & $2.33 \mathrm{E}+03$ & $7.65 \mathrm{E}-05$ & 45 \\
\hline LONG-TERM & DIRECT EXPOSU & RE PATHWAYS & 0.9942 & $6.75 \mathrm{E}+01$ & $2.64 \mathrm{E}+01$ & $1.78 E+02$ & $2.57 E+02$ & $7.09 \mathrm{E}+02$ & $9.41 E+02$ & $1.33 E+03$ & $7.65 \mathrm{E}-05$ & 45 \\
\hline TOTAL ING & ESTION PATHWAY & S DOSE & 0.9943 & $1.705+00$ & $2.50 E-02$ & $6.02 E+00$ & $8.37 E+00$ & $1.07 E+01$ & $1.24 \mathrm{E}+01$ & $2.66 \mathrm{E}+02$ & $9.94 E-06$ & 25 \\
\hline LONG-TERH & GROUNDSHINE D & OSE & 0.9942 & $6.72 E+01$ & $2.61 E+01$ & $1.77 E+02$ & $2.57 \mathrm{E}+02$ & $7.09 \mathrm{E}+02$ & $9.41 E+02$ & $1.32 \mathrm{E}+03$ & $7.65 \mathrm{E}-05$ & 45 \\
\hline LONG-TERM & RESUSPENSION & DOSE & 0.9942 & $2.785-01$ & $1.09 E-01$ & $7.32 E-01$ & $1.14 E+00$ & $2.87 E+00$ & $3.89 E+00$ & $5.478+00$ & $7.65 \mathrm{E}-05$ & 45 \\
\hline POP. DEPE & NDENT DECONTAM & IINATION DOSE & 0.0000 & $0.00 E+00$ & $0.00 E+00$ & $0.00 E+00$ & $0.00 \mathrm{E}+00$ & $0.00 E+00$ & $0.00 E+00$ & $0.00 \mathrm{E}+00$ & $0.00 \mathrm{E}+00$ & 0 \\
\hline AREA DEPE & NDENT DECONTAM & IINATION DOSE & 0.0000 & $0.00 E+00$ & $0.00 E+00$ & $0.00 E+00$ & $0.00 E+00$ & $0.00 E+00$ & $0.00 E+00$ & $0.00 \mathrm{E}+00$ & $0.00 \mathrm{E}+00$ & 0 \\
\hline MILK DIRE & CT-DEPOSITION & DOSE & 0.5503 & $3.04 E-01$ & $3.65 E-03$ & $9.26 \mathrm{E}-01$ & $1.12 \mathrm{E}+00$ & $1.62 \mathrm{E}+00$ & $2.09 E+00$ & $2.40 \mathrm{E}+00$ & $9.94 \mathrm{E}-06$ & 25 \\
\hline CROP DIRE & CT-DEPOSITION & DOSE & 0.5503 & $1.25 E+00$ & $1.16 E-02$ & $5.20 \mathrm{~B}+00$ & $6.588+00$ & $1.01 E+01$ & $1.12 \mathrm{E}+01$ & $1.38 E+01$ & $9.94 \mathrm{E}-06$ & 25 \\
\hline MILK ROOT & -UPTAKE DOSE & & 0.9943 & $4.00 E-02$ & $5.06 E-02$ & $7.25 E-02$ & $7.87 \mathrm{E}-02$ & $9.51 \mathrm{E}-02$ & NOT-FOUND & $1.12 E-01$ & $3.53 \mathrm{E}-03$ & 96 \\
\hline CROP ROOT & -UPTAKE DOSE & & 0.9943 & $8.85 E-02$ & $1.02 E-01$ & $2.38 \mathrm{E}-01$ & $1.58 \mathrm{E}-01$ & $2.12 \mathrm{E}-01$ & NOT-FOUND & $2.47 E-01$ & $3.53 \mathrm{z}-03$ & 96 \\
\hline WATER ING & ESTION DOSE & & 0.9731 & $1.46 \Xi-02$ & $7.31 E-03$ & $3.39 E-02$ & $3.85 E-02$ & $5.26 E-02$ & NOT-FOUND & $6.97 E-02$ & $3.46 \mathrm{E}-03$ & 96 \\
\hline ECONONIC C & OST MEASURES & $-8.1 \mathrm{~K}$ & KM & & & & & & & & & \\
\hline TOTAL ECO & NOMIC COSTS & & 0.0038 & $1.80 E+01$ & $0.00 E+00$ & $0.00 E+00$ & $0.00 E+00$ & $0.00 E+00$ & UND & $5.648+03$ & $2.44 \mathrm{E}-03$ & 16 \\
\hline POP. DEPE & NDENT COSTS & & 0.0000 & $0.00 E+00$ & $0.00 E+00$ & $0.00 \mathrm{E}+00$ & $0.00 E+00$ & $0.00 E+00$ & $0.00 E+00$ & $0.00 \mathrm{E}+00$ & $0.00 \mathrm{E}+00$ & 0 \\
\hline AREA DEPE & NDENT COSTS & & 0.0038 & $1.80 \mathrm{E}+01$ & $0.00 E+00$ & $0.00 E+00$ & $0.00 E+00$ & $0.00 E+00$ & NOT-FOUND & $5.64 E+03$ & $2.44 \mathrm{E}-03$ & 16 \\
\hline MILK DISE & OSAL $\cos T$ & & 0.0038 & $4.75 E+00$ & $0.00 \mathrm{E}+00$ & $0.00 E+00$ & $0.00 E+00$ & $0.00 \mathrm{E}+00$ & NOT-FOUND & $1.49 E+03$ & $2.44 E-03$ & 16 \\
\hline CROP DISE & OSAL COST & & 0.0038 & $1.33 E+01$ & $0.00 E+00$ & $0.00 E+00$ & $0.00 E+00$ & $0.00 E+00$ & NOT-FOUND & $4.15 E+03$ & $2.44 \mathrm{E}-03$ & 16 \\
\hline ECONONIC C & OST MEASURES ( & $0.5 \mathrm{~K}$ & $\mathrm{KM}$ & & & & & & & & & \\
\hline TOTAL ECC & NOMIC COSTS & & 0.0038 & $1.80 E+01$ & $0.00 E+00$ & $0.00 E+00$ & $0.00 \mathrm{E}+00$ & $0.00 E+00$ & NOT-FOUND & $5.64 E+03$ & $2.44 E-03$ & 16 \\
\hline POP. DEPE & NDENT COSTS & & 0.0000 & $0.00 \mathrm{E}+00$ & $0.00 E+00$ & $0.00 E+00$ & $0.00 E+00$ & $0.00 \mathrm{E}+00$ & $0.00 \mathrm{E}+00$ & $0.00 \mathrm{E}+00$ & $0.00 \mathrm{E}+00$ & 0 \\
\hline AREA DEPE & NDENT COSTS & & 0.0038 & $1.80 \mathrm{E}+01$ & $0.002+00$ & $0.00 E+00$ & $0.00 E+00$ & $0.00 E+00$ & NOT-FOUND & $5.64 \mathrm{E}+03$ & $2.44 \mathrm{E}-03$ & 16 \\
\hline AREA DEPE & NDENT DECONTAM & SINATION COST & 0.0000 & $0.00 \mathrm{E}+00$ & $0.00 E+00$ & $0.00 E+00$ & $0.00 E+00$ & $0.00 E+00$ & $0.00 E+00$ & $0.00 \mathrm{z}+00$ & $0.00 E+00$ & 0 \\
\hline AREA DEPE & NDENI INTERDIC & TION COST & 0.0000 & $0.00 E+00$ & $0.00 E+00$ & $0.00 \mathrm{E}+00$ & $0.00 E+00$ & $0.00 \mathrm{E}+00$ & $0.00 \mathrm{E}+00$ & $0.00 \mathrm{E}+00$ & $0.00 E+00$ & 0 \\
\hline AREA DEPI & NDENS CONDEMNA & TTION COST & 0.0000 & $0.00 \mathrm{E}+00$ & $0.00 \Sigma+00$ & $0.00 E+00$ & $0.00 E+00$ & $0.00 E+00$ & $0.00 \mathrm{E}+00$ & $0.00 \mathrm{E}+00$ & $0.00 E+00$ & 0 \\
\hline EVACUATIC & N AND RELOCATI & $\operatorname{con} \cos T$ & 0.0000 & $0.00 E+00$ & $0.00 \mathrm{z}+00$ & $0.00 E+00$ & $0.00 E+00$ & $0.00 \mathrm{E}+00$ & $0.00 \mathrm{E}+00$ & $0.00 E+00$ & $0.00 E+00$ & 0 \\
\hline MILX DISI & OSAI COST & & 0.0038 & $4.75 E+00$ & $0.00 \Xi+00$ & $0.00 \Sigma+00$ & $0.00 E+00$ & $0.00 E+00$ & NOT-FOUND & $1.49 E+03$ & $2.44 E-03$ & 26 \\
\hline CROP DISI & OSAL COST & & 0.0038 & $1.33 \mathrm{E}+01$ & $0.00 \mathrm{E}+00$ & $0.008+00$ & $0.00 E+00$ & $0.00 \mathrm{E}+00$ & NOT-FOUND & $4.15 \mathrm{E}+03$ & $2.44 E-03$ & 26 \\
\hline MaXIMOM LC & NG-TERM ACTIC & DISTANCE (XM) & & & & & & & & & & \\
\hline MILK DISI & OSAI DIST. & & 0.0038 & $6.12 \mathrm{E}-03$ & $0.00 \mathrm{E}+00$ & $0.00 \mathrm{~B}+00$ & $0.00 \mathrm{E}+00$ & $0.00 E+00$ & NOT-FOUND & $1.61 \mathrm{E}+00$ & $3.80 E-03$ & 16 \\
\hline CROP DIS: & OSAL DIST. & & 0.0038 & $6.12 E-03$ & $0.00 E+00$ & $0.00 E+00$ & $0.00 \mathrm{E}+00$ & $0.00 \mathrm{E}+00$ & NOT-FOUND & $1.61 E+00$ & $3.80 \mathrm{E}-03$ & 16 \\
\hline
\end{tabular}


per port call. For the probability of a non-zero result, for consequence quantiles, and for the largest consequence found for any single weather trail (the peak consequence), the absolute probability of occurrence per port call of the listed result is the product of the source term probability per port call and either the probability of the non-zero result, the quantile probability, or the probability of the peak result. For example, the probability per port call of an accident that leads to 2.60 radiation-induced cancer fatalities 20 to 40 years after the time of the accident (the 99 th quantile result) is

$$
\mathrm{P}_{\mathrm{EAS}} \times \mathrm{P}_{99 \text { th Quantile }}=\left(5 \times 10^{-9}\right)(0.01)=5 \times 10^{-11} \text { per port call }
$$

Figure 24 presents the CCDF for cancer fatalities among the population located within one mile of the channel accident location at Newark, NJ. Figure 24 shows that there is one chance in a thousand (probability $=1.0 \mathrm{E}-03$ ) that an accident that leads to an accident category EA5 release from a cask that contains the BR-2 inventory will produce about seven cancer deaths. Thus, the 99.9th quantile of the CCDF has a value of about seven. Inspection of the CCDF also shows that the tail of the distribution has a probability of occurrence of almost 1.0E-04 and a magnitude of about 17 . Of course, these are the values produced by the weather trial that led to the largest result among the full set of weather trials.

Fractional numbers of cancer fatalities are presented in Tabile 30 and are displayed in Figure 24 because MACCS estimates cancer fatalities as the product of an individual cancer risk (the chance that an individual contracts and dies from cancer given a specific radiation exposure) and the number of people who received that exposure. For example, suppose that one hundred thousand people receive radiation exposures so large that each of these people has one chance in a million of contracting and dying from cancer. Then, the number of cancer fatalities that would be expected to occur among this population group 20 to 40 years in the future is $10^{5} \times 10^{-6}=0.1$. Thus, fractional numbers of cancer fatalities are predicted by MACCS whenever the reciprocal of the number of people who receive a given radiation dose is larger than the individual risk of contracting and dying from cancer given that the individual received the dose.

The results presented in Table 30 illustrate patterns that are general over all of the calculations performed. First, both cancer deaths and population dose increase monotonically as distance range increases (e.g., $0-1.6 \mathrm{~km}, 0-8.1 \mathrm{~km}, \ldots, 0-80.5 \mathrm{~km}$ ). Second, the centerline dose to an individual standing under the plume decreases monotonically with increasing distance, as it should, until it reaches the last computational interval $(64.4-80.5 \mathrm{~km})$ where counterintuitively it increases. It increases because, during all calculations, rain was artificially forced to occur when the radioactive plume entered this computational interval in order to ensure that all radioactive particulates in the plume deposit onto the ground before the plume exits the computational grid at $80.5 \mathrm{~km}$ from the accident location. Deposition of all remaining radioactive particulates onto the ground within the last computational interval ensures that all radioactivity that might enter food pathways at some time after the accident does enter those pathways. Third, total population dose is caused almost entirely by long-term groundshine exposures (external direct exposure to radiation emitted by radionuclides 


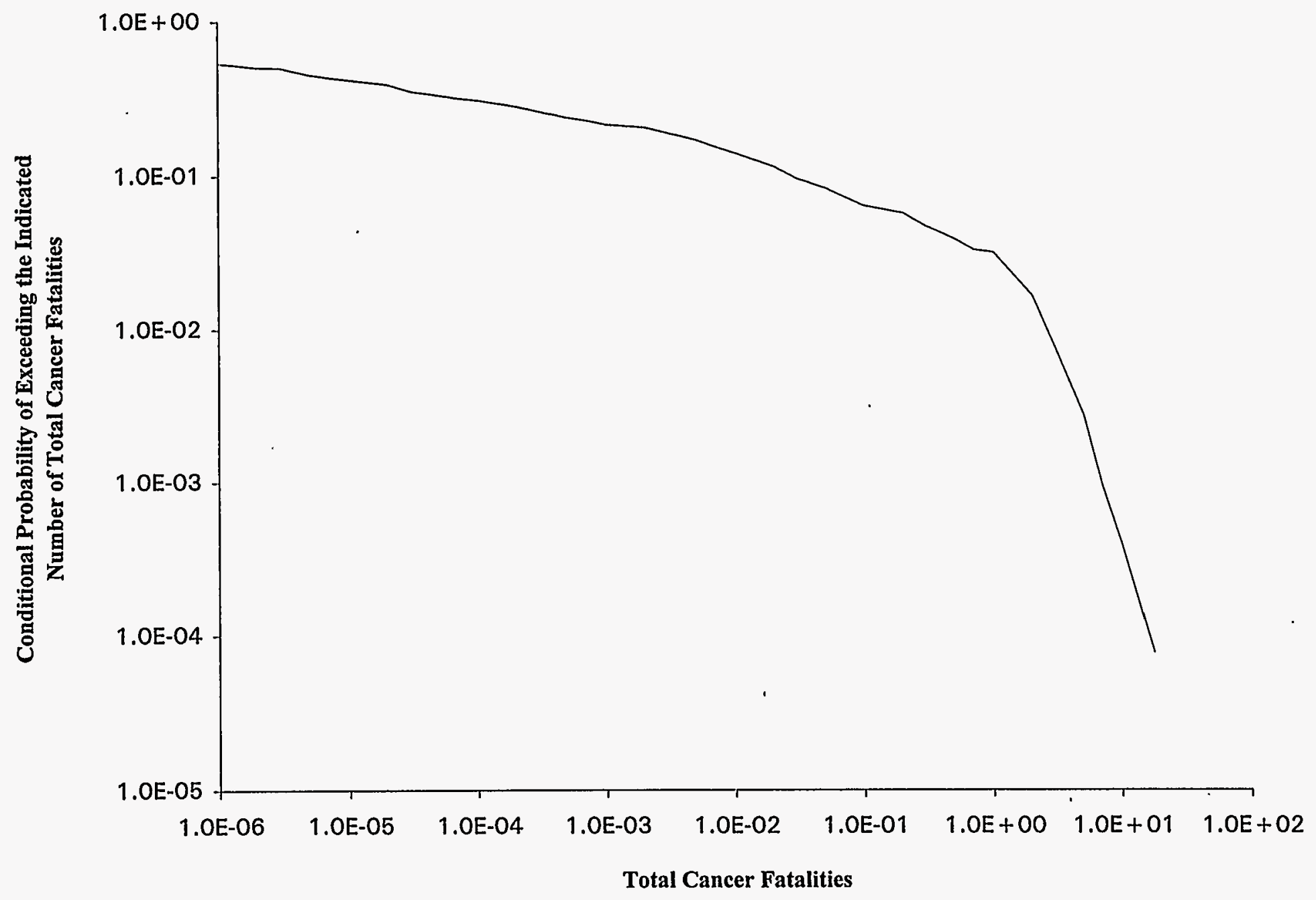

Figure 24. Total Cancer Fatalities, 0-1.6 km, Newark Port, Channel Location, BR-2 Inventory, EA5 Release Fractions, Variable NY Meteorology 
deposited on the ground). Fourth, the economic losses (costs) caused by the accident are very small (expected value of $\$ 18$; peak value of $\$ 5640$ ) and entirely attributable to the disposal of contaminated crops and milk by farms located close to the accident site (the largest disposal distance found was $1.6 \mathrm{~km}$ ).

The values of mean (expected) centerline dose $\left(D_{C L}\right)$ presented in Table 30 are plotted versus distance (d) in Figure 25. The figure shows that on a $\log -\log$ plot, dose decreases linearly with distance with a slope very close to minus one. Therefore, as one would expect, individual centerline dose is inversely proportional to distance $\left[D_{C L}=1 / d\right]$.

Table 30 presents a breakdown by exposure pathways of long-term population dose [calculated as a 50-year wholebody dose by the Effective Dose Equivalent (EDE) method using 50-year dose conversion factors, and thus labeled EDEWBODY POP. DOSE]. Inspection of this breakdown and comparison of the total long-term pathway dose to the total population dose shows

- that total population dose $(69.3 \mathrm{~Sv})$ is almost entirely due to the dose delivered by longterm exposure pathways (69.2 Sv);

- that only a small dose $(0.1 \mathrm{~Sv}=69.3 \mathrm{~Sv}-69.2 \mathrm{~Sv})$ is delivered by short-term (acute) pathways;

- that long-term dose is caused mainly by direct exposure pathways (67.5 Sv) and only secondarily by ingestion pathways $(1.70 \mathrm{~Sv})$;

- that groundshine $(67.2 \mathrm{~Sv})$ causes almost all long-term direct dose and that resuspension (external direct exposure to radiation emitted by radionuclides resuspended from the ground) causes the rest $(0.3 \mathrm{~Sv})$;

- that the dose from radioactivity deposited directly on food crops $(1.25 \mathrm{~Sv})$ or on grass consumed by milk cows ( $0.30 \mathrm{~Sv})$ accounts for most of the ingestion dose; and

- that the rest of the ingestion dose is caused by root uptake (to food crops, $0.09 \mathrm{~Sv}$; to grass and fodder crops, $0.04 \mathrm{~Sv}$ ) with drinking of contaminated water causing only a very small dose $(0.01 \mathrm{~Sv})$.

\subsubsection{Archival Tables}

Results for all of the 312 base case calculations are presented in archival tables in Part B of the Appendix. Because the pattern of result magnitudes discussed in the preceding section was general, the full set of results displayed in Table 30 was pared down during the construction of the archival tables presented in Appendix B. Thus, the archival tables contain results for only a limited set of distance ranges $(0-1.6 \mathrm{~km}, 0-8.1 \mathrm{~km}, 0-16.1 \mathrm{~km}, 0-80.5 \mathrm{~km})$ and only for those long-term dose pathways and cost measures that account for most doses or costs. 


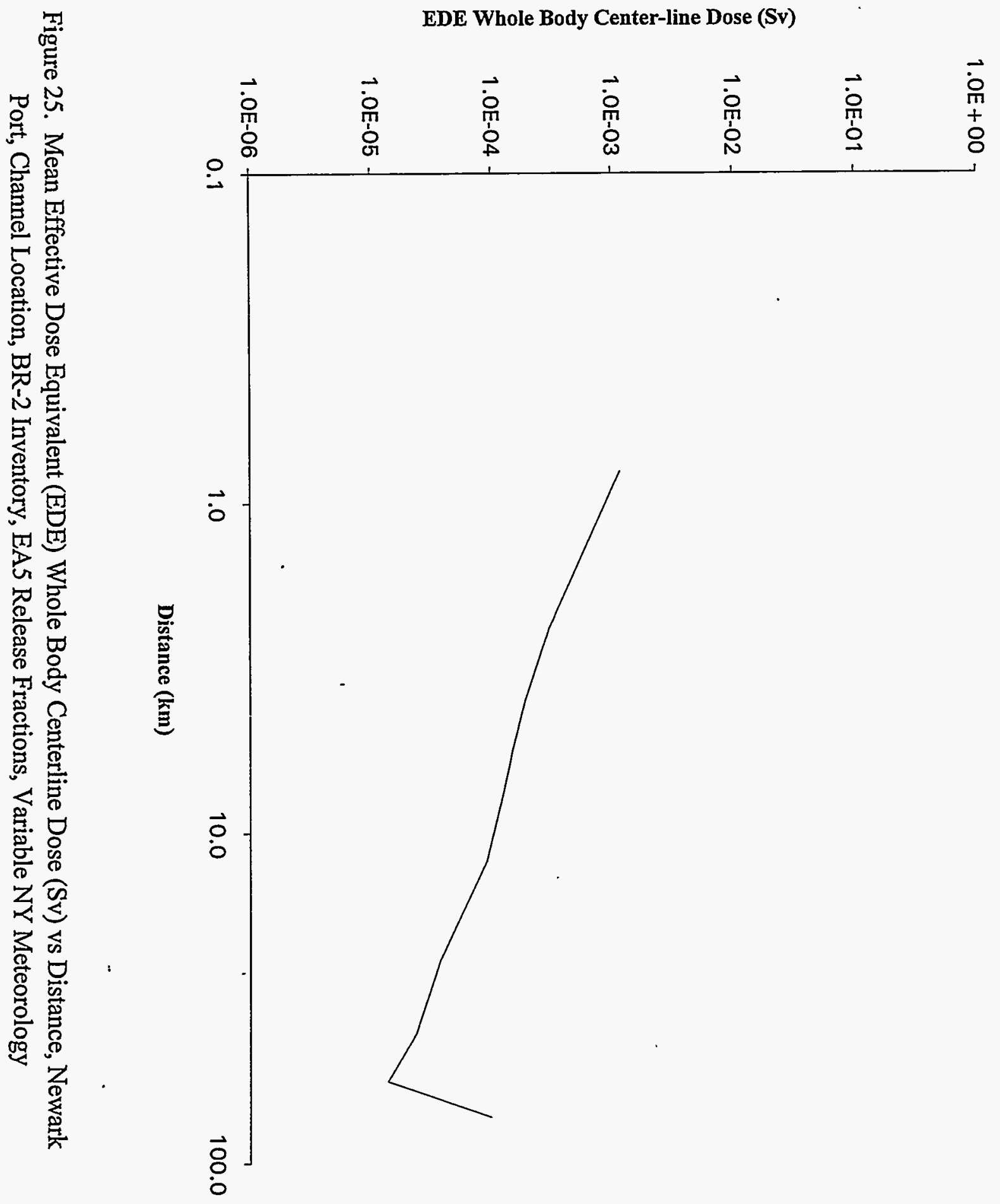




\subsubsection{Principal Base Case Results}

Values for Population Dose, Cancer Fatalities, and Costs for the distance range 0-80 km, and Centerline Dose and Centerline Cancer Risk for the distance range 0-1.6 km are presented in Table 31, Mean (Expected) Values; Table 32, 99.9th Quantile Values; Table 33, Largest (Peak) Result Calculated; and Table 34, Conditional Probability of the Largest Result Calculated. Table 31 shows that the expected total 50-year population dose within 50 miles $(80.5 \mathrm{~km})$ of the accident location varies from a low of $9.72 \times 10^{-6} \mathrm{~Sv}$ for the MOTSU dock calculation that used the TRIGA inventory, EA4 release fractions, and Cape Hatteras weather, to a high of $69.3 \mathrm{~Sv}$ for the Newark channel calculation that used the BR-2 inventory, EA5 release fractions, and New York City weather.

Since the total population within 50 miles of the Newark channel accident location is about 16 million people and typical plumes are about two compass sectors wide, a typical accident plume will expose about two million people to radiation. Thus, for the largest base-case mean result obtained, the average 50-year individual dose over the total exposed population is about $69 \mathrm{~Sv} / 2.0 \times 10^{6}$ people $=3.5 \times 10^{-5} \mathrm{~Sv}$ per person. To place this average, 50-year mean accident dose in perspective, it should be compared to the average 50-year dose that individuals normally receive from natural (e.g., cosmic rays, radon, terrestrial radionuclides) and routine man-made (e.g., medical X-rays) radiation sources. As the average annual dose from natural and routine man-made radiation sources is $3.6 \times 10^{-3} \mathrm{~Sv}$ [BEIR90], an average 50-year dose from natural and man-made sources is $0.18 \mathrm{~Sv}$, which is 5000 times larger than the largest, individual, 50-year mean accident dose presented in Table 31, the mean accident dose that was calculated for the Newark channel accident location using the BR-2 inventory with EA5 release fractions.

Table 33 shows that the largest value (peak result) calculated for the 50-year population dose within 50 miles of any accident location was $1450 \mathrm{~Sv}$ and that this result was obtained for the Newark channel calculation that used the BR-2 inventory, EA6 release fractions, and New York City weather. Dividing by the two million people exposed by the accident gives an average, 50-year individual dose over the exposed population of about $7.3 \times 10^{-4} \mathrm{~Sv}$, which is 250 times smaller than a normal 50-year individual dose from natural and routine man-made radiation sources. In addition, Table 34 shows that the conditional probability of this result was $7.65 \times 10^{-5}$ (conditional on the accident having occurred). Since the probability of this accident occurring is about $6 \times 10^{-10}$ per port call, the chance of having this result is about $5 \times$ $10^{-14}$ per port call.

Table 31 also shows that mean (expected) individual 50-year centerline doses at a distance of 0.5 mile from the accident location (the midpoint of the $0-1.6 \mathrm{~km}$ computational interval) range from a low of $6.04 \times 10^{-8} \mathrm{~Sv}$ for the MOTSU and Norfolk calculations that used the TRIGA inventory, EA4 release fractions, and Cape Hatteras weather, to a high of $1.17 \mathrm{x}$ $10^{-3} \mathrm{~Sv}$ for the Newark calculations that used the BR-2 inventory, EA5 release fractions, and New York City weather. Thus, the largest expected 50-year individual dose is 160 times smaller than a normal 50-year individual dose, which suggests that the mean risk to a 
Table 31. Mean Values of Population Dose, Cancer Fatalities, Costs, Centerline Individual Dose and Centerline Individual Risk for EA Accident Categories

EDE Whole Body Population Dose, 0-80 $\mathrm{km}$ (SV)

\begin{tabular}{lccc} 
& & \multicolumn{3}{c}{ BR-2 } \\
Site/LOC & EA4 & $E A 5$ & $E A 6$ \\
CHA-D & $2.40 E-04$ & $4.15 E+00$ & $4.13 E+00$ \\
CHA-C & $3.78 E-04$ & $4.18 E+00$ & $4.21 E+00$ \\
CNC-D & $4.40 E-04$ & $2.07 E+01$ & $2.21 E+01$ \\
CNC-C & $9.44 E-04$ & $3.31 E+01$ & $3.40 E+01$ \\
GAL-D & $7.26 E-04$ & $1.44 E+01$ & $1.58 E+01$ \\
GAI-C & $3.23 E-04$ & $1.42 E+01$ & $1.55 E+01$ \\
JAC-D & $2.79 E-04$ & $6.82 E+00$ & $6.76 E+00$ \\
JAC-C & $2.58 E-04$ & $5.33 E+00$ & $5.45 E+00$ \\
IOS-D & $2.13 E-03$ & $4.71 E+01$ & $4.82 E+01$ \\
IOS-C & $8.09 E-04$ & $4.26 E+01$ & $4.40 E+01$ \\
MOT-D & $7.24 E-05$ & $2.08 E+00$ & $2.21 E+00$ \\
NEW-D & $2.33 E-03$ & $6.55 E+01$ & $6.51 E+01$ \\
NEW-C & $3.76 E-03$ & $6.93 E+01$ & $6.77 E+01$ \\
NOR-D & $5.52 E-04$ & $8.54 E+00$ & $8.32 E+00$ \\
NOR-C & $3.02 E-04$ & $6.65 E+00$ & $6.64 E+00$ \\
PHI-D & $1.77 E-03$ & $2.81 E+01$ & $2.78 E+01$ \\
PHI-C & $8.48 E-04$ & $2.74 E+01$ & $2.81 E+01$ \\
POR-D & $7.70 E-04$ & $1.17 E+01$ & $1.19 E+01$ \\
POR-C & $5.33 E-04$ & $1.12 E+01$ & $1.15 E+01$ \\
SAV-D & $5.60 E-04$ & $4.91 E+00$ & $5.01 E+00$ \\
SAV-C & $1.34 E-04$ & $3.82 E+00$ & $3.93 E+00$ \\
SEA-C & $1.31 E-04$ & $7.54 E+00$ & $8.29 E+00$ \\
TAC-D & $5.55 E-04$ & $1.73 E+01$ & $1.83 E+01$ \\
TAC-C & $3.87 E-04$ & $1.43 E+01$ & $1.50 E+01$ \\
WIL-D & $3.80 E-04$ & $4.82 E+00$ & $5.02 E+00$ \\
WIL-C & $9.65 E-05$ & $2.07 E+00$ & $2.20 E+00$
\end{tabular}

$\begin{array}{ccc}\text { EA4 } & \text { REF } & \text { EA } \\ 9.55 E-05 & 1.54 E+00 & 1.53 E+00 \\ 1.51 E-04 & 1.55 E+00 & 1.56 E+00 \\ 1.76 E-04 & 7.97 E+00 & 8.51 E+00 \\ 3.77 E-04 & 1.29 E+01 & 1=32 E+01 \\ 2.90 E-04 & 5.45 E+00 & 6.00 E+00 \\ 1.29 E-04 & 5.36 E+00 & 5.89 E+00 \\ 1.11 E-04 & 2.55 E+00 & 2.52 E+00 \\ 1.03 E-04 & 1.99 E+00 & 2.03 E+00 \\ 8.52 E-04 & 1.85 E+01 & 1.89 E+01 \\ 3.23 E-04 & 1.67 E+01 & 1.73 E+01 \\ 2.88 E-05 & 7.45 E-01 & 7.91 E-01 \\ 9.30 E-04 & 2.58 E+01 & 2.56 E+01 \\ 1.50 E-03 & 2.73 E+01 & 2.67 E+01 \\ 2.20 E-04 & 3.25 E+00 & 3.15 E+00 \\ 1.21 E-04 & 2.51 E+00 & 2.50 E+00 \\ 7.08 E-04 & 1.10 E+01 & 1.08 E+01 \\ 3.39 E-04 & 1.07 E+01 & 1.09 E+01 \\ 3.07 E-04 & 4.45 E+00 & 4.50 E+00 \\ 2.13 E-04 & 4.26 E+00 & 4.36 E+00 \\ 2.23 E-04 & 1.80 E+00 & 1.83 E+00 \\ 5.32 E-05 & 1.38 E+00 & 1.42 E+00 \\ 5.21 E-05 & 2.84 E+00 & 3.12 E+00 \\ 2.21 E-04 & 6.67 E+00 & 7.02 E+00 \\ 1.55 E-04 & 5.50 E+00 & 5.73 E+00 \\ 1.51 E-04 & 1.79 E+00 & 1.86 E+00 \\ 3.84 E-05 & 7.47 E-01 & 7.96 E-01\end{array}$

$\begin{array}{lccc} & & \text { OSIRIS } \\ \text { Site/LOC } & \text { EA4 } & \text { EA5 } & \text { EA6 } \\ \text { CHA-D } & 2.84 E-04 & 3.48 E+00 & 3.43 E+00 \\ \text { CHA-C } & 4.66 E-04 & 3.50 E+00 & 3.50 E+00 \\ \text { CNC-D } & 5.28 E-04 & 1.89 E+01 & 2.02 E+01 \\ \text { CNC-C } & 1.19 E-03 & 3.11 E+01 & 3.20 E+01 \\ \text { GAI-D } & 8.78 E-04 & 1.27 E+01 & 1.40 E+01 \\ \text { GAI-C } & 3.69 E-04 & 1.24 E+01 & 1.37 E+01 \\ \text { JAC-D } & 3.28 E-04 & 5.84 E+00 & 5.74 E+00 \\ \text { JAC-C } & 3.01 E-04 & 4.51 E+00 & 4.58 E+00 \\ \text { LOS-D } & 2.71 E-03 & 4.49 E+01 & 4.59 E+01 \\ \text { LOS-C } & 1.02 E-03 & 4.06 E+01 & 4.19 E+01 \\ \text { MOT-D } & 7.35 E-05 & 1.60 E+00 & 1.69 E+00 \\ \text { NEW-D } & 2.97 E-03 & 6.30 E+01 & 6.27 E+01 \\ \text { NEW-C } & 4.81 E-03 & 6.67 E+01 & 6.53 E+01 \\ \text { NOR-D } & 6.82 E-04 & 7.59 E+00 & 7.33 E+00 \\ \text { NOR-C } & 3.68 E-04 & 5.83 E+00 & 5.78 E+00 \\ \text { PHI-D } & 2.25 E-03 & 2.65 E+01 & 2.62 E+01 \\ \text { PHI-C } & 1.06 E-03 & 2.57 E+01 & 2.64 E+01 \\ \text { POR-D } & 9.55 E-04 & 1.04 E+01 & 1.05 E+01 \\ \text { POR-C } & 6.49 E-04 & 9.92 E+00 & 1.01 E+01 \\ \text { SAV-D } & 6.85 E-04 & 3.98 E+00 & 4.04 E+00 \\ \text { SAV-C } & 1.43 E-04 & 3.02 E+00 & 3.09 E+00 \\ \text { SEA-C } & 1.46 E-04 & 6.56 E+00 & 7.22 E+00 \\ \text { TAC-D } & 6.72 E-04 & 1.58 E+01 & 1.67 E+01 \\ \text { TAC-C } & 4.71 E-04 & 1.30 E+01 & 1.35 E+01 \\ \text { WII-D } & 4.60 E-04 & 4.06 E+00 & 4.21 E+00 \\ \text { WII-C } & 1.07 E-04 & 1.63 E+00 & 1.73 E+00\end{array}$

$\begin{array}{ccc}\text { EA4 } & \text { TRIGA } & \text { EA } \\ 2.97 E-05 & 5.32 E-01 & 5.26 E-01 \\ 4.58 E-05 & 5.35 E-01 & 5.37 E-01 \\ 5.43 E-05 & 2.78 E+00 & 2.97 E+00 \\ 1.13 E-04 & 4.52 E+00 & 4.63 E+00 \\ 8.94 E-05 & 1.90 E+00 & 2.08 E+00 \\ 4.13 E-05 & 1.86 E+00 & 2.04 E+00 \\ 3.48 E-05 & 8.84 E-01 & 8.71 E-01 \\ 3.22 E-05 & 6.87 E-01 & 6.99 E-01 \\ 2.54 E-04 & 6.49 E+00 & 6.62 E+00 \\ 9.72 E-05 & 5.86 E+00 & 6.05 E+00 \\ 9.72 E-06 & 2.54 E-01 & 2.70 E-01 \\ 2.77 E-04 & 9.07 E+00 & 9.00 E+00 \\ 4.46 E-04 & 9.60 E+00 & 9.37 E+00 \\ 6.69 E-05 & 1.13 E+00 & 1.09 E+00 \\ 3.70 E-05 & 8.73 E-01 & 8.67 E-01 \\ 2.11 E-04 & 3.84 E+00 & 3.79 E+00 \\ 1.02 E-04 & 3.74 E+00 & 3.83 E+00 \\ 9.32 E-05 & 1.55 E+00 & 1.56 E+00 \\ 6.52 E-05 & 1.48 E+00 & 1.51 E+00 \\ 6.82 E-05 & 6.18 E-01 & 6.28 E-01 \\ 1.75 E-05 & 4.74 E-01 & 4.86 E-01 \\ 1.68 E-05 & 9.86 E-01 & 1.08 E+00 \\ 6.81 E-05 & 2.33 E+00 & 2.45 E+00 \\ 4.75 E-05 & 1.92 E+00 & 2.00 E+00 \\ 4.66 E-05 & 6.19 E-01 & 6.43 E-01 \\ 1.24 E-05 & 2.56 E-01 & 2.72 E-01 \\ & & \end{array}$


Table 31. Mean Values of Population Dose, Cancer Fatalities, Costs, Centerline Individual Dose and Centerline Individual Risk for EA Accident Categories (Continued)

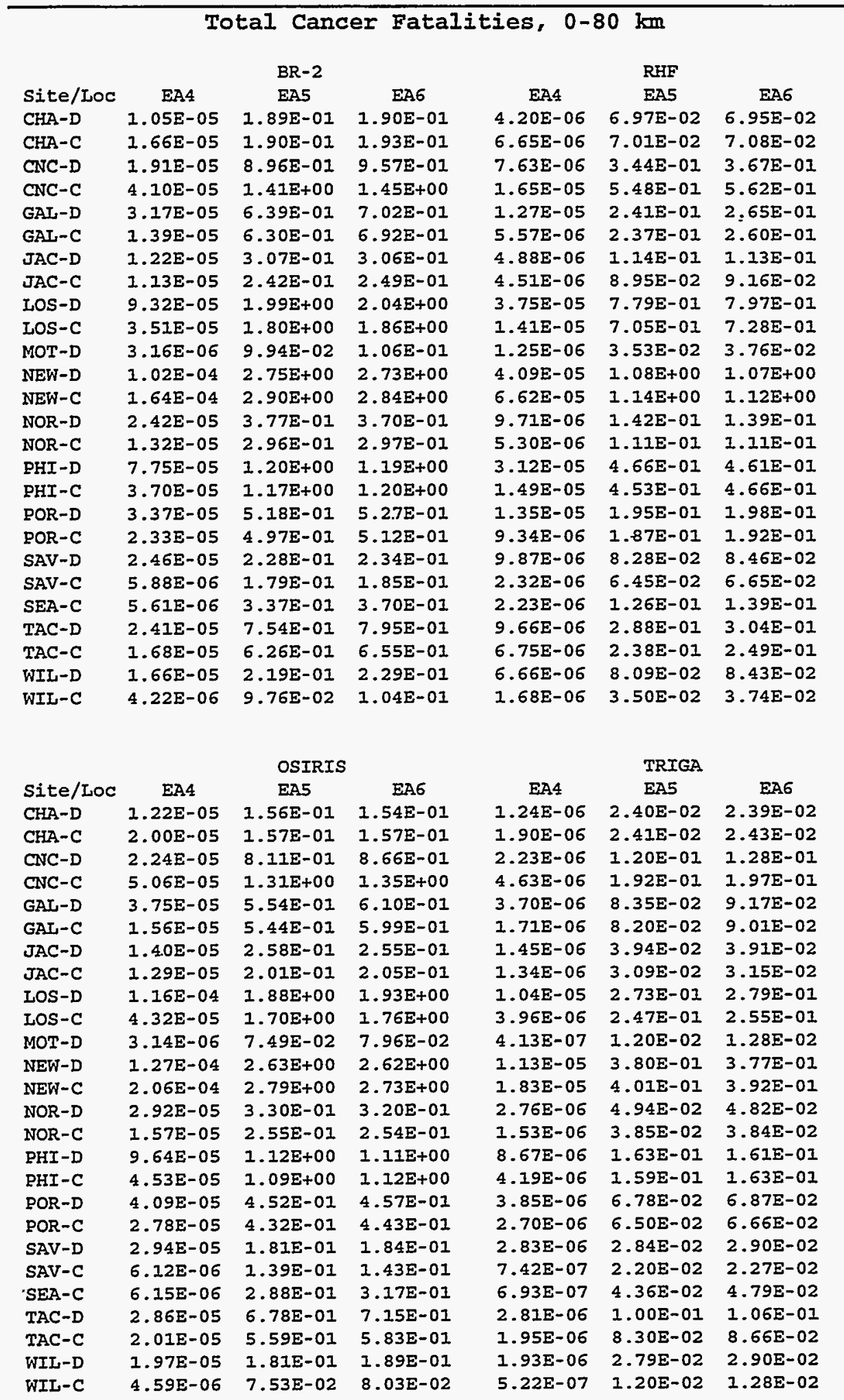


Table 31. Mean Values of Population Dose, Cancer Fatalities, Costs, Centerline Individual Dose and Centerline Individual Risk for EA Accident Categories (Continued)

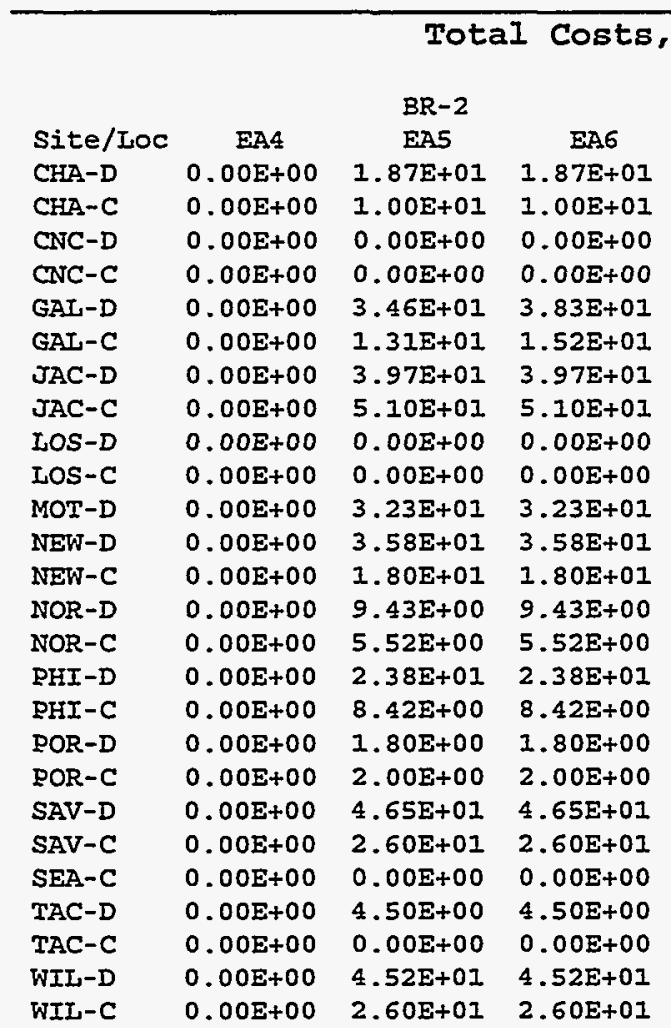

$0-80 \mathrm{~km}$

$\begin{array}{ccc} & R H F & \\ 0.004 & E A 5 & E A 6 \\ 0.00 E+00 & 0.00 E+00 & 0.00 E+00 \\ 0.00 E+00 & 0.00 E+00 & 0.00 E+00 \\ 0.00 E+00 & 0.00 E+00 & 0.00 E+00 \\ 0.00 E+00 & 7.60 E+00 & 7.00 E+00 \\ 0.00 E+00 & 2.50 E+00 & 2.50 E+00 \\ 0.00 E+00 & 0.00 E+00 & 0.00 E+00 \\ 0.00 E+00 & 0.00 E+00 & 0.00 E+00 \\ 0.00 E+00 & 0.00 E+00 & 0.00 E+00 \\ 0.00 E+00 & 0.00 E+00 & 0.00 E+00 \\ 0.00 E+00 & 1.20 E+01 & 1.20 E+01 \\ 0.00 E+00 & 0.00 E+00 & 0.00 E+00 \\ 0.00 E+00 & 0.00 E+00 & 0.00 E+00 \\ 0.00 E+00 & 3.51 E+00 & 3.51 E+00 \\ 0.00 E+00 & 2.06 E+00 & 2.06 E+00 \\ 0.00 E+00 & 3.40 E+00 & 3.40 E+00 \\ 0.00 E+00 & 1.20 E+00 & 1.20 E+00 \\ 0.00 E+00 & 9.02 E-01 & 9.02 E-01 \\ 0.00 E+00 & 9.98 E-01 & 9.98 E-01 \\ 0.00 E+00 & 0.00 E+00 & 0.00 E+00 \\ 0.00 E+00 & 0.00 E+00 & 0.00 E+00 \\ 0.00 E+00 & 0.00 E+00 & 0.00 E+00 \\ 0.00 E+00 & 2.25 E+00 & 2.25 E+00 \\ 0.00 E+00 & 0.00 E+00 & 0.00 E+00 \\ 0.00 E+00 & 1.68 E+01 & 1.68 E+01 \\ 0.00 E+00 & 9.66 E+00 & 9.66 E+00\end{array}$

$\begin{array}{lccc}\text { Site/LOC } & \text { EA4 } & \text { OSIRIS } \\ \text { CHA-D } & 0.00 E+00 & 1.27 E+01 & 1.27 E+01 \\ \text { CHA-C } & 0.00 E+00 & 6.76 E+00 & 6.76 E+00 \\ \text { CNC-D } & 0.00 E+00 & 0.00 E+00 & 0.00 E+00 \\ \text { CNC-C } & 0.00 E+00 & 0.00 E+00 & 0.00 E+00 \\ \text { GAI-D } & 0.00 E+00 & 1.78 E+01 & 2.65 E+01 \\ \text { GAI-C } & 0.00 E+00 & 5.86 E+00 & 9.59 E+00 \\ \text { JAC-D } & 0.00 E+00 & 2.76 E+01 & 2.76 E+01 \\ \text { JAC-C } & 0.00 E+00 & 3.55 E+01 & 3.55 E+01 \\ \text { LOS-D } & 0.00 E+00 & 0.00 E+00 & 0.00 E+00 \\ \text { LOS-C } & 0.00 E+00 & 0.00 E+00 & 0.00 E+00 \\ \text { MOT-D } & 0.00 E+00 & 2.02 E+01 & 2.02 E+01 \\ \text { NEW-D } & 0.00 E+00 & 1.56 E+01 & 1.56 E+01 \\ \text { NEW-C } & 0.00 E+00 & 7.87 E+00 & 7.87 E+00 \\ \text { NOR-D } & 0.00 E+00 & 5.92 E+00 & 5.92 E+00 \\ \text { NOR-C } & 0.00 E+00 & 3.47 E+00 & 3.47 E+00 \\ \text { PHI-D } & 0.00 E+00 & 2.04 E+01 & 2.38 E+01 \\ \text { PHI-C } & 0.00 E+00 & 7.22 E+00 & 8.42 E+00 \\ \text { POR-D } & 0.00 E+00 & 1.80 E+00 & 1.80 E+00 \\ \text { POR-C } & 0.00 E+00 & 2.00 E+00 & 2.00 E+00 \\ \text { SAV-D } & 0.00 E+00 & 3.28 E+01 & 3.28 E+01 \\ \text { SAV-C } & 0.00 E+00 & 1.76 E+01 & 1.76 E+01 \\ \text { SEA-C } & 0.00 E+00 & 0.00 E+00 & 0.00 E+00 \\ \text { TAC-D } & 0.00 E+00 & 4.50 E+00 & 4.50 E+00 \\ \text { TAC-C } & 0.00 E+00 & 0.00 E+00 & 0.00 E+00 \\ \text { WIL-D } & 0.00 E+00 & 2.84 E+01 & 2.84 E+01 \\ \text { WIL-C } & 0.00 E+00 & 1.63 E+01 & 1.63 E+01\end{array}$

$\begin{array}{ccc}\text { EA4 } & \text { TRIGA } & \text { EA5 } \\ 0.00 E+00 & 0.00 E+00 & 0.00 E+00 \\ 0.00 E+00 & 0.00 E+00 & 0.00 E+00 \\ 0.00 E+00 & 0.00 E+00 & 0.00 E+00 \\ 0.00 E+00 & 0.00 E+00 & 0.00 E+00 \\ 0.00 E+00 & 0.00 E+00 & 0.00 E+00 \\ 0.00 E+00 & 0.00 E+00 & 0.00 E+00 \\ 0.00 E+00 & 0.00 E+00 & 0.00 E+00 \\ 0.00 E+00 & 0.00 E+00 & 0.00 E+00 \\ 0.00 E+00 & 0.00 E+00 & 0.00 E+00 \\ 0.00 E+00 & 0.00 E+00 & 0.00 E+00 \\ 0.00 E+00 & 0.00 E+00 & 0.00 E+00 \\ 0.00 E+00 & 0.00 E+00 & 0.00 E+00 \\ 0.00 E+00 & 0.00 E+00 & 0.00 E+00 \\ 0.00 E+00 & 0.00 E+00 & 0.00 E+00 \\ 0.00 E+00 & 0.00 E+00 & 0.00 E+00 \\ 0.00 E+00 & 0.00 E+00 & 0.00 E+00 \\ 0.00 E+00 & 0.00 E+00 & 0.00 E+00 \\ 0.00 E+00 & 0.00 E+00 & 0.00 E+00 \\ 0.00 E+00 & 0.00 E+00 & 0.00 E+00 \\ 0.00 E+00 & 0.00 E+00 & 0.00 E+00 \\ 0.00 E+00 & 0.00 E+00 & 0.00 E+00 \\ 0.00 E+00 & 0.00 E+00 & 0.00 E+00 \\ 0.00 E+00 & 0.00 E+00 & 0.00 E+00 \\ 0.00 E+00 & 0.00 E+00 & 0.00 E+00 \\ 0.00 E+00 & 0.00 E+00 & 0.00 E+00 \\ 0.00 E+00 & 0.00 E+00 & 0.00 E+00\end{array}$


Table 31. Mean Values of Population Dose, Cancer Fatalities, Costs, Centerline Individual Dose and Centerline Individual Risk for EA Accident Categories (Continued)

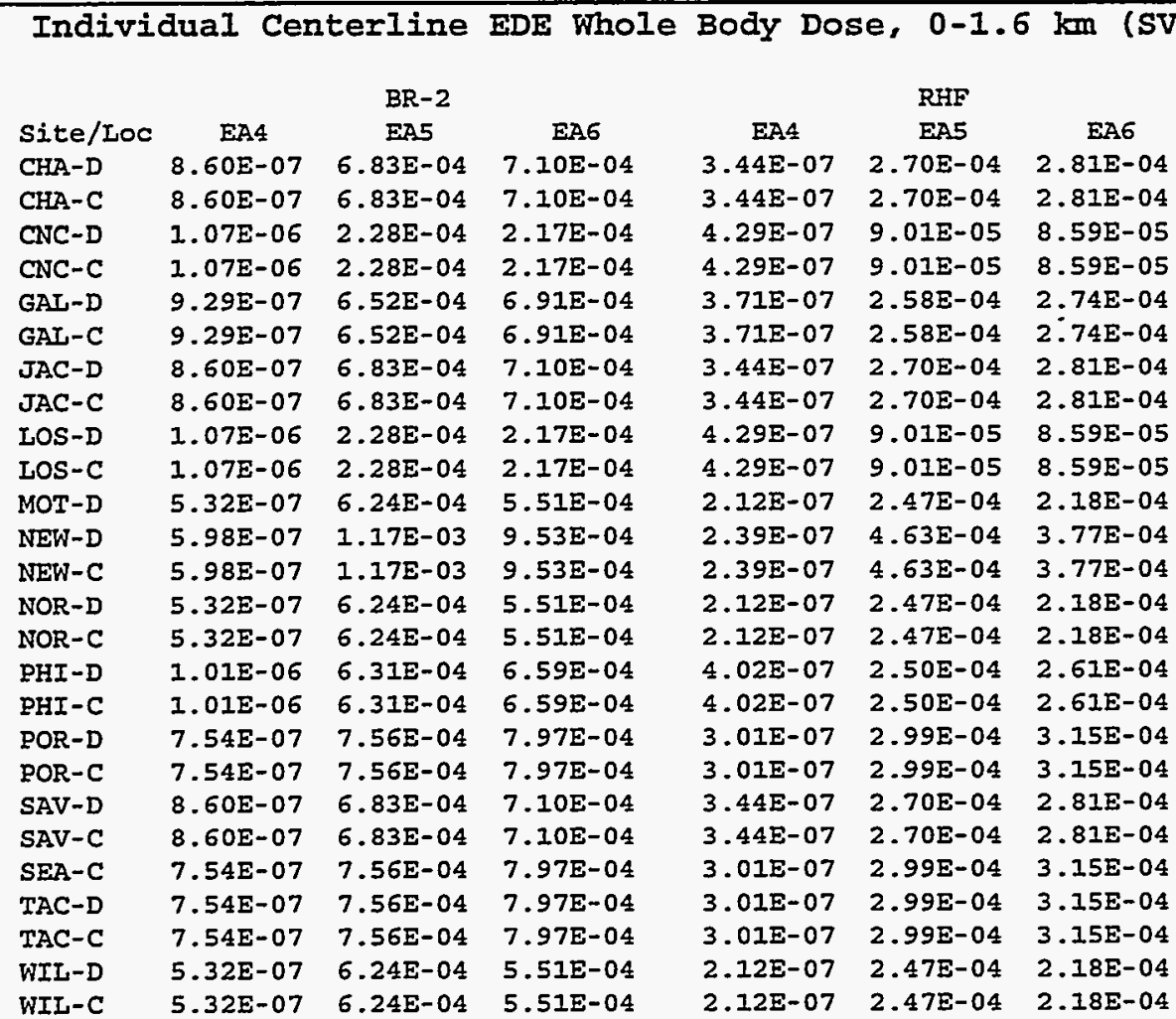

$\begin{array}{lccc}\text { Site/LOC } & \text { EA4 } & \text { OSIRIS } \\ \text { CHA-D } & 1.17 E-06 & 6.63 E-04 & 6.91 E-04 \\ \text { CHA-C } & 1.17 E-06 & 6.63 E-04 & 6.91 E-04 \\ \text { CNC-D } & 1.46 E-06 & 2.21 E-04 & 2.11 E-04 \\ \text { CNC-C } & 1.46 E-06 & 2.21 E-04 & 2.11 E-04 \\ \text { GAL-D } & 1.26 E-06 & 6.33 E-04 & 6.73 E-04 \\ \text { GAI-C } & 1.26 E-06 & 6.33 E-04 & 6.73 E-04 \\ \text { JAC-D } & 1.17 E-06 & 6.63 E-04 & 6.91 E-04 \\ \text { JAC-C } & 1.17 E-06 & 6.63 E-04 & 6.91 E-04 \\ \text { LOS-D } & 1.46 E-06 & 2.21 E-04 & 2.11 E-04 \\ \text { LOS-C } & 1.46 E-06 & 2.23 E-04 & 2.11 E-04 \\ \text { MOT-D } & 7.17 E-07 & 6.06 E-04 & 5.36 E-04 \\ \text { NEW-D } & 8.04 E-07 & 1.13 E-03 & 9.27 E-04 \\ \text { NEW-C } & 8.04 E-07 & 1.13 E-03 & 9.27 E-04 \\ \text { NOR-D } & 7.17 E-07 & 6.06 E-04 & 5.36 E-04 \\ \text { NOR-C } & 7.17 E-07 & 6.06 E-04 & 5.36 E-04 \\ \text { PHI-D } & 1.37 E-06 & 6.13 E-04 & 6.41 E-04 \\ \text { PHI-C } & 1.37 E-06 & 6.13 E-04 & 6.41 E-04 \\ \text { POR-D } & 1.02 E-06 & 7.33 E-04 & 7.75 E-04 \\ \text { POR-C } & 1.02 E-06 & 7.33 E-04 & 7.75 E-04 \\ \text { SAV-D } & 1.17 E-06 & 6.63 E-04 & 6.91 E-04 \\ \text { SAV-C } & 1.17 E-06 & 6.63 E-04 & 6.91 E-04 \\ \text { SEA-C } & 1.02 E-06 & 7.33 E-04 & 7.75 E-04 \\ \text { TAC-D } & 1.02 E-06 & 7.33 E-04 & 7.75 E-04 \\ \text { TAC-C } & 1.02 E-06 & 7.33 E-04 & 7.75 E-04 \\ \text { WIL-D } & 7.17 E-07 & 6.06 E-04 & 5.36 E-04 \\ \text { WIL-C } & 7.17 E-07 & 6.06 E-04 & 5.36 E-04\end{array}$

$\begin{array}{ccc}\text { EA4 } & \text { TRIGA } & \text { EA5 } \\ 9.71 E-08 & 9.51 E-05 & 9.88 E-05 \\ 9.71 E-08 & 9.51 E-05 & 9.88 E-05 \\ 1.21 E-07 & 3.17 E-05 & 3.02 E-05 \\ 1.21 E-07 & 3.17 E-05 & 3.02 E-05 \\ 1.05 E-07 & 9.08 E-05 & 9.62 E-05 \\ 1.05 E-07 & 9.08 E-05 & 9.62 E-05 \\ 9.71 E-08 & 9.51 E-05 & 9.88 E-05 \\ 9.71 E-08 & 9.51 E-05 & 9.88 E-05 \\ 1.21 E-07 & 3.17 E-05 & 3.02 E-05 \\ 1.21 E-07 & 3.17 E-05 & 3.02 E-05 \\ 6.04 E-08 & 8.69 E-05 & 7.67 E-05 \\ 6.81 E-08 & 1.63 E-04 & 1.33 E-04 \\ 6.81 E-08 & 1.63 E-04 & 1.33 E-04 \\ 6.04 E-08 & 8.69 E-05 & 7.67 E-05 \\ 6.04 E-08 & 8.69 E-05 & 7.67 E-05 \\ 1.14 E-07 & 8.78 E-05 & 9.16 E-05 \\ 1.14 E-07 & 8.78 E-05 & 9.16 E-05 \\ 8.57 E-08 & 1.05 E-04 & 1.11 E-04 \\ 8.57 E-08 & 1.05 E-04 & 1.11 E-04 \\ 9.71 E-08 & 9.51 E-05 & 9.88 E-05 \\ 9.71 E-08 & 9.51 E-05 & 9.88 E-05 \\ 8.57 E-08 & 1.05 E-04 & 1.11 E-04 \\ 8.57 E-08 & 1.05 E-04 & 1.11 E-04 \\ 8.57 E-08 & 1.05 E-04 & 1.11 E-04 \\ 6.04 E-08 & 8.69 E-05 & 7.67 E-05 \\ 6.04 E-08 & 8.69 E-05 & 7.67 E-05\end{array}$


Table 31. Mean Values of Population Dose, Cancer Fatalities, Costs, Centerline Individual Dose and Centerline Individual Risk for EA Accident Categories (Concluded)

\begin{tabular}{|c|c|c|c|c|c|c|}
\hline \multirow[b]{3}{*}{ Site/Ioc } & Individual & \multicolumn{2}{|c|}{ - Centerline } & Cancer Risk, & \multicolumn{2}{|c|}{$0-1.6 \mathrm{~km}$} \\
\hline & & $B R-2$ & & & $\mathrm{RHF}$ & \\
\hline & EA4 & EA5 & EAG & EA4 & EAS & EA6 \\
\hline CHA-D & $4.10 \mathrm{E}-08$ & $2.85 E-05$ & $2.96 \mathrm{E}-05$ & $1.66 \mathrm{E}-08$ & $1.13 E-05$ & $1.17 \mathrm{E}-05$ \\
\hline $\mathrm{CHA}-\mathrm{C}$ & $4.10 E-08$ & $2.85 E-05$ & $2.96 E-05$ & $1.66 \mathrm{E}-08$ & $1.13 E-05$ & $1.17 \mathrm{E}-05$ \\
\hline CNC-D & $5.12 E-08$ & $9.50 E-06$ & $9.06 \mathrm{E}-06$ & $2.08 E-08$ & $3.75 \mathrm{E}-06$ & $3.58 \mathrm{E}-06$ \\
\hline CNC-C & $5.12 \mathrm{E}-08$ & $9.50 \mathrm{E}-06$ & $9.06 \mathrm{E}-06$ & $2.08 E-08$ & $3.75 \mathrm{E}-06$ & $3.58 E-06$ \\
\hline GAI-D & $4.43 E-08$ & $2.72 \mathrm{E}-05$ & $2.88 \mathrm{E}-0.5$ & $1.80 E-08$ & $1.08 E-05$ & I.14E-05 \\
\hline GAI-C & $4.43 E-08$ & $2.72 \mathrm{E}-05$ & $2.88 E-05$ & $1.80 \Xi-08$ & $1.08 \mathrm{E}-05$ & $1.14 \mathrm{E}-05$ \\
\hline JAC-D & $4.10 \mathrm{E}-08$ & $2.85 E-05$ & $2.96 E-05$ & $1.66 E-08$ & $1.13 \mathrm{E}-05$ & $1.17 E-05$ \\
\hline JAC-C & $4.10 \mathrm{E}-08$ & $2.85 \mathrm{E}-05$ & $2.96 E-05$ & $1.66 \mathrm{E}-08$ & $1.13 E-05$ & $1.17 \mathrm{E}-05$ \\
\hline IOS-D & $5.12 E-08$ & $9.50 \mathrm{E}-06$ & $9.06 \mathrm{E}-06$ & $2.08 \mathrm{E}-08$ & $3.75 \mathrm{E}-06$ & $3.58 \mathrm{E}-06$ \\
\hline IOS-C & $5.12 \mathrm{E}-08$ & $9.50 \mathrm{E}-06$ & $9.06 E-06$ & $2.08 E-08$ & $3.75 \mathrm{E}-06$ & $3.58 E-06$ \\
\hline MOT-D & $2.5 I E-08$ & $2.60 \mathrm{E}-05$ & $2.30 E-05$ & $1.02 E-08$ & $1.03 E-05$ & $9.08 \mathrm{E}-06$ \\
\hline NEW-D & $2.80 E-08$ & $4.88 \mathrm{E}-05$ & $3.97 \mathrm{E}-0.5$ & $1.14 \mathrm{E}-08$ & $1.93 \mathrm{E}-05$ & $1.57 \mathrm{E}-05$ \\
\hline NEW-C & $2.80 E-08$ & $4.88 \mathrm{E}-05$ & $3.97 \mathrm{E}-05$ & $1.14 E-08$ & $1.93 \mathrm{E}-05$ & $1.57 \mathrm{E}-05$ \\
\hline NOR-D & $2.51 E-08$ & $2.60 \mathrm{E}-05$ & $2.30 E-05$ & $1.02 \mathrm{E}-08$ & $1.03 \mathrm{E}-05$ & $9.08 \mathrm{E}-06$ \\
\hline NOR-C & $2.5 I E-08$ & $2.60 \mathrm{E}-05$ & $2.30 E-05$ & $1.02 E-08$ & $1.03 E-05$ & $9.08 E-06$ \\
\hline PHI-D & $4.80 \mathrm{E}-08$ & $2.63 \mathrm{E}-05$ & $2.75 E-05$ & $1.95 E-08$ & $1.04 E-05$ & $1.09 E-05$ \\
\hline PHI-C & $4.80 E-08$ & $2.63 E-05$ & $2.75 E-05$ & $1.95 E-08$ & $1.04 \mathrm{E}-05$ & $1.09 \mathrm{E}-05$ \\
\hline POR-D & $3.55 \mathrm{E}-08$ & $3.15 E-05$ & $3.32 \mathrm{E}-05$ & $1.44 E-08$ & $1.25 E-05$ & $1.31 \mathrm{E}-05$ \\
\hline POR-C & $3.55 E-08$ & $3.15 E-05$ & $3.32 \mathrm{E}-05$ & $1.44 \mathrm{E}-08$ & $1.25 \mathrm{E}-05$ & $1.31 \mathrm{E}-05$ \\
\hline$S A V-D$ & $4.10 E-08$ & $2.85 \mathrm{E}-05$ & $2.96 \mathrm{E}-05$ & $1.66 \mathrm{E}-08$ & $1.13 \mathrm{E}-05$ & $1.17 \mathrm{E}-05$ \\
\hline$S A V-C$ & $4.10 \mathrm{E}-08$ & $2.85 E-05$ & $2.96 E-05$ & $1.66 \mathrm{E}-08$ & $1.13 E-05$ & $1.17 \mathrm{E}-05$ \\
\hline$S E A-C$ & $3.55 E-08$ & $3.15 E-05$ & $3.32 \mathrm{E}-05$ & $1.44 \mathrm{E}-08$ & $1.25 \mathrm{E}-05$ & $1.31 \mathrm{E}-05$ \\
\hline$T A C-D$ & $3.55 E-08$ & $3.15 E-05$ & $3.32 E-05$ & $1.44 E-08$ & $1.25 \mathrm{E}-05$ & $1.31 \mathrm{E}-0.5$ \\
\hline $\mathrm{TAC}-\mathrm{C}$ & $3.55 E-08$ & $3.15 E-05$ & $3.32 E-05$ & $1.44 E-08$ & $1.25 \mathrm{E}-05$ & $1.31 \mathrm{E}-0.5$ \\
\hline WIL-D & $2.51 E-08$ & $2.60 \mathrm{E}-05$ & $2.30 \mathrm{E}-05$ & $1.02 E-08$ & $1.03 E-05$ & $9.08 E-06$ \\
\hline \multirow[t]{2}{*}{ WIL-C } & $2.51 E-08$ & $2.60 E-05$ & $2.30 \mathrm{E}-05$ & $1.02 E-08$ & $1.03 E-05$ & $9.08 E-06$ \\
\hline & \multicolumn{3}{|c|}{ OSIRIS } & \multicolumn{3}{|c|}{ TRIGA } \\
\hline Site/Loc & EA4 & EA5 & EA6 & EA4 & EAS & EA6 \\
\hline CHA-D & $5.38 \mathrm{E}-08$ & $2.76 \mathrm{E}-05$ & $2.87 E-05$ & $4.29 E-09$ & $3.96 \mathrm{E}-06$ & 4. IIE-06 \\
\hline CHA-C & $5.38 E-08$ & $2.76 E-05$ & $2.87 \mathrm{E}-05$ & $4.29 E-09$ & $3.96 \mathrm{E}-06$ & $4.11 E-06$ \\
\hline CNC-D & $6.73 E-08$ & $9.19 E-06$ & $8.79 E-06$ & $5.36 E-09$ & $1.32 \mathrm{E}-06$ & $1.26 \mathrm{E}-06$ \\
\hline $\mathrm{CNC}-\mathrm{C}$ & $6.73 \mathrm{E}-08$ & $9.19 \mathrm{E}-06$ & $8.79 E-06$ & $5.36 E-09$ & $1.32 \mathrm{E}-06$ & $1.26 E-06$ \\
\hline GAI-D & $5.81 E-08$ & $2.63 E-05$ & $2.80 E-05$ & $4.63 E-09$ & $3.78 \mathrm{E}-06$ & $4.0 I E-06$ \\
\hline GAI-C & $5.81 E-08$ & $2.63 \mathrm{E}-05$ & $2.80 E-05$ & $4.63 E-09$ & $3.78 \mathrm{E}-06$ & 4. $01 E-06$ \\
\hline$J A C-D$ & $5.3 .8 E-08$ & $2.76 \mathrm{E}-05$ & $2.87 E-05$ & $4.29 E-09$ & $3.96 \mathrm{E}-06$ & 4. IIE-06 \\
\hline $\mathrm{JAC}-\mathrm{C}$ & $5.38 E-08$ & $2.76 \mathrm{E}-05$ & $2.87 E-05$ & $4.29 E-09$ & $3.96 E-06$ & $4.11 E-06$ \\
\hline LOS-D & $6.73 E-08$ & $9.19 E-06$ & $8.79 E-06$ & $5.36 \mathrm{E}-09$ & $1.32 \mathrm{E}-06$ & $1.26 \mathrm{E}-06$ \\
\hline LOS-C & $6.73 E-08$ & $9.19 E-06$ & $8.79 \mathrm{E}-06$ & $5.36 \mathrm{E}-09$ & $1.32 \mathrm{E}-06$ & $1.26 \mathrm{E}-06$ \\
\hline MOT-D & $3.28 E-08$ & $2.52 E-05$ & $2.23 E-05$ & $2.64 E-09$ & $3.62 E-06$ & $3.19 E-06$ \\
\hline NEW-D & $3.66 E-08$ & $4.72 E-05$ & $3.86 \mathrm{E}-05$ & $2.96 E-09$ & $6.78 \mathrm{E}-06$ & $5.52 \mathrm{E}-06$ \\
\hline NEW-C & $3.66 E-08$ & $4.72 \mathrm{E}-05$ & $3.86 E-05$ & $2.96 E-09$ & $6.78 E-06$ & $5.52 \mathrm{E}-06$ \\
\hline NOR-D & $3.28 E-08$ & $2.52 E-05$ & $2.23 E-05$ & $2.64 E-09$ & $3.62 E-06$ & $3.19 \mathrm{E}-06$ \\
\hline NOR-C & $3.28 E-08$ & $2.52 \mathrm{E}-05$ & $2.23 E-05$ & $2.64 E-09$ & $3.62 \mathrm{E}-06$ & $3.19 E-06$ \\
\hline PHI-D & $6.30 E-08$ & $2.55 \mathrm{E}-05$ & $2.67 E-05$ & $5.01 E-09$ & $3.66 \mathrm{E}-06$ & $3.82 E-06$ \\
\hline $\mathrm{PHI}-\mathrm{C}$ & $6.30 E-08$ & $2.55 E-05$ & $2.67 E-05$ & 5.0IE-09 & $3.66 \mathrm{E}-06$ & $3.82 E-06$ \\
\hline POR-D & $4.63 E-08$ & $3.05 E-05$ & $3.23 E-05$ & $3.74 \mathrm{E}-09$ & $4.38 E-06$ & $4.62 E-06$ \\
\hline POR-C & $4.63 E-08$ & $3.05 E-05$ & $3.23 E-05$ & $3.74 \mathrm{E}-09$ & $4.38 E-06$ & $4.62 E-06$ \\
\hline$S A V-D$ & $5.38 \mathrm{E}-08$ & $2.76 E-05$ & $2.87 E-05$ & $4.29 E-09$ & $3.96 E-06$ & $4.11 E-06$ \\
\hline $\mathrm{SAV}-\mathrm{C}$ & $5.38 E-08$ & $2.76 \mathrm{E}-05$ & $2.87 E-05$ & $4.29 E-09$ & $3.96 E-06$ & $4.11 E-06$ \\
\hline$S E A-C$ & $4.63 E-08$ & $3.05 E-05$ & $3.23 E-05$ & $3.74 E-09$ & $4.38 E-06$ & $4.62 \mathrm{E}-06$ \\
\hline TAC-D & $4.63 E-08$ & $3.05 E-05$ & $3.23 E-05$ & $3.74 E-09$ & $4.38 \mathrm{E}-06$ & $4.62 E-06$ \\
\hline $\mathrm{TAC}-\mathrm{C}$ & $4.63 E-08$ & $3.05 E-05$ & $3.23 E-05$ & $3.74 E-09$ & $4.38 \mathrm{E}-06$ & $4.62 \mathrm{E}-06$ \\
\hline WIL-D & $3.28 E-08$ & $2.52 E-05$ & $2.23 E-05$ & $2.64 E-09$ & $3.62 \mathrm{E}-06$ & $3.19 E-06$ \\
\hline WIL $-C$ & $3.28 \mathrm{E}-08$ & $2.52 E-05$ & $2.23 E-05$ & $2.64 E-09$ & $3.62 \mathrm{E}-06$ & $3.19 \mathrm{E}-06$ \\
\hline
\end{tabular}




\section{Table 32. 99th Quantile Values of Population Dose, Cancer Fatalities, Costs, Centerline Individual Dose and Centerline Individual Risk for EA Accident Categories}

EDE Whole Body Population Dose, 0-80 km (SV)

\begin{tabular}{|c|c|c|c|}
\hline & & BR-2 & \\
\hline /r & EA4 & EA5 & EA6 \\
\hline $\mathrm{HA}-\mathrm{D}$ & $1.20 E-03$ & $4.63 E+01$ & $5.26 \mathrm{E}+01$ \\
\hline $\mathrm{CHA}-\mathrm{C}$ & $3.40 \mathrm{E}-03$ & $9.03 E+01$ & $9.75 E+01$ \\
\hline CNC-D & $3.31 E-03$ & $9.47 E+01$ & $1.02 \mathrm{E}+02$ \\
\hline CNC-C & $1.06 \mathrm{E}-02$ & $1.55 \mathrm{E}+02$ & $1.73 E+02$ \\
\hline GAL-D & $5.03 E-03$ & $1.33 \mathrm{E}+02$ & $1.38 \mathrm{E}+02$ \\
\hline GAL-C & $1.37 E-03$ & $8.70 E+01$ & $1.16 \mathrm{E}+02$ \\
\hline JAC-D & $1.29 E-03$ & $7.23 E+01$ & $7.86 \mathrm{E}+01$ \\
\hline JAC-C & $1.26 \mathrm{E}-03$ & $6.40 \mathrm{E}+01$ & $6.77 \mathrm{E}+01$ \\
\hline LOS-D & NOT-FOUND & $2.67 E+02$ & $2.70 \mathrm{E}+02$ \\
\hline LOS-C & $3.66 \Xi-03$ & $2.19 E+02$ & $2.41 E \div 02$ \\
\hline MOT-D & $5.03 E-04$ & $2.46 \mathrm{E}+01$ & $2.63 E+01$ \\
\hline NEW-D & $1.20 E-02$ & $5.87 \mathrm{E}+02$ & $6.37 E+02$ \\
\hline NEW-C & $3.13 E-02$ & $9.41 E+02$ & $1.08 \mathrm{E}+03$ \\
\hline NOR-D & $3.40 E-03$ & $1.03 \mathrm{E}+02$ & $1.10 \mathrm{E} \div 02$ \\
\hline NOR-C & $1.62 \mathrm{E}-03$ & $9.02 \mathrm{E}+01$ & $1.00 \mathrm{E} \div 02$ \\
\hline PHI-D & $8.45 E-03$ & $3.10 E+02$ & $3.32 E+02$ \\
\hline PHI-C & $5.07 \mathrm{E}-03$ & $2.86 \mathrm{E}+02$ & $2.98 E \div 02$ \\
\hline POR-D & $3.16 E-03$ & $1.09 \mathrm{E}+02$ & $1.13 E+02$ \\
\hline POR-C & $3.48 \mathrm{E}-03$ & $1.01 E+02$ & $1.04 E+02$ \\
\hline SAV-D & $5.26 E-03$ & $1.26 E+02$ & $1.28 \mathrm{E}+02$ \\
\hline SAV-C & $8.01 E-04$ & $4.37 E+01$ & $4.44 E+01$ \\
\hline SEA-C & $8.69 E-04$ & $5.53 E+01$ & $5.99 E+0 I$ \\
\hline TAC-D & $1.55 E-03$ & $8.36 E+01$ & $8.67 \mathrm{E}+01$ \\
\hline TAC-C & $1.87 E-03$ & $9.69 \mathrm{E}+01$ & $1.01 \mathrm{E}+02$ \\
\hline $4-D$ & $4.47 E-03$ & $7.09 E+01$ & $7.65 \mathrm{E}+01$ \\
\hline$-C$ & $1.03 E-03$ & 1 & $2.79 E+01$ \\
\hline
\end{tabular}

$\begin{array}{ccc} & R H F \\ 3.82 E-04 & 1.71 E+01 & 2.04 E+01 \\ 1.23 E-03 & 3.70 E+01 & 4.13 E+01 \\ 1.29 E-03 & 3.41 E+01 & 3.56 E+01 \\ 3.77 E-03 & 5.55 E+01 & 5.20 E+01 \\ 2.01 E-03 & 4.90 E+01 & 4.92 E+01 \\ 6.77 E-04 & 3.72 E+01 & 3.93 E+01 \\ 5.59 E-04 & 2.78 E+01 & 3.07 E+01 \\ 5.28 E-04 & 2.45 E+01 & 2.69 E+01 \\ N 0 T-F 00 N D & 1.02 E+02 & 1.04 E+02 \\ 1.38 E-03 & 9.72 E+01 & 9.84 E+01 \\ 1.80 E-04 & 8.87 E+00 & 9.48 E+00 \\ 4.24 E-03 & 2.42 E+02 & 2.52 E+02 \\ 1.19 E-02 & 3.86 E+02 & 3.99 E+02 \\ 1.40 E-03 & 4.04 E+01 & 4.41 E+01 \\ 7.13 E-04 & 3.35 E+01 & 3.56 E+01 \\ 3.45 E-03 & 1.15 E+02 & 1.18 E+02 \\ 2.03 E-03 & 1.05 E+02 & 1.08 E+02 \\ 1.18 E-03 & 4.62 E+01 & 4.90 E+01 \\ 1.35 E-03 & 3.55 E+01 & 4.37 E+01 \\ 2.10 E-03 & 5.56 E+01 & 5.98 E+01 \\ 3.33 E-04 & 1.59 E+01 & 1.72 E+01 \\ 3.54 E-04 & 2.10 E+01 & 2.29 E+01 \\ 7.01 E-04 & 3.51 E+01 & 3.60 E+01 \\ 7.23 E-04 & 3.65 E+01 & 4.21 E+01 \\ 1.79 E-03 & 2.75 E+01 & 2.98 E+01 \\ 3.89 E-04 & 8.70 E+00 & 9.96 E+00\end{array}$

$\begin{array}{ccc} & \text { TRIGA } \\ \text { EA4 } & \text { EA5 } & E A 6 \\ 1.30 E-04 & 6.21 E+00 & 7.13 E+00 \\ 3.98 E-04 & 1.22 E+01 & 1.37 E+01 \\ 3.87 E-04 & 1.17 E+01 & 1.22 E+01 \\ 1.17 E-03 & 1.91 E+01 & 1.97 E+01 \\ 5.35 E-04 & 1.66 E+01 & 1.92 E+01 \\ 2.01 E-04 & 1.30 E+01 & 1.38 E+01 \\ 1.45 E-04 & 1.01 E+01 & 1.05 E+01 \\ 1.55 E-04 & 8.55 E+00 & 9.22 E+00 \\ \text { NOT-FOUND } & 3.32 E+01 & 3.64 E+01 \\ 5.13 E-04 & 3.14 E+01 & 3.12 E+01 \\ 6.25 E-05 & 2.90 E+00 & 2.95 E+00 \\ 1.34 E-03 & 8.29 E+01 & 8.68 E+01 \\ 3.52 E-03 & 1.33 E+02 & 1.42 E+02 \\ 4.59 E-04 & 1.30 E+01 & 1.39 E+01 \\ 2.06 E-04 & 1.16 E+01 & 1.24 E+01 \\ 1.00 E-03 & 4.65 E+01 & 5.03 E+01 \\ 6.95 E-04 & 4.13 E+01 & 4.63 E+01 \\ 3.55 E-04 & 1.40 E+01 & 1.59 E+01 \\ 4.02 E-04 & 1.19 E+01 & 1.46 E+01 \\ 6.05 E-04 & 2.04 E+01 & 2.16 E+01 \\ 9.87 E-05 & 5.65 E+00 & 5.42 E+00 \\ 1.12 E-04 & 7.43 E+00 & 8.11 E+00 \\ 2.09 E-04 & 1.19 E+01 & 1.23 E+01 \\ 2.20 E-04 & 1.29 E+01 & 1.52 E+01 \\ 5.10 E-04 & 9.33 E+00 & 3.08 E+01 \\ 1.18 E-04 & 3.00 E+00 & 3.11 E+00\end{array}$


Table 32. 99th Quantile Values of Population Dose, Cancer Fatalities, Costs, Centerline Individual Dose and Centerline Individual Risk for EA Accident Categories (Continued)

Total Cancer Fatalities, 0-80 $\mathrm{km}$

\begin{tabular}{lccc} 
& & \multicolumn{3}{c}{ BR-2 } \\
Site/IOC & EA4 & EA5 & EA6 \\
CHA-D & $4.33 E-05$ & $1.98 E+00$ & $2.24 E+00$ \\
CHA-C & $1.30 E-04$ & $3.96 E+00$ & $4.27 E+00$ \\
CNC-D & $1.43 E-04$ & $4.07 E+00$ & $4.38 E+00$ \\
CNC-C & $4.60 E-04$ & $6.20 E+00$ & $6.23 E+00$ \\
GAI-D & $2.07 E-04$ & $4.93 E+00$ & $5.12 E+00$ \\
GAI-C & $7.04 E-05$ & $3.88 E+00$ & $4.09 E+00$ \\
JAC-D & $5.80 E-05$ & $3.10 E+00$ & $3.21 E+00$ \\
JAC-C & $6.04 E-05$ & $2.71 E+00$ & $2.87 E+00$ \\
IOS-D & NOT-EOUND & $1.03 E+01$ & $1.05 E+01$ \\
IOS-C & $1.98 E-04$ & $9.81 E+00$ & $1.01 E+01$ \\
MOT-D & $2.32 E-05$ & $1.22 E+00$ & $1.33 E+00$ \\
NEW-D & $4.40 E-04$ & $2.46 E+01$ & $2.58 E+01$ \\
NEW-C & $1.29 E-03$ & $3.89 E+01$ & $4.36 E+01$ \\
NOR-D & $1.55 E-04$ & $4.23 E+00$ & $4.63 E+00$ \\
NOR-C & $7.23 E-05$ & $3.59 E+00$ & $3.97 E+00$ \\
PHI-D & $3.54 E-04$ & $1.18 E+01$ & $1.23 E+01$ \\
EHI-C & $2.03 E-04$ & $1.22 E+01$ & $1.12 E+01$ \\
POR-D & $1.47 E-04$ & $4.90 E+00$ & $5.16 E+00$ \\
POR-C & $1.48 E-04$ & $3.78 E+00$ & $4.71 E+00$ \\
SAV-D & $2.23 E-04$ & $5.68 E+00$ & $6.22 E+00$ \\
SAV-C & $3.52 E-05$ & $1.79 E+00$ & $1.93 E+00$ \\
SEA-C & $3.73 E-05$ & $2.41 E+00$ & $2.61 E+00$ \\
TAC-D & $7.55 E-05$ & $3.60 E+00$ & $3.74 E+00$ \\
TAC-C & $8.26 E-05$ & $3.94 E+00$ & $4.73 E+00$ \\
WIL-D & $1.99 E-04$ & $2.90 E+00$ & $3.25 E+00$ \\
WIL-C & $4.89 E-05$ & $1.04 E+00$ & $1.16 E+00$
\end{tabular}

$\begin{array}{ccc} & \text { RHF } & \\ 1.63 E & E A 5 & E A 6 \\ 7.14 E-05 & 1.81 E-01 & 8.41 E-01 \\ 5.84 E-05 & 1.28 E+00 & 1.35 E+00 \\ 1.80 E-04 & 2.55 E+00 & 2.59 E+00 \\ 7.64 E-05 & 1.96 E+00 & 2.07 E+00 \\ 2.89 E-05 & 1.49 E+00 & 1.54 E+00 \\ 2.38 E-05 & 1.12 E+00 & 1.15 E+00 \\ 2.29 E-05 & 1.08 E+00 & 1.14 E+00 \\ \text { NOT-FOUND } & 4.49 E+00 & 4.52 E+00 \\ 7.39 E-05 & 3.39 E+00 & 3.90 E+00 \\ 8.61 E-06 & 4.08 E-01 & 4.42 E-01 \\ 1.72 E-04 & 1.10 E+01 & 1.15 E+01 \\ 5.34 E-04 & 1.47 E+01 & 1.67 E+01 \\ 6.51 E-05 & 1.62 E+00 & 1.81 E+00 \\ 3.08 E-05 & 1.39 E+00 & 1.43 E+00 \\ 1.29 E-04 & 5.18 E+00 & 5.55 E+00 \\ 9.95 E-05 & 4.74 E+00 & 4.93 E+00 \\ 6.01 E-05 & 1.96 E+00 & 2.03 E+00 \\ 6.08 E-05 & 1.56 E+00 & 1.84 E+00 \\ 1.01 E-04 & 2.20 E+00 & 2.45 E+00 \\ 1.28 E-05 & 6.84 E-01 & 7.04 E-01 \\ 1.40 E-05 & 9.06 E-01 & 9.68 E-01 \\ 3.03 E-05 & 1.32 E+00 & 1.42 E+00 \\ 3.19 E-05 & 1.59 E+00 & 1.87 E+00 \\ 7.68 E-05 & 1.17 E+00 & 1.21 E+00 \\ 1.96 E-05 & 4.13 E-01 & 4.66 E-01\end{array}$

\begin{tabular}{lccc} 
& & \multicolumn{3}{c}{ OSIRIS } \\
SIte/LOC & EA4 & EA5 & $E A 6$ \\
CHA-D & $5.58 E-05$ & $1.85 E+00$ & $2.10 E+00$ \\
CHA-C & $2.10 E-04$ & $3.84 E+00$ & $4.13 E+00$ \\
CNC-D & $1.72 E-04$ & $3.44 E+00$ & $3.60 E+00$ \\
CNC-C & $5.48 E-04$ & $5.55 E+00$ & $5.25 E+00$ \\
GAI-D & $2.28 E-04$ & $4.90 E+00$ & $5.00 E+00$ \\
GAI-C & $7.96 E-05$ & $3.72 E+00$ & $3.98 E+00$ \\
JAC-D & $6.80 E-05$ & $2.85 E+00$ & $3.09 E+00$ \\
JAC-C & $7.28 E-05$ & $2.44 E+00$ & $2.70 E+00$ \\
IOS-D & NOT-FOUND & $1.02 E+01$ & $1.04 E+01$ \\
LOS-C & $2.16 E-04$ & $9.80 E+00$ & $1.01 E+01$ \\
MOT-D & $2.26 E-05$ & $8.76 E-01$ & $9.29 E-01$ \\
NEW-D & $5.94 E-04$ & $2.43 E+01$ & $2.54 E+01$ \\
NEW-C & $1.57 E-03$ & $3.87 E+01$ & $4.17 E+01$ \\
NOR-D & $2.02 E-04$ & $4.08 E+00$ & $4.45 E+00$ \\
NOR-C & $8.85 E-05$ & $3.46 E+00$ & $3.59 E+00$ \\
PHI-D & $4.18 E-04$ & $1.16 E+01$ & $1.22 E+01$ \\
PHI-C & $2.99 E-04$ & $1.06 E+01$ & $1.09 E+01$ \\
POR-D & $1.74 E-04$ & $4.71 E+00$ & $5.01 E+00$ \\
POR-C & $1.99 E-04$ & $3.63 E+00$ & $4.59 E+00$ \\
SAV-D & $3.03 E-04$ & $5.56 E+00$ & $6.22 E+00$ \\
SAV-C & $3.74 E-05$ & $1.60 E+00$ & $1.72 E+00$ \\
SEA-C & $4.24 E-05$ & $2.14 E+00$ & $2.32 E+00$ \\
TAC-D & $9.51 E-05$ & $3.53 E+00$ & $3.68 E+00$ \\
TAC-C & $9.61 E-05$ & $3.83 E+00$ & $4.72 E+00$ \\
WII-D & $2.63 E-04$ & $2.79 E+00$ & $3.11 E+00$ \\
WII-C & $5.28 E-05$ & $8.65 E-01$ & $9.96 E-01$ \\
& & &
\end{tabular}

$\begin{array}{ccc}\text { EA4 } & \text { TRIGA } & \text { EAS } \\ 5.50 E-06 & 2.67 E-01 & 2.89 E-01 \\ 1.60 E-05 & 4.94 E-01 & 5.80 E-01 \\ 1.60 E-05 & 5.30 E-01 & 5.55 E-01 \\ 5.25 E-05 & 8.80 E-01 & 8.78 E-01 \\ 2.18 E-05 & 7.00 E-01 & 7.31 E-01 \\ 7.95 E-06 & 5.73 E-01 & 5.88 E-01 \\ 6.67 E-06 & 3.91 E-01 & 4.34 E-01 \\ 6.50 E-06 & 3.53 E-01 & 3.75 E-01 \\ \text { N0T-FOUND } & 1.45 E+00 & 1.58 E+00 \\ 2.08 E-05 & 1.18 E+00 & 1.19 E+00 \\ 2.67 E-06 & 1.43 E-01 & 1.47 E-01 \\ 5.49 E-05 & 3.48 E+00 & 3.83 E+00 \\ 1.40 E-04 & 5.75 E+00 & 6.28 E+00 \\ 1.85 E-05 & 5.99 E-01 & 6.50 E-01 \\ 8.46 E-06 & 5.25 E-01 & 5.47 E-01 \\ 3.88 E-05 & 1.90 E+00 & 2.05 E+00 \\ 2.85 E-05 & 1.78 E+00 & 1.85 E+00 \\ 1.61 E-05 & 6.89 E-01 & 7.13 E-01 \\ 1.63 E-05 & 5.45 E-01 & 6.19 E-01 \\ 2.41 E-05 & 7.91 E-01 & 8.82 E-01 \\ 3.71 E-06 & 2.45 E-01 & 2.62 E-01 \\ 4.16 E-06 & 3.17 E-01 & 3.47 E-01 \\ 8.41 E-06 & 5.55 E-01 & 5.74 E-01 \\ 9.47 E-06 & 5.25 E-01 & 6.20 E-01 \\ 2.05 E-05 & 3.98 E-01 & 4.27 E-01 \\ 5.15 E-06 & 1.45 E-01 & 1.55 E-01\end{array}$


Table 32. 99th Quantile Values of Population Dose, Cancer

Fatalities, Costs, Centerline Individual Dose and

Centerline Individual Risk for EA Accident

Categories (Continued)

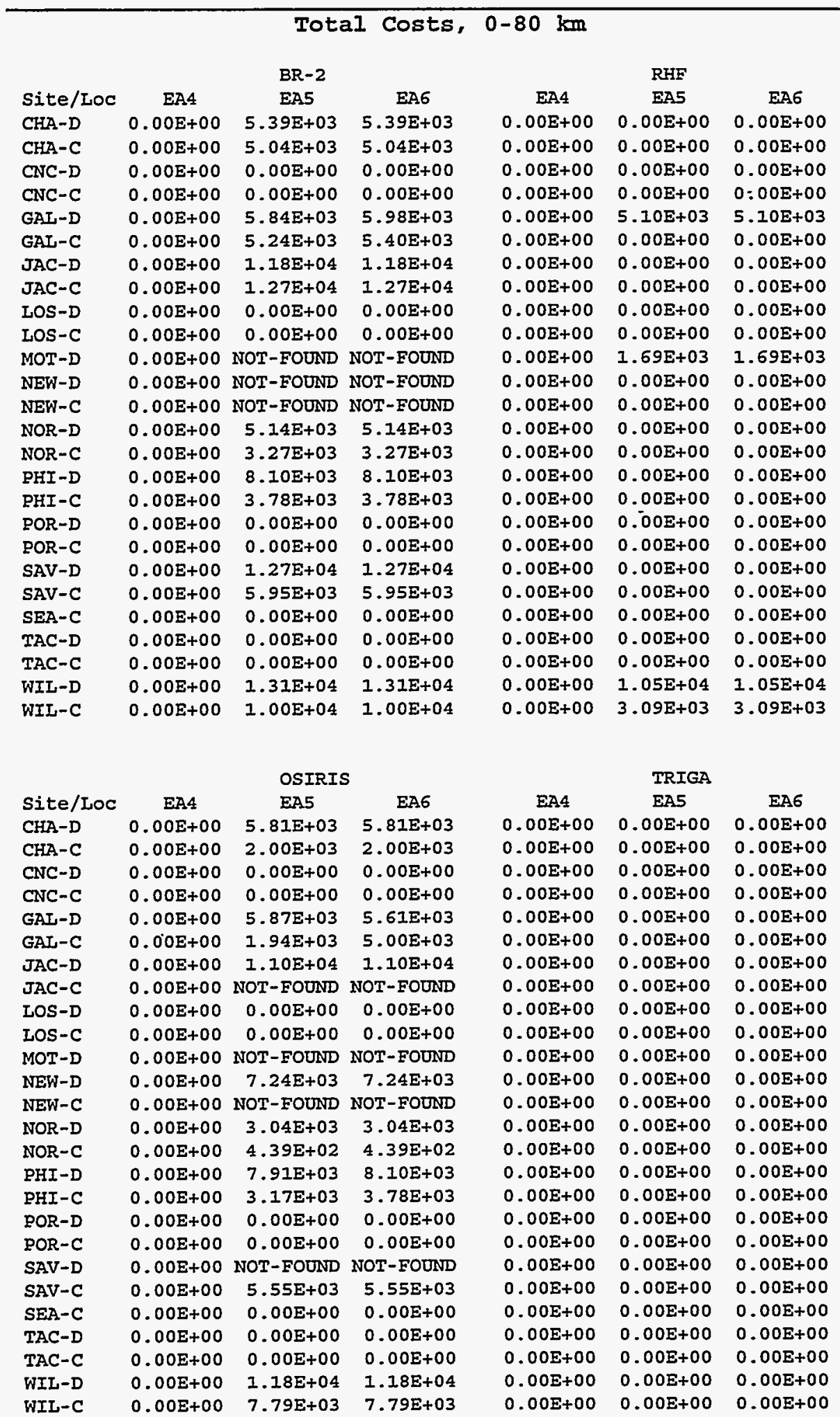


Table 32. 99th Quantile Values of Population Dose, Cancer Fatalities, Costs, Centerline Individual Dose and Centerline Individual Risk for EA Accident Categories (Continued)

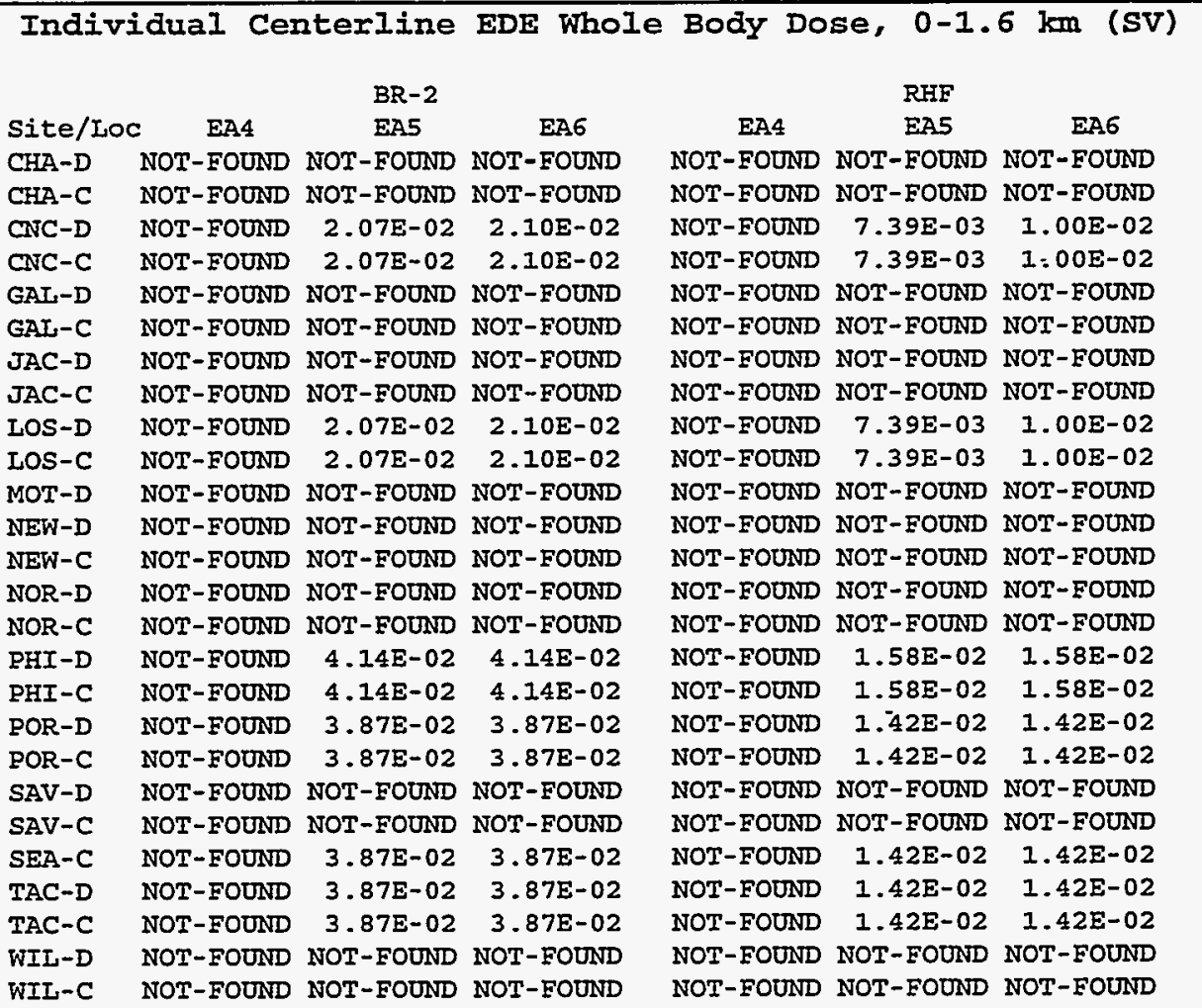
\begin{tabular}{lccc}
\multicolumn{3}{c}{ OSIRIS } \\
Site/LOC EA4 & EAS & EA6 \\
CHA-D NOT-FOUND NOT-FOUND NOT-FOUND
\end{tabular} CHA-C NOT-FOUND NOT-FOUND NOT-FOUND CNC-D NOT-FOUND 2.06E-02 2.09E-02 CNC-C NOT-FOUND 2.06E-02 2.09E-02 GAI-D NOT-FOUND NOT-FOUND NOT-FOUND GAI-C NOT-FOUND NOT-FOUND NOT-FOUND JAC-D NOT-FOUND NOT-FOUND NOT-FOUND JAC-C NOT-FOUND NOT-FOUND NOT-FOUND IOS-D NOT-FOUND $2.06 \mathrm{E}-02 \quad 2.09 \mathrm{E}-02$ IOS-C NOT-FOUND $2.06 \mathrm{E}-02 \quad 2.09 \mathrm{E}-02$ MOT-D NOT-FOUND NOT-FOUND NOT-FOUND NEW-D NOT-FOUND NOT-FOUND NOT-FOUND NEW-C NOT-FOUND NOT-FOUND NOT-FOUND NOR-D NOT-FOUND NOT-FOUND NOT-FOUND NOR-C NOT-FOUND NOT-FOUND NOT-FOUND PHI-D NOT-FOUND 4.05E-02 4.14E-02 PHI-C NOT-FOUND 4.05E-02 4.14E-02 POR-D NOT-FOUND 3.87E-02 3.87E-02 POR-C NOT-FOUND 3.87E-02 3.87E-02 SAV-D NOT-FOUND NOT-FOUND NOT-EOUND SAV-C NOT-FOUND NOT-FOUND NOT-FOUND SEA-C NOT-FOUND 3.87E-02 3.87E-02 TAC-D NOT-FOUND $3.87 E-02 \quad 3.87 E-02$ TAC-C NOT-FOUND 3.87E-02 3.87E-02 WIL-D NOT-FOUND NOT-FOUND NOT-FOUND WIL-C NOT-FOUND NOT-FOUND NOT-FOUND 


\section{Table 32. 99th Quantile Values of Population Dose, Cancer Fatalities, Costs, Centerline Individual Dose and Centerline Individual Risk for EA Accident Categories (Concluded)}

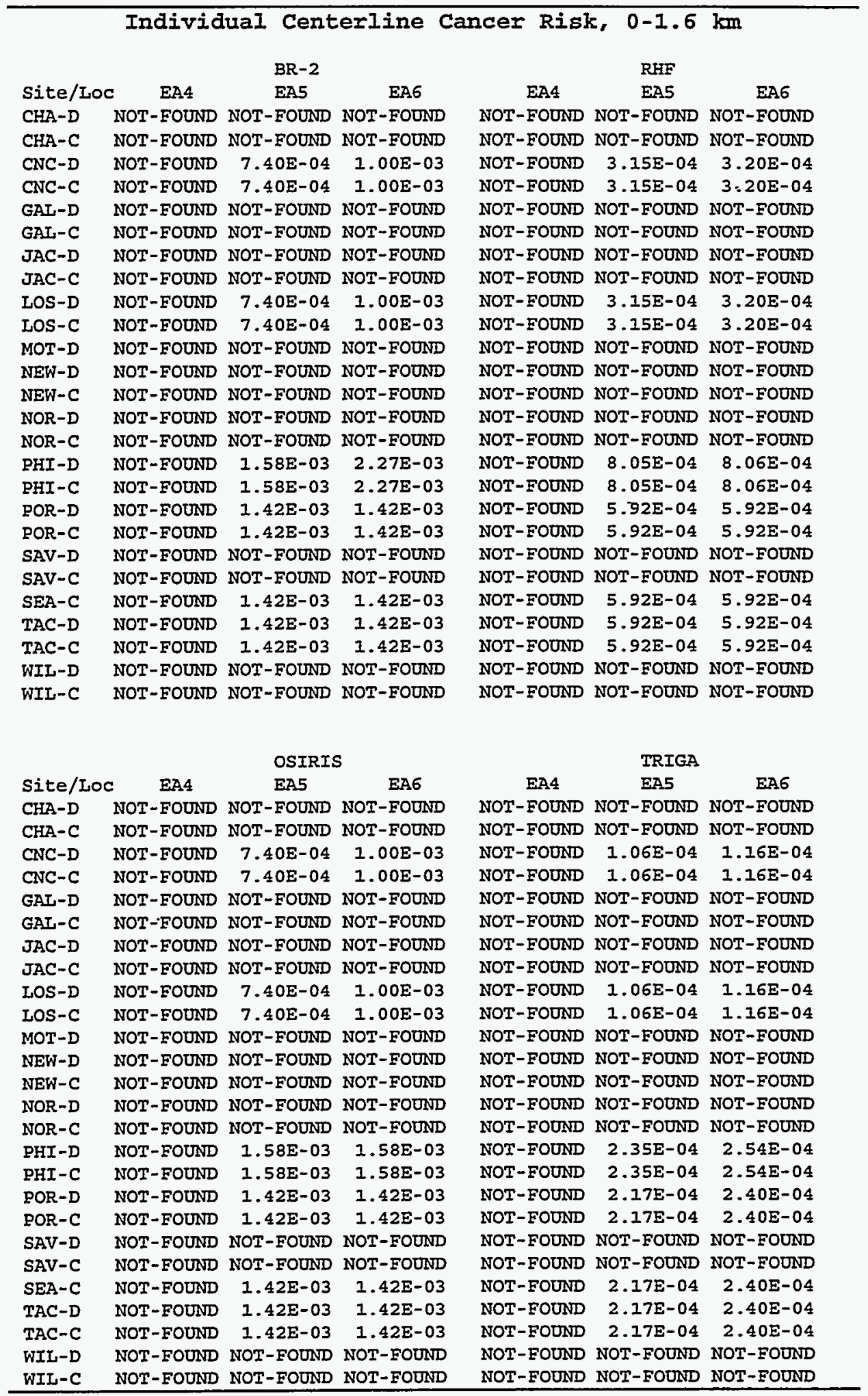


Table 33. Peak Values of Population Dose, Cancer Fatalities, Costs, Centerline Individual Dose and Centerline Individual Risk for EA Accident Categories

EDE Whole Body Population Dose, $0-80 \mathrm{~km}$ (SV)

$\begin{array}{lccc} & & \text { BR-2 } & \\ \text { Site/LOC } & \text { EA4 } & \text { EAS } & \text { EA6 } \\ \text { CHA-D } & 2.82 E-03 & 1.04 E+02 & 1.10 E+02 \\ \text { CHA-C } & 4.41 E-03 & 2.12 E+02 & 2.31 E+02 \\ \text { CNC-D } & 3.35 E-03 & 1.02 E+02 & 1.11 E+02 \\ \text { CNC-C } & 1.42 E-02 & 6.71 E+02 & 7.27 E+02 \\ \text { GAI-D } & 5.60 E-03 & 2.33 E+02 & 2.54 E+02 \\ \text { GAI-C } & 2.09 E-03 & 1.85 E+02 & 2.02 E+02 \\ \text { JAC-D } & 2.15 E-03 & 1.10 E+02 & 1.20 E+02 \\ \text { JAC-C } & 1.90 E-03 & 1.12 E+02 & 1.23 E+02 \\ \text { LOS-D } & 1.30 E-02 & 3.94 E+02 & 4.29 E+02 \\ \text { IOS-C } & 5.97 E-03 & 3.47 E+02 & 3.76 E+02 \\ \text { MOT-D } & 7.72 E-04 & 4.61 E+01 & 5.03 E+01 \\ \text { NEW-D } & 1.86 E-02 & 1.13 E+03 & 1.24 E+03 \\ \text { NEW-C } & 3.41 E-02 & 1.33 E+03 & 1.45 E+03 \\ \text { NOR-D } & 4.29 E-03 & 1.66 E+02 & 1.81 E+02 \\ \text { NOR-C } & 2.78 E-03 & 1.64 E+02 & 1.78 E+02 \\ \text { PHI-D } & 1.13 E-02 & 7.15 E+02 & 7.80 E+02 \\ \text { BHI-C } & 8.77 E-03 & 4.87 E+02 & 5.31 E+02 \\ \text { POR-D } & 3.85 E-03 & 1.69 E+02 & 1.85 E+02 \\ \text { POR-C } & 3.94 E-03 & 1.70 E+02 & 1.85 E+02 \\ \text { SAV-D } & 6.18 E-03 & 2.39 E+02 & 2.60 E+02 \\ \text { SAV-C } & 1.43 E-03 & 7.65 E+01 & 8.00 E+01 \\ \text { SEA-C } & 9.93 E-04 & 5.62 E+01 & 6.13 E+01 \\ \text { TAC-D } & 2.67 E-03 & 1.18 E+02 & 1.29 E+02 \\ \text { TAC-C } & 3.13 E-03 & 1.70 E+02 & 1.85 E+02 \\ \text { WIL-D } & 5.50 E-03 & 1.49 E+02 & 1.63 E+02 \\ \text { WII-C } & 1.18 E-03 & 3.28 E+01 & 3.58 E+01 \\ & & & \end{array}$

\begin{tabular}{|c|c|c|}
\hline & RFF & \\
\hline EA4 & EAS & EA6 \\
\hline $.12 E-03$ & $4.07 E+01$ & $4.32 E+01$ \\
\hline $1.76 \mathrm{E}-03$ & $8.56 E+01$ & $9.34 E+01$ \\
\hline $1.33 E-03$ & $4.03 E+01$ & $4.40 E+01$ \\
\hline $.70 E-03$ & $2.66 E+02$ & $2.88 E+02$ \\
\hline $.22 E-03$ & $9.59 E+01$ & $1: 05 \mathrm{E}+02$ \\
\hline $8.28 E-04$ & $7.23 E+01$ & $7.89 \mathrm{E}+01$ \\
\hline $3.53 E-04$ & $4.28 E+01$ & $4.66 \mathrm{E}+01$ \\
\hline $7.52 E-04$ & $4.59 \mathrm{E}+01$ & $5.01 E+01$ \\
\hline $5.20 \mathrm{E}-03$ & I. $56 \mathrm{E}+02$ & 1. $70 \mathrm{E}+02$ \\
\hline $2.39 E-03$ & I. $37 \mathrm{E}+02$ & $1.49 \mathrm{E}+02$ \\
\hline $2.98 \mathrm{E}-04$ & $1.71 \mathrm{E}+01$ & $1.86 \mathrm{E}+01$ \\
\hline $7.44 \mathrm{E}-03$ & $4.48 \mathrm{E}+02$ & $4.89 \mathrm{E}+02$ \\
\hline $1.36 \mathrm{E}-02$ & $5.25 \mathrm{E}+02$ & $5.73 \mathrm{E}+02$ \\
\hline $1.71 E-03$ & $6.49 E+01$ & $7.06 \mathrm{E}+01$ \\
\hline $1.11 E-03$ & $6.44 \mathrm{E}+01$ & $7.00 E+01$ \\
\hline $4.52 \mathrm{E}-03$ & $2.82 \mathrm{E}+02$ & $3.08 E+02$ \\
\hline $3.50 \Xi-03$ & $1.92 E+02$ & $2.10 \mathrm{E}+02$ \\
\hline $1.54 \mathrm{E}-03$ & $6.69 \mathrm{E}+01$ & $7.30 \mathrm{E}+01$ \\
\hline $1.57 \mathrm{E}-03$ & $6.66 \mathrm{E}+01$ & $7.27 \mathrm{E}+01$ \\
\hline $2.46 \mathrm{E}-03$ & $9.64 \mathrm{E}+01$ & $1.05 E+02$ \\
\hline $5.66 \mathrm{E}-04$ & $2.94 \mathrm{E}+01$ & $3.07 \mathrm{E}+01$ \\
\hline $3.93 E-04$ & $2.14 \mathrm{E}+01$ & $2.33 E+01$ \\
\hline $1.06 E-03$ & $4.66 \mathrm{E}+01$ & $5.09 E+01$ \\
\hline $1.25 E-03$ & $6.64 \mathrm{E}+01$ & $7.25 E+01$ \\
\hline $2.20 \mathrm{E}-03$ & $5.91 \mathrm{E}+01$ & $6.44 \mathrm{E}+01$ \\
\hline $4.71 E-04$ & $1.29 \mathrm{E}+01$ & $1.4 I E+01$ \\
\hline
\end{tabular}

\begin{tabular}{ccc} 
& TRIGA & \multicolumn{1}{c}{$E A 6$} \\
$3.41 E-04$ & $1.43 E+01$ & $1.51 E+01$ \\
$5.23 E-04$ & $3.00 E+01$ & $3.27 E+01$ \\
$4.00 E-04$ & $1.42 E+01$ & $1.55 E+01$ \\
$1.72 E-03$ & $9.34 E+01$ & $1.01 E+02$ \\
$6.69 E-04$ & $3.36 E+01$ & $3.66 E+01$ \\
$2.56 E-04$ & $2.53 E+01$ & $2.76 E+01$ \\
$2.61 E-04$ & $1.50 E+01$ & $1.63 E+01$ \\
$2.31 E-04$ & $1.61 E+01$ & $1.76 E+01$ \\
$1.54 E-03$ & $5.49 E+01$ & $5.98 E+01$ \\
$7.21 E-04$ & $4.83 E+01$ & $5.23 E+01$ \\
$9.74 E-05$ & $5.88 E+00$ & $6.42 E+00$ \\
$2.24 E-03$ & $1.58 E+02$ & $1.72 E+02$ \\
$4.01 E-03$ & $1.85 E+02$ & $2.02 E+02$ \\
$5.08 E-04$ & $2.27 E+01$ & $2.47 E+01$ \\
$3.36 E-04$ & $2.26 E+01$ & $2.45 E+01$ \\
$1.36 E-03$ & $9.91 E+01$ & $1.08 E+02$ \\
$1.06 E-03$ & $6.75 E+01$ & $7.36 E+01$ \\
$4.64 E-04$ & $2.35 E+01$ & $2.57 E+01$ \\
$4.67 E-04$ & $2.34 E+01$ & $2.55 E+01$ \\
$7.32 E-04$ & $3.38 E+01$ & $3.69 E+01$ \\
$1.75 E-04$ & $1.03 E+01$ & $1.07 E+01$ \\
$1.22 E-04$ & $7.44 E+00$ & $8.11 E+00$ \\
$3.23 E-04$ & $1.64 E+01$ & $1.79 E+01$ \\
$3.78 E-04$ & $2.33 E+01$ & $2.54 E+01$ \\
$6.51 E-04$ & $2.08 E+01$ & $2.27 E+01$ \\
$1.41 E-04$ & $4.57 E+00$ & $4.99 E+00$
\end{tabular}


Table 33. Peak Values of Population Dose, Cancer Fatalities, Costs, Centerline Individual Dose and Centerline Individual Risk for EA Accident Categories (Continued)

\begin{tabular}{|c|c|c|c|c|c|c|}
\hline \multirow[b]{3}{*}{ Site/Loc } & \multicolumn{6}{|c|}{ Total Cancer } \\
\hline & & BR-2 & & & RHF & \\
\hline & EA4 & EA5 & EAG & EA4 & EA5 & EA6 \\
\hline$C H A-D$ & $1.20 \mathrm{E}-04$ & $4.41 E+00$ & $4.69 E+00$ & $4.80 E-05$ & $1.72 E+00$ & $1.83 \mathrm{E}+00$ \\
\hline $\mathrm{CHA}-\mathrm{C}$ & $1.95 \mathrm{E}-04$ & $8.90 E+00$ & $9.71 \mathrm{E}+00$ & $7.83 E-05$ & $3.60 E+00$ & $3.93 E+00$ \\
\hline CNC-D & $1.49 \mathrm{E}-04$ & $4.31 E+00$ & $4.68 \mathrm{E}+00$ & $5.96 E-05$ & $1.68 \mathrm{E}+00$ & $1.83 \mathrm{E}+00$ \\
\hline CNC-C & $6.01 E-04$ & $2.80 E+0 I$ & $3.03 E+01$ & $2.42 \mathrm{E}-04$ & $1.11 E+01$ & $1.20 \mathrm{E}+01$ \\
\hline GAL-D & $2.48 \mathrm{E}-04$ & $9.97 E+00$ & $1.09 \mathrm{E}+01$ & $9.90 \mathrm{E}-05$ & $4.08 \mathrm{E}+00$ & $4.45 \mathrm{E}+00$ \\
\hline GAI-C & $9.02 \mathrm{E}-05$ & $7.89 E+00$ & $8.61 E+00$ & $3.57 \mathrm{E}-05$ & $3.07 E+00$ & $3.35 \mathrm{E}+00$ \\
\hline JAC-D & $9.25 E-05$ & $4.7 I E+00$ & $5.12 \mathrm{E}+00$ & $3.68 \mathrm{E}-05$ & $1.82 \mathrm{E}+00$ & $1.98 \mathrm{E}+00$ \\
\hline JAC-C & $8.20 \mathrm{E}-05$ & $4.71 E+00$ & $5.13 E+00$ & $3.26 \mathrm{E}-05$ & $1.93 \mathrm{E}+00$ & $2.11 E+00$ \\
\hline LOS-D & $5.75 \mathrm{E}-04$ & $1.64 \mathrm{E}+01$ & $1.79 E+01$ & $2.31 E-04$ & $6.50 \mathrm{E}+00$ & $7.08 \mathrm{E}+00$ \\
\hline IOS-C & $2.52 \mathrm{E}-04$ & $1.45 E+01$ & $1.57 \mathrm{E}+01$ & $1.01 \mathrm{E}-04$ & $5.73 E+00$ & $6.20 E+00$ \\
\hline MOT-D & $3.49 \mathrm{E}-05$ & $2.10 \mathrm{E}+00$ & $2.29 E+00$ & $1.34 \mathrm{E}-05$ & $7.69 \mathrm{E}-01$ & $8.39 \mathrm{E}-01$ \\
\hline NEW-D & $7.88 E-04$ & $4.72 \mathrm{E}+01$ & $5.16 E+01$ & $3.17 E-04$ & $1.87 \mathrm{E}+01$ & $2.04 \mathrm{E}+01$ \\
\hline NEW-C & $1.50 \mathrm{E}-03$ & $5.53 E+01$ & $6.04 E+01$ & $6.06 \mathrm{E}-04$ & $2.19 E+01$ & $2.39 E+01$ \\
\hline NOR-D & $1.89 \mathrm{E}-04$ & $7.09 E+00$ & $7.71 E+00$ & $7.62 E-05$ & $2.75 \mathrm{E}+00$ & $2.99 \mathrm{E}+00$ \\
\hline NOR-C & $1.19 \mathrm{E}-04$ & $6.92 \mathrm{E}+00$ & $7.52 \mathrm{E}+00$ & $4.75 E-05$ & $2.71 E+00$ & $2.94 \mathrm{E}+00$ \\
\hline PHI-D & $4.79 \mathrm{E}-04$ & $2.99 E+01$ & $3.26 \mathrm{E}+01$ & $1.93 E-04$ & $1.18 \mathrm{E}+01$ & $1.29 \mathrm{E}+01$ \\
\hline PHI-C & $3.71 E-04$ & $2.04 E+01$ & $2.23 E+01$ & $1.49 \mathrm{E}-04$ & $8.03 E+00$ & $8.77 E+00$ \\
\hline POR-D & $1.68 \mathrm{E}-04$ & $7.05 \mathrm{E}+00$ & $7.70 E+00$ & $6.74 \mathrm{E}-05$ & $2.79 E+00$ & $3.04 \mathrm{E}+00$ \\
\hline POR-C & $1.74 \mathrm{E}-04$ & $7.18 \mathrm{E}+00$ & $7.84 E+00$ & $7.00 \mathrm{E}-05$ & $2.81 E+00$ & $3.06 E+00$ \\
\hline SAV-D & $2.74 E-04$ & $1.00 \mathrm{E}+01$ & $1.09 \mathrm{E}+01$ & $1.10 \mathrm{E}-04$ & $4.07 E+00$ & $4.44 \mathrm{E}+00$ \\
\hline SAV-C & $6.15 \mathrm{E}-05$ & $3.32 \mathrm{E}+00$ & $3.48 \mathrm{E}+00$ & $2.44 \mathrm{E}-05$ & $1.27 \mathrm{E}+00$ & $1.33 \mathrm{E} \div 00$ \\
\hline SEA-C & $4.27 E-05$ & $2.47 \mathrm{E}+00$ & $2.69 E+00$ & $1.69 \mathrm{E}-05$ & $9.33 E-01$ & $1.02 \mathrm{E}+00$ \\
\hline TAC-D & $1.24 \mathrm{E}-04$ & $5.03 E+00$ & $5.49 E+00$ & $4.54 E-05$ & $1.95 \mathrm{E}+00$ & $2.12 \mathrm{E}+00$ \\
\hline TAC-C & $1.33 E-04$ & $7.18 \mathrm{E}+00$ & $7.84 \mathrm{E}+00$ & $5.34 E-05$ & $2.80 E+00$ & $3.06 E+00$ \\
\hline WIL-D & $2.43 E-04$ & $6.24 E+00$ & $6.80 E+00$ & $9.80 E-05$ & $2.46 \mathrm{E}+00$ & $2.69 \mathrm{E}+00$ \\
\hline WIL-C & $5.22 \mathrm{E}-05$ & $1.41 E+00$ & $1.54 \mathrm{E}+00$ & $2.10 \mathrm{E}-05$ & $5.42 \mathrm{E}-01$ & $5.92 E-01$ \\
\hline
\end{tabular}

\begin{tabular}{lccc} 
& \multicolumn{3}{c}{ OSIRIS } \\
Site/LOC & EA4 & EA5 & EA6 \\
CHA-D & $1.45 E-04$ & $4.14 E+00$ & $4.41 E+00$ \\
CHA-C & $2.41 E-04$ & $8.72 E+00$ & $9.53 E+00$ \\
CNC-D & $1.80 E-04$ & $4.11 E+00$ & $4.50 E+00$ \\
CNC-C & $7.40 E-04$ & $2.71 E+01$ & $2.94 E+01$ \\
GAL-D & $2.99 E-04$ & $9.37 E+00$ & $1.00 E+01$ \\
GAI-C & $1.04 E-04$ & $7.36 E+00$ & $8.04 E+00$ \\
JAC-D & $1.09 E-04$ & $4.36 E+00$ & $4.75 E+00$ \\
JAC-C & $9.56 E-05$ & $4.67 E+00$ & $5.11 E+00$ \\
LOS-D & $7.18 E-04$ & $1.59 E+01$ & $1.74 E+01$ \\
LOS-C & $3.10 E-04$ & $1.40 E+01$ & $1.52 E+01$ \\
MOT-D & $3.42 E-05$ & $1.71 E+00$ & $1.87 E+00$ \\
NEW-D & $9.71 E-04$ & $4.57 E+01$ & $5.00 E+01$ \\
NEW-C & $1.90 E-03$ & $5.36 E+01$ & $5.86 E+01$ \\
NOR-D & $2.37 E-04$ & $6.60 E+00$ & $7.20 E+00$ \\
NOR-C & $1.44 E-04$ & $6.56 E+00$ & $7.14 E+00$ \\
PHI-D & $5.91 E-04$ & $2.88 E+01$ & $3.15 E+01$ \\
PHI-C & $4.53 E-04$ & $1.96 E+01$ & $2.14 E+01$ \\
POR-D & $2.07 E-04$ & $6.83 E+00$ & $7.47 E+00$ \\
POR-C & $2.16 E-04$ & $6.79 E+00$ & $7.42 E+00$ \\
SAV-D & $3.39 E-04$ & $9.82 E+00$ & $1.07 E+01$ \\
SAV-C & $7.12 E-05$ & $2.98 E+00$ & $3.12 E+00$ \\
SEA-C & $4.96 E-05$ & $2.16 E+00$ & $2.36 E+00$ \\
TAC-D & $1.36 E-04$ & $4.76 E+00$ & $5.21 E+00$ \\
TAC-C & $1.64 E-04$ & $6.77 E+00$ & $7.40 E+00$ \\
WIL-D & $3.05 E-04$ & $6.03 E+00$ & $6.58 E+00$ \\
WIL-C & $6.42 E-05$ & $1.32 E+00$ & $1.44 E+00$
\end{tabular}

$\begin{array}{ccc}\text { EA4 } & \text { TRIGA } \\ 1.37 E-05 & 6.02 E-01 & 6.39 E-01 \\ 2.17 E-05 & 1.26 E+00 & 1.38 E+00 \\ 1.68 E-05 & 5.90 E-01 & 6.44 E-01 \\ 6.84 E-05 & 3.89 E+00 & 4.22 E+00 \\ 2.79 E-05 & 1.43 E+00 & 1.55 E+00 \\ 1.05 E-05 & 1.07 E+00 & 1.17 E+00 \\ 1.07 E-05 & 6.37 E-01 & 6.93 E-01 \\ 9.47 E-06 & 6.77 E-01 & 7.38 E-01 \\ 6.37 E-05 & 2.29 E+00 & 2.49 E+00 \\ 2.87 E-05 & 2.01 E+00 & 2.18 E+00 \\ 4.24 E-06 & 2.65 E-01 & 2.88 E-01 \\ 8.94 E-05 & 6.56 E+00 & 7.16 E+00 \\ 1.66 E-04 & 7.69 E+00 & 8.39 E+00 \\ 2.10 E-05 & 9.63 E-01 & 1.05 E+00 \\ 1.35 E-05 & 9.50 E-01 & 1.03 E+00 \\ 5.44 E-05 & 4.14 E+00 & 4.52 E+00 \\ 4.23 E-05 & 2.82 E+00 & 3.08 E+00 \\ 1.87 E-05 & 9.80 E-01 & 1.07 E+00 \\ 1.94 E-05 & 9.84 E-01 & 1.07 E+00 \\ 3.04 E-05 & 1.43 E+00 & 1.55 E+00 \\ 7.14 E-06 & 4.42 E-01 & 4.62 E-01 \\ 4.99 E-06 & 3.24 E-01 & 3.53 E-01 \\ 1.31 E-05 & 6.83 E-01 & 7.45 E-01 \\ 1.51 E-05 & 9.82 E-01 & 1.07 E+00 \\ 2.69 E-05 & 8.70 E-01 & 9.48 E-01 \\ 5.94 E-06 & 1.93 E-01 & 2.10 E-01\end{array}$


Table 33. Peak Values of Population Dose, Cancer Fatalities, Costs, Centerline Individual Dose and Centerline Individual Risk for EA Accident Categories (Continued)

\begin{tabular}{|c|c|c|c|c|c|c|}
\hline & & $B R-2$ & & & RHF & \\
\hline Site/Loc & EA4 & EA5 & EA6 & EA4 & EA.5 & EA6 \\
\hline CHA-D & $0.00 E+00$ & $2.61 E+04$ & $2.61 E+04$ & $0.00 E+00$ & $0.00 E+00$ & $0.00 E+00$ \\
\hline $\mathrm{CHA}-\mathrm{C}$ & $0.00 \mathrm{E}+00$ & $2.55 \mathrm{E}+04$ & $2.55 E+04$ & $0.00 E+00$ & $0.00 \mathrm{E}+00$ & $0.00 E+00$ \\
\hline CNC-D & $0.00 \mathrm{E}+00$ & $0.00 \mathrm{E}+00$ & $0.00 \mathrm{E}+00$ & $0.00 \mathrm{E}+00$ & $0.00 E+00$ & $0.00 E+00$ \\
\hline CNC-C & $0.00 E+00$ & $0.00 \mathrm{E}+00$ & $0.00 E+00$ & $0.00 E \div 00$ & $0.00 E+00$ & $0.00 \mathrm{E} \div 00$ \\
\hline GAL-D & $0.00 E+00$ & $2.53 E+04$ & $2.53 E+04$ & $0.00 \mathrm{E} \div 00$ & $6.48 E+03$ & $6.48 E+03$ \\
\hline GAL-C & $0.00 E+00$ & $2.27 E+04$ & $2.27 E+04$ & $0.00 E+00$ & $5.84 \mathrm{E}+03$ & $5.84 E+03$ \\
\hline JAC-D & $0.00 \Xi+00$ & $5.45 E+04$ & $5.45 E+04$ & $0.00 E+00$ & $0.00 E+00$ & $0.00 \mathrm{E}+00$ \\
\hline JAC-C & $0.00 E+00$ & $5.90 \mathrm{E}+04$ & $5.90 \mathrm{E}+04$ & $0.00 E \div 00$ & $0.00 E+00$ & $0.00 E+00$ \\
\hline LOS-D & $0.00 \mathrm{E}+00$ & $0.00 E+00$ & $0.00 E+00$ & $0.00 \mathrm{E}+00$ & $0.00 \mathrm{E}+00$ & $0.00 \mathrm{E}+00$ \\
\hline LOS-C & $0.00 E+00$ & $0.00 \mathrm{E}+00$ & $0.00 \mathrm{E}+00$ & $0.00 E+00$ & $0.00 E+00$ & $0.00 E+00$ \\
\hline MOT-D & 0.00 & $1.47 \mathrm{E}+04$ & 1.47 & $.00 E \div 00$ & $.47 E+04$ & $1.47 \mathrm{E}+04$ \\
\hline NEW-D & 0.00 & $1.31 E+04$ & 1.3 & $.00 \mathrm{E}+00$ & $0.00 E+00$ & $0.00 \mathrm{E}+00$ \\
\hline NEW-C & 0.00 & 5.6 & 03 & $.00 E+00$ & $0.00 E+00$ & $0.00 \mathrm{E}+00$ \\
\hline NOR-D & .00 & +03 & +03 & $0.00 \mathrm{E} \div 00$ & $6.14 E+03$ & $6.14 \mathrm{E} \div 03$ \\
\hline NOR-C & 0.00 & $4.91 \mathrm{E}+03$ & $4.91 E+03$ & $0.00 E+00$ & $4.91 E+03$ & $4.91 E+03$ \\
\hline PHI-D & $0.00 \mathrm{E}+00$ & $9.14 \mathrm{E}+03$ & $9.14 \mathrm{E}+03$ & $0.00 \mathrm{E}+00$ & $9.14 \mathrm{E}+03$ & $9.14 E+03$ \\
\hline PHI-C & $0.00 \mathrm{E}+00$ & $6.53 E+03$ & $6.53 E+03$ & $0.00 \mathrm{E} \div 00$ & $6.53 E+03$ & $6.53 E+03$ \\
\hline POR-D & $0.00 E+00$ & $3.22 \mathrm{E}+03$ & $3.22 E \div 03$ & $0.00 E+00$ & $3.22 E+03$ & $3.22 E+03$ \\
\hline POR-C & $0.00 E+00$ & $3.22 \mathrm{E}+03$ & $3.22 E+03$ & $0.00 \mathrm{E}+00$ & $3.22 \mathrm{E}+03$ & $3.22 \mathrm{E}+03$ \\
\hline SAV-D & $0.00 \mathrm{E}+00$ & $4.33 E+04$ & $4.33 E+04$ & $0.00 E+00$ & $0.00 E+00$ & $0.00 E \div 00$ \\
\hline SAV-C & $0.00 E+00$ & $3.95 E+04$ & $3.95 \Xi \div 04$ & $0.00 E+00$ & $0.00 E+00$ & $0.00 E+00$ \\
\hline$S E A-C$ & $0.00 E+00$ & $0.00 \mathrm{E}+00$ & $0.00 \mathrm{E}+00$ & $0.00 E+00$ & $0.00 E+00$ & $0.00 \mathrm{E}+00$ \\
\hline TAC-D & $0.00 \mathrm{E}+00$ & $8.08 E+03$ & $8.08 E+03$ & $0.00 E+00$ & $8.08 E+03$ & $8.08 E \div 03$ \\
\hline TAC-C & $0.00 E+00$ & $0.00 \mathrm{E}+00$ & $0.00 E+00$ & $0.00 E+00$ & $0.00 E+00$ & $0.00 E+00$ \\
\hline WIL-D & $0.00 \mathrm{E}+00$ & $1.47 \mathrm{E}+04$ & $1.47 E+04$ & $0.00 \mathrm{E}+00$ & $1.47 E+04$ & $1.47 \mathrm{E}+04$ \\
\hline w & $0.00 \mathrm{E}+00$ & $1.32 \mathrm{E}+04$ & $1.32 \mathrm{E}+04$ & $0.00 E+00$ & $1.32 \mathrm{E}+04$ & $1.32 E+04$ \\
\hline
\end{tabular}

\begin{tabular}{|c|c|c|c|c|c|c|}
\hline \multirow[b]{2}{*}{ Site/Loc } & \multicolumn{3}{|c|}{ OSIRIS } & \multicolumn{3}{|c|}{ TRIGA } \\
\hline & EA4 & EA5 & EA6 6 & EA4 & EA5 & EA6 \\
\hline CHA-D & $0.00 \mathrm{E}+00$ & $6.53 E+03$ & $6.53 E+03$ & $0.00 E+00$ & $0.00 \mathrm{E}+00$ & $0.00 \mathrm{E}+00$ \\
\hline CHA-C & $0.00 E+00$ & $5.87 E+03$ & $5.87 E+03$ & $0.00 \mathrm{E}+00$ & $0.00 E+00$ & $0.00 \mathrm{E}+00$ \\
\hline$C N C-D$ & $0.00 E+00$ & $0.00 \mathrm{E}+00$ & $0.00 \mathrm{E}+00$ & $0.00 E+00$ & $0.00 \mathrm{E}+00$ & $0.00 \mathrm{E}+00$ \\
\hline CNC-C & $0.00 \mathrm{E}+00$ & $0.00 E+00$ & $0.00 \mathrm{E}+00$ & $0.00 \mathrm{E}+00$ & $0.00 \mathrm{E}+00$ & $0.00 E+00$ \\
\hline GAI-D & $0.00 \mathrm{E}+00$ & $6.48 E+03$ & $2.53 \mathrm{E}+04$ & $0.00 E+00$ & $0.00 \mathrm{E}+00$ & $0.00 E+00$ \\
\hline GAI-C & $0.0 .0 \mathrm{E}+00$ & $5.84 E+03$ & $2.27 \mathrm{E}+04$ & $0.00 \mathrm{E}+00$ & $0.00 \mathrm{E}+00$ & $0.00 E+00$ \\
\hline JAC-D & $0.00 \mathrm{E}+00$ & $1.49 E+04$ & $1.49 E+04$ & $0.00 \mathrm{E}+00$ & $0.00 E+00$ & $0.00 \mathrm{E}+00$ \\
\hline JAC-C & $0.00 \mathrm{E}+00$ & $1.42 E+04$ & $1.42 \mathrm{E}+04$ & $0.00 E+00$ & $0.00 \mathrm{E}+00$ & $0.00 \mathrm{E}+00$ \\
\hline IOS-D & $0.00 \mathrm{E}+00$ & $0.00 \Xi+00$ & $0.00 \mathrm{E}+00$ & $0.00 \mathrm{E}+00$ & $0.00 \mathrm{E}+00$ & $0.00 E+00$ \\
\hline IOS-C & $0.00 \mathrm{E}+00$ & $0.00 E \div 00$ & $0.00 \mathrm{E}+00$ & $0.00 \mathrm{E}+00$ & $0.00 \mathrm{E}+00$ & $0.00 E+00$ \\
\hline MOT-D & $0.00 \mathrm{E}+00$ & $1.47 E+04$ & $1.47 \mathrm{E}+04$ & $0.00 \mathrm{E}+00$ & $0.00 \mathrm{E}+00$ & $0.00 \mathrm{E}+00$ \\
\hline NEW-D & $0.00 \mathrm{E}+00$ & $1.31 E+04$ & $1.31 E+04$ & $0.00 \mathrm{E}+00$ & $0.00 \mathrm{E}+00$ & $0.00 \mathrm{E}+00$ \\
\hline NEW-C & $0.00 \mathrm{E}+00$ & $5.64 E+03$ & $5.64 \mathrm{E}+03$ & $0.00 \mathrm{E}+00$ & $0.00 \mathrm{E}+00$ & $0.00 E+00$ \\
\hline NOR-D & $0.00 \mathrm{E}+00$ & $6.14 E+03$ & $6.14 E+03$ & $0.00 E+00$ & $0.00 \mathrm{E}+00$ & $0.00 \mathrm{E}+00$ \\
\hline NOR-C & $0.00 E+00$ & $4.91 \mathrm{E}+03$ & $4.91 E+03$ & $0.00 \mathrm{E}+00$ & $0.00 \mathrm{E}+00$ & $0.00 \mathrm{E}+00$ \\
\hline PHI-D & $0.00 E+00$ & $9.14 E+03$ & $9.14 \mathrm{E}+03$ & $0.00 \mathrm{E}+00$ & $0.00 E+00$ & $0.00 \mathrm{E}+00$ \\
\hline PHI-C & $0.00 E+00$ & $6.53 E+03$ & $6.53 E+03$ & $0.00 \mathrm{E}+00$ & $0.00 E+00$ & $0.00 E+00$ \\
\hline POR-D & $0.00 \mathrm{E}+00$ & $3.22 \mathrm{E}+03$ & $3.22 E+03$ & $0.00 \mathrm{E}+00$ & $0.00 \mathrm{E}+00$ & $0.00 \mathrm{E}+00$ \\
\hline POR-C & $0.00 E \div 00$ & $3.22 \mathrm{E}+03$ & $3.22 \mathrm{E}+03$ & $0.00 E+00$ & $0.00 E+00$ & $0.00 E+00$ \\
\hline SAV-D & $0.00 E+00$ & $1.08 \mathrm{E}+04$ & $1.08 E+04$ & $0.00 E+00$ & $0.00 \mathrm{E}+00$ & $0.00 \mathrm{E}+00$ \\
\hline SAV-C & $0.00 E+00$ & $1.03 \mathrm{E}+04$ & $1.03 E+04$ & $0.00 \mathrm{E}+00$ & $0.00 \mathrm{E}+00$ & $0.00 E+00$ \\
\hline SEA-C & $0.00 E+00$ & $0.00 \mathrm{E}+00$ & $0.00 E+00$ & $0.00 E+00$ & $0.00 E+00$ & $0.00 E+00$ \\
\hline TAC-D & $0.00 E+00$ & $8.08 E+03$ & $8.08 E \div 03$ & $0.00 \mathrm{E}+00$ & $0.00 E+00$ & $0.00 \mathrm{E}+00$ \\
\hline TAC-C & $0.00 E+00$ & $0.00 \mathrm{E}+00$ & $0.00 E+00$ & $0.00 E+00$ & $0.00 \mathrm{E}+00$ & $0.00 \mathrm{E}+00$ \\
\hline WIL-D & $0.00 E+00$ & $1.47 \mathrm{E}+04$ & $1.47 \mathrm{E}+04$ & $0.00 E+00$ & $0.00 \mathrm{E}+00$ & $0.00 \mathrm{E}+00$ \\
\hline WIL-C & $0.00 \mathrm{E}+00$ & $1.32 \mathrm{E}+04$ & $1.32 \mathrm{E}+04$ & $0.00 \Xi \div 00$ & $0.00 \mathrm{E}+00$ & $0.00 \mathrm{E}+00$ \\
\hline
\end{tabular}


Table 33. Peak Values of Population Dose, Cancer Fatalities, Costs, Centerline Individual Dose and Centerline Individual Risk for EA Accident Categories (Continued)

\begin{tabular}{|c|c|c|c|c|c|c|}
\hline & & BR-2 & & & RHF & \\
\hline Site/Loc & EA4 & EA5 & EA6 & EA4 & EA5 & EA6 6 \\
\hline$C H A-D$ & $3.66 \mathrm{E}-06$ & $5.85 \mathrm{E}-02$ & $6.39 E-02$ & $1.46 \Xi-06$ & $2.32 \mathrm{E}-02$ & $2.53 E$ \\
\hline $\mathrm{HA}-\mathrm{C}$ & $3.66 \mathrm{E}-06$ & $5.85 \mathrm{E}-02$ & $6.39 E-02$ & $1.46 \mathrm{E}-06$ & $2.32 E-02$ & $2.53 \mathrm{E}-$ \\
\hline NC-D & $3.66 \mathrm{E}-06$ & $2.51 E-02$ & $2.74 E-02$ & $1.46 \mathrm{E}-06$ & $9.94 \mathrm{E}-03$ & $1.08 \mathrm{E}-0$ \\
\hline NC $-C$ & $3.66 \mathrm{E}-06$ & $2.51 E-02$ & $2.74 E-02$ & $1.46 \mathrm{E}-06$ & $9.94 \mathrm{E}-03$ & $1.08 \mathrm{E}-0$ \\
\hline$A L-D$ & $3.66 E-06$ & $.34 E-02$ & $5.82 \mathrm{E}-02$ & $.46 E-06$ & $2.11 E-02$ & $2: 31 \mathrm{E}-0$ \\
\hline AI-C & $3.66 \mathrm{E}-06$ & $.34 E-02$ & $5.82 E-02$ & $.46 \mathrm{E}-06$ & $2.11 E-02$ & $2.31 E-0$ \\
\hline$A C-D$ & $3.66 \mathrm{E}-06$ & $5.85 \mathrm{E}-02$ & $6.39 \mathrm{E}$ & $46 E-06$ & $2.32 \mathrm{E}-02$ & $2.53 \mathrm{E}-0$ \\
\hline AC-C & $3.66 E-06$ & $5.85 E-02$ & $6.39 \mathrm{E}$ & $46 E-06$ & $2.32 \mathrm{E}-02$ & $2.53 \mathrm{E}-0$ \\
\hline$O S-D$ & $3.66 \mathrm{E}-06$ & $2.51 \mathrm{E}-02$ & $2.74 \mathrm{E}$ & $46 E-06$ & $9.94 \mathrm{E}-03$ & $1.08 \mathrm{E}-0$ \\
\hline LOS-C & $3.66 E-06$ & $2.51 E-02$ & $2.74 \mathrm{E}$ & $1.46 \mathrm{E}-06$ & $9.94 \mathrm{E}-03$ & $1.08 \mathrm{E}-0$ \\
\hline MOT-D & $3.66 \mathrm{E}-06$ & $5.96 \mathrm{E}-02$ & $6.50 \mathrm{E}$ & $1.46 \mathrm{E}-06$ & $2.36 E-02$ & $2.57 \mathrm{E}-$ \\
\hline NEW-D & $3.66 E-06$ & $4.12 \mathrm{E}-02$ & $4.50 \mathrm{E}$ & $46 E-06$ & $1.63 \mathrm{E}-02$ & $1.78 \mathrm{E}-0$ \\
\hline NEW-C & $3.66 \mathrm{E}-06$ & $4.12 \mathrm{E}-02$ & $4.50 \mathrm{E}$ & $46 E-06$ & $1.63 \mathrm{E}-02$ & $1.78 \mathrm{E}-0$ \\
\hline NOR -D & $3.66 \mathrm{E}-06$ & $5.96 \mathrm{E}-02$ & $6.50 \mathrm{E}$ & $.46 \mathrm{E}-06$ & $2.36 \mathrm{E}-02$ & $2.57 \mathrm{E}-0$ \\
\hline NOR-C & $3.66 E-06$ & $5.96 \mathrm{E}-02$ & $6.50 \mathrm{E}$ & $.46 E-06$ & $2.36 \mathrm{E}-02$ & $2.57 \mathrm{E}-0$ \\
\hline PHI-D & $3.66 \mathrm{E}-06$ & $6.06 \mathrm{E}-02$ & $6.61 E-02$ & $.46 \mathrm{E}-06$ & $2.40 \mathrm{E}-02$ & $2.62 \mathrm{E}-0$ \\
\hline PHI-C & $3.66 \mathrm{E}-06$ & $6.06 \mathrm{E}-02$ & $6.61 \mathrm{E}-02$ & $.46 E-06$ & $2.40 \mathrm{E}-02$ & $2.62 \mathrm{E}-0$ \\
\hline POR-D & $3.66 \mathrm{E}-06$ & $5.64 \mathrm{E}-02$ & $6.15 E-02$ & $1.46 \mathrm{E}-06$ & $2.23 E-02$ & $2.43 \mathrm{E}-0$ \\
\hline POR-C & $3.66 \mathrm{E}-06$ & $5.64 \mathrm{E}-02$ & $6.15 \mathrm{E}-02$ & $1.46 \mathrm{E}-06$ & $2.23 \mathrm{E}-02$ & $2.43 \mathrm{E}-0$ \\
\hline SAV-D & $3.66 \mathrm{E}-06$ & $5.85 E-02$ & $6.39 \mathrm{E}-02$ & $1.46 \mathrm{E}-06$ & $2.32 \mathrm{E}-02$ & $2.53 \mathrm{E}-0$ \\
\hline SAV-C & $3.66 \mathrm{E}-06$ & $5.85 E-02$ & $6.39 \mathrm{E}-02$ & $1.46 E-06$ & $2.32 \mathrm{E}-02$ & $2.53 \mathrm{E}-0$ \\
\hline SEA-C & $3.66 \mathrm{E}-06$ & $5.64 \mathrm{E}-02$ & $6.15 \mathrm{E}-02$ & $1.46 \mathrm{E}-06$ & $2.23 E-02$ & $2.43 E-0$ \\
\hline$A C-D$ & $3.66 \mathrm{E}-06$ & $5.64 E-02$ & $6.15 \mathrm{E}-02$ & $1.46 \mathrm{E}-06$ & $2.23 \mathrm{E}-02$ & $2.43 E-0$ \\
\hline$A C-C$ & $3.66 E-06$ & $5.64 E-02$ & $6.15 \mathrm{E}-02$ & $1.46 \mathrm{E}-06$ & $2.23 E-02$ & $2.43 \mathrm{E}-$ \\
\hline$L-D$ & $3.66 \mathrm{E}-06$ & $5.96 E-02$ & $6.50 \mathrm{E}-02$ & $1.46 \mathrm{E}-06$ & $2.36 \mathrm{E}-02$ & $2.57 \mathrm{E}-$ \\
\hline$I-C$ & $3.66 E-06$ & $5.96 \mathrm{E}-02$ & $6.50 \mathrm{E}-02$ & $1.46 E-06$ & $2.36 \mathrm{E}-02$ & $2.57 \mathrm{E}-$ \\
\hline
\end{tabular}

\begin{tabular}{lccc} 
& \multicolumn{3}{c}{ OSIRIS } \\
Site/LOC & EA4 & EA5 & EA6 \\
CHA-D & $5.06 E-06$ & $5.68 E-02$ & $6.21 E-02$ \\
CHA-C & $5.06 E-06$ & $5.68 E-02$ & $6.21 E-02$ \\
CNC-D & $5.06 E-06$ & $2.44 E-02$ & $2.67 E-02$ \\
CNC-C & $5.06 E-06$ & $2.44 E-02$ & $2.67 E-02$ \\
GAI-D & $5.06 E-06$ & $5.18 E-02$ & $5.67 E-02$ \\
GAI-C & $5.06 E-06$ & $5.18 E-02$ & $5.67 E-02$ \\
JAC-D & $5.06 E-06$ & $5.68 E-02$ & $6.21 E-02$ \\
JAC-C & $5.06 E-06$ & $5.68 E-02$ & $6.21 E-02$ \\
LOS-D & $5.06 E-06$ & $2.44 E-02$ & $2.67 E-02$ \\
LOS-C & $5.06 E-06$ & $2.44 E-02$ & $2.67 E-02$ \\
MOT-D & $5.06 E-06$ & $5.78 E-02$ & $6.32 E-02$ \\
NEW-D & $5.06 E-06$ & $4.00 E-02$ & $4.38 E-02$ \\
NEW-C & $5.06 E-06$ & $4.00 E-02$ & $4.38 E-02$ \\
NOR-D & $5.06 E-06$ & $5.78 E-02$ & $6.32 E-02$ \\
NOR-C & $5.06 E-06$ & $5.78 E-02$ & $6.32 E-02$ \\
PHI-D & $5.06 E-06$ & $5.88 E-02$ & $6.43 E-02$ \\
PHI-C & $5.06 E-06$ & $5.88 E-02$ & $6.43 E-02$ \\
POR-D & $5.06 E-06$ & $5.47 E-02$ & $5.98 E-02$ \\
POR-C & $5.06 E-06$ & $5.47 E-02$ & $5.98 E-02$ \\
SAV-D & $5.06 E-06$ & $5.68 E-02$ & $6.21 E-02$ \\
SAV-C & $5.06 E-06$ & $5.68 E-02$ & $6.21 E-02$ \\
SEA-C & $5.06 E-06$ & $5.47 E-02$ & $5.98 E-02$ \\
TAC-D & $5.06 E-06$ & $5.47 E-02$ & $5.98 E-02$ \\
TAC-C & $5.06 E-06$ & $5.47 E-02$ & $5.98 E-02$ \\
WIL-D & $5.06 E-06$ & $5.78 E-02$ & $6.32 E-02$ \\
WIL-C & $5.06 E-06$ & $5.78 E-02$ & $6.32 E-02$
\end{tabular}

$\begin{array}{ccc}\text { EA4 } & \text { TRIGA } & \\ 4.06 E-07 & 8.15 E-03 & 8.89 E-03 \\ 4.06 E-07 & 8.15 E-03 & 8.89 E-03 \\ 4.06 E-07 & 3.50 E-03 & 3.81 E-03 \\ 4.06 E-07 & 3.50 E-03 & 3.81 E-03 \\ 4.06 E-07 & 7.43 E-03 & 8.10 E-03 \\ 4.06 E-07 & 7.43 E-03 & 8.10 E-03 \\ 4.06 E-07 & 8.15 E-03 & 8.89 E-03 \\ 4.06 E-07 & 8.15 E-03 & 8.89 E-03 \\ 4.06 E-07 & 3.50 E-03 & 3.81 E-03 \\ 4.06 E-07 & 3.50 E-03 & 3.81 E-03 \\ 4.06 E-07 & 8.29 E-03 & 9.04 E-03 \\ 4.06 E-07 & 5.74 E-03 & 6.26 E-03 \\ 4.06 E-07 & 5.74 E-03 & 6.26 E-03 \\ 4.06 E-07 & 8.29 E-03 & 9.04 E-03 \\ 4.06 E-07 & 8.29 E-03 & 9.04 E-03 \\ 4.06 E-07 & 8.43 E-03 & 9.20 E-03 \\ 4.06 E-07 & 8.43 E-03 & 9.20 E-03 \\ 4.06 E-07 & 7.85 E-03 & 8.56 E-03 \\ 4.06 E-07 & 7.85 E-03 & 8.56 E-03 \\ 4.06 E-07 & 8.15 E-03 & 8.89 E-03 \\ 4.06 E-07 & 8.15 E-03 & 8.89 E-03 \\ 4.06 E-07 & 7.85 E-03 & 8.56 E-03 \\ 4.06 E-07 & 7.85 E-03 & 8.56 E-03 \\ 4.06 E-07 & 7.85 E-03 & 8.56 E-03 \\ 4.06 E-07 & 8.29 E-03 & 9.04 E-03 \\ 4.06 E-07 & 8.29 E-03 & 9.04 E-03\end{array}$


Table 33. Peak Values of Population Dose, Cancer Fatalities, Costs, Centerline Individual Dose and Centerline Individual Risk for EA Accident Categories (Concluded)

\begin{tabular}{|c|c|c|c|c|c|c|}
\hline & Individual & \multicolumn{2}{|c|}{ Centerline } & Cancer Risk, & \multirow{2}{*}{$\begin{array}{c}0-1.6 \\
\text { RHF }\end{array}$} & \multirow[t]{2}{*}{$\mathrm{km}$} \\
\hline & \multicolumn{3}{|c|}{ BR-2 } & \multirow[b]{2}{*}{ EA4 } & & \\
\hline Site/Loc & EAL4 & EAS & EA6 & & EA5 & EA6 \\
\hline CHA-D & $1.79 E-07$ & $2.44 E-03$ & $2.66 \mathrm{E}-03$ & $7.29 E-08$ & $9.65 E-04$ & $1.05 \mathrm{E}-03$ \\
\hline $\mathrm{CHA}-\mathrm{C}$ & $1.79 \mathrm{E}-07$ & $2.44 E-03$ & $2.66 \mathrm{E}-03$ & $7.29 E-08$ & $9.65 E-04$ & $1.05 E-03$ \\
\hline CNC-D & $1.79 \mathrm{E}-07$ & $1.05 \mathrm{E}-03$ & $1.14 \mathrm{E}-03$ & $7.29 \mathrm{E}-08$ & $4.74 \mathrm{E}-04$ & $4.52 E-04$ \\
\hline $\mathrm{CNC}-\mathrm{C}$ & $1.79 E-07$ & $1.05 \mathrm{E}-03$ & $1.14 E-03$ & $7.29 \mathrm{E}-08$ & $4.14 E-04$ & $4.52 E-04$ \\
\hline GAI-D & $1.79 \mathrm{E}-07$ & $2.23 E-03$ & $2.43 E-03$ & $7.29 \mathrm{E}-08$ & $8.80 E-04$ & $9.60 \mathrm{E}-04$ \\
\hline GAL-C & $1.79 \mathrm{E}-07$ & $2.23 E-03$ & $2.43 E-03$ & $7.29 \mathrm{E}-08$ & $8.80 E-04$ & $9: 60 E-04$ \\
\hline$J A C-D$ & 1. $79 \mathrm{E}-07$ & $2.44 E-03$ & $2.66 \mathrm{E}-03$ & $7.29 \mathrm{E}-08$ & $9.65 \mathrm{E}-04$ & 2. $05 E-03$ \\
\hline JAC-C & $1.79 \mathrm{E}-07$ & $2.44 E-03$ & $2.66 \mathrm{E}-03$ & $7.29 E-08$ & $9.65 E-04$ & $1.05 \mathrm{E}-03$ \\
\hline LOS-D & $1.79 E-07$ & $2.05 \mathrm{E}-03$ & $1.14 \mathrm{E}-03$ & $7.29 E-08$ & $4.14 E-04$ & $4.52 E-04$ \\
\hline IOS-C & $1.79 \pm-07$ & $1.05 \mathrm{E}-03$ & $1.14 E-03$ & $7.29 \mathrm{E}-08$ & $4.14 \mathrm{E}-04$ & $4.52 E-04$ \\
\hline MOT-D & $1.79 E-07$ & $2.48 E-03$ & $2.71 \mathrm{E}-03$ & $7.29 E-08$ & $9.82 E-04$ & $1.07 \mathrm{E}-03$ \\
\hline NEW-D & $1.79 \mathrm{E}-07$ & $1.72 \mathrm{E}-03$ & $1.88 \mathrm{E}-03$ & $7.29 E-08$ & $6.80 E-04$ & $7.42 E-04$ \\
\hline NEW-C & $1.79 \mathrm{E}-07$ & $1.72 \mathrm{E}-03$ & $1.88 \mathrm{E}-03$ & $7.29 E-08$ & $6.80 E-04$ & $7.42 \mathrm{E}-04$ \\
\hline NOR-D & $1.79 E-07$ & $2.48 E-03$ & $2.71 E-03$ & $7.29 \mathrm{E}-08$ & $9.82 E-04$ & $1.07 \mathrm{E}-03$ \\
\hline NOR-C & $1.79 \mathrm{E}-07$ & $2.48 E-03$ & $2.71 E-03$ & $7.29 E-08$ & $9.82 E-04$ & 1. 07E-03 \\
\hline PHI-D & $1.79 E-07$ & $2.53 E-03$ & $2.76 \mathrm{E}-03$ & $7.29 E-08$ & $9.98 E-04$ & $1.09 \mathrm{E}-03$ \\
\hline PHI-C & $1.79 E-07$ & $2.53 E-03$ & $2.76 E-03$ & $7.29 \mathrm{E}-08$ & $9.98 E-04$ & I. $09 \mathrm{E}-03$ \\
\hline POR-D & $1.79 \mathrm{E}-07$ & $2.35 E-03$ & $2.57 E-03$ & $7.29 E-08$ & $9.29 \pm-04$ & 1. 01E-03 \\
\hline POR-C & $1.79 \mathrm{E}-07$ & $2.35 E-03$ & $2.57 E-03$ & $7.29 E-08$ & $9.29 \mathrm{E}-04$ & $1.01 E-03$ \\
\hline$S A V-D$ & $1.79 E-07$ & $2.44 E-03$ & $2.66 E-03$ & $7.29 E-08$ & $9.65 E-04$ & $1.05 E-03$ \\
\hline SAV-C & $1.79 \mathrm{E}-07$ & $2.44 E-03$ & $2.66 \mathrm{E}-03$ & $7.29 \mathrm{E}-08$ & $9.65 \mathrm{E}-04$ & $1.05 E-03$ \\
\hline$S E A-C$ & $1.79 \mathrm{E}-07$ & $2.35 E-03$ & $2.57 E-03$ & $7.29 E-08$ & $9.29 E-04$ & $1.012-03$ \\
\hline TAC-D & $1.79 E-07$ & $2.35 E-03$ & $2.57 E-03$ & $7.29 E-08$ & $9.29 E-04$ & 1. $01 E-03$ \\
\hline TAC-C & $1.79 \mathrm{E}-07$ & $2.35 E-03$ & $2.57 E-03$ & $7.29 \mathrm{E}-08$ & $9.29 E-04$ & 1. 01E-03 \\
\hline WIL-D & $1.79 E-07$ & $2.48 E-03$ & $2.71 \mathrm{E}-03$ & $7.29 E-08$ & $9.82 E-04$ & $1.07 \mathrm{E}-03$ \\
\hline \multirow[t]{2}{*}{ WII-C } & $1.79 \mathrm{E}-07$ & $2.48 E-03$ & $2.7 I E-03$ & $7.29 \mathrm{E}-08$ & $9.82 E-04$ & $1.07 E-03$ \\
\hline & \multicolumn{3}{|c|}{ OSIRIS } & \multicolumn{3}{|c|}{ TRIGA } \\
\hline Site/Ioc & EA4 & EA5 & EA6 & EA4 & EA5 & EA6 \\
\hline CHA-D & $2.39 E-07$ & $2.36 \mathrm{E}-03$ & $2.59 \mathrm{E}-03$ & $1.84 \mathrm{E}-08$ & $3.39 E-04$ & $3.70 \mathrm{E}-04$ \\
\hline $\mathrm{CHA}-\mathrm{C}$ & $2.39 E-07$ & $2.36 \mathrm{E}-03$ & $2.59 E-03$ & I. $84 \mathrm{E}-08$ & $3.39 E-04$ & $3.70 E-04$ \\
\hline CNC-D & $2.39 E-07$ & $1.01 \mathrm{E}-03$ & $1.11 E-03$ & $1.84 \mathrm{E}-08$ & $1.46 \mathrm{E}-04$ & $1.59 E-04$ \\
\hline $\mathrm{CNC}-\mathrm{C}$ & $2.39 E-07$ & $1.01 \mathrm{E}-03$ & $1.11 \mathrm{E}-03$ & $1.84 \mathrm{E}-08$ & $1.46 \mathrm{E}-04$ & $1.59 \mathrm{E}-04$ \\
\hline GAL-D & $2.39 E-07$ & $2.15 E-03$ & $2.36 \mathrm{E}-03$ & $1.84 \mathrm{E}-08$ & $3.09 E-04$ & $3.37 E-04$ \\
\hline GAI-C & $2.3,9 E-07$ & $2.15 E-03$ & $2.36 E-03$ & $1.84 \mathrm{E}-08$ & $3.09 E-04$ & $3.37 \mathrm{E}-04$ \\
\hline$J A C-D$ & $2.39 E-07$ & $2.36 \mathrm{E}-03$ & $2.59 E-03$ & $1.84 E-08$ & $3.39 E-04$ & $3.70 \mathrm{E}-04$ \\
\hline $\mathrm{JAC}-\mathrm{C}$ & $2.39 E-07$ & $2.36 \mathrm{E}-03$ & $2.59 E-03$ & $1.84 \mathrm{E}-08$ & $3.39 E-04$ & $3.70 \mathrm{E}-04$ \\
\hline LOS-D & $2.39 E-07$ & $1.01 \mathrm{E}-03$ & $1.11 E-03$ & $1.84 \mathrm{E}-08$ & $1.46 \mathrm{E}-04$ & $1.59 \mathrm{E}-04$ \\
\hline LOS-C & $2.39 E-07$ & $1.01 E-03$ & $1.11 \mathrm{E}-03$ & 1. $84 E-08$ & $1.46 \mathrm{E}-04$ & 1. $59 \mathrm{E}-04$ \\
\hline MOT-D & $2.39 E-07$ & $2.40 E-03$ & $2.63 E-03$ & $1.84 E-08$ & $3.45 E-04$ & $3.77 E-04$ \\
\hline NEW-D & $2.39 E-07$ & $1.67 \mathrm{E}-03$ & $1.82 \mathrm{E}-03$ & 1. $84 \mathrm{E}-08$ & $2.39 E-04$ & $2.61 E-04$ \\
\hline NEW-C & $2.39 E-07$ & $1.67 \mathrm{E}-03$ & $1.82 E-03$ & $1.84 E-08$ & $2.39 \mathrm{E}-04$ & $2.61 E-04$ \\
\hline NOR-D & $2.39 E-07$ & $2.40 \mathrm{E}-03$ & $2.63 E-03$ & $1.84 \mathrm{E}-08$ & $3.45 \mathrm{E}-04$ & $3.77 E-04$ \\
\hline NOR-C & $2.39 \mathrm{E}-07$ & $2.40 \mathrm{E}-03$ & $2.63 E-03$ & 1. $84 \mathrm{E}-08$ & $3.45 E-04$ & $3.77 \mathrm{E}-04$ \\
\hline PHI-D & $2.39 E-07$ & $2.45 \mathrm{E}-03$ & $2.68 E-03$ & $1.84 \mathrm{E}-08$ & $3.51 E-04$ & $3.83 E-04$ \\
\hline $\mathrm{PHI}-\mathrm{C}$ & $2.39 \mathrm{E}-07$ & $2.45 \mathrm{E}-03$ & $2.68 E-03$ & $1.84 E-08$ & $3.51 E-04$ & $3.83 E-04$ \\
\hline POR-D & $2.39 E-07$ & $2.28 E-03$ & $2.49 E-03$ & $1.84 \mathrm{E}-08$ & $3.27 E-04$ & $3.56 \mathrm{E}-04$ \\
\hline POR-C & $2.39 E-07$ & $2.28 E-03$ & $2.49 E-03$ & $1.84 E-08$ & $3.27 E-04$ & $3.56 E-04$ \\
\hline SAV-D & $2.39 \mathrm{E}-07$ & $2.36 E-03$ & $2.59 E-03$ & $1.84 E-08$ & $3.39 E-04$ & $3.70 \mathrm{E}-04$ \\
\hline$S A V-C$ & $2.39 E-07$ & $2.36 E-03$ & $2.59 \mathrm{E}-03$ & $1.84 \mathrm{E}-08$ & $3.39 \mathrm{E}-04$ & $3.70 \mathrm{E}-04$ \\
\hline SEA-C & $2.39 E-07$ & $2.28 E-03$ & $2.49 \mathrm{E}-03$ & $1.84 \mathrm{E}-08$ & $3.27 E-04$ & $3.56 \mathrm{E}-04$ \\
\hline TAC-D & $2.39 E-07$ & $2.28 E-03$ & $2.49 \mathrm{E}-03$ & $1.84 \mathrm{E}-08$ & $3.27 \mathrm{E}-04$ & $3.56 E-04$ \\
\hline TAC-C & $2.39 E-07$ & $2.28 E-03$ & $2.49 E-03$ & $1.84 \mathrm{E}-08$ & $3.27 \mathbf{E}-04$ & $3.56 E-04$ \\
\hline WIL-D & $2.39 E-07$ & $2.40 E-03$ & $2.63 E-03$ & $1.84 \mathrm{E}-08$ & $3.45 E-04$ & $3.77 \mathrm{E}-04$ \\
\hline$W I I-C$ & $2.39 E-07$ & $2.40 \mathrm{E}-03$ & $2.63 E-03$ & $1.84 \mathrm{E}-08$ & $3.45 E-04$ & $3.77 \Xi-04$ \\
\hline
\end{tabular}


Table 34. Conditional Probabilities of Peak Values of Population Dose, Cancer Fatalities, Costs, Centerline Individual Dose and Centerline Individual Risk for EA Accident Categories

EDE Whole Body Population Dose, 0-80 km (SV)

$\begin{array}{lccc} & & & \text { BR-2 } \\ \text { Site/LOC } & \text { EA4 } & \text { EA5 } & \text { EA6 } \\ \text { CHA-D } & 1.01 E-05 & 1.01 E-05 & 1.01 E-05 \\ \text { CHA-C } & 7.77 E-06 & 4.44 E-06 & 4.44 E-06 \\ \text { CNC-D } & 8.47 E-04 & 1.18 E-05 & 1.18 E-05 \\ \text { CNC-C } & 7.58 E-06 & 7.58 E-06 & 7.58 E-06 \\ \text { GAI-D } & 7.80 E-06 & 9.75 E-06 & 9.75 E-06 \\ \text { GAL-C } & 7.80 E-06 & 9.75 E-06 & 9.75 E-06 \\ \text { JAC-D } & 6.03 E-06 & 6.03 E-06 & 6.03 E-06 \\ \text { JAC-C } & 6.08 E-06 & 8.06 E-06 & 8.06 E-06 \\ \text { LOS-D } & 1.83 E-03 & 3.42 E-06 & 3.42 E-06 \\ \text { LOS-C } & 4.91 E-06 & 2.81 E-06 & 2.81 E-06 \\ \text { MOT-D } & 1.67 E-05 & 2.76 E-05 & 2.76 E-05 \\ \text { NEW-D } & 2.03 E-05 & 2.03 E-05 & 2.03 E-05 \\ \text { NEW-C } & 2.50 E-04 & 7.65 E-05 & 7.65 E-05 \\ \text { NOR-D } & 3.51 E-04 & 9.62 E-06 & 9.62 E-06 \\ \text { NOR-C } & 1.07 E-05 & 1.61 E-05 & 1.61 E-05 \\ \text { RHI-D } & 3.17 E-06 & 3.17 E-06 & 3.17 E-06 \\ \text { PHI-C } & 2.44 E-05 & 2.44 E-05 & 2.44 E-05 \\ \text { POR-D } & 1.26 E-05 & 1.09 E-05 & 1.09 E-05 \\ \text { POR-C } & 3.19 E-04 & 1.09 E-05 & 1.09 E-05 \\ \text { SAV-D } & 1.13 E-05 & 6.22 E-06 & 6.22 E-06 \\ \text { SAV-C } & 1.30 E-05 & 1.14 E-05 & 1.14 E-05 \\ \text { SEA-C } & 1.36 E-04 & 6.79 E-04 & 6.79 E-04 \\ \text { TAC-D } & 5.33 E-06 & 1.14 E-05 & 1.14 E-05 \\ \text { TAC-C } & 1.08 E-05 & 1.08 E-05 & 1.08 E-05 \\ \text { WII-D } & 3.26 E-04 & 1.16 E-04 & 1.16 E-04 \\ \text { WII-C } & 3.04 E-04 & 1.08 E-04 & 1.08 E-04\end{array}$

$\begin{array}{ccc}\text { EA4 } & \text { RHE } & \text { EAS } \\ 1.01 E-05 & 1.01 E-05 & 1.01 E-05 \\ 7.77 E-06 & 4.44 E-06 & 4.44 E-06 \\ 8.47 E-04 & 1.18 E-05 & 1.18 E-05 \\ 7.58 E-06 & 7.58 E-06 & 7.58 E-06 \\ 7.80 E-06 & 7.80 E-06 & 7.80 E-06 \\ 7.80 E-06 & 9.75 E-06 & 9.75 E-06 \\ 6.03 E-06 & 6.03 E-06 & 6.03 E-06 \\ 6.08 E-06 & 8.06 E-06 & 8.06 E-06 \\ 1.83 E-03 & 3.42 E-06 & 3.42 E-06 \\ 4.91 E-06 & 2.81 E-06 & 2.81 E-06 \\ 1.67 E-05 & 2.76 E-05 & 2.76 E-05 \\ 2.03 E-05 & 2.03 E-05 & 2.03 E-05 \\ 2.50 E-04 & 7.65 E-05 & 7.65 E-05 \\ 3.51 E-04 & 9.62 E-06 & 9.62 E-06 \\ 1.07 E-05 & 1.61 E-05 & 1.61 E-05 \\ 3.17 E-06 & 3.17 E-06 & 3.17 E-06 \\ 2.44 E-05 & 2.44 E-05 & 2.44 E-05 \\ 1.26 E-05 & 1.09 E-05 & 1.09 E-05 \\ 3.19 E-04 & 1.09 E-05 & 1.09 E-05 \\ 1.13 E-05 & 6.22 E-06 & 6.22 E-06 \\ 1.30 E-05 & 1.14 E-05 & 1.14 E-05 \\ 1.36 E-04 & 6.79 E-04 & 6.79 E-04 \\ 5.33 E-06 & 1.14 E-05 & 1.14 E-05 \\ 1.08 E-05 & 1.08 E-05 & 1.08 E-05 \\ 3.26 E-04 & 1.16 E-04 & 1.16 E-04 \\ 3.04 E-04 & 1.08 E-04 & 1.08 E-04\end{array}$

\begin{tabular}{lccc} 
& \multicolumn{3}{c}{ OSIRIS } \\
Site/LOC & EA4 & EA5 & EA6 \\
CHA-D & $1.01 E-05$ & $1.01 E-05$ & $1.01 E-05$ \\
CHA-C & $7.77 E-06$ & $4.44 E-06$ & $4.44 E-06$ \\
CNC-D & $8.47 E-04$ & $1.18 E-05$ & $1.18 E-05$ \\
CNC-C & $7.58 E-06$ & $7.58 E-06$ & $7.58 E-06$ \\
GAI-D & $7.80 E-06$ & $7.80 E-06$ & $9.75 E-06$ \\
GAI-C & $7.80 E-06$ & $9.75 E-06$ & $9.75 E-06$ \\
JAC-D & $6.03 E-06$ & $6.03 E-06$ & $6.03 E-06$ \\
JAC-C & $6.08 E-06$ & $8.06 E-06$ & $8.06 E-06$ \\
LOS-D & $1.83 E-03$ & $3.42 E-06$ & $3.42 E-06$ \\
LOS-C & $4.91 E-06$ & $2.81 E-06$ & $2.81 E-06$ \\
MOT-D & $2.76 E-05$ & $2.76 E-05$ & $2.76 E-05$ \\
NEW-D & $2.03 E-05$ & $2.03 E-05$ & $2.03 E-05$ \\
NEW-C & $2.50 E-04$ & $7.65 E-05$ & $7.65 E-05$ \\
NOR-D & $3.51 E-04$ & $9.62 E-06$ & $9.62 E-06$ \\
NOR-C & $1.07 E-05$ & $1.61 E-05$ & $1.61 E-05$ \\
PHI-D & $3.17 E-06$ & $3.17 E-06$ & $3.17 E-06$ \\
PHI-C & $2.44 E-05$ & $2.44 E-05$ & $2.44 E-05$ \\
POR-D & $1.26 E-05$ & $1.09 E-05$ & $1.09 E-05$ \\
POR-C & $3.19 E-04$ & $1.09 E-05$ & $1.09 E-05$ \\
SAV-D & $1.13 E-05$ & $6.22 E-06$ & $6.22 E-06$ \\
SAV-C & $1.30 E-05$ & $1.14 E-05$ & $1.14 E-05$ \\
SEA-C & $1.97 E-04$ & $9.80 E-04$ & $9.80 E-04$ \\
TAC-D & $5.33 E-06$ & $1.14 E-05$ & $1.14 E-05$ \\
TAC-C & $1.08 E-05$ & $1.08 E-05$ & $1.08 E-05$ \\
WII-D & $3.26 E-04$ & $1.16 E-04$ & $1.16 E-04$ \\
WII-C & $3.04 E-04$ & $1.08 E-04$ & $1.08 E-04$ \\
& & &
\end{tabular}

$\begin{array}{ccc}\text { EA4 } & \text { TRIGA } & \text { EAS } \\ 1.01 E-05 & 1.01 E-05 & 1.01 E-05 \\ 7.77 E-06 & 4.44 E-06 & 4.44 E-06 \\ 8.47 E-04 & 1.18 E-05 & 1.18 E-05 \\ 7.58 E-06 & 7.58 E-06 & 7.58 E-06 \\ 7.80 E-05 & 7.80 E-06 & 7.80 E-06 \\ 7.80 E-06 & 9.75 E-06 & 9.75 E-06 \\ 6.03 E-06 & 6.03 E-06 & 6.03 E-06 \\ 6.08 E-06 & 8.06 E-06 & 8.06 E-06 \\ 1.83 E-03 & 3.42 E-06 & 3.42 E-06 \\ 4.91 E-06 & 2.81 E-06 & 2.81 E-06 \\ 1.67 E-05 & 2.76 E-05 & 2.76 E-05 \\ 2.03 E-05 & 2.03 E-05 & 2.03 E-05 \\ 2.50 E-04 & 7.65 E-05 & 7.65 E-05 \\ 3.51 E-04 & 9.62 E-06 & 9.62 E-06 \\ 1.07 E-05 & 1.61 E-05 & 1.61 E-05 \\ 3.17 E-06 & 3.17 E-06 & 3.17 E-06 \\ 2.44 E-05 & 2.44 E-05 & 2.44 E-05 \\ 1.26 E-05 & 1.09 E-05 & 1.09 E-05 \\ 3.19 E-04 & 1.09 E-05 & 1.09 E-05 \\ 1.13 E-05 & 6.22 E-06 & 6.22 E-06 \\ 1.30 E-05 & 1.14 E-05 & 1.14 E-05 \\ 1.36 E-04 & 9.80 E-04 & 9.80 E-04 \\ 5.33 E-06 & 1.14 E-05 & 1.14 E-05 \\ 1.08 E-05 & 1.08 E-05 & 1.08 E-05 \\ 3.26 E-04 & 1.16 E-04 & 1.16 E-04 \\ 3.04 E-04 & 1.08 E-04 & 1.08 E-04\end{array}$


Table 34. Conditional Probabilities of Peak Values of Population Dose, Cancer Fatalities, Costs, Centerline Individual Dose and Centerline Individual Risk for EA Accident Categories (Continued)

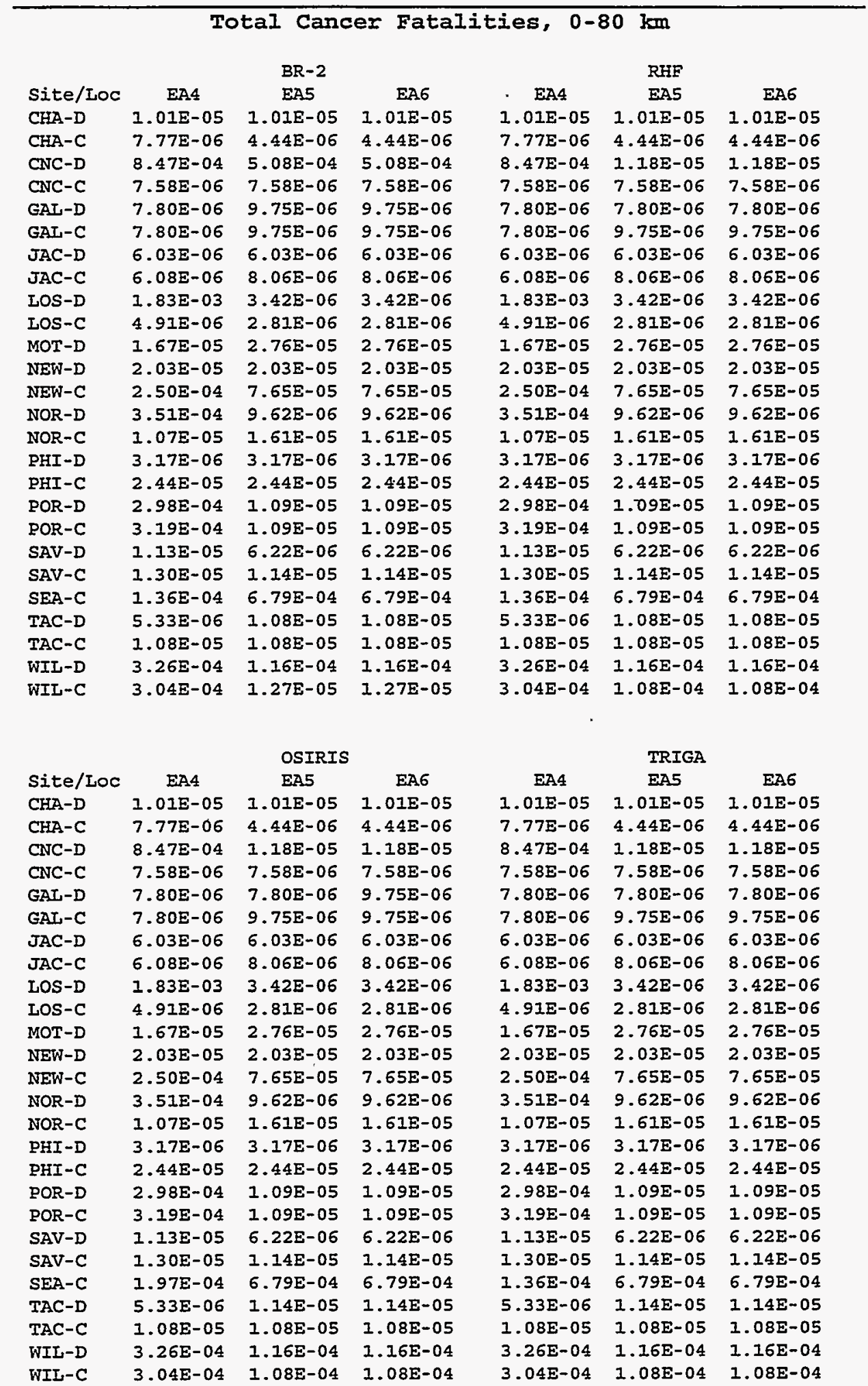


Table 34. Conditional Probabilities of Peak Values of Population Dose, Cancer Fatalities, Costs, Centerline Individual Dose and Centerline Individual Risk for EA Accident Categories (Continued)

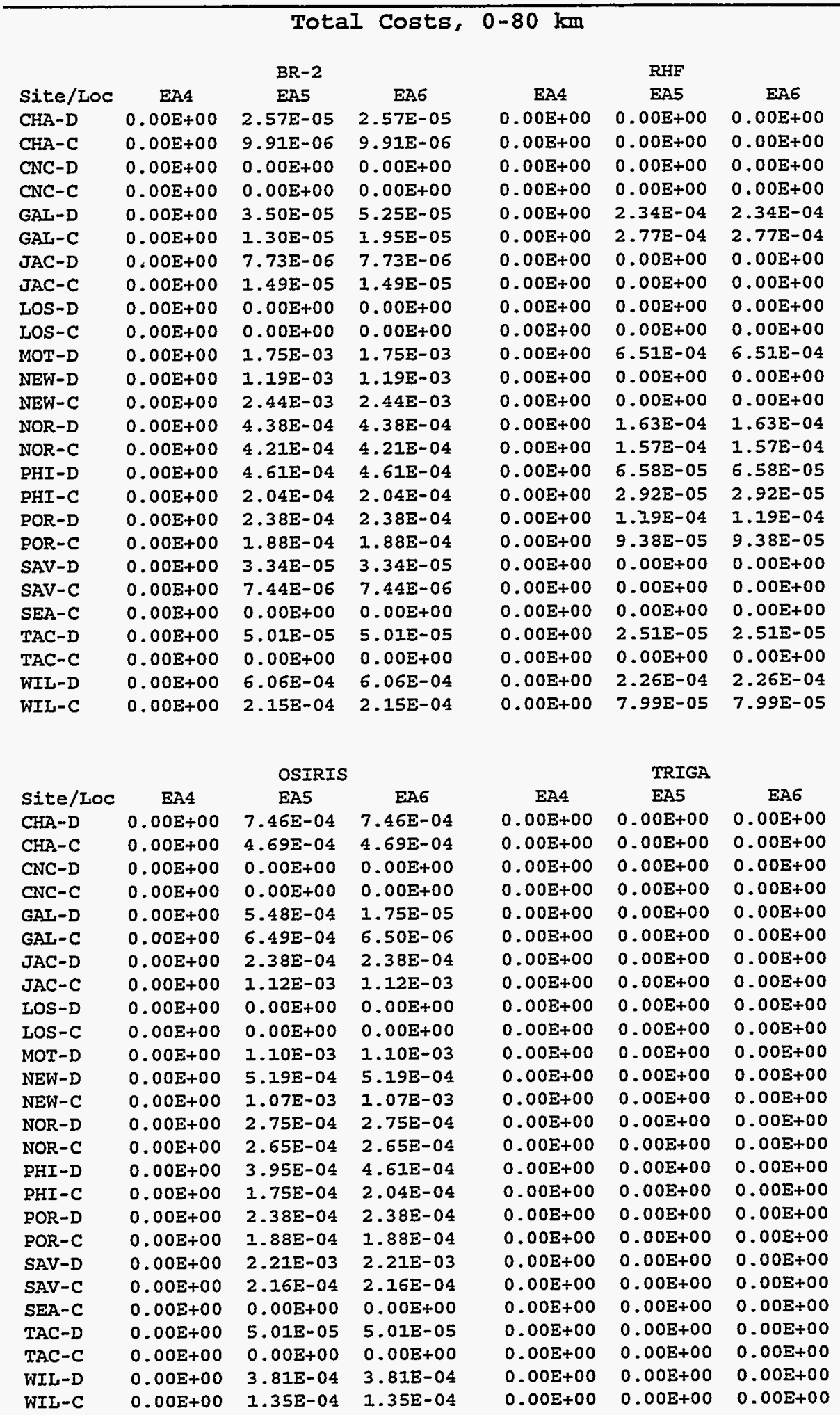


Table 34. Conditional Probabilities of Peak Values of Population Dose, Cancer Fatalities, Costs, Centerline Individual Dose and Centerline Individual Risk for EA Accident Categories (Continued)

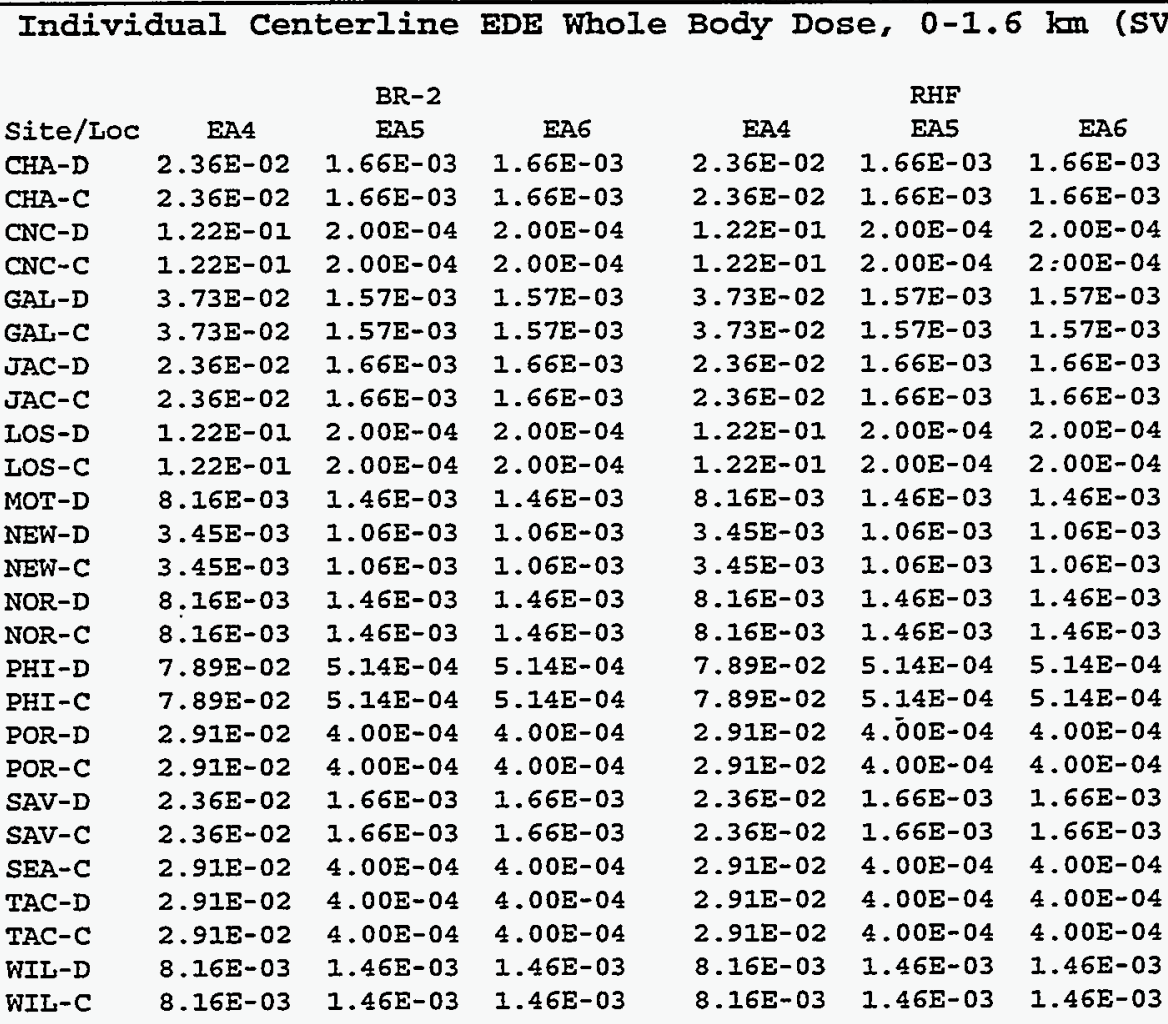

\begin{tabular}{|c|c|c|c|c|c|c|}
\hline & & & & & TRIGA & \\
\hline /LOC & EA4 & EA5 & EA6 6 & EA4 & EA5 & EA6 \\
\hline$H A-D$ & $2.36 \mathrm{E}-02$ & $1.66 \mathrm{E}-03$ & $1.66 \mathrm{E}-03$ & $2.36 \mathrm{E}-02$ & $1.66 \mathrm{E}-03$ & $1.66 \mathrm{E}-03$ \\
\hline$A A-C$ & $2.36 \mathrm{E}-02$ & $1.66 \mathrm{E}-03$ & $1.66 \mathrm{E}-03$ & $2.36 E-02$ & $1.66 \mathrm{E}-03$ & $1.66 \mathrm{E}-03$ \\
\hline SC-D & $1.22 \mathrm{E}-01$ & $2.00 \mathrm{E}-04$ & $2.00 \mathrm{E}-04$ & $1.22 \mathrm{E}-01$ & $2.00 E-04$ & $2.00 \mathrm{E}-04$ \\
\hline NC-C & $1.22 \mathrm{E}-01$ & $2.00 \mathrm{E}-04$ & $2.00 \mathrm{E}-04$ & $1.22 \mathrm{E}-01$ & $2.00 \mathrm{E}-04$ & $2.00 E-04$ \\
\hline$A L-D$ & $3.73 \mathrm{E}-02$ & $1.57 \mathrm{E}-03$ & $1.57 \mathrm{E}-03$ & $3.73 E-02$ & $1.57 \mathrm{E}-03$ & $1.57 \mathrm{E}-03$ \\
\hline GAL-C & 3.73E-02 & $1.57 E-03$ & $1.57 \mathrm{E}-03$ & $3.73 E-02$ & $1.57 \mathrm{E}-03$ & $1.57 E-03$ \\
\hline$A C-D$ & $2.36 \mathrm{E}-02$ & $1.66 E-03$ & $1.66 \mathrm{E}-03$ & $.36 E-02$ & $1.66 \mathrm{E}-03$ & $1.66 \mathrm{E}-03$ \\
\hline$A C-C$ & $2.36 E-02$ & $1.66 \mathrm{E}-03$ & $1.66 \mathrm{E}-03$ & $2.36 \mathrm{E}-02$ & $1.66 \mathrm{E}-03$ & $1.66 \mathrm{E}-03$ \\
\hline OS-D & $1.22 \mathrm{E}-01$ & $2.00 E-04$ & $2.00 E-04$ & $1.22 \mathrm{E}-01$ & $2.00 \mathrm{E}-04$ & $2.00 E-04$ \\
\hline LOS-C & $1.22 \mathrm{E}-01$ & $2.00 E-04$ & $2.00 E-04$ & $1.22 \mathrm{E}-01$ & $2.00 \mathrm{E}-04$ & $2.00 E-04$ \\
\hline MOT-D & $8.16 E-03$ & $1.46 \mathrm{E}-03$ & $1.46 \mathrm{E}-03$ & $.16 \mathrm{E}-03$ & $1.46 \mathrm{E}-03$ & $1.46 \mathrm{E}-03$ \\
\hline NEW-D & $3.45 \mathrm{E}-03$ & $1.06 \mathrm{E}-03$ & $1.06 \mathrm{E}-03$ & $3.45 E-03$ & $1.06 \mathrm{E}-03$ & $1.06 E-03$ \\
\hline NEW-C & $3.45 \mathrm{E}-03$ & $1.06 \mathrm{E}-03$ & $1.06 \mathrm{E}-03$ & -03 & $1.06 \mathrm{E}-03$ & $1.06 \mathrm{E}-03$ \\
\hline NOR-D & $8.16 \mathrm{E}-03$ & $1.46 \mathrm{E}-03$ & $1.46 \mathrm{E}-03$ & $16 E-03$ & $1.46 \mathrm{E}-03$ & $1.46 \mathrm{E}-03$ \\
\hline NOR-C & $8.16 \mathrm{E}-03$ & $1.46 \mathrm{E}-03$ & $1.46 \mathrm{E}-03$ & $.16 E-03$ & $1.46 \mathrm{E}-03$ & $1.46 \mathrm{E}-0$ \\
\hline PHI-D & $7.89 E-02$ & $5.14 \mathrm{E}-04$ & $5.14 \mathrm{E}-04$ & $.89 \mathrm{E}-02$ & $5.14 E-04$ & $5.14 E-0$ \\
\hline HI - C & 02 & $5.14 \mathrm{E}-04$ & $5.14 E-04$ & $.89 E-02$ & $5.14 E-04$ & $5.14 E-$ \\
\hline$O R-D$ & -02 & $4.00 \mathrm{E}-04$ & $4.00 E-04$ & $.9 I E-02$ & $4.00 \mathrm{E}-04$ & $4.00 \mathrm{E}-0$ \\
\hline OR-C & $E-02$ & $4.00 \mathrm{E}-04$ & $4.00 \mathrm{E}-04$ & $.91 E-02$ & $4.00 \mathrm{E}-04$ & $4.00 \mathrm{E}-$ \\
\hline$\Delta A V-D$ & $2.36 \mathrm{E}-02$ & $1.66 \mathrm{E}-03$ & $1.66 \mathrm{E}-03$ & $2.36 \mathrm{E}-02$ & $1.66 \mathrm{E}-03$ & $1.66 \mathrm{E}-0$ \\
\hline & $2.36 \mathrm{E}-02$ & $1.66 \mathrm{E}-03$ & $1.66 \mathrm{E}-03$ & $2.36 E-02$ & $1.66 \mathrm{E}-03$ & $1.66 \mathrm{E}-0$ \\
\hline & $2.91 \mathrm{E}-02$ & $4.00 \mathrm{E}-04$ & $4.00 \mathrm{E}-04$ & $2.91 E-02$ & $4.00 \mathrm{E}-04$ & $4.00 \mathrm{E}-0$ \\
\hline & $.91 E-02$ & $4.00 \mathrm{E}-04$ & $4.00 E-04$ & $2.91 E-02$ & $4.00 \mathrm{E}-04$ & $4.00 \mathrm{E}-0$ \\
\hline & $.91 E-02$ & $4.00 \mathrm{E}-04$ & $4.00 \mathrm{E}-04$ & $2.91 E-02$ & $4.00 \mathrm{E}-04$ & $4.00 \mathrm{E}-0$ \\
\hline & $8.16 \mathrm{E}-03$ & $1.46 \mathrm{E}-03$ & $1.46 \mathrm{E}-03$ & $8.16 E-03$ & $1.46 \mathrm{E}-03$ & $1.46 \mathrm{E}-0$ \\
\hline $1-C$ & $16 \mathrm{E}-03$ & $1.46 \mathrm{E}-03$ & $1.46 \mathrm{E}-03$ & $8.16 \mathrm{E}-03$ & $1.46 \mathrm{E}-03$ & $1.46 \mathrm{E}-$ \\
\hline
\end{tabular}


Table 34. Conditional Probabilities of Peak Values of Population Dose, Cancer Fatalities, Costs, Centerline Individual Dose and Centerline Individual Risk for EA Accident Categories (Concluded)

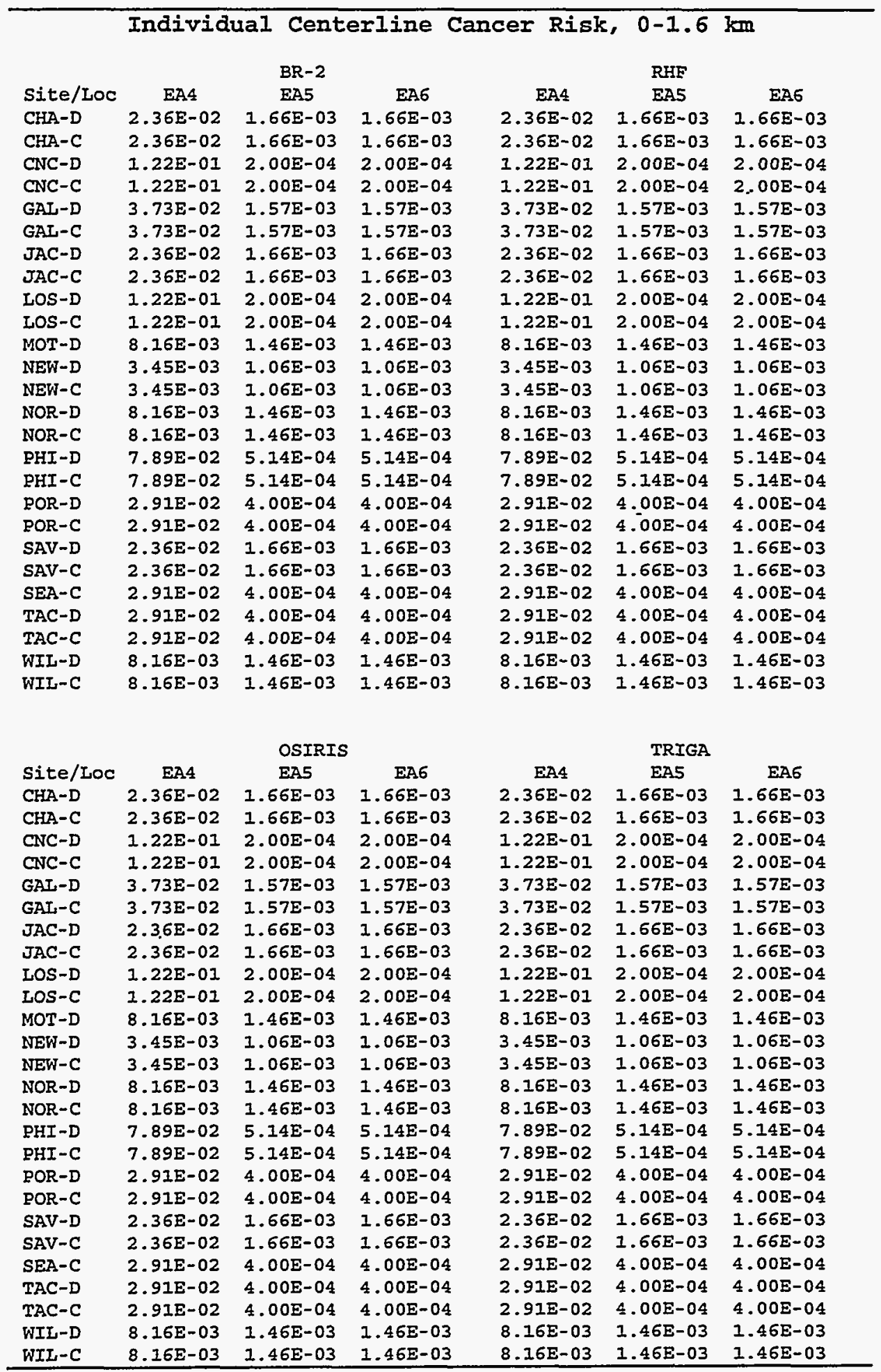


maximally exposed member of the general population is not of great concern. Table 33 shows that the largest value (peak result) calculated for an individual, 50-year centerline dose for a person located 0.5 mile from the accident location was $6.61 \times 10^{-2} \mathrm{~Sv}$ and that this result was obtained for the Philadelphia calculations that used the BR-2 inventory, EA6 release fractions, and Washington DC weather. Table 34 shows that the conditional probability of this result is $5.14 \times 10^{-4}$ (conditional on the accident having occurred). Since the probability of occurrence of an EA6 accident is $6 \times 10^{-10}$ per port call, the chance that a maximally exposed individual will receive an accident dose that is 2.7 times smaller than a normal, 50-year individual dose is about $3 \times 10^{-13}$ per port call.

Table 31 shows that the number of cancer deaths, expected to occur $20^{\circ}$ to 40 years after the accident among the population located at the time of the accident within 50 miles of the accident site, ranges from $4.1 \times 10^{-7}$ for the MOTSU dock calculation that used the TRIGA inventory, EA4 release fractions, and Cape Hatteras weather, to almost 3 for the Newark channel calculation that used the BR-2 inventory, EA5 release fractions, and New York City weather. If all three of the cancer deaths predicted to occur as a result of the accident at the Newark site should happen to occur in the same year, then the death rate among the two million people exposed to radiation by this accident would be $3 / 2 \times 10^{6}=1.5 \times 10^{-6}$ deaths per year. Since the normal death rate due to all types of cancer is about 200 deaths per 100,000 people per year [WA92] or $2.0 \times 10^{-3}$ deaths per year, the largest mean (expected) death rate for any base case calculation is 1000 times smaller than the normal death rate due to cancer.

Table 33 shows that the largest number of cancer deaths obtained for any weather trial in any base case calculation was 60 and that this result was obtained for the Newark channel calculation that used the BR-2 inventory, EA6 release fractions, and New York City weather. Again, if all of these deaths were to occur in the same year, 20 to 40 years in the future (a very improbable outcome), the death rate during that year among the population exposed to radiation by the accident would be $3 \times 10^{-5}$ or 68 times lower than the normal death rate due to cancer among this population. Table 34 shows that the conditional probability of this result is $7.65 \times 10^{-5}$ (conditional on the occurrence of the accident), and thus the absolute probability of occurrence of this result is about $5 \times 10^{-14}$ per port call, as the probability of occurrence of an EA6 accident is about $6 \times 10^{-10}$ per port call. Thus, even the largest number of cancer deaths predicted by this MACCS calculation would be wholly undetectable in the exposed population by the best of epidemiological studies.

Figures 26 and 27 present CCDFs for population dose and cancer fatalities among the population located within 50 miles of the accident site $(0-80 \mathrm{~km})$ for each of the thirteen ports studied. The figures display the range and probability (conditional on the occurrence of the accident) of these two consequence measures. Figure 26 shows that any large accident (a ship collision that leads to an EA5 release from a BR-2 inventory is a large accident) will lead to a 50 -year population dose of $0.1 \mathrm{~Sv}$, that the values of the 99th quantile (conditional probability of 1.0E-02) range from about $20 \mathrm{~Sv}$ to about $400 \mathrm{~Sv}$, and that the largest (peak) result calculated ranges from about $46 \mathrm{~Sv}$ to about $1100 \mathrm{~Sv}$. Figure 27 shows that a large accident has about one chance in 10 (range of 0.002 to 0.6 ) of causing at least one cancer death among 


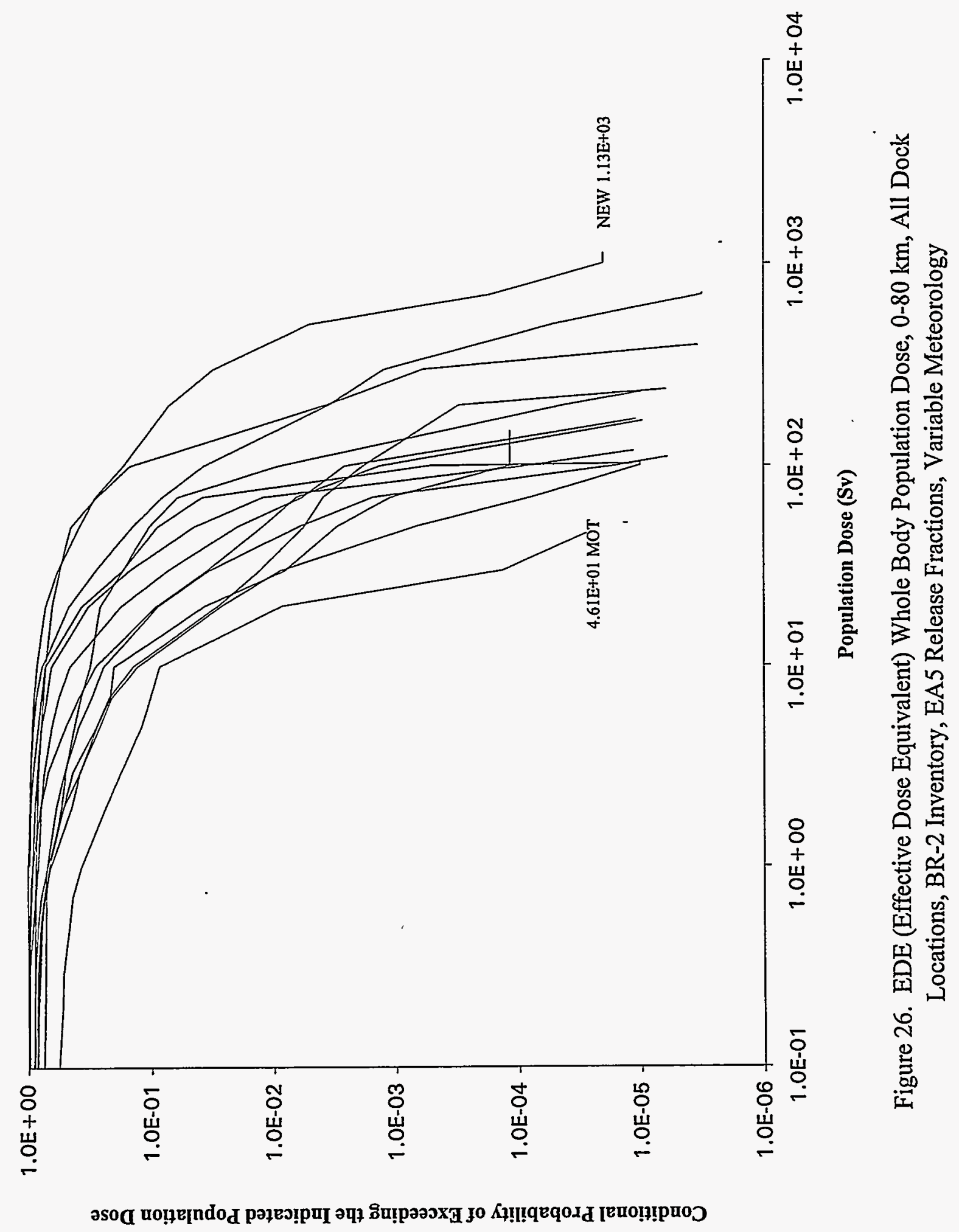




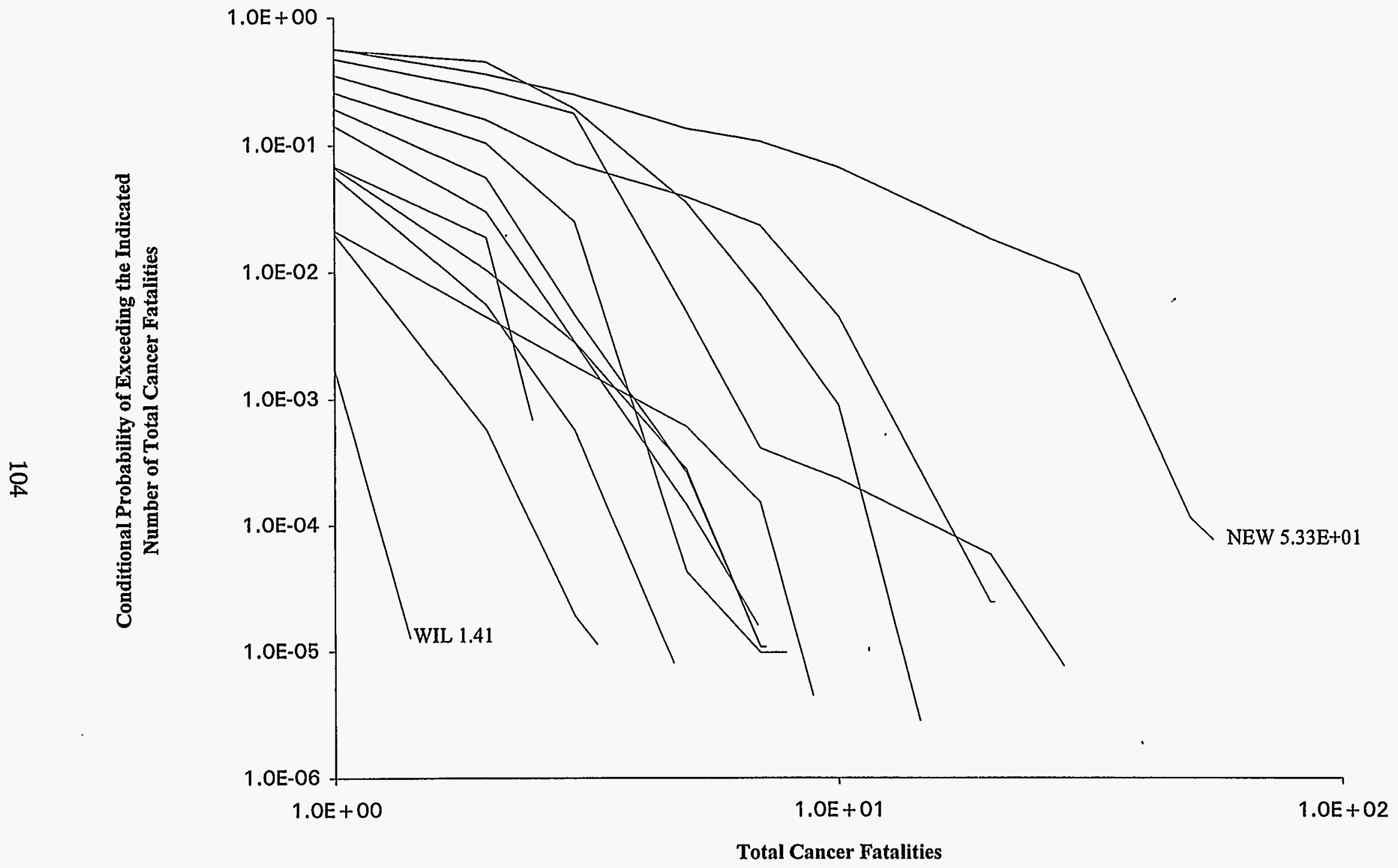

Figure 27. Total Cancer Fatalities, 0-80 km, All Channel Locations, BR-2 Inventory, EA5 Release Fractions, Variable Meteorology 
the exposed population 20 to 40 years in the future, that the values of the 99.9th quantile range from 1 cancer fatality to about 40 cancer deaths, and that the largest (peak) result calculated ranges from 1.4 to 55 deaths due to cancer some 20 to 40 years after the time of the accident.

Figure 28 presents CCDFs for the 50 -year population dose and cancer fatalities for the distance range $0-80.5 \mathrm{~km}$ for both the dock and channel locations at the Charleston port. Figures 29 through 39 present the same set of CCDFs for each of the other twelve ports examined. In all of these figures, the two cancer fatality CCDFs lie below and to the left of the two population dose CCDFs. These figures show that at ten of the fourteen ports the dock and channel CCDFs for both population dose and cancer fatalities are quite similar; and that at the remaining four ports (Concord, Charleston, Savannah, and Wilmington) the dock and channel CCDFs are similar until the 99th quantile is reached (that is, lower quantiles differ significantly). These results show that moving the coordinates of the origin of a population distribution a small distance (a few miles) has little effect on population dose or cancer fatalities among a population located within 50 miles of the accident location (Table 19 lists the coordinates of the origins of the polar coordinate population distributions used in these calculations).

\subsection{High-Temperature Calculations}

The high-temperature calculations estimated the consequences that might result if any one of twenty ship accidents (4 inventories, each run with 5 sets of release fractions, the release fractions for Accident Categories EIS4, EIS5A, EIS5B, EIS6A, and EIS6B) occurred at any of the twenty-six accident locations examined. Thus, $4 \times 5 \times 26=520$ high-temperature MACCS calculations were performed.

The five accident categories examined by this set of calculations consist of two hightemperature categories, two lower temperature categories, and one ambient temperature category. Section 3.2.3 described the development of the release fractions used in these calculations.

The two high-temperature Accident Categories, EIS5B and EIS6B, address the behavior of spent research reactor fuels when heated to temperatures above $900 \mathrm{~K}$, where Al-U alloy fuels melt and, if exposed to air, TRIGA fuel burns. The two lower-temperature categories, EIS5A and EIS6A, address the behavior of spent research reactor fuels when exposed to severe fires that do not heat the fuels to temperatures that exceed $900 \mathrm{~K}$. The one ambient-temperature category addresses the behavior of research reactor fuels during ship collisions that do not lead to fires. Although only two of the five categories address high-temperature events, where fuel melting or combustion may occur, MACCS calculations were performed for all five categories because their release fractions and/or their probabilities of occurrence differed significantly from those specified in the EA for Accident Categories EA4, EA5, and EA6.

As was the case for the EA Accident Category MACCS calculations (the base case calculations), no early fatalities or injuries were predicted for any of the 520 EIS accident 


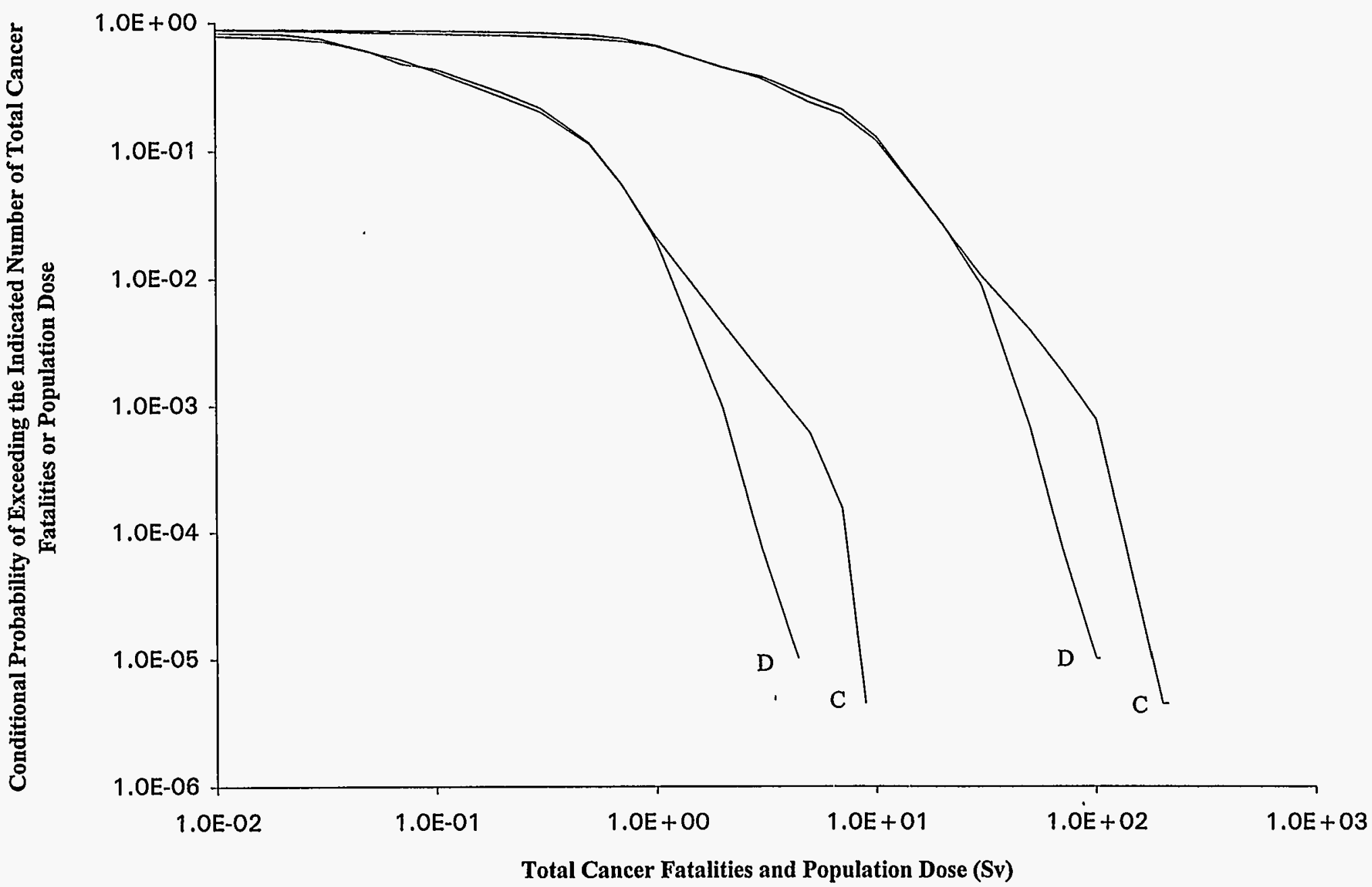

Figure 28. Total Cancer Fatalities and EDE Whole Body Population Dose (Sv), 0.80 km, Charleston Dock (D) and Channel (C) Locations, BR-2 Inventory, EA5 Release Fractions, Variable Meteorology 


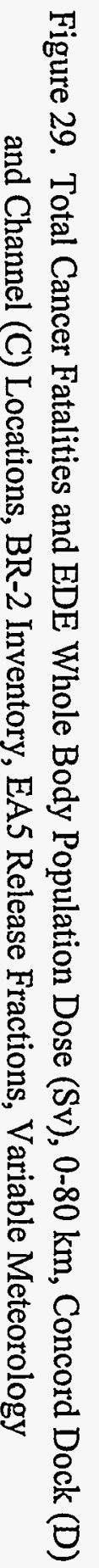

Conditional Probability of Exceeding the Indicated Number of Total Cancer Fatalities or Population Dose

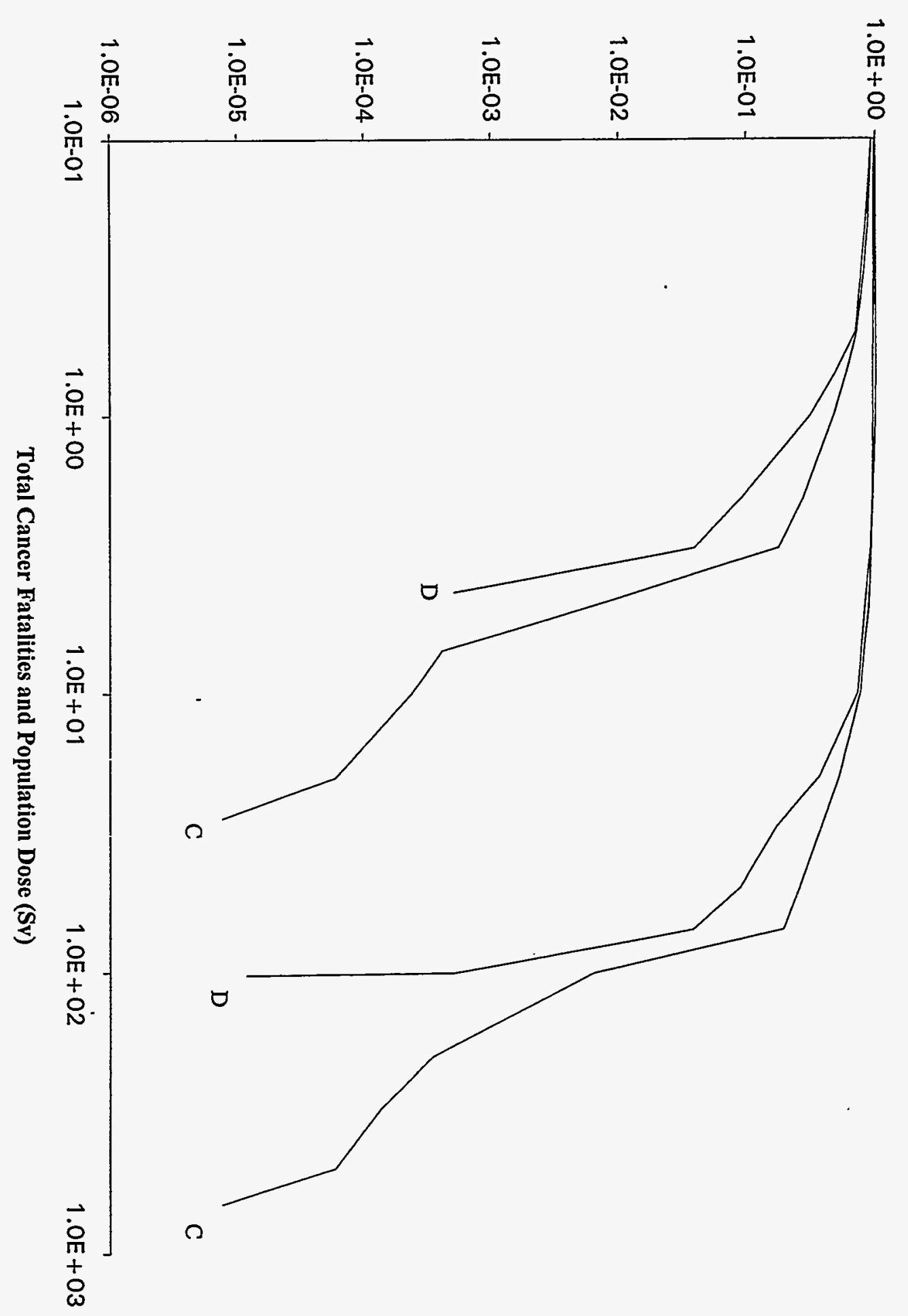




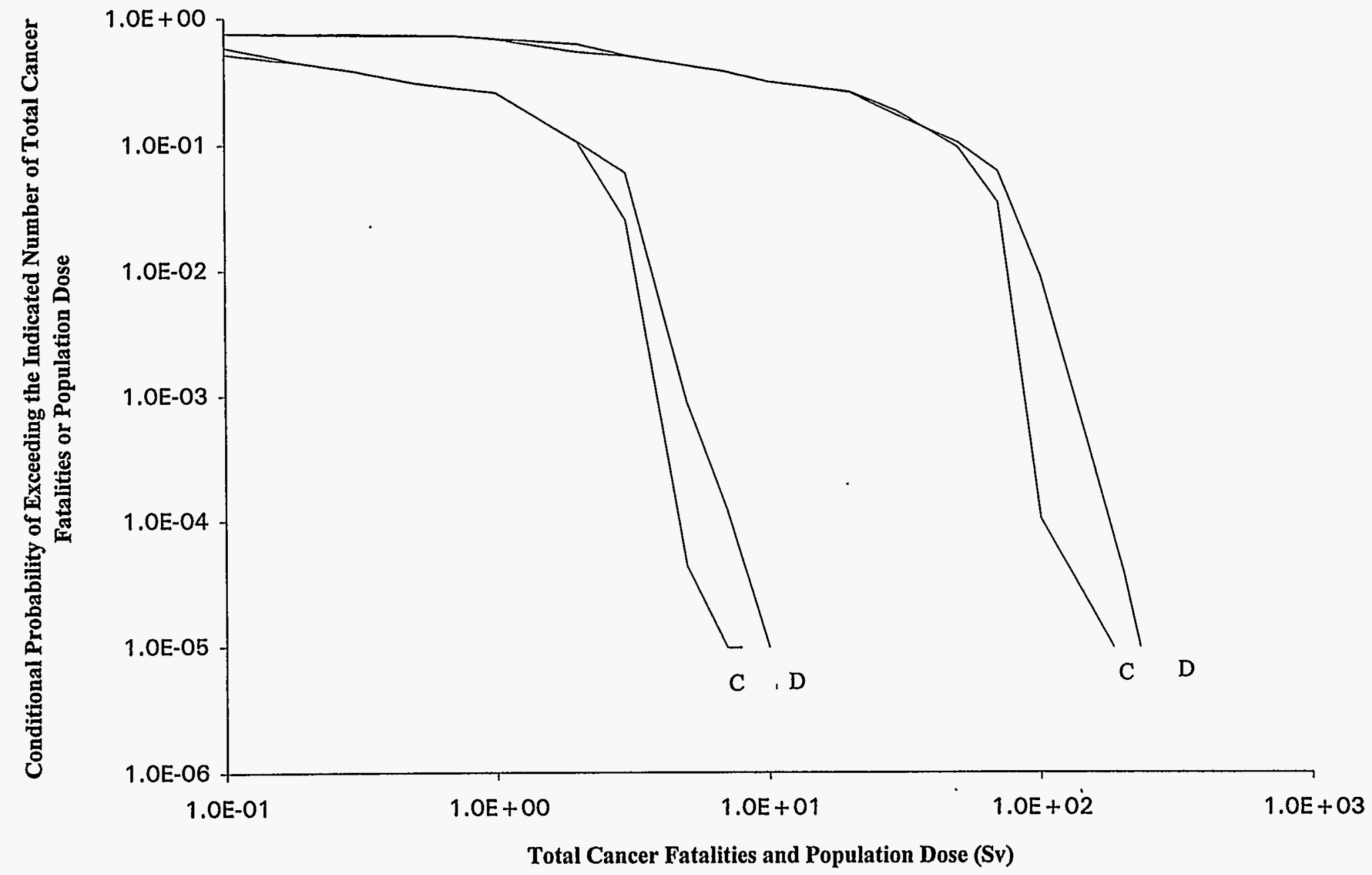

Figure 30. Total Cancer Fatalities and EDE Whole Body Population Dose (Sv), 0-80 km, Galveston Dock (D) and Channel (C) Locations, BR-2 Inventory, EA5 Release Fractions, Variable Meteorology 


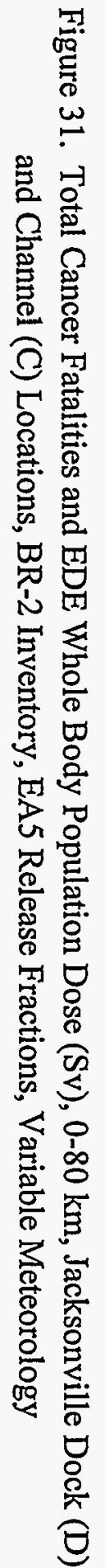

\section{Conditional Probability of Exceeding the Indicated Number of Total Cancer} Fatalities or Population Dose

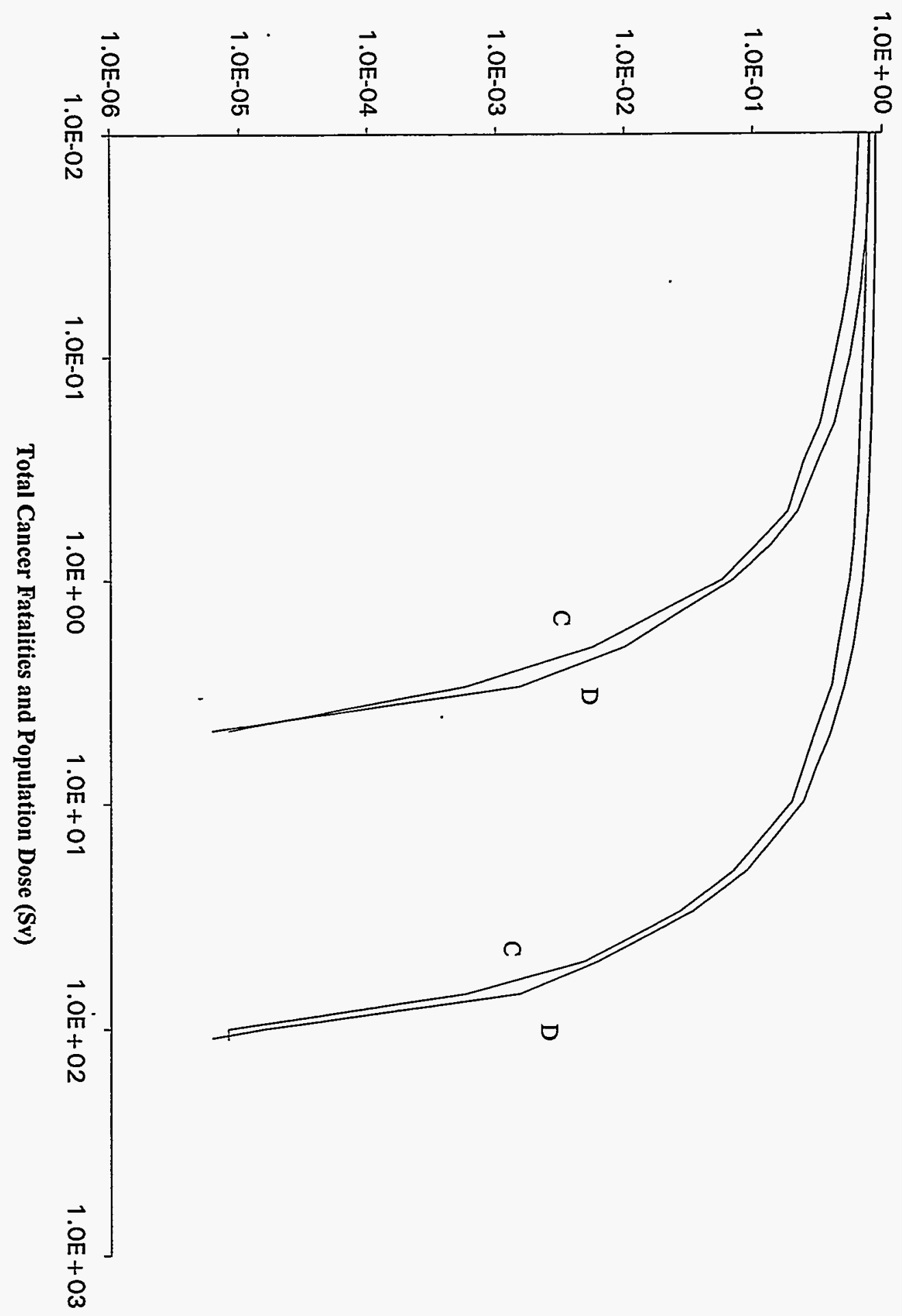




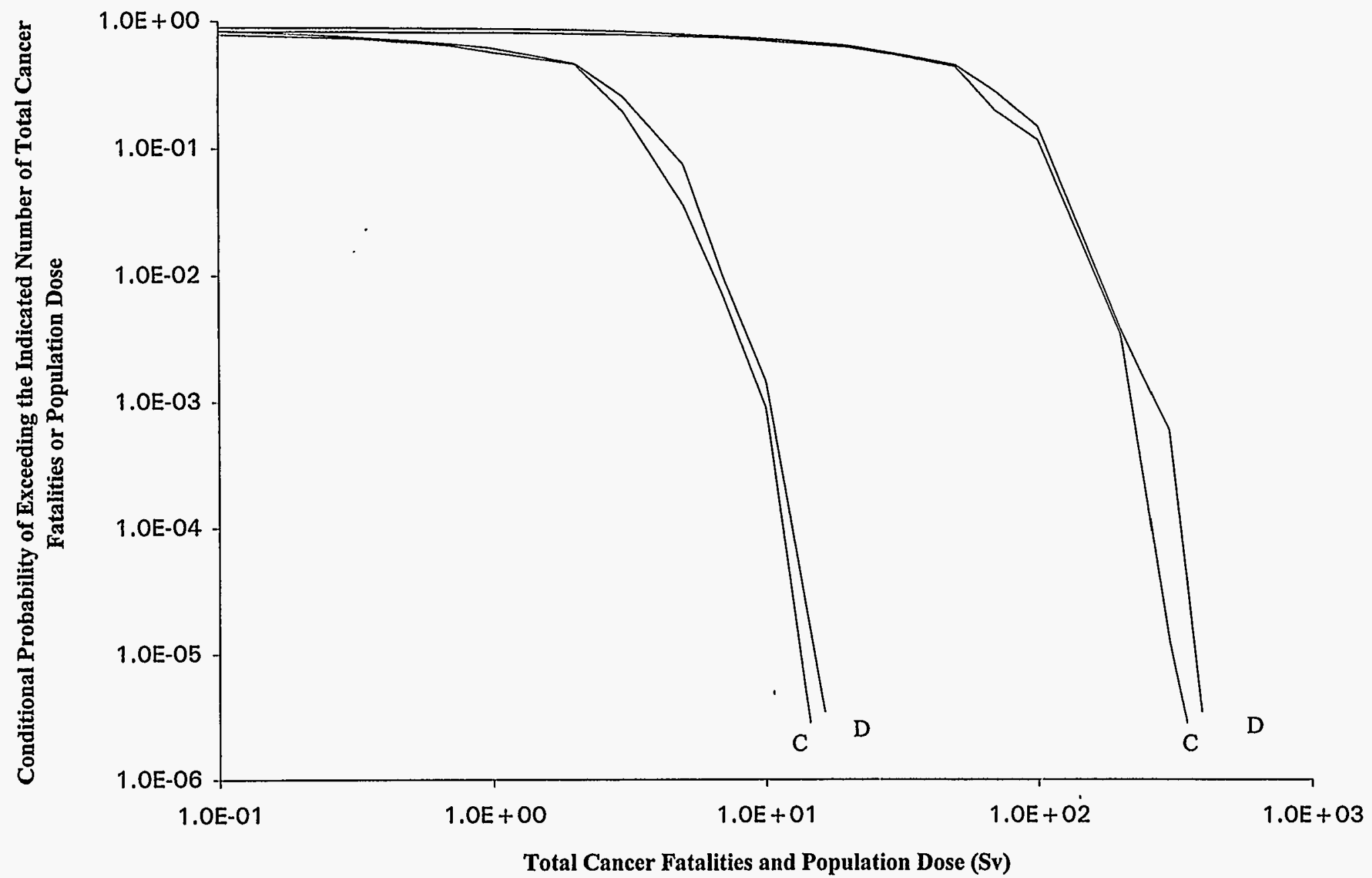

Figure 32. Total Cancer Fatalities and EDE Whole Body Population Dose (Sv), 0-80 km, Long Beach Dock (D) and Channel (C) Locations, BR-2 Inventory, EA5 Release Fractions, Variable Meteorology 


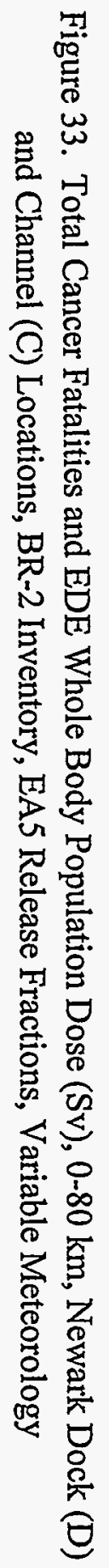

Conditional Probability of Exceeding the Indicated Number of Total Cancer Fatalities or Population Dose

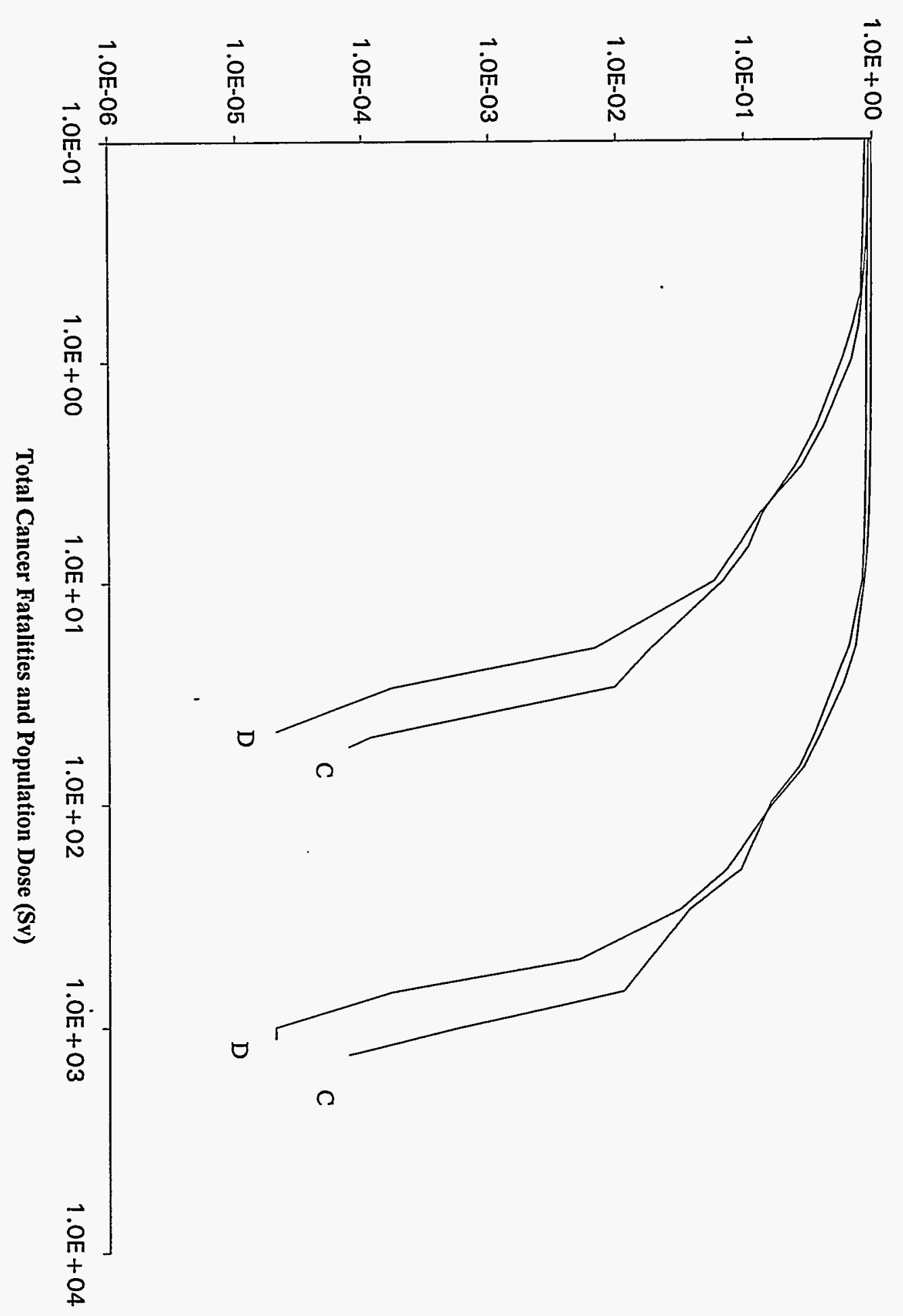




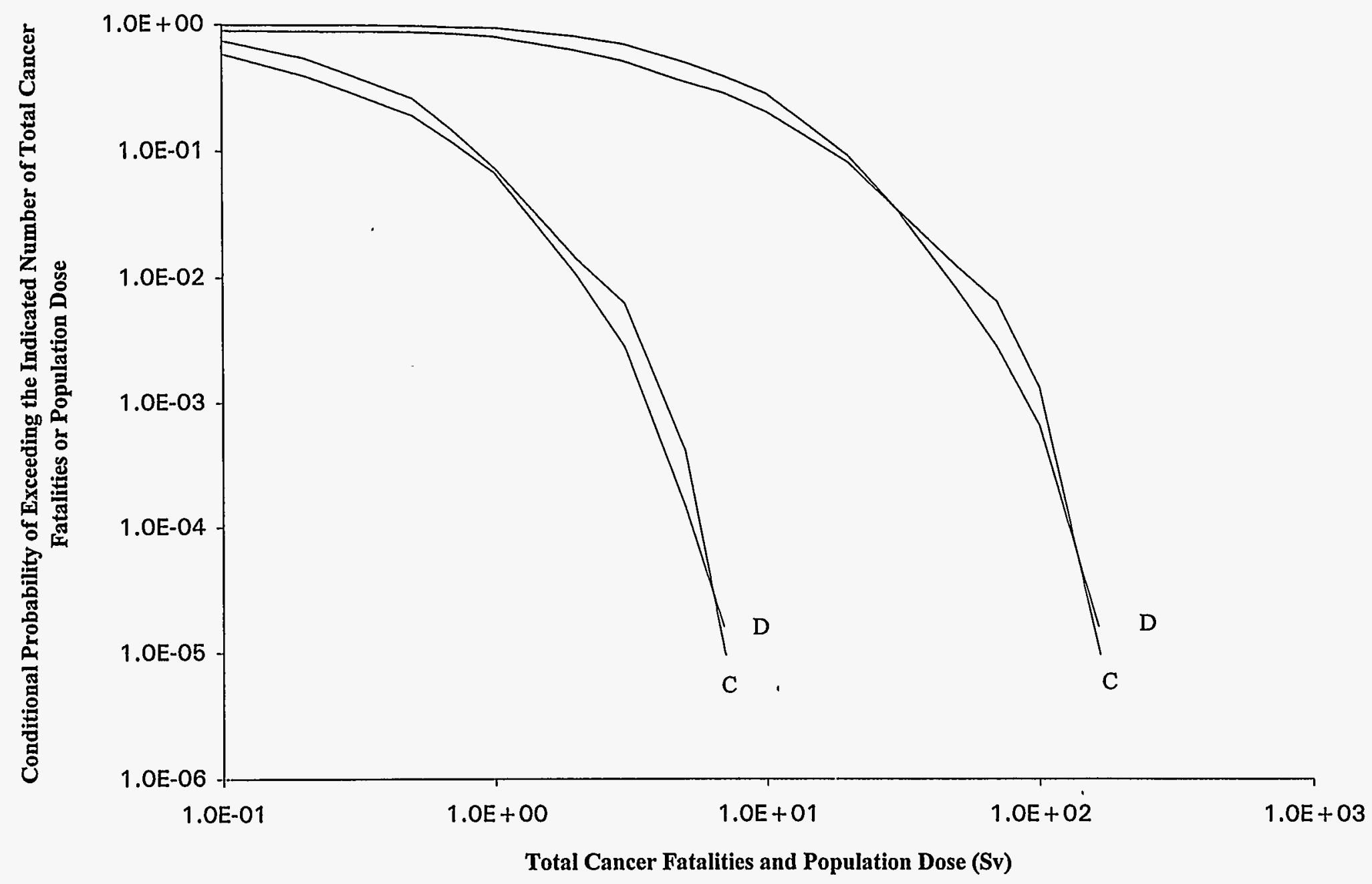

Figure 34. Total Cancer Fatalities and EDE Whole Body Population Dose (Sv), 0-80 km, Norfolk Dock (D) and Channel (C) Locations, BR-2 Inventory, EA5 Release Fractions, Variable Meteorology 


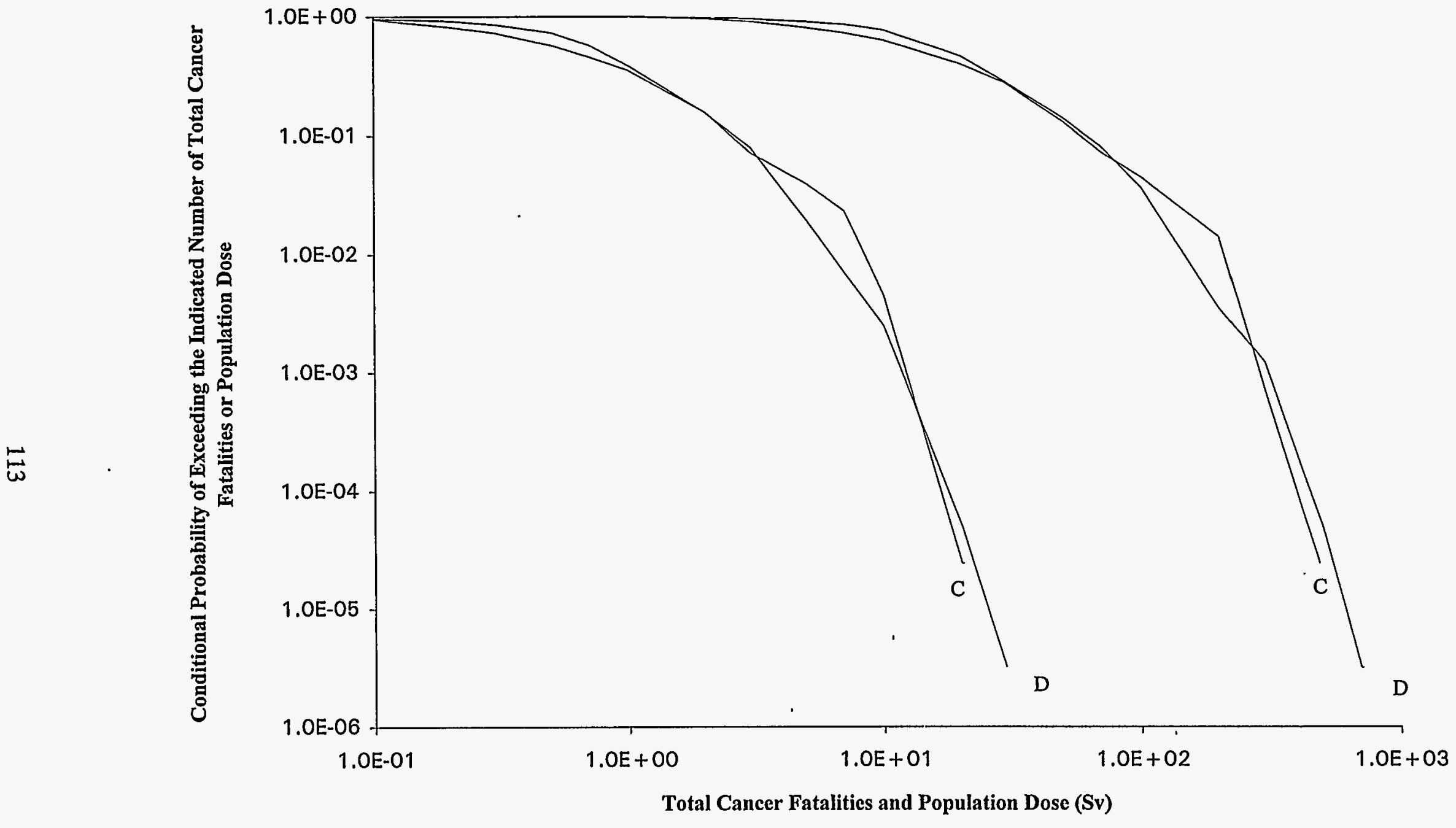

Figure 35. Total Cancer Fatalities and EDE Whole Body Population Dose (Sv), 0-80 km, Philadelphia Dock (D) and Channel (C) Locations, BR-2 Inventory, EA5 Release Fractions, Variable Meteorology 


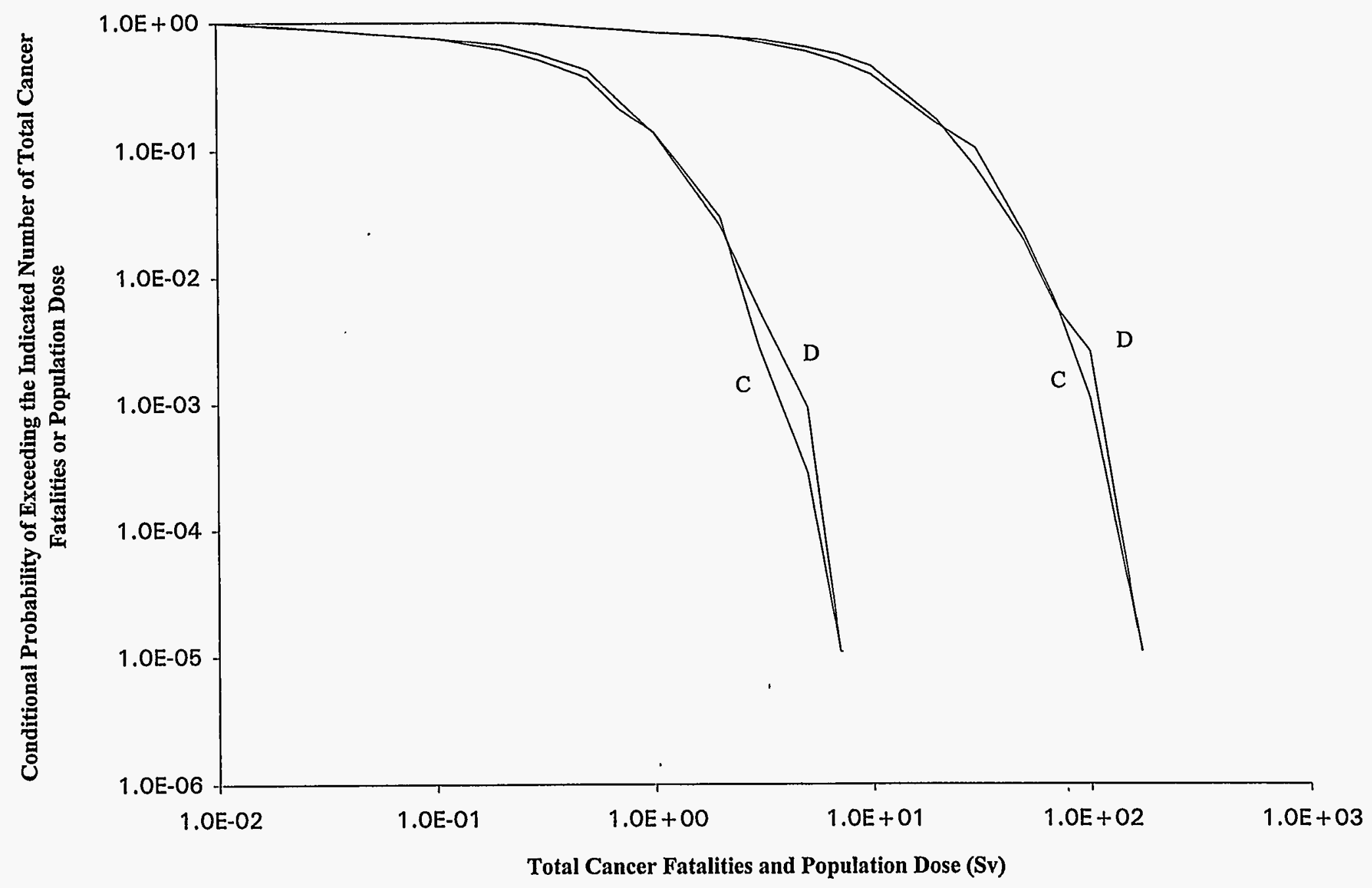

Figure 36. Total Cancer Fatalities and EDE Whole Body Population Dose (Sv), 0-80 km, Portland Dock (D) and Channel (C) Locations, BR-2 Inventory, EA5 Release Fractions, Variable Meteorology 


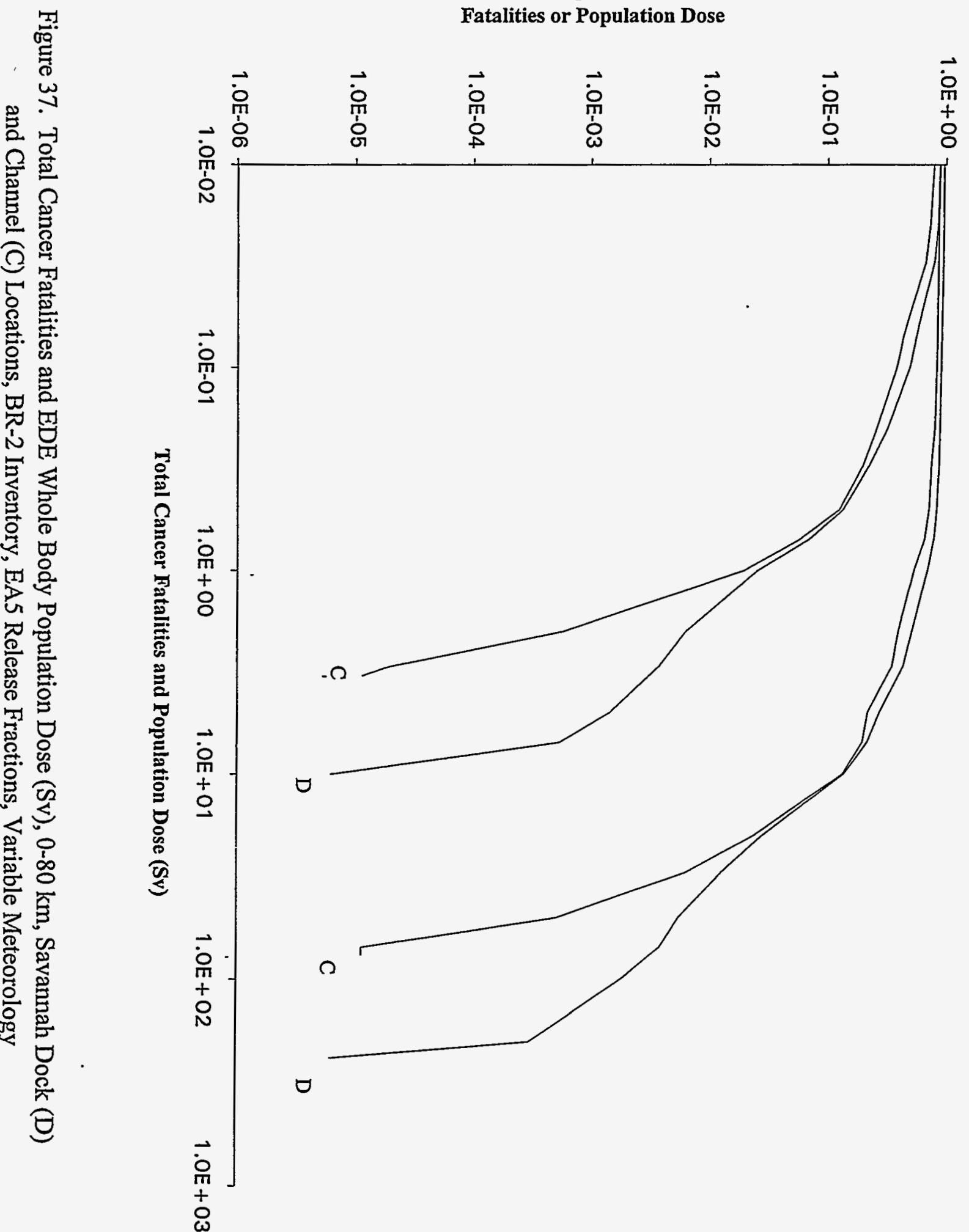




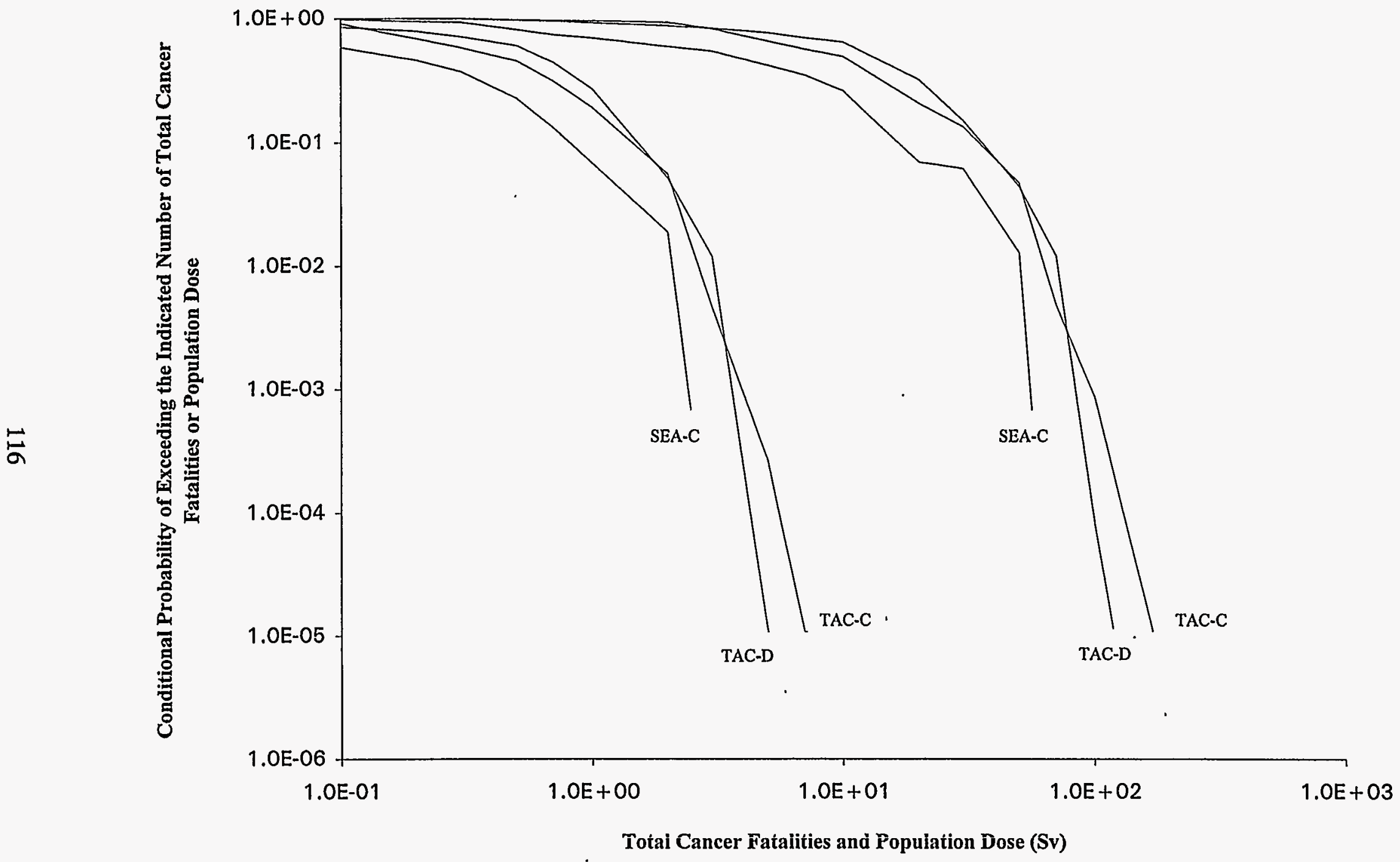

Figure 38. Total Cancer Fatalities and EDE Whole Body Population Dose (Sv), 0-80 km, Tacoma Dock (D) and Channel (C) and Seattle Channel (C) Locations, BR-2 Inventory, EA5 Release Fractions, Variable Meteorology 


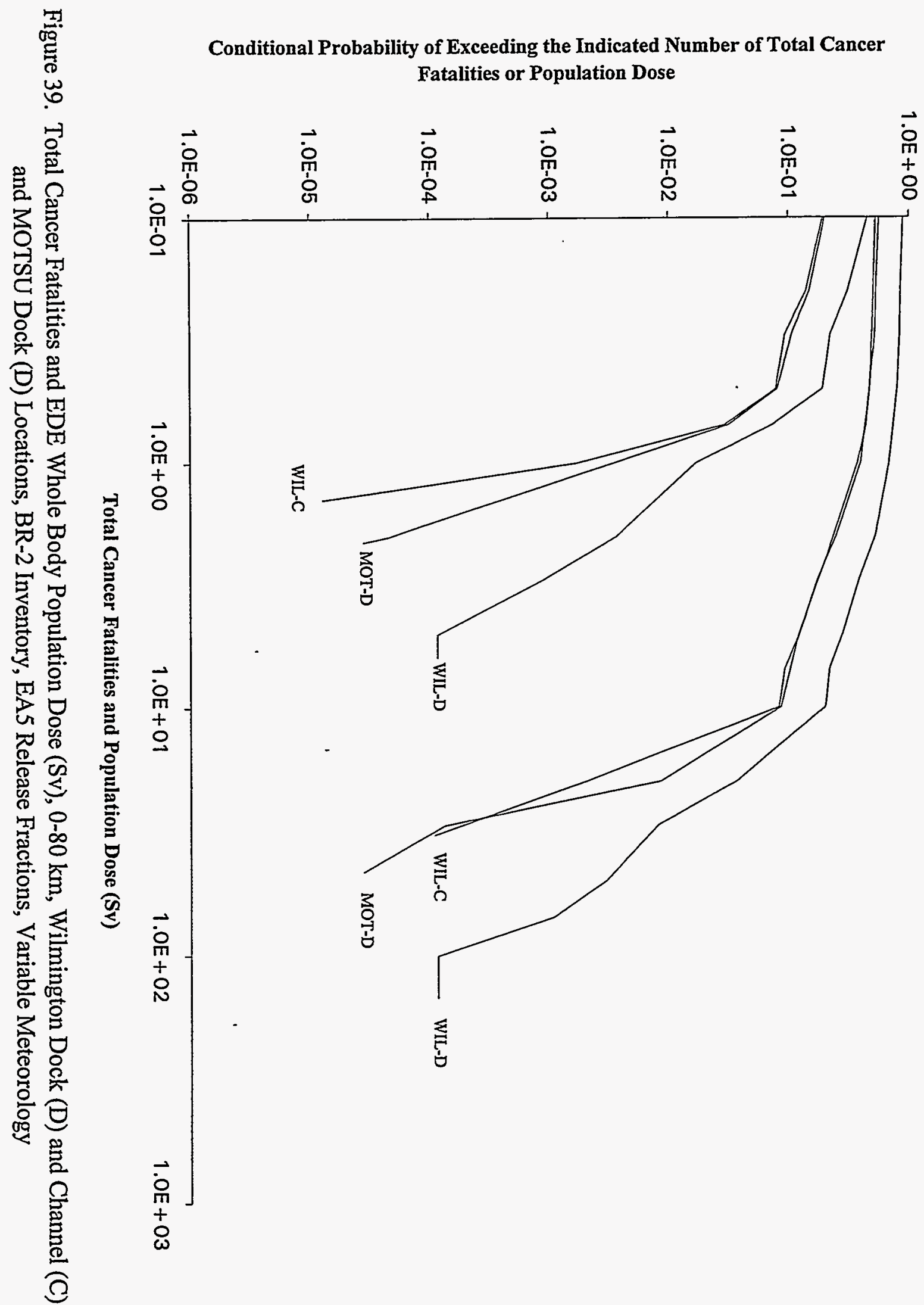


category calculations. And, as was done for the base case calculations, the results of the hightemperature series of calculations are also summarized in result tables, which are archived in Part $\mathrm{C}$ of the Appendix.

Values for Population Dose, Cancer Fatalities, and Costs for the distance range $0-80 \mathrm{~km}$, and Centerline Dose and Centerline Cancer Risk for the distance range 0-1.6 km are presented in Table 35, Mean (Expected) Values; Table 36, 99.9th Quantile Values; Table 37, Largest (Peak) Result Calculated; and Table 38, Conditional Probability of the Largest Result Calculated. Table 35 shows that the expected total 50-year population dose within 50 miles $(80.5 \mathrm{~km})$ of the accident location varies from a low of $2.87 \times 10^{-5} \mathrm{~Sv}$ for the MOTSU dock calculation that used the RHF inventory, EIS4 release fractions, and Cape Hatteras weather to a high of $6440 \mathrm{~Sv}$ for the Newark dock calculation that used the BR-2 inventory, EIS6B release fractions, and New York City weather. Since the total population within 50 miles of the Newark channel accident location is about 16 million people and typical plumes are about two compass sectors wide, a typical accident plume will expose about two million people to radiation. Therefore, for the mean result obtained for the largest high-temperature event, the average 50-year individual dose over the total exposed population is about $6440 \mathrm{~Sv} / 2.0 \times 10^{6}$ people $=3.2 \times 10^{-3} \mathrm{~Sv}$ per person, which is 56 times smaller than the average 50 -year $0.18 \mathrm{~Sv}$ dose people normally receive from natural and routine man-made exposures [BEIR90].

Table 37 shows that the largest value (peak result) calculated for the 50-year population dose within 50 miles of any accident location was $1.44 \times 10^{5} \mathrm{~Sv}$ and that this result was obtained for the Newark channel calculation that used the BR-2 inventory, EIS6B release fractions, and New York City weather. Dividing by the two million people exposed by the accident gives an average 50-year individual dose over the exposed population of about $7.2 \times 10^{-2} \mathrm{~Sv}$, which is 2.5 times smaller than the average individual $0.18 \mathrm{~Sv}$ dose people would normally receive over a 50-year period. In addition, Table 38 shows that the probability of this result was $1.45 \mathrm{x}$ $10^{-5}$, conditional on the accident having occurred. Since the probability of this accident occurring is about $6 \times 10^{-11}$ per port call, the chance of having this result is about $9 \times 10^{-16}$ per port call.

Table 35 also shows that mean (expected) individual 50-year centerline doses at a distance of 0.5 miles from the accident location (the midpoint of the $0-1.6 \mathrm{~km}$ computational interval) range from a low of $2.51 \times 10^{-8} \mathrm{~Sv}$ for the Concord and Los Angeles calculations that used the RHF inventory, EIS5A release fractions, and Santa Maria CA weather, to a high of $2.68 \times$ $10^{-2} \mathrm{~Sv}$ for the Portland, Seattle, and Tacoma calculations that used the Osiris inventory, EIS6B release fractions, and Seattle weather. Thus, the largest expected 50-year individual dose is about 6.7 times smaller than a normal 50 -year individual dose. Table 37 shows that the largest value (peak result) calculated for the individual centerline dose for a person located 0.5 mile from the accident location was $0.275 \mathrm{~Sv}$ and that this result was obtained for the Galveston calculations that used the Osiris inventory, EIS6B release fractions, and Lake Charles LA weather. Table 34 shows that the probability of this result is $9.75 \times 10^{-6}$ conditional on the accident having occurred. Since the probability of occurrence of an EIS6B accident is about $6 \times 10^{-11}$ per port call, the chance that a maximally exposed individual will 
Table 35. Mean Values of Population Dose, Cancer Fatalities, Costs, Centerline Individual Dose and Centerline Individual Risk for EIS Accident Categories

\section{EDE Whole Body Population Dose, $0-80 \mathrm{~km}$ (SV)}

\begin{tabular}{lccccc} 
& \multicolumn{5}{c}{ BR-2 } \\
Site/LOC & EIS4 & EIS5A & EIS5B & EIS6A & EIS6B \\
CHA-D & $2.38 E-04$ & $1.35 E-03$ & $4.48 E+01$ & $1.91 E-03$ & $3.84 E+02$ \\
CHA-C & $3.76 E-04$ & $1.35 E-03$ & $4.48 E+01$ & $1.93 E-03$ & $3.73 E+02$ \\
CNC-D & $4.37 E-04$ & $6.06 E-03$ & $2.25 E+02$ & $9.11 E-03$ & $2.24 E+03$ \\
CNC-C & $9.33 E-04$ & $9.53 E-03$ & $3.60 E+02$ & $1.38 E-02$ & $3.45 E+03$ \\
GAL-D & $7.24 E-04$ & $4.57 E-03$ & $1.55 E+02$ & $7.09 E-03$ & $1.55 E+03$ \\
GAL-C & $3.22 E-04$ & $4.52 E-03$ & $1.54 E+02$ & $6.99 E-03$ & $1.56 E+03$ \\
JAC-D & $2.78 E-04$ & $2.19 E-03$ & $7.39 E+01$ & $3.08 E-03$ & $6.48 E+02$ \\
JAC-C & $2.56 E-04$ & $1.74 E-03$ & $5.77 E+01$ & $2.52 E-03$ & $5.20 E+02$ \\
LOS-D & $2.11 E-03$ & $1.35 E-02$ & $5.13 E+02$ & $1.94 E-02$ & $4.87 E+03$ \\
LOS-C & $7.98 E-04$ & $1.22 E-02$ & $4.64 E+02$ & $1.77 E-02$ & $4.47 E+03$ \\
MOT-D & $7.23 E-05$ & $7.73 E-04$ & $2.25 E+01$ & $1.16 E-03$ & $2.14 E+02$ \\
NEW-D & $2.31 E-03$ & $1.83 E-02$ & $7.12 E+02$ & $2.55 E-02$ & $6.44 E+03$ \\
NEW-C & $3.74 E-03$ & $1.93 E-02$ & $7.49 E+02$ & $2.64 E-02$ & $6.39 E+03$ \\
NOR-D & $5.49 E-04$ & $2.70 E-03$ & $9.24 E+01$ & $3.73 E-03$ & $7.85 E+02$ \\
NOR-C & $3.01 E-04$ & $2.14 E-03$ & $7.21 E+01$ & $3.04 E-03$ & $6.47 E+02$ \\
PHI-D & $1.76 E-03$ & $8.11 E-03$ & $3.05 E+02$ & $1.13 E-02$ & $2.64 E+03$ \\
PHI-C & $8.40 E-04$ & $7.93 E-03$ & $2.98 E+02$ & $1.15 E-02$ & $2.75 E+03$ \\
POR-D & $7.65 E-04$ & $3.67 E-03$ & $1.27 E+02$ & $5.27 E-03$ & $1.15 E+03$ \\
POR-C & $5.30 E-04$ & $3.53 E-03$ & $1.22 E+02$ & $5.13 E-03$ & $1.14 E+03$ \\
SAV-D & $5.58 E-04$ & $1.63 E-03$ & $5.22 E+01$ & $2.37 E-03$ & $4.29 E+02$ \\
SAV-C & $1.34 E-04$ & $1.31 E-03$ & $4.13 E+01$ & $1.92 E-03$ & $3.75 E+02$ \\
SEA-C & $1.30 E-04$ & $2.35 E-03$ & $8.21 E+01$ & $3.64 E-03$ & $8.37 E+02$ \\
TAC-D & $5.51 E-04$ & $5.19 E-03$ & $1.89 E+02$ & $7.70 E-03$ & $1.83 E+03$ \\
TAC-C & $3.85 E-04$ & $4.34 E-03$ & $1.56 E+02$ & $6.39 E-03$ & $1.51 E+03$ \\
WIL-D & $3.78 E-04$ & $1.59 E-03$ & $5.14 E+01$ & $2.34 E-03$ & $4.61 E+02$ \\
WIL-C & $9.63 E-05$ & $7.48 E-04$ & $2.22 E+01$ & $1.13 E-03$ & $2.12 E+02$
\end{tabular}

$\begin{array}{ccccc}\text { EIS4 } & \text { EIS5A } & \text { EIS } 5 B & \text { EIS6A } & \text { EIS6B } \\ 9.50 \mathrm{E}-05 & 5.36 \mathrm{E}-04 & 1.67 \mathrm{E}+01 & 7.58 \mathrm{E}-04 & 1.51 \mathrm{E}+02 \\ 1.50 \mathrm{E}-04 & 5.37 \mathrm{E}-04 & 1.68 \mathrm{E}+01 & 7.68 \mathrm{E}-04 & 1.49 \mathrm{E}+02 \\ 1.74 \mathrm{E}-04 & 2.42 \mathrm{E}-03 & 8.68 \mathrm{E}+01 & 3.63 \mathrm{E}-03 & 8.66 \mathrm{E}+02 \\ 3.72 \mathrm{E}-04 & 3.80 \mathrm{E}-03 & 1.41 \mathrm{E}+02 & 5.49 \mathrm{E}-03 & 1.35 \mathrm{E}+03 \\ 2.89 \mathrm{E}-04 & 1.83 \mathrm{E}-03 & 5.90 \mathrm{E}+01 & 2.83 \mathrm{E}-03 & 5.94 \mathrm{E}+02 \\ 1.29 \mathrm{E}-04 & 1.80 \mathrm{E}-03 & 5.83 \mathrm{E}+01 & 2.79 \mathrm{E}-03 & 5.95 \mathrm{E}+02 \\ 1.10 \mathrm{E}-04 & 8.69 \mathrm{E}-04 & 2.78 \mathrm{E}+01 & 1.22 \mathrm{E}-03 & 2.53 \mathrm{E}+02 \\ 1.02 \mathrm{E}-04 & 6.91 \mathrm{E}-04 & 2.16 \mathrm{E}+01 & 1.00 \mathrm{E}-03 & 2.01 \mathrm{E}+02 \\ 8.42 \mathrm{E}-04 & 5.39 \mathrm{E}-03 & 2.01 \mathrm{E}+02 & 7.75 \mathrm{E}-03 & 1.92 \mathrm{E}+03 \\ 3.19 \mathrm{E}-04 & 4.88 \mathrm{E}-03 & 1.82 \mathrm{E}+02 & 7.08 \mathrm{E}-03 & 1.76 \mathrm{E}+03 \\ 2.87 \mathrm{E}-05 & 3.08 \mathrm{E}-04 & 8.08 \mathrm{E}+00 & 4.63 \mathrm{E}-04 & 7.89 \mathrm{E}+01 \\ 9.24 \mathrm{E}-04 & 7.32 \mathrm{E}-03 & 2.81 \mathrm{E}+02 & 1.02 \mathrm{E}-02 & 2.59 \mathrm{E}+03 \\ 1.49 \mathrm{E}-03 & 7.70 \mathrm{E}-03 & 2.97 \mathrm{E}+02 & 1.05 \mathrm{E}-02 & 2.65 \mathrm{E}+03 \\ 2.19 \mathrm{E}-04 & 1.08 \mathrm{E}-03 & 3.53 \mathrm{E}+01 & 1.49 \mathrm{E}-03 & 3.13 \mathrm{E}+02 \\ 1.20 \mathrm{E}-04 & 8.55 \mathrm{E}-04 & 2.74 \mathrm{E}+01 & 1.21 \mathrm{E}-03 & 2.52 \mathrm{E}+02 \\ 7.01 \mathrm{E}-04 & 3.23 \mathrm{E}-03 & 1.19 \mathrm{E}+02 & 4.50 \mathrm{E}-03 & 1.08 \mathrm{E}+03 \\ 3.35 \mathrm{E}-04 & 3.16 \mathrm{E}-03 & 1.16 \mathrm{E}+02 & 4.57 \mathrm{E}-03 & 1.11 \mathrm{E}+03 \\ 3.05 \mathrm{E}-04 & 1.46 \mathrm{E}-03 & 4.84 \mathrm{E}+01 & 2.10 \mathrm{E}-03 & 4.52 \mathrm{E}+02 \\ 2.11 \mathrm{E}-04 & 1.41 \mathrm{E}-03 & 4.64 \mathrm{E}+01 & 2.05 \mathrm{E}-03 & 4.39 \mathrm{E}+02 \\ 2.22 \mathrm{E}-04 & 6.49 \mathrm{E}-04 & 1.94 \mathrm{E}+01 & 9.40 \mathrm{E}-04 & 1.71 \mathrm{E}+02 \\ 5.30 \mathrm{E}-05 & 5.20 \mathrm{E}-04 & 1.50 \mathrm{E}+01 & 7.60 \mathrm{E}-04 & 1.42 \mathrm{E}+02 \\ 5.20 \mathrm{E}-05 & 9.38 \mathrm{E}-04 & 3.09 \mathrm{E}+01 & 1.45 \mathrm{E}-03 & 3.18 \mathrm{E}+02 \\ 2.20 \mathrm{E}-04 & 2.07 \mathrm{E}-03 & 7.26 \mathrm{E}+01 & 3.07 \mathrm{E}-03 & 7.13 \mathrm{E}+02 \\ 1.53 \mathrm{E}-04 & 1.73 \mathrm{E}-03 & 5.98 \mathrm{E}+01 & 2.55 \mathrm{E}-03 & 5.83 \mathrm{E}+02 \\ 1.51 \mathrm{E}-04 & 6.34 \mathrm{E}-04 & 1.94 \mathrm{E}+01 & 9.32 \mathrm{E}-04 & 1.80 \mathrm{E}+02 \\ 3.84 \mathrm{E}-05 & 2.98 \mathrm{E}-04 & 8.10 \mathrm{E}+00 & 4.50 \mathrm{E}-04 & 7.88 \mathrm{E}+01\end{array}$


Table 35. Mean Values of Population Dose, Cancer Fatalities, Costs, Centerline Individual Dose and Centerline Individual Risk for EIS Accident Categories (Continued)

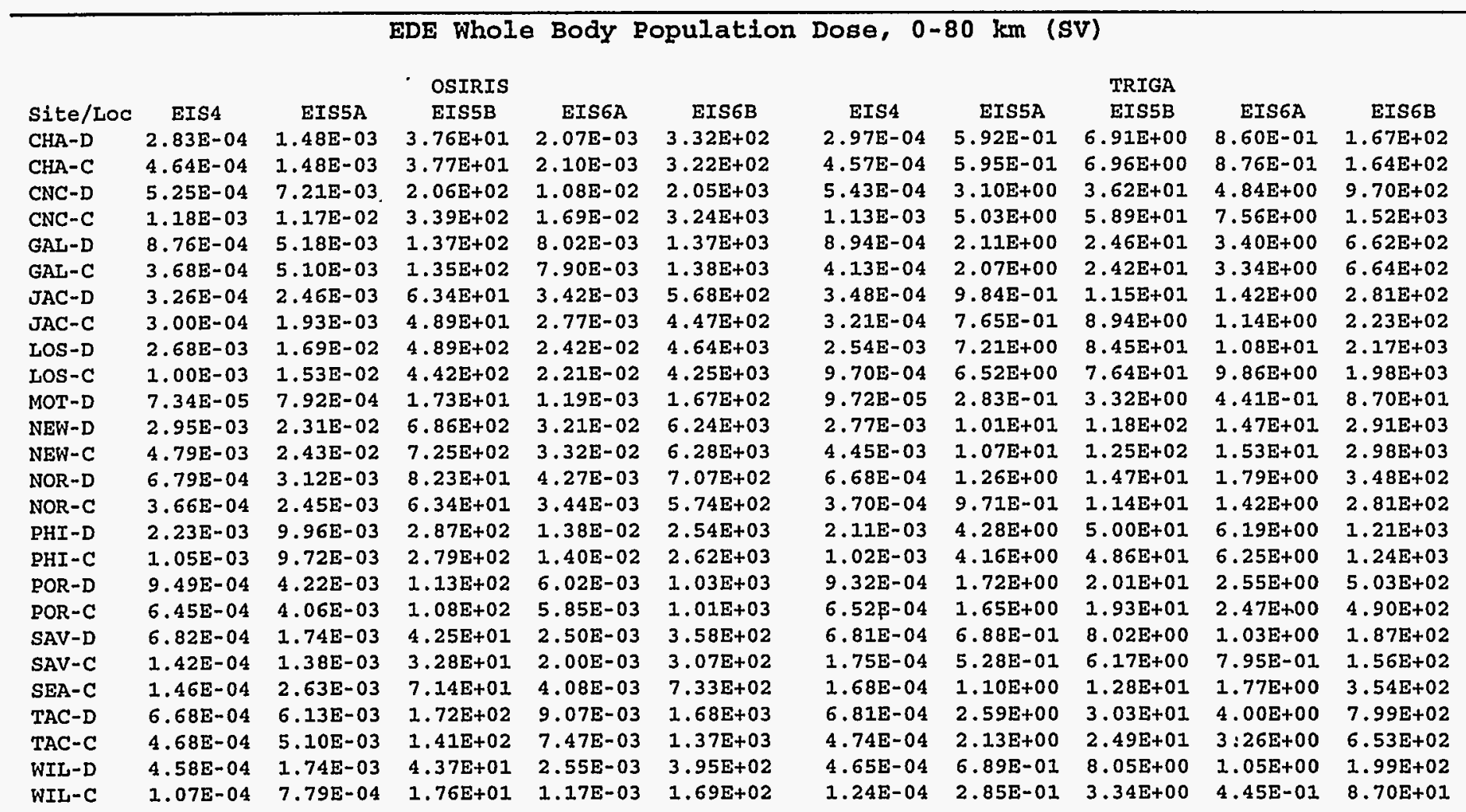


Table 35. Mean Values of Population Dose, Cancer Fatalities, Costs, Centerline Individual Dose and Centerline Individual Risk for EIS Accident Categories (Continued)

Total Cancer Fatalities, $0-80 \mathrm{~km}$

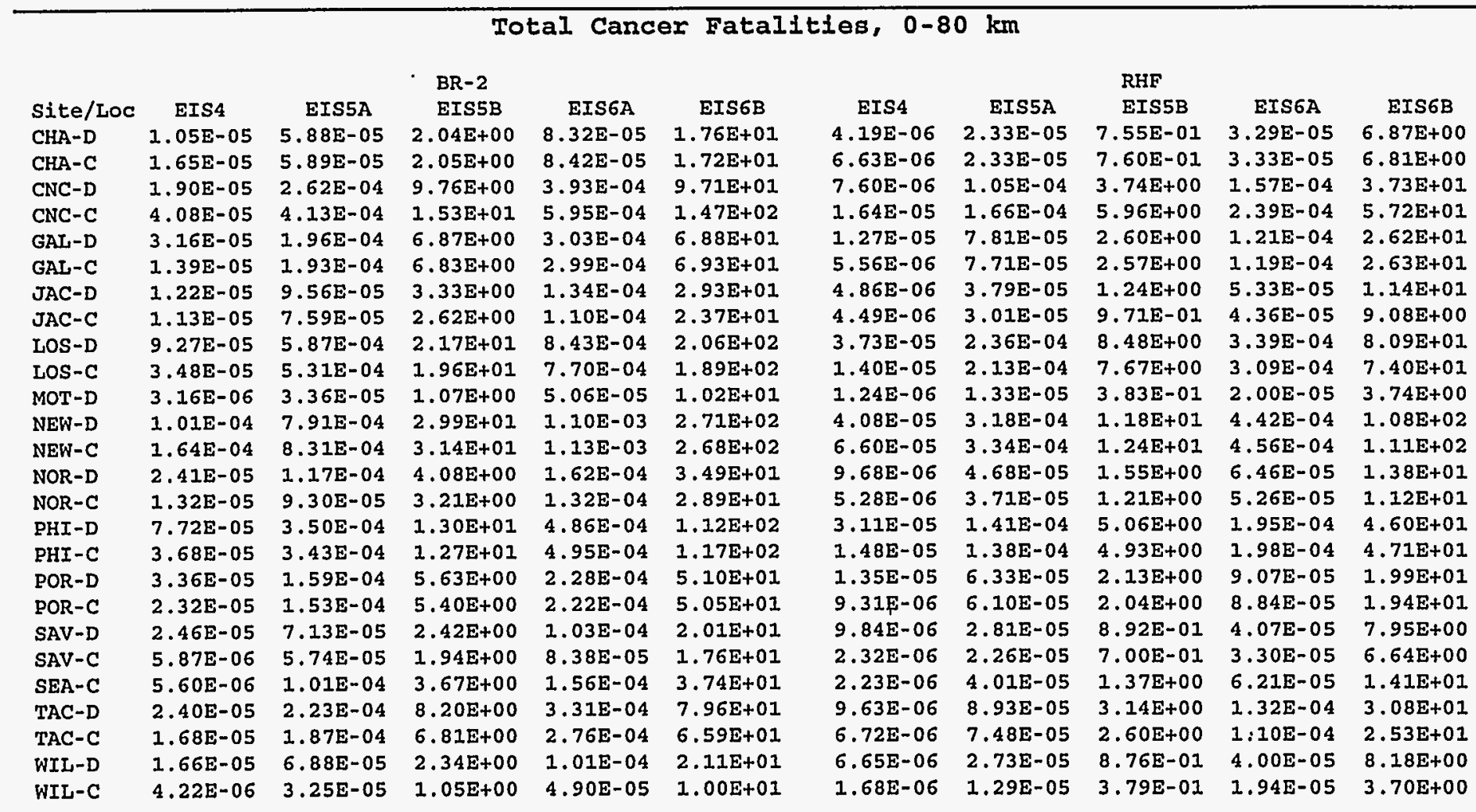


Table 35. Mean Values of Population Dose, Cancer Fatalities, Costs, Centerline Individual Dose and Centerline Individual Risk for EIS Accident Categories (Continued)

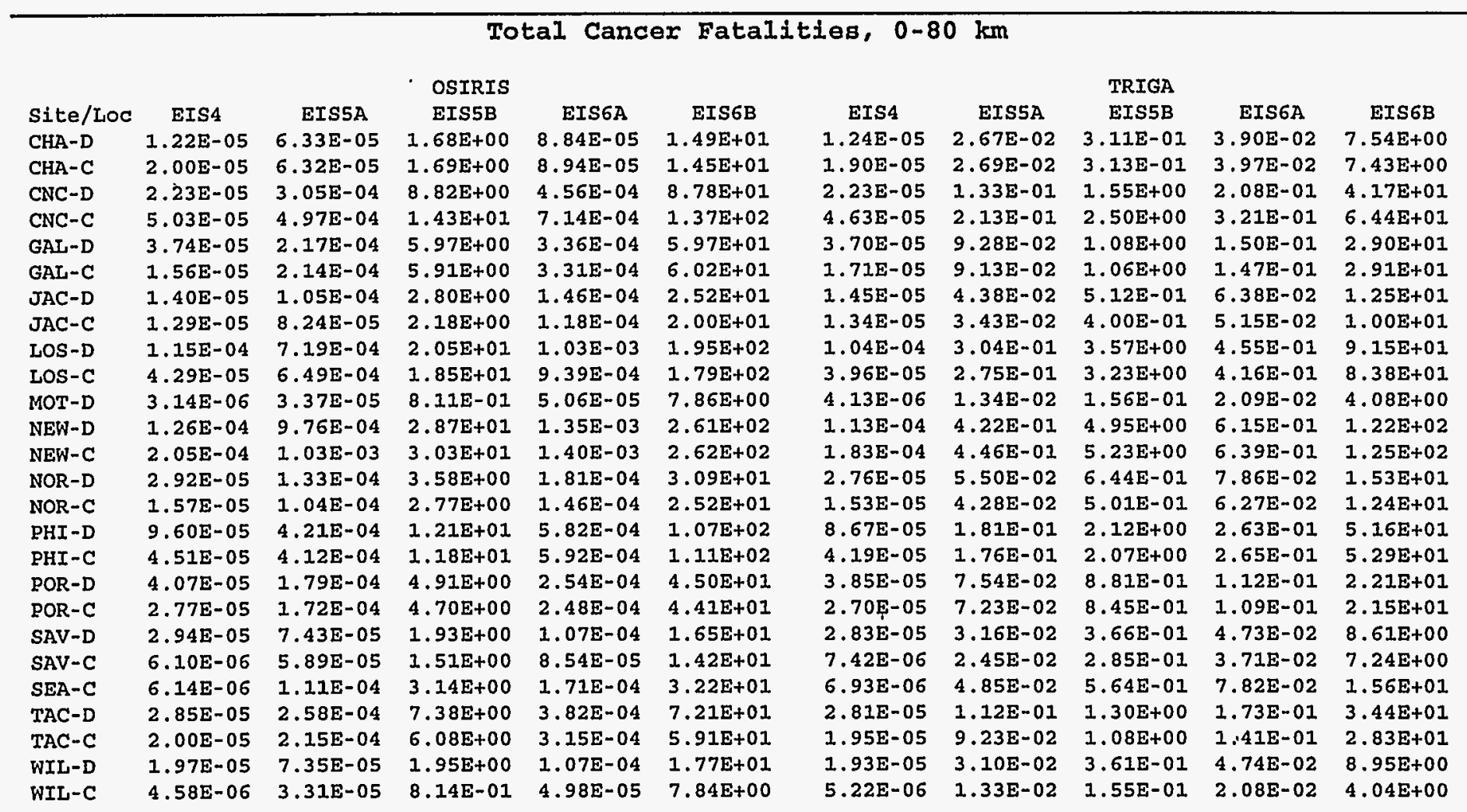


Table 35. Mean Values of Population Dose, Cancer Fatalities, Costs, Centerline Individual Dose and Centerline Individual Risk for EIS Accident Categories (Continued)

\begin{tabular}{|c|c|c|c|c|c|c|c|c|c|c|}
\hline & & & $\mathrm{BR}-2$ & & & & & RHF & & \\
\hline Site/Loc & EIS4 & EIS5A & EIS5B & EIS6A & EIS6B & EIS4 & EIS5A & EIS5B & EIS6A & EIS6B \\
\hline CHA-D & $0.00 \mathrm{E}+00$ & $0.00 \mathrm{E}+00$ & $2.09 E+04$ & $0.00 \mathrm{E}+00$ & $2.84 \mathrm{E}+06$ & $0.00 \mathrm{E}+00$ & $0.00 \mathrm{E}+00$ & $2.35 \mathrm{E}+03$ & $0.00 \mathrm{E}+00$ & $2.29 \mathrm{E}+05$ \\
\hline $\mathrm{CHA}-\mathrm{C}$ & $0.00 E+00$ & $0.00 \mathrm{E}+00$ & $6.54 \mathrm{E}+04$ & $0.00 \mathrm{E}+00$ & $3.56 E+06$ & $0.00 E+00$ & $0.00 \mathrm{E}+00$ & $7.19 \mathrm{E}+03$ & $0.00 E+00$ & $7.10 \mathrm{E}+05$ \\
\hline CNC-D & $0.00 \mathrm{E}+00$ & $0.00 \mathrm{E}+00$ & $1.26 \mathrm{E}+03$ & $0.00 \mathrm{E}+00$ & $1.86 \mathrm{E}+05$ & $0.00 \mathrm{E}+00$ & $0.00 \mathrm{E}+00$ & $5.67 E+00$ & $0.00 \mathrm{E}+00$ & $1.48 \mathrm{E}+04$ \\
\hline $\mathrm{CNC}-\mathrm{C}$ & $0.00 \mathrm{E}+00$ & $0.00 \mathrm{E}+00$ & $2.64 \mathrm{E}+01$ & $0.00 \mathrm{E}+00$ & $8.31 E+05$ & $0.00 \mathrm{E}+00$ & $0.00 \mathrm{E}+00$ & $0.00 \mathrm{E}+00$ & $0.00 \mathrm{E}+00$ & $5.40 \mathrm{E}+04$ \\
\hline GAL-D & $0.00 \mathrm{E}+00$ & $0.00 \mathrm{E}+00$ & $1.91 \mathrm{E}+05$ & $0.00 \mathrm{E}+00$ & $3.17 E+06$ & $0.00 \mathrm{E}+00$ & $0.00 \mathrm{E}+00$ & $1.75 E+04$ & $0.00 \mathrm{E}+00$ & $1.03 E+06$ \\
\hline GAL-C & $0.00 \mathrm{E}+00$ & $0.00 \mathrm{E}+00$ & $3.42 \mathrm{E}+03$ & $0.00 \mathrm{E}+00$ & $1.06 \mathrm{E}+06$ & $0.00 \mathrm{E}+00$ & $0.00 \mathrm{E}+00$ & $3.25 \mathrm{E}+02$ & $0.00 \mathrm{E}+00$ & $1.40 \mathrm{E}+05$ \\
\hline JAC-D & $0.00 \mathrm{E}+00$ & $0.00 \mathrm{E}+00$ & $4.20 E+03$ & $0.00 \mathrm{E}+00$ & $1.83 E+06$ & $0.00 \mathrm{E}+00$ & $0.00 \mathrm{E}+00$ & $4.79 \mathrm{E}+02$ & $0.00 \mathrm{E}+00$ & $1.54 \mathrm{E}+05$ \\
\hline JAC-C & $0.00 \mathrm{E}+00$ & $0.00 \mathrm{E}+00$ & $1.69 \mathrm{E}+04$ & $0.00 \mathrm{E}+00$ & $1.81 E+06$ & $0.00 E+00$ & $0.00 \mathrm{E}+00$ & $1.90 \mathrm{E}+03$ & $0.00 \mathrm{E}+00$ & $3.22 \mathrm{E}+05$ \\
\hline LOS-D & $0.00 \mathrm{E}+00$ & $0.00 \mathrm{E}+00$ & $1.30 \mathrm{E}+04$ & $0.00 \mathrm{E}+00$ & $2.92 \mathrm{E}+06$ & $0.00 \mathrm{E}+00$ & $0.00 \mathrm{E}+00$ & $1.01 \mathrm{E}+01$ & $0.00 \mathrm{E}+00$ & $3.17 \mathrm{E}+05$ \\
\hline LOS-C & $0.00 \mathrm{E}+00$ & $0.00 \mathrm{E}+00$ & $4.28 \mathrm{E}+00$ & $0.00 \mathrm{E}+00$ & $2.00 E+05$ & $0.00 \mathrm{E}+00$ & $0.00 \mathrm{E}+00$ & $9.46 \mathrm{E}-02$ & $0.00 \mathrm{E}+00$ & $2.41 E+02$ \\
\hline MOT-D & $0.00 \mathrm{E}+00$ & $0.00 \mathrm{E}+00$ & $1.19 \mathrm{E}+03$ & $0.00 \mathrm{E}+00$ & $1.03 E+05$ & $0.00 \mathrm{E}+00$ & $0.00 \mathrm{E}+00$ & $1.80 \mathrm{E}+02$ & $0.00 \mathrm{E}+00$ & $8.89 E+03$ \\
\hline NEW-D & $0.00 \mathrm{E}+00$ & $0.00 \mathrm{E}+00$ & $1.86 \mathrm{E}+05$ & $0.00 \mathrm{E}+00$ & $2.06 \mathrm{E}+07$ & $0.00 E+00$ & $0.00 \mathrm{E}+00$ & $7.23 E+03$ & $0.00 \mathrm{E}+00$ & $2.69 E+06$ \\
\hline NEW-C & $0.00 \mathrm{E}+00$ & $0.00 \mathrm{E}+00$ & $6.15 \mathrm{E}+05$ & $0.00 \mathrm{E}+00$ & $5.47 \mathrm{E}+07$ & $0.00 \mathrm{E}+00$ & $0.00 \mathrm{E}+00$ & $2.34 \mathrm{E}+04$ & $0.00 \mathrm{E}+00$ & $7.63 \mathrm{E}+06$ \\
\hline NOR-D & $0.00 \mathrm{E}+00$ & $0.00 \mathrm{E}+00$ & $5.48 \mathrm{E}+04$ & $0.00 \mathrm{E}+00$ & $4.94 \mathrm{E}+06$ & $0.00 \mathrm{E}+00$ & $0.00 \mathrm{E}+00$ & $3.73 E+03$ & $0.00 \mathrm{E}+00$ & $6.36 \mathrm{E}+05$ \\
\hline NOR-C & $0.00 \mathrm{E}+00$ & $0.00 E+00$ & $2.13 \mathrm{E}+04$ & $0.00 \mathrm{E}+00$ & $2.08 \mathrm{E}+06$ & $0.00 E+00$ & $0.00 \mathrm{E}+00$ & $1.44 \mathrm{E}+03$ & $0.00 \mathrm{E}+00$ & $1.93 \mathrm{E}+05$ \\
\hline PHI-D & $0.00 \mathrm{E}+00$ & $0.00 \mathrm{E}+00$ & $1.26 \mathrm{E}+05$ & $0.00 \mathrm{E}+00$ & $1.35 \mathrm{E}+07$ & $0.00 \mathrm{E}+00$ & $0.00 \mathrm{E}+00$ & $1.24 \mathrm{E}+04$ & $0.00 \mathrm{E}+00$ & $2.08 \mathrm{E}+06$ \\
\hline PHI-C & $0.00 \mathrm{E}+00$ & $0.00 \mathrm{E}+00$ & $3.40 \mathrm{E}+04$ & $0.00 \mathrm{E}+00$ & $4.31 E+06$ & $0.00 \mathrm{E}+00$ & $0.00 \mathrm{E}+00$ & $3.37 E+03$ & $0.00 E+00$ & $6.32 \mathrm{E}+05$ \\
\hline POR-D & $0.00 \mathrm{E}+00$ & $0.00 \mathrm{E}+00$ & $1.49 \mathrm{E}+04$ & $0.00 \mathrm{E}+00$ & $5.38 E+06$ & $0.00 \mathrm{E}+00$ & $0.00 \mathrm{E}+00$ & $7.41 E+02$ & $0.00 \mathrm{E}+00$ & $5.29 E+05$ \\
\hline POR-C & $0.00 E+00$ & $0.00 \mathrm{E}+00$ & $2.12 E+04$ & $0.00 \mathrm{E}+00$ & $2.43 \mathrm{E}+06$ & $0.00 \mathrm{~F}+00$ & $0.00 \mathrm{E}+00$ & $1.04 E+03$ & $0.00 \mathrm{E}+00$ & $3.67 E+05$ \\
\hline SAV-D & $0.00 \mathrm{E}+00$ & $0.00 \mathrm{E}+00$ & $1.28 \mathrm{E}+05$ & $0.00 \mathrm{E}+00$ & $4.69 \mathrm{E}+06$ & $0.00 \mathrm{E}+00$ & $0.00 \mathrm{E}+00$ & $1.43 E+04$ & $0.00 \mathrm{E}+00$ & $1.11 E+06$ \\
\hline SAV-C & $0.00 \mathrm{E}+00$ & $0.00 \mathrm{E}+00$ & $1.42 \mathrm{E}+03$ & $0.00 \mathrm{E}+00$ & $3.07 \mathrm{E}+05$ & $0.00 \mathrm{E}+00$ & $0.00 \mathrm{E}+00$ & $1.95 E+02$ & $0.00 \mathrm{E}+00$ & $1.98 \mathrm{E}+04$ \\
\hline SEA-C & $0.00 \mathrm{E}+00$ & $0.00 \mathrm{E}+00$ & $2.51 E+01$ & $0.00 \mathrm{E}+00$ & $4.95 \mathrm{E}+04$ & $0.00 \mathrm{E}+00$ & $0.00 \mathrm{E}+00$ & $1.35 \mathrm{E}-01$ & $0.00 \mathrm{E}+00$ & $1.39 \mathrm{E}+03$ \\
\hline TAC-D & $0.00 \mathrm{E}+00$ & $0.00 \mathrm{E}+00$ & $6.55 E+02$ & $0.00 \mathrm{E}+00$ & $1.84 \mathrm{E}+06$ & $0.00 \mathrm{E}+00$ & $0.00 \mathrm{E}+00$ & $1.55 \mathrm{E}+02$ & $0.00 \mathrm{E}+00$ & $1.17 \mathrm{E}+05$ \\
\hline TAC-C & $0.00 E+00$ & $0.00 \mathrm{E}+00$ & $4.95 E+01$ & $0.00 \mathrm{E}+00$ & $6.51 \mathrm{E}+05$ & $0.00 \mathrm{E}+00$ & $0.00 \mathrm{E}+00$ & $2.66 \mathrm{E}-01$ & $0,00 E+00$ & $2.42 \mathrm{E}+04$ \\
\hline WIL-D & $0.00 \mathrm{E}+00$ & $0.00 \mathrm{E}+00$ & $9.64 \mathrm{E}+04$ & $0.00 \mathrm{E}+00$ & $2.56 \mathrm{E}+06$ & $0.00 \mathrm{E}+00$ & $0.00 \mathrm{E}+00$ & $6.64 E+03$ & $0.00 \mathrm{E}+00$ & $6.78 \mathrm{E}+05$ \\
\hline WIL-C & $0.00 \mathrm{E}+00$ & $0.00 \mathrm{E}+00$ & $1.54 \mathrm{E}+04$ & $0.00 \mathrm{E}+00$ & $3.32 \mathrm{E}+05$ & $0.00 \mathrm{E}+00$ & $0.00 \mathrm{E}+00$ & $1.13 \mathrm{E}+03$ & $0.00 \mathrm{E}+00$ & $1.01 E+05$ \\
\hline
\end{tabular}


Table 35. Mean Values of Population Dose, Cancer Fatalities, Costs, Centerline Individual Dose and Centerline Individual Risk for EIS Accident Categories (Continued)

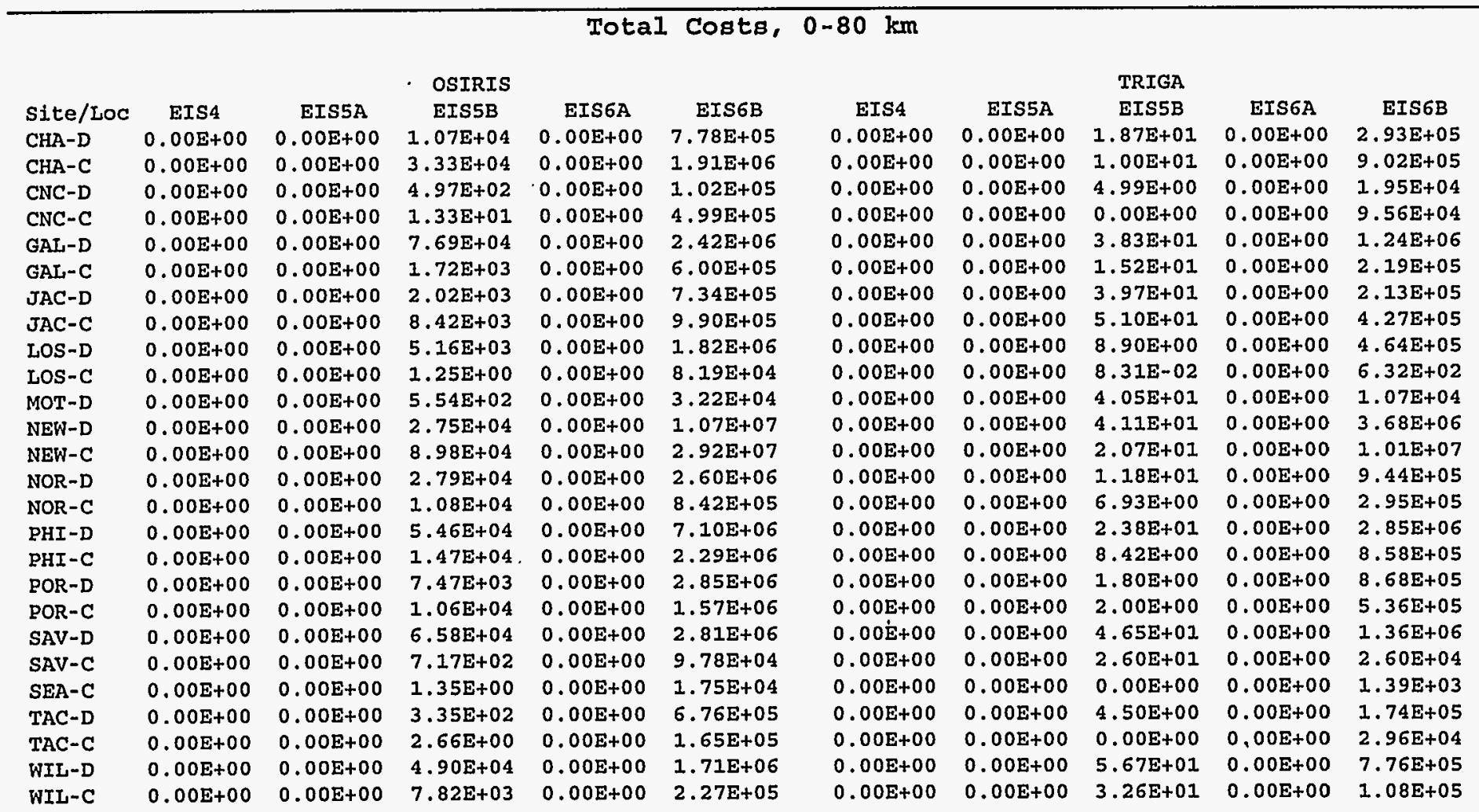


Table 35. Mean Values of Population Dose, Cancer Fatalities, Costs, Centerline Individual Dose and Centerline Individual Risk for EIS Accident Categories (Continued)

\begin{tabular}{|c|c|c|c|c|c|c|c|c|c|c|}
\hline \multirow[b]{3}{*}{ Site/Loc } & \multirow[b]{3}{*}{ EIS4 } & \multicolumn{3}{|c|}{ Individual Centerline } & \multirow{3}{*}{$\begin{array}{c}\text { EDE Whole } \\
\text { EIS6B }\end{array}$} & \multicolumn{2}{|c|}{ Body Dose, $0-1.6$} & $\mathrm{~km} \mathrm{(SV)}$ & \multirow[b]{3}{*}{ EIS6A } & \multirow[b]{3}{*}{ EIS6B } \\
\hline & & & $B R-2$ & & & & & SWLE & & \\
\hline & & EIS5A & EIS5B & EIS6A & & EIS4 & EIS5A & EIS5B & & \\
\hline CHA -D & $8.54 \mathrm{E}-07$ & $1.82 \mathrm{E}-07$ & $5.00 z-03$ & $2.64 E-07$ & $2.14 \mathrm{E}-02$ & $3.41 E-07$ & $7.26 \mathrm{E}-08$ & $2.58 \mathrm{E}-03$ & $1.06 \mathrm{E}-07$ & $8.19 \mathrm{E}-03$ \\
\hline $\mathrm{CHA}-\mathrm{C}$ & $8.54 \mathrm{E}-07$ & $1.82 \mathrm{E}-07$ & $5.00 E-03$ & $2.64 \mathrm{E}-07$ & $1.14 \mathrm{E}-02$ & $3.41 E-07$ & $7.26 \mathrm{E}-08$ & $2.58 \mathrm{E}-03$ & $1.06 \mathrm{E}-07$ & $8.19 \mathrm{E}-03$ \\
\hline CNC-D & $1.07 \mathrm{E}-06$ & $6.27 E-08$ & $2.14 \mathrm{E}-03$ & $8.31 E-08$ & $7.53 \mathrm{E}-03$ & $4.25 \mathrm{E}-07$ & $2.51 E-08$ & $9.81 \mathrm{E}-04$ & $3.32 \mathrm{E}-08$ & $5.23 \mathrm{E}-03$ \\
\hline CNC-C & $1.07 \mathrm{E}-06$ & $6.27 \mathrm{E}-08$ & $2.14 \mathrm{E}-03$ & $8.31 \mathrm{E}-08$ & $7.53 \mathrm{E}-03$ & $4.25 E-07$ & $2.51 E-08$ & $9.81 \mathrm{E}-04$ & $3.32 \mathrm{E}-08$ & $5.23 \mathrm{E}-03$ \\
\hline GAL-D & $9.22 \mathrm{E}-07$ & $1.73 E-07$ & $4.25 \mathrm{E}-03$ & $2.58 \mathrm{E}-07$ & $6.68 \mathrm{E}-03$ & $3.68 \mathrm{E}-07$ & $6.93 E-08$ & $2.46 \mathrm{E}-03$ & $1.03 \mathrm{E}-07$ & $7.32 \mathrm{E}-03$ \\
\hline GAI-C & $9.22 \mathrm{E}-07$ & $1.73 \mathrm{E}-07$ & $4.25 E-03$ & $2.58 E-07$ & $6.68 \mathrm{E}-03$ & $3.68 \mathrm{E}-07$ & $6.93 \mathrm{E}-08$ & $2.46 \mathrm{E}-03$ & $1.03 \mathrm{E}-07$ & $7.32 \mathrm{E}-03$ \\
\hline JAC-D & $8.54 \mathrm{E}-07$ & $1.82 \mathrm{E}-07$ & $5.00 \mathrm{E}-03$ & $2.64 \mathrm{E}-07$ & $1.14 \mathrm{E}-02$ & $3.41 E-07$ & $7.26 \mathrm{E}-08$ & $2.58 \mathrm{E}-03$ & $1.06 \mathrm{E}-07$ & $8.19 \mathrm{E}-03$ \\
\hline JAC-C & $8.54 \mathrm{E}-07$ & $1.82 \mathrm{E}-07$ & $5.00 \mathrm{E}-03$ & $2.64 \mathrm{E}-07$ & $1.14 \mathrm{E}-02$ & $3.41 E-07$ & $7.26 \mathrm{E}-08$ & $2.58 E-03$ & $1.06 \mathrm{E}-07$ & $8.19 \mathrm{E}-03$ \\
\hline LOS-D & $1.07 \mathrm{E}-06$ & $6.27 E-08$ & $2.14 \mathrm{E}-03$ & $8.31 \mathrm{E}-08$ & $7.53 \mathrm{E}-03$ & $4.25 E-07$ & $2.51 E-08$ & $9.81 \mathrm{E}-04$ & $3.32 \mathrm{E}-08$ & $5.23 E-03$ \\
\hline LOS-C & $1.07 \mathrm{E}-06$ & $6.27 E-08$ & $2.14 E-03$ & $8.33 \mathrm{E}-08$ & $7.53 E-03$ & $4.25 \Sigma-07$ & $2.51 E-08$ & $9.81 E-04$ & $3.32 \mathrm{E}-08$ & $5.23 E-03$ \\
\hline MOT-D & $5.28 \mathrm{E}-07$ & $1.72 \mathrm{E}-07$ & $4.83 E-03$ & $2.07 \mathrm{E}-07$ & $1.14 \mathrm{E}-02$ & $2.11 E-07$ & $6.85 E-08$ & $2.50 \mathrm{E}-03$ & $8.26 \mathrm{E}-08$ & $1.01 \mathrm{E}-02$ \\
\hline NEW-D & $5.94 \mathrm{E}-07$ & $3.25 E-07$ & $1.03 \mathrm{E}-02$ & $3.58 E-07$ & $1.39 \mathrm{E}-02$ & $2.37 E-07$ & $1.30 \mathrm{E}-07$ & $4.94 E-03$ & $1.43 \mathrm{E}-07$ & $1.67 \mathrm{E}-02$ \\
\hline NEW-C & $5.94 \mathrm{E}-07$ & $3.25 \mathrm{E}-07$ & $1.03 \mathrm{E}-02$ & $3.58 \mathrm{E}-07$ & $1.39 \mathrm{E}-02$ & $2.37 \mathrm{E}-07$ & $1.30 \mathrm{E}-07$ & $4.94 \mathrm{E}-03$ & $1.43 \mathrm{E}-07$ & $1.67 \mathrm{E}-02$ \\
\hline NOR-D & $5.28 E-07$ & $1.72 \mathrm{E}-07$ & $4.83 \mathrm{E}-03$ & $2.07 \mathrm{E}-07$ & $1.14 \mathrm{E}-02$ & $2.11 \mathrm{E}-07$ & $6.85 E-08$ & $2.50 \mathrm{E}-03$ & $8.26 \mathrm{E}-08$ & $1.01 \mathrm{E}-02$ \\
\hline NOR -C & $5.28 \mathrm{E}-07$ & $1.72 \mathrm{E}-07$ & $4.83 \mathrm{E}-03$ & $2.07 E-07$ & $1.14 \mathrm{E}-02$ & $2.11 \mathrm{E}-07$ & $6.85 E-08$ & $2.50 \mathrm{E}-03$ & $8.26 \mathrm{E}-08$ & $1.01 \mathrm{E}-02$ \\
\hline PHI-D & $9.98 \mathrm{E}-07$ & $1.68 \mathrm{E}-07$ & $5.52 \mathrm{E}-03$ & $2.45 \mathrm{E}-07$ & $1.15 \mathrm{E}-02$ & $3.98 \mathrm{E}-07$ & $6.71 \mathrm{E}-08$ & $2.55 \mathrm{E}-03$ & $9.79 \mathrm{E}-08$ & $1.06 \mathrm{E}-02$ \\
\hline PHI-C & $9.98 E-07$ & $1.68 \mathrm{E}-07$ & $5.52 \mathrm{E}-03$ & $2.45 \mathrm{E}-07$ & $1.15 \mathrm{E}-02$ & $3.98 \mathrm{E}-07$ & $6.71 \mathrm{E}-08$ & $2.55 E-03$ & $9.79 \mathrm{E}-08$ & $1.06 \mathrm{E}-02$ \\
\hline POR-D & $7.48 \mathrm{E}-07$ & $2.06 E-07$ & $7.46 \mathrm{E}-03$ & $3.05 E-07$ & $2.42 \mathrm{E}-02$ & $2.99 \mathrm{E}-07$ & $8.24 \mathrm{E}-08$ & $3.21 E-03$ & $1.22 \mathrm{E}-07$ & $1.66 \mathrm{E}-02$ \\
\hline POR-C & $7.48 \mathrm{E}-07$ & $2.06 \mathrm{E}-07$ & $7.46 \mathrm{E}-03$ & $3.05 \mathrm{E}-07$ & $2.42 \mathrm{E}-02$ & $2.99 \mathrm{E}-07$ & $8.24 \mathrm{E}-08$ & $3.21 E-03$ & $1.22 E-07$ & $1.66 \mathrm{E}-02$ \\
\hline SAV-D & $8.54 \mathrm{E}-07$ & 1. $82 \mathrm{E}-07$ & $5.00 \mathrm{E}-03$ & $2.64 \mathrm{E}-07$ & $1.14 \mathrm{E}-02$ & $3.41 \mathrm{E}-07$ & $7.26 \mathrm{E}-08$ & $2.58 \mathrm{E}-03$ & $1.06 \mathrm{E}-07$ & $8.19 \mathrm{E}-03$ \\
\hline SAV-C & $8.54 \mathrm{E}-07$ & $1.82 \mathrm{E}-07$ & $5.00 \mathrm{E}-03$ & $2.64 E-07$ & $1.14 \mathrm{E}-02$ & $3.41 E-07$ & $7.26 E-08$ & $2.58 \mathrm{E}-03$ & $1.06 \mathrm{E}-07$ & $8.19 E-03$ \\
\hline SEA-C & $7.48 \mathrm{E}-07$ & $2.06 \mathrm{E}-07$ & $7.46 \mathrm{E}-03$ & $3.05 E-07$ & $2.42 \mathrm{E}-02$ & $2.99 \mathrm{E}-07$ & $8.24 E-08$ & $3.21 \mathrm{E}-03$ & $1.22 \mathrm{E}-07$ & $1.66 \mathrm{E}-02$ \\
\hline TAC-D & $7.48 \mathrm{E}-07$ & $2.06 E-07$ & $7.46 \mathrm{E}-03$ & $3.05 \mathrm{E}-07$ & $2.42 \mathrm{E}-02$ & $2.99 \mathrm{E}-07$ & $8.24 \mathrm{E}-08$ & $3.21 \mathrm{E}-03$ & $1.22 \mathrm{E}-07$ & $1.66 \mathrm{E}-02$ \\
\hline TAC-C & $7.48 \mathrm{E}-07$ & $2.06 \mathrm{E}-07$ & $7.46 \mathrm{E}-03$ & $3.05 \mathrm{E}-07$ & $2.42 \mathrm{E}-02$ & $2.99 \mathrm{E}-07$ & $8.24 \mathrm{E}-08$ & $3.21 \mathrm{E}-03$ & $1.22 \mathrm{E}-07$ & $1.66 \mathrm{E}-02$ \\
\hline WIL-D & $5.28 E-07$ & $1.72 \mathrm{E}-07$ & $4.83 \mathrm{E}-03$ & $2.07 \mathrm{E}-07$ & $1.14 \mathrm{E}-02$ & $2.11 \mathrm{E}-07$ & $6.85 \mathrm{E}-08$ & $2.50 \mathrm{E}-03$ & $8.26 E-08$ & $1.01 \mathrm{E}-02$ \\
\hline WIL-C & $5.28 \mathrm{E}-07$ & 1. $72 \mathrm{E}-07$ & $4.83 \mathrm{E}-03$ & $2.07 \mathrm{E}-07$ & $1.14 \mathrm{E}-02$ & $2.11 \mathrm{E}-07$ & $6.85 E-08$ & $2.50 \mathrm{E}-03$ & $8.26 E-08$ & $1.01 \mathrm{E}-02$ \\
\hline
\end{tabular}


Table 35. Mean Values of Population Dose, Cancer Fatalities, Costs, Centerline Individual Dose and Centerline Individual Risk for EIS Accident Categories (Continued)

\begin{tabular}{|c|c|c|c|c|c|c|c|c|c|c|}
\hline \multirow[b]{2}{*}{ Site/Loc } & \multicolumn{4}{|c|}{ Individual Centerline } & EDE Whole & \multicolumn{2}{|c|}{ Body Dose, $0-1.6$} & $\mathrm{~km}$ (SV) & \multirow[b]{2}{*}{ EIS6A } & \multirow[b]{2}{*}{ EIS6B } \\
\hline & EIS4 & EIS5A & EIS5B & EIS6A & EIS6B & EIS4 & EIS5A & EIS5B & & \\
\hline CHA-C & $1.16 \mathrm{E}-06$ & $2.29 \mathrm{E}-07$ & $5.40 \mathrm{E}-03$ & $3.32 E-07$ & $1.19 \mathrm{E}-02$ & $9.70 \mathrm{E}-07$ & $1.06 \mathrm{E}-04$ & $1.23 \mathrm{E}-03$ & $1.61 \mathrm{E}-04$ & $8.68 \mathrm{E}-03$ \\
\hline CNC-D & $1.45 \mathrm{E}-06$ & $7.98 \mathrm{E}-08$ & $2.24 \mathrm{E}-03$ & $1.05 E-07$ & $8.26 \mathrm{E}-03$ & $1.21 E-06$ & $3.52 \mathrm{E}-05$ & $4.12 \mathrm{E}-04$ & $4.93 \mathrm{E}-05$ & $5.70 \mathrm{E}-03$ \\
\hline CNC-C & $1.45 \mathrm{E}-06$ & $7.98 \mathrm{E}-08$ & $2.24 \mathrm{E}-03$ & $1.05 \mathrm{E}-07$ & $8.26 \mathrm{E}-03$ & $1.21 \mathrm{E}-06$ & $3.52 E-05$ & $4.12 \mathrm{E}-04$ & $4.93 \mathrm{E}-05$ & $5.70 \mathrm{E}-03$ \\
\hline GAL-D & $1.25 E-06$ & $2.19 \mathrm{E}-07$ & $5.04 \mathrm{E}-03$ & $3.24 \mathrm{E}-07$ & $6.93 \mathrm{E}-03$ & $1.05 \mathrm{E}-06$ & $1.01 \mathrm{E}-04$ & $1.18 \mathrm{E}-03$ & $1.57 \mathrm{E}-04$ & $7.97 \mathrm{E}-03$ \\
\hline $\mathrm{JAC}-\mathrm{C}$ & $1.16 \mathrm{E}-06$ & $2.29 \mathrm{E}-07$ & $5.40 \mathrm{E}-03$ & $3.32 E-07$ & $1.19 \mathrm{E}-02$ & $9.70 \mathrm{E}-07$ & $1.06 \mathrm{E}-04$ & $1.23 \mathrm{E}-03$ & $1.61 E-04$ & $8.68 \mathrm{E}-03$ \\
\hline LOS-D & $1.45 \mathrm{E}-06$ & $7.98 \mathrm{E}-08$ & $2.24 \mathrm{E}-03$ & $1.05 E-07$ & $8.26 E-03$ & $1.21 \mathrm{E}-06$ & $3.52 \mathrm{E}-05$ & $4.12 \mathrm{E}-04$ & $4.93 E-05$ & $5.70 \mathrm{E}-03$ \\
\hline LOS-C & $1.45 \mathrm{E}-06$ & $7.98 E-08$ & $2.24 \mathrm{E}-03$ & $1.05 \mathrm{E}-07$ & $8.26 \mathrm{E}-03$ & $1.21 \mathrm{E}-06$ & $3.52 \mathrm{E}-05$ & $4.12 \mathrm{E}-04$ & $4.93 \mathrm{E}-05$ & $5.70 \mathrm{E}-03$ \\
\hline MOT-D & $7.13 E-07$ & $2.18 E-07$ & $5.64 \mathrm{E}-03$ & $2.61 \mathrm{E}-07$ & $1.29 \mathrm{E}-02$ & $6.03 \mathrm{E}-07$ & $9.66 \mathrm{E}-05$ & $1.13 \mathrm{E}-03$ & $1.25 \mathrm{E}-04$ & $1.04 \mathrm{E}-02$ \\
\hline NEW-D & $7.99 E-07$ & $4.15 \mathrm{E}-07$ & $1.17 \mathrm{E}-02$ & $4.52 \mathrm{E}-07$ & $1.83 \mathrm{E}-02$ & $6.80 \mathrm{E}-07$ & $1.81 \mathrm{E}-04$ & $2.12 \mathrm{E}-03$ & $2.16 \mathrm{E}-04$ & $1.82 \mathrm{E}-02$ \\
\hline NEW-C & $7.99 E-07$ & $4.15 \mathrm{E}-07$ & 1. $27 \mathrm{E}-02$ & $4.52 \mathrm{E}-07$ & $1.83 \mathrm{E}-02$ & $6.80 \mathrm{E}-07$ & $1.81 \mathrm{E}-04$ & $2.12 \mathrm{E}-03$ & $2.16 \mathrm{E}-04$ & 1. 82E-02 \\
\hline NOR-D & $7.13 \mathrm{E}-07$ & $2.18 \mathrm{E}-07$ & $5.64 \mathrm{E}-03$ & $2.61 E-07$ & $1.29 \mathrm{E}-02$ & $6.03 \mathrm{E}-07$ & $9.66 \mathrm{E}-05$ & $1.13 \mathrm{E}-03$ & $1.25 \mathrm{E}-04$ & $1.04 \mathrm{E}-02$ \\
\hline POR-C & $1.01 \mathrm{E}-06$ & $2.62 \mathrm{E}-07$ & $7.42 \mathrm{E}-03$ & $3.87 E-07$ & $2.68 \mathrm{E}-02$ & $8.56 \mathrm{E}-07$ & $1.17 \mathrm{E}-04$ & $1.37 \mathrm{E}-03$ & $1.81 \mathrm{E}-04$ & $1.56 \mathrm{E}-02$ \\
\hline SAV-D & $1.16 \mathrm{E}-06$ & $2.29 \mathrm{E}-07$ & $5.40 \mathrm{E}-03$ & $3.32 \mathrm{E}-07$ & $1.19 \mathrm{E}-02$ & $9.70 \mathrm{E}-07$ & $1.06 \mathrm{E}-04$ & $1.23 \mathrm{E}-03$ & $1.61 \mathrm{E}-04$ & $8.68 \mathrm{E}-03$ \\
\hline SAV-C & $1.16 \mathrm{E}-06$ & $2.29 \mathrm{E}-07$ & $5.40 \mathrm{E}-03$ & $3.32 \mathrm{E}-07$ & $1.19 \mathrm{E}-02$ & $9.70 \mathrm{E}-07$ & $1.06 \mathrm{E}-04$ & $1.23 \mathrm{E}-03$ & $1.61 \mathrm{E}-04$ & $8.68 \mathrm{E}-03$ \\
\hline SEA-C & $1.01 \mathrm{E}-06$ & $2.62 \mathrm{E}-07$ & $7.42 \mathrm{E}-03$ & $3.87 E-07$ & $2.68 \mathrm{E}-02$ & $8.56 \mathrm{E}-07$ & $1.27 \mathrm{E}-04$ & $1.37 \mathrm{E}-03$ & $1.81 \mathrm{E}-04$ & $1.56 \mathrm{E}-02$ \\
\hline TAC-D & $1.01 \mathrm{E}-06$ & $2.62 \mathrm{E}-07$ & $7.42 \mathrm{E}-03$ & $3.87 \mathrm{E}-07$ & $2.68 \mathrm{E}-02$ & $8.56 \mathrm{E}-07$ & $1.17 \mathrm{E}-04$ & $1.37 \mathrm{E}-03$ & $1.81 \mathrm{E}-04$ & $1.56 \mathrm{E}-02$ \\
\hline TAC-C & $1.01 \mathrm{E}-06$ & $2.62 \mathrm{E}-07$ & $7.42 \mathrm{E}-03$ & $3.87 E-07$ & $2.68 \mathrm{E}-02$ & $8.56 \mathrm{E}-07$ & $1.17 \mathrm{E}-04$ & $1.37 \mathrm{E}-03$ & $1 . .81 \mathrm{E}-04$ & $1.56 \mathrm{E}-02$ \\
\hline WIL-D & $7.13 E-07$ & $2.18 \mathrm{E}-07$ & $5.64 \mathrm{E}-03$ & $2.61 E-07$ & $1.29 \mathrm{E}-02$ & $6.03 \mathrm{E}-07$ & $9.66 \mathrm{E}-05$ & $1.13 \mathrm{E}-03$ & $1.25 \mathrm{E}-04$ & $1.04 \mathrm{E}-02$ \\
\hline WIL-C & $7.13 E-07$ & $2.18 \mathrm{E}-07$ & $5.64 \mathrm{E}-03$ & $2.61 \mathrm{E}-07$ & $1.29 \mathrm{E}-02$ & $6.03 E-07$ & $9.66 \mathrm{E}-05$ & $1.13 \mathrm{E}-03$ & $1.25 \mathrm{E}-04$ & $1.04 \mathrm{E}-02$ \\
\hline
\end{tabular}


Table 35. Mean Values of Population Dose, Cancer Fatalities, Costs, Centerline Individual Dose and Centerline Individual Risk for EIS Accident Categories (Continued)

Individual Centerline Cancer Risk, 0-1.6 km

$\begin{array}{lccccc}\text { Site/LOC } & \text { EIS4 } & \text { EIS5A } & \begin{array}{c}\text { EIS5B } \\ \text { CIS-2 }\end{array} & \text { EIS6A } & \text { EIS6B } \\ \text { CHA-D } & 4.08 E-08 & 7.71 E-09 & 2.08 E-04 & 1.12 E-08 & 4.76 E-04 \\ \text { CHA-C } & 4.08 E-08 & 7.71 E-09 & 2.08 E-04 & 1.12 E-08 & 4.76 E-04 \\ \text { CNC-D } & 5.10 E-08 & 2.70 E-09 & 8.94 E-05 & 3.55 E-09 & 3.14 E-04 \\ \text { CNC-C } & 5.10 E-08 & 2.70 E-09 & 8.94 E-05 & 3.55 E-09 & 3.14 E-04 \\ \text { GAL-D } & 4.40 E-08 & 7.35 E-09 & 1.77 E-04 & 1.09 E-08 & 2.79 E-04 \\ \text { GAL-C } & 4.40 E-08 & 7.35 E-09 & 1.77 E-04 & 1.09 E-08 & 2.79 E-04 \\ \text { JAC-D } & 4.08 E-08 & 7.71 E-09 & 2.08 E-04 & 1.12 E-08 & 4.76 E-04 \\ \text { JAC-C } & 4.08 E-08 & 7.71 E-09 & 2.08 E-04 & 1.12 E-08 & 4.76 E-04 \\ \text { LOS-D } & 5.10 E-08 & 2.70 E-09 & 8.94 E-05 & 3.55 E-09 & 3.14 E-04 \\ \text { LOS-C } & 5.10 E-08 & 2.70 E-09 & 8.94 E-05 & 3.55 E-09 & 3.14 E-04 \\ \text { MOT-D } & 2.50 E-08 & 7.38 E-09 & 2.02 E-04 & 8.78 E-09 & 4.74 E-04 \\ \text { NEW-D } & 2.79 E-08 & 1.41 E-08 & 4.30 E-04 & 1.52 E-08 & 5.78 E-04 \\ \text { NEW-C } & 2.79 E-08 & 1.41 E-08 & 4.30 E-04 & 1.52 E-08 & 5.78 E-04 \\ \text { NOR-D } & 2.50 E-08 & 7.38 E-09 & 2.02 E-04 & 8.78 E-09 & 4.74 E-04 \\ \text { NOR-C } & 2.50 E-08 & 7.38 E-09 & 2.02 E-04 & 8.78 E-09 & 4.74 E-04 \\ \text { PHI-D } & 4.77 E-08 & 7.11 E-09 & 2.30 E-04 & 1.04 E-08 & 4.79 E-04 \\ \text { PHI-C } & 4.77 E-08 & 7.11 E-09 & 2.30 E-04 & 1.04 E-08 & 4.79 E-04 \\ \text { POR-D } & 3.53 E-08 & 8.85 E-09 & 3.11 E-04 & 1.31 E-08 & 1.01 E-03 \\ \text { POR-C } & 3.53 E-08 & 8.85 E-09 & 3.11 E-04 & 1.31 E-08 & 1.01 E-03 \\ \text { SAV-D } & 4.08 E-08 & 7.71 E-09 & 2.08 E-04 & 1.12 E-08 & 4.76 E-04 \\ \text { SAV-C } & 4.08 E-08 & 7.71 E-09 & 2.08 E-04 & 1.12 E-08 & 4.76 E-04 \\ \text { SEA-C } & 3.53 E-08 & 8.85 E-09 & 3.11 E-04 & 1.31 E-08 & 1.01 E-03 \\ \text { TAC-D } & 3.53 E-08 & 8.85 E-09 & 3.11 E-04 & 1.31 E-08 & 1.01 E-03 \\ \text { TAC-C } & 3.53 E-08 & 8.85 E-09 & 3.11 E-04 & 1.31 E-08 & 1.01 E-03 \\ \text { WIL-D } & 2.50 E-08 & 7.38 E-09 & 2.02 E-04 & 8.78 E-09 & 4.74 E-04 \\ \text { WIL-C } & 2.50 E-08 & 7.38 E-09 & 2.02 E-04 & 8.78 E-09 & 4.74 E-04\end{array}$

\begin{tabular}{|c|c|c|c|c|}
\hline \multicolumn{5}{|c|}{ RHF } \\
\hline EIS4 & EIS5A & S5B & EIS6A & EIS6B \\
\hline $1.65 E-08$ & $3.10 \mathrm{E}-09$ & $1.08 \mathrm{E}-04$ & $4.49 \mathrm{E}-09$ & $3.41 \mathrm{E}-04$ \\
\hline $1.65 E-08$ & $3.10 \mathrm{E}-09$ & $1.08 \mathrm{E}-04$ & $4.49 E-09$ & $3.41 \mathrm{E}-04$ \\
\hline 2.07E-08 & $1.09 \mathrm{E}-09$ & $4.09 \mathrm{E}-05$ & $1.43 E-09$ & $2.18 \mathrm{E}-04$ \\
\hline $2.07 E-08$ & $1.09 \mathrm{E}-09$ & $4.09 E-05$ & $1.43 \mathrm{E}-09$ & $2.18 \mathrm{E}-04$ \\
\hline 1. $79 \mathrm{E}-08$ & 2.96E-09 & $1.03 \mathrm{E}-04$ & $4.39 E-09$ & $3.05 \mathrm{E}-04$ \\
\hline $1.79 E-08$ & $2.96 \mathrm{E}-09$ & $1.03 \mathrm{E}-04$ & $4.39 E-09$ & $3.05 E-04$ \\
\hline $1.65 \mathrm{E}-08$ & $3.10 \mathrm{E}-09$ & $1.08 \mathrm{E}-04$ & $4.49 \mathrm{E}-09$ & $3.41 \mathrm{E}-04$ \\
\hline $1.65 \mathrm{E}-08$ & $3.10 \mathrm{E}-09$ & $1.08 \mathrm{E}-04$ & $4.49 \mathrm{E}-09$ & 1E-04 \\
\hline 2.0 & $1.09 \mathrm{E}-09$ & $4.09 E-05$ & $3 E-09$ & $2.18 \mathrm{E}-04$ \\
\hline $2.07 E-08$ & $1.09 \mathrm{E}-09$ & $4.09 \mathrm{E}-05$ & $1.43 \mathrm{E}-09$ & $2.18 \mathrm{E}-04$ \\
\hline $1.01 E-08$ & $2.97 \mathrm{E}-09$ & $1.04 \mathrm{E}-04$ & $3.53 \mathrm{E}-09$ & $4.20 \mathrm{E}-04$ \\
\hline $1.13 \mathrm{E}-08$ & $5.66 \mathrm{E}-09$ & $2.06 E-04$ & $6.12 \mathrm{E}-09$ & $6.97 \mathrm{E}-04$ \\
\hline $1.13 \mathrm{E}-08$ & $5.66 \mathrm{E}-09$ & $2.06 \mathrm{E}-04$ & $6.12 \mathrm{E}-09$ & $6.97 \mathrm{E}-04$ \\
\hline $1.01 \mathrm{E}-08$ & $2.97 \mathrm{E}-09$ & $1.04 \mathrm{E}-04$ & $3.53 \mathrm{E}-09$ & $4.20 \mathrm{E}-04$ \\
\hline $1.01 \mathrm{E}-08$ & $2.97 \mathrm{E}-09$ & $1.04 \mathrm{E}-04$ & -09 & $0 E-04$ \\
\hline 08 & 09 & 04 & & 7 \\
\hline 08 & 19 & $6 E-04$ & $4.16 \mathrm{E}-09$ & $4.40 \mathrm{E}-04$ \\
\hline $.43 E-08$ & $3.56 \mathrm{E}-09$ & $1.34 \mathrm{E}-04$ & $5.26 \mathrm{E}-09$ & $6.91 \mathrm{E}-04$ \\
\hline $1.43 \mathrm{E}-08$ & $3.56 \mathrm{E}-09$ & $1.34 \mathrm{E}-04$ & $5.26 \mathrm{E}-09$ & $6.91 E-04$ \\
\hline $1.65 \mathrm{E}-08$ & $3.10 \mathrm{E}-09$ & $1.08 \mathrm{E}-04$ & $4.49 E-09$ & $3.41 E-04$ \\
\hline $1.65 \mathrm{E}-08$ & $3.10 \mathrm{E}-09$ & $1.08 \mathrm{E}-04$ & $4.49 \mathrm{E}-09$ & $3.41 \mathrm{E}-04$ \\
\hline $1.43 \mathrm{E}-08$ & $3.56 \mathrm{E}-09$ & $1.34 \mathrm{E}-04$ & $5.26 \mathrm{E}-09$ & $6.91 E-04$ \\
\hline $1.43 \mathrm{E}-08$ & $3.56 \mathrm{E}-09$ & $1.34 \mathrm{E}-04$ & 26E-09 & $91 \mathrm{E}-04$ \\
\hline $43 E-08$ & 3. & .04 & 9 & 14 \\
\hline & & $1.04 \mathrm{E}-04$ & $3.53 E-09$ & $4.20 \mathrm{E}-04$ \\
\hline $.01 E-08$ & $2.97 \mathrm{E}-09$ & $1.04 \mathrm{E}-04$ & $3.53 \mathrm{E}-09$ & $4.20 \mathrm{E}-04$ \\
\hline
\end{tabular}


Table 35. Mean Values of Population Dose, Cancer Fatalities, Costs, Centerline Individual Dose and Centerline Individual Risk for EIS Accident Categories (Concluded)

\begin{tabular}{|c|c|c|c|c|c|c|c|c|c|c|}
\hline \multirow[b]{3}{*}{ Site/Loc } & \multicolumn{10}{|c|}{ Individual Centerline Cancer Risk, } \\
\hline & & & OSIRIS & & & & & TRIGA & & \\
\hline & EIS4 & EIS5A & EIS5B & EIS6A & EIS6B & EIS4 & EIS5A & EIS5B & EIS6A & EIS6B \\
\hline CHA-D & $5.36 \mathrm{E}-08$ & $9.53 E-09$ & $2.25 \mathrm{E}-04$ & $1.38 \mathrm{E}-08$ & $4.96 \mathrm{E}-04$ & $4.28 \mathrm{E}-08$ & $4.40 \mathrm{E}-06$ & $5.13 \mathrm{E}-05$ & $6.71 \mathrm{E}-06$ & $3.62 \mathrm{E}-04$ \\
\hline $\mathrm{CHA}-\mathrm{C}$ & $5.36 \mathrm{E}-08$ & $9.53 \mathrm{E}-09$ & $2.25 \mathrm{E}-04$ & $1.38 \mathrm{E}-08$ & $4.96 \mathrm{E}-04$ & $4.28 \mathrm{E}-08$ & $4.40 \mathrm{E}-06$ & $5.13 \mathrm{E}-05$ & $6.71 \mathrm{E}-06$ & $3.62 \mathrm{E}-04$ \\
\hline CNC-D & $6.70 \mathrm{E}-08$ & $3.37 E-09$ & $9.32 \mathrm{E}-05$ & $4.41 E-09$ & $3.44 \mathrm{E}-04$ & $5.35 \mathrm{E}-08$ & $1.47 E-06$ & $1.72 \mathrm{E}-05$ & $2.05 \mathrm{E}-06$ & $2.38 \mathrm{E}-04$ \\
\hline CNC-C & $6.70 \mathrm{E}-08$ & $3.37 \mathrm{E}-09$ & $9.32 \mathrm{E}-05$ & $4.41 \mathrm{E}-09$ & $3.44 \mathrm{E}-04$ & $5.35 \mathrm{E}-08$ & $1.47 \mathrm{E}-06$ & $1.72 \mathrm{E}-05$ & $2.05 E-06$ & $2.38 \mathrm{E}-04$ \\
\hline GAL-D & $5.79 \mathrm{E}-08$ & $9.08 \mathrm{E}-09$ & $2.10 \mathrm{E}-04$ & $1.35 \mathrm{E}-08$ & $2.88 \mathrm{E}-04$ & $4.63 \mathrm{E}-08$ & $4.20 E-06$ & $4.90 \mathrm{E}-05$ & $6.53 E-06$ & $3.32 E-04$ \\
\hline GAL-C & $5.79 \mathrm{E}-08$ & $9.08 \mathrm{E}-09$ & $2.10 \mathrm{E}-04$ & $1.35 \mathrm{E}-08$ & $2.88 \mathrm{E}-04$ & $4.63 \mathrm{E}-08$ & $4.20 \mathrm{E}-06$ & $4.90 \mathrm{E}-05$ & $6.53 \mathrm{E}-06$ & $3.32 \mathrm{E}-04$ \\
\hline JAC-D & $5.36 \mathrm{E}-08$ & $9.53 E-09$ & $2.25 \mathrm{E}-04$ & $1.38 \mathrm{E}-08$ & $4.96 \mathrm{E}-04$ & $4.28 \mathrm{E}-08$ & $4.40 E-06$ & $5.13 \mathrm{E}-05$ & $6.71 \mathrm{E}-06$ & $3.62 \mathrm{E}-04$ \\
\hline JAC-C & $5.36 \mathrm{E}-08$ & $9.53 \mathrm{E}-09$ & $2.25 \mathrm{E}-04$ & $1.38 \mathrm{E}-08$ & $4.96 \mathrm{E}-04$ & $4.28 \mathrm{E}-08$ & $4.40 \mathrm{E}-06$ & $5.13 \mathrm{E}-05$ & $6.71 \mathrm{E}-06$ & $3.62 \mathrm{E}-04$ \\
\hline LOS-D & $6.70 \mathrm{E}-08$ & $3.37 \mathrm{E}-09$ & $9.32 \mathrm{E}-05$ & $4.41 E-09$ & $3.44 \mathrm{E}-04$ & $5.35 \mathrm{E}-08$ & $1.47 \mathrm{E}-06$ & $1.72 \mathrm{E}-05$ & $2.05 \mathrm{E}-06$ & $2.38 \mathrm{E}-04$ \\
\hline LOS-C & $6.70 \mathrm{E}-08$ & $3.37 \mathrm{E}-09$ & $9.32 \mathrm{E}-05$ & $4.41 \mathrm{E}-09$ & $3.44 \mathrm{E}-04$ & $5.35 \mathrm{E}-08$ & $1.47 E-06$ & $1.72 \mathrm{E}-05$ & $2.05 \mathrm{E}-06$ & $2.38 \mathrm{E}-04$ \\
\hline MOT-D & $3.26 \mathrm{E}-08$ & $9.19 \mathrm{E}-09$ & $2.35 \mathrm{E}-04$ & $1.08 \mathrm{E}-08$ & $5.38 \mathrm{E}-04$ & $2.64 \mathrm{E}-08$ & $4.02 \mathrm{E}-06$ & $4.71 \mathrm{E}-05$ & $5.20 \mathrm{E}-06$ & $4.34 \mathrm{E}-04$ \\
\hline NEW-D & $3.64 E-08$ & $1.76 \mathrm{E}-08$ & $4.86 \mathrm{E}-04$ & $1.88 \mathrm{E}-08$ & $7.61 \mathrm{E}-04$ & $2.96 \mathrm{E}-08$ & $7.53 \mathrm{E}-06$ & $8.85 \mathrm{E}-05$ & $9.00 \mathrm{E}-06$ & $7.59 \mathrm{E}-04$ \\
\hline NEW-C & $3.64 \mathrm{E}-08$ & 1. $76 \mathrm{E}-08$ & $4.86 \mathrm{E}-04$ & $1.88 \mathrm{E}-08$ & $7.61 \mathrm{E}-04$ & $2.96 \mathrm{E}-08$ & $7.53 \mathrm{E}-06$ & $8.85 \mathrm{E}-05$ & $9.00 \mathrm{E}-06$ & $7.59 \mathrm{E}-04$ \\
\hline NOR-D & $3.26 \mathrm{E}-08$ & $9.19 \mathrm{E}-09$ & $2.35 E-04$ & $1.08 \mathrm{E}-08$ & $5.38 \mathrm{E}-04$ & $2.64 \mathrm{E}-08$ & $4.02 E-06$ & $4.71 \mathrm{E}-05$ & $5.20 \mathrm{E}-06$ & $4.34 \mathrm{E}-04$ \\
\hline NOR-C & $3.26 \mathrm{E}-08$ & $9.19 \mathrm{E}-09$ & $2.35 \mathrm{E}-04$ & $1.08 \mathrm{E}-08$ & $5.38 \mathrm{E}-04$ & $2.64 \mathrm{E}-08$ & $4.02 \mathrm{E}-06$ & $4.71 \mathrm{E}-05$ & $5.20 \mathrm{E}-06$ & $4.34 E-04$ \\
\hline PHI-D & $6.28 E-08$ & $8.79 E-09$ & $2.42 \mathrm{E}-04$ & $1.28 \mathrm{E}-08$ & $5.12 \mathrm{E}-04$ & $5.01 \mathrm{E}-08$ & $4.07 E-06$ & $4.74 E-05$ & $6.22 \mathrm{E}-06$ & $4.79 \mathrm{E}-04$ \\
\hline PHI-C & $6.28 \mathrm{E}-08$ & $8.79 E-09$ & $2.42 \mathrm{E}-04$ & $1.28 \mathrm{E}-08$ & $5.12 \mathrm{E}-04$ & $5.01 \mathrm{E}-08$ & $4.07 \mathrm{E}-06$ & $4.74 E-05$ & $6.22 \mathrm{E}-06$ & $4.79 \mathrm{E}-04$ \\
\hline POR-D & $4.62 \mathrm{E}-08$ & $1.10 \mathrm{E}-08$ & $3.09 \mathrm{E}-04$ & $1.62 \mathrm{E}-08$ & $1.11 \mathrm{E}-03$ & $3.74 \mathrm{E}-08$ & $4.87 \mathrm{E}-06$ & $5.70 \mathrm{E}-05$ & $7.52 \mathrm{E}-06$ & $6.54 \mathrm{E}-04$ \\
\hline POR-C & $4.62 \mathrm{E}-08$ & $1.10 \mathrm{E}-08$ & $3.09 \mathrm{E}-04$ & $1.62 \mathrm{E}-08$ & $1.11 \mathrm{E}-03$ & $3.74 \mathrm{E}-08$ & $4.87 \mathrm{E}-06$ & $5.70 \mathrm{E}-05$ & $7.52 \mathrm{E}-06$ & $6.54 \mathrm{E}-04$ \\
\hline SAV-D & $5.36 E-08$ & $9.53 \mathrm{E}-09$ & $2.25 \mathrm{E}-04$ & $1.38 \mathrm{E}-08$ & $4.96 E-04$ & $4.28 \mathrm{E}-08$ & $4.40 \mathrm{E}-06$ & $5.13 \mathrm{E}-05$ & $6.71 E-06$ & $3.62 \mathrm{E}-04$ \\
\hline SAV-C & $5.36 \mathrm{E}-08$ & $9.53 \mathrm{E}-09$ & $2.25 \mathrm{E}-04$ & $1.38 \mathrm{E}-08$ & $4.96 \mathrm{E}-04$ & $4.28 \mathrm{E}-08$ & $4.40 \mathrm{E}-06$ & $5.13 E-05$ & $6.71 \mathrm{E}-06$ & $3.62 \mathrm{E}-04$ \\
\hline SEA-C & $4.62 \mathrm{E}-08$ & $1.10 \mathrm{E}-08$ & $3.09 E-04$ & $1.62 \mathrm{E}-08$ & $1.11 E-03$ & $3.74 \mathrm{E}-08$ & $4.87 E-06$ & $5.70 \mathrm{E}-05$ & $7.52 E-06$ & $6.54 \mathrm{E}-04$ \\
\hline TAC-D & $4.62 \mathrm{E}-08$ & $1.10 \mathrm{E}-08$ & $3.09 \mathrm{E}-04$ & $1.62 \mathrm{E}-08$ & $1.11 \mathrm{E}-03$ & $3.74 \mathrm{E}-08$ & $4.87 \mathrm{E}-06$ & $5.70 \mathrm{E}-05$ & $7.52 E-06$ & $6.54 \mathrm{E}-04$ \\
\hline TAC-C & $4.62 \mathrm{E}-08$ & $1.10 \mathrm{E}-08$ & $3.09 \mathrm{E}-04$ & $1.62 \mathrm{E}-08$ & $1.11 E-03$ & $3.74 \mathrm{E}-08$ & $4.87 \mathrm{E}-06$ & $5.70 \mathrm{E}-05$ & $7.52 \mathrm{E}-06$ & $6.54 \mathrm{E}-04$ \\
\hline WIL-D & $3.26 \mathrm{E}-08$ & $9.19 \mathrm{E}-09$ & $2.35 E-04$ & $1.08 \mathrm{E}-08$ & $5.38 E-04$ & $2.64 \mathrm{E}-08$ & $4.02 \mathrm{E}-06$ & $4.71 E-05$ & $5.20 \mathrm{E}-06$ & $4.34 \mathrm{E}-04$ \\
\hline WIL-C & $3.26 \mathrm{E}-08$ & $9.19 \mathrm{E}-09$ & $2.35 E-04$ & $1.08 \mathrm{E}-08$ & $5.38 \mathrm{E}-04$ & $2.64 \mathrm{E}-08$ & $4.02 \mathrm{E}-06$ & $4.71 \mathrm{E}-05$ & $5.20 \mathrm{E}-06$ & $4.34 \mathrm{E}-04$ \\
\hline
\end{tabular}


Table 36. 99th Quantile Values of Population Dose, Cancer Fatalities, Costs, Centerline Individual Dose and Centerline Individual Risk for EIS Accident Categories

EDE Whole Body Population Dose, $0-80 \mathrm{~km}$ (SV)

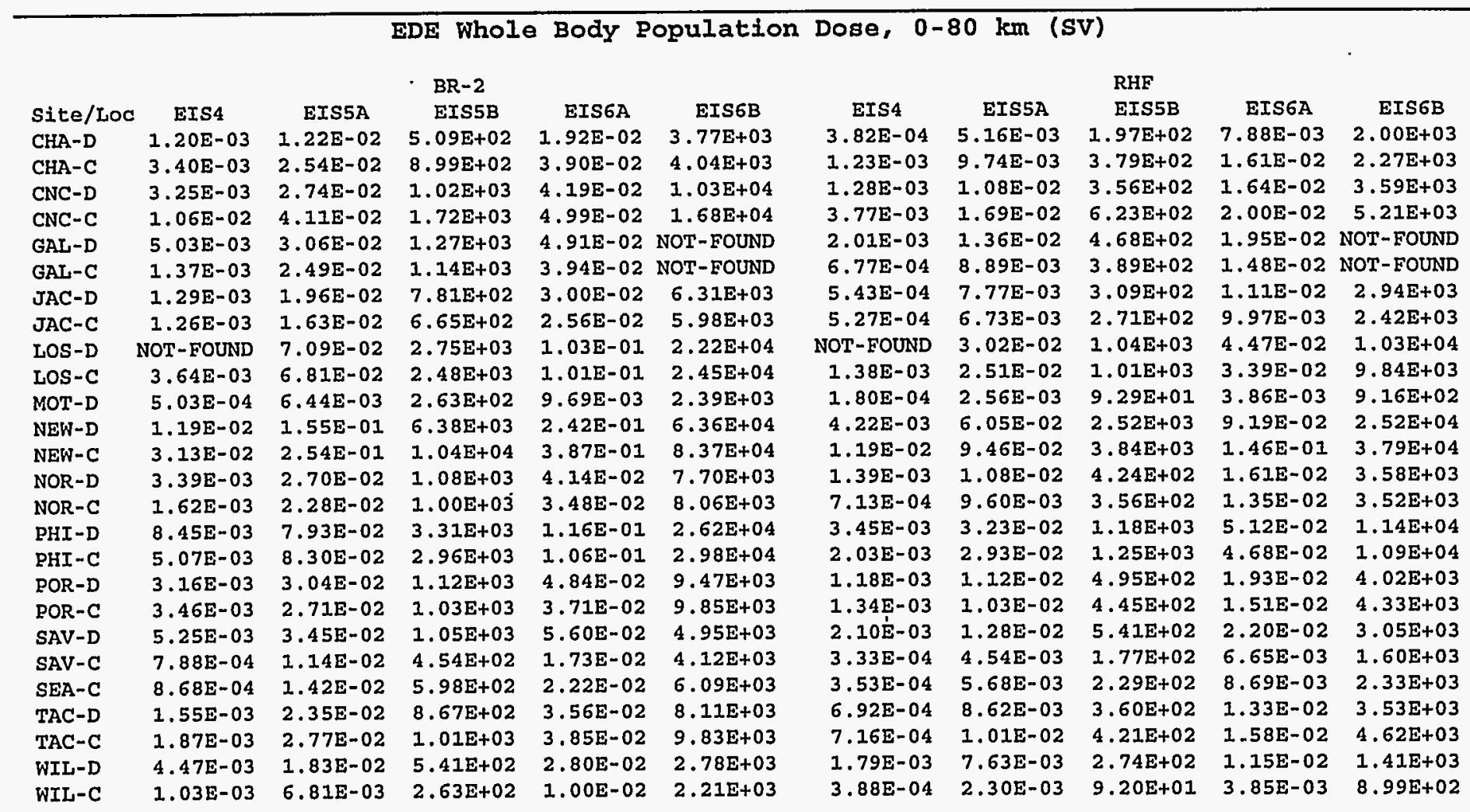


Table 36. 99th Quantile Values of Population Dose, Cancer Fatalities, Costs, Centerline Individual Dose and Centerline Individual Risk for EIS Accident Categories (Continued)

\begin{tabular}{|c|c|c|c|c|c|c|c|c|c|c|}
\hline \multirow[b]{3}{*}{ Site/Loc } & \multirow{3}{*}{\multicolumn{3}{|c|}{$\begin{array}{ll} & \text { EDE Whole } \\
& \cdot \text { OSIRIS } \\
\text { EIS5A } & \text { EIS5B }\end{array}$}} & \multicolumn{5}{|c|}{ Body Population Dose, $0-80 \mathrm{~km} \mathrm{(SV)}$} & \multirow[b]{3}{*}{ EIS6A } & \multirow[b]{3}{*}{ EIS6B } \\
\hline & & & & & & & & TRIGA & & \\
\hline & & & & EIS6A & EIS6B & EIS4 & EIS5A & EIS5B & & \\
\hline CHA-D & $1.32 \mathrm{E}-03$ & $1.42 \mathrm{E}-02$ & $4.67 E+02$ & $2.40 \mathrm{E}-02$ & $4.16 \mathrm{E}+03$ & $1.30 \mathrm{E}-03$ & $7.34 \mathrm{E}+00$ & $8.40 E+01$ & $1.16 \mathrm{E}+01$ & $2.15 \mathrm{E}+03$ \\
\hline $\mathrm{CHA}-\mathrm{C}$ & $5.07 \mathrm{E}-03$ & $2.93 \mathrm{E}-02$ & $9.01 \mathrm{E}+02$ & $4.56 \mathrm{E}-02$ & $4.30 \mathrm{E}+03$ & $3.98 \mathrm{E}-03$ & $1.42 \mathrm{E}+01$ & $1.69 \mathrm{E}+02$ & $2.23 E+01$ & $2.39 E+03$ \\
\hline CNC-D & $3.97 \mathrm{E}-03$ & $3.38 \mathrm{E}-02$ & $9.55 \mathrm{E}+02$ & $5.05 E-02$ & $9.56 \mathrm{E}+03$ & $3.86 \mathrm{E}-03$ & 1. $24 \mathrm{E}+01$ & $1.35 \mathrm{E}+02$ & $2.19 \mathrm{E}+01$ & $3.82 \mathrm{E}+03$ \\
\hline $\mathrm{CNC}-\mathrm{C}$ & $1.20 \mathrm{E}-02$ & $4.58 \mathrm{E}-02$ & $1.68 \mathrm{E}+03$ & $6.65 \mathrm{E}-02$ & $1.67 \mathrm{E}+04$ & $1.17 \mathrm{E}-02$ & $2.21 E+01$ & $2.61 E+02$ & $3.00 \mathrm{E}+01$ & $6.56 \mathrm{E}+03$ \\
\hline GAL-D & $5.43 \mathrm{E}-03$ & $4.08 \mathrm{E}-02$ & $1.18 \mathrm{E}+03$ & $5.54 \mathrm{E}-02$ & NOT-FOUND & $5.35 E-03$ & $1.92 \mathrm{E}+01$ & $2.00 E+02$ & $3.00 \mathrm{E}+01$ & NOT-FOUND \\
\hline GAL-C & $1.90 \mathrm{E}-03$ & $2.63 \mathrm{E}-02$ & $8.51 E+02$ & $4.20 \mathrm{E}-02$ & NOT-FOUND & $2.01 \mathrm{E}-03$ & $1.43 E+01$ & $1.50 \mathrm{E}+02$ & $2.35 E+01$ & NOT-FOUND \\
\hline JAC-D & $1.46 \mathrm{E}-03$ & $2.33 E-02$ & $7.27 E+02$ & $3.41 E-02$ & $6.63 E+03$ & $1.45 \mathrm{E}-03$ & $1.08 E+01$ & $1.14 \mathrm{E}+02$ & $1.56 \mathrm{E}+01$ & $3.19 E+03$ \\
\hline JAC-C & $1.55 \mathrm{E}-03$ & $2.14 \mathrm{E}-02$ & $6.41 \mathrm{E}+02$ & $3.19 \mathrm{E}-02$ & $5.80 \mathrm{E}+03$ & $1.55 \mathrm{E}-03$ & $9.54 E+00$ & $1.12 \mathrm{E}+02$ & $1.41 E+01$ & $2.66 \mathrm{E}+03$ \\
\hline LOS-D & NOT-FOUND & $9.16 \mathrm{E}-02$ & $2.73 E+03$ & $1.15 \mathrm{E}-01$ & $2.17 \mathrm{E}+04$ & NOT-FOUND & $4.03 E+01$ & $4.58 \mathrm{E}+02$ & $6.16 \mathrm{E}+01$ & $1.07 \mathrm{E}+04$ \\
\hline LOS-C & $5.30 E-03$ & $8.31 \mathrm{E}-02$ & $2.25 E+03$ & $1.12 \mathrm{E}-01$ & $2.19 \mathrm{E}+04$ & $5.13 E-03$ & $3.31 E+01$ & $4.03 E+02$ & $5.14 E+01$ & $1.03 \mathrm{E}+04$ \\
\hline MOT-D & $4.65 E-04$ & $6.62 \mathrm{E}-03$ & $1.83 \mathrm{E}+02$ & $9.76 \mathrm{E}-03$ & $1.79 \mathrm{E}+03$ & $6.25 \mathrm{E}-04$ & $2.96 \mathrm{E}+00$ & $3.85 E+01$ & $4.90 E+00$ & $9.35 \mathrm{E}+02$ \\
\hline NEW-D & $1.39 E-02$ & $2.19 \mathrm{E}-01$ & $6.12 E+03$ & $3.27 \mathrm{E}-01$ & $6.08 \mathrm{E}+04$ & $1.34 \mathrm{E}-02$ & $8.77 E+01$ & $1.15 E+03$ & $1.42 \mathrm{E}+02$ & $3.24 \mathrm{E}+04$ \\
\hline NEW-C & $3.78 E-02$ & $3.25 \mathrm{E}-01$ & $9.45 E+03$ & $4.63 \mathrm{E}-01$ & $8.48 \mathrm{E}+04$ & $3.52 \mathrm{E}-02$ & $1.46 \mathrm{E}+02$ & $1.65 \mathrm{E}+03$ & $2.44 \mathrm{E}+02$ & $4.00 \mathrm{E}+04$ \\
\hline NOR-D & $4.62 E-03$ & $3.29 \mathrm{E}-02$ & $1.04 \mathrm{E}+03$ & $5.14 \mathrm{E}-02$ & $8.26 \mathrm{E}+03$ & 4.59E-03 & $1.41 \mathrm{E}+01$ & $1.80 \mathrm{E}+02$ & $2.51 E+01$ & $3.74 \mathrm{E}+03$ \\
\hline NOR-C & $2.07 E-03$ & $3.01 \mathrm{E}-02$ & $9.29 \mathrm{E}+02$ & $4.54 \mathrm{E}-02$ & $8.52 E+03$ & $2.06 E-03$ & $1.24 \mathrm{E}+01$ & $1.42 \mathrm{E}+02$ & $2.16 \mathrm{E}+01$ & $4.31 E+03$ \\
\hline PHI-D & 1.11E-02 & $1.03 \mathrm{E}-01$ & $3.23 E+03$ & $1.38 \mathrm{E}-01$ & $2.98 \mathrm{E}+04$ & $1.00 \mathrm{E}-02$ & $5.09 E+01$ & $5.53 E+02$ & $7.67 \mathrm{E}+01$ & $1.21 \mathrm{E}+04$ \\
\hline PHI-C & $6.98 \mathrm{E}-03$ & $9.56 \mathrm{E}-02$ & $2.92 \mathrm{E}+03$ & $1.57 \mathrm{E}-01$ & $2.96 \mathrm{E}+04$ & $6.95 \mathrm{E}-03$ & $4.68 \mathrm{E}+01$ & $4.93 E+02$ & $6.81 E+01$ & $1.30 \mathrm{E}+04$ \\
\hline POR-D & $3.65 \mathrm{E}-03$ & $3.62 \mathrm{E}-02$ & 1. $11 E+03$ & $5.73 \mathrm{E}-02$ & $1.02 \mathrm{E}+04$ & $3.55 \mathrm{E}-03$ & $1.64 \mathrm{E}+01$ & $2.03 E+02$ & $2.92 E+01$ & $5.04 \mathrm{E}+03$ \\
\hline POR-C & $4.25 E-03$ & $3.10 \mathrm{E}-02$ & $1.01 E+03$ & $5.06 \mathrm{E}-02$ & $9.71 E+03$ & $4.01 E-03$ & $1.48 \mathrm{E}+01$ & $1.85 \mathrm{E}+02$ & $2.24 \mathrm{E}+01$ & $4.73 \mathrm{E}+03$ \\
\hline SAV-D & $7.05 E-03$ & $5.02 \mathrm{E}-02$ & $1.08 E+03$ & $7.37 \mathrm{E}-02$ & $5.08 \mathrm{E}+03$ & $6.05 \dot{E}-03$ & $2.16 \mathrm{E}+01$ & $2.38 E+02$ & $3.38 \mathrm{E}+01$ & 3.10E+03 \\
\hline$S A V-C$ & $8.70 E-04$ & $1.22 \mathrm{E}-02$ & $4.00 E+02$ & $1.89 \mathrm{E}-02$ & $3.90 \mathrm{E}+03$ & $9.87 E-04$ & $6.30 \mathrm{E}+00$ & $6.94 E+01$ & $9.69 \mathrm{E}+00$ & $1.80 \mathrm{E}+03$ \\
\hline$S E A-C$ & $1.12 \mathrm{E}-03$ & $1.72 \mathrm{E}-02$ & $5.58 \mathrm{E}+02$ & $2.65 \mathrm{E}-02$ & $5.69 E+03$ & $1.12 \mathrm{E}-03$ & $8.26 \mathrm{E}+00$ & $9.58 \mathrm{E}+01$ & $1.32 \mathrm{E}+01$ & $2.63 E+03$ \\
\hline TAC-D & $2.18 \mathrm{E}-03$ & $2.64 \mathrm{E}-02$ & $8.50 \mathrm{E}+02$ & $4.05 E-02$ & $8.05 E+03$ & $2.09 \mathrm{E}-03$ & $1.24 \mathrm{E}+01$ & $1.42 \mathrm{E}+02$ & $2.27 \mathrm{E}+01$ & $3.80 \mathrm{E}+03$ \\
\hline TAC-C & $2.38 \mathrm{E}-03$ & $3.08 E-02$ & $9.92 \mathrm{E}+02$ & $4.93 \mathrm{E}-02$ & $9.84 E+03$ & $2.20 \mathrm{E}-03$ & $1.53 \mathrm{E}+01$ & $1.87 \mathrm{E}+02$ & $2,23 \mathrm{E}+01$ & $4.79 E+03$ \\
\hline WIL-D & $5.46 \mathrm{E}-03$ & $2.24 \mathrm{E}-02$ & $5.91 E+02$ & $3.33 \mathrm{E}-02$ & $2.80 \mathrm{E}+03$ & $5.10 \mathrm{E}-03$ & $1.12 \mathrm{E}+01$ & $1.18 E+02$ & $1.67 \mathrm{E}+01$ & $1.45 \mathrm{E}+03$ \\
\hline WIL-C & $1.20 \mathrm{E}-03$ & $6.87 \mathrm{E}-03$ & $1.89 E+02$ & $1.02 \mathrm{E}-02$ & $1.69 \mathrm{E}+03$ & $1.18 \mathrm{E}-03$ & $3.14 \mathrm{E}+00$ & $3.51 E+01$ & $5.13 \mathrm{E}+00$ & $9.07 \mathrm{E}+02$ \\
\hline
\end{tabular}


Table 36. 99th Quantile Values of Population Dose, Cancer Fatalities, Costs, Centerline Individual Dose and Centerline Individual Risk for EIS Accident Categories (Continued)

\begin{tabular}{|c|c|c|c|c|c|}
\hline & & & \multicolumn{3}{|c|}{ Total Cancer } \\
\hline & & & BR-2 & & \\
\hline Site/Loc & EIS4 & EIS5A & EIS5B & EIS6A & EIS6B \\
\hline CHA -D & $4.33 \mathrm{E}-05$ & $5.52 \mathrm{E}-04$ & $2.19 \mathrm{E}+01$ & $8.29 \mathrm{E}-04$ & $1.56 \mathrm{E}+02$ \\
\hline $\mathrm{CHA}-\mathrm{C}$ & $1.29 \mathrm{E}-04$ & $9.90 \mathrm{E}-04$ & $3.87 E+01$ & $1.69 \mathrm{E}-03$ & $1.81 E+02$ \\
\hline CNC-D & $1.42 \mathrm{E}-04$ & $1.22 \mathrm{E}-03$ & $4.39 \mathrm{E}+01$ & $1.80 \mathrm{E}-03$ & $3.71 E+02$ \\
\hline $\mathrm{CNC}-\mathrm{C}$ & $3.91 E-04$ & $1.75 \mathrm{E}-03$ & $6.27 \mathrm{E}+01$ & $2.58 \mathrm{E}-03$ & $6.09 \mathrm{E}+02$ \\
\hline GAL-D & $2.07 E-04$ & $1.41 E-03$ & $4.60 E+01$ & $2.03 \mathrm{E}-03$ & NOT-FOUND \\
\hline GAL-C & $7.04 \mathrm{E}-05$ & $1.24 \mathrm{E}-03$ & $3.98 \mathrm{E}+01$ & $1.52 \mathrm{E}-03$ & NOT-FOUND \\
\hline JAC-D & $5.79 \mathrm{E}-05$ & $8.19 \mathrm{E}-04$ & $3.15 \mathrm{E}+01$ & $1.13 \mathrm{E}-03$ & $2.57 E+02$ \\
\hline JAC-C & $6.02 \mathrm{E}-05$ & $7.44 \mathrm{E}-04$ & $2.85 E+01$ & $1.10 \mathrm{E}-03$ & $2.47 E+02$ \\
\hline LOS-D & NOT-FOUND & $3.03 \mathrm{E}-03$ & $1.05 \mathrm{E}+02$ & $4.77 \mathrm{E}-03$ & $1.00 \mathrm{E}+03$ \\
\hline LOS-C & $1.98 E-04$ & $3.00 \mathrm{E}-03$ & $1.04 \mathrm{E}+02$ & $3.95 \mathrm{E}-03$ & $1.01 E+03$ \\
\hline MOT-D & $2.32 \mathrm{E}-05$ & $2.78 \mathrm{E}-04$ & $1.35 \mathrm{E}+01$ & $4.33 E-04$ & $1.15 E+02$ \\
\hline NEW-D & $4.40 \mathrm{E}-04$ & $6.43 E-03$ & $2.58 \mathrm{E}+02$ & $1.12 \mathrm{E}-02$ & $2.56 \mathrm{E}+03$ \\
\hline $\mathrm{NEW}-\mathrm{C}$ & $1.28 \mathrm{E}-03$ & $1.12 \mathrm{E}-02$ & $3.98 \mathrm{E}+02$ & $1.48 \mathrm{E}-02$ & $3.56 \mathrm{E}+03$ \\
\hline NOR-D & $1.54 \mathrm{E}-04$ & $1.11 \mathrm{E}-03$ & $4.39 E+01$ & $1.74 \mathrm{E}-03$ & $3.19 \mathrm{E}+02$ \\
\hline NOR-C & $7.22 \mathrm{E}-05$ & $1.01 \mathrm{E}-03$ & $3.94 \mathrm{E}+01$ & $1.40 \mathrm{E}-03$ & $3.21 E+02$ \\
\hline PHI-D & $3.53 \mathrm{E}-04$ & $3.35 \mathrm{E}-03$ & $1.23 \mathrm{E}+02$ & $5.42 \mathrm{E}-03$ & $1.07 \mathrm{E}+03$ \\
\hline PHI -C & $2.03 E-04$ & $3.41 \mathrm{E}-03$ & $1.29 \mathrm{E}+02$ & $4.79 \mathrm{E}-03$ & 1. $12 \mathrm{E}+03$ \\
\hline POR-D & $1.46 \mathrm{E}-04$ & $1.16 \mathrm{E}-03$ & $5.10 \mathrm{E}+01$ & $1.98 \mathrm{E}-03$ & $3.58 \mathrm{E}+02$ \\
\hline POR -C & $1.47 \mathrm{E}-04$ & $1.05 E-03$ & $4.63 \mathrm{E}+01$ & $1.77 \mathrm{E}-03$ & $4.50 E+02$ \\
\hline SAV-D & $2.23 E-04$ & $1.30 \mathrm{E}-03$ & $5.24 E+01$ & $2.32 \mathrm{E}-03$ & $2.02 E+02$ \\
\hline$S A V-C$ & $3.52 \mathrm{E}-0.5$ & $4.73 \mathrm{E}-04$ & $1.87 \mathrm{E}+01$ & $7.02 \mathrm{E}-04$ & $1.72 E+02$ \\
\hline SEA-C & $3.73 E-05$ & $6.17 \mathrm{E}-04$ & $2.61 E+01$ & $9.45 \mathrm{E}-04$ & $2.66 \mathrm{E}+02$ \\
\hline$T A C-D$ & $7.55 \mathrm{E}-05$ & $9.15 \mathrm{E}-04$ & $3.74 E+01$ & $1.39 \mathrm{E}-03$ & $3.46 \mathrm{E}+02$ \\
\hline TAC-C & $8.26 \mathrm{E}-05$ & $1.03 \mathrm{E}-03$ & $4.74 \mathrm{E}+01$ & $1.63 \mathrm{E}-03$ & $4.31 E+02$ \\
\hline WIL-D & $1.99 \mathrm{E}-04$ & $7.87 \mathrm{E}-04$ & $2.28 \mathrm{E}+01$ & $1.18 \mathrm{E}-03$ & $1.36 \mathrm{E}+02$ \\
\hline WIL-C & $4.51 \mathrm{E}-05$ & $2.98 \mathrm{E}-04$ & $1.16 \mathrm{E}+01$ & $4.66 \mathrm{E}-04$ & $1.05 E+02$ \\
\hline
\end{tabular}

\section{ties, $0-80 \mathrm{~km}$}

\begin{tabular}{|c|c|c|c|c|}
\hline & & $\mathrm{HF}$ & & \\
\hline$S 4$ & EIS5A & EIS5B & A & $B$ \\
\hline E-05 & $.8 E-$ & $.41 \mathrm{E}+00$ & $3.34 \mathrm{E}-04$ & $8.16 \mathrm{E}$ \\
\hline $0 E-05$ & $29 \mathrm{E}-04$ & $67 E+01$ & & $1.03 \mathrm{E}$ \\
\hline $82 E-05$ & $64 \mathrm{E}-04$ & $35 E+01$ & $32 E-04$ & $1.36 \mathrm{E}+$ \\
\hline $80 E-04$ & $.30 \mathrm{E}-04$ & $.61 \mathrm{E}+01$ & $9.40 \mathrm{E}-04$ & $2.59 \mathrm{E}+02$ \\
\hline $64 \mathrm{E}-05$ & $.21 \mathrm{E}-04$ & $.93 E+01$ & $8.71 E-04$ & NOT \\
\hline $89 \mathrm{E}-05$ & $4.04 \mathrm{E}-04$ & $1.48 \mathrm{E}+01$ & $6.21 \mathrm{E}-04$ & NOT-FOUND \\
\hline $37 E-05$ & $.16 E-04$ & $1.16 \mathrm{E}+01$ & $5.07 E-04$ & $1.13 \mathrm{E}+02$ \\
\hline $2.29 \mathrm{E}-05$ & 3.1 & $.13 E+01$ & 4.3 & $.12 \mathrm{E}+02$ \\
\hline NOT-FOU & 1.12 & $4.57 E+01$ & 1. & $4.08 \mathrm{E}+02$ \\
\hline $7.32 \mathrm{E}-05$ & $1.09 \mathrm{E}-03$ & $4.03 E+01$ & 1.59 & $3.95 \mathrm{E}+02$ \\
\hline $8.61 \mathrm{E}$ & $1.04 E-04$ & 7. $35 \mathrm{E}+00$ & 1.62 & $4.33 E+01$ \\
\hline 1.72 & 2.5 & $1.15 \mathrm{E}+02$ & 4. & $1.15 \mathrm{E}+03$ \\
\hline 5.33 & 4. & $1.58 \mathrm{E}+02$ & & 03 \\
\hline .4 & & 1 & & +02 \\
\hline $3.08 E-05$ & -04 & $.43 E+01$ & 6.2 & $1.38 \mathrm{E}+02$ \\
\hline $1.29 \mathrm{E}-04$ & $1.22 \mathrm{E}-03$ & $.55 \mathrm{E}+02$ & $2.14 \mathrm{E}-03$ & $5.44 \mathrm{E}+02$ \\
\hline $9.95 \mathrm{E}$ & $1.33 \mathrm{E}-03$ & $4.93 \mathrm{E}+01$ & 1.93 & $4.97 \mathrm{E}+02$ \\
\hline 5.961 & $5.07 E-04$ & $2.03 E+01$ & $7.81 E-04$ & $1.91 \mathrm{E}+02$ \\
\hline 6.02 & 4 & 84 & 04 & $.81 E+02$ \\
\hline 1 & & & & +02 \\
\hline & & 0 & 4 & \\
\hline $1.40 \mathrm{E}-05$ & $2.44 \mathrm{E}$ & $.68 \mathrm{E}$ & 3.75 & $9.68 \mathrm{E}+01$ \\
\hline 3.03 & 3.7 & $.39 E+01$ & 5.91 & $1.34 \mathrm{E}+02$ \\
\hline $19 E-05$ & $4.75 E-04$ & $1.88 \mathrm{E}+01$ & $6.78 E-04$ & $1.87 \mathrm{E}+02$ \\
\hline $63 E-05$ & $25 E-04$ & $.12 \mathrm{E}+01$ & $4.66 \mathrm{E}-04$ & $7.09 \mathrm{E}+01$ \\
\hline & 4 & 00 & -04 & $31 E+01$ \\
\hline
\end{tabular}


Table 36. 99th Quantile Values of Population Dose, Cancer Fatalities, Costs, Centerline Individual Dose and Centerline Individual Risk for EIS Accident Categories (Continued)

Total Cancer Fatalities, 0-80 km

\begin{tabular}{|c|c|c|c|c|c|c|c|c|c|c|}
\hline & & & OSIRIS & & & & & TRIGA & & \\
\hline $\begin{array}{l}\text { Site/LoC } \\
\text { CHA-D }\end{array}$ & $\begin{array}{c}\text { EIS4 } \\
5.58 \mathrm{E}-05\end{array}$ & $\begin{array}{c}\text { EIS5A } \\
6.31 E-04\end{array}$ & $\begin{array}{c}\text { EIS5B } \\
2.07 \mathrm{E}+01\end{array}$ & $\begin{array}{c}\text { EIS6A } \\
9.95 E-04\end{array}$ & $\begin{array}{c}\text { EIS6B } \\
1.68 \mathrm{E}+02\end{array}$ & $\begin{array}{c}\text { EIS4 } \\
5.50 \mathrm{E}-05\end{array}$ & $\begin{array}{c}\text { EIS5A } \\
3.04 E-01\end{array}$ & $\begin{array}{l}\text { 3.SSB } \\
3.52 \mathrm{E}+00\end{array}$ & $\begin{array}{c}\text { EIS6A } \\
4.79 \mathrm{E}-01\end{array}$ & $\begin{array}{c}\text { EIS6B } \\
8.76 \mathrm{E}+01\end{array}$ \\
\hline $\mathrm{CHA}-\mathrm{C}$ & $2.09 \mathrm{E}-04$ & $1.15 \mathrm{E}-03$ & $3.62 \mathrm{E}+01$ & $1.89 \mathrm{E}-03$ & $1.86 \mathrm{E}+02$ & $1.60 \mathrm{E}-04$ & $5.94 E-01$ & $6.81 E+00$ & $9.33 \mathrm{E}-01$ & $1.04 E+02$ \\
\hline CNC-D & $1.71 \mathrm{E}-04$ & $1.47 \mathrm{E}-03$ & $3.59 E+01$ & $2.22 \mathrm{E}-03$ & $3.65 \mathrm{E}+02$ & $1.60 \mathrm{E}-04$ & $5.62 \mathrm{E}-01$ & $7.35 \mathrm{E}+00$ & $9.54 E-01$ & $1.85 \mathrm{E}+02$ \\
\hline $\mathrm{CNC}-\mathrm{C}$ & $5.42 \mathrm{E}-04$ & $2.10 \mathrm{E}-03^{\circ}$ & $6.23 E+01$ & $2.88 \mathrm{E}-03$ & $5.09 \mathrm{E}+02$ & $5.25 \mathrm{E}-04$ & $8.90 \mathrm{E}-01$ & $1.12 \mathrm{E}+01$ & $1.68 \mathrm{E}+00$ & $2.86 \mathrm{E}+02$ \\
\hline GAL-D & $2.28 \mathrm{E}-04$ & $1.67 \mathrm{E}-03$ & $4.56 E+01$ & $2.55 \mathrm{E}-03$ & NOT-FOUND & $2.18 \mathrm{E}-04$ & $7.31 \mathrm{E}-01$ & $9.40 \mathrm{E}+00$ & $1.35 \mathrm{E}+00$ & NOT-FOUND \\
\hline GAL-C & $7.96 \mathrm{E}-05$ & $1.36 \mathrm{E}-03$ & $3.93 \mathrm{E}+01$ & $1.61 \mathrm{E}-03$ & NOT-FOUND & $7.95 \mathrm{E}-05$ & $5.86 \mathrm{E}-01$ & $6.21 E+00$ & $8.83 E-01$ & NOT-FOUND \\
\hline JAC-D & $6.80 \mathrm{E}-05$ & $1.01 \mathrm{E}-03$ & $3.08 \mathrm{E}+01$ & $1.29 \mathrm{E}-03$ & $2.86 E+02$ & $6.67 \mathrm{E}-05$ & $4.45 E-01$ & $5.33 \mathrm{E}+00$ & $7.34 \mathrm{E}-01$ & $1.21 \mathrm{E}+02$ \\
\hline JAC-C & $7.27 \mathrm{E}-05$ & $.81 E-04$ & $2.72 E+01$ & $1.29 \mathrm{E}-03$ & $2.37 \mathrm{E}+02$ & $6.50 \mathrm{E}-05$ & $3.82 \mathrm{E}-01$ & $4.68 \mathrm{E}+00$ & $6.46 \mathrm{E}-01$ & $1.16 \mathrm{E}+02$ \\
\hline LOS-D & NOT-FOUND & $3.65 \mathrm{E}-03$ & $1.04 \mathrm{E}+02$ & $5.52 \mathrm{E}-03$ & $1.00 \mathrm{E}+03$ & NOT-FOUND & $1.65 \mathrm{E}+00$ & $2.02 E+01$ & $2.59 E+00$ & $5.05 E+02$ \\
\hline LOS-C & $2.16 \mathrm{E}-04$ & $.28 \mathrm{E}-03$ & $1.01 E+02$ & $5.07 E-03$ & $1.01 E+03$ & $2.08 \mathrm{E}-04$ & $1.25 E+00$ & $1.64 \mathrm{E}+01$ & $2.16 \mathrm{E}+00$ & $4.89 E+02$ \\
\hline MOT-D & $2.26 \mathrm{E}-05$ & $2.81 \mathrm{E}-04$ & $9.26 \mathrm{E}+00$ & $4.32 \mathrm{E}-04$ & $8.60 E+01$ & $2.67 E-05$ & $1.48 \mathrm{E}-01$ & $1.69 \mathrm{E}+00$ & $2.52 \mathrm{E}-01$ & $4.51 \mathrm{E}+01$ \\
\hline NEW-D & $5.94 \mathrm{E}-04$ & $8.09 E-03$ & $2.54 E+02$ & $1.26 \mathrm{E}-02$ & $2.53 E+03$ & $5.49 \mathrm{E}-04$ & $3.91 E+00$ & $4.19 E+01$ & $5.99 E+00$ & $1.23 E+03$ \\
\hline NEW-C & $1.56 \mathrm{E}-03$ & $1.31 E-02$ & $4.05 E+02$ & $1.81 \mathrm{E}-02$ & $3.72 E+03$ & $1.40 \mathrm{E}-03$ & $6.31 E+00$ & $6.64 \mathrm{E}+01$ & $9.45 E+00$ & $1.51 \mathrm{E}+03$ \\
\hline NOR-D & $2.02 \mathrm{E}-04$ & $1.28 \mathrm{E}-03$ & $4.25 E+01$ & $2.13 \mathrm{E}-03$ & $3.30 \mathrm{E}+02$ & $1.85 E-04$ & $6.54 \mathrm{E}-01$ & $7.63 E+00$ & $1.05 \mathrm{E}+00$ & $1.66 \mathrm{E}+02$ \\
\hline NOR-C & $8.83 E-05$ & 1.16 & $3.60 \mathrm{E}+01$ & $1.84 \mathrm{E}-03$ & $3.35 \mathrm{E}+02$ & $8.46 \mathrm{E}-05$ & $5.66 \mathrm{E}-01$ & $6.75 E+00$ & $9.23 E-01$ & $1.75 \mathrm{E}+02$ \\
\hline PHI-D & $4.18 E-04$ & $4.51 \mathrm{E}-03$ & $1.21 E+02$ & $6.78 \mathrm{E}-03$ & $1.11 \mathrm{E}+03$ & $3.88 \mathrm{E}-04$ & $2.05 \mathrm{E}+00$ & $2.28 \mathrm{E}+01$ & $3.23 E+00$ & $6.18 \mathrm{E}+02$ \\
\hline PHI-C & $2.99 \mathrm{E}-04$ & $4.21 E-03$ & $1.27 \mathrm{E}+02$ & $6.58 \mathrm{E}-03$ & $1.09 \mathrm{E}+03$ & $2.85 E-04$ & $1.85 \mathrm{E}+00$ & $2.01 E+01$ & $2.91 E+00$ & $5.70 \mathrm{E}+02$ \\
\hline POR-D & $1.73 \mathrm{E}-04$ & $1.37 \mathrm{E}-03$ & $4.94 E+01$ & $2.32 \mathrm{E}-03$ & $4.04 E+02$ & $1.61 E-04$ & $7.38 \mathrm{E}-01$ & $8.46 \mathrm{E}+00$ & $1.11 E+00$ & $2.08 \mathrm{E}+02$ \\
\hline POR-C & $1.99 \mathrm{E}-04$ & $1.24 \mathrm{E}-03$ & $4.54 \mathrm{E}+02$ & $2.05 E-03$ & $4.34 E+02$ & $1.63 E-04$ & $6.45 \mathrm{E}-01$ & $7.27 E+00$ & $1.01 E+00$ & $1.92 \mathrm{E}+02$ \\
\hline SAV-D & $3.03 E-04$ & $2.02 \mathrm{E}-03$ & $5.24 E+01$ & $3.06 \mathrm{E}-03$ & $2.09 E+02$ & $2.41 \mathrm{E}-04$ & $8.83 \mathrm{E}-01$ & $1.03 E+01$ & $1.28 \mathrm{E}+00$ & $1.12 \mathrm{E}+02$ \\
\hline$S A V-C$ & $3.72 \mathrm{E}-05$ & $5.91 \mathrm{E}-04$ & $1.78 \mathrm{E}+01$ & $8.13 E-04$ & $1.61 \mathrm{E}+02$ & $3.71 E-05$ & $2.76 \mathrm{E}-01$ & $3.01 E+00$ & $4.31 E-01$ & $8.32 \mathrm{E}+01$ \\
\hline SEA-C & $4.24 \mathrm{E}-05$ & $7.16 \mathrm{E}-04$ & $2.31 E+01$ & $1.10 \mathrm{E}-03$ & $2.35 E+02$ & $4.16 \mathrm{E}-05$ & $3.53 \mathrm{E}-01$ & $4.02 E+00$ & $5.67 \mathrm{E}-01$ & $1.12 \mathrm{E}+02$ \\
\hline TAC-D & $9.51 E-05$ & $1.19 \mathrm{E}-03$ & $3.67 \mathrm{E}+01$ & $1.56 \mathrm{E}-03$ & $3.54 \mathrm{E}+02$ & $8.41 E-05$ & $5.78 \mathrm{E}-01$ & $6.11 E+00$ & $8.45 E-01$ & $1.45 \mathrm{E}+02$ \\
\hline TAC-C & $9.61 \mathrm{E}-05$ & $1.25 \mathrm{E}-03$ & $4.71 E+01$ & $1.97 \mathrm{E}-03$ & $4.33 E+02$ & $9.47 \mathrm{E}-05$ & $6.39 \mathrm{E}-01$ & $7.07 E+00$ & $9.92 \mathrm{E}-01$ & $1.94 \mathrm{E}+02$ \\
\hline WIL-D & $2.63 \mathrm{E}-04$ & $9.32 \mathrm{E}-04$ & $2.51 E+01$ & $1.29 \mathrm{E}-03$ & $1.29 \mathrm{E}+02$ & $2.05 \mathrm{E}-04$ & $4.58 \mathrm{E}-01$ & $5.18 \mathrm{E}+00$ & $7.32 \mathrm{E}-01$ & $7.12 \mathrm{E}+01$ \\
\hline WIL-C & $5.28 \mathrm{E}-05$ & $2.98 \mathrm{E}-04$ & $9.05 \mathrm{E}+00$ & $4.73 \mathrm{E}-04$ & $8.54 E+01$ & $5.15 \mathrm{E}-05$ & $1.57 \mathrm{E}-01$ & $1.82 E+00$ & $2.27 \mathrm{E}-01$ & $4.35 E+01$ \\
\hline
\end{tabular}


Table 36. 99th Quantile Values of Population Dose, Cancer Fatalities, Costs, Centerline Individual Dose and Centerline Individual Risk for EIS Accident Categories (Continued)

\begin{tabular}{|c|c|c|c|c|c|c|c|c|c|c|}
\hline $\mathrm{CHA}-\mathrm{C}$ & $0.00 \mathrm{E}+00$ & $0.00 \mathrm{E}+00$ & $2.16 \mathrm{E}+07$ & $0.00 \mathrm{E}+00$ & $5.37 E+08$ & $0.00 \mathrm{E}+00$ & $0.00 E+00$ & $3.87 E+05$ & $0.00 \mathrm{E}+00$ & $1.68 \mathrm{E}+08$ \\
\hline CNC-D & $0.00 \mathrm{E}+00$ & $0.00 \mathrm{E}+00$ & $9.28 \mathrm{E}+03$ & $0.00 \mathrm{E}+00$ & $7.03 E+07$ & $0.00 \mathrm{E}+00$ & $0.00 \mathrm{E}+00$ & $0.00 \mathrm{E}+00$ & $0.00 \mathrm{E}+00$ & $3.06 \mathrm{E}+05$ \\
\hline $\mathrm{CNC}-\mathrm{C}$ & $0.00 E+00$ & $0.00 E+00$ & $0.00 E+00$ & $0.00 \mathrm{E}+00$ & $1.62 \mathrm{E}+08$ & $0,00 \mathrm{E}+00$ & $0.00 \mathrm{E}+00$ & $0.00 \mathrm{E}+00$ & $0.00 \mathrm{E}+00$ & $3.55 \mathrm{E}+06$ \\
\hline GAL-D & $0.00 \mathrm{E}+00$ & $0.00 \mathrm{E}+00$ & $4.97 E+07$ & $0.00 \mathrm{E}+00$ & $5.96 \mathrm{E}+08$ & $0.00 \mathrm{E}+00$ & $0.00 \mathrm{E}+00$ & $9.87 E+06$ & $0.00 \mathrm{E}+00$ & $1.74 \mathrm{E}+08$ \\
\hline JAC-C & $0.00 \mathrm{E}+00$ & $0.00 \mathrm{E}+00$ & $4.04 E+06$ & $0.00 \mathrm{E}+00$ & $3.20 E+08$ & $0.00 \mathrm{E}+00$ & $0.00 \mathrm{E} \div 00$ & $4.59 E+05$ & $0.00 \mathrm{E}+00$ & $7.85 \mathrm{E}+07$ \\
\hline LOS-D & $0.00 \mathrm{E}+00$ & $0.00 \mathrm{E}+00$ & $3.27 E+06$ & $0.00 \mathrm{E}+00$ & $8.24 E+08$ & $0.00 \mathrm{E}+00$ & $0.00 E+00$ & $0.00 \mathrm{E}+00$ & $0.00 \mathrm{E}+00$ & $1.11 \mathrm{E}+08$ \\
\hline LOS-C & $0.00 \mathrm{E}+00$ & $0.00 \mathrm{E}+00$ & $0.00 \mathrm{E}+00$ & $0.00 \mathrm{E}+00$ & $2.32 \mathrm{E}+07$ & $0.00 \mathrm{E}+00$ & $0.00 E+00$ & $0.00 E+00$ & $0.00 \mathrm{E}+00$ & $3.68 \mathrm{E}+03$ \\
\hline MOT-D & $0.00 \mathrm{E}+00$ & $0.00 \mathrm{E}+00$ & $2.13 E+05$ & $0.00 \mathrm{E}+00$ & $1.31 \mathrm{E}+07$ & $0.00 \mathrm{E}+00$ & $0.00 \mathrm{E}+00$ & $5.27 E+04$ & $0.00 \mathrm{E}+00$ & $1.13 \mathrm{E}+06$ \\
\hline NEW-D & $0.00 \mathrm{E}+00$ & $0.00 \mathrm{E}+00$ & $3.60 \mathrm{E}+07$ & $0.00 \mathrm{E}+00$ & $1.01 \mathrm{E}+09$ & $0.00 \mathrm{E}+00$ & $0.00 \mathrm{E}+00$ & $5.61 E+04$ & $0.00 \mathrm{E}+00$ & $2.84 \mathrm{E}+08$ \\
\hline NEW-C & $0.00 \mathrm{E}+00$ & $0.00 \mathrm{E}+00$ & $1.27 E+08$ & $0.00 \mathrm{E}+00$ & $3.38 \mathrm{E}+09$ & $0.00 \mathrm{E}+00$ & $0.00 \mathrm{E}+00$ & $2.56 E+04$ & $0.00 \mathrm{E}+00$ & $9.10 \mathrm{E}+08$ \\
\hline NOR-D & $0.00 \mathrm{E}+00$ & $0.00 \mathrm{E}+00$ & $1.24 \mathrm{E}+07$ & $0.00 \mathrm{E}+00$ & $5.61 \mathrm{E}+08$ & $0.00 \mathrm{E}+00$ & $0.00 \mathrm{E}+00$ & $2.75 E+04$ & $0.00 \mathrm{E}+00$ & $1.20 \mathrm{E}+08$ \\
\hline POR-C & $0.00 \mathrm{E}+00$ & $0.00 E+00$ & $4.82 E+06$ & $0.00 E+00$ & $2.49 \mathrm{E}+08$ & $0.00 \mathrm{E}+00$ & $0.00 \mathrm{E}+00$ & $8.67 \mathrm{E}+03$ & $0.00 \mathrm{E}+00$ & $5.81 E+07$ \\
\hline SAV-D & $0.00 E+00$ & $0.00 \mathrm{E}+00$ & $3.66 \mathrm{E}+07$ & $0.00 \mathrm{E}+00$ & $7.48 \mathrm{E}+08$ & $0.00 \mathrm{E}+00$ & $0.00 \mathrm{E}+00$ & $4.39 \mathrm{E}+06$ & $0.00 \mathrm{E}+00$ & $2.34 \mathrm{E}+08$ \\
\hline$S A V-C$ & $0.00 \mathrm{E}+00$ & $0.00 \mathrm{E}+00$ & $1.52 \mathrm{E}+05$ & $0.00 \mathrm{E}+00$ & $4.53 \mathrm{E}+07$ & $0.00 \mathrm{E}+00$ & $0.00 \mathrm{E}+00$ & $3.70 \mathrm{E}+04$ & $0.00 \mathrm{E}+00$ & $3.69 \mathrm{E}+06$ \\
\hline SEA-C & $0.00 \mathrm{E}+00$ & $0.00 \mathrm{E}+00$ & $6.06 \mathrm{E}+03$ & $0.00 \mathrm{E}+00$ & $2.68 \mathrm{E}+06$ & $0.00 \mathrm{E}+00$ & $0.00 \mathrm{E}+00$ & $0.00 \mathrm{E}+00$ & $0.00 \mathrm{E}+00$ & $2.31 \mathrm{E}+05$ \\
\hline TAC-D & $0.00 \mathrm{E}+00$ & $0.00 \mathrm{E}+00$ & $1.14 \mathrm{E}+05$ & $0.00 \mathrm{E}+00$ & $2.93 \mathrm{E}+08$ & $0.00 \mathrm{E}+00$ & $0.00 \mathrm{E}+00$ & $1.07 E+04$ & $0.00 \mathrm{E}+00$ & $3.83 \mathrm{E}+07$ \\
\hline TAC-C & $0.00 \mathrm{E}+00$ & $0.00 \mathrm{E}+00$ & $1.58 \mathrm{E}+04$ & $0.00 \mathrm{E}+00$ & $1.59 \mathrm{E}+08$ & $0.00 \mathrm{E}+00$ & $0.00 \mathrm{E}+00$ & $0.00 E+00$ & $0.00 \mathrm{E}+00$ & $5.09 \mathrm{E}+06$ \\
\hline WIL-D & $0.00 \mathrm{E}+00$ & $0.00 \mathrm{E}+00$ & $2.37 E+07$ & $0.00 \mathrm{E}+00$ & $3.34 \mathrm{E}+08$ & $0.00 \mathrm{E}+00$ & $0.00 \mathrm{E}+00$ & $9.83 \mathrm{E}+04$ & $0.00 \mathrm{E}+00$ & $1.21 \mathrm{E}+08$ \\
\hline WIL-C & $0.00 \mathrm{E}+00$ & $0.00 \mathrm{E}+00$ & $3.66 \mathrm{E}+06$ & $0.00 \mathrm{E}+00$ & $6.92 \mathrm{E}+07$ & $0.00 \mathrm{E}+00$ & $0.00 E+00$ & $5.31 E+04$ & $0.00 \mathrm{E}+00$ & $3.06 E+07$ \\
\hline
\end{tabular}


Table 36. 99th Quantile Values of Population Dose, Cancer Fatalities, Costs, Centerline Individual Dose and Centerline Individual Risk for EIS Accident Categories (Continued)

\begin{tabular}{|c|c|c|c|c|c|c|c|c|c|c|}
\hline Site/Loc & EIS4 & EIS5A & EIS5B & EIS6A & EIS6B & EIS4 & EIS5A & EIS5B & EIS6A & EIS6B \\
\hline $\mathrm{CHA}-\mathrm{C}$ & $0.00 \mathrm{E}+00$ & $0.00 \mathrm{E}+00$ & $1.03 E+07$ & $0.00 E+00$ & $4.25 E+08$ & $0.00 \mathrm{E}+00$ & $0.00 \mathrm{E}+00$ & $5.04 E+03$ & $0.00 \mathrm{E}+00$ & $1.89 \mathrm{E}+08$ \\
\hline CNC-D & $0.00 \mathrm{E}+00$ & $0.00 \mathrm{E}+00$ & $7.82 \mathrm{E}+03$ & $0.00 \mathrm{E}+00$ & $2.22 E+07$ & $0.00 \mathrm{E}+00$ & $0.00 \mathrm{E}+00$ & $0.00 E+00$ & $0.00 \mathrm{E}+00$ & $3.44 E+05$ \\
\hline $\mathrm{CNC}-\mathrm{C}$ & $0.00 \mathrm{E}+00$ & $0.00 \mathrm{E}+00$ & $0.00 E+00$ & $0.00 E+00$ & $5.82 \mathrm{E}+07$ & $0.00 \mathrm{E}+00$ & $0.00 \mathrm{E}+00$ & $0.00 \mathrm{E}+00$ & $0.00 E+00$ & $4.57 E+06$ \\
\hline GAL-D & $0.00 \mathrm{E}+00$ & $0.00 \mathrm{E}+00$ & $2.01 E+07$ & $0.00 \mathrm{E}+00$ & $5.18 \mathrm{E}+08$ & $0.00 \mathrm{E}+00$ & $0.00 \mathrm{E}+00$ & $5.98 E+03$ & $0.00 \mathrm{E}+00$ & $2.23 E+08$ \\
\hline JAC-C & $0.00 E+00$ & $0.00 \mathrm{E}+00$ & $1.78 \mathrm{E}+06$ & $0.00 \mathrm{E}+00$ & $1.83 E+08$ & $0.00 \mathrm{E}+00$ & $0.00 \mathrm{E}+00$ & $1.27 E+04$ & $0.00 \mathrm{E}+00$ & $8.38 E+07$ \\
\hline LOS-D & $0.00 \mathrm{E}+00$ & $0.00 \mathrm{E}+00$ & $5.33 E+04$ & $0.00 \mathrm{E}+00$ & $5.23 \mathrm{E}+08$ & $0.00 \mathrm{E}+00$ & $0.00 \mathrm{E}+00$ & $0.00 \mathrm{E}+00$ & $0.00 \mathrm{E}+00$ & $1.30 E+08$ \\
\hline LOS-C & $0.00 E+00$ & $0.00 \mathrm{E}+00$ & $0.00 \mathrm{E}+00$ & $0.00 \mathrm{E}+00$ & $3.26 \mathrm{E}+06$ & $0.00 \mathrm{E}+00$ & $0.00 \mathrm{E}+00$ & $0.00 \mathrm{E}+00$ & $0.00 \mathrm{E}+00$ & $8.48 \mathrm{E}+03$ \\
\hline MOT-D & $0.00 \mathrm{E}+00$ & $0.00 \mathrm{E}+00$ & 1. $15 E+05$ & $0.00 \mathrm{E}+00$ & $3.82 E+06$ & $0.00 \mathrm{E}+00$ & $0.00 \mathrm{E}+00$ & NOT-FOUND & $0.00 \mathrm{E}+00$ & $1.44 E+06$ \\
\hline NEW-D & $0.00 \mathrm{E}+00$ & $0.00 \mathrm{E}+00$ & $9.44 E+06$ & $0.00 \mathrm{E}+00$ & $8.18 \mathrm{E}+08$ & $0.00 E+00$ & $0.00 \mathrm{E}+00$ & NOT-FOUND & $0.00 \mathrm{E}+00$ & $3.38 E+08$ \\
\hline NEW-C & $0.00 E+00$ & $0.00 E+00$ & $5.07 E+07$ & $0.00 E+00$ & $2.17 E+09$ & $0.00 E+00$ & $0.00 \mathrm{E}+00$ & NOT-FOUND & $0.00 \mathrm{E}+00$ & $1.05 \mathrm{E}+09$ \\
\hline NOR-D & $0.00 E+00$ & $0.00 \mathrm{E}+00$ & $7.10 E+06$ & $0.00 \mathrm{E}+00$ & $3.64 E+08$ & $0.00 \mathrm{E}+00$ & $0.00 \mathrm{E}+00$ & $5.40 E+03$ & $0.00 \mathrm{E}+00$ & $1.91 \mathrm{E}+08$ \\
\hline POR-C & $0.00 \mathrm{E}+00$ & $0.00 \mathrm{E}+00$ & $1.31 \mathrm{E}+06$ & $0.00 \mathrm{E}+00$ & $1.63 E+08$ & $0.00 \mathrm{E}+00$ & $0.00 \mathrm{E}+00$ & $0.00 \mathrm{E}+00$ & $0.00 \mathrm{E}+00$ & $9.06 \mathrm{E}+07$ \\
\hline$S A V-D$ & $0.00 \mathrm{E}+00$ & $0.00 \mathrm{E}+00$ & $1.77 \mathrm{E}+07$ & $0.00 \mathrm{E}+00$ & $5.65 E+08$ & $0.00 \mathrm{E}+00$ & $0.00 \mathrm{E}+00$ & $1.27 \mathrm{E}+04$ & $0.00 \mathrm{E}+00$ & $3.14 \mathrm{E}+08$ \\
\hline$S A V-C$ & $0.00 \mathrm{E}+00$ & $0.00 \mathrm{E}+00$ & $9.38 \mathrm{E}+04$ & $0.00 E+00$ & $1.85 E+07$ & $0.00 \mathrm{E}+00$ & $0.00 \mathrm{E}+00$ & $5.95 E+03$ & $0.00 \mathrm{E}+00$ & $5.30 \mathrm{E}+06$ \\
\hline$S E A-C$ & $0.00 \mathrm{E}+00$ & $0.00 E+00$ & $0.00 \mathrm{E}+00$ & $0.00 \mathrm{E}+00$ & $2.15 \mathrm{E}+06$ & $0.00 E+00$ & $0.00 \mathrm{E}+00$ & $0.00 \mathrm{E}+00$ & $0.00 \mathrm{E}+00$ & $2.31 E+05$ \\
\hline$T A C-D$ & $0.00 \mathrm{E}+00$ & $0.00 \mathrm{E}+00$ & $5.44 \mathrm{E}+04$ & $0.00 \mathrm{E}+00$ & $1.24 \mathrm{E}+08$ & $0.00 \mathrm{E}+00$ & $0.00 \mathrm{E}+00$ & $0.00 \mathrm{E}+00$ & $0.00 E+00$ & $5.24 \mathrm{E}+07$ \\
\hline TAC-C & $0.00 \mathrm{E}+00$ & $0.00 \mathrm{E}+00$ & $0.00 \mathrm{E}+00$ & $0.00 E+00$ & $4.36 \mathrm{E}+07$ & $0.00 E+00$ & $0.00 \mathrm{E}+00$ & $0.00 \mathrm{E}+00$ & $0.00 E+00$ & $1.05 \mathrm{E}+07$ \\
\hline WIL-D & $0.00 \mathrm{E}+00$ & $0.00 \mathrm{E}+00$ & $1.45 \mathrm{E}+07$ & $0.00 \mathrm{E}+00$ & $2.68 \mathrm{E}+08$ & $0.00 E+00$ & $0.00 \mathrm{E}+00$ & $1.38 \mathrm{E}+04$ & $0.00 E+00$ & $1.53 \mathrm{E}+08$ \\
\hline WIL-C & $0.00 \mathrm{E}+00$ & $0.00 E+00$ & $2.11 E+06$ & $0.00 \mathrm{E}+00$ & $5.08 E+07$ & $0.00 \mathrm{E}+00$ & $0.00 \mathrm{E}+00$ & $1.05 E+04$ & $0.00 \mathrm{E}+00$ & $3.17 \mathrm{E}+07$ \\
\hline
\end{tabular}


Table 36. 99th Quantile Values of Population Dose, Cancer Fatalities, Costs, Centerline Individual Dose and Centerline Individual Risk for EIS Accident Categories (Continued)

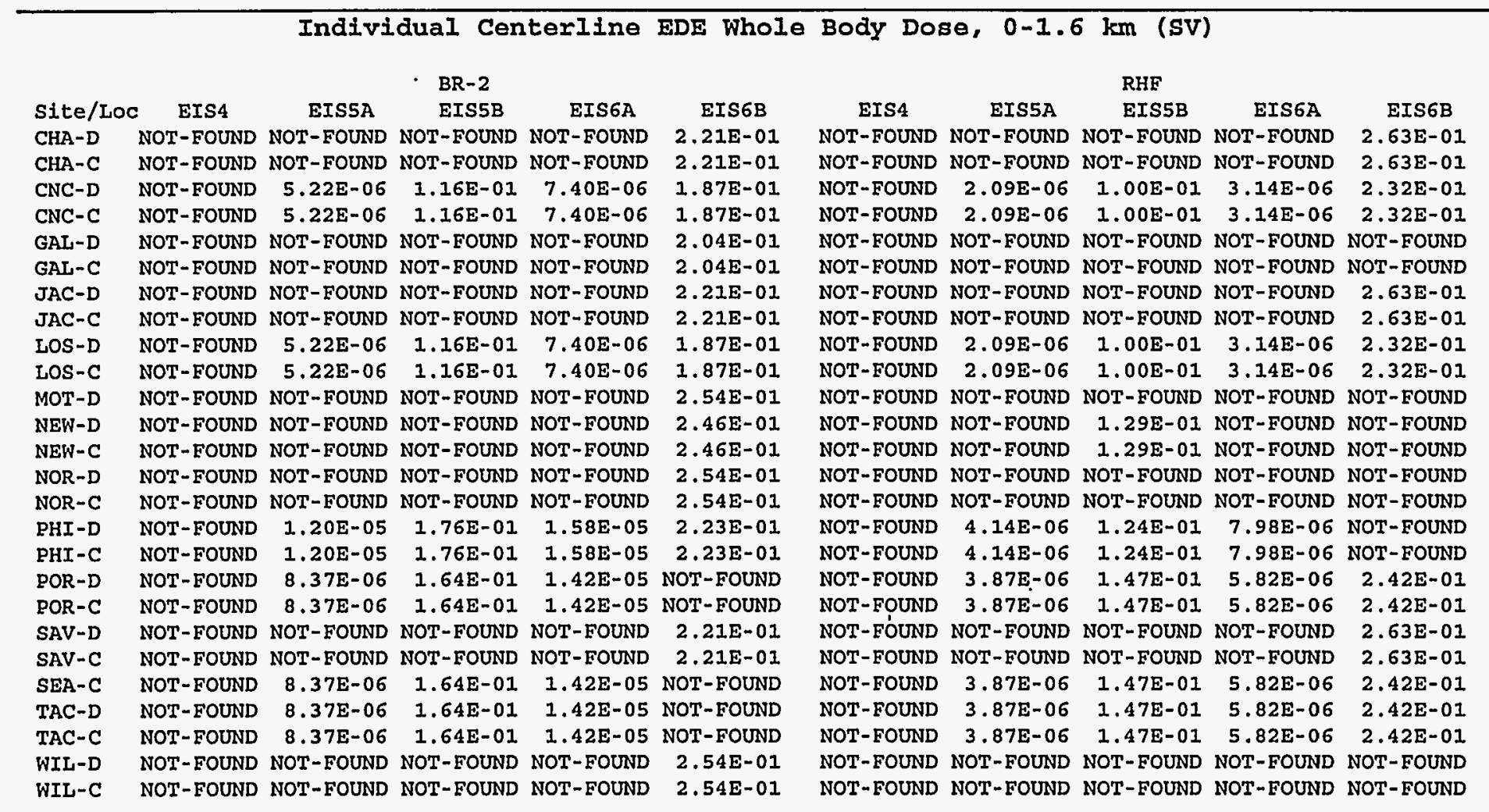


Table 36. 99th Quantile Values of Population Dose, Cancer Fatalities, Costs, Centerline Individual Dose and Centerline Individual Risk for EIS Accident Categories (Continued)

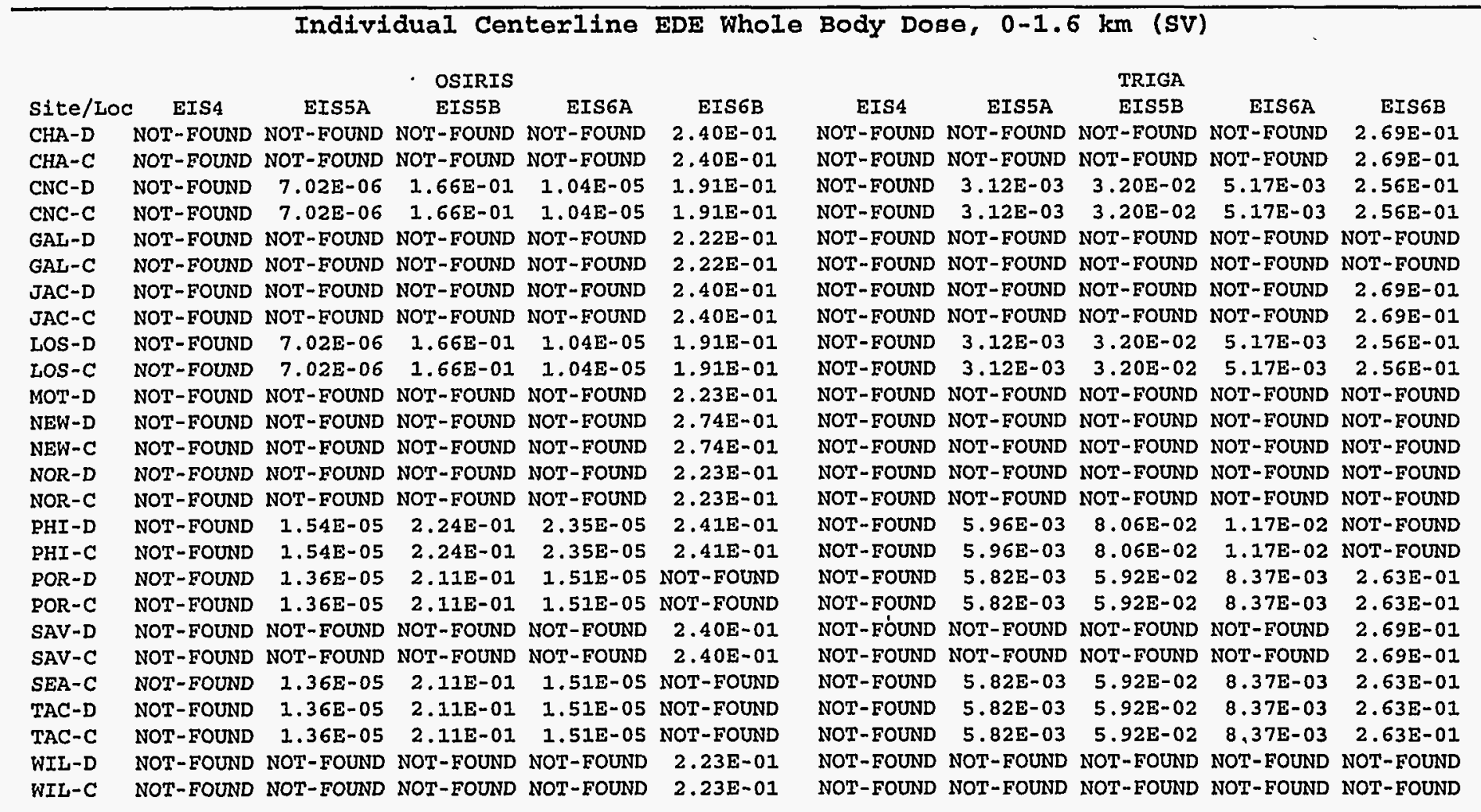


Table 36. 99th Quantile Values of Population Dose, Cancer Fatalities,

Costs, Centerline Individual Dose and Centerline

Individual Risk for EIS Accident Categories (Continued)

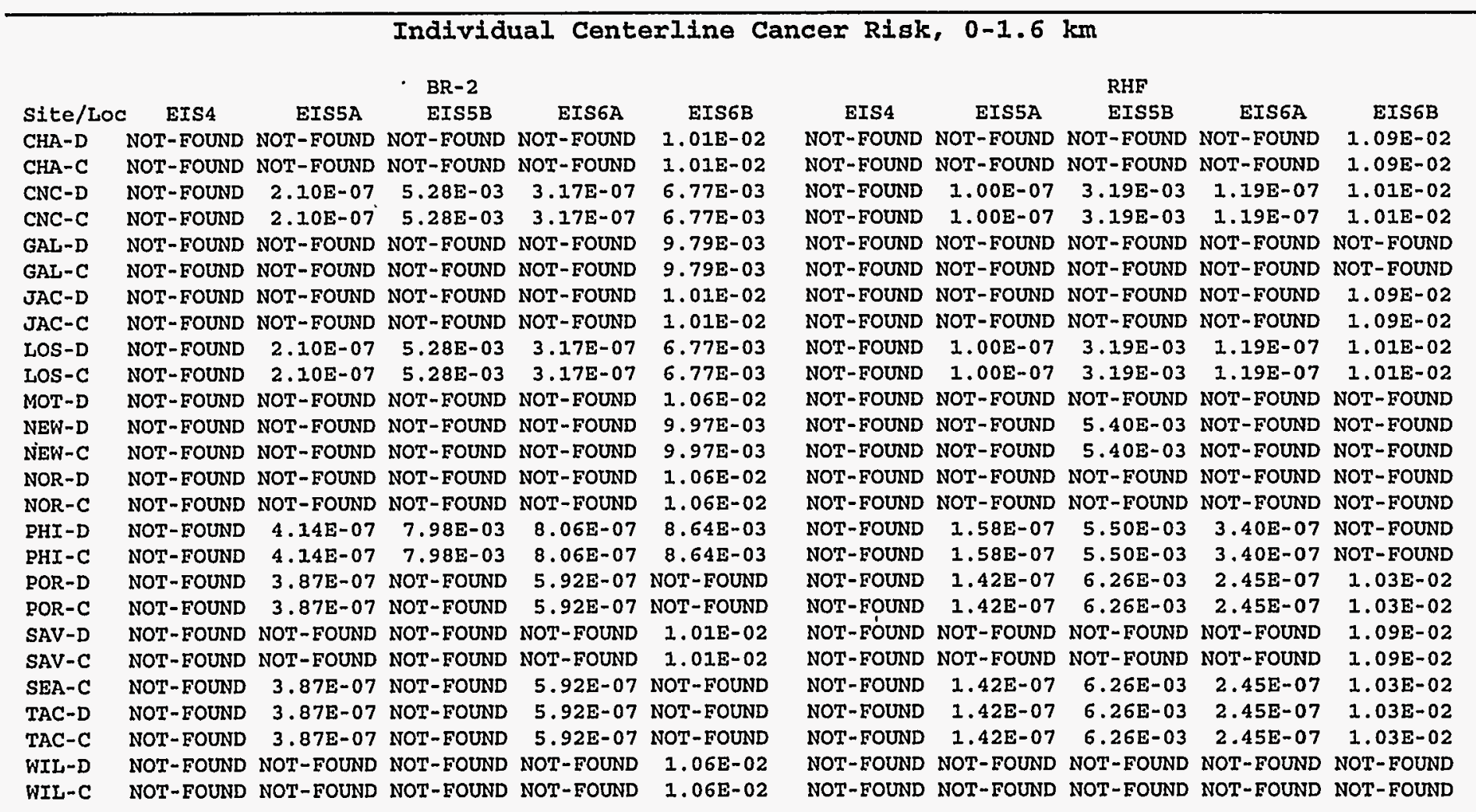


Table 36. 99th Quantile Values of Population Dose, Cancer Fatalities, Costs, Centerline Individual Dose and Centerline Individual Risk for EIS Accident Categories (Concluded)

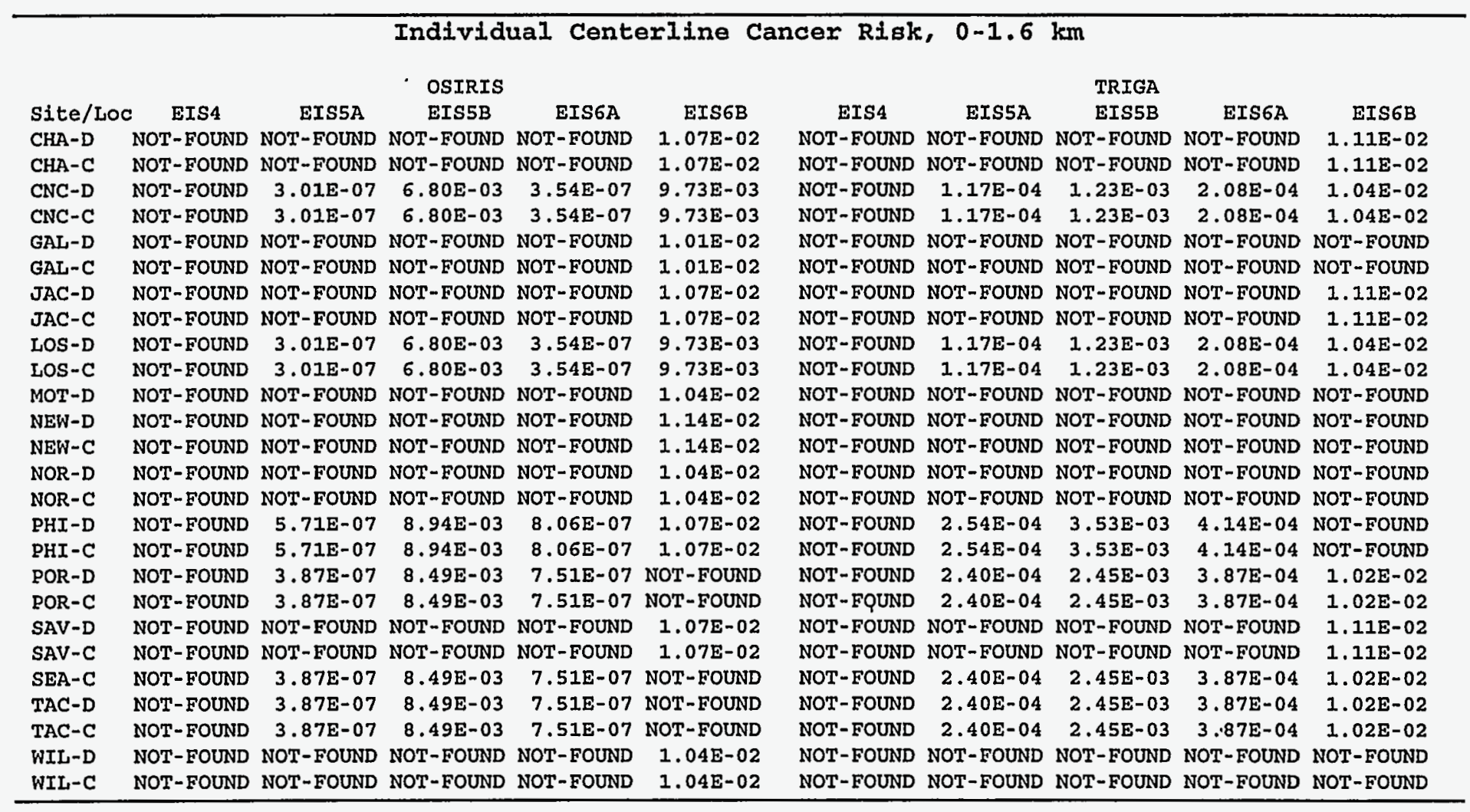


Table 37. Peak Values of Population Dose, Cancer Fatalities, Costs, Centerline Individual Dose and Centerline Individual Risk for EIS Accident Categories

\section{EDE Whole Body Population Dose, $0-80 \mathrm{~km}$ (SV)}

$\begin{array}{lccccc}\text { Site/LOC } & \text { EIS4 } & \text { EIS5A } & \begin{array}{c}\text { BR-2 } \\ \text { EIS5B }\end{array} & \text { EIS6A } & \text { EIS6B } \\ \text { CHA-D } & 2.82 E-03 & 2.74 E-02 & 1.08 E+03 & 4.09 E-02 & 5.58 E+03 \\ \text { CHA-C } & 4.38 E-03 & 5.68 E-02 & 1.57 E+03 & 8.73 E-02 & 6.02 E+03 \\ \text { CNC-D } & 3.33 E-03 & 2.91 E-02 & 1.11 E+03 & 4.46 E-02 & 1.13 E+04 \\ \text { CNC-C } & 1.42 E-02 & 1.76 E-01 & 7.31 E+03 & 2.68 E-01 & 4.02 E+04 \\ \text { GAL-D } & 5.57 E-03 & 6.42 E-02 & 2.24 E+03 & 9.88 E-02 & 1.16 E+04 \\ \text { GAL-C } & 2.09 E-03 & 4.83 E-02 & 1.84 E+03 & 7.43 E-02 & 1.04 E+04 \\ \text { JAC-D } & 2.14 E-03 & 2.88 E-02 & 1.11 E+03 & 4.41 E-02 & 9.49 E+03 \\ \text { JAC-C } & 1.89 E-03 & 3.05 E-02 & 1.07 E+03 & 4.68 E-02 & 9.98 E+03 \\ \text { LOS-D } & 1.29 E-02 & 1.04 E-01 & 4.06 E+03 & 1.59 E-01 & 3.17 E+04 \\ \text { LOS-C } & 5.97 E-03 & 9.28 E-02 & 3.78 E+03 & 1.41 E-01 & 3.37 E+04 \\ \text { MOT-D } & 7.71 E-04 & 1.21 E-02 & 5.02 E+02 & 1.86 E-02 & 3.37 E+03 \\ \text { NEW-D } & 1.86 E-02 & 2.95 E-01 & 1.23 E+04 & 4.54 E-01 & 1.26 E+05 \\ \text { NEW-C } & 3.38 E-02 & 3.46 E-01 & 1.42 E+04 & 5.33 E-01 & 1.44 E+05 \\ \text { NOR-D } & 4.26 E-03 & 4.35 E-02 & 1.72 E+03 & 6.67 E-02 & 1.14 E+04 \\ \text { NOR-C } & 2.77 E-03 & 4.29 E-02 & 1.75 E+03 & 6.57 E-02 & 1.17 E+04 \\ \text { PHI-D } & 1.13 E-02 & 1.86 E-01 & 7.69 E+03 & 2.86 E-01 & 4.20 E+04 \\ \text { PHI-C } & 8.76 E-03 & 1.27 E-01 & 5.30 E+03 & 1.95 E-01 & 5.30 E+04 \\ \text { POR-D } & 3.84 E-03 & 4.49 E-02 & 1.84 E+03 & 6.91 E-02 & 1.33 E+04 \\ \text { POR-C } & 3.91 E-03 & 4.42 E-02 & 1.83 E+03 & 6.81 E-02 & 1.64 E+04 \\ \text { SAV-D } & 6.15 E-03 & 6.42 E-02 & 1.78 E+03 & 9.86 E-02 & 7.13 E+03 \\ \text { SAV-C } & 1.43 E-03 & 2.04 E-02 & 8.32 E+02 & 2.99 E-02 & 7.31 E+03 \\ \text { SEA-C } & 9.92 E-04 & 1.47 E-02 & 6.12 E+02 & 2.26 E-02 & 6.24 E+03 \\ \text { TAC-D } & 2.66 E-03 & 3.16 E-02 & 1.28 E+03 & 4.86 E-02 & 1.02 E+04 \\ \text { TAC-C } & 3.12 E-03 & 4.42 E-02 & 1.84 E+03 & 6.80 E-02 & 1.59 E+04 \\ \text { WIL-D } & 5.48 E-03 & 3.98 E-02 & 8.62 E+02 & 6.11 E-02 & 3.81 E+03 \\ \text { WIL-C } & 1.18 E-03 & 9.42 E-03 & 3.13 E+02 & 1.45 E-02 & 2.53 E+03\end{array}$

\begin{tabular}{|c|c|c|c|c|}
\hline & & RHF & & \\
\hline 54 & EIS5 & EIS5B & EIS6A & EIS61 \\
\hline 3 & $09 \mathrm{E}-02$ & $43 E+02$ & $63 \mathrm{E}$ & W \\
\hline $74 E-03$ & $26 \mathrm{E}-02$ & $96 E+02$ & $.48 E-02$ & $.49 \mathrm{E}+\mathrm{C}$ \\
\hline $32 E-03$ & $16 \mathrm{E}-02$ & $.39 \mathrm{E}+02$ & $.77 \mathrm{E}-02$ & $.48 E+03$ \\
\hline$E-03$ & $3 E-02$ & $.89 E+03$ & $.07 \mathrm{E}-01$ & $.62 E+04$ \\
\hline LE-03 & $5 E-02$ & $.98 E+02$ & $.92 \mathrm{E}-02$ & $4.45 E+03$ \\
\hline$E-04$ & $2 E-02$ & $.26 E+02$ & $95 E-02$ & $.98 \mathrm{E}+03$ \\
\hline & 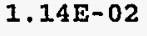 & 02 & 12 & $E+03$ \\
\hline & 2 & 75 & 02 & +03 \\
\hline 3 & 2 & 1.70 & 12 & $1.41 E+04$ \\
\hline $39 \mathrm{E}-03$ & $1 E-02$ & $1.50 \mathrm{E}+03$ & $.64 \mathrm{E}-02$ & $1.51 \mathrm{E}+04$ \\
\hline 4 & $.71 E-03$ & $1.86 \mathrm{E}$ & $7.25 E-03$ & $1.90 \mathrm{E}+03$ \\
\hline & 1 & 33 & $.81 E-01$ & $.97 E+04$ \\
\hline 2 & & & 1 & +04 \\
\hline & & & & \\
\hline .1 & 2 & 7.01 & 2 . & 6 \\
\hline $.50 E-03$ & $43 E-02$ & $3.06 \mathrm{E}+03$ & $.14 \mathrm{E}-01$ & $2.34 \mathrm{E}+04$ \\
\hline $.49 E-03$ & $5.06 E-02$ & $2.09 E+03$ & $.78 \mathrm{E}-02$ & $2.10 E+04$ \\
\hline $.53 \mathrm{E}$ & $1.80 \mathrm{E}-$ & $7.29 E+02$ & $.76 \mathrm{E}-02$ & $7.43 E+03$ \\
\hline $.56 \mathrm{E}$ & $1.76 \mathrm{E}-02$ & $7.25 \mathrm{E}+02$ & $.71 \mathrm{E}-02$ & $7.12 E+03$ \\
\hline 3 & $E-02$ & $1.00 \mathrm{E}+03$ & $.93 \mathrm{E}-02$ & $.14 \mathrm{E}+03$ \\
\hline 4 & 3 & 02 & 02 & $.85 E+03$ \\
\hline & & & & \\
\hline .0 & & 5.0 & 32 & +03 \\
\hline .25 & & 7.23 & 02 & $7.06 \mathrm{E}+03$ \\
\hline & & 4.04 & 2.44 & $2.09 E+03$ \\
\hline $9 \mathrm{E}$ & $7 E-03$ & $1.17 \mathrm{E}$ & $5: 81 \mathrm{E}-03$ & 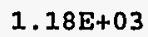 \\
\hline
\end{tabular}


Table 37. Peak Values of Population Dose, Cancer Fatalities, Costs, Centerline Individual Dose and Centerline Individual Risk for EIS Accident Categories (Continued)

EDE Whole Body Population Dose, $0-80 \mathrm{~km}$ (SV)

\begin{tabular}{|c|c|c|c|c|c|c|c|c|c|c|}
\hline \multirow[b]{3}{*}{ Site/Loc } & \multicolumn{10}{|c|}{ EDE Whole Body } \\
\hline & & & OSIRIS & & & & & TRIGA & & \\
\hline & EIS4 & EIS5A & EIS5B & EIS6A & EIS6B & EIS4 & EIS5A & EIS5B & EIS6A & EIS6B \\
\hline CHA-D & $3.48 \mathrm{E}-03$ & $3.35 \mathrm{E}-02$ & $1.04 \mathrm{E}+03$ & $4.99 \mathrm{E}-02$ & $6.29 \mathrm{E}+03$ & $3.41 E-03$ & $1.58 \mathrm{E}+01$ & $1.84 \mathrm{E}+02$ & $2.47 \mathrm{E}+01$ & $3.40 \mathrm{E}+03$ \\
\hline $\mathrm{CHA}-\mathrm{C}$ & $5.55 \mathrm{E}-03$ & $6.99 \mathrm{E}-02$ & $2.05 \mathrm{E}+03$ & $1.07 E-01$ & $6.40 E+03$ & $5.23 E-03$ & $3.34 \mathrm{E}+01$ & $3.79 \mathrm{E}+02$ & $5.34 \mathrm{E}+01$ & $3.39 \mathrm{E}+03$ \\
\hline CNC-D & $4.12 \mathrm{E}-03$ & $3.64 \mathrm{E}-02$ & $1.08 \mathrm{E}+03$ & $5.59 \mathrm{E}-02$ & $1.10 E+04$ & $4.00 \mathrm{E}-03$ & $1.58 \mathrm{E}+01$ & $1.83 \mathrm{E}+02$ & $2.52 \mathrm{E}+01$ & $5.03 E+03$ \\
\hline CNC-C & $1.79 \mathrm{E}-02$ & $2.20 \mathrm{E}-01$ & $7.09 E+03$ & $3.36 \mathrm{E}-01$ & $4.52 \mathrm{E}+04$ & $1.72 \mathrm{E}-02$ & $1.04 \mathrm{E}+02$ & $1.21 \mathrm{E}+03$ & $1.65 \mathrm{E}+02$ & $2.76 \mathrm{E}+04$ \\
\hline GAL-D & $6.90 \mathrm{E}-03$ & $7.76 \mathrm{E}-02$ & $2.16 \mathrm{E}+03$ & $1.19 \mathrm{E}-01$ & $1.05 \mathrm{E}+04$ & $6.69 \mathrm{E}-03$ & $3.73 \mathrm{E}+01$ & $4.07 \mathrm{E}+02$ & $5.97 \mathrm{E}+01$ & $4.92 \mathrm{E}+03$ \\
\hline GAL-C & $2.47 E-03$ & $5.87 \mathrm{E}-02$ & $1.78 \mathrm{E}+03$ & $9.02 \mathrm{E}-02$ & $9.31 E+03$ & $2.55 \mathrm{E}-03$ & $2.82 \mathrm{E}+01$ & $3.27 \mathrm{E}+02$ & $4.51 \mathrm{E}+01$ & $4.39 \mathrm{E}+03$ \\
\hline JAC-D & $2.58 \mathrm{E}-03$ & $3.47 \mathrm{E}-02$ & $1.06 \mathrm{E}+03$ & $5.32 \mathrm{E}-02$ & $1.01 E+04$ & $2.61 \mathrm{E}-03$ & $1.67 \mathrm{E}+01$ & $1.93 \mathrm{E}+02$ & $2.66 \mathrm{E}+01$ & $4.79 \mathrm{E}+03$ \\
\hline JAC-C & $2.26 \mathrm{E}-03$ & $3.74 \mathrm{E}-02$ & $1.16 \mathrm{E}+03$ & $5.76 \mathrm{E}-02$ & $9.65 \mathrm{E}+03$ & $2.31 \mathrm{E}-03$ & $1.79 \mathrm{E}+01$ & $2.01 \mathrm{E}+02$ & $2.86 \mathrm{E}+01$ & $4.44 \mathrm{E}+03$ \\
\hline LOS-D & $1.65 \mathrm{E}-02$ & $1.30 \mathrm{E}-01$ & $3.94 \mathrm{E}+03$ & $1.99 \mathrm{E}-01$ & $3.08 E+04$ & $.54 \mathrm{E}-02$ & $6.10 E+01$ & $7.09 \mathrm{E}+02$ & $9.74 \mathrm{E}+01$ & $1.49 \mathrm{E}+04$ \\
\hline LOS-C & $7.48 \mathrm{E}-03$ & $1.17 \mathrm{E}-01$ & $3.67 E+03$ & $1.77 \mathrm{E}-01$ & $3.38 E+04$ & $21 E-03$ & $5.38 \mathrm{E}+01$ & $6.26 \mathrm{E}+02$ & $8.52 \mathrm{E}+01$ & $1.70 \mathrm{E}+04$ \\
\hline MOT-D & $7.73 E-04$ & $1.31 \mathrm{E}-02$ & $4.19 E+02$ & $2.01 \mathrm{E}-02$ & $3.13 \mathrm{E}+03$ & $9.74 \mathrm{E}-04$ & $6.54 \mathrm{E}+00$ & $7.53 \mathrm{E}+02$ & $1.05 \mathrm{E}+01$ & $1.72 \mathrm{E}+03$ \\
\hline$N E W-D$ & $2.34 \mathrm{E}-02$ & $3.69 \mathrm{E}-01$ & $1.20 \mathrm{E}+04$ & $5.68 \mathrm{E}-01$ & $1.22 \mathrm{E}+05$ & $2.24 \mathrm{E}-02$ & $1.75 E+02$ & $2.03 \mathrm{E}+03$ & $2.80 \mathrm{E}+02$ & $5.58 E+04$ \\
\hline NEW-C & $4.37 \mathrm{E}-02$ & $4.33 \mathrm{E}-01$ & $1.38 \mathrm{E}+04$ & $6.67 \mathrm{E}-01$ & $1.40 E+05$ & $4.01 \mathrm{E}-02$ & $2.05 E+02$ & $2.39 \mathrm{E}+03$ & $3.29 \mathrm{E}+02$ & $6.39 \mathrm{E}+04$ \\
\hline NOR-D & $5.46 \mathrm{E}-03$ & $5.29 \mathrm{E}-02$ & $1.66 \mathrm{E}+03$ & $8.10 \mathrm{E}-02$ & 1. $37 \mathrm{E}+04$ & $5.07 \mathrm{E}-03$ & $2.53 E+01$ & $2.93 \mathrm{E}+02$ & $4.03 \mathrm{E}+01$ & $6.42 \mathrm{E}+03$ \\
\hline NOR-C & $3.44 \mathrm{E}-03$ & $5.30 \mathrm{E}-02$ & $1.70 \mathrm{E}+03$ & $8.15 E-02$ & $1.34 \mathrm{E}+04$ & $3.35 E-03$ & $2.51 E+01$ & $2.92 \mathrm{E}+02$ & $4.00 \mathrm{E}+01$ & $6.47 \mathrm{E}+03$ \\
\hline PHI-D & $1.42 \mathrm{E}-02$ & $2.32 \mathrm{E}-01$ & $7.45 \mathrm{E}+03$ & $3.56 \mathrm{E}-01$ & $5.73 \mathrm{E}+04$ & $1.36 \mathrm{E}-02$ & $1.10 \mathrm{E}+02$ & $1.28 \mathrm{E}+03$ & $1.76 \mathrm{E}+02$ & $2.62 E+04$ \\
\hline $\mathrm{PHI}-\mathrm{C}$ & 1.0 & $1.58 \mathrm{E}-01$ & $5.11 E+03$ & $2.42 \mathrm{E}-01$ & $5.14 \mathrm{E}+04$ & $1.06 \mathrm{E}-02$ & $7.50 \mathrm{E}+01$ & $8.71 E+02$ & $1.20 \mathrm{E}+02$ & $2.35 \mathrm{E}+04$ \\
\hline POR-D & $4.80 \mathrm{E}-03$ & $5.60 \mathrm{E}-02$ & $1.79 \mathrm{E}+03$ & $8.62 \mathrm{E}-02$ & $1.60 \mathrm{E}+04$ & $4.64 \mathrm{E}-03$ & $2.62 E+01$ & $3.04 \mathrm{E}+02$ & $4.19 E+01$ & $7.65 \mathrm{E}+03$ \\
\hline POR-C & $4.96 \mathrm{E}-03$ & $5.43 E-02$ & $1.76 \mathrm{E}+03$ & $8.35 E-02$ & 1. $74 \mathrm{E}+04$ & $4.67 \mathrm{E}-03$ & $2.60 \mathrm{E}+01$ & $3.01 \mathrm{E}+02$ & $4.16 \mathrm{E}+01$ & $7.98 \mathrm{E}+03$ \\
\hline SAV-D & $7.80 \mathrm{E}-03$ & $7.86 \mathrm{E}-02$ & $2.25 \mathrm{E}+03$ & $1.21 \mathrm{E}-01$ & $7.68 \mathrm{E}+03$ & $7.32 \mathrm{E}-03$ & 3. $76 \mathrm{E}+01$ & $4.26 \mathrm{E}+02$ & $6.01 E+01$ & $4.12 \mathrm{E}+03$ \\
\hline SAV-C & $1.69 \mathrm{E}-03$ & $2.42 \mathrm{E}-02$ & $7.59 \mathrm{E}+02$ & $3.53 \mathrm{E}-02$ & $6.86 \mathrm{E}+03$ & $1.75 \mathrm{E}-03$ & $1.14 \mathrm{E}+01$ & 1. $32 \mathrm{E}+02$ & $1.75 \mathrm{E}+01$ & $3.19 E+03$ \\
\hline SEA-C & $1.19 \mathrm{E}-03$ & $1.73 \mathrm{E}-02$ & $5.59 E+02$ & $2.66 \mathrm{E}-02$ & $5.70 \mathrm{E}+03$ & $1.22 \mathrm{E}-03$ & $8.27 E+00$ & $9.59 \mathrm{E}+01$ & $1.32 \mathrm{E}+01$ & $2.63 \mathrm{E}+03$ \\
\hline TAC-D & $3.25 \mathrm{E}-03$ & $3.94 \mathrm{E}-02$ & $1.25 \mathrm{E}+03$ & $6.06 \mathrm{E}-02$ & $1.14 \mathrm{E}+04$ & $3.23 \mathrm{E}-03$ & $1.82 \mathrm{E}+01$ & $2.12 \mathrm{E}+02$ & $2.92 \mathrm{E}+01$ & $5.25 \mathrm{E}+03$ \\
\hline TAC-C & $3.93 \mathrm{E}-03$ & $5.40 \mathrm{O}-02$ & $3.75 E+03$ & $8.32 E-02$ & 1. $73 E+04$ & $3.78 E-03$ & $2.59 E+01$ & $3.00 E+02$ & $4.24 E+01$ & $7.92 \mathrm{E}+03$ \\
\hline WIL-D & $7.04 \mathrm{E}-03$ & $4.95 E-02$ & $9.09 \mathrm{E}+02$ & $7.61 \mathrm{E}-02$ & $4.03 \mathrm{E}+03$ & $6.50 \mathrm{E}-03$ & $2.32 E+01$ & $2.69 \mathrm{E}+02$ & $3.70 \mathrm{E}+01$ & $2.09 \mathrm{E}+03$ \\
\hline WIL-C & $1.48 \mathrm{E}-03$ & $1.15 \mathrm{E}-02$ & $2.56 \mathrm{E}+02$ & $1.76 \mathrm{E}-02$ & $2.69 \mathrm{E}+03$ & $1.41 \mathrm{E}-03$ & $5.09 \mathrm{E}+00$ & $5.87 \mathrm{E}+01$ & $8.14 \mathrm{E}+00$ & $1.29 \mathrm{E}+03$ \\
\hline
\end{tabular}


Table 37. Peak Values of Population Dose, Cancer Fatalities, Costs, Centerline Individual Dose and Centerline Individual Risk for EIS Accident Categories (Continued)

Total Cancer Fatalities, $0-80 \mathrm{~km}$

\begin{tabular}{|c|c|c|c|c|c|c|c|c|c|c|}
\hline & & & BR-2 & & & & & RHF & & \\
\hline Site/Loc & EIS4 & EIS5A & EIS5B & EIS6A & EIS6B & EIS4 & EIS5A & EIS5B & EIS6A & EIS6B \\
\hline CHA -D & $1.20 \mathrm{E}-04$ & $1.17 \mathrm{E}-03$ & $4.56 \mathrm{E}+01$ & $1.74 \mathrm{E}-03$ & $2.33 \mathrm{E}+02$ & $4.80 \mathrm{E}-05$ & $4.66 \mathrm{E}-04$ & $1.87 E+02$ & $6.94 \mathrm{E}-04$ & $1.36 \mathrm{E}+02$ \\
\hline $\mathrm{CHA}-\mathrm{C}$ & $1.94 \mathrm{E}-04$ & $2.40 \mathrm{E}-03$ & $6.53 E+01$ & $3.69 \mathrm{E}-03$ & $2.52 E+02$ & $7.79 \mathrm{E}-05$ & $9.60 \mathrm{E}-04$ & $3.74 \mathrm{E}+01$ & $1.48 \mathrm{E}-03$ & $1.46 \mathrm{E}+02$ \\
\hline CNC-D & $1.49 \mathrm{E}-04$ & $1.29 \mathrm{E}-03$ & $4.69 E+01$ & $1.98 \mathrm{E}-03$ & $4.72 \mathrm{E}+02$ & $5.94 \mathrm{E}-05$ & $5.17 E-04$ & $1.83 E+01$ & $7.92 \mathrm{E}-04$ & $1.86 \mathrm{E}+02$ \\
\hline CNC-C & $6.01 \mathrm{E}-04$ & $7.39 \mathrm{E}-03$ & $3.05 E+02$ & $1.13 \mathrm{E}-02$ & $1.68 \mathrm{E}+03$ & $.42 \mathrm{E}-04$ & $2.97 \mathrm{E}-03$ & $1.20 E+02$ & $4.53 \mathrm{E}-03$ & $1.09 \mathrm{E}+03$ \\
\hline GAL-D & $2.47 \mathrm{E}-04$ & $2.73 E-03$ & $9.36 E+01$ & $4.20 \mathrm{E}-03$ & $5.08 \mathrm{E}+02$ & $9.87 \mathrm{E}-05$ & $1.09 \mathrm{E}-03$ & $3.75 E+01$ & $1.67 \mathrm{E}-03$ & $1.93 E+02$ \\
\hline GAL-C & $9.01 E-05$ & $2.05 E-03$ & $7.66 \mathrm{E}+01$ & $3.15 E-03$ & $4.58 \mathrm{E}+02$ & $3.57 \mathrm{E}-05$ & $8.28 \mathrm{E}-04$ & $3.03 E+01$ & $1.26 \mathrm{E}-03$ & $1.74 \mathrm{E}+02$ \\
\hline JAC-D & $9.23 \mathrm{E}-05$ & $1.22 \mathrm{E}-03$ & $4.70 \mathrm{E}+01$ & $1.87 \mathrm{E}-03$ & $3.98 \mathrm{E}+02$ & $3.67 \mathrm{E}-05$ & $4.87 \mathrm{E}-04$ & $1.94 \mathrm{E}+01$ & $7.46 \mathrm{E}-04$ & $1.78 \mathrm{E}+02$ \\
\hline JAC-C & $8.18 \mathrm{E}-05$ & $1.29 \mathrm{E}-03$ & $4.54 \mathrm{E}+01$ & $1.98 \mathrm{E}-03$ & $4.18 \mathrm{E}+02$ & $3.25 E-05$ & $5.15 E-04$ & $1.98 \mathrm{E}+01$ & $7.91 \mathrm{E}-04$ & $1.65 \mathrm{E}+02$ \\
\hline LOS-D & $5.71 E-04$ & $4.37 E-03$ & $1.69 \mathrm{E}+02$ & $6.69 \mathrm{E}-03$ & 1. $32 \mathrm{E}+03$ & $2.30 \mathrm{E}-04$ & $1.75 \mathrm{E}-03$ & $7.08 E+01$ & $2.69 \mathrm{E}-03$ & $5.89 E+02$ \\
\hline LOS-C & $2.52 \mathrm{E}-04$ & $3.92 \mathrm{E}-03$ & $1.58 \mathrm{E}+02$ & $5.96 \mathrm{E}-03$ & $1.40 \mathrm{E}+03$ & $2.01 E-04$ & 1. $58 \mathrm{E}-03$ & $6.23 E+01$ & $2.40 \mathrm{E}-03$ & $6.30 \mathrm{E}+02$ \\
\hline MOT-D & $3.49 \mathrm{E}-05$ & $5.32 \mathrm{E}-04$ & $2.28 E+01$ & $8.19 \mathrm{E}-04$ & $1.45 \mathrm{E}+02$ & $1.34 \mathrm{E}-05$ & $2.07 E-04$ & $8.38 E+00$ & $3.18 \mathrm{E}-04$ & $8.55 E+01$ \\
\hline NEW-D & $7.87 \mathrm{E}-04$ & $1.24 E-02$ & $5.14 \mathrm{E}+02$ & $1.91 \mathrm{E}-02$ & $5.23 E+03$ & $3.16 \mathrm{E}-04$ & $4.98 \mathrm{E}-03$ & $2.03 E+02$ & $7.66 \mathrm{E}-03$ & $2.07 E+03$ \\
\hline NEW-C & $1.49 \mathrm{E}-03$ & $1.45 \mathrm{E}-02$ & $5.91 E+02$ & $2.24 \mathrm{E}-02$ & $6.00 \mathrm{E}+03$ & $6.03 E-04$ & $5.84 \mathrm{E}-03$ & $2.34 E+02$ & $8.99 \mathrm{E}-03$ & $2.38 \mathrm{E}+03$ \\
\hline NOR-D & $1.88 \mathrm{E}-04$ & $1.85 \mathrm{E}-03$ & $7.24 \mathrm{E}+01$ & $2.83 E-03$ & $4.77 \mathrm{E}+02$ & $7.59 \mathrm{E}-05$ & $7.38 \mathrm{E}-04$ & $3.00 \mathrm{E}+01$ & $1.13 \mathrm{E}-03$ & $2.40 \mathrm{E}+02$ \\
\hline NOR-C & $1.18 \mathrm{E}-04$ & $1.82 \mathrm{E}-03$ & $7.30 \mathrm{E}+01$ & $2.78 \mathrm{E}-03$ & $4.90 \mathrm{E}+02$ & $4.73 E-05$ & $7.27 \mathrm{E}-04$ & $2.95 \mathrm{E}+01$ & $1.11 \mathrm{E}-03$ & $2.85 \mathrm{E}+02$ \\
\hline PHI-D & $4.79 \mathrm{E}-04$ & $7.83 E-03$ & $3.21 \mathrm{E}+02$ & $1.20 \mathrm{E}-02$ & $1.75 \mathrm{E}+03$ & $1.92 \mathrm{E}-04$ & $3.14 \mathrm{E}-03$ & $1.28 \mathrm{E}+02$ & $4.83 \mathrm{E}-03$ & $9.75 E+02$ \\
\hline PHI-C & $3.71 \mathrm{E}-04$ & $5.34 \mathrm{E}-03$ & $2.22 \mathrm{E}+02$ & $8.21 \mathrm{E}-03$ & $2.21 E+03$ & $1.49 \mathrm{E}-04$ & $2.14 \mathrm{E}-03$ & $8.75 E+01$ & $3.29 \mathrm{E}-03$ & $8.73 E+02$ \\
\hline POR-D & $1.67 \mathrm{E}-04$ & $1.88 E-03$ & $7.68 \mathrm{E}+01$ & $2.90 \mathrm{E}-03$ & $5.56 \mathrm{E}+02$ & $6.70 \mathrm{E}-05$ & $7.58 \mathrm{E}-04$ & $3.04 E+01$ & $1.17 \mathrm{E}-03$ & $3.10 \mathrm{E}+02$ \\
\hline POR-C & $1.74 \mathrm{E}-04$ & $1.87 \mathrm{E}-03$ & $7.74 \mathrm{E}+01$ & $2.88 \mathrm{E}-03$ & $6.86 \mathrm{E}+02$ & $6.97 \mathrm{E}-05$ & $7.47 \mathrm{E}-04$ & $3.06 \mathrm{E}+01$ & $1.15 \mathrm{E}-03$ & $2.98 \mathrm{E}+02$ \\
\hline$S A V-D$ & $2.73 E-04$ & $2.71 E-03$ & $7.46 \mathrm{E}+01$ & $4.17 \mathrm{E}-03$ & $2.98 \mathrm{E}+02$ & $1.09 \mathrm{E}-04$ & $1.08 \mathrm{E}-03$ & $4.20 \mathrm{E}+01$ & $1.67 \mathrm{E}-03$ & $3 E+02$ \\
\hline$S A V-C$ & $6.14 \mathrm{E}-05$ & $8.82 \mathrm{E}-04$ & $3.61 E+01$ & $1.29 \mathrm{E}-03$ & $3.12 \mathrm{E}+02$ & $2.43 \mathrm{E}-05$ & $3.50 \mathrm{E}-04$ & $1.38 \mathrm{E}+01$ & $5.11 \mathrm{E}-04$ & $1.21 \mathrm{E}+02$ \\
\hline SEA-C & $4.26 \mathrm{E}-05$ & $6.33 E-04$ & $2.69 \mathrm{E}+01$ & $9.74 \mathrm{E}-04$ & $2.74 \mathrm{E}+02$ & $1.69 \mathrm{E}-05$ & $2.49 \mathrm{E}-04$ & $1.02 \mathrm{E}+01$ & $3.84 \mathrm{E}-04$ & $1.04 \mathrm{E}+02$ \\
\hline TAC-D & $1.14 \mathrm{E}-04$ & $1.33 \mathrm{E}-03$ & $5.35 \mathrm{E}+0 \mathrm{I}$ & $2.04 \mathrm{E}-03$ & $4.25 \mathrm{E}+02$ & $4.54 \mathrm{E}-05$ & $5.34 E-04$ & $2.12 \mathrm{E}+02$ & $8.21 \mathrm{E}-04$ & $1.98 \mathrm{E}+02$ \\
\hline TAC-C & $1.32 \mathrm{E}-04$ & $1.87 E-03$ & $7.76 \mathrm{E}+01$ & $2.87 \mathrm{E}-03$ & $6.67 \mathrm{E}+02$ & $5.33 E-05$ & $7.46 \mathrm{E}-04$ & $3.05 E+01$ & $1.15 \mathrm{E}-03$ & $2: 95 E+02$ \\
\hline WIL-D & $2.42 \mathrm{E}-04$ & $1.67 \mathrm{E}-03$ & $3.60 \mathrm{E}+01$ & $2.57 \mathrm{E}-03$ & $1.65 \mathrm{E}+02$ & $9.77 \mathrm{E}-05$ & $6.72 \mathrm{E}-04$ & $1.68 \mathrm{E}+01$ & $1.03 \mathrm{E}-03$ & $9.02 \mathrm{E}+01$ \\
\hline WIL-C & $5.20 \mathrm{E}-05$ & $3.96 \mathrm{E}-04$ & $1.45 \mathrm{E}+01$ & $6.09 \mathrm{E}-04$ & $1.12 \mathrm{E}+02$ & $2.09 \mathrm{E}-05$ & $1.59 \mathrm{E}-04$ & $5.31 E+00$ & $2: 45 \mathrm{E}-04$ & $5.35 \mathrm{E}+01$ \\
\hline
\end{tabular}


Table 37. Peak Values of Population Dose, Cancer Fatalities, Costs, Centerline Individual Dose and Centerline Individual Risk for EIS Accident Categories (Continued)

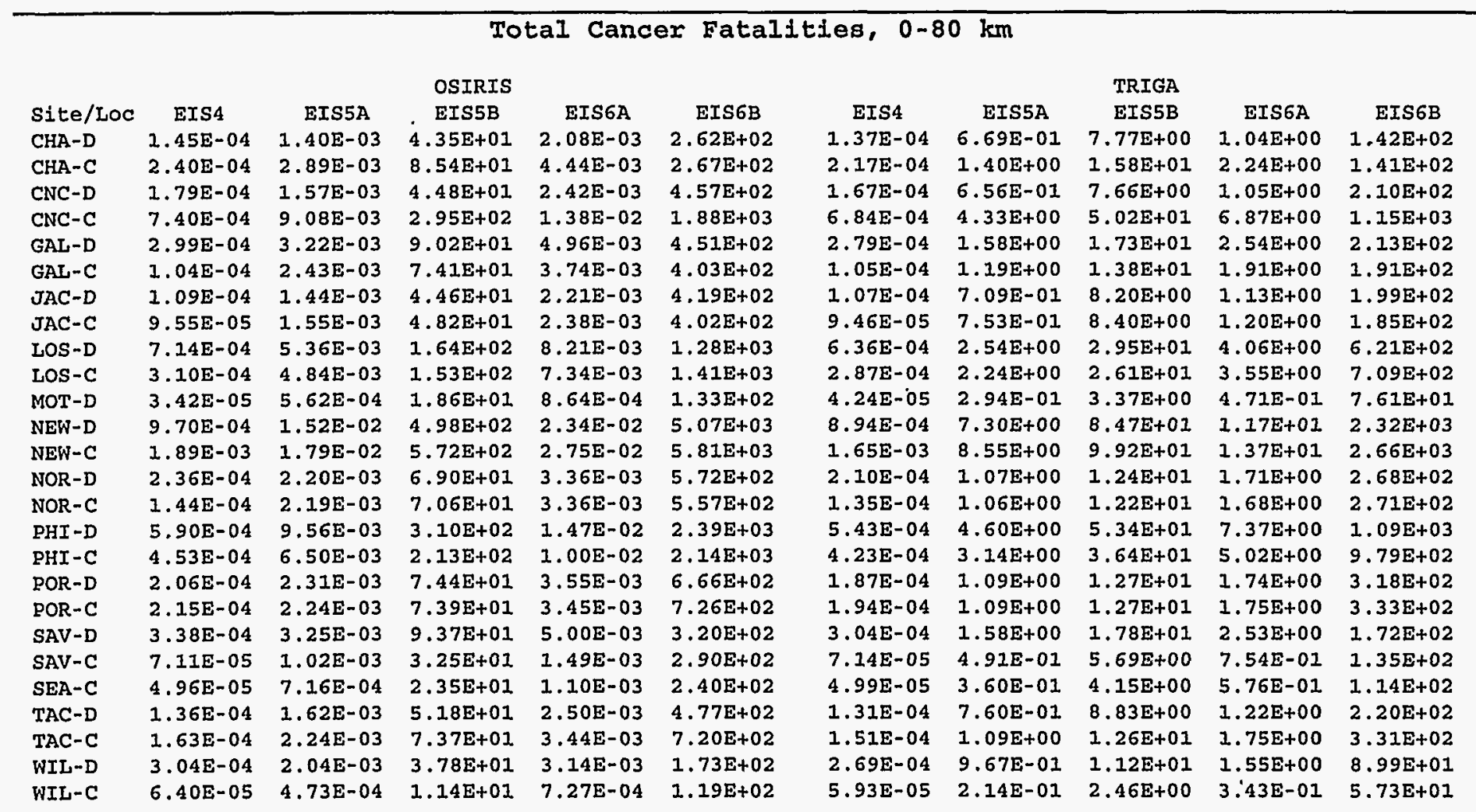


Table 37. Peak Values of Population Dose, Cancer Fatalities, Costs, Centerline Individual Dose and Centerline Individual Risk for EIS Accident Categories (Continued)

\begin{tabular}{|c|c|c|c|c|c|c|c|c|c|c|}
\hline Site/LOC & EIS4 & EIS5A & EIS5B & EIS6A & EIS6B & EIS4 & EIS5A & EIS5B & EIS6A & EIS6B \\
\hline CHA-C & $0.00 \mathrm{E}+00$ & $0.00 \mathrm{E}+00$ & $8.69 E+07$ & $0.00 \mathrm{E}+00$ & $9.97 \mathrm{E}+08$ & $0.00 \mathrm{E}+00$ & $0.00 \mathrm{E}+00$ & $1.22 \mathrm{E}+07$ & $0.00 \mathrm{E}+00$ & $7.40 E+08$ \\
\hline CNC-D & $0.00 \mathrm{E}+00$ & $0.00 \mathrm{E}+00$ & $1.25 \mathrm{E}+07$ & $0.00 \mathrm{E}+00$ & $1.54 \mathrm{E}+08$ & $0.00 \mathrm{E}+00$ & $0.00 \mathrm{E}+00$ & $1.53 \mathrm{E}+04$ & $0.00 \mathrm{E}+00$ & $1.04 \mathrm{E}+08$ \\
\hline CNC-C & $0.00 \mathrm{E}+00$ & $0.00 E+00$ & $1.13 \mathrm{E}+05$ & $0.00 E+00$ & $4.78 E+09$ & $0.00 \mathrm{E}+00$ & $0.00 \mathrm{E}+00$ & $0.00 \mathrm{E}+00$ & $0.00 \mathrm{E}+00$ & $2.66 \mathrm{E}+08$ \\
\hline GAL-D & $0.00 \mathrm{E}+00$ & $0.00 \mathrm{E}+00^{\circ}$ & $1.31 E+08$ & $0.00 \mathrm{E}+00$ & $1.85 \mathrm{E}+09$ & $0.00 \mathrm{E}+00$ & $0.00 \mathrm{E}+00$ & $1.62 \mathrm{E}+07$ & $0.00 \mathrm{E}+00$ & $6.28 \mathrm{E}+08$ \\
\hline JAC-C & $0.00 \mathrm{E}+00$ & $0.00 \mathrm{E}+00$ & $6.76 \mathrm{E}+07$ & $0.00 \mathrm{E}+00$ & $6.50 \mathrm{E}+08$ & $0.00 \mathrm{E}+00$ & $0.00 \mathrm{E}+00$ & $3.63 E+06$ & $0.00 E+00$ & $4.79 E+08$ \\
\hline LOS-D & $0.00 \mathrm{E}+00$ & $0.00 \mathrm{E}+00$ & $3.75 \mathrm{E}+07$ & $0.00 \mathrm{E}+00$ & $2.33 E+09$ & $0.00 \mathrm{E}+00$ & $0.00 \mathrm{E}+00$ & $1.53 \mathrm{E}+04$ & $0.00 \mathrm{E}+00$ & $4.78 E+08$ \\
\hline LOS-C & $0.00 \mathrm{E}+00$ & $0.00 \mathrm{E}+00$ & $1.14 \mathrm{E}+05$ & $0.00 \mathrm{E}+00$ & $1.02 E+09$ & $0.00 \mathrm{E}+00$ & $0.00 \mathrm{E}+00$ & $3.06 \mathrm{E}+03$ & $0.00 \mathrm{E}+00$ & $1.51 E+06$ \\
\hline MOT-D & $0.00 \mathrm{E}+00$ & $0.00 \mathrm{E}+00$ & $3.66 \mathrm{E}+05$ & $0.00 \mathrm{E}+00$ & $9.61 E+07$ & $0.00 \mathrm{E}+00$ & $0.00 \mathrm{E}+00$ & $1.32 \mathrm{E}+05$ & $0.00 \mathrm{E}+00$ & $2.40 E+07$ \\
\hline NEW-D & $0.00 \mathrm{E}+00$ & $0.00 \mathrm{E}+00$ & $1.35 \mathrm{E}+08$ & $0.00 \mathrm{E}+00$ & $2.01 \mathrm{E}+09$ & $0.00 \mathrm{E}+00$ & $0.00 \mathrm{E}+00$ & $3.66 \mathrm{E}+07$ & $0.00 \mathrm{E}+00$ & $5.27 E+08$ \\
\hline NEW-C & $0.00 \mathrm{E}+00$ & $0.00 \mathrm{E}+00$ & $4.25 E+08$ & $0.00 \mathrm{E}+00$ & $6.64 \mathrm{E}+09$ & $0.00 \mathrm{E}+00$ & $0.00 \mathrm{E}+00$ & $1.15 \mathrm{E}+08$ & $0.00 E+00$ & $2.16 \mathrm{E}+09$ \\
\hline POR-C & $0.00 \mathrm{E}+00$ & $0.00 \mathrm{E}+00$ & $7.58 \mathrm{E}+07$ & $0.00 \mathrm{E}+00$ & $7.96 \mathrm{E}+08$ & $0.00 \mathrm{E}+00$ & $0.00 \mathrm{E}+00$ & $1.40 \mathrm{E}+07$ & $0.00 \mathrm{E}+00$ & $2.57 \mathrm{E}+08$ \\
\hline$S A V-D$ & $0.00 \mathrm{E}+00$ & $0.00 \mathrm{E}+00$ & $1.17 E+08$ & $0.00 \mathrm{E}+00$ & $1.29 \mathrm{E}+09$ & $0.00 \mathrm{E}+00$ & $0.00 \mathrm{E}+00$ & $2.11 E+07$ & $0.00 \mathrm{E}+00$ & $8.14 E+08$ \\
\hline SAV-C & $0.00 \mathrm{E}+00$ & $0.00 \mathrm{E}+00$ & $2.48 \mathrm{E}+05$ & $0.00 \mathrm{E}+00$ & $2.69 \mathrm{E}+08$ & $0.00 \mathrm{E}+00$ & $0.00 \mathrm{E}+00$ & $8.11 \mathrm{E}+04$ & $0.00 \mathrm{E}+00$ & $5.81 E+07$ \\
\hline SEA-C & $0.00 \mathrm{E}+00$ & $0.00 \mathrm{E}+00$ & $1.24 \mathrm{E}+05$ & $0.00 \mathrm{E}+00$ & $1.23 E+07$ & $0.00 E+00$ & $0.00 \mathrm{E}+00$ & $8.08 E+03$ & $0.00 E+00$ & $6.52 \mathrm{E}+05$ \\
\hline TAC-D & $0.00 \mathrm{E}+00$ & $0.00 \mathrm{E}+00$ & $2.09 E+06$ & $0.00 \mathrm{E}+00$ & $1.06 \mathrm{E}+09$ & $0.00 \mathrm{E}+00$ & $0.00 \mathrm{E}+00$ & $3.82 \mathrm{E}+05$ & $0.00 \mathrm{E}+00$ & $2.88 E+08$ \\
\hline TAC-C & $0.00 \mathrm{E}+00$ & $0.00 \mathrm{E}+00$ & $1.49 \mathrm{E}+05$ & $0.00 \mathrm{E}+00$ & $3.97 \mathrm{E}+08$ & $0.00 \mathrm{E}+00$ & $0.00 \mathrm{E}+00$ & $2.02 \mathrm{E}+04$ & $0.00 \mathrm{E}+00$ & $4.31 E+07$ \\
\hline WIL-D & $0.00 \mathrm{E}+00$ & $0.00 \mathrm{E}+00$ & $1.20 \mathrm{E}+08$ & $0.00 \mathrm{E}+00$ & $5.94 \mathrm{E}+08$ & $0.00 \mathrm{E}+00$ & $0.00 \mathrm{E}+00$ & $2.14 \mathrm{E}+07$ & $0.00 \mathrm{E}+00$ & $2.18 \mathrm{E}+08$ \\
\hline WIL-C & $0.00 \mathrm{E}+00$ & $0.00 \mathrm{E}+00$ & $2.33 E+07$ & $0.00 \mathrm{E}+00$ & $1.05 E+08$ & $0.00 \mathrm{E}+00$ & $0.00 \mathrm{E}+00$ & $4.17 \mathrm{E}+06$ & $0.00 E+00$ & $5.73 E+07$ \\
\hline
\end{tabular}


Table 37. Peak Values of Population Dose, Cancer Fatalities, Costs, Centerline Individual Dose and Centerline Individual Risk for EIS Accident Categories (Continued)

\begin{tabular}{|c|c|c|c|c|c|c|c|c|c|c|}
\hline & & & OSIRIS & & & & & TRIGA & & \\
\hline Site/Loc & EIS4 & EIS5A & EIS5B & EIS6A & EIS6B & EIS4 & EIS5A & EIS5B & EIS6A & EIS6B \\
\hline CHA-D & $0.00 \mathrm{E}+00$ & $0.00 \mathrm{E}+00$ & $1.83 \mathrm{E}+07$ & $0.00 \mathrm{E}+00$ & $4.36 \mathrm{E}+08$ & $0.00 \mathrm{E}+00$ & $0.00 \mathrm{E}+00$ & $2.61 \mathrm{E}+04$ & $0.00 \mathrm{E}+00$ & $3.34 \mathrm{E}+08$ \\
\hline $\mathrm{CHA}-\mathrm{C}$ & $0.00 E+00$ & $0.00 E+00$ & $6.09 \mathrm{E}+07$ & $0.00 \mathrm{E}+00$ & $8.99 \mathrm{E}+08$ & $0.00 \mathrm{E}+00$ & $0.00 \mathrm{E}+00$ & $2.55 E+04$ & $0.00 \mathrm{E}+00$ & $8.26 \mathrm{E}+08$ \\
\hline CNC-D & $0.00 \mathrm{E}+00$ & $0.00 \mathrm{E}+00$ & $1.24 \mathrm{E}+07$ & $0.00 \mathrm{E}+00$ & $1.19 \mathrm{E}+08$ & $0.00 \mathrm{E}+00$ & $0.00 \mathrm{E}+00$ & $1.53 \mathrm{E}+04$ & $0.00 \mathrm{E}+00$ & $1.18 \mathrm{E}+08$ \\
\hline $\mathrm{CNC}-\mathrm{C}$ & $0.00 \mathrm{E}+00$ & $0.00 E+00$ & $3.67 \mathrm{E}+04$ & $0.00 \mathrm{E}+00$ & $2.94 \mathrm{E}+09$ & $0.00 \mathrm{E}+00$ & $0.00 \mathrm{E}+00$ & $0.00 \mathrm{E}+00$ & $0.00 \mathrm{E}+00$ & $1.09 E+09$ \\
\hline GAL-D & $0.00 \mathrm{E}+00$ & $0.00 \mathrm{E}+00$ & $9.05 \mathrm{E}+07$ & $0.00 E+00$ & $1.64 \mathrm{E}+09$ & $0.00 \mathrm{E}+00$ & $0.00 \mathrm{E}+00$ & $2.53 \mathrm{E}+04$ & $0.00 \mathrm{E}+00$ & $6.94 \mathrm{E}+08$ \\
\hline GAL-C & $0.00 \mathrm{E}+00$ & $0.00 \mathrm{E}+00$ & $3.37 \mathrm{E}+07$ & $0.00 \mathrm{E}+00$ & $1.32 \mathrm{E}+09$ & $0.00 \mathrm{E}+00$ & $0.00 \mathrm{E}+00$ & $2.27 \mathrm{E}+04$ & $0.00 \mathrm{E}+00$ & $6.07 \mathrm{E}+08$ \\
\hline JAC-D & $0.00 E+00$ & $0.00 \mathrm{E}+00$ & $5.36 \mathrm{E}+06$ & $0.00 \mathrm{E}+00$ & $4.12 \mathrm{E}+08$ & $0.00 \mathrm{E}+00$ & $0.00 \mathrm{E}+00$ & $5.45 \mathrm{E}+04$ & $0.00 \mathrm{E}+00$ & $2.70 E+08$ \\
\hline JAC-C & $0.00 E+00$ & $0.00 \mathrm{E}+00$ & $1.79 \mathrm{E}+07$ & $0.00 \mathrm{E}+00$ & $5.21 \mathrm{E}+08$ & $0.00 \mathrm{E}+00$ & $0.00 \mathrm{E}+00$ & $5.90 E+04$ & $0.00 \mathrm{E}+00$ & $4.95 E+08$ \\
\hline LOS-D & $0.00 \mathrm{E}+00$ & $0.00 \mathrm{E}+00$ & $3.74 \mathrm{E}+07$ & $0.00 \mathrm{E}+00$ & $1.82 \mathrm{E}+09$ & $0.00 \mathrm{E}+00$ & $0.00 \mathrm{E}+00$ & $1.53 \mathrm{E}+04$ & $0.00 \mathrm{E}+00$ & $8.08 E+08$ \\
\hline LOS-C & $0.00 E+00$ & $0.00 E+00$ & $3.52 \mathrm{E}+04$ & $0.00 E+00$ & $9.26 \mathrm{E}+08$ & $0.00 E+00$ & $0.00 \mathrm{E}+00$ & $3.06 \mathrm{E}+03$ & $0.00 \mathrm{E}+00$ & $3.50 \mathrm{E}+07$ \\
\hline MOT-D & $0.00 \mathrm{E}+00$ & $0.00 \mathrm{E}+00$ & $3.66 \mathrm{E}+05$ & $0.00 \mathrm{E}+00$ & $3.05 E+07$ & $0.00 \mathrm{E}+00$ & $0.00 \mathrm{E}+00$ & $1.47 \mathrm{E}+04$ & $0.00 \mathrm{E}+00$ & $2.90 \mathrm{E}+07$ \\
\hline NEW-D & $0.00 \mathrm{E}+00$ & $0.00 \mathrm{E}+00$ & $3.67 E+07$ & $0.00 \mathrm{E}+00$ & $1.57 \mathrm{E}+09$ & $0.00 \mathrm{E}+00$ & $0.00 \mathrm{E}+00$ & $1.31 E+04$ & $0.00 \mathrm{E}+00$ & $6.36 \mathrm{E}+08$ \\
\hline NEW-C & $0.00 \mathrm{E}+00$ & $0.00 \mathrm{E}+00$ & $1.15 \mathrm{E}+08$ & $0.00 E+00$ & $4.39 \mathrm{E}+09$ & $0,00 E+00$ & $0.00 \mathrm{E}+00$ & $5.64 \mathrm{E}+03$ & $0.00 \mathrm{E}+00$ & $2.39 E+09$ \\
\hline NOR-D & $0.00 \mathrm{E}+00$ & $0.00 \mathrm{E}+00$ & $7.85 E+07$ & $0.00 \mathrm{E}+00$ & $8.99 \mathrm{E}+08$ & $0.00 \mathrm{E}+00$ & $0.00 \mathrm{E}+00$ & $6.14 \mathrm{E}+03$ & $0.00 \mathrm{E}+00$ & $3.09 E+08$ \\
\hline NOR-C & $0.00 \mathrm{E}+00$ & $0.00 \mathrm{E}+00$ & $3.38 \mathrm{E}+07$ & $0.00 \mathrm{E}+00$ & $5.54 \mathrm{E}+08$ & $0.00 \mathrm{E}+00$ & $0.00 \mathrm{E}+00$ & $4.91 \mathrm{E}+03$ & $0.00 \mathrm{E}+00$ & $3.51 E+08$ \\
\hline PHI-D & $0.00 \mathrm{E}+00$ & $0.00 \mathrm{E}+00$ & $1.63 \mathrm{E}+08$ & $0.00 \mathrm{E}+00$ & $4.72 \mathrm{E}+09$ & $0.00 \mathrm{E}+00$ & $0.00 \mathrm{E}+00$ & $9.14 \mathrm{E}+03$ & $0.00 \mathrm{E}+00$ & $1.66 \mathrm{E}+09$ \\
\hline PHI-C & $0.00 \mathrm{E}+00$ & $0.00 \mathrm{E}+00$ & $7.34 \mathrm{E}+07$ & $0.00 \mathrm{E}+00$ & $1.31 E+09$ & $0.00 \mathrm{E}+00$ & $0.00 \mathrm{E}+00$ & $6.53 \mathrm{E}+03$ & $0.00 \mathrm{E}+00$ & $4.54 E+08$ \\
\hline POR-D & $0.00 E+00$ & $0.00 \mathrm{E}+00$ & $4.23 \mathrm{E}+07$ & $0.00 \mathrm{E}+00$ & $9.15 \mathrm{E}+08$ & $0.00 E+00$ & $0.00 \mathrm{E}+00$ & $3.22 \mathrm{E}+03$ & $0.00 \mathrm{E}+00$ & $4.38 E+08$ \\
\hline POR-C & $0.00 \mathrm{E}+00$ & $0.00 \mathrm{E}+00$ & $6.35 \mathrm{E}+07$ & $0.00 \mathrm{E}+00$ & $6.80 \mathrm{E}+08$ & $0.00 \mathrm{E}+00$ & $0.00 \mathrm{E}+00$ & $3.22 \mathrm{E}+03$ & $0.00 \mathrm{E}+00$ & $2.88 \mathrm{E}+08$ \\
\hline$S A V-D$ & $0.00 \mathrm{E}+00$ & $0.00 E+00$ & $1.05 E+08$ & $0.00 E+00$ & $1.11 E+09$ & $0.00 \mathrm{E}+00$ & $0.00 E+00$ & $4.33 E+04$ & $0.00 \mathrm{E}+00$ & $8.95 E+08$ \\
\hline SAV-C & $0.00 \mathrm{E}+00$ & $0.00 \mathrm{E}+00$ & $2.48 \mathrm{E}+05$ & $0.00 E+00$ & $1.35 \mathrm{E}+08$ & $0.00 \mathrm{E}+00$ & $0.00 \mathrm{E}+00$ & $3.95 E+04$ & $0.00 \mathrm{E}+00$ & $8.77 E+07$ \\
\hline SEA-C & $0.00 E+00$ & $0.00 \mathrm{E}+00$ & $8.08 \mathrm{E}+03$ & $0.00 \mathrm{E}+00$ & $1.19 \mathrm{E}+07$ & $0.00 \mathrm{E}+00$ & $0.00 \mathrm{E}+00$ & $0.00 \mathrm{E}+00$ & $0.00 \mathrm{E}+00$ & $6.52 \mathrm{E}+05$ \\
\hline TAC-D & $0.00 \mathrm{E}+00$ & $0.00 \mathrm{E}+00$ & $1.73 \mathrm{E}+06$ & $0.00 \mathrm{E}+00$ & $9.18 \mathrm{E}+08$ & $0.00 \mathrm{E}+00$ & $0.00 \mathrm{E}+00$ & $8.08 \mathrm{E}+03$ & $0.00 \mathrm{E}+00$ & $3.29 E+08$ \\
\hline TAC-C & $0.00 \mathrm{E}+00$ & $0.00 E+00$ & $2.02 \mathrm{E}+04$ & $0.00 E+00$ & $2.97 \mathrm{E}+08$ & $0.00 \mathrm{E}+00$ & $0.00 \mathrm{E}+00$ & $0.00 E+00$ & $0.00 \mathrm{E}+00$ & $4.31 E+07$ \\
\hline WIL-D & $0.00 \mathrm{E}+00$ & $0.00 \mathrm{E}+00$ & $1.11 E+08$ & $0.00 \mathrm{E}+00$ & $5.25 E+08$ & $0.00 \mathrm{E}+00$ & $0.00 \mathrm{E}+00$ & $1.47 \mathrm{E}+04$ & $0.00 \mathrm{E}+00$ & $2.70 \mathrm{E}+08$ \\
\hline WIL-C & $0.00 \mathrm{E}+00$ & $0.00 \mathrm{E}+00$ & $2.14 E+07$ & $0.00 \mathrm{E}+00$ & $9.97 E+07$ & $0.00 \mathrm{E}+00$ & $0.00 \mathrm{E}+00$ & $1.32 \mathrm{E}+04$ & $0.00 \mathrm{E}+00$ & $6.62 \mathrm{E}+07$ \\
\hline
\end{tabular}


Table 37. Peak Values of Population Dose, Cancer Fatalities, Costs, Centerline Individual Dose and Centerline Individual Risk for EIS Accident Categories (Continued)

\section{Individual Centerline EDE Whole Body Dose, 0-1.6 km (SV)}

\begin{tabular}{|c|c|c|c|c|c|c|c|c|c|c|}
\hline & & & BR-2 & & & & & RHF & & \\
\hline Site/Loc & EIS4 & EIS5A & EIS5B & EIS6A & EIS6B & EIS4 & EIS5A & EIS5B & EIS6A & EIS6B \\
\hline CHA-D & $3.62 \mathrm{E}-06$ & $1.53 \mathrm{E}-05$ & $2.30 \mathrm{E}-01$ & $2.36 E-05$ & $2.44 \mathrm{E}-01$ & $1.45 \mathrm{E}-06$ & $6.12 \mathrm{E}-06$ & $1.49 \mathrm{E}-01$ & $9.42 \mathrm{E}-06$ & $2.63 E-01$ \\
\hline $\mathrm{CHA}-\mathrm{C}$ & $3.62 \mathrm{E}-06$ & $1.53 \mathrm{E}-05$ & $2.30 \mathrm{E}-01$ & $2.36 \mathrm{E}-05$ & $2.44 \mathrm{E}-01$ & $1.45 \mathrm{E}-06$ & $6.12 \mathrm{E}-06$ & $1.49 \mathrm{E}-01$ & $9.42 \mathrm{E}-06$ & $2.63 E-01$ \\
\hline CNC-D & $3.62 \mathrm{E}-06$ & $6.58 \mathrm{E}-06$ & $1.33 \mathrm{E}-01$ & $3.01 \mathrm{E}-05$ & $2.37 E-01$ & $1.45 \mathrm{E}-06$ & $2.63 \mathrm{E}-06$ & $1.08 \mathrm{E}-01$ & $4.04 \mathrm{E}-06$ & $2.63 E-01$ \\
\hline CNC-C & $3.62 \mathrm{E}-06$ & $6.58 \mathrm{E}-06$ & $1.33 \mathrm{E}-01$ & $1.01 \mathrm{E}-05$ & $2.37 \mathrm{E}-01$ & $1.45 \mathrm{E}-06$ & $2.63 \mathrm{E}-06$ & $1.08 \mathrm{E}-01$ & $4.04 \mathrm{E}-06$ & $2.63 \mathrm{E}-01$ \\
\hline GAL-D & $3.62 \mathrm{E}-06$ & $1.39 \mathrm{E}-05$ & $2.18 \mathrm{E}-01$ & $2.14 \mathrm{E}-05$ & $2.48 \mathrm{E}-01$ & $.45 \mathrm{E}-06$ & $5.57 \mathrm{E}-06$ & $1.64 \mathrm{E}-01$ & 8.57 & $2.59 \mathrm{E}-01$ \\
\hline GAI-C & $3.62 \mathrm{E}-06$ & $1.39 E-05$ & $2.18 \mathrm{E}-01$ & $2.14 \mathrm{E}-05$ & $2.48 \mathrm{E}-01$ & $1.45 \mathrm{E}-06$ & $5.57 \mathrm{E}-06$ & $1.64 \mathrm{E}-01$ & $8.57 \mathrm{E}-06$ & $2.59 \mathrm{E}-0 \mathrm{I}$ \\
\hline JAC-D & $3.62 \mathrm{E}-06$ & $1.53 E-05$ & $2.30 \mathrm{E}-01$ & $2.36 \mathrm{E}-05$ & $2.44 \mathrm{E}-01$ & $1.45 \mathrm{E}-06$ & $6.12 \mathrm{E}-06$ & $1.49 \mathrm{E}-01$ & $9.42 \mathrm{E}-06$ & $2.63 \mathrm{E}-01$ \\
\hline JAC-C & $3.62 \mathrm{E}-06$ & $1.53 \mathrm{E}-05$ & $2.30 \mathrm{E}-01$ & $2.36 \mathrm{E}-05$ & $2.44 \mathrm{E}-01$ & $1.45 \mathrm{E}-06$ & $6.12 \mathrm{E}-06$ & $1.49 \mathrm{E}-01$ & $9.42 \mathrm{E}-06$ & $2.63 \mathrm{E}-01$ \\
\hline LOS-D & $3.62 \mathrm{E}-06$ & $6.58 \mathrm{E}-06$ & $1.33 \mathrm{E}-01$ & $1.01 \mathrm{E}-05$ & $2.37 \mathrm{E}-01$ & $E-06$ & $2.63 \mathrm{E}-06$ & $1.08 \mathrm{E}-01$ & 06 & E-01 \\
\hline LOS-C & $3.62 \mathrm{E}-06$ & $6.58 \mathrm{E}-06$ & $1.33 \mathrm{E}-01$ & $1.01 \mathrm{E}-05$ & $2.37 E-01$ & $.45 \mathrm{E}-06$ & $2.63 \mathrm{E}-06$ & $1.08 \mathrm{E}-01$ & 06 & $2-01$ \\
\hline MOT-D & $3.62 \mathrm{E}-06$ & $1,57 \mathrm{E}-05$ & $2.33 \mathrm{E}-01$ & $2.41 \mathrm{E}-05$ & $2.54 \mathrm{E}-01$ & $.45 \mathrm{E}-06$ & $6.26 \mathrm{E}-06$ & $1.26 \mathrm{E}-01$ & 06 & $E-01$ \\
\hline NEW-D & $3.62 \mathrm{E}-06$ & $1.08 \mathrm{E}-05$ & $1.87 \mathrm{E}-01$ & $1.66 \mathrm{E}-05$ & $2.46 \mathrm{E}-01$ & $45 E-06$ & 4.31 & $1.30 \mathrm{E}-01$ & 06 & E-01 \\
\hline NEW-C & $3.62 \mathrm{E}-06$ & $1.08 \mathrm{E}-05$ & $1.87 \mathrm{E}-01$ & $1.66 \mathrm{E}-05$ & $2.46 \mathrm{E}-01$ & $1.45 \mathrm{E}-06$ & $4.31 E-06$ & $1.30 \mathrm{E}-01$ & $6.64 \mathrm{E}-06$ & $2.61 \mathrm{E}-01$ \\
\hline NOR-D & $3.62 \mathrm{E}-06$ & $1.57 \mathrm{E}-05$ & $2.33 \mathrm{E}-01$ & $2.41 \mathrm{E}-05$ & $2.54 \mathrm{E}-01$ & $1.45 E-06$ & $6.26 \mathrm{E}-06$ & $1.26 \mathrm{E}-01$ & $9.63 \mathrm{E}-06$ & $2.63 \mathrm{E}-01$ \\
\hline NOR-C & $3.62 \mathrm{E}-06$ & $1.57 \mathrm{E}-05$ & $2.33 \mathrm{E}-01$ & $2.41 E-05$ & $2.54 \mathrm{E}-01$ & $1.45 \mathrm{E}-06$ & $6.26 \mathrm{E}-06$ & $1.26 \mathrm{E}-01$ & $9.63 E-06$ & $2.63 \mathrm{E}-01$ \\
\hline PHI-D & $3.62 \mathrm{E}-06$ & $1.59 \mathrm{E}-05$ & $2.35 \mathrm{E}-01$ & $2.44 \mathrm{E}-05$ & $2.46 \mathrm{E}-01$ & $.45 E-06$ & $3-06$ & 1.44 & -06 & $2.58 \mathrm{E}-01$ \\
\hline PHI-C & $3.62 \mathrm{E}-06$ & $1.59 \mathrm{E}-05$ & $2.35 \mathrm{E}-01$ & $2.44 \mathrm{E}-05$ & $2.46 \mathrm{E}-01$ & $.45 \mathrm{E}-06$ & $6.34 \mathrm{E}-06$ & $1.44 \mathrm{E}-01$ & $9.75 E-06$ & $2.58 \mathrm{E}-01$ \\
\hline POR-D & $3.62 \mathrm{E}-06$ & $1.48 \mathrm{E}-05$ & $2.25 \mathrm{E}-01$ & $2.27 E-05$ & $2.44 \mathrm{E}-01$ & $1.45 \mathrm{E}-06$ & $5.90 \mathrm{E}-06$ & $1.57 \mathrm{E}-01$ & $9.07 E-06$ & $2.63 \mathrm{E}-01$ \\
\hline POR-C & $3.62 \mathrm{E}-06$ & $1.48 \mathrm{E}-05$ & $2.25 \mathrm{E}-01$ & $2.27 E-05$ & $2.44 \mathrm{E}-01$ & $1.45 \mathrm{E}-06$ & $5.90 \mathrm{E}-06$ & $1.57 \mathrm{E}-01$ & $9.07 E-06$ & $2.63 \mathrm{E}-01$ \\
\hline SAV-D & $3.62 \mathrm{E}-06$ & $1.53 \mathrm{E}-05$ & $2.30 \mathrm{E}-01$ & $2.36 \mathrm{E}-05$ & $2.44 \mathrm{E}-01$ & $.45 E-06$ & $6.12 \mathrm{E}-06$ & $1.49 \mathrm{E}-01$ & $9.42 \mathrm{E}-06$ & $2.63 \mathrm{E}-01$ \\
\hline SAV-C & $3.62 \mathrm{E}-06$ & $1.53 \mathrm{E}-05$ & $2.30 \mathrm{E}-01$ & $2.36 \mathrm{E}-05$ & $2.44 \mathrm{E}-01$ & $1.45 \mathrm{E}-06$ & $6.12 \mathrm{E}-06$ & $1.49 \mathrm{E}-01$ & $9.42 \mathrm{E}-06$ & $2.63 \mathrm{E}-01$ \\
\hline SEA-C & $3.62 \mathrm{E}-06$ & $1.48 \mathrm{E}-05$ & $2.25 \mathrm{E}-01$ & $2.27 \mathrm{E}-05$ & $2.44 E-01$ & $1.45 \mathrm{E}-06$ & $5.90 \mathrm{E}-06$ & $1.57 \mathrm{E}-01$ & $9.07 \mathrm{E}-06$ & $2.63 \mathrm{E}-01$ \\
\hline TAC-D & $3.62 \mathrm{E}-06$ & $1.48 \mathrm{E}-05$ & $2.25 \mathrm{E}-01$ & $2.27 \mathrm{E}-05$ & $2.44 \mathrm{E}-01$ & $1.45 \mathrm{E}-06$ & $5.90 \mathrm{E}-06$ & $1.57 \mathrm{E}-01$ & $9.07 E-06$ & $2.63 \mathrm{E}-01$ \\
\hline TAC-C & $3.62 \mathrm{E}-06$ & $1.48 \mathrm{E}-05$ & $2.25 \mathrm{E}-01$ & $2.27 \mathrm{E}-05$ & $2.44 \mathrm{E}-01$ & $1.45 \mathrm{E}-06$ & $5.90 \mathrm{E}-06$ & $1.57 \mathrm{E}-01$ & $9.07 E-06$ & $2.63 E-01$ \\
\hline WIL-D & $3.62 \mathrm{E}-06$ & $1.57 \mathrm{E}-05$ & $2.33 \mathrm{E}-01$ & $2.41 \mathrm{E}-05$ & $2.54 \mathrm{E}-01$ & $1.45 \mathrm{E}-06$ & $6.26 \mathrm{E}-06$ & $1.26 \mathrm{E}-01$ & $9.63 E-06$ & $2.63 \mathrm{E}-01$ \\
\hline WIL-C & $3.62 \mathrm{E}-06$ & $1.57 \mathrm{E}-05$ & $2.33 \mathrm{E}-01$ & $2.41 E-05$ & $2.54 \mathrm{E}-01$ & $1.45 \mathrm{E}-06$ & $6.26 \mathrm{E}-06$ & $1.26 \mathrm{E}-01$ & $9.63 \mathrm{E}-06$ & $2.63 \mathrm{E}-01$ \\
\hline
\end{tabular}


Table 37. Peak Values of Population Dose, Cancer Fatalities, Costs, Centerline Individual Dose and Centerline Individual Risk for EIS Accident Categories (Continued)

Individual Centerline EDE Whole Body Dose, 0-1.6 km (SV)

\begin{tabular}{|c|c|c|c|c|c|c|c|c|c|c|}
\hline \multirow[b]{3}{*}{ Site/Loc } & \multicolumn{4}{|c|}{ Individual Centerline } & EDE Whole & \multicolumn{2}{|c|}{ Body Dose, $0-1.6$} & $\mathrm{~km}(\mathrm{sV})$ & \multirow{3}{*}{\multicolumn{2}{|c|}{ EIS6B }} \\
\hline & & & OSIRIS & & & & & TRIGA & & \\
\hline & EIS4 & EIS5A & EIS5B & EIS6A & EIS6B & EIS4 & EIS5A & EIS5B & & \\
\hline CHA $-D$ & $5.03 E-06$ & $1.92 \mathrm{E}-05$ & $2.64 \mathrm{E}-01$ & $2.96 \mathrm{E}-05$ & $2.74 \mathrm{E}-01$ & $4.06 \mathrm{E}-06$ & $9.06 \mathrm{E}-03$ & $1.05 \mathrm{E}-01$ & $1.45 \mathrm{E}-02$ & $2.69 \mathrm{E}-01$ \\
\hline $\mathrm{CHA}-\mathrm{C}$ & $5.03 E-06$ & $1.92 \mathrm{E}-05$ & $2.64 \mathrm{E}-01$ & $2.96 \mathrm{E}-05$ & $2.74 \mathrm{E}-01$ & $4.06 \mathrm{E}-06$ & $9.06 \mathrm{E}-03$ & $1.05 \mathrm{E}-01$ & $1.45 \mathrm{E}-02$ & $2.69 \mathrm{E}-03$ \\
\hline CNC-D & $5.03 E-06$ & $8.25 \mathrm{E}-06$ & $1.73 \mathrm{E}-01$ & $1.27 \mathrm{E}-05$ & $2.69 \mathrm{E}-01$ & $4.06 \mathrm{E}-06$ & $3.89 E-03$ & $4.52 \mathrm{E}-02$ & $6.22 \mathrm{E}-03$ & $2.63 \mathrm{E}-01$ \\
\hline CNC-C & $5.03 \mathrm{E}-06$ & $8.25 \mathrm{E}-06$ & $1.73 \mathrm{E}-01$ & $1.27 \mathrm{E}-05$ & $2.69 \mathrm{E}-01$ & $4.06 \mathrm{E}-06$ & $3.89 E-03$ & $4.52 \mathrm{E}-02$ & $6.22 E-03$ & $2.63 \mathrm{E}-01$ \\
\hline GAL-D & $5.03 E-06$ & $1.75 \mathrm{E}-05$ & $2.55 \mathrm{E}-01$ & $2.69 E-05$ & $2.75 \mathrm{E}-01$ & $4.06 \mathrm{E}-06$ & $8.26 \mathrm{E}-03$ & $9.60 \mathrm{E}-02$ & $1.32 \mathrm{E}-02$ & $2.65 \mathrm{E}-01$ \\
\hline GAL-C & $5.03 E-06$ & $1.75 \mathrm{E}-05$ & $2.55 \mathrm{E}-01$ & $2.69 \mathrm{E}-05$ & $2.75 \mathrm{E}-01$ & $4.06 \mathrm{E}-06$ & $8.26 \mathrm{E}-03$ & $9.60 \mathrm{E}-02$ & $1.32 \mathrm{E}-02$ & $2.65 E-01$ \\
\hline JAC-D & $5.03 E-06$ & $1.92 \mathrm{E}-05$ & $2.64 \mathrm{E}-01$ & $2.96 \mathrm{E}-05$ & $2.74 \mathrm{E}-01$ & $4.06 \mathrm{E}-06$ & $9.06 \mathrm{E}-03$ & $1.05 \mathrm{E}-01$ & $1.45 \mathrm{E}-02$ & $2.69 \mathrm{E}-01$ \\
\hline JAC-C & $5.03 E-06$ & $1.92 \mathrm{E}-05$ & $2.64 \mathrm{E}-01$ & $2.96 \mathrm{E}-05$ & $2.74 E-01$ & $4.06 \mathrm{E}-06$ & $9.06 \mathrm{E}-03$ & $1.05 \mathrm{E}-01$ & $1.45 \mathrm{E}-02$ & $2.69 \mathrm{E}-01$ \\
\hline LOS-D & $5.03 E-06$ & $8.25 \mathrm{E}-06$ & $1.73 \mathrm{E}-01$ & $1.27 \mathrm{E}-05$ & $2.69 \mathrm{E}-01$ & $4.06 \mathrm{E}-06$ & $3.89 \mathrm{E}-03$ & $4.52 \mathrm{E}-02$ & $6.22 \mathrm{E}-03$ & $2.63 \mathrm{E}-01$ \\
\hline LOS-C & $5.03 E-06$ & $8.25 \mathrm{E}-06$ & $1.73 \mathrm{E}-01$ & $1.27 \mathrm{E}-05$ & $2.69 \mathrm{E}-01$ & $4.06 \mathrm{E}-06$ & $3.89 \mathrm{E}-03$ & $4.52 \mathrm{E}-02$ & $6.22 \mathrm{E}-03$ & $2.63 \mathrm{E}-01$ \\
\hline MOT-D & $5.03 E-06$ & $1.97 \mathrm{E}-05$ & $2.66 \mathrm{E}-01$ & $3.03 \mathrm{E}-05$ & $2.74 \mathrm{E}-01$ & $4.06 \mathrm{E}-06$ & $9.22 \mathrm{E}-03$ & $1.07 E-01$ & $1.47 \mathrm{E}-02$ & $2.67 \mathrm{E}-01$ \\
\hline NEW-D & $5.03 E-06$ & $1.35 \mathrm{E}-05$ & $2.15 \mathrm{E}-01$ & $2.08 \mathrm{E}-05$ & $2.74 \mathrm{E}-01$ & $4.06 \mathrm{E}-06$ & $6.38 \mathrm{E}-03$ & $7.42 \mathrm{E}-02$ & $1.02 E-02$ & $2.67 \mathrm{E}-01$ \\
\hline NEW-C & $5.03 E-06$ & $1.35 \mathrm{E}-05$ & $2.15 E-01$ & $2.08 \mathrm{E}-05$ & $2.74 \mathrm{E}-01$ & $4.06 \mathrm{E}-06$ & $6.38 \mathrm{E}-03$ & $7.42 \mathrm{E}-02$ & 1. $02 E-02$ & $2.67 \mathrm{E}-01$ \\
\hline NOR-D & $5.03 E-06$ & $1.97 \mathrm{E}-05$ & $2.66 \mathrm{E}-01$ & $3.03 \mathrm{E}-05$ & $2.74 \mathrm{E}-01$ & $4.06 \mathrm{E}-06$ & $9.22 \mathrm{E}-03$ & $1.07 \mathrm{E}-01$ & $1.47 \mathrm{E}-02$ & $2.67 \mathrm{E}-01$ \\
\hline NOR-C & $5.03 E-06$ & $1.97 \mathrm{E}-05$ & $2.66 \mathrm{E}-01$ & $3.03 \mathrm{E}-05$ & $2.74 \mathrm{E}-01$ & $4.06 \mathrm{E}-06$ & $9.22 \mathrm{E}-03$ & $1.07 \mathrm{E}-01$ & $1.47 \mathrm{E}-02$ & $2.67 \mathrm{E}-01$ \\
\hline PHI -D & $5.03 \mathrm{E}-06$ & $1.99 \mathrm{E}-05$ & $2.68 \mathrm{E}-01$ & $3.06 \mathrm{E}-05$ & $2.74 \mathrm{E}-01$ & $4.06 \mathrm{E}-06$ & $9.38 \mathrm{E}-03$ & $1.09 \mathrm{E}-01$ & $1.50 \mathrm{E}-02$ & $2.64 \mathrm{E}-01$ \\
\hline PHI-C & $5.03 E-06$ & $1.99 \mathrm{E}-05$ & $2.68 \mathrm{E}-01$ & $3.06 \mathrm{E}-05$ & $2.74 \mathrm{E}-01$ & $4.06 \mathrm{E}-06$ & $9.38 \mathrm{E}-03$ & $1.09 \mathrm{E}-01$ & $1.50 \mathrm{E}-02$ & $2.64 \mathrm{E}-0 \mathrm{I}$ \\
\hline POR-D & $5.03 \mathrm{E}-06$ & $1.85 \mathrm{E}-05$ & $2.61 \mathrm{E}-01$ & $2.85 \mathrm{E}-05$ & $2.74 \mathrm{E}-01$ & $4.06 \mathrm{E}-06$ & $8.72 \mathrm{E}-03$ & $1.01 \mathrm{E}-01$ & $1.40 \mathrm{E}-02$ & $2.68 \mathrm{E}-01$ \\
\hline POR-C & $5.03 \mathrm{E}-06$ & $1.85 \mathrm{E}-05$ & $2.61 E-02$ & $2.85 \mathrm{E}-05$ & $2.74 E-01$ & $4.06 E-06$ & $8.72 \mathrm{E}-03$ & $1.01 E-01$ & $1.40 \mathrm{E}-02$ & $2.68 \mathrm{E}-01$ \\
\hline$S A V-D$ & $5.03 \mathrm{E}-06$ & $1.92 \mathrm{E}-05$ & $2.64 \mathrm{E}-01$ & $2.96 \mathrm{E}-05$ & $2.74 \mathrm{E}-01$ & $4.06 E-06$ & $9.06 \mathrm{E}-03$ & $1.05 \mathrm{E}-01$ & $1.45 E-02$ & $2.69 \mathrm{E}-01$ \\
\hline$S A V-C$ & $5.03 \mathrm{E}-06$ & $1.92 \mathrm{E}-05$ & $2.64 \mathrm{E}-01$ & $2.96 \mathrm{E}-05$ & $2.74 \mathrm{E}-01$ & $4.06 \mathrm{E}-06$ & $9.06 \mathrm{E}-03$ & $1.05 \mathrm{E}-01$ & $1.45 \mathrm{E}-02$ & $2.69 \mathrm{E}-01$ \\
\hline SEA-C & $5.03 \mathrm{E}-06$ & $1.85 \mathrm{E}-05$ & $2.61 \mathrm{E}-01$ & $2.85 \mathrm{E}-05$ & $2.74 \mathrm{E}-01$ & $4.06 \mathrm{E}-06$ & $8.72 \mathrm{E}-03$ & $1.01 \mathrm{E}-01$ & $1.40 \mathrm{E}-02$ & $2.68 \mathrm{E}-01$ \\
\hline TAC-D & $5.03 E-06$ & $1.85 \mathrm{E}-05$ & $2.61 E-01$ & $2.85 E-05$ & $2.74 \mathrm{E}-01$ & $4.06 E-06$ & $8.72 \mathrm{E}-03$ & $1.01 E-01$ & $1.40 \mathrm{E}-02$ & $2.68 \mathrm{E}-01$ \\
\hline TAC-C & $5.03 E-06$ & $1.85 \mathrm{E}-05$ & $2.61 \mathrm{E}-01$ & $2.85 \mathrm{E}-05$ & $2.74 E-01$ & $4.06 E-06$ & $8.72 E-03$ & $1.01 E-01$ & $1.40 E-02$ & $2.68 \mathrm{E}-01$ \\
\hline WIL-D & $5.03 \mathrm{E}-06$ & $1.97 \mathrm{E}-05$ & $2.66 \mathrm{E}-01$ & $3.03 \mathrm{E}-05$ & $2.74 \mathrm{E}-01$ & $4.06 \mathrm{E}-06$ & $9.22 \mathrm{E}-03$ & $1.07 \mathrm{E}-01$ & $1.47 \mathrm{E}-02$ & $2.67 \mathrm{E}-01$ \\
\hline WIL-C & $5.03 \mathrm{E}-06$ & $1.97 \mathrm{E}-05$ & $2.66 \mathrm{E}-01$ & $3.03 E-05$ & $2.74 \mathrm{E}-01$ & $4.06 \mathrm{E}-06$ & $9.22 \mathrm{E}-03$ & $1.07 \mathrm{E}-01$ & $1: 47 E-02$ & $2.67 \mathrm{E}-01$ \\
\hline
\end{tabular}


Table 37. Peak Values of Population Dose, Cancer Fatalities, Costs, Centerline Individual Dose and Centerline Individual Risk for EIS Accident Categories (Continued)

\section{Individual Centerline Cancer Risk, $0-1.6 \mathrm{~km}$}

\begin{tabular}{lccccc}
\hline & \multicolumn{5}{c}{ Individual Centerline Can } \\
& \multicolumn{5}{c}{ BR-2 } \\
Site/LOC & EIS4 & EIS5A & EIS5B & EIS6A & EIS6B \\
CHA-D & $1.78 \mathrm{E}-07$ & $6.45 \mathrm{E}-07$ & $9.57 \mathrm{E}-03$ & $9.93 \mathrm{E}-07$ & $1.02 \mathrm{E}-02$ \\
CHA-C & $1.78 \mathrm{E}-07$ & $6.45 \mathrm{E}-07$ & $9.57 \mathrm{E}-03$ & $9.93 \mathrm{E}-07$ & $1.02 \mathrm{E}-02$ \\
CNC-D & $1.78 \mathrm{E}-07$ & $2.77 \mathrm{E}-07$ & $5.56 \mathrm{E}-03$ & $4.26 \mathrm{E}-07$ & $9.85 \mathrm{E}-03$ \\
CNC-C & $1.78 \mathrm{E}-07$ & $2.77 \mathrm{E}-07$ & $5.56 \mathrm{E}-03$ & $4.26 \mathrm{E}-07$ & $9.85 \mathrm{E}-03$ \\
GAL-D & $1.78 \mathrm{E}-07$ & $5.86 \mathrm{E}-07$ & $9.06 \mathrm{E}-03$ & $9.02 \mathrm{E}-07$ & $1.03 \mathrm{E}-02$ \\
GAI-C & $1.78 \mathrm{E}-07$ & $5.86 \mathrm{E}-07$ & $9.06 \mathrm{E}-03$ & $9.02 \mathrm{E}-07$ & $1.03 \mathrm{E}-02$ \\
JAC-D & $1.78 \mathrm{E}-07$ & $6.45 \mathrm{E}-07$ & $9.57 \mathrm{E}-03$ & $9.93 \mathrm{E}-07$ & $1.02 \mathrm{E}-02$ \\
JAC-C & $1.78 \mathrm{E}-07$ & $6.45 \mathrm{E}-07$ & $9.57 \mathrm{E}-03$ & $9.93 \mathrm{E}-07$ & $1.02 \mathrm{E}-02$ \\
LOS-D & $1.78 \mathrm{E}-07$ & $2.77 \mathrm{E}-07$ & $5.56 \mathrm{E}-03$ & $4.26 \mathrm{E}-07$ & $9.85 \mathrm{E}-03$ \\
LOS-C & $1.78 \mathrm{E}-07$ & $2.77 \mathrm{E}-07$ & $5.56 \mathrm{E}-03$ & $4.26 \mathrm{E}-07$ & $9.85 \mathrm{E}-03$ \\
MOT-D & $1.78 \mathrm{E}-07$ & $6.61 \mathrm{E}-07$ & $9.68 \mathrm{E}-03$ & $1.02 \mathrm{E}-06$ & $1.06 \mathrm{E}-02$ \\
NEW-D & $1.78 \mathrm{E}-07$ & $4.55 \mathrm{E}-07$ & $7.79 \mathrm{E}-03$ & $7.00 \mathrm{E}-07$ & $1.02 \mathrm{E}-02$ \\
NEW-C & $1.78 \mathrm{E}-07$ & $4.55 \mathrm{E}-07$ & $7.79 \mathrm{E}-03$ & $7.00 \mathrm{E}-07$ & $1.02 \mathrm{E}-02$ \\
NOR-D & $1.78 \mathrm{E}-07$ & $6.61 \mathrm{E}-07$ & $9.68 \mathrm{E}-03$ & $1.02 \mathrm{E}-06$ & $1.06 \mathrm{E}-02$ \\
NOR-C & $1.78 \mathrm{E}-07$ & $6.61 \mathrm{E}-07$ & $9.68 \mathrm{E}-03$ & $1.02 \mathrm{E}-06$ & $1.06 \mathrm{E}-02$ \\
PHI-D & $1.78 \mathrm{E}-07$ & $6.68 \mathrm{E}-07$ & $9.77 \mathrm{E}-03$ & $1.03 \mathrm{E}-06$ & $1.02 \mathrm{E}-02$ \\
PHI-C & $1.78 \mathrm{E}-07$ & $6.68 \mathrm{E}-07$ & $9.77 \mathrm{E}-03$ & $1.03 \mathrm{E}-06$ & $1.02 \mathrm{E}-02$ \\
POR-D & $1.78 \mathrm{E}-07$ & $6.21 \mathrm{E}-07$ & $9.36 \mathrm{E}-03$ & $9.56 \mathrm{E}-07$ & $1.01 \mathrm{E}-02$ \\
POR-C & $1.78 \mathrm{E}-07$ & $6.21 \mathrm{E}-07$ & $9.36 \mathrm{E}-03$ & $9.56 \mathrm{E}-07$ & $1.01 \mathrm{E}-02$ \\
SAV-D & $1.78 \mathrm{E}-07$ & $6.45 \mathrm{E}-07$ & $9.57 \mathrm{E}-03$ & $9.93 \mathrm{E}-07$ & $1.02 \mathrm{E}-02$ \\
SAV-C & $1.78 \mathrm{E}-07$ & $6.45 \mathrm{E}-07$ & $9.57 \mathrm{E}-03$ & $9.93 \mathrm{E}-07$ & $1.02 \mathrm{E}-02$ \\
SEA-C & $1.78 \mathrm{E}-07$ & $6.21 \mathrm{E}-07$ & $9.36 \mathrm{E}-03$ & $9.56 \mathrm{E}-07$ & $1.01 \mathrm{E}-02$ \\
TAC-D & $1.78 \mathrm{E}-07$ & $6.21 \mathrm{E}-07$ & $9.36 \mathrm{E}-03$ & $9.56 \mathrm{E}-07$ & $1.01 \mathrm{E}-02$ \\
TAC-C & $1.78 \mathrm{E}-07$ & $6.21 \mathrm{E}-07$ & $9.36 \mathrm{E}-03$ & $9.56 \mathrm{E}-07$ & $1.01 \mathrm{E}-02$ \\
WIL-D & $1.78 \mathrm{E}-07$ & $6.61 \mathrm{E}-07$ & $9.68 \mathrm{E}-03$ & $1.02 \mathrm{E}-06$ & $1.06 \mathrm{E}-02$ \\
WIL-C & $1.78 \mathrm{E}-07$ & $6.61 \mathrm{E}-07$ & $9.68 \mathrm{E}-03$ & $1.02 \mathrm{E}-06$ & $1.06 \mathrm{E}-02$
\end{tabular}

$\begin{array}{ccccc}\text { EIS4 } & \text { EIS5A } & \text { EIS } \\ 7.24 \mathrm{E}-08 & 2.59 \mathrm{E}-07 & 6.22 \mathrm{E}-03 & 3.99 \mathrm{E}-07 & 1.09 \mathrm{E}-02 \\ 7.24 \mathrm{E}-08 & 2.59 \mathrm{E}-07 & 6.22 \mathrm{E}-03 & 3.99 \mathrm{E}-07 & 1.09 \mathrm{E}-02 \\ 7.24 \mathrm{E}-08 & 1.11 \mathrm{E}-07 & 4.51 \mathrm{E}-03 & 1.71 \mathrm{E}-07 & 1.09 \mathrm{E}-02 \\ 7.24 \mathrm{E}-08 & 1.11 \mathrm{E}-07 & 4.51 \mathrm{E}-03 & 1.71 \mathrm{E}-07 & 1.09 \mathrm{E}-02 \\ 7.24 \mathrm{E}-08 & 2.35 \mathrm{E}-07 & 6.84 \mathrm{E}-03 & 3.62 \mathrm{E}-07 & 1.08 \mathrm{E}-02 \\ 7.24 \mathrm{E}-08 & 2.35 \mathrm{E}-07 & 6.84 \mathrm{E}-03 & 3.62 \mathrm{E}-07 & 1.08 \mathrm{E}-02 \\ 7.24 \mathrm{E}-08 & 2.59 \mathrm{E}-07 & 6.22 \mathrm{E}-03 & 3.99 \mathrm{E}-07 & 1.09 \mathrm{E}-02 \\ 7.24 \mathrm{E}-08 & 2.59 \mathrm{E}-07 & 6.22 \mathrm{E}-03 & 3.99 \mathrm{E}-07 & 1.09 \mathrm{E}-02 \\ 7.24 \mathrm{E}-08 & 1.11 \mathrm{E}-07 & 4.51 \mathrm{E}-03 & 1.71 \mathrm{E}-07 & 1.09 \mathrm{E}-02 \\ 7.24 \mathrm{E}-08 & 1.11 \mathrm{E}-07 & 4.51 \mathrm{E}-03 & 1.71 \mathrm{E}-07 & 1.09 \mathrm{E}-02 \\ 7.24 \mathrm{E}-08 & 2.66 \mathrm{E}-07 & 5.25 \mathrm{E}-03 & 4.09 \mathrm{E}-07 & 1.09 \mathrm{E}-02 \\ 7.24 \mathrm{E}-08 & 1.83 \mathrm{E}-07 & 5.41 \mathrm{E}-03 & 2.82 \mathrm{E}-07 & 1.09 \mathrm{E}-02 \\ 7.24 \mathrm{E}-08 & 1.83 \mathrm{E}-07 & 5.41 \mathrm{E}-03 & 2.81 \mathrm{E}-07 & 1.09 \mathrm{E}-02 \\ 7.24 \mathrm{E}-08 & 2.66 \mathrm{E}-07 & 5.25 \mathrm{E}-03 & 4.09 \mathrm{E}-07 & 1.09 \mathrm{E}-02 \\ 7.24 \mathrm{E}-08 & 2.66 \mathrm{E}-07 & 5.25 \mathrm{E}-03 & 4.09 \mathrm{E}-07 & 1.09 \mathrm{E}-02 \\ 7.24 \mathrm{E}-08 & 2.68 \mathrm{E}-07 & 6.02 \mathrm{E}-03 & 4.13 \mathrm{E}-07 & 1.07 \mathrm{E}-02 \\ 7.24 \mathrm{E}-08 & 2.68 \mathrm{E}-07 & 6.02 \mathrm{E}-03 & 4.13 \mathrm{E}-07 & 1.07 \mathrm{E}-02 \\ 7.24 \mathrm{E}-08 & 2.50 \mathrm{E}-07 & 6.55 \mathrm{E}-03 & 3.84 \mathrm{E}-07 & 1.09 \mathrm{E}-02 \\ 7.24 \mathrm{E}-08 & 2.50 \mathrm{E}-07 & 6.55 \mathrm{E}-03 & 3.84 \mathrm{E}-07 & 1.09 \mathrm{E}-02 \\ 7.24 \mathrm{E}-08 & 2.59 \mathrm{E}-07 & 6.22 \mathrm{E}-03 & 3.99 \mathrm{E}-07 & 1.09 \mathrm{E}-02 \\ 7.24 \mathrm{E}-08 & 2.59 \mathrm{E}-07 & 6.22 \mathrm{E}-03 & 3.99 \mathrm{E}-07 & 1.09 \mathrm{E}-02 \\ 7.24 \mathrm{E}-08 & 2.50 \mathrm{E}-07 & 6.55 \mathrm{E}-03 & 3.84 \mathrm{E}-07 & 1.09 \mathrm{E}-02 \\ 7.24 \mathrm{E}-08 & 2.50 \mathrm{E}-07 & 6.55 \mathrm{E}-03 & 3.84 \mathrm{E}-07 & 1.09 \mathrm{E}-02 \\ 7.24 \mathrm{E}-08 & 2.50 \mathrm{E}-07 & 6.55 \mathrm{E}-03 & 3.84 \mathrm{E}-07 & 1.09 \mathrm{E}-02 \\ 7.24 \mathrm{E}-08 & 2.66 \mathrm{E}-07 & 5.25 \mathrm{E}-03 & 4.09 \mathrm{E}-07 & 1.09 \mathrm{E}-02 \\ 7.24 \mathrm{E}-08 & 2.66 \mathrm{E}-07 & 5.25 \mathrm{E}-03 & 4.09 \mathrm{E}-07 & 1.09 \mathrm{E}-02\end{array}$


Table 37. Peak Values of Population Dose, Cancer Fatalities, Costs, Centerline Individual Dose and Centerline Individual Risk for EIS Accident Categories (Concluded)

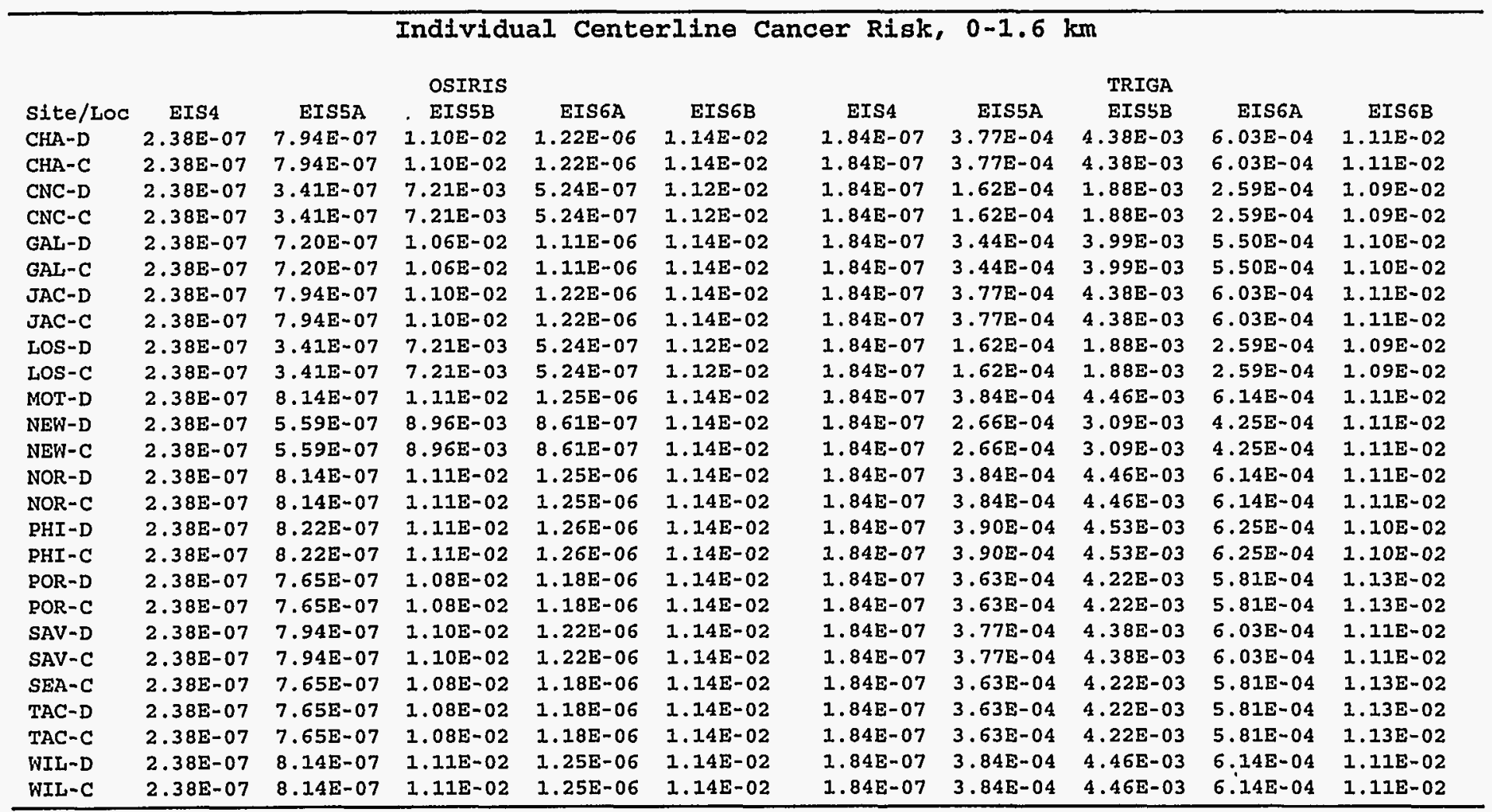


Table 38. Conditional Probability of Peak Values of Population Dose, Cancer Fatalities, Costs, Centerline Individual Dose and Centerline Individual Risk for EIS Accident Categories

EDE Whole Body Population Dose, 0-80 km (SV)

\begin{tabular}{lccccc} 
& \multicolumn{5}{c}{ BR-2 } \\
Site/LOC & EIS4 & EIS5A & EIS5B & EIS6A & EIS6B \\
CHA-D & $1.01 \mathrm{E}-05$ & $1.01 \mathrm{E}-05$ & $1.01 \mathrm{E}-05$ & $1.01 \mathrm{E}-05$ & $8.88 \mathrm{E}-06$ \\
CHA-C & $7.77 \mathrm{E}-06$ & $4.44 \mathrm{E}-06$ & $6.44 \mathrm{E}-05$ & $4.44 \mathrm{E}-06$ & $4.44 \mathrm{E}-06$ \\
CNC-D & $8.47 \mathrm{E}-04$ & $5.08 \mathrm{E}-04$ & $1.18 \mathrm{E}-05$ & $5.08 \mathrm{E}-04$ & $1.18 \mathrm{E}-05$ \\
CNC-C & $7.58 \mathrm{E}-06$ & $7.58 \mathrm{E}-06$ & $7.58 \mathrm{E}-06$ & $7.58 \mathrm{E}-06$ & $4.33 \mathrm{E}-06$ \\
GAL-D & $7.80 \mathrm{E}-06$ & $7.80 \mathrm{E}-06$ & $9.75 \mathrm{E}-06$ & $7.80 \mathrm{E}-06$ & $3.40 \mathrm{E}-03$ \\
GAL-C & $7.80 \mathrm{E}-06$ & $9.75 \mathrm{E}-06$ & $9.75 \mathrm{E}-06$ & $9.75 \mathrm{E}-06$ & $3.40 \mathrm{E}-03$ \\
JAC-D & $6.03 \mathrm{E}-06$ & $6.03 \mathrm{E}-06$ & $6.03 \mathrm{E}-06$ & $6.03 \mathrm{E}-06$ & $1.46 \mathrm{E}-05$ \\
JAC-C & $6.08 \mathrm{E}-06$ & $8.06 \mathrm{E}-06$ & $4.37 \mathrm{E}-05$ & $8.06 \mathrm{E}-06$ & $4.37 \mathrm{E}-05$ \\
LOS-D & $1.83 \mathrm{E}-03$ & $3.42 \mathrm{E}-06$ & $3.42 \mathrm{E}-06$ & $3.42 \mathrm{E}-06$ & $4.83 \mathrm{E}-06$ \\
LOS-C & $4.91 \mathrm{E}-06$ & $2.81 \mathrm{E}-06$ & $2.81 \mathrm{E}-06$ & $2.81 \mathrm{E}-06$ & $4.83 \mathrm{E}-06$ \\
MOT-D & $1.67 \mathrm{E}-05$ & $2.76 \mathrm{E}-05$ & $2.76 \mathrm{E}-05$ & $2.76 \mathrm{E}-05$ & $2.76 \mathrm{E}-05$ \\
NEW-D & $2.03 \mathrm{E}-05$ & $2.03 \mathrm{E}-05$ & $2.03 \mathrm{E}-05$ & $2.03 \mathrm{E}-05$ & $2.03 \mathrm{E}-05$ \\
NEW-C & $2.50 \mathrm{E}-04$ & $7.65 \mathrm{E}-05$ & $1.16 \mathrm{E}-05$ & $7.65 \mathrm{E}-05$ & $1.45 \mathrm{E}-05$ \\
NOR-D & $3.51 \mathrm{E}-04$ & $9.62 \mathrm{E}-06$ & $9.62 \mathrm{E}-06$ & $9.62 \mathrm{E}-06$ & $9.62 \mathrm{E}-06$ \\
NOR-C & $1.07 \mathrm{E}-05$ & $1.61 \mathrm{E}-05$ & $1.61 \mathrm{E}-05$ & $1.61 \mathrm{E}-05$ & $4.88 \mathrm{E}-06$ \\
PHI-D & $3.17 \mathrm{E}-06$ & $3.17 \mathrm{E}-06$ & $3.17 \mathrm{E}-06$ & $3.17 \mathrm{E}-06$ & $7.78 \mathrm{E}-06$ \\
PHI-C & $2.44 \mathrm{E}-05$ & $2.44 \mathrm{E}-05$ & $2.44 \mathrm{E}-05$ & $2.44 \mathrm{E}-05$ & $2.44 \mathrm{E}-05$ \\
POR-D & $1.26 \mathrm{E}-05$ & $1.09 \mathrm{E}-05$ & $1.09 \mathrm{E}-05$ & $1.09 \mathrm{E}-05$ & $1.09 \mathrm{E}-05$ \\
POR-C & $3.19 \mathrm{E}-04$ & $1.09 \mathrm{E}-05$ & $1.09 \mathrm{E}-05$ & $1.09 \mathrm{E}-05$ & $1.09 \mathrm{E}-05$ \\
SAV-D & $1.13 \mathrm{E}-05$ & $6.22 \mathrm{E}-06$ & $6.64 \mathrm{E}-06$ & $6.22 \mathrm{E}-06$ & $6.22 \mathrm{E}-06$ \\
SAV-C & $1.30 \mathrm{E}-05$ & $1.14 \mathrm{E}-05$ & $1.14 \mathrm{E}-05$ & $1.14 \mathrm{E}-05$ & $1.14 \mathrm{E}-05$ \\
SEA-C & $1.36 \mathrm{E}-04$ & $6.79 \mathrm{E}-04$ & $6.79 \mathrm{E}-04$ & $6.79 \mathrm{E}-04$ & $6.79 \mathrm{E}-04$ \\
TAC-D & $5.33 \mathrm{E}-06$ & $1.14 \mathrm{E}-05$ & $1.14 \mathrm{E}-05$ & $1.14 \mathrm{E}-05$ & $2.98 \mathrm{E}-05$ \\
TAC-C & $1.08 \mathrm{E}-05$ & $1.08 \mathrm{E}-05$ & $1.08 \mathrm{E}-05$ & $1.08 \mathrm{E}-05$ & $1.08 \mathrm{E}-05$ \\
WIL-D & $3.26 \mathrm{E}-04$ & $1.16 \mathrm{E}-04$ & $1.16 \mathrm{E}-04$ & $1.16 \mathrm{E}-04$ & $9.93 \mathrm{E}-05$ \\
WIL-C & $3.04 \mathrm{E}-04$ & $1.08 \mathrm{E}-04$ & $2.98 \mathrm{E}-05$ & $1.08 \mathrm{E}-04$ & $4.59 \mathrm{E}-05$
\end{tabular}

\begin{tabular}{|c|c|c|c|c|}
\hline & ELSSSA & $\begin{array}{l}\text { RHF } \\
\text { EIS5B }\end{array}$ & ELSE & \\
\hline E-05 & $1 E-05$ & $1 \mathrm{E}-05$ & $1 \mathrm{E}$ & $01 E$ \\
\hline $7 E-06$ & 6 & 06 & 6 & $8 E$ \\
\hline$E-04$ & 4 & $8 E-05$ & $08 E-04$ & $8-$ \\
\hline 06 & & $58 \mathrm{E}-06$ & 06 & 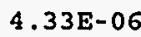 \\
\hline 06 & -06 & $80 E-06$ & 06 & E-03 \\
\hline-06 & 6 & $75 E-06$ & 06 & E-03 \\
\hline 6 & & 16 & & -05 \\
\hline .081 & & .06 & & \\
\hline .8 & 6 & $.42 \mathrm{E}-\mathrm{C}$ & & \\
\hline-0 & 5 & $1 E-06$ & 36 & $2-06$ \\
\hline & & $.76 E-05$ & 05 & $.76 \mathrm{E}-05$ \\
\hline 5 & & $3 \mathrm{E}$ & & -05 \\
\hline 4 & & 5 & & 05 \\
\hline & & 06 & & \\
\hline & & 05 & & \\
\hline .1 & 6 & $7 E-06$ & & \\
\hline .4 & & $4 \mathrm{E}-05$ & 05 & $2.44 \mathrm{E}-05$ \\
\hline 1.2 & 5 & 5 & 05 & $1.09 \mathrm{E}-05$ \\
\hline & & $\mathrm{E}$ & 05 & E-05 \\
\hline & & 16 & 06 & $.24 \mathrm{E}-05$ \\
\hline & & & & .05 \\
\hline & & & & \\
\hline .3 & & $4 E-$ & & \\
\hline 0 & & $.08 \mathrm{E}$ & & \\
\hline & & 4 & & \\
\hline & 4 & 3E-05 & $1.08 \mathrm{E}-04$ & $2.68 \mathrm{E}-04$ \\
\hline
\end{tabular}


Table 38. Conditional Probability of Peak Values of Population Dose, Cancer Fatalities, Costs, Centerline Individual Dose and Centerline Individual Risk for EIS Accident Categories (Continued)

\section{EDE Whole Body Population Dose, 0-80 km (SV)}

\begin{tabular}{|c|c|c|c|c|c|c|c|c|c|c|}
\hline & & & OSI & & & & & TRIGA & & \\
\hline Site/Loc & EIS4 & EIS5A & EIS5B & EIS6A & EIS6B & EIS4 & FTS5A & & IIS6A & EIS6B \\
\hline CHA-D & $1.01 \mathrm{E}-05$ & $.01 E-05$ & $1.01 E-05$ & $1.01 E-05$ & $.88 \mathrm{E}-06$ & $1.01 \mathrm{E}-05$ & $1.01 E-05$ & $1.01 E-05$ & $.01 E-05$ & $.01 \mathrm{E}-05$ \\
\hline $\mathrm{CHA}-\mathrm{C}$ & $7.77 \mathrm{E}$ & $.44 \mathrm{E}-06$ & $4.44 \mathrm{E}-06$ & $4.44 \mathrm{E}-06$ & $4.44 \mathrm{E}-06$ & $.77 \mathrm{E}-06$ & $4.44 \mathrm{E}-06$ & $4.44 \mathrm{E}-06$ & -06 & 06 \\
\hline CNC-D & $8.47 \mathrm{E}-04$ & $.08 \mathrm{E}-04$ & $2.18 \mathrm{E}-05$ & $5.08 E-04$ & $1.18 \mathrm{E}-05$ & $47 \mathrm{E}-04$ & $1.18 \mathrm{E}-05$ & $1.18 \mathrm{E}-05$ & 05 & -05 \\
\hline $\mathrm{CNC}-\mathrm{C}$ & $7.58 \mathrm{E}-0.6$ & $.58 \mathrm{E}-06$ & $7.58 \mathrm{E}-06$ & $7.58 \mathrm{E}-06$ & $4.33 \mathrm{E}-06$ & $58 \mathrm{E}-06$ & $7.58 \mathrm{E}-06$ & 7.58 & & 06 \\
\hline GAL-D & $7.80 \mathrm{E}-06$ & $.80 \mathrm{E}-06$ & $9.75 \mathrm{E}-06$ & $7.80 \mathrm{E}-06$ & $3.40 \mathrm{E}-03$ & $7.80 \mathrm{E}-06$ & $7.80 \mathrm{E}-06$ & .06 & .06 & -03 \\
\hline GAI-C & $7.80 \mathrm{E}$ & 9.7 & $9.75 \mathrm{E}$ & $9.75 \mathrm{E}-06$ & $3.40 \mathrm{E}-03$ & E-06 & $9.75 E-06$ & $9.75 E-06$ & 06 & -03 \\
\hline JAC-D & 6.03 & $6.03 E-06$ & $6.03 \mathrm{E}-06$ & $6.03 E-06$ & & E-06 & $6.03 \mathrm{E}-06$ & & & \\
\hline JAC & 6.0 & -06 & $8.06 E-06$ & $8.06 \mathrm{E}-06$ & & 06 & $8.06 \mathrm{E}-06$ & 06 & & \\
\hline LOS-D & 1.8 & .06 & 3.42 & 3.4 & .8 r & 03 & $3.42 \mathrm{E}-06$ & 06 & & .05 \\
\hline LOS-C & $4.91 E-06$ & $.81 E-06$ & 2.811 & $2.81 E-06$ & 1.9 & 06 & $2.81 E-06$ & 06 & 06 & -06 \\
\hline MOT-D & -05 & -05 & .76 & 2.7 & & & $2.76 E-05$ & & & -05 \\
\hline NEW-D & 05 & 2.03 & $2.03 \mathrm{E}-05$ & $2.03 E-05$ & $2.03 \mathrm{E}-05$ & -05 & $2.03 E-05$ & 2.03E-05 & 05 & 2.03 \\
\hline NEW-C & 2.50 & -05 & $1.16 \mathrm{E}-05$ & 7.6 & 05 & 04 & $7.65 E-05$ & 7.6 & 05 & 1.45 \\
\hline NOR-D & 4 & 9. & 9.62 & & & & $9.62 \mathrm{E}-06$ & & & .06 \\
\hline NOR-C & 1.0 & & 1.61 & & & & $1.61 E-05$ & & & 05 \\
\hline PHI-D & 6 & 06 & 3.17 & 3.1 & 16 & 06 & $3.17 \mathrm{E}-06$ & 06 & & 06 \\
\hline PHI-C & 2.44 & $2.44 \mathrm{E}-05$ & $2.44 \mathrm{E}-05$ & $2.44 \mathrm{E}-05$ & 2.44 & .05 & $2.44 E-05$ & 05 & 05 & -05 \\
\hline POR-D & $1.26 \mathrm{E}-05$ & $1.09 \mathrm{E}-05$ & $1.09 \mathrm{E}-05$ & $1.09 E-05$ & $1.09 \mathrm{E}-05$ & $.26 \mathrm{E}-05$ & $1.09 \mathrm{E}-05$ & .05 & 05 & -05 \\
\hline POR-C & $3.19 \mathrm{E}-04$ & $1.09 \mathrm{E}-05$ & $1.09 \mathrm{E}-05$ & $1.09 E-05$ & $1.09 \mathrm{E}-05$ & 19Ę-04 & $1.09 \mathrm{E}-05$ & $1.09 \mathrm{E}-05$ & $1.09 \mathrm{E}-05$ & $1.09 \mathrm{E}-05$ \\
\hline SAV-D & $1.13 E-05$ & $6.22 E-06$ & $6.64 \mathrm{E}-06$ & $6.22 \mathrm{E}-06$ & $6.22 \mathrm{E}-06$ & $.13 \mathrm{E}-05$ & $6.22 \mathrm{E}-06$ & $6.22 \mathrm{E}-06$ & $6.22 E-06$ & $1.24 \mathrm{E}-05$ \\
\hline SAV-C & $1.30 \mathrm{E}-05$ & $1.14 \mathrm{E}-05$ & $1.14 \mathrm{E}-05$ & $1.14 \mathrm{E}-05$ & $1.14 \mathrm{E}-05$ & 30E-05 & $1.14 E-05$ & 1.14 & $1.14 \mathrm{E}-05$ & $1.14 \mathrm{E}-05$ \\
\hline SEA-C & $1.97 \mathrm{E}-04$ & -04 & 9.80 & & & & $9.80 \mathrm{E}-04$ & 04 & 04 & -04 \\
\hline TAC-D & & $1.14 \mathrm{E}-05$ & $1.14 E-05$ & $1.14 \mathrm{E}-05$ & & -06 & $1.14 \mathrm{E}-05$ & -05 & $1.14 \mathrm{E}-05$ & $1.08 \mathrm{E}-05$ \\
\hline TAC-C & & $1.08 \mathrm{E}-05$ & $1.08 \mathrm{E}-05$ & & & -05 & $1.08 \mathrm{E}-05$ & & $1.08 \mathrm{E}-05$ & $1.08 \mathrm{E}-05$ \\
\hline WIL-D & $\begin{array}{l}04 \\
04\end{array}$ & & 04 & & & 26E-04 & $.16 \mathrm{E}-04$ & 04 & $.16 \mathrm{E}-04$ & $9.93 E-05$ \\
\hline WIL & $04 E-04$ & 04 & 04 & $1.08 \mathrm{E}-04$ & $2.68 \mathrm{E}-04$ & $.04 \mathrm{E}-04$ & $.08 \mathrm{E}$ & $.08 \mathrm{E}-04$ & $1.08 \mathrm{E}-04$ & $68 \mathrm{E}-$ \\
\hline
\end{tabular}


Table 38. Conditional Probability of Peak Values of Population Dose, Cancer Fatalities, Costs, Centerline Individual Dose and Centerline Individual Risk for EIS Accident Categories (Continued)

\section{Total Cancer Fatalities, $0-80 \mathrm{~km}$}

\begin{tabular}{lcccccc}
\hline & & \multicolumn{5}{c}{ Total Cancer Fatal } \\
& \multicolumn{5}{c}{ BR-2 } \\
Site/LOC & EIS4 & EIS5A & EIS5B & EIS6A & EIS6B \\
CHA-D & $1.01 E-05$ & $1.01 E-05$ & $1.01 \mathrm{E}-05$ & $1.01 \mathrm{E}-05$ & $8.88 \mathrm{E}-06$ \\
CHA-C & $7.77 \mathrm{E}-06$ & $4.44 \mathrm{E}-06$ & $6.44 \mathrm{E}-05$ & $4.44 \mathrm{E}-06$ & $4.44 \mathrm{E}-06$ \\
CNC-D & $8.47 \mathrm{E}-04$ & $5.08 \mathrm{E}-04$ & $5.08 \mathrm{E}-04$ & $5.08 \mathrm{E}-04$ & $1.18 \mathrm{E}-05$ \\
CNC-C & $7.58 \mathrm{E}-06$ & $7.58 \mathrm{E}-06$ & $7.58 \mathrm{E}-06$ & $7.58 \mathrm{E}-06$ & $4.33 \mathrm{E}-06$ \\
GAL-D & $7.80 \mathrm{E}-06$ & $7.80 \mathrm{E}-06$ & $9.75 \mathrm{E}-06$ & $7.80 \mathrm{E}-06$ & $3.40 \mathrm{E}-03$ \\
GAL-C & $7.80 \mathrm{E}-06$ & $9.75 \mathrm{E}-06$ & $9.75 \mathrm{E}-06$ & $9.75 \mathrm{E}-06$ & $3.40 \mathrm{E}-03$ \\
JAC-D & $6.03 \mathrm{E}-06$ & $6.03 \mathrm{E}-06$ & $6.03 \mathrm{E}-06$ & $6.03 \mathrm{E}-06$ & $1.27 \mathrm{E}-05$ \\
JAC-C & $6.08 \mathrm{E}-06$ & $8.06 \mathrm{E}-06$ & $4.37 \mathrm{E}-05$ & $8.06 \mathrm{E}-06$ & $4.37 \mathrm{E}-05$ \\
LOS-D & $1.83 \mathrm{E}-03$ & $3.42 \mathrm{E}-06$ & $3.42 \mathrm{E}-06$ & $3.42 \mathrm{E}-06$ & $4.83 \mathrm{E}-06$ \\
LOS-C & $4.91 \mathrm{E}-06$ & $2.81 \mathrm{E}-06$ & $2.81 \mathrm{E}-06$ & $2.81 \mathrm{E}-06$ & $4.83 \mathrm{E}-06$ \\
MOT-D & $1.67 \mathrm{E}-05$ & $2.76 \mathrm{E}-05$ & $2.76 \mathrm{E}-05$ & $2.76 \mathrm{E}-05$ & $2.76 \mathrm{E}-05$ \\
NEW-D & $2.03 \mathrm{E}-05$ & $2.03 \mathrm{E}-05$ & $2.03 \mathrm{E}-05$ & $2.03 \mathrm{E}-05$ & $2.03 \mathrm{E}-05$ \\
NEW-C & $2.50 \mathrm{E}-04$ & $7.65 \mathrm{E}-05$ & $1.16 \mathrm{E}-05$ & $7.65 \mathrm{E}-05$ & $1.45 \mathrm{E}-05$ \\
NOR-D & $3.51 \mathrm{E}-04$ & $9.62 \mathrm{E}-06$ & $9.62 \mathrm{E}-06$ & $9.62 \mathrm{E}-06$ & $9.62 \mathrm{E}-06$ \\
NOR-C & $1.07 \mathrm{E}-05$ & $1.61 \mathrm{E}-05$ & $1.61 \mathrm{E}-05$ & $1.61 \mathrm{E}-05$ & $4.88 \mathrm{E}-06$ \\
PHI-D & $3.17 \mathrm{E}-06$ & $3.17 \mathrm{E}-06$ & $3.17 \mathrm{E}-06$ & $3.17 \mathrm{E}-06$ & $7.78 \mathrm{E}-06$ \\
PHI-C & $2.44 \mathrm{E}-05$ & $2.44 \mathrm{E}-05$ & $2.44 \mathrm{E}-05$ & $2.44 \mathrm{E}-05$ & $2.44 \mathrm{E}-05$ \\
POR-D & $2.98 \mathrm{E}-04$ & $1.09 \mathrm{E}-05$ & $1.09 \mathrm{E}-05$ & $1.09 \mathrm{E}-05$ & $1.09 \mathrm{E}-05$ \\
POR-C & $3.19 \mathrm{E}-04$ & $1.09 \mathrm{E}-05$ & $1.09 \mathrm{E}-05$ & $1.09 \mathrm{E}-05$ & $1.09 \mathrm{E}-05$ \\
SAV-D & $1.13 \mathrm{E}-05$ & $6.22 \mathrm{E}-06$ & $6.64 \mathrm{E}-06$ & $6.22 \mathrm{E}-06$ & $6.22 \mathrm{E}-06$ \\
SAV-C & $1.30 \mathrm{E}-05$ & $1.14 \mathrm{E}-05$ & $1.14 \mathrm{E}-05$ & $1.14 \mathrm{E}-05$ & $1.14 \mathrm{E}-05$ \\
SEA-C & $1.36 \mathrm{E}-04$ & $6.79 \mathrm{E}-04$ & $6.79 \mathrm{E}-04$ & $6.79 \mathrm{E}-04$ & $6.79 \mathrm{E}-04$ \\
TAC-D & $5.33 \mathrm{E}-06$ & $1.14 \mathrm{E}-05$ & $1.14 \mathrm{E}-05$ & $1.14 \mathrm{E}-05$ & $2.98 \mathrm{E}-05$ \\
TAC-C & $1.08 \mathrm{E}-05$ & $1.08 \mathrm{E}-05$ & $1.08 \mathrm{E}-05$ & $1.08 \mathrm{E}-05$ & $1.08 \mathrm{E}-05$ \\
WIL-D & $3.26 \mathrm{E}-04$ & $1.16 \mathrm{E}-04$ & $1.16 \mathrm{E}-04$ & $1.16 \mathrm{E}-04$ & $9.93 \mathrm{E}-05$ \\
WIL-C & $3.04 \mathrm{E}-04$ & $1.08 \mathrm{E}-04$ & $2.98 \mathrm{E}-05$ & $1.08 \mathrm{E}-04$ & $4.59 \mathrm{E}-05$
\end{tabular}

$\begin{array}{ccccc}\text { EIS4 } & \text { EIS5A } & \begin{array}{c}\text { RHF } \\ \text { EIS5B }\end{array} & \text { EIS6A } & \text { EIS6B } \\ 1.01 E-05 & 1.01 E-05 & 1.01 E-05 & 1.01 E-05 & 1.01 \mathrm{E}-05 \\ 7.77 \mathrm{E}-06 & 4.44 \mathrm{E}-06 & 4.44 \mathrm{E}-06 & 4.44 \mathrm{E}-06 & 8.88 \mathrm{E}-06 \\ 8.47 \mathrm{E}-04 & 5.08 \mathrm{E}-04 & 1.18 \mathrm{E}-05 & 5.08 \mathrm{E}-04 & 1.18 \mathrm{E}-05 \\ 7.58 \mathrm{E}-06 & 7.58 \mathrm{E}-06 & 7.58 \mathrm{E}-06 & 7.58 \mathrm{E}-06 & 4.33 \mathrm{E}-06 \\ 7.80 \mathrm{E}-06 & 7.80 \mathrm{E}-06 & 7.80 \mathrm{E}-06 & 7.80 \mathrm{E}-06 & 3.40 \mathrm{E}-03 \\ 7.80 \mathrm{E}-06 & 9.75 \mathrm{E}-06 & 9.75 \mathrm{E}-06 & 9.75 \mathrm{E}-06 & 3.40 \mathrm{E}-03 \\ 6.03 \mathrm{E}-06 & 6.03 \mathrm{E}-06 & 6.03 \mathrm{E}-06 & 6.03 \mathrm{E}-06 & 1.46 \mathrm{E}-05 \\ 6.08 \mathrm{E}-06 & 8.06 \mathrm{E}-06 & 8.06 \mathrm{E}-06 & 8.06 \mathrm{E}-06 & 4.37 \mathrm{E}-05 \\ 1.83 \mathrm{E}-03 & 3.42 \mathrm{E}-06 & 3.42 \mathrm{E}-06 & 3.42 \mathrm{E}-06 & 3.53 \mathrm{E}-05 \\ 4.91 \mathrm{E}-06 & 2.81 \mathrm{E}-06 & 2.81 \mathrm{E}-06 & 2.81 \mathrm{E}-06 & 2.81 \mathrm{E}-06 \\ 1.67 \mathrm{E}-05 & 2.76 \mathrm{E}-05 & 2.76 \mathrm{E}-05 & 2.76 \mathrm{E}-05 & 2.76 \mathrm{E}-05 \\ 2.03 \mathrm{E}-05 & 2.03 \mathrm{E}-05 & 2.03 \mathrm{E}-05 & 2.03 \mathrm{E}-05 & 2.03 \mathrm{E}-05 \\ 2.50 \mathrm{E}-04 & 7.65 \mathrm{E}-05 & 1.16 \mathrm{E}-05 & 7.65 \mathrm{E}-05 & 1.16 \mathrm{E}-05 \\ 3.51 \mathrm{E}-04 & 9.62 \mathrm{E}-06 & 9.62 \mathrm{E}-06 & 9.62 \mathrm{E}-06 & 9.62 \mathrm{E}-06 \\ 1.07 \mathrm{E}-05 & 1.61 \mathrm{E}-05 & 1.61 \mathrm{E}-05 & 1.61 \mathrm{E}-05 & 1.61 \mathrm{E}-05 \\ 3.17 \mathrm{E}-06 & 3.17 \mathrm{E}-06 & 3.17 \mathrm{E}-06 & 3.17 \mathrm{E}-06 & 7.78 \mathrm{E}-06 \\ 2.44 \mathrm{E}-05 & 2.44 \mathrm{E}-05 & 2.44 \mathrm{E}-05 & 2.44 \mathrm{E}-05 & 2.44 \mathrm{E}-05 \\ 2.98 \mathrm{E}-04 & 1.09 \mathrm{E}-05 & 1.09 \mathrm{E}-05 & 1.09 \mathrm{E}-05 & 1.09 \mathrm{E}-05 \\ 3.19 \mathrm{E}-04 & 1.09 \mathrm{E}-05 & 1.09 \mathrm{E}-05 & 1.09 \mathrm{E}-05 & 1.09 \mathrm{E}-05 \\ 1.13 \mathrm{E}-05 & 6.22 \mathrm{E}-06 & 6.22 \mathrm{E}-06 & 6.22 \mathrm{E}-06 & 1.24 \mathrm{E}-05 \\ 1.30 \mathrm{E}-05 & 1.14 \mathrm{E}-05 & 1.14 \mathrm{E}-05 & 1.14 \mathrm{E}-05 & 1.14 \mathrm{E}-05 \\ 1.36 \mathrm{E}-04 & 6.79 \mathrm{E}-04 & 6.79 \mathrm{E}-04 & 6.79 \mathrm{E}-04 & 6.79 \mathrm{E}-04 \\ 5.33 \mathrm{E}-06 & 1.14 \mathrm{E}-05 & 1.08 \mathrm{E}-05 & 1.14 \mathrm{E}-05 & 1.08 \mathrm{E}-05 \\ 1.08 \mathrm{E}-05 & 1.08 \mathrm{E}-05 & 1.08 \mathrm{E}-05 & 1.08 \mathrm{E}-05 & 1.08 \mathrm{E}-05 \\ 3.26 \mathrm{E}-04 & 1.16 \mathrm{E}-04 & 1.16 \mathrm{E}-04 & 1.16 \mathrm{E}-04 & 9.93 \mathrm{E}-05 \\ 3.04 \mathrm{E}-04 & 1.08 \mathrm{E}-04 & 1.27 \mathrm{E}-05 & 1.08 \mathrm{E}-04 & 2.98 \mathrm{E}-05\end{array}$


Table 38. Conditional Probability of Peak Values of Population Dose, Cancer Fatalities, Costs, Centerline Individual Dose and Centerline Individual Risk for EIS Accident Categories (Continued)

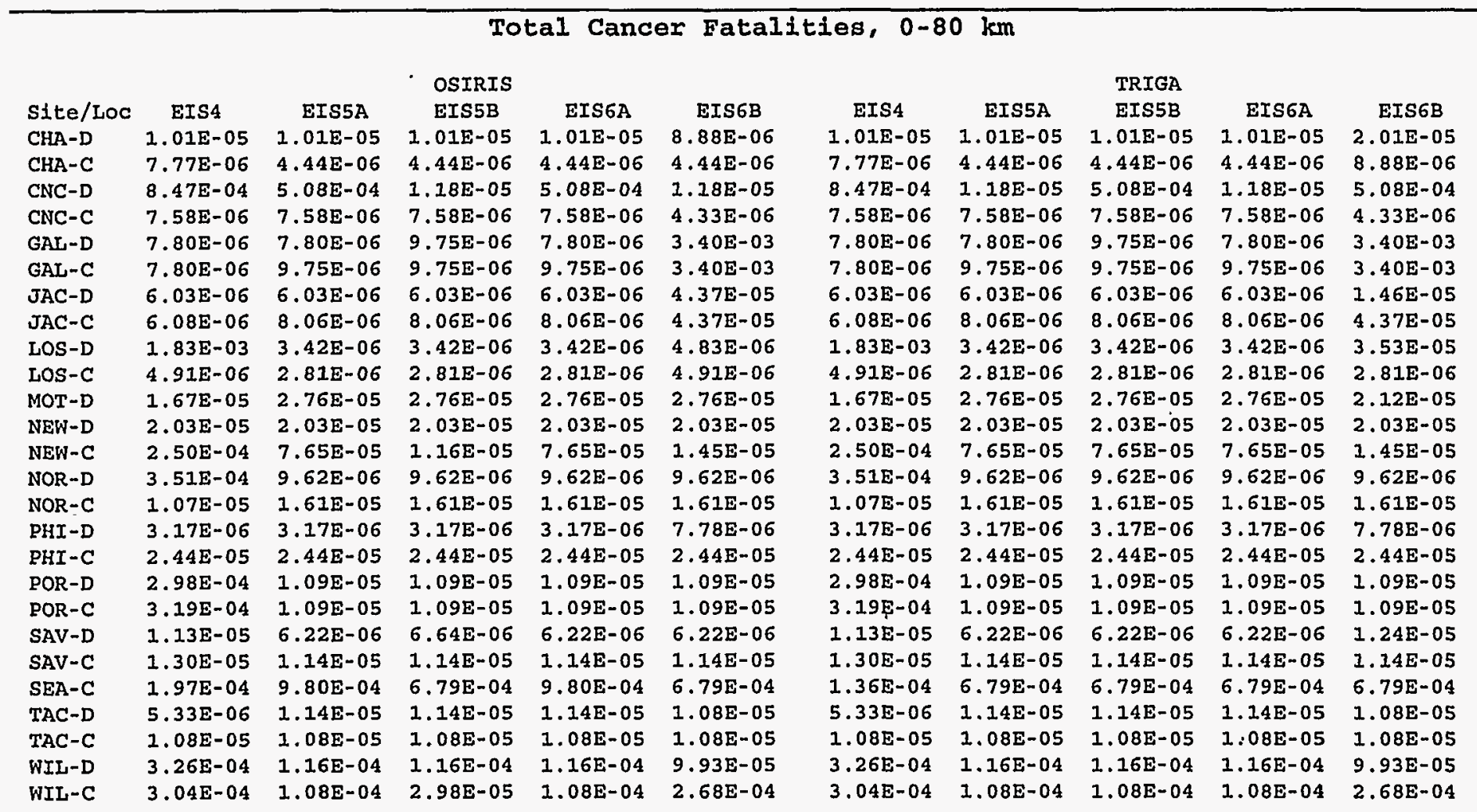


Table 38. Conditional Probability of Peak Values of Population Dose, Cancer Fatalities, Costs, Centerline Individual Dose and Centerline Individual Risk for EIS Accident Categories (Continued)

\begin{tabular}{|c|c|c|c|c|c|c|c|c|c|c|}
\hline & & & $\mathrm{BR}-2$ & & & & & RHF & & \\
\hline Site/Loc & EIS4 & EIS5A & EIS5B & EIS6A & EIS6B & EIS4 & EIS5A & EIS5B & EIS6A & EIS6B \\
\hline CHA-D & $0.00 \mathrm{E}+00$ & $0.00 \mathrm{E}+00$ & $1.31 \mathrm{E}-04$ & $0.00 \mathrm{E}+00$ & $2.01 E-05$ & $0.00 \mathrm{E}+00$ & $0.00 E+00$ & $1.31 \mathrm{E}-04$ & $0.00 \mathrm{E}+00$ & $4.34 \mathrm{E}-06$ \\
\hline $\mathrm{CHA}-\mathrm{C}$ & $0.00 \mathrm{E}+00$ & $0.00 \mathrm{E}+00$ & $5.47 \mathrm{E}-06$ & $0.00 \mathrm{E}+00$ & $1.54 \mathrm{E}-04$ & $0.00 \mathrm{E}+00$ & $0.00 \mathrm{E}+00$ & $7.93 \mathrm{E}-05$ & $0.00 \mathrm{E}+00$ & $4.44 \mathrm{E}-06$ \\
\hline CNC-D & $0.00 \mathrm{E}+00$ & $0.00 \mathrm{E}+00$ & $2.31 \mathrm{E}-05$ & $0.00 \mathrm{E}+00$ & $5.06 E-05$ & $0.00 \mathrm{E}+00$ & $0.00 \mathrm{E}+00$ & $1.77 \mathrm{E}-05$ & $0.00 \mathrm{E}+00$ & $2.87 \mathrm{E}-05$ \\
\hline $\mathrm{CNC}-\mathrm{C}$ & $0.00 \mathrm{E}+00$ & $0.00 E+00$ & $3.58 \mathrm{E}-05$ & $0.00 \mathrm{E}+00$ & $7.58 \mathrm{E}-06$ & $0.00 \mathrm{E}+00$ & $0.00 E+00$ & $0.00 \mathrm{E}+00$ & $0.00 \mathrm{E}+00$ & $3.14 \mathrm{E}-05$ \\
\hline GAL-D & $0.00 \mathrm{E}+00$ & $0.00 \mathrm{E}+00$ & $7.80 \mathrm{E}-06$ & $0.00 \mathrm{E}+00$ & $1.37 E-05$ & $0.00 \mathrm{E}+00$ & $0.00 E+00$ & $1.07 \mathrm{E}-04$ & $0.00 \mathrm{E}+00$ & $9.75 \mathrm{E}-06$ \\
\hline GAI-C & $0.00 \mathrm{E}+00$ & $0.00 \mathrm{E}+00$ & $9.19 \mathrm{E}-06$ & $0.00 \mathrm{E}+00$ & $9.75 \mathrm{E}-06$ & $0.00 \mathrm{E}+00$ & $0.00 \mathrm{E}+00$ & $1.26 \mathrm{E}-04$ & $0.00 \mathrm{E}+00$ & $9.75 \mathrm{E}-06$ \\
\hline JAC-D & $0.00 \mathrm{E}+00$ & $0.00 \mathrm{E}+00$ & $8.06 \mathrm{E}-06$ & $0.00 \mathrm{E}+00$ & $1.52 \mathrm{E}-05$ & $0.00 \mathrm{E}+00$ & $0.00 E+00$ & $8.25 E-05$ & $0.00 \mathrm{E}+00$ & $9.19 \mathrm{E}-06$ \\
\hline JAC-C & $0.00 \mathrm{E}+00$ & $0.00 \mathrm{E}+00$ & $8.06 \mathrm{E}-06$ & $0.00 \mathrm{E}+00$ & $6.08 \mathrm{E}-06$ & $0.00 \mathrm{E}+00$ & $0.00 \mathrm{E}+00$ & $8.34 E-05$ & $0.00 \mathrm{E}+0.0$ & $8.06 \mathrm{E}-06$ \\
\hline LOS-D & $0.00 \mathrm{E}+00$ & $0.00 \mathrm{E}+00$ & $4.98 \mathrm{E}-05$ & $0.00 \mathrm{E}+00$ & $6.18 \mathrm{E}-05$ & $0.00 \mathrm{E}+00$ & $0.00 \mathrm{E}+00$ & $3.82 \mathrm{E}-05$ & $0.00 \mathrm{E}+00$ & $6.18 \mathrm{E}-05$ \\
\hline LOS-C & $0.00 \mathrm{E}+00$ & $0.00 \mathrm{E}+00$ & $1.27 \mathrm{E}-05$ & $0.00 \mathrm{E}+00$ & $4.91 \mathrm{E}-06$ & $0.00 \mathrm{E}+00$ & $0.00 \mathrm{E}+00$ & $1.45 \mathrm{E}-05$ & $0.00 \mathrm{E}+00$ & $1.76 \mathrm{E}-06$ \\
\hline MOT-D & $0.00 \mathrm{E}+00$ & $0.00 E+00$ & $2.57 \mathrm{E}-04$ & $0.00 E+00$ & $7.04 E-06$ & $0.00 \mathrm{E}+00$ & $0.00 E+00$ & $2.57 E-05$ & $0.00 \mathrm{E}+00$ & $4.69 \mathrm{E}-06$ \\
\hline NEW-D & $0.00 \mathrm{E}+00$ & $0.00 \mathrm{E}+00$ & $6.75 \mathrm{E}-05$ & $0.00 \mathrm{E}+00$ & $2.64 \mathrm{E}-06$ & $0.00 \mathrm{E}+00$ & $0.00 E+00$ & $6.75 E-05$ & $0.00 \mathrm{E}+00$ & $9.20 \mathrm{E}-05$ \\
\hline NEW-C & $0.00 \mathrm{E}+00$ & $0.00 \mathrm{E}+00$ & $7.65 \mathrm{E}-05$ & $0.00 \mathrm{E}+00$ & $1.16 \mathrm{E}-05$ & $0.00 E+00$ & $0.00 \mathrm{E}+00$ & $7.65 E-05$ & $0.00 \mathrm{E}+00$ & $7.65 \mathrm{E}-05$ \\
\hline NOR-D & $0.00 \mathrm{E}+00$ & $0.00 \mathrm{E}+00$ & $1.25 \mathrm{E}-04$ & $0.00 \mathrm{E}+00$ & $1.11 \mathrm{E}-05$ & $.00 E+00$ & $0.00 \mathrm{E}+00$ & $1.25 \mathrm{E}-04$ & +00 & $6.41 \mathrm{E}-06$ \\
\hline NOR-C & $0.00 \mathrm{E}+00$ & $0.00 \mathrm{E}+00$ & $1.49 \mathrm{E}-04$ & $0.00 \mathrm{E}+00$ & $1.61 \mathrm{E}-05$ & $0.00 \mathrm{E}+00$ & 0.0 & 1.49 & 0.0 & $7 E-05$ \\
\hline PHI-D & $0.00 \mathrm{E}+00$ & $0.00 \mathrm{E}+00$ & $4.69 \mathrm{E}-05$ & $0.00 \mathrm{E}+00$ & $3.17 E-06$ & $0.00 \mathrm{E}+00$ & $0.00 \mathrm{E}+00$ & $1.41 \mathrm{E}-04$ & $0.00 \mathrm{E}+00$ & $3.17 \mathrm{E}-06$ \\
\hline PHI-C & $0.00 \mathrm{E}+00$ & $0.00 \mathrm{E}+00$ & $1.43 \mathrm{E}-05$ & $0.00 E \div 00$ & $5.02 \mathrm{E}-06$ & $0.00 \mathrm{E}+00$ & $0.00 E+00$ & $4.28 \mathrm{E}-05$ & $0.00 \mathrm{E}+00$ & $3.50 \mathrm{E}-05$ \\
\hline POR-D & $0.00 \mathrm{E}+00$ & $0.00 \mathrm{E}+00$ & $1.26 \mathrm{E}-05$ & $0.00 \mathrm{E}+00$ & $3.60 \mathrm{E}-06$ & $0.00 \mathrm{E}+00$ & $0.00 \mathrm{E}+00$ & $1.26 \mathrm{E}-05$ & $0.00 \mathrm{E}+00$ & $2.81 \mathrm{E}-05$ \\
\hline POR-C & $0.00 \mathrm{E}+00$ & $0.00 \mathrm{E}+00$ & $1.35 \mathrm{E}-05$ & $0.00 E+00$ & $7.34 \mathrm{E}-05$ & $0.00 \mathrm{E}+00$ & $0.00 E+00$ & $1.35 \mathrm{E}-05$ & $0.00 \mathrm{E}+00$ & $3.02 \mathrm{E}-05$ \\
\hline SAV-D & $0.00 \mathrm{E}+00$ & $0.00 \mathrm{E}+00$ & $9.38 \mathrm{E}-05$ & $0.00 \mathrm{E}+00$ & $6.64 \mathrm{E}-06$ & $0.00 \mathrm{E}+00$ & $0.00 \mathrm{E}+00$ & $9.38 \mathrm{E}-05$ & $0.00 \mathrm{E}+00$ & $1.29 \mathrm{E}-05$ \\
\hline SAV-C & $0.00 \mathrm{E}+00$ & $0.00 \mathrm{E}+00$ & $4.82 \mathrm{E}-05$ & $0.00 \mathrm{E}+00$ & $6.64 \mathrm{E}-06$ & $0.00 \mathrm{E}+00$ & $0.00 \mathrm{E}+00$ & $1.94 \mathrm{E}-05$ & $0.00 \mathrm{E}+00$ & $6.64 \mathrm{E}-06$ \\
\hline SEA-C & $0.00 \mathrm{E}+00$ & $0.00 E+00$ & $1.13 \mathrm{E}-05$ & $0.00 \mathrm{E}+00$ & $4.95 \mathrm{E}-06$ & $0.00 \mathrm{E}+00$ & $0.00 \mathrm{E}+00$ & $1.54 \mathrm{E}-05$ & $0.00 \mathrm{E}+00$ & $2.30 \mathrm{E}-04$ \\
\hline TAC-D & $0.00 \mathrm{E}+00$ & $0.00 E+00$ & $1.96 \mathrm{E}-05$ & $0.00 E+00$ & $1.52 \mathrm{E}-06$ & $0.00 \mathrm{E}+00$ & $0.00 E+00$ & $1.96 \mathrm{E}-05$ & $0.00 \mathrm{E}+00$ & $5.33 \mathrm{E}-06$ \\
\hline TAC-C & $0.00 \mathrm{E}+00$ & $0.00 \mathrm{E}+00$ & $3.42 \mathrm{E}-06$ & $0.00 \mathrm{E}+00$ & $1.08 \mathrm{E}-05$ & $0.00 \mathrm{E}+00$ & $0.00 \mathrm{E}+00$ & $3.42 \mathrm{E}-06$ & $0.00 \mathrm{E}+00$ & $3.79 \mathrm{E}-05$ \\
\hline WIL-D & $0.00 \mathrm{E}+00$ & $0.00 \mathrm{E}+00$ & $1.16 \mathrm{E}-04$ & $0.00 \mathrm{E}+00$ & $9.11 \mathrm{E}-06$ & $0.00 \mathrm{E}+00$ & $0.00 \mathrm{E}+00$ & $1.16 \mathrm{E}-04$ & $0.00 \mathrm{E}+0.0$ & $1.16 \mathrm{E}-04$ \\
\hline WIL-C & $0.00 E+00$ & $0.00 E+00$ & $1.08 \mathrm{E}-04$ & $0.00 \mathrm{E}+00$ & $8.49 \mathrm{E}-06$ & $0.00 \mathrm{E}+00$ & $0.00 E+00$ & $1.08 \mathrm{E}-04$ & $0.00 \mathrm{E}+00$ & $1.08 \mathrm{E}-04$ \\
\hline
\end{tabular}


Table 38. Conditional Probability of Peak Values of Population Dose, Cancer Fatalities, Costs, Centerline Individual Dose and Centerline Individual Risk for EIS Accident Categories (Continued)

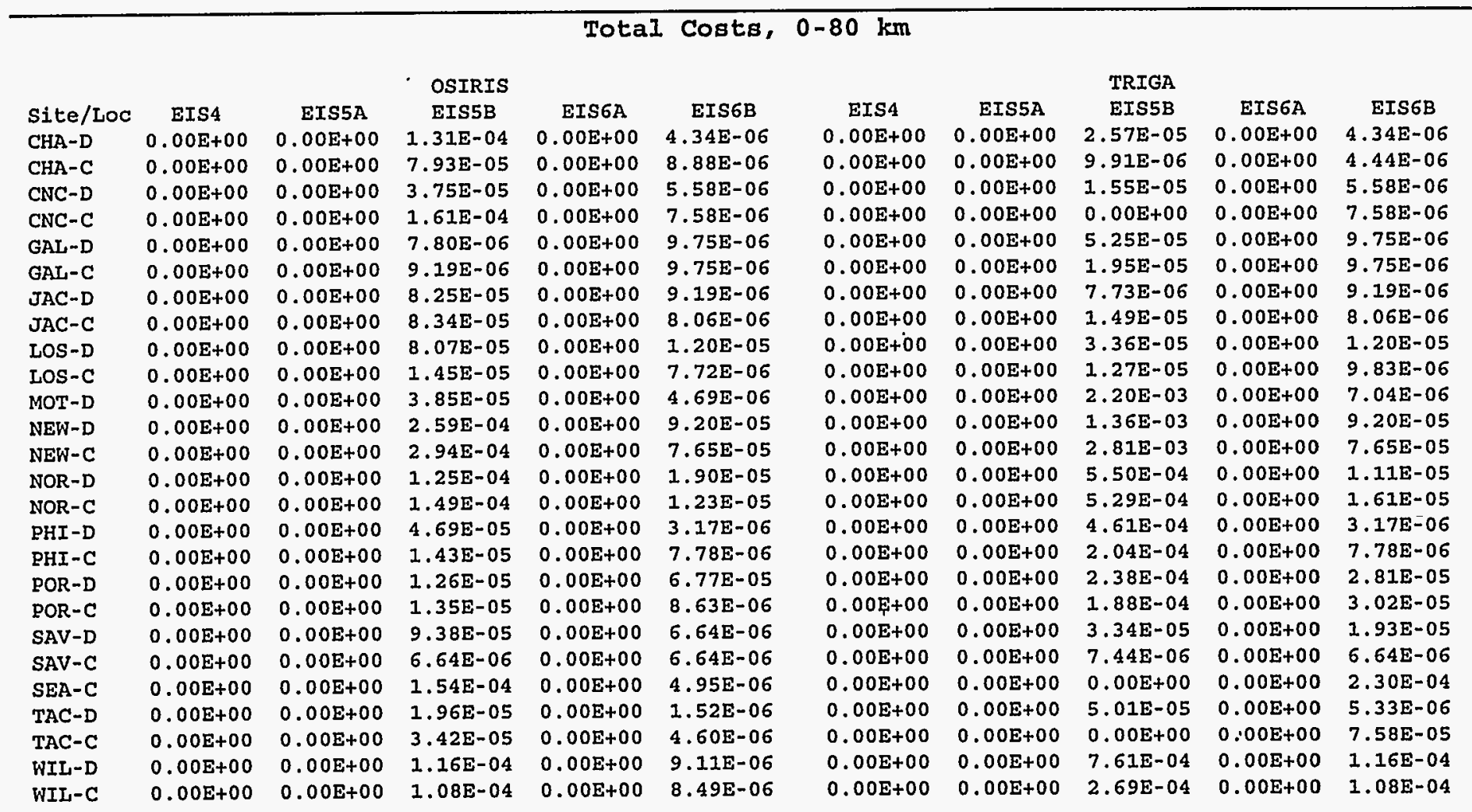


Table 38. Conditional Probability of Peak Values of Population Dose, Cancer Fatalities, Costs, Centerline Individual Dose and Centerline Individual Risk for EIS Accident Categories (Continued)

\begin{tabular}{|c|c|c|c|c|c|c|c|c|c|c|}
\hline \multirow[b]{3}{*}{ Site/Loc } & \multicolumn{4}{|c|}{ Individual Centerline } & \multirow{3}{*}{$\begin{array}{c}\text { EDE Whole } \\
\text { EIs6B }\end{array}$} & \multicolumn{2}{|c|}{ Body Dose, 0-1.6 } & $\mathrm{km}$ (SV) & \multirow[b]{3}{*}{ EIS6A } & \multirow[b]{3}{*}{ EIS6B } \\
\hline & & & BR-2 & & & & & $\mathrm{R}$ & & \\
\hline & EIS4 & EIS5A & EIS5B & EIS6A & & EIS4 & EIS5A & EIS5B & & \\
\hline CHA-D & $2.36 \mathrm{E}-02$ & $1.66 \mathrm{E}-03$ & $1.66 \mathrm{E}-03$ & $1.66 \mathrm{E}-03$ & $1.14 \mathrm{E}-04$ & $2.36 \mathrm{E}-02$ & $1.66 \mathrm{E}-03$ & $1.66 \mathrm{E}-03$ & $1.66 \mathrm{E}-03$ & $9.99 \mathrm{E}-04$ \\
\hline CHA-C & $2.36 \mathrm{E}-02$ & $1.66 \mathrm{E}-03$ & $1.66 \mathrm{E}-03$ & $1.66 \mathrm{E}-03$ & $1.14 \mathrm{E}-04$ & $2.36 \mathrm{E}-02$ & $1.66 \mathrm{E}-03$ & $1.66 \mathrm{E}-03$ & $1.66 \mathrm{E}-03$ & $9.99 \mathrm{E}-04$ \\
\hline CNC-D & $1.22 \mathrm{E}-01$ & $2.00 \mathrm{E}-04$ & $2.00 \mathrm{E}-04$ & $2.00 \mathrm{E}-04$ & $8.28 \mathrm{E}-04$ & $1.22 \mathrm{E}-01$ & $2.00 \mathrm{E}-04$ & $2.00 \mathrm{E}-04$ & $2.00 \mathrm{E}-04$ & $2.00 \mathrm{E}-04$ \\
\hline CNC-C & $1.22 \mathrm{E}-01$ & $2.00 \mathrm{E}-04$ & $2.00 E-04$ & $2.00 \mathrm{E}-04$ & $8.28 E-04$ & $1.22 \mathrm{E}-01$ & $2.00 E-04$ & $2.00 \mathrm{E}-04$ & $2.00 \mathrm{E}-04$ & $2.00 \mathrm{E}-04$ \\
\hline GAL-D & $3.73 E-02$ & $1.57 \mathrm{E}-03$ & $1.57 \mathrm{E}-03$ & $1.57 \mathrm{E}-03$ & $4.85 \mathrm{E}-04$ & $3.73 \mathrm{E}-02$ & $1.57 \mathrm{E}-03$ & $1.34 \mathrm{E}-03$ & $1.57 \mathrm{E}-03$ & $1.34 \mathrm{E}-03$ \\
\hline GAL-C & $3.73 \mathrm{E}-02$ & $1.57 E-03$ & $1.57 \mathrm{E}-03$ & $1.57 E-03$ & $4.85 E-04$ & $3.73 \mathrm{E}-02$ & $2.57 \mathrm{E}-03$ & $1.34 \mathrm{E}-03$ & $1.57 \mathrm{E}-03$ & $1.34 \mathrm{E}-03$ \\
\hline JAC-D & $2.36 \mathrm{E}-02$ & $1.66 \mathrm{E}-03$ & $1.66 \mathrm{E}-03$ & $1.66 \mathrm{E}-03$ & $1.14 \mathrm{E}-04$ & $2.36 \mathrm{E}-02$ & $1.66 \mathrm{E}-03$ & $1.66 \mathrm{E}-03$ & $1.66 \mathrm{E}-03$ & $9.99 \mathrm{E}-04$ \\
\hline JAC-C & $2.36 \mathrm{E}-02$ & $1.66 \mathrm{E}-03$ & $1.66 \mathrm{E}-03$ & $1.66 \mathrm{E}-03$ & $1.14 \mathrm{E}-04$ & $2.36 \mathrm{E}-02$ & $1.66 \mathrm{E}-03$ & $1.66 \mathrm{E}-03$ & $1.66 \mathrm{E}-03$ & $9.99 \mathrm{E}-04$ \\
\hline LOS-D & $1.22 \mathrm{E}-01$ & $2.00 \mathrm{E}-04$ & $2.00 \mathrm{E}-04$ & $2.00 \mathrm{E}-04$ & $8.28 \mathrm{E}-04$ & $1.22 \mathrm{E}-01$ & $2.00 \mathrm{E}-04$ & $2.00 \mathrm{E}-04$ & $2.00 \mathrm{E}-04$ & $2.00 \mathrm{E}-04$ \\
\hline LOS-C & $1.22 \mathrm{E}-01$ & $2.00 \mathrm{E}-04$ & $2.00 \mathrm{E}-04$ & $2.00 \mathrm{E}-04$ & $8.28 \mathrm{E}-04$ & $1.22 \mathrm{E}-01$ & $2.00 \mathrm{E}-04$ & $2.00 \mathrm{E}-04$ & $2.00 \mathrm{E}-04$ & $2.00 \mathrm{E}-04$ \\
\hline MOT-D & $8.16 \mathrm{E}-03$ & $1.46 \mathrm{E}-03$ & $1.46 \mathrm{E}-03$ & $1.46 \mathrm{E}-03$ & $9.99 E-04$ & $8.16 \mathrm{E}-03$ & $1.46 \mathrm{E}-03$ & $1.46 \mathrm{E}-03$ & $1.46 \mathrm{E}-03$ & $2.45 \mathrm{E}-03$ \\
\hline NEW-D & $3.45 \mathrm{E}-03$ & $1.06 \mathrm{E}-03$ & $1.06 \mathrm{E}-03$ & $1.06 \mathrm{E}-03$ & $9.70 \mathrm{E}-04$ & $3.45 \mathrm{E}-03$ & $1.06 \mathrm{E}-03$ & $9.70 \mathrm{E}-04$ & $1.06 \mathrm{E}-03$ & $3.00 \mathrm{E}-03$ \\
\hline NEW-C & $3.45 \mathrm{E}-03$ & $1.06 \mathrm{E}-03$ & $1.06 \mathrm{E}-03$ & $1.06 \mathrm{E}-03$ & $9.70 \mathrm{E}-04$ & $3.45 \mathrm{E}-03$ & $1.06 \mathrm{E}-03$ & $9.70 \mathrm{E}-04$ & $1.06 \mathrm{E}-03$ & $3.00 \mathrm{E}-03$ \\
\hline NOR-D & B. $16 \mathrm{E}-03$ & $1.46 \mathrm{E}-03$ & $1.46 \mathrm{E}-03$ & $1.46 \mathrm{E}-03$ & $9.99 \mathrm{E}-04$ & $8.16 \mathrm{E}-03$ & $1.46 \mathrm{E}-03$ & $1.46 \mathrm{E}-03$ & $1.46 \mathrm{E}-03$ & $2.45 \mathrm{E}-03$ \\
\hline NOR-C & $8.26 \mathrm{E}-03$ & $1.46 \mathrm{E}-03$ & $1.46 \mathrm{E}-03$ & $1.46 \mathrm{E}-03$ & $9.99 \mathrm{E}-04$ & $8.16 \mathrm{E}-03$ & $1.46 \mathrm{E}-03$ & $1.46 \mathrm{E}-03$ & $1.46 \mathrm{E}-03$ & $2.45 \mathrm{E}-03$ \\
\hline PHI-D & $7.89 \mathrm{E}-02$ & $5.14 \mathrm{E}-04$ & $5.14 \mathrm{E}-04$ & $5.14 \mathrm{E}-04$ & $1.14 \mathrm{E}-04$ & $7.89 \mathrm{E}-02$ & $5.14 \mathrm{E}-04$ & $5.14 \mathrm{E}-04$ & $5.14 \mathrm{E}-04$ & $2.23 \mathrm{E}-03$ \\
\hline PHI-C & $7.89 \mathrm{E}-02$ & $5.14 \mathrm{E}-04$ & $5.14 \mathrm{E}-04$ & $5.14 \mathrm{E}-04$ & $1.14 \mathrm{E}-04$ & $7.89 \mathrm{E}-02$ & $5.14 \mathrm{E}-04$ & $5.14 \mathrm{E}-04$ & $5.14 \mathrm{E}-04$ & $2.23 E-03$ \\
\hline POR-D & $2.91 E-02$ & $4.00 \mathrm{E}-04$ & $4.00 \mathrm{E}-04$ & $4.00 \mathrm{E}-04$ & $3.14 \mathrm{E}-03$ & $2.91 \mathrm{E}-02$ & $4.00 \mathrm{E}-04$ & $8.56 \mathrm{E}-04$ & $4.00 E-04$ & $4.00 \mathrm{E}-04$ \\
\hline POR-C & 2.91E-02 & $4.00 \mathrm{E}-04$ & $4.00 \mathrm{E}-04$ & $4.00 \mathrm{E}-04$ & $3.14 \mathrm{E}-03$ & $2.91 \mathrm{~F}-02$ & $4.00 \mathrm{E}-04$ & $8.56 \mathrm{E}-04$ & $4.00 \mathrm{E}-04$ & $4.00 \mathrm{E}-04$ \\
\hline SAV-D & $2.36 \mathrm{E}-02$ & $1.66 \mathrm{E}-03$ & $1.66 \mathrm{E}-03$ & $1.66 \mathrm{E}-03$ & $1.14 \mathrm{E}-04$ & $2.36 \mathrm{E}-02$ & $1.66 \mathrm{E}-03$ & $1.66 \mathrm{E}-03$ & $1.66 \mathrm{E}-03$ & $9.99 E-04$ \\
\hline SAV-C & $2.36 \mathrm{E}-02$ & $1.66 \mathrm{E}-03$ & $1.66 \mathrm{E}-03$ & $1.66 \mathrm{E}-03$ & $1.14 \mathrm{E}-04$ & $2.36 \mathrm{E}-02$ & $1.66 \mathrm{E}-03$ & $1.66 \mathrm{E}-03$ & $1.66 \mathrm{E}-03$ & $9.99 \mathrm{E}-04$ \\
\hline SEA-C & $2.91 \mathrm{E}-02$ & $4.00 \mathrm{E}-04$ & $4.00 \mathrm{E}-04$ & $4.00 \mathrm{E}-04$ & $3.14 \mathrm{E}-03$ & $2.91 E-02$ & $4.00 \mathrm{E}-04$ & $8.56 \mathrm{E}-04$ & $4.00 \mathrm{E}-04$ & $4.00 \mathrm{E}-04$ \\
\hline TAC-D & $2.91 \mathrm{E}-02$ & $4.00 \mathrm{E}-04$ & $4.00 \mathrm{E}-04$ & $4.00 \mathrm{E}-04$ & $3.14 \mathrm{E}-03$ & $2.91 \mathrm{E}-02$ & $4.00 \mathrm{E}-04$ & $8.56 \mathrm{E}-04$ & $4.00 \mathrm{E}-04$ & $4.00 \mathrm{E}-04$ \\
\hline TAC-C & $2.91 \mathrm{E}-02$ & $4.00 \mathrm{E}-04$ & $4.00 E-04$ & $4.00 \mathrm{E}-04$ & $3.14 \mathrm{E}-03$ & $2.91 \mathrm{E}-02$ & $4.00 \mathrm{E}-04$ & $8.56 \mathrm{E}-04$ & $4,00 E-04$ & $4.00 E-04$ \\
\hline WIL-D & $8.16 \mathrm{E}-03$ & $1.46 \mathrm{E}-03$ & $1.46 \mathrm{E}-03$ & $1.46 \mathrm{E}-03$ & $9.99 \mathrm{E}-04$ & $8.16 \mathrm{E}-03$ & $1.46 \mathrm{E}-03$ & $1.46 \mathrm{E}-03$ & $1.46 \mathrm{E}-03$ & $2.45 \mathrm{E}-03$ \\
\hline WIL-C & $8.16 \mathrm{E}-03$ & $1.46 \mathrm{E}-03$ & $1.46 \mathrm{E}-03$ & $1.46 \mathrm{E}-03$ & $9.99 \mathrm{E}-04$ & $8.16 \mathrm{E}-03$ & $1.46 \mathrm{E}-03$ & $1.46 \mathrm{E}-03$ & $1.46 E-03$ & $2.45 E-03$ \\
\hline
\end{tabular}


Table 38. Conditional Probability of Peak Values of Population Dose, Cancer Fatalities, Costs, Centerline Individual Dose and Centerline Individual Risk for EIS Accident Categories (Continued)

\begin{tabular}{|c|c|c|c|c|c|c|c|c|c|c|}
\hline \multirow[b]{3}{*}{ Site/Loc } & \multicolumn{4}{|c|}{ Individual Centerline } & EDE Whole & \multicolumn{2}{|c|}{ Body Dose, 0-1.6 } & $\mathrm{km} \mathrm{(SV)}$ & \multirow[b]{3}{*}{ EIS6A } & \multirow[b]{3}{*}{ EIS6B } \\
\hline & & & OSIRIS & & & & & TRIGA & & \\
\hline & $\begin{array}{c}\text { EIS4 } \\
2.36 E-02\end{array}$ & $\begin{array}{l}\text { EIS5A } \\
.66 \mathrm{E}-03\end{array}$ & $\begin{array}{l}\text { EIS5B } \\
.66 \mathrm{E}-03\end{array}$ & $\begin{array}{l}\text { EIS6A } \\
.66 \mathrm{E}-03\end{array}$ & EIS6B & $\begin{array}{l}\text { EIS4 } \\
.36 \mathrm{E}-02\end{array}$ & $\begin{array}{l}\text { EIS5A } \\
.66 E-03\end{array}$ & $\begin{array}{l}\text { EIS5B } \\
.66 \mathrm{E}-03\end{array}$ & & \\
\hline $\mathrm{CHA}-\mathrm{C}$ & $2.36 \mathrm{E}-02$ & $1.66 \mathrm{E}-03$ & $1.66 \mathrm{E}-03$ & $1.66 \mathrm{E}-03$ & $1.14 \mathrm{E}-04$ & $2.36 \mathrm{E}-02$ & $1.66 \mathrm{E}-03$ & $1.66 \mathrm{E}-03$ & $1.66 \mathrm{E}-03$ & $9.99 \mathrm{E}-04$ \\
\hline CNC-D & $1.22 \mathrm{E}-01$ & $2.00 \mathrm{E}-04$ & $8.28 \mathrm{E}-04$ & $2.00 \mathrm{E}-04$ & $8.28 \mathrm{E}-04$ & $1.22 \mathrm{E}-01$ & $2.00 \mathrm{E}-04$ & $2.00 \mathrm{E}-04$ & $2.00 \mathrm{E}-04$ & $8.28 \mathrm{E}-04$ \\
\hline CNC-C & $1.22 \mathrm{E}-01$ & $2.00 \mathrm{E}-04$ & $8.28 \mathrm{E}-04$ & $2.00 E-04$ & $8.28 \mathrm{E}-04$ & $1.22 \mathrm{E}-01$ & $2.00 \mathrm{E}-04$ & $2.00 \mathrm{E}-04$ & $2.00 \mathrm{E}-04$ & $8.28 \mathrm{E}-04$ \\
\hline GAL $-D$ & $3.73 \mathrm{E}-02$ & $1.57 \mathrm{E}-03$ & $1.57 \mathrm{E}-03$ & $1.57 \mathrm{E}-03$ & $4.85 \mathrm{E}-04$ & $3.73 E-02$ & $1.57 \mathrm{E}-03$ & $1.57 E-03$ & $1.57 \mathrm{E}-03$ & $1.34 \mathrm{E}-03$ \\
\hline GAL-C & $3.73 E-02$ & $.57 \mathrm{E}-03$ & $1.57 \mathrm{E}-03$ & $1.57 \mathrm{E}-03$ & $4.85 E-04$ & $.73 \mathrm{E}-02$ & $1.57 \mathrm{E}-03$ & $1.57 \mathrm{E}-03$ & -03 & \\
\hline JAC-D & $2.36 \mathrm{E}-02$ & $.66 \mathrm{E}-03$ & $1.66 \mathrm{E}-03$ & $1.66 \mathrm{E}-03$ & $1.14 \mathrm{E}$ & $36 \mathrm{E}-02$ & $1.66 \mathrm{E}-03$ & $1.66 \mathrm{E}-03$ & 03 & \\
\hline JAC-C & $2.36 \mathrm{E}-02$ & $1.66 \mathrm{E}-03$ & $1.66 \mathrm{E}-03$ & $1.66 \mathrm{E}-03$ & $1.14 \mathrm{E}-04$ & $2.36 \mathrm{E}-02$ & $1.66 \mathrm{E}-03$ & $1.66 \mathrm{E}-03$ & $1.66 \mathrm{E}-03$ & 9.99 \\
\hline LOS-D & $1.22 \mathrm{E}-01$ & $2.00 \mathrm{E}-04$ & $8.28 \mathrm{E}-04$ & $2.00 \mathrm{E}-04$ & $8.28 \mathrm{E}-04$ & $1.22 \mathrm{E}-01$ & $2.00 \mathrm{E}-04$ & $2.00 \mathrm{E}-04$ & 2.00 & $8.28 \mathrm{E}-04$ \\
\hline LOS-C & $1.22 \mathrm{E}-01$ & $2.00 \mathrm{E}-04$ & $8.28 \mathrm{E}-04$ & $2.00 E-04$ & $8.28 \mathrm{E}-04$ & 1. $22 \mathrm{E}-01$ & $2.00 \mathrm{E}-04$ & $2.00 \mathrm{E}-04$ & 2.00 & 8.28 \\
\hline MOT-D & $8.16 \mathrm{E}-03$ & $1.46 \mathrm{E}-03$ & $1.46 \mathrm{E}-03$ & $1.46 \mathrm{E}-03$ & $1.14 \mathrm{E}-04$ & $8.16 \mathrm{E}-03$ & $1.46 \mathrm{E}-03$ & $1.46 \mathrm{E}-03$ & -03 & 2. \\
\hline NEW-D & $3.45 E-03$ & $1.06 \mathrm{E}-03$ & $1.06 \mathrm{E}-03$ & $1.06 \mathrm{E}-03$ & $9.70 \mathrm{E}-04$ & $.45 \mathrm{E}-03$ & $1.06 \mathrm{E}-03$ & $1.06 \mathrm{E}-03$ & -03 & \\
\hline NEW-C & $3.45 \mathrm{E}-03$ & $.06 \mathrm{E}-03$ & $1.06 \mathrm{E}-03$ & $1.06 E-03$ & $9.70 \mathrm{E}-04$ & $3.45 \mathrm{E}-03$ & $1.06 \mathrm{E}-03$ & $1.06 \mathrm{E}-03$ & $1.06 \mathrm{E}-03$ & $3.00 \mathrm{E}-03$ \\
\hline NOR - D & $8.16 \mathrm{E}-03$ & $1.46 \mathrm{E}-03$ & $1.46 \mathrm{E}-03$ & $1.46 \mathrm{E}-03$ & $1.14 \mathrm{E}-04$ & $8.16 \mathrm{E}-03$ & $1.46 \mathrm{E}-03$ & $1.46 \mathrm{E}-03$ & $1.46 \mathrm{E}-03$ & $2.45 \mathrm{E}-03$ \\
\hline NOR-C & $8.16 \mathrm{E}-03$ & $1.46 \mathrm{E}-03$ & $1.46 \mathrm{E}-03$ & $1.46 \mathrm{E}-03$ & $1.14 \mathrm{E}-04$ & $8.16 \mathrm{E}-03$ & $1.46 \mathrm{E}-03$ & $1.46 \mathrm{E}-03$ & $1.46 \mathrm{E}-03$ & $2.45 \mathrm{E}-03$ \\
\hline PHI-D & $7.89 \mathrm{E}-02$ & $5.14 \mathrm{E}-04$ & $5.14 \mathrm{E}-04$ & $5.14 \mathrm{E}-04$ & $1.14 \mathrm{E}-04$ & $7.89 \mathrm{E}-02$ & $5.14 E-04$ & $5.14 \mathrm{E}-04$ & 5.1 & $2.23 \mathrm{E}-03$ \\
\hline PHI -C & $7.89 \mathrm{E}-02$ & $5.14 \mathrm{E}-04$ & $5.14 \mathrm{E}-04$ & $5.14 \mathrm{E}-04$ & $1.14 \mathrm{E}-04$ & $7.89 E-02$ & $5.14 \mathrm{E}-04$ & $5.14 \mathrm{E}-04$ & -04 & 2.2 \\
\hline POR-D & 2.91 & -04 & $4.00 \mathrm{E}-04$ & $4.00 \mathrm{E}-04$ & 03 & $2.91 \mathrm{E}-02$ & $4.00 E-04$ & $4.00 \mathrm{E}-04$ & .04 & 8. \\
\hline POR-C & 2.91 & $4.00 \mathrm{E}-04$ & $4.00 \mathrm{E}-04$ & $4.00 E-04$ & $3.14 \mathrm{E}-03$ & $.91 \mathrm{E}-02$ & $4.00 \mathrm{E}-04$ & $4.00 \mathrm{E}-04$ & $4.00 \mathrm{E}-04$ & $8.56 \mathrm{E}-04$ \\
\hline SAV-D & $2.36 \mathrm{E}-02$ & $1.66 \mathrm{E}-03$ & $1.66 \mathrm{E}-03$ & $1.66 \mathrm{E}-03$ & $1.14 \mathrm{E}-04$ & $2.36 \mathrm{E}-02$ & $1.66 \mathrm{E}-03$ & $1.66 \mathrm{E}-03$ & $1.66 \mathrm{E}-03$ & $9.99 \mathrm{E}-04$ \\
\hline SAV-C & $2.36 \mathrm{E}-02$ & $1.66 \mathrm{E}-03$ & $1.66 \mathrm{E}-03$ & $1.66 \mathrm{E}-03$ & $1.14 \mathrm{E}-04$ & $2.36 \mathrm{E}-02$ & $1.66 \mathrm{E}-03$ & $1.66 \mathrm{E}-03$ & $1.66 \mathrm{E}-03$ & $9.99 \mathrm{E}-04$ \\
\hline SEA-C & $2.91 \mathrm{E}-02$ & $4.00 \mathrm{E}-04$ & $4.00 \mathrm{E}-04$ & $4.00 E-04$ & $3.14 \mathrm{E}-03$ & 2.91E-02 & $4.00 \mathrm{E}-04$ & $4.00 \mathrm{E}-04$ & $4.00 \mathrm{E}-04$ & $8.56 \mathrm{E}-04$ \\
\hline TAC-D & $2.91 E-02$ & $4.00 \mathrm{E}-04$ & $4.00 \mathrm{E}-04$ & $4.00 \mathrm{E}-04$ & $3.14 \mathrm{E}-03$ & $2.91 \mathrm{E}-02$ & $4.00 \mathrm{E}-04$ & $4.00 \mathrm{E}-04$ & $4.00 \mathrm{E}-04$ & $8.56 E-04$ \\
\hline TAC-C & $2.91 \mathrm{E}-02$ & $4.00 \mathrm{E}-04$ & $4.00 \mathrm{E}-04$ & $4.00 E-04$ & $3.14 \mathrm{E}-03$ & $2.91 E-02$ & $4.00 E-04$ & $4.00 \mathrm{E}-04$ & $4.00 \mathrm{E}-04$ & $8.56 \mathrm{E}-04$ \\
\hline WIL-D & $8.16 \mathrm{E}-03$ & $1.46 \mathrm{E}-03$ & $1.46 \mathrm{E}-03$ & $1.46 \mathrm{E}-03$ & $1.14 \mathrm{E}-04$ & $8.16 E-03$ & $1.46 \pm-03$ & $1.46 \mathrm{E}-03$ & $1.46 E-03$ & $2.45 \mathrm{E}-03$ \\
\hline WIL-C & $8.16 \mathrm{E}-03$ & $1.46 \mathrm{E}-03$ & $1.46 \mathrm{E}-03$ & $1.46 \mathrm{E}-03$ & $1.14 \mathrm{E}-04$ & $8.16 \mathrm{E}-03$ & $1.46 \mathrm{E}-03$ & $1.46 \mathrm{E}-03$ & $1.46 \mathrm{E}-03$ & $2.45 E-03$ \\
\hline
\end{tabular}


Table 38. Conditional Probability of Peak Values of Population Dose, Cancer Fatalities, Costs, Centerline Individual Dose and Centerline Individual Risk for EIS Accident Categories (Continued)

\section{Individual Centerline Cancer Risk, $0-1.6 \mathrm{~km}$}

\begin{tabular}{|c|c|c|c|c|c|c|c|c|c|c|}
\hline & & & BR-2 & & & & & RHF & & \\
\hline ite/Loc & EIS4 & EIS5A & & A & EIS & 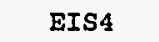 & $E$ & EIS5B & EIS6A & EIS6B \\
\hline $\mathrm{HA}-\mathrm{D}$ & $2.36 \mathrm{E}-02$ & $.66 \mathrm{E}-03$ & $66 \mathrm{E}-03$ & $.66 \mathrm{E}-03$ & $.14 \mathrm{E}-04$ & $.36 E-02$ & $1.66 \mathrm{E}-03$ & $1.66 \mathrm{E}-03$ & $1.66 \mathrm{E}-03$ & $9.99 E-04$ \\
\hline $\mathrm{HA}-\mathrm{C}$ & $2.36 \mathrm{E}-02$ & $.66 \mathrm{E}-03$ & $.66 E-03$ & $1.66 \mathrm{E}-03$ & $14 \mathrm{E}-04$ & $.36 \mathrm{E}-02$ & $1.66 \mathrm{E}-03$ & $1.66 \mathrm{E}-03$ & $.66 E-03$ & $9.99 \mathrm{E}-04$ \\
\hline CNC-D & $1.22 \mathrm{E}-01$ & $.00 \mathrm{E}-04$ & $.00 E-04$ & $2.00 \mathrm{E}-04$ & $.28 \mathrm{E}-04$ & L. $22 \mathrm{E}-01$ & $2.00 \mathrm{E}-04$ & $2.00 \mathrm{E}-04$ & $.00 E-04$ & $2.00 \mathrm{E}-04$ \\
\hline $\mathrm{NC}-\mathrm{C}$ & $1.22 \mathrm{E}-01$ & $.00 \mathrm{E}-04$ & $.00 \mathrm{E}-04$ & $2.00 \mathrm{E}-04$ & $3.28 E-04$ & $.22 E-01$ & $2.00 \mathrm{E}-04$ & $2.00 \mathrm{E}-04$ & $.00 \mathrm{E}-04$ & $2.00 \mathrm{E}-04$ \\
\hline$A L-D$ & $3.73 \mathrm{E}-02$ & $.57 E-03$ & $1.57 \mathrm{E}-03$ & $1.57 E-03$ & $4.85 E-04$ & $.73 \mathrm{E}-02$ & $1.57 \mathrm{E}-03$ & $1.34 \mathrm{E}-03$ & 1.57 & E-03 \\
\hline GAL -C & $3.73 \mathrm{E}-02$ & $.57 E-03$ & $1.57 \mathrm{E}-03$ & $1.57 \mathrm{E}-03$ & $4.85 \mathrm{E}-04$ & $.73 E-02$ & $1.57 E-03$ & 1. $34 \mathrm{E}-03$ & $1.57 \mathrm{E}-03$ & -03 \\
\hline JAC-D & $2.36 \mathrm{E}-02$ & $1.66 \mathrm{E}-03$ & $1.66 \mathrm{E}-03$ & $1.66 \mathrm{E}-03$ & $1.14 \mathrm{E}-04$ & $.36 \mathrm{E}-02$ & $1.66 \mathrm{E}-03$ & $1.66 \mathrm{E}-03$ & -03 & $9.99 E-04$ \\
\hline JAC-C & $2.36 \mathrm{E}-02$ & $1.66 \mathrm{E}-03$ & 1.66 & $1.66 \mathrm{E}-03$ & $1.14 \mathrm{E}-04$ & $.36 \mathrm{E}-02$ & $1.66 \mathrm{E}-03$ & $1.66 \mathrm{E}-03$ & 03 & -04 \\
\hline LOS-D & $1.22 \mathrm{E}-01$ & $2-04$ & .04 & $2.00 \mathrm{E}-04$ & $8.28 E-04$ & $22 \mathrm{E}-01$ & $2.00 \mathrm{E}-04$ & $2.00 \mathrm{E}-04$ & 04 & -04 \\
\hline LOS-C & $1.22 \mathrm{E}-01$ & $.00 \mathrm{E}-04$ & 2.00 & $2.00 \mathrm{E}-04$ & $8.28 \mathrm{E}-04$ & $.22 \mathrm{E}-01$ & $2.00 \mathrm{E}-04$ & $2.00 \mathrm{E}-04$ & 04 & -04 \\
\hline OT-D & $8.16 \mathrm{E}-03$ & $1.46 \mathrm{E}-03$ & -03 & $1.46 \mathrm{E}-03$ & $9.99 \mathrm{E}-04$ & $.16 \mathrm{E}-03$ & 1.46 & 1.46 & 03 & \\
\hline EW-D & $3.45 \mathrm{E}-03$ & $.06 \mathrm{E}-03$ & 1.06 & $1.06 \mathrm{E}-03$ & $9.70 \mathrm{E}-04$ & $.45 \mathrm{E}-03$ & $1.06 \mathrm{E}-03$ & $9.70 \mathrm{E}$ & 03 & \\
\hline$E W-C$ & $3.45 \mathrm{E}-03$ & $1.06 \mathrm{E}-03$ & 1.06 & $1.06 \mathrm{E}-03$ & $9.70 \mathrm{E}-04$ & $.45 E-03$ & $1.06 \mathrm{E}-03$ & $9.70 \mathrm{E}-04$ & 1 . & -03 \\
\hline NOR-D & $8.16 \mathrm{E}-03$ & $1.46 \mathrm{E}-03$ & 1.46 & $1.46 \mathrm{E}-03$ & $9.99 \mathrm{E}-04$ & $.16 \mathrm{E}-03$ & $1.46 \mathrm{E}-03$ & $1.46 \mathrm{E}-03$ & 1.46 & $9-03$ \\
\hline NOR-C & 8.1 & -03 & 1.46 & $1.46 \mathrm{E}-03$ & $9.99 \mathrm{E}-04$ & $.16 \mathrm{E}-03$ & $1.46 \mathrm{E}-03$ & $1.46 \mathrm{E}-03$ & 1.46 & $2.45 \mathrm{E}-03$ \\
\hline PHI -D & -02 & -04 & & $5.14 \mathrm{E}-04$ & $1.14 \mathrm{E}-04$ & $7.89 \mathrm{E}-02$ & $5.14 \mathrm{E}-04$ & $5.14 \mathrm{E}-04$ & 5.14 & $2.23 \mathrm{E}-03$ \\
\hline PHI -C & 7.8 & & & 5.14 & $1.14 \mathrm{E}-04$ & $.89 \mathrm{E}-02$ & $5.14 \mathrm{E}-04$ & $5.14 \mathrm{E}-04$ & 5.14 & $2.23 E-03$ \\
\hline POR-D & $2.91 \mathrm{E}-02$ & $4.00 \mathrm{E}-04$ & 1.26 & 4.00 & 3 & $91 E-02$ & $4.00 \mathrm{E}-04$ & $8.56 \mathrm{E}-04$ & $4.00 \mathrm{E}-04$ & $4.00 E-04$ \\
\hline POR-C & $2.91 \mathrm{E}-02$ & $4.00 \mathrm{E}-04$ & $1.26 \mathrm{E}-03$ & $4.00 \mathrm{E}-04$ & $3.14 \mathrm{E}-03$ & $.91 E-02$ & $4.00 \mathrm{E}-04$ & $8.56 \mathrm{E}-04$ & $4.00 \mathrm{E}-04$ & $4.00 \mathrm{E}-04$ \\
\hline SAV-D & $2.36 \mathrm{E}-02$ & $1.66 \mathrm{E}-03$ & $1.66 \mathrm{E}-03$ & $.66 E-03$ & $1.14 \mathrm{E}-04$ & $.36 \mathrm{E}-02$ & $1.66 \mathrm{E}-03$ & $1.66 \mathrm{E}-03$ & $1.66 \mathrm{E}-03$ & $9.99 \mathrm{E}-04$ \\
\hline SAV-C & $2.36 \mathrm{E}-02$ & $1.66 \mathrm{E}-03$ & $1.66 \mathrm{E}-03$ & $1.66 \mathrm{E}-03$ & $1.14 \mathrm{E}-04$ & $.36 \mathrm{E}-02$ & $1.66 \mathrm{E}-03$ & $1.66 \mathrm{E}-03$ & 1.66 & $9.99 \mathrm{E}-04$ \\
\hline SEA-C & $2.91 \mathrm{E}-02$ & $4.00 \mathrm{E}-04$ & $1.26 \mathrm{E}-03$ & $4.00 \mathrm{E}-04$ & $3.14 \mathrm{E}-03$ & $.91 \mathrm{E}-02$ & $4.00 \mathrm{E}-04$ & $8.56 \mathrm{E}-04$ & 4.00 & $3-04$ \\
\hline TAC-D & $2.91 \mathrm{E}-02$ & $4.00 \mathrm{E}-04$ & $1.26 \mathrm{E}-03$ & $4.00 \mathrm{E}-04$ & $3.14 \mathrm{E}-03$ & $2.91 \mathrm{E}-02$ & $4.00 \mathrm{E}-04$ & $8.56 \mathrm{E}-04$ & 4.001 & $4.00 \mathrm{E}-04$ \\
\hline$A C-C$ & E-02 & $4.00 \mathrm{E}-04$ & $1.26 \mathrm{E}-03$ & $4.00 E-04$ & $3.14 E-03$ & $2.91 \mathrm{E}-02$ & $4.00 \mathrm{E}-04$ & $8.56 \mathrm{E}-04$ & $4: 00 \mathrm{E}-04$ & $4.00 \mathrm{E}-04$ \\
\hline IL-D & $8.16 \mathrm{E}-03$ & $1.46 \mathrm{E}-03$ & $1.46 \mathrm{E}-03$ & $1.46 \mathrm{E}-03$ & $9.99 \mathrm{E}-04$ & $8.16 \mathrm{E}-03$ & $1.46 \mathrm{E}-03$ & $1.46 \mathrm{E}-03$ & $1.46 \mathrm{E}-03$ & $2.45 E-03$ \\
\hline WIL-C & $8.16 \mathrm{E}-03$ & $1.46 \mathrm{E}-03$ & $1.46 \mathrm{E}-03$ & $1.46 \mathrm{E}-03$ & $9.99 E-04$ & $8.16 E-03$ & $1.46 \mathrm{E}-03$ & $1.46 \mathrm{E}-03$ & $1.46 \mathrm{E}-03$ & $2.45 E-03$ \\
\hline
\end{tabular}


Table 38. Conditional Probability of Peak Values of Population Dose, Cancer Fatalities, Costs, Centerline Individual Dose and Centerline Individual Risk for EIS Accident Categories (Concluded)

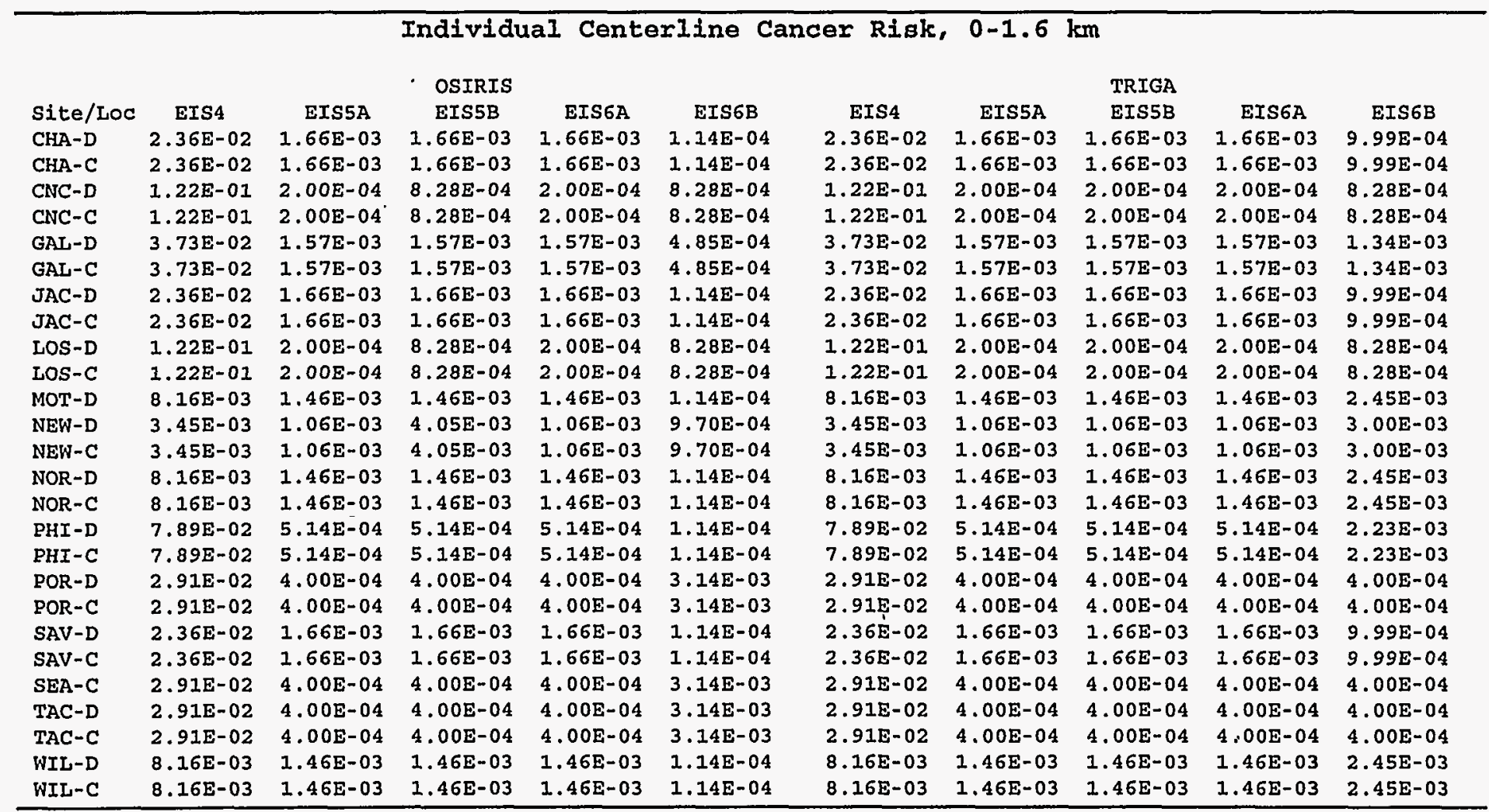


receive a dose that is about 1.5 times larger than a normal 50 -year individual dose is about $6 \mathrm{x}$ $10^{-16}$ per port call.

Table 35 shows that the number of cancer deaths, expected to occur 20 to 40 years after the accident among the population located at the time of the accident within 50 miles of the accident site, ranges from $1.24 \times 10^{-6}$ for the MOTSU dock calculation that used the RHF inventory, EIS4 release fractions, and Cape Hatteras weather to 271 for the Newark dock calculation that used the BR-2 inventory, EIS6B release fractions, and New York City weather. If these 271 cancer fatalities occur more or less uniformly over the twenty-year period that begins twenty years after the accident, then the accident will lead to a cancer death rate of about 14 people per year during that twenty-year period. If the largest yearly cancer death rate caused by the accident is twice the average rate, then during some years perhaps 30 people will die from cancers induced by the radiation exposures they received following the accident. Thus, the largest cancer death rate that might be caused by the accident is $30 / 2 \times 10^{6}$ $=1.5 \times 10^{-5}$ where $2 \times 10^{6}$ is the number of people exposed to radiation as a result of the hypothesized accident at the Newark dock location. Since the normal death rate due to all types of cancer is about 200 deaths per 100,000 people per year [WA92] or $2.0 \times 10^{-3}$ deaths per year, the largest mean (expected) death rate for any high-temperature event calculation is more than 100 times smaller than the normal death rate due to cancer.

Table 37 shows that the largest number of cancer deaths obtained for any weather trial in any high-temperature event calculation was 6000 and that this result was obtained for the Newark channel calculation that used the BR-2 inventory, EIS6B release fractions, and New York City weather. Again, if the largest yearly cancer death rate during the period 20 to 40 years after the accident, when these cancers appear in the exposed population, is twice the average rate, then the largest yearly cancer death rate obtained for any high-temperature event calculation will be about $[2 \times 6000 / 20] /\left[2 \times 10^{6}\right]=3 \times 10^{-4}$, which is 10 times smaller than the normal death rate due to cancer. Table 38 shows that this result has a conditional probability of $1.45 \times 10^{-5}$ (conditional on the occurrence of the accident), and thus an absolute probability of occurrence of about $9 \times 10^{-14}$ per port call, as the probability of occurrence of an EIS6B accident is about $6 \times 10^{-11}$ per port call. Thus, even the largest number of cancer deaths predicted by this MACCS calculation would probably not be capable of detection among the exposed population by the best of epidemiological studies.

Figures 40 and 41 present CCDFs for population dose and cancer fatalities among the population located within 50 miles of the accident site $(0-80 \mathrm{~km})$ for each of the thirteen ports studied. The figures display the range and probability (conditional on the occurrence of the accident) of these two consequence measures. Figure 40 shows that any large accident (a ship collision that leads to an EISB release from a BR-2 inventory is a large accident) will lead to a 50-year population dose of at least $1.0 \mathrm{~Sv}$, that the values of the 99th quantile (conditional probability of 1.0E-02) range from about $2 \times 10^{3}$ to $5 \times 10^{4} \mathrm{~Sv}$, and that the largest (peak) result calculated ranges from about $3 \times 10^{3}$ to a little more than $1 \times 10^{5} \mathrm{~Sv}$. Figure 41 shows that a large accident has a 70 percent chance (range of 0.5 to 1.0) of causing at least one cancer death among the exposed population 20 to 40 years in the future, that the values of the 


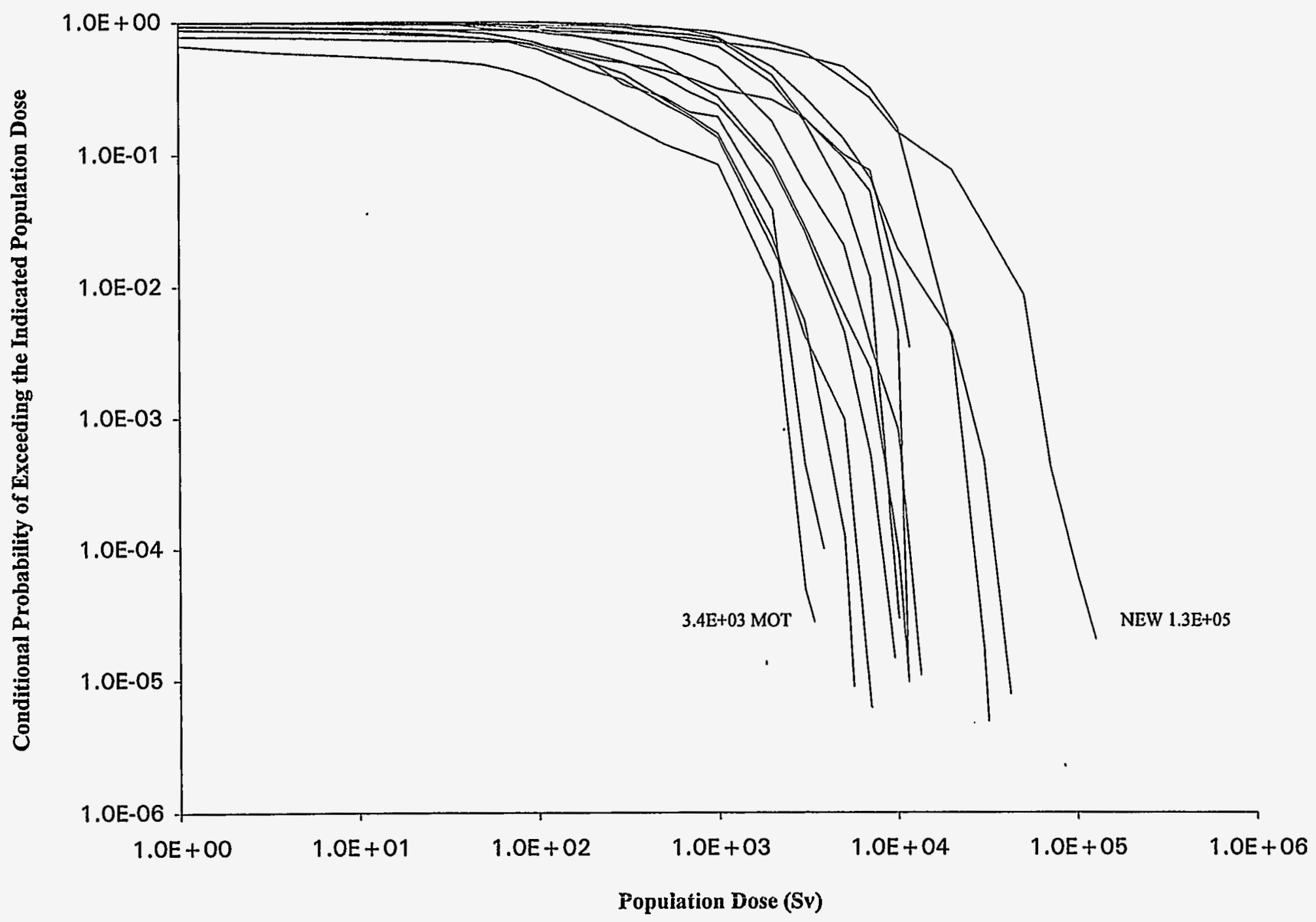

Figure 40. EDE Whole Body Population Dose, $0-80 \mathrm{~km}$, All Dock Locations, BR-2 Inventory, EIS6B Release Fractions, Variable Meteorology 


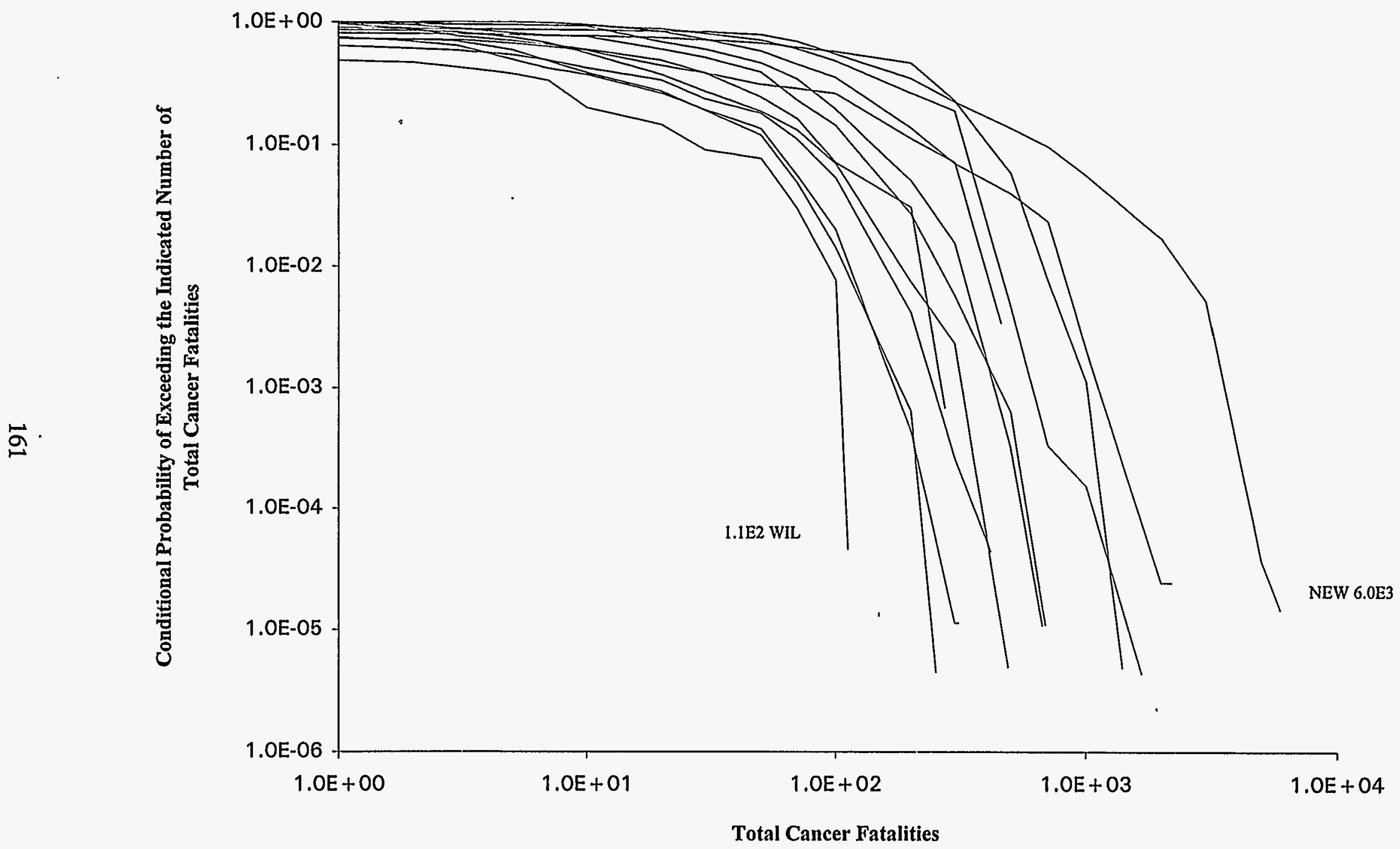

Figure 41. Total Cancer Fatalities, 0-80 km, All Channel Locations, BR-2 Inventory, EIS6B Release Fractions, Variable Meteorology 
99.9th quantile range from 100 to 3500 cancer fatalities, and that the largest (peak) result calculated ranges from 110 to 6000 deaths due to cancer some 20 to 40 years after the time of the accident.

Figure 42 presents CCDFs for the 50-year population dose and cancer fatalities for the distance range $0-80.5 \mathrm{~km}$ for both the dock and channel locations at the Charleston port. Figures 43 through 53 present the same set of CCDFs for each of the other twelve ports examined. In all of these figures, the pair of cancer fatality CCDFs lie below and to the left of the pair of population dose CCDFs. These figures show that the dock and channel CCDFs for both population dose and cancer fatalities are quite similar at twelve of the thirteen ports, and that at the remaining port (Concord), the dock and channel CCDFs are similar until the 99th quantile is reached (that is, lower quantiles diverge). Thus, as was found for the base case calculations, these results show that moving the coordinates of the origin of a population distribution a small distance (a few miles) has little effect on predictions of population dose or cancer fatalities among a population located within 50 miles of the accident location (Table 19 lists the coordinates of the origins of the polar coordinate population distributions used in these calculations).

\subsection{Sensitivity Calculations}

Two types of sensitivity calculations were performed, calculations that examined the effect of using meteorological data recorded at a National Weather Service station located some distance from the port, and calculations that examined the impacts of alternative choices concerning acute health-effect dose conversion factors, shielding parameters, release fractions, workforce populations, puff and tail releases, and release of CRUD. The meteorological sensitivity calculations compared results obtained using variable meteorology recorded at a National Weather Service station to results obtained using constant meteorology recorded at the port. All other sensitivity calculations were performed by modifying the Charleston base case dock calculation as was appropriate in order to examine the parameter of interest. All of the sensitivity calculations used the BR-2 inventory, and EA5 release fractions were used in all calculations except those that examined sensitivity to release fractions values.

\subsubsection{Variable Versus Constant Meteorology}

Constant meteorology calculations were performed for seven of the thirteen ports studied: Charleston, Los Angeles, Newark, Norfolk, Philadelphia, Portland, and MOTSU/Wilmington (remember that the Wilmington channel location is the channel location for both the Wilmington commercial port and the MOTSU military port). For each port examined, two sets of constant meteorology calculations were performed. Both used the joint frequency distribution of windspeed ( 6 windspeed ranges) and stability class ( 6 stability classes) by wind direction (16 compass sectors) for the port being analyzed as the meteorological input data for MACCS. Each calculation was run two times, once for no rain and once assuming that it was raining throughout the entire simulation. Therefore, each MACCS constant meteorology calculation consisted of $6 \times 6 \times 16 \times 2=1152$ constant meteorology trials. From these 1152 
Conditional Probability of Exceeding the Indicated Number of Total Cancer Fatalities or Population Dose

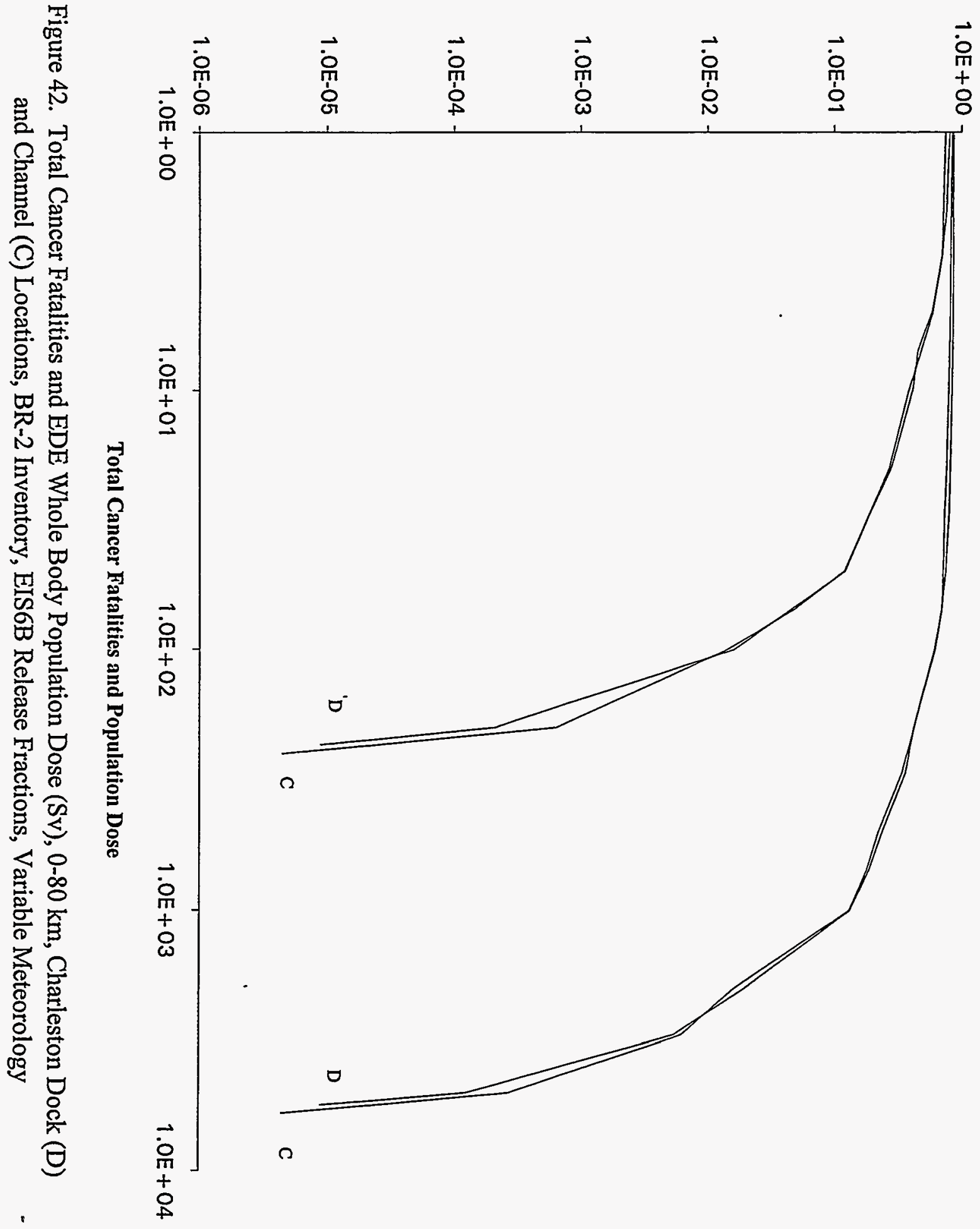




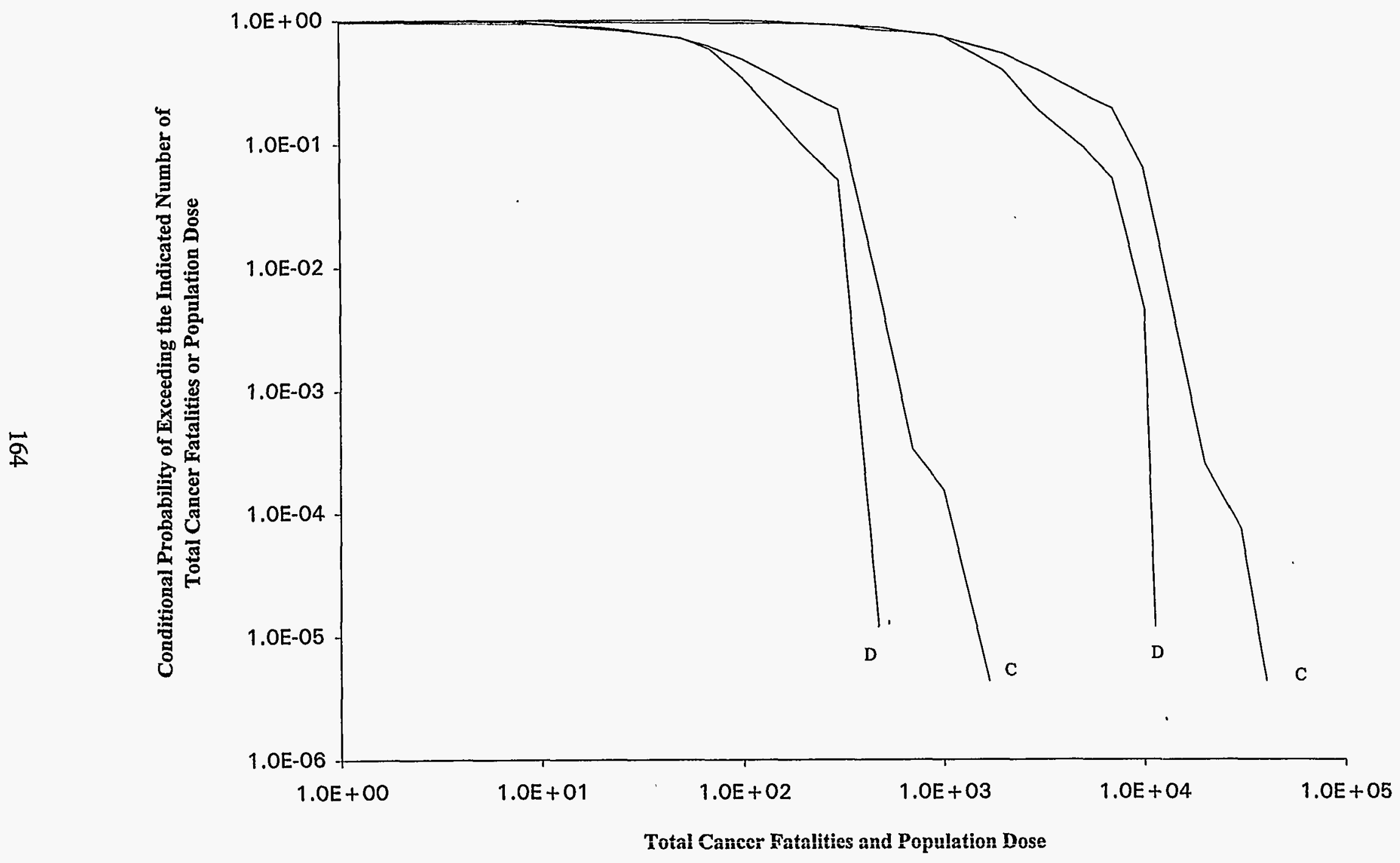

Figure 43. Total Cancer Fatalities and EDE Whole Body Population Dose (Sv), 0-80 km, Concord Dock (D) and (C) Channel Locations, BR-2 Inventory, EIS6B Release Fractions, Variable Meteorology 


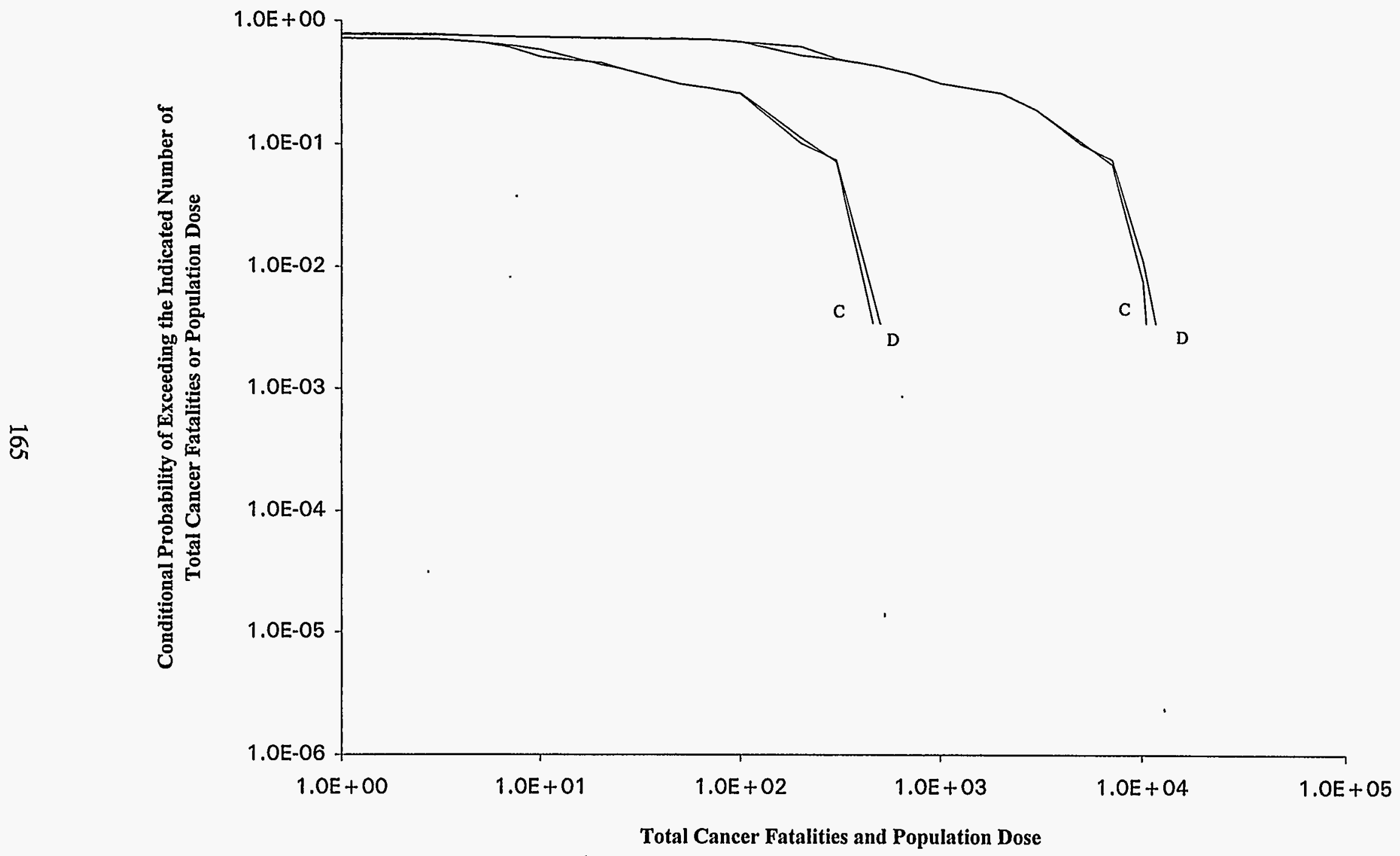

Figure 44. Total Cancer Fatalities and EDE Whole Body Population Dose (Sv), 0-80 km, Galveston Dock (D) and Channel (C) Locations, BR-2 Inventory, EIS6B Release Fractions, Variable Meteorology 


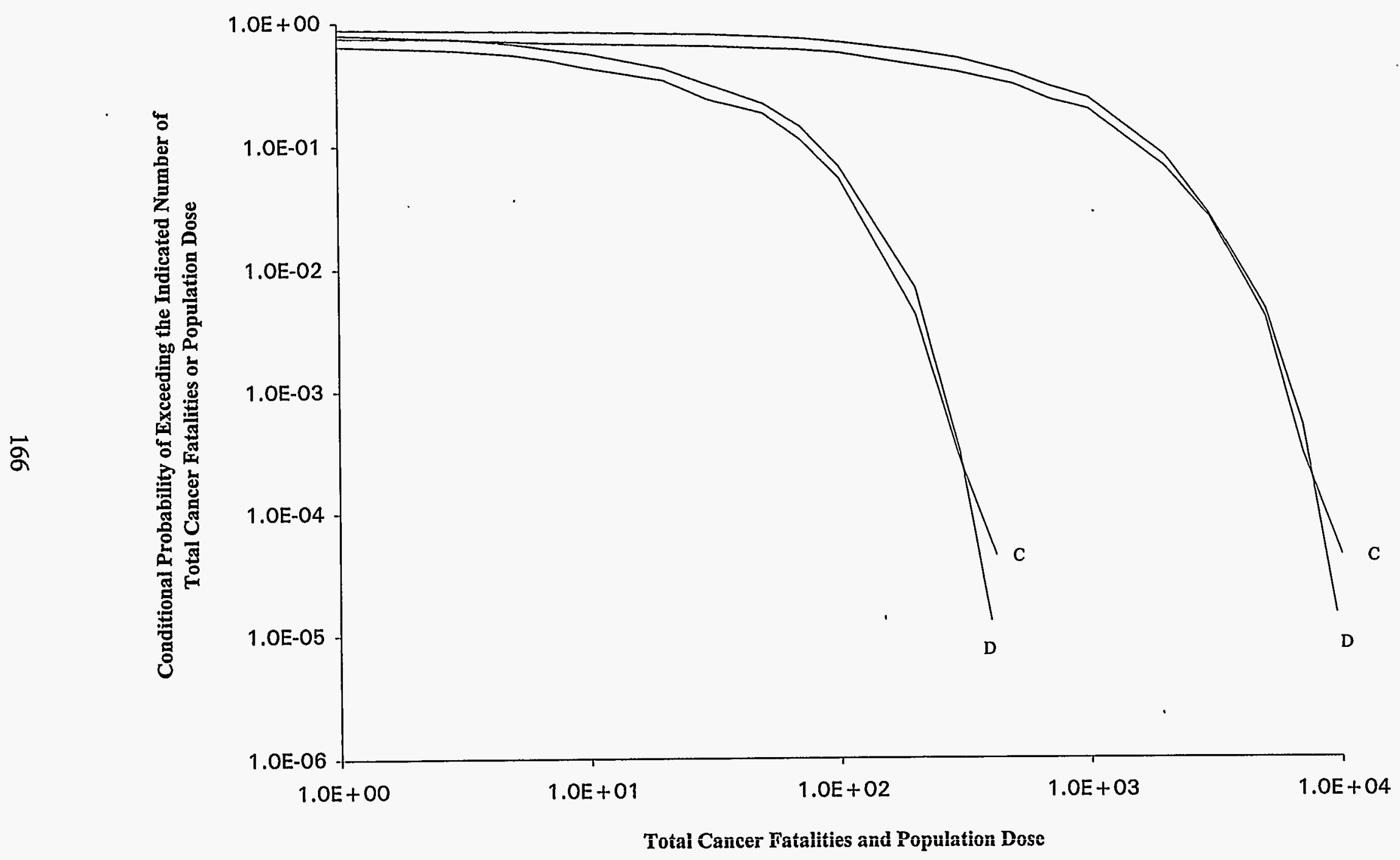

Figure 45. Total Cancer Fatalities and EDE Whole Body Population Dose (Sv), 0-80 km, Jacksonville Dock (D) and Channel (C) Locations, BR-2 Inventory, EIS6B Release Fractions, Variable Meteorology 


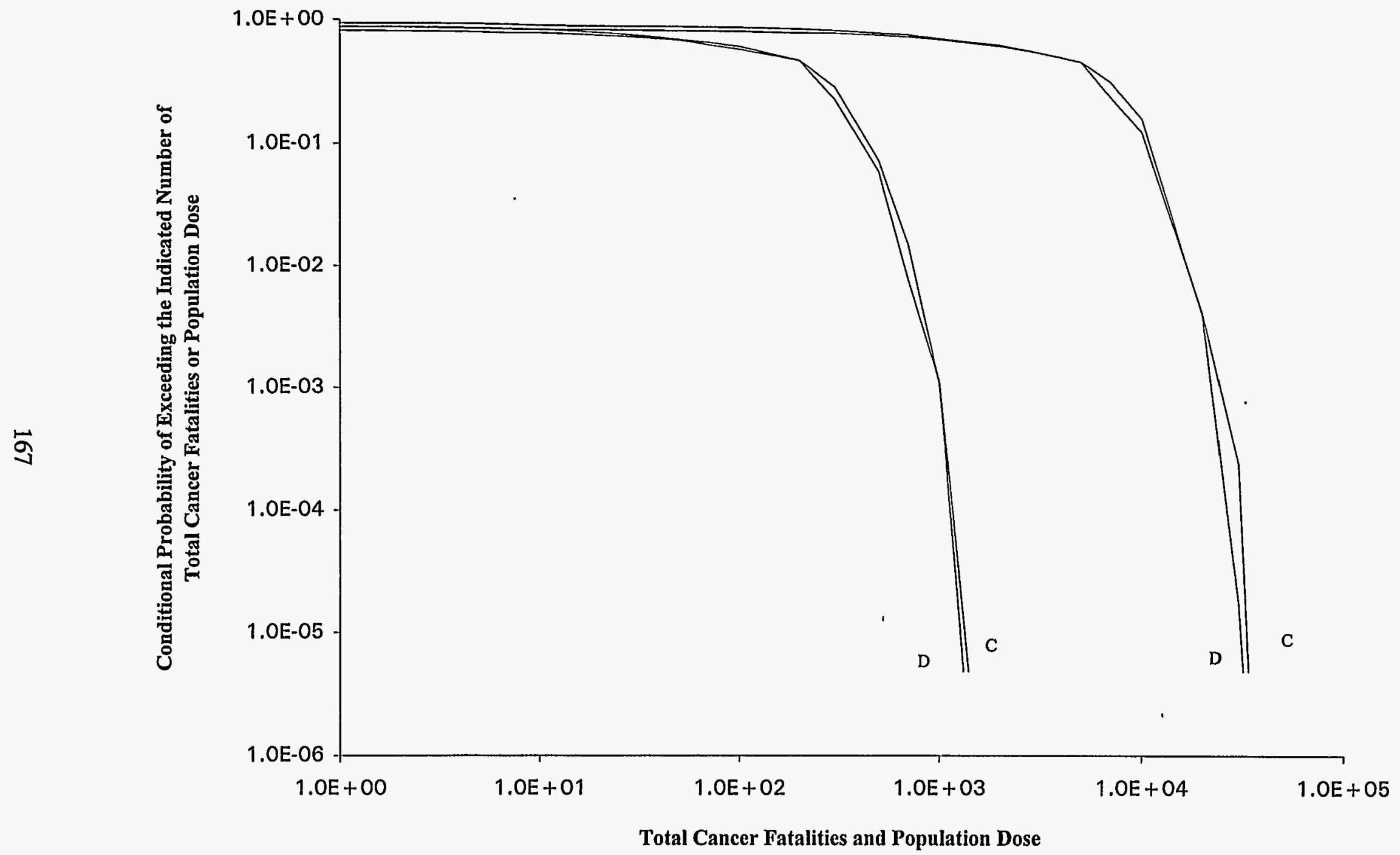

Figure 46. Total Cancer Fatalities and EDE Whole Body Population Dose (Sv), 0-80 km, Los Angeles Dock (D) and Channel (C) Locations, BR-2 Inventory, EIS6B Release Fractions, Variable Meteorology 


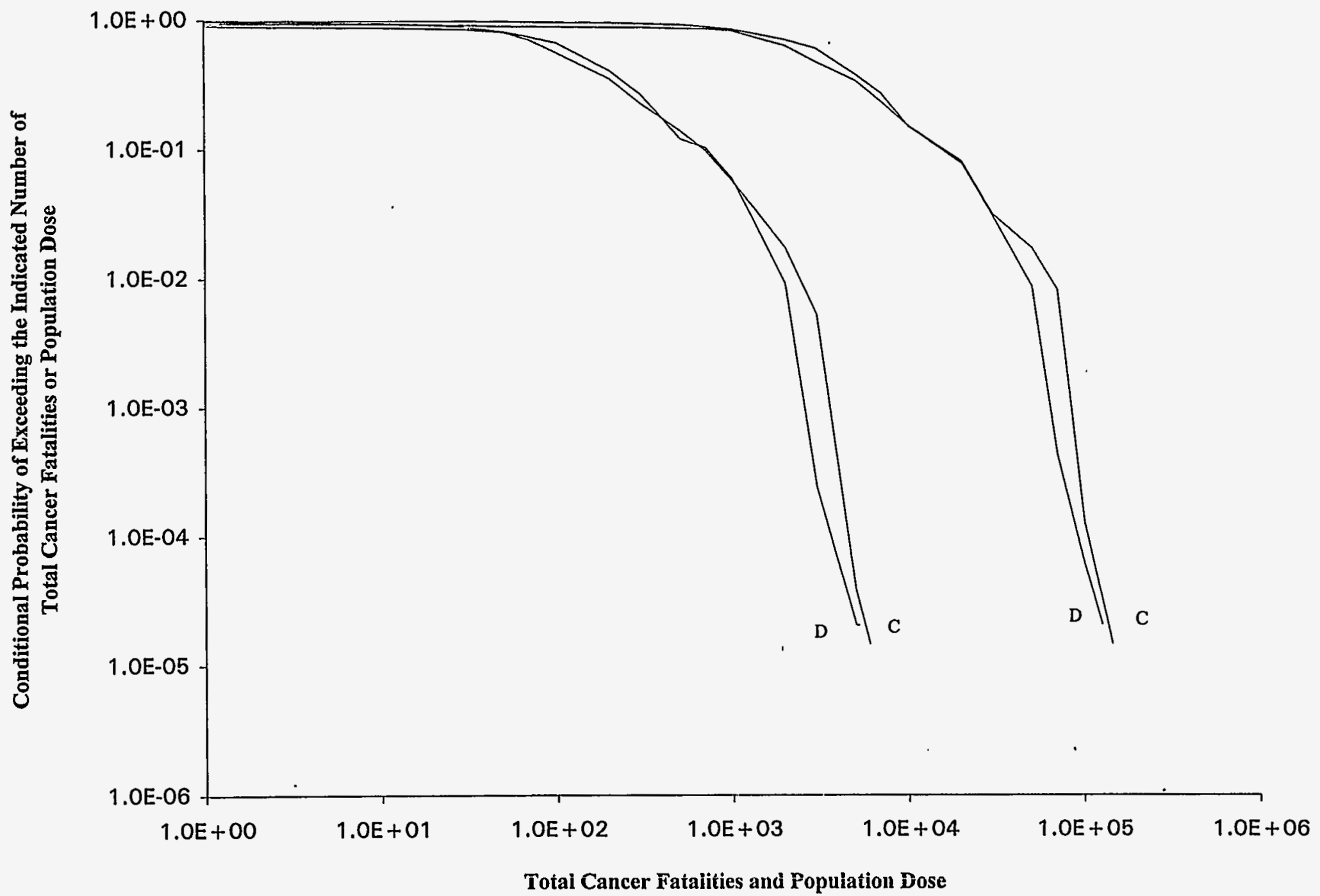

Figure 47. Total Cancer Fatalities and EDE Whole Body Population Dose (Sv), 0-80 km, Newark Dock (D) and Channel (C) Locations, BR-2 Inventory, EIS6B Release Fractions, Variable Meteorology 
Conditional Probability of Exceeding the Indicated Number of Total Cancer Fatalities or Population Dose

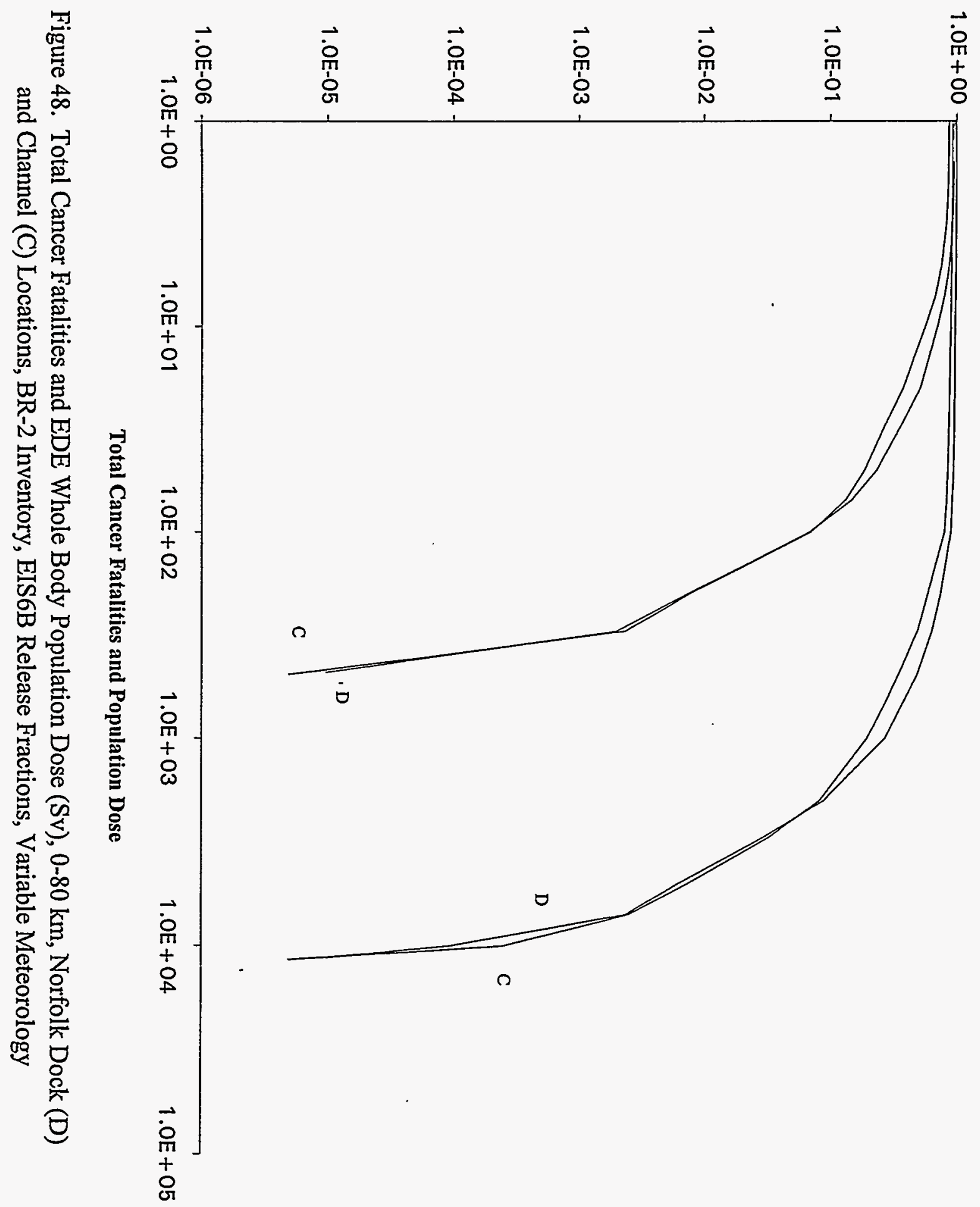




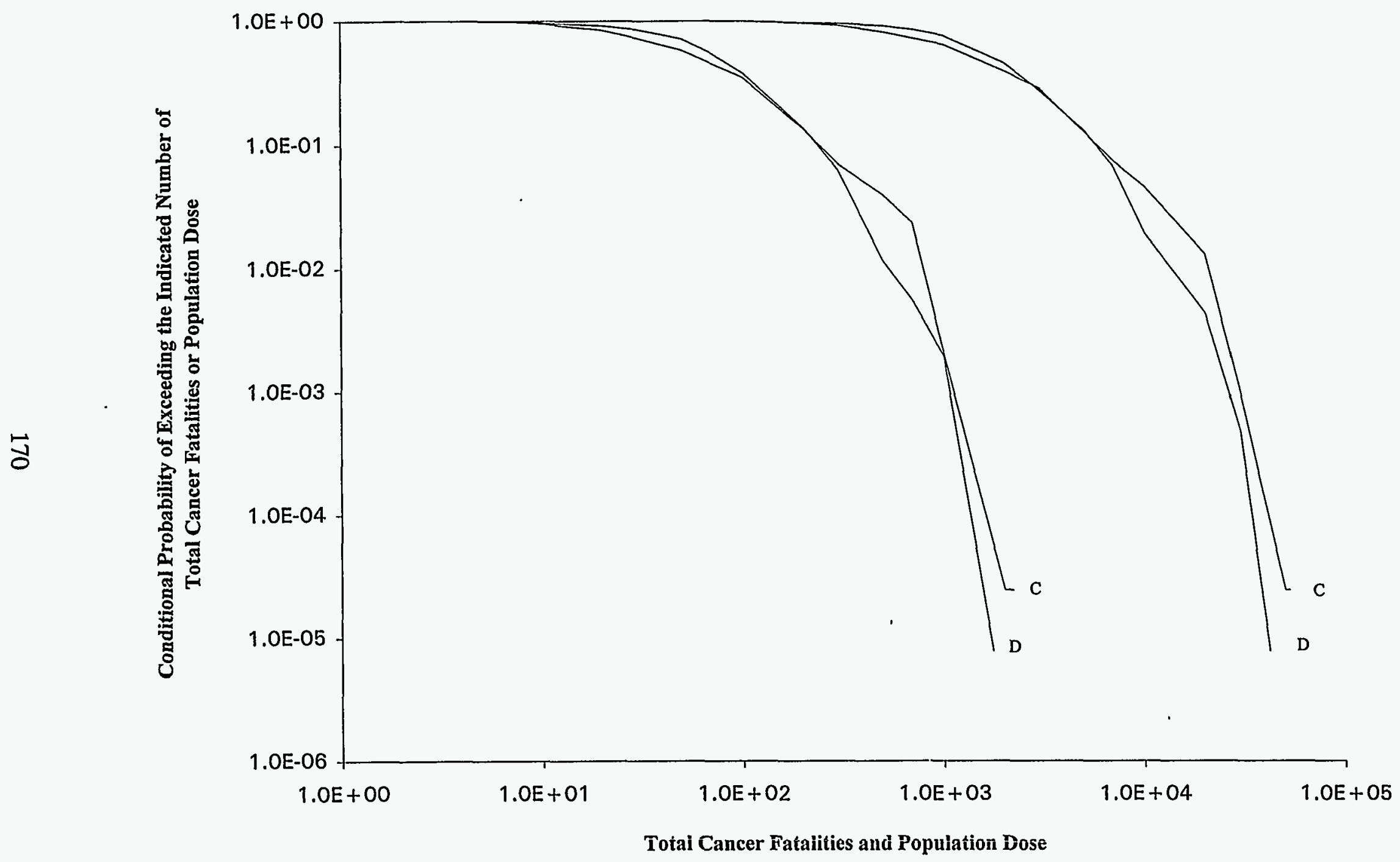

Figure 49. Total Cancer Fatalities and EDE Whole Body Population Dose (Sv), 0-80 km, Philadelphia Dock (D) and Channel (C) Locations, BR-2 Inventory, EIS6B Release Fractions, Variable Meteorology 
Conditional Probability of Exceeding the Indicated Number of Total Cancer Fatalities or Population Dose

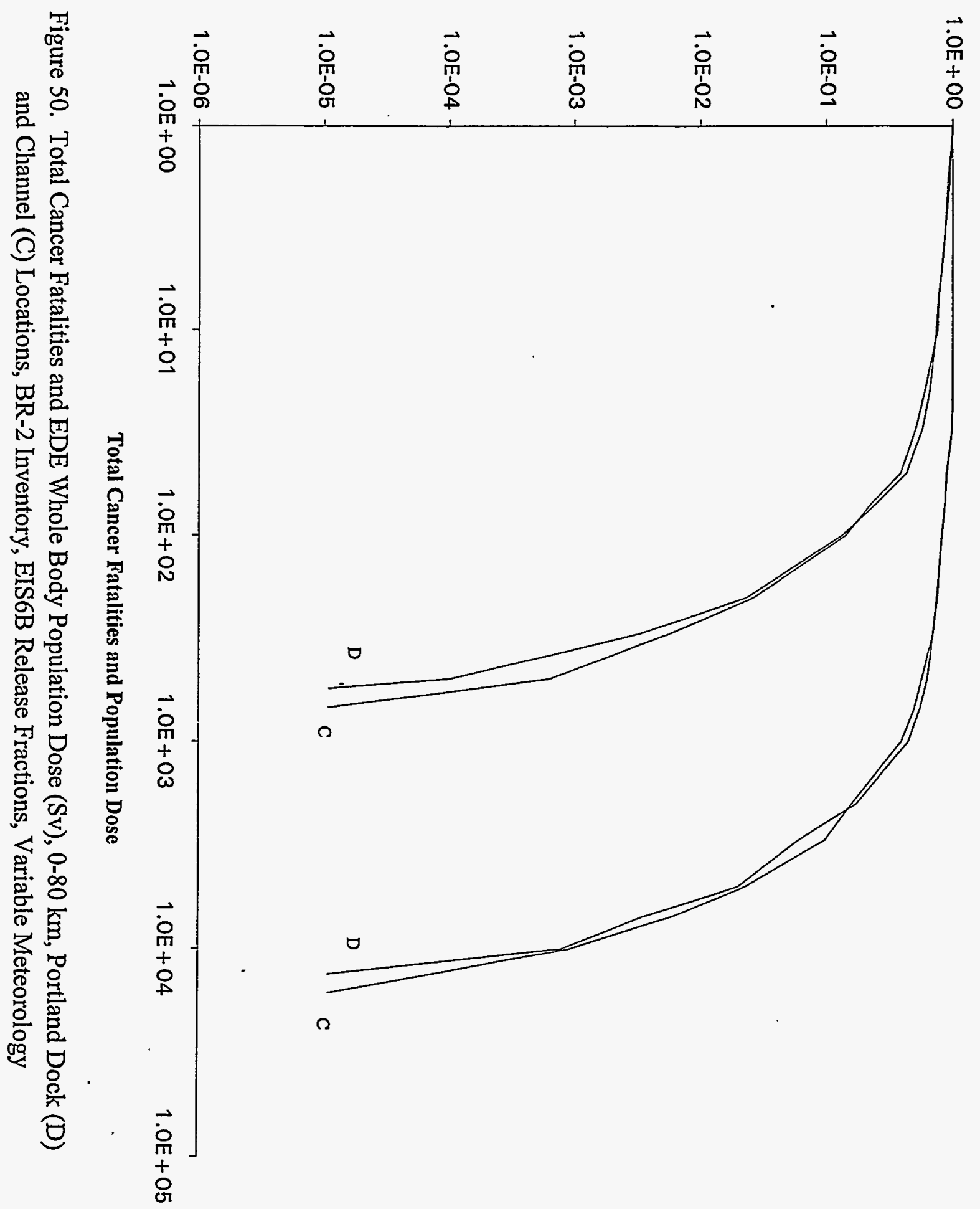




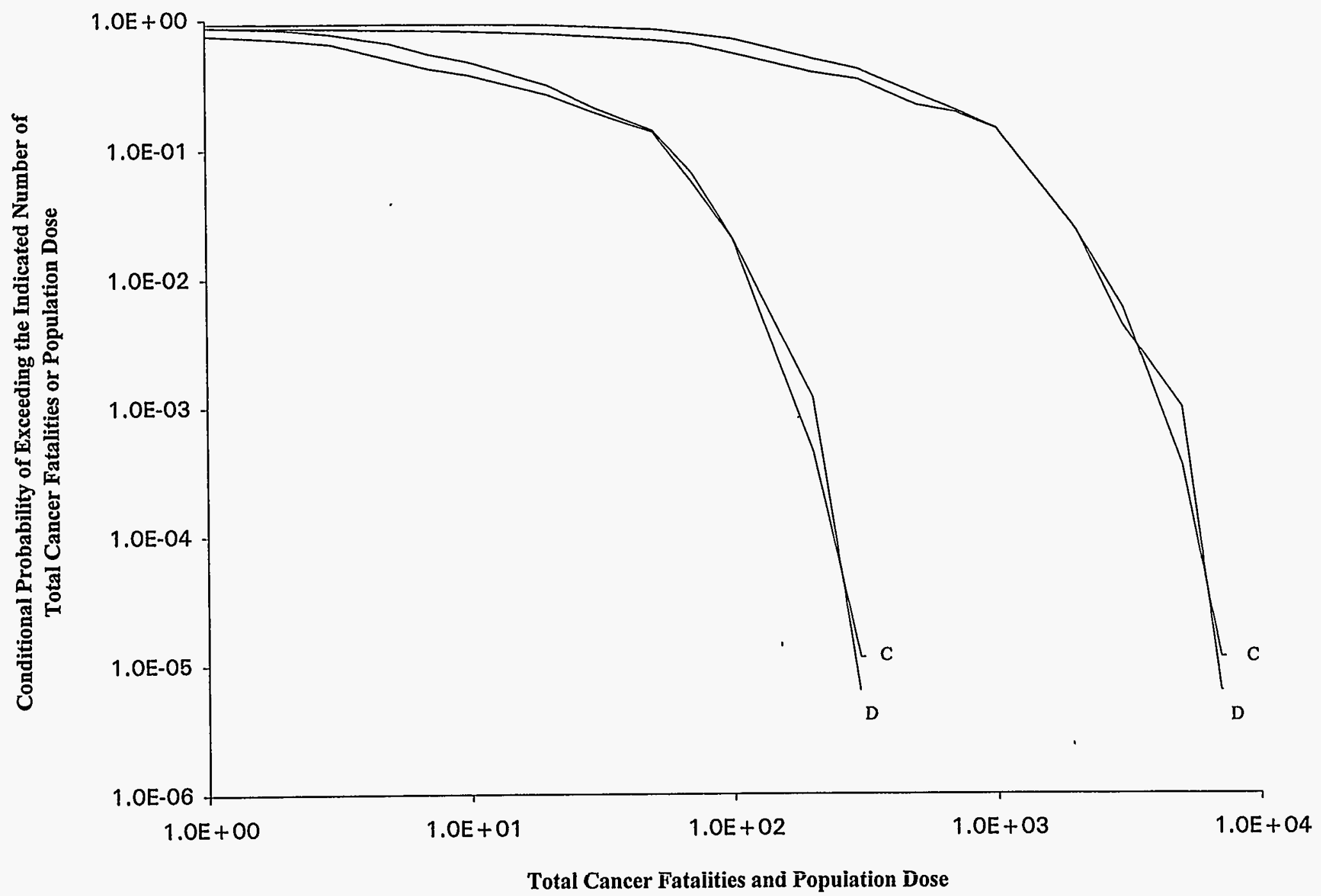

Figure 51. Total Cancer Fatalities and EDE Whole Body Population Dose (Sv), 0-80 km, Savannah Dock (D) and Channel (C) Locations, BR-2 Inventory, EIS6B Release Fractions, Variable Meteorology 


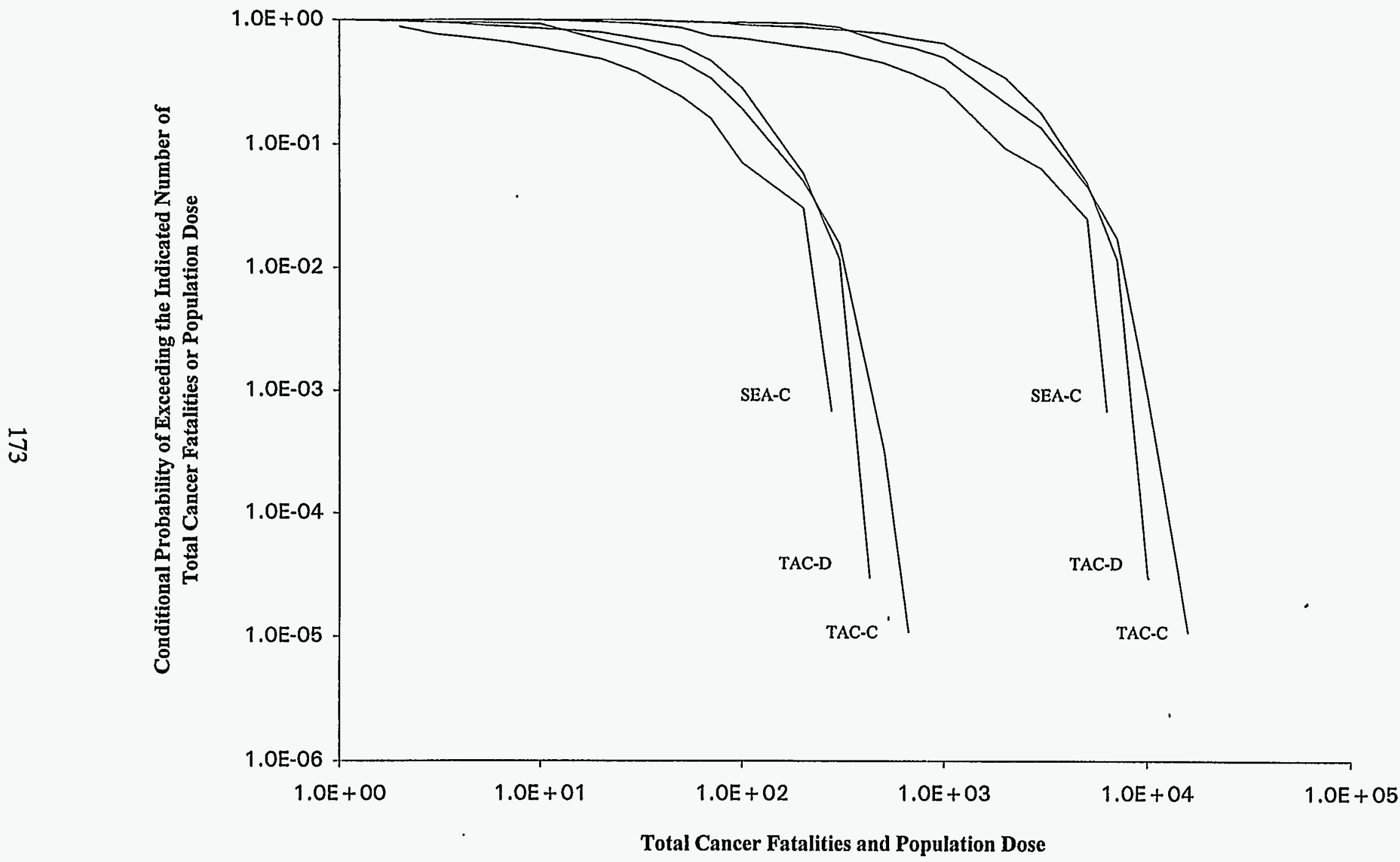

Figure 52. Total Cancer Fatalities and EDE Whole Body Population Dose (Sv), 0-80 km, Tacoma Dock (D) and Channel (C) and Seattle Channel (C) Locations, BR-2 Inventory, EIS6B Release Fractions, Variable Meteorology 


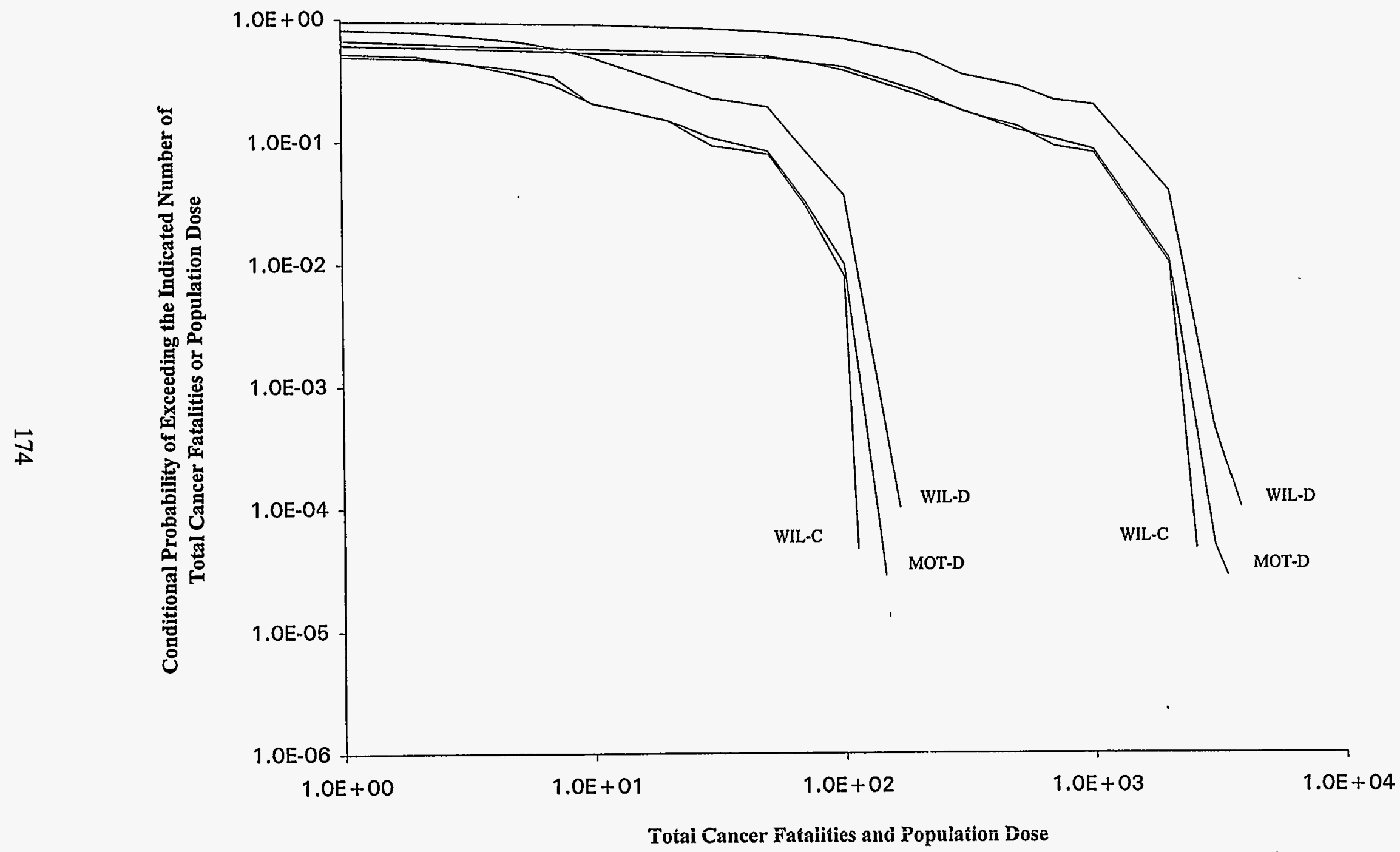

Figure 53. Total Cancer Fatalities and EDE Whole Body Population Dose (Sv), 0-80 km, Wilmington Dock (D) and Channel (C) and MOTSU Dock (D) Locations, BR-2 Inventory, EIS6B Release Fractions, Variable Meteorology 
trials, a CCDF and a mean (expected result) were constructed for each consequence measure calculated.

For each of the seven ports examined, Table 39 compares the expected (mean) and 99.9th quantile values of the 50-year population dose and cancer fatalities obtained using variable meteorology for the distance range $0-80.5 \mathrm{~km}$ to the values obtained using constant meteorology. Inspection of the table shows that the mean values are quite similar. For example, for the population dose, the ratio of the variable meteorology result to the constant meteorology result has an average value and standard deviation of $1.51 \pm 0.96$ for the population dose and $1.60 \pm 1.07$ for cancer fatalities. The Wilmington dock calculation yielded the largest values for these ratios, 4.73 for the mean population dose and 5.01 for cancer fatalities. Thus, the use of meteorological data recorded at a nearby National Weather Service station yields expected (mean) values for the 50-year population dose and cancer fatalities that are on average about 50 to 60 percent larger than the values obtained using constant meteorological conditions developed for each of the six Pasquil-Gifford stability classes from data recorded at the harbor.

Table 39. Mean and 99.9th Quantile Values for Population Dose and

Cancer Fatalities Calculated Using Variable and

Constant Meteorology for Seven Ports

\begin{tabular}{|c|c|c|c|c|c|c|c|c|}
\hline \multirow{3}{*}{$\begin{array}{l}\text { EDE } \\
\text { Site/LOC }\end{array}$} & \multirow{2}{*}{\multicolumn{4}{|c|}{$\begin{array}{c}\text { E Whole Body Population Dose, } 0-80 \mathrm{~km} \text { (Sv) } \\
\text { Mean }\end{array}$}} & \multicolumn{4}{|c|}{ Total Cancer Fatalities, $0-80 \mathrm{~km}$} \\
\hline & & & & & Me & & 99.9 th & uantile \\
\hline & Var & Const & Var & Const & Var & Const & Var & Const \\
\hline CHA $-D$ & $4.15 E+00$ & $3.06 E+00$ & $4.63 E+01$ & $2.13 E+01$ & $1.89 E-01$ & $1.29 \mathrm{E}-01$ & $1.98 \mathrm{E}+00$ & $8.43 E-0 I$ \\
\hline CHA-C & $4.18 E+00$ & $3.41 E+00$ & $9.03 E+01$ & $3.71 E+01$ & $1.90 E-01$ & $1.43 \mathrm{E}-01$ & $3.96 E+00$ & $2.01 E+00$ \\
\hline LOS-D & $4.71 E+01$ & $3.44 \mathrm{E}+01$ & $2.67 E+02$ & $1.19 E+02$ & $1.99 E+00$ & $1.44 \mathrm{E}+00$ & $1.03 E+01$ & $5.35 E+00$ \\
\hline LOS-C & $4.26 \mathrm{E}+01$ & $3.31 E+01$ & $2.19 E+02$ & $8.16 E+01$ & $1.80 \mathrm{E}+00$ & $1.38 \mathrm{E}+00$ & $9.81 E+00$ & $3.43 E+00$ \\
\hline NEW-D & $6.55 E+01$ & $5.47 E+01$ & $5.87 E+02$ & $2.32 E+02$ & $2.75 E+00$ & $2.28 \mathrm{E}+00$ & $2.46 \mathrm{E}+01$ & $9.54 \mathrm{E}+00$ \\
\hline NEW-C & $6.93 E+01$ & $5.89 E+01$ & $9.41 E+02$ & NOT-FOUND & $2.90 \mathrm{E}+00$ & $2.46 \mathrm{E}+00$ & $3.89 E+01$ & NOT-FOUND \\
\hline NOR-D & $8.54 E+00$ & $8.88 E+00$ & $1.03 E+02$ & $7.26 \mathrm{E}+01$ & $3.77 E-01$ & $3.72 E-01$ & $4.23 E+00$ & $3.07 E+00$ \\
\hline NOR-C & $6.65 \mathrm{E}+00$ & $6.76 E+00$ & $9.02 \mathrm{E}+01$ & $3.51 E+0 I$ & $2.96 E-0 I$ & $2.83 \mathrm{E}-01$ & $3.59 E+00$ & $1.34 \mathrm{E}+00$ \\
\hline PHI-D & $2.81 E+01$ & $2.53 E+01$ & $3.10 E+02$ & NOT-FOUND & $1.20 E+00$ & $1.06 \mathrm{E}+00$ & $1.18 \mathrm{E}+01$ & $1.34 E+00$ \\
\hline PHI-C & $2.74 E+01$ & $2.01 E+01$ & $2.86 \mathrm{E}+02$ & $5.91 E+01$ & $1.17 E+00$ & $8.40 \mathrm{E}-01$ & $1.22 \mathrm{E}+01$ & $2.45 E+00$ \\
\hline POR-D & $1.17 \mathrm{E}+01$ & $1.08 \mathrm{E}+01$ & $1.09 E+02$ & $7.76 E+01$ & $5.18 \mathrm{E}-01$ & $4.54 \mathrm{E}-01$ & $4.90 \mathrm{E}+00$ & $3.29 E+00$ \\
\hline POR-C & $1.12 \mathrm{E}+01$ & $8.76 E+00$ & $1.01 E+02$ & $3.88 E+01$ & $4.97 \mathrm{E}-01$ & $3.68 \mathrm{E}-01$ & $3.78 \mathrm{E}+00$ & $1.51 E+00$ \\
\hline MOT-D & $4.82 \mathrm{E}+00$ & $1.02 E+00$ & $7.09 E+01$ & NOT-FOUND & $2.19 E-01$ & $4.37 E-02$ & $2.90 E+00$ & $1.51 \mathrm{E}+00$ \\
\hline WIL-C & $2.07 E+00$ & $1.05 E+00$ & $2.25 E+01$ & $5.47 E^{\circ}+00$ & $9.76 \mathrm{E}-02$ & $4.49 \mathrm{E}-02$ & $1.04 \mathrm{E}+00$ & $2.22 \mathrm{E}-0 \mathrm{I}$ \\
\hline
\end{tabular}

The 99.9th quantile values of the population dose and cancer fatalities among the population that resides within 50 miles $(80.5 \mathrm{~km})$ of the harbor results agree less well. For several ports, the 99.9th quantile is missing for the constant meteorology calculation (those denoted by NOTFOUND in Table 39), which means that the probability of the largest result obtained for any of the 1152 trials run during each constant meteorology calculation was larger than $1.0 \times 10^{-3}$ for that particular calculation. For the locations that yielded a 99.9th quantile value for both the variable and constant meteorology calculation, the ratio of the 99.9th quantile variable 
meteorology result to the 99.9 th quantile constant meteorology result has a value of $2.64 \pm$ 1.02 for the population dose and $3.09 \pm 2.03$ for cancer fatalities. The 99.9 th quantile values obtained using variable meteorology are on average 2.6 to 3.1 times larger than the 99.9th quantile values obtained using constant meteorology. This suggests that the importance sampling scheme used by MACCS to select weather sequences from a year of variable meteorological data is able to find weather sequences that lead to adverse results not represented in the sets of constant meteorological conditions found in the Joint Frequency Distributions of windspeed and atmospheric stability by wind direction that were recorded at the harbors. That this should be so is easy to understand, since the occurrence of rain, not upon release but at some later time when the plume is passing over some downwind highly populated region, is usually the cause of peak results in MACCS calculations. Because rain at some downwind location was not modeled by the constant meteorology calculations, these results should differ significantly from those obtained using variable meteorology, especially for the higher quantiles of result distributions.

Figure 54 presents CCDFs for Charleston of the population dose and cancer fatalities over the distance range $0-80.5 \mathrm{~km}$ obtained using both variable and constant meteorology. All four calculations used the BR-2 inventory and EA5 release fractions. The dose calculation was performed for the Charleston dock location, and the cancer fatality calculation was performed for the Charleston channel location. Figures 55 through 60 present similar results for the other six ports for which constant meteorology calculations were performed. Inspection of the figures shows that the constant and variable meteorology CCDFs are quite similar until the 90th quantile of the distributions are reached, and diverge increasingly as higher quantiles are passed, with the constant meteorology CCDF generally falling off faster than the variable meteorology CCDF (smaller consequence value at any consequence probability). Thus, the figures confirm the conclusion reached by inspection of Table 39, that variable and constant meteorology yield quite similar estimates of mean results and that adverse meteorological conditions are more likely to be captured if weather sequences are selected by importance sampling from a year of variable data than if constant meteorological conditions are used.

\subsubsection{Other Sensitivity Calculations}

In addition to the constant meteorology sensitivity calculations, sensitivity calculations were also performed that examined the effect on consequences of (1) plume buoyancy, (2) the size of the set of nuclides used to specify inventories, (3) alternative release fractions, (4) workforce population, and (5) CRUD release. Table 40 summarizes the calculations performed. For all of these calculations, the reference calculation was the base case Newark dock (NEW-D) or channel (NEW-C) calculation that used the BR-2 inventory, EA5 release fractions, and variable meteorology recorded at the New York City National Weather Service station. The workforce sensitivity calculations used the Newark dock population distribution. All of the other sensitivity calculations used the Newark channel population distribution. Table 41 presents mean and peak population doses and cancer fatalities for two distance ranges, $0-1.6 \mathrm{~km}$ and $0-80 \mathrm{~km}$, for all of the "other" sensitivity calculations, and also for the reference Newark base case calculations to which sensitivity calculation results should be compared. 


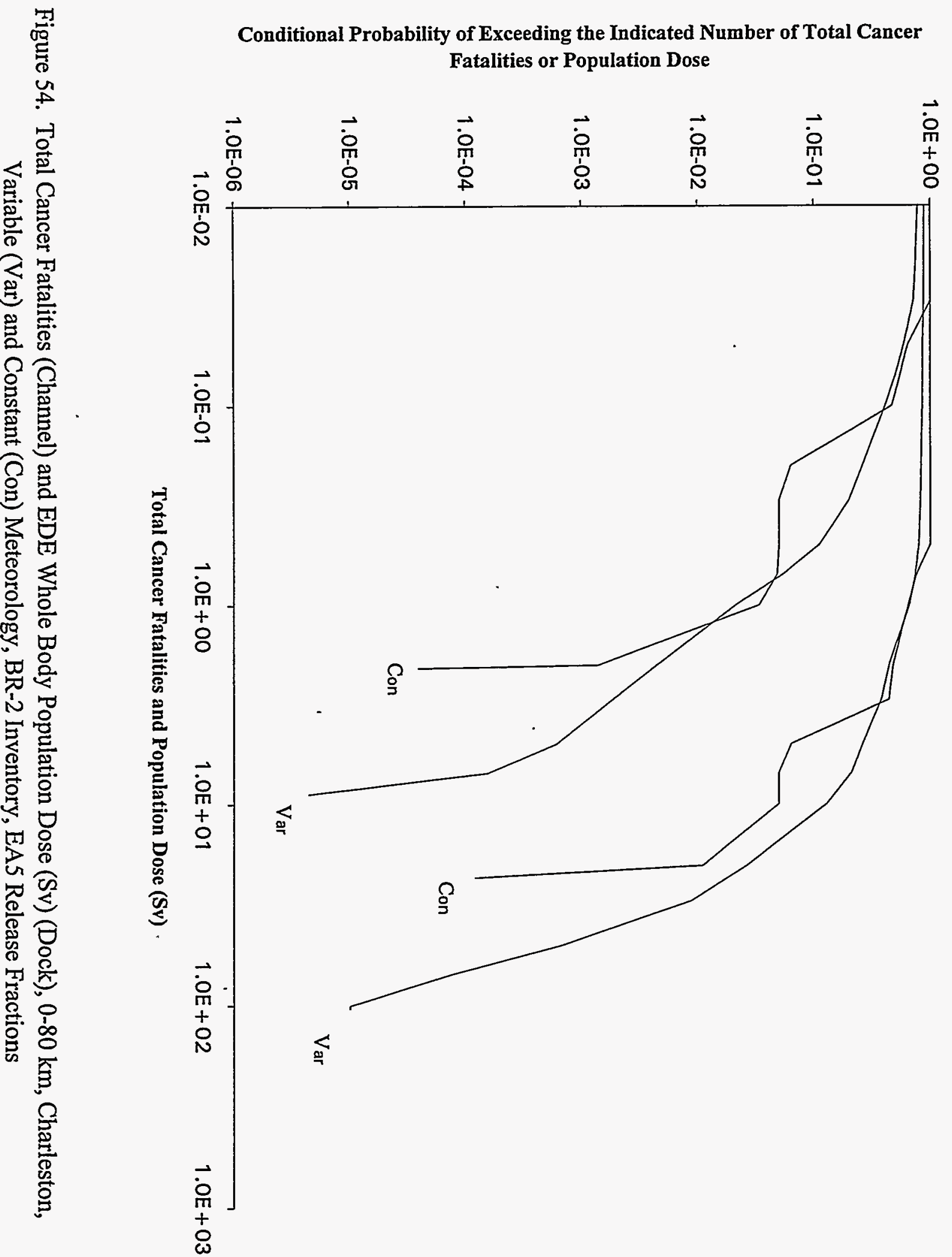




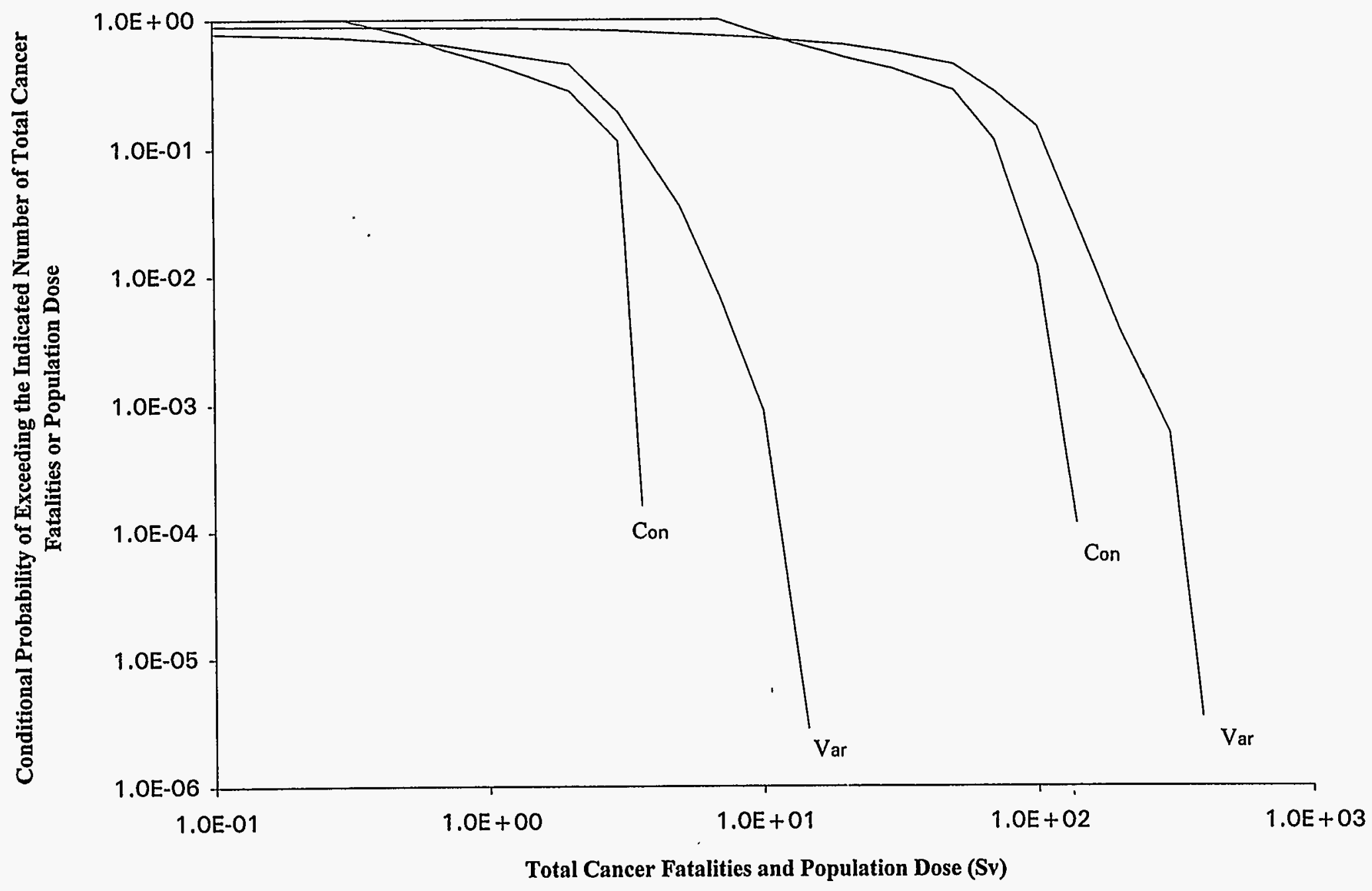

Figure 55. Total Cancer Fatalities (Channel) and EDE Whole Body Population Dose (Sv) (Dock), 0-80 km, Los Angeles, Variable (Var) and Constant (Con) Meteorology, BR-2 Inventory, EA5 Release Fractions 


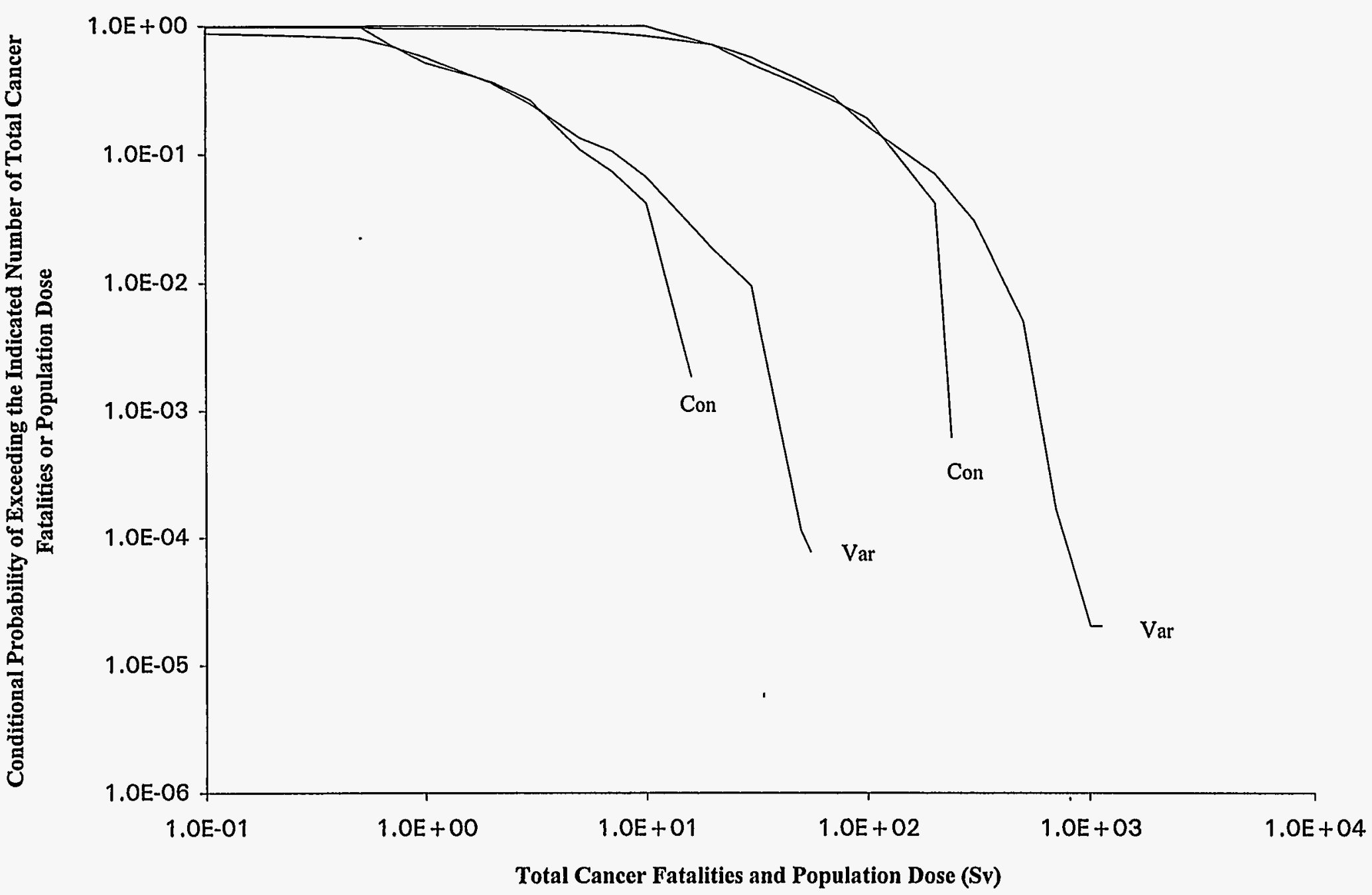

Figure 56. Total Cancer Fatalities (Channel) and EDE Whole Body Population Dose (Sv) (Dock), 0-80 km, Newark, Variable (Var) and Constant (Con) Meteorology, BR-2 Inventory, EA5 Release Fractions 


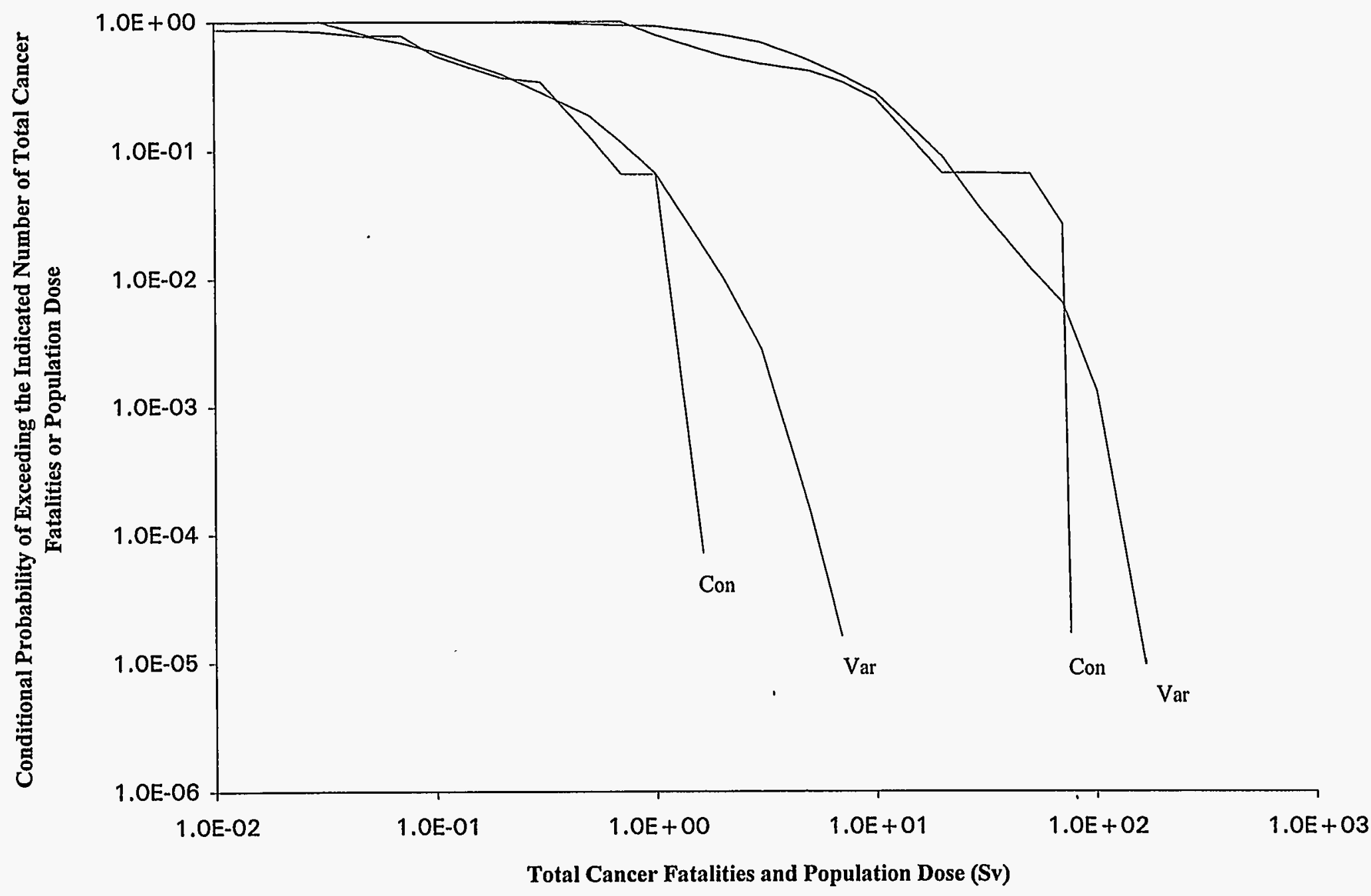

Figure 57. Total Cancer Fatalities (Channel) and EDE Whole Body Population Dose (Sv) (Dock), 0-80 km, Norfolk, Variable (Var) and Constant (Con) Meteorology, BR-2 Inventory, EA5 Release Fractions 


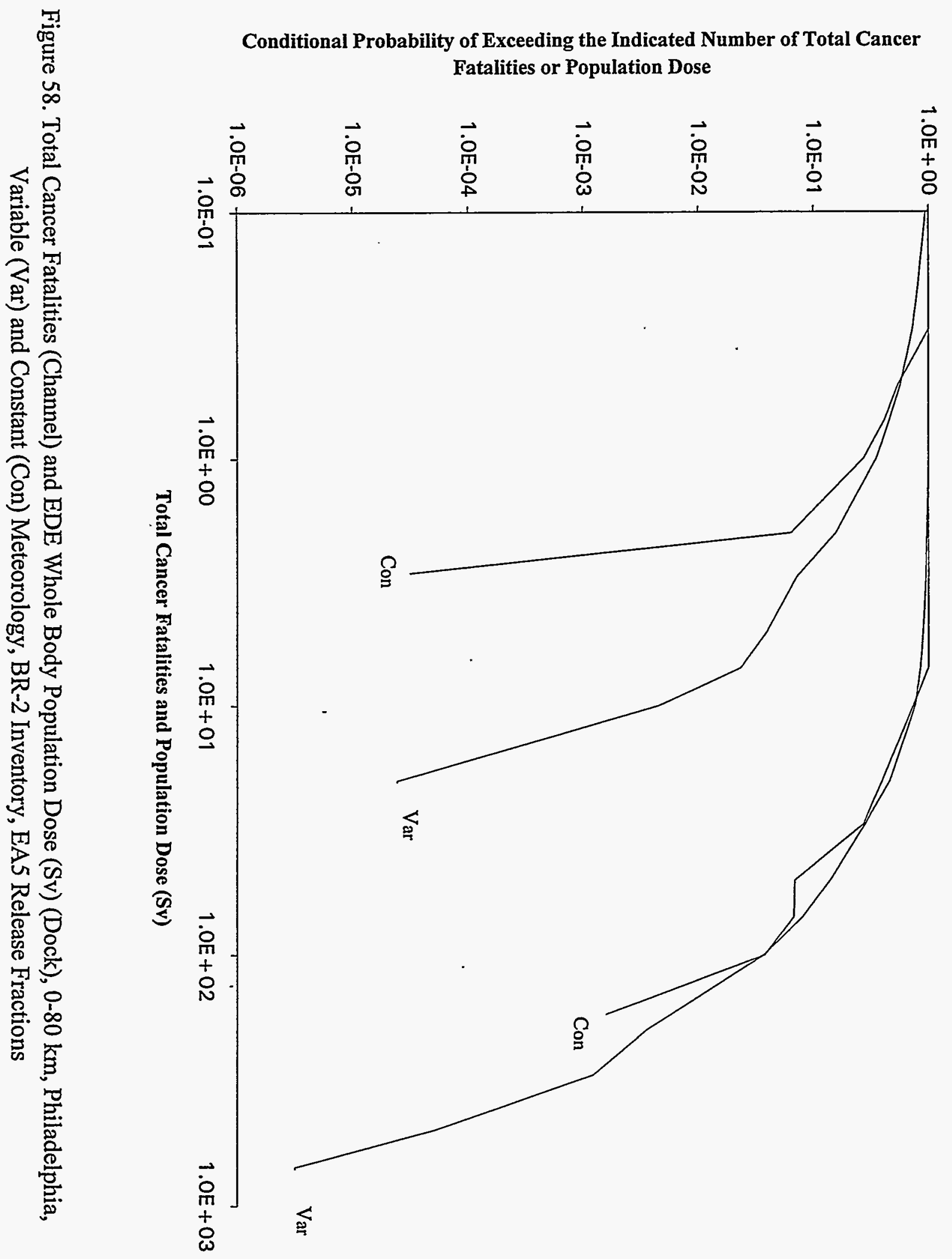




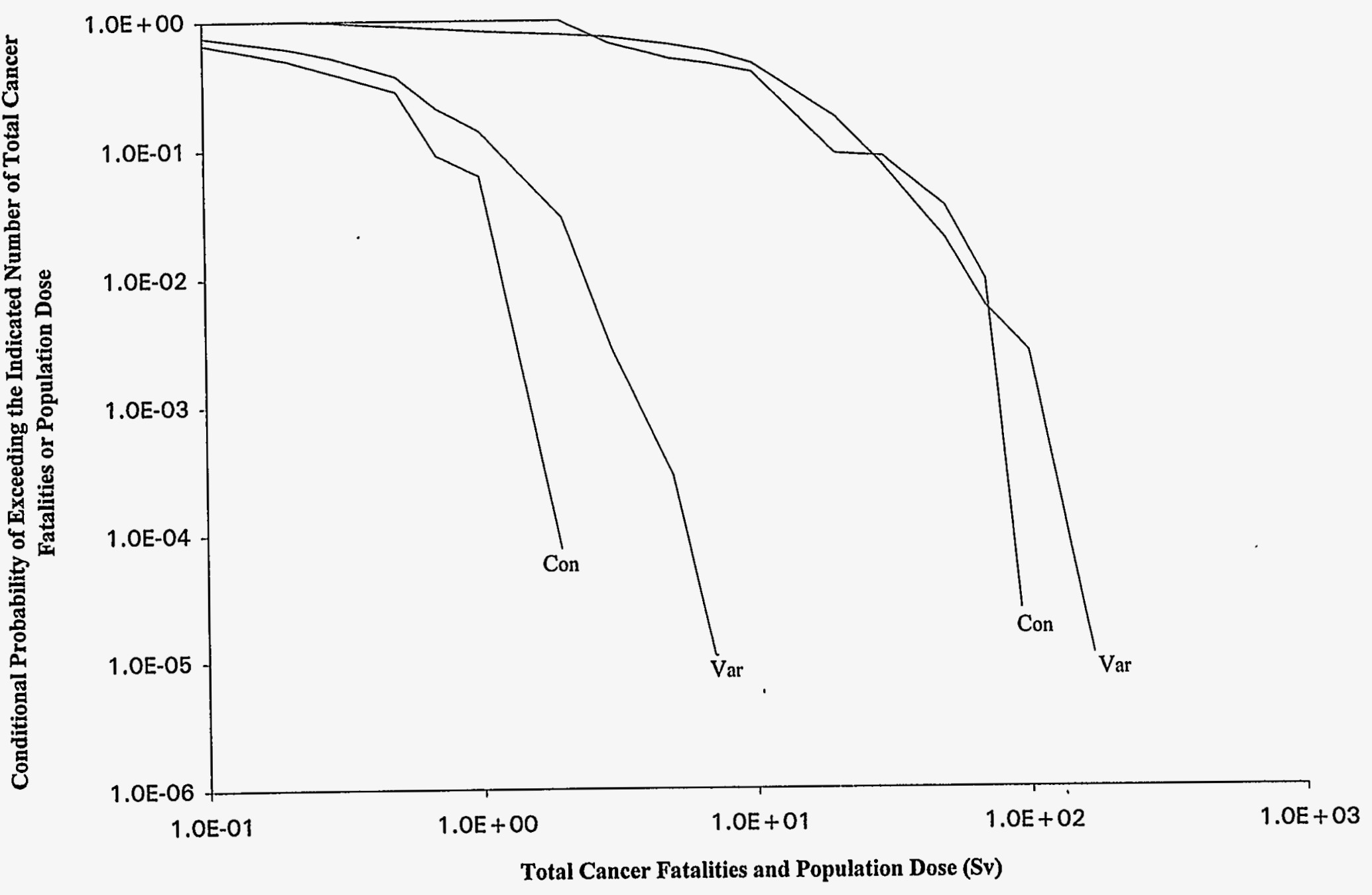

Figure 59. Total Cancer Fatalities (Channel) and EDE Whole Body Population Dose (Sv) (Dock), 0-80 km, Portland, Variable (Var) and Constant (Con) Meteorology, BR-2 Inventory, EA5 Release Fractions 


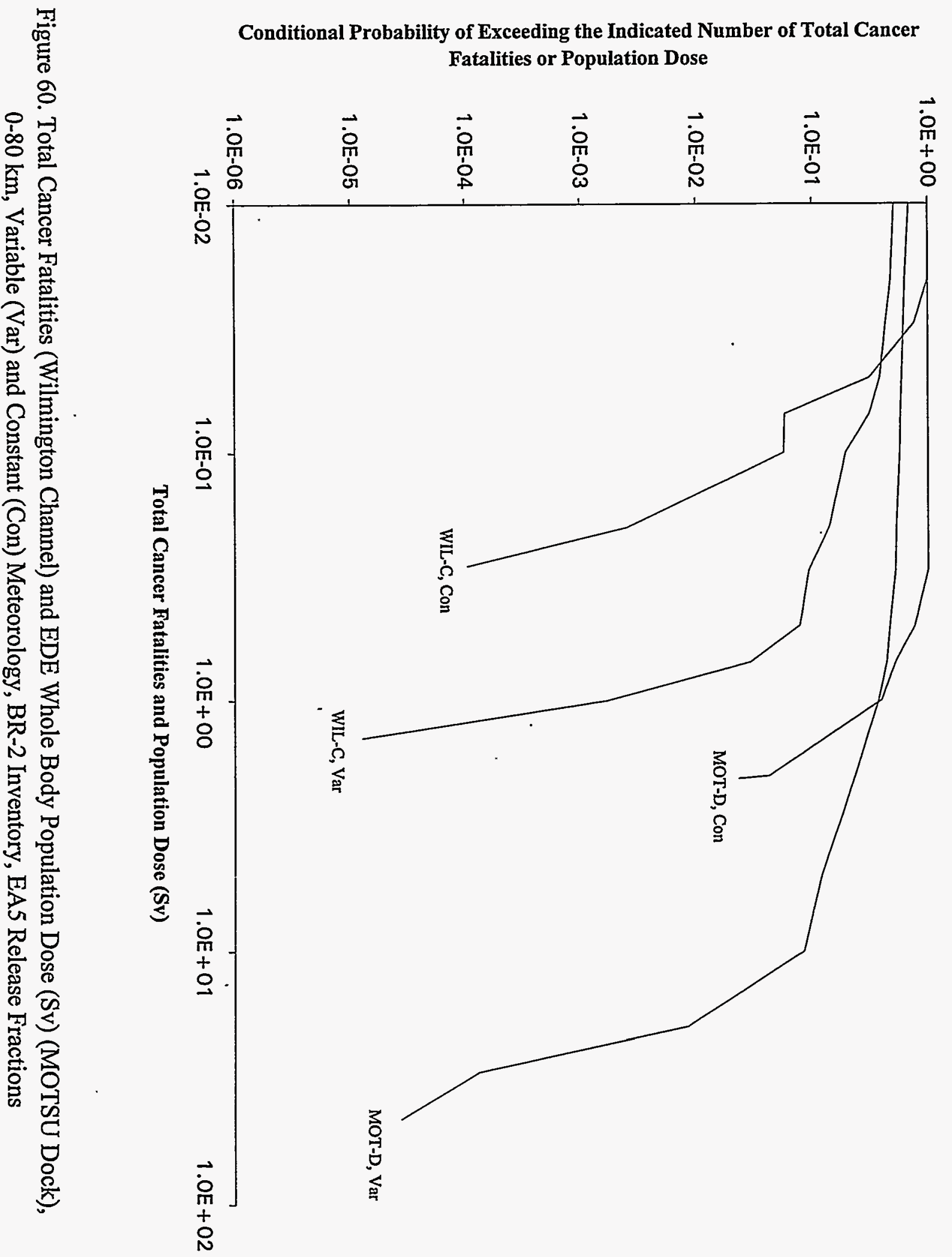


Table 40. Other Sensitivity Calculations

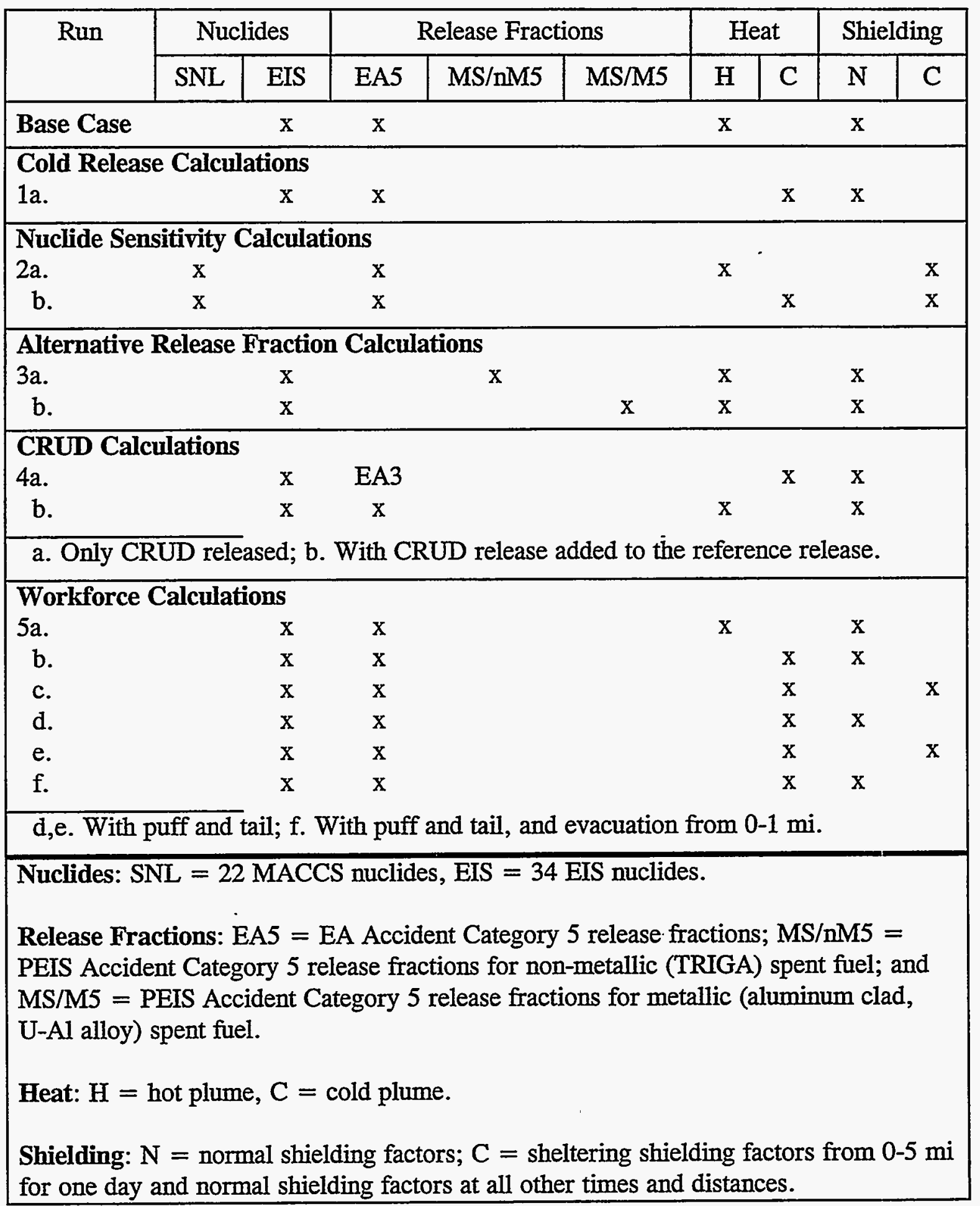


Table 41. Results for Other Sensitivity Studies

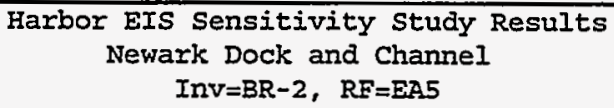

\begin{tabular}{|c|c|c|c|c|c|c|c|c|}
\hline \multirow[b]{2}{*}{ Run } & $\begin{array}{r}\text { EDE Whole } \\
0-1.6\end{array}$ & $\begin{array}{l}\text { le Body Pc } \\
.6 \mathrm{~km}\end{array}$ & $\begin{array}{r}\text { lation Dos } \\
0-8\end{array}$ & $\begin{array}{l}e(S v) \\
0 \mathrm{~km}\end{array}$ & \multicolumn{4}{|c|}{ Total Cancer Fatalities } \\
\hline & Mean & Peak & Mean & Peak & Mean & Peak & Mean & Peak \\
\hline NEW-C & $2.46 E+00$ & $4.21 E+02$ & $6.83 E+01$ & $1.33 E+03$ & $1.03 \mathrm{E}-01$ & $1.75 E \div 01$ & $2.87 E+00$ & $6.53 E+01$ \\
\hline IA & $4.20 E+01$ & $1.14 \mathrm{E}+03$ & $1.69 E+02$ & $1.51 E+03$ & $1.75 E+00$ & $4.76 \Xi+01$ & $7.07 E+00$ & $6.29 E+01$ \\
\hline $2 \mathrm{~A}$ & $2.36 \mathrm{E}+00$ & $4.21 E+02$ & $6.93 \mathrm{E}+01$ & $1.33 \mathrm{E}+03$ & $9.85 \mathrm{E}-02$ & $1.75 E+01$ & $2.90 E+00$ & $5.53 E+01$ \\
\hline B & $4.20 \mathrm{E}+01$ & $1.14 \mathrm{E}+03$ & $1.69 \mathrm{E}+02$ & $1.51 E+03$ & $1.75 \mathrm{E}+00$ & $4.76 E+01$ & $7.07 E+00$ & $6.29 \mathrm{E}+01$ \\
\hline $3 \mathrm{~A}$ & $5.37 E-01$ & $9.54 E+0 I$ & $1.57 E+01$ & $3.01 E+02$ & $2.24 \mathrm{E}-02$ & $3.98 \mathrm{E}+00$ & $6.61 E-01$ & $1.26 \mathrm{E}+01$ \\
\hline B & $2.70 \mathrm{E}-03$ & $4.77 E-01$ & $7.89 \mathrm{E}-02$ & $1.51 E+00$ & $1.12 \mathrm{E}-04$ & I.99E-02 & $3.31 E-03$ & $6.28 \mathrm{E}-02$ \\
\hline $4 \mathrm{~A}$ & $7.39 E+00$ & $2.01 E+02$ & $2.95 E+01$ & $2.66 \mathrm{E}+02$ & $3.19 \mathrm{E}-01$ & $8.70 E+00$ & $1.27 E+00$ & $1.15 \mathrm{E}+01$ \\
\hline B & $2.78 \mathrm{E}+00$ & $4.94 \mathrm{E}+02$ & $8.12 \mathrm{E}+01$ & $1.56 \mathrm{E}+03$ & $1.16 \mathrm{E}-01$ & $2.07 \mathrm{E}+01$ & $3.42 \mathrm{E} \div 00$ & $6.54 E+01$ \\
\hline NEW-D & $5.25 E-0 I$ & $1.33 E+02$ & $6.16 E+01$ & $1.13 \mathrm{E}+03$ & $2.19 E-02$ & $5.56 E+00$ & $2.59 E+00$ & $4.72 \mathrm{E}+0 \mathrm{I}$ \\
\hline $5 \mathrm{~A}$ & $1.05 E+00$ & $1.44 \mathrm{E}+02$ & $6.60 \mathrm{E}+01$ & $1.13 \mathrm{E}+03$ & $4.38 \mathrm{E}-02$ & $6.02 E+00$ & $2.77 E+00$ & 4. $72 \mathrm{E}+0 \mathrm{I}$ \\
\hline B & $1.87 \mathrm{E}+01$ & $4.04 \mathrm{E}+02$ & $1.12 E+02$ & $8.46 E+02$ & $7.80 \mathrm{E}-01$ & $1.68 \mathrm{E}+01$ & $4.69 \mathrm{E}+00$ & $3.53 E+01$ \\
\hline C & $1.86 \mathrm{E}+01$ & $4.03 E+02$ & $1.12 E+02$ & $8.45 E+02$ & $7.78 E-01$ & $1.68 \mathrm{E}+01$ & $4.68 E+00$ & $3.53 E+01$ \\
\hline D & $1.94 \mathrm{E}+01$ & $4.04 E+02$ & $1.16 \mathrm{E}+02$ & $7.25 \mathrm{E}+02$ & $8.10 \mathrm{E}-01$ & $1.69 \mathrm{E}+01$ & $4.84 E+00$ & $3.02 E+01$ \\
\hline 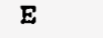 & $1.94 E+01$ & $4.04 E+02$ & $1.15 E+02$ & $7.25 \mathrm{E}+02$ & $8.08 E-01$ & $1.68 \mathrm{E} \div 03$ & $4.83 E+00$ & $3.02 E+01$ \\
\hline $\boldsymbol{F}$ & $1.94 \mathrm{E}+01$ & $4.03 E+02$ & $1.15 \mathrm{E}+02$ & $7.25 \mathrm{E}+02$ & $8.08 E-01$ & $1.68 \mathrm{E}+01$ & $4.83 E+00$ & $3.02 E+01$ \\
\hline
\end{tabular}

\subsubsection{Plume Buoyancy}

As Table 1 shows, the EA5 release scenario leads to a severe hot fire. Thus, the first sensitivity calculation performed examined the effect of plume buoyancy (i.e., of plume rise) on accident consequences. This was done by repeating the Newark channel reference calculation, setting the sensible heat content of the release to zero. This change produces a cold plume that is not subject to plume rise and thus is not lofted over the population located close to the release point (the accident location). The results of this sensitivity calculation are presented in Table 41.

Table 41 shows that changing the reference Newark channel calculation to a cold release not subject to plume rise causes mean and peak population doses and cancer fatalities to increase somewhat for the $0-80 \mathrm{~km}(0-50 \mathrm{mi})$ distance range and substantially for the $0-1.6 \mathrm{~km}(0-1 \mathrm{mi})$ distance range. For the $0-80 \mathrm{~km}$ distance range, mean population dose and cancer fatalities both increase by factors of 2.5, peak population dose increases by a factor of 1.1 , and peak cancer fatalities decrease by a factor of 0.96 . For the $0-1.6 \mathrm{~km}$ distance range, mean population dose and cancer fatalities both increase by factors of 17 , and peak population dose and cancer fatalities both increase by factors of 2.7. Thus, if engulfing fires increase release magnitudes, consequence magnitudes will not increase proportionately because the fire will produce a hot plume that will be lofted over nearby populations, decreasing radiation exposures and thus health effects among those populations. 


\subsubsection{Size of the Nuclide Set}

Table 5 presents the four inventories used in this study. Each inventory contains 34 radionuclides. The default set of radionuclides used by MACCS does not contain dose conversion factors for 13 of these 34 radionuclides. These 13 radionuclides are $\mathrm{H}-3, \mathrm{Sn}-123$, $\mathrm{Sb}-125, \mathrm{Te}-125 \mathrm{~m}, \mathrm{Pm}-147, \mathrm{Pm}-148 \mathrm{~m}, \mathrm{Eu}-154, \mathrm{Eu}-155, \mathrm{U}-234, \mathrm{U}-235, \mathrm{U}-238, \mathrm{Am}-242 \mathrm{~m}$, and Am-243. Chronic health-effect dose conversion factors for all 13 of these radionuclides were available [DOE88b,c] and were added to the MACCS dose conversion factor library for this study. However, because acute health-effect dose conversion factors were neither available nor easy to construct, all calculations performed for this study were run using acute health-effect dose conversion factors that had values of zero for these 13 radionuclides.

The impact of using acute dose conversion factors that had values of zero for 13 of the radionuclides in the inventories used in this study was examined by two sensitivity calculations. For these calculations, the reference Newark channel calculation was repeated with the 13 radionuclides (for which acute health-effect dose conversion factors were unavailable) removed from the BR-2 inventory used in the reference calculation. The calculation was performed twice, once assuming a hot release, as was done in the reference Newark calculation, and once assuming a cold release. Table 41 shows that removing the 13 radionuclides for which acute health-effect dose conversion factors were unavailable from the BR-2 inventory had no significant impact on either mean or peak values of the population dose or cancer fatalities over the distance ranges $0-1.6 \mathrm{~km}$ and $0-80 \mathrm{~km}$ for either calculation. The cold release results are identical to those obtained using all 34 radionuclides in the full BR-2 inventory. The hot release mean values differ by no more than 5 percent from the results obtained using all 34 radionuclides. The hot release $0-80 \mathrm{~km}$ peak cancer fatality prediction is 15 percent lower than the result obtained using all 34 radionuclides. All other hot release peak values are the same as those obtained using all 34 radionuclides. Thus, the 13 radionuclides for which acute dose conversion factors were not available do not contribute significantly to chronic (long-term) dose or health effects, which suggests that none should have a significant impact on acute health effects.

The relative contributions to radiation exposures of the nuclides in an inventory can be estimated by normalizing the ratio of each nuclide's curie amount and A2 value by the sum of those ratios, where an $\mathrm{A} 2$ value is the curie amount of the radionuclide that produces significant radiation doses [IAEA61, IAEA85]. The RADSEL code was used to perform this calculation for the set of 34 nuclides in the inventories used in this study. The RADSEL calculation showed that only one radionuclide, $\mathrm{Pm}$ - 147 (in the set of 13 nuclides for which acute health-effect dose conversion factors were lacking), contributes significantly to the longterm dose at the 99.9 percent level. More importantly, the calculation also showed that $\mathrm{Pm}-147$ accounts for only 0.5 percent of the total dose produced by the full set of 34 radionuclides. Thus, the 21 nuclides in the inventories for which acute health-effect conversion factors were available account for all significant contributions to dose. Therefore, using acute health-effect dose conversion factors with values of zero for 13 of the 34 radionuclides in the inventories used in this study is not believed to have had a significant impact on the estimation of acute health effects, especially since none of these nuclides contributes significantly to 
chronic dose or health effects and since no acute effects were observed at any level, including peak results for any calculation performed during this study.

\subsubsection{Alternative Release Fractions}

Release fractions for metallic (aluminum clad) and non-metallic (TRIGA) fuel for truck and rail accidents are presented in the DOE Programmatic Environmental Impact Statement (PEIS) for Spent Nuclear Fuel (SNF) and the Idaho National Engineering Laboratory (INEL) [DOE94b]. Table 42 presents the values of these release fractions for a Category 5 accident. For ease of comparison, the EA release fractions for Accident Category 5, that were used in all of the base case calculations performed for this study, are repeated in this table.

Table 42. Modal Study Release Fractions

\begin{tabular}{|c|c|c|cc|}
\hline \multirow{3}{*}{$\begin{array}{c}\text { Severity } \\
\text { Category }\end{array}$} & \multirow{3}{*}{ Element Group } & \multicolumn{3}{|c|}{ Release Fraction } \\
\cline { 3 - 5 } & $\mathrm{E}$ & \multicolumn{2}{|c|}{ Programmatic SNF and EIS INEL } \\
\cline { 3 - 5 } & $\mathrm{Kr}$ & $1.0 \mathrm{E}-1$ & Metallic & Non-Metallic \\
\hline $\mathrm{EA5}$ & $\mathrm{Cs}$ & $9.0 \mathrm{E}-4$ & $3.9 \mathrm{E}-1$ & $3.9 \mathrm{E}-1$ \\
& $\mathrm{Ru}$ & $1.0 \mathrm{E}-6$ & $1.0 \mathrm{E}-6$ & $2.0 \mathrm{E}-4$ \\
& Part & $5.0 \mathrm{E}-8$ & $1.4 \mathrm{E}-7$ & $4.8 \mathrm{E}-5$ \\
& & \multicolumn{3}{|c}{} \\
& \multicolumn{3}{|c}{} \\
\end{tabular}

Inspection of the table shows that PEIS release fractions for metallic fuels are smaller than EA release fractions by factors of 900 for $\mathrm{Cs}$ and 5 for $\mathrm{Ru}$ and Particulates, but larger by a factor of 4 for $\mathrm{Kr}$. For non-metallic fuels, PEIS release fractions are larger than EA release fractions by factors of 4 for $\mathrm{Kr}, 48$ for $\mathrm{Ru}$, and 40 for Particulates, but smaller by a factor of 4.5 for Cs. Therefore, since Cs largely determines population dose and cancer fatalities, as would be expected, Table 41 shows that mean and peak population doses and cancer fatalities for the distance ranges $0-1.6 \mathrm{~km}$ and $0-80 \mathrm{~km}$ obtained using EA release fractions are about 5 times larger than the results obtained using PEIS non-metallic fuel release fractions, and are about 1000 times larger than the results obtained using Modal Study metallic fuel release fractions. Therefore, since Accident Category 5 largely determines risk, use of EA release fractions is conservative, at least with respect to use of SNF and INEL PEIS [DOE94b] release fractions.

\subsubsection{CRUD Release}

During the operation of power reactors, radioactive Co is formed by neutron activation of chemical deposits on the outer surfaces of fuel rods. Thus, during transportation accidents, release of these radioactive deposits, usually referred to as CRUD, can be a significant contributor to the size of the accident source term. . 
Because CRUD formation is not normally a problem for research reactors [DOE86, DOE88c, DOE91], radioactive Co is not present in the inventories used in this study, and the sets of release fractions used do not contain fractions for CRUD release. The potential impact of CRUD release on research reactor spent-fuel accident source terms was examined by performing two sensitivity calculations. For these calculations, after scaling to match the size of the Osiris inventory used in this study, the Co- 60 content of the spent fuel inventory for a DOE test reactor [DOE94b] was added to the BR-2 inventory that was used in these sensitivity calculations (Co-58 was ignored as it should largely have decayed away before the fuel is shipped). Then, two sensitivity calculations were performed. Both calculations added $360 \mathrm{Ci}$ of Co- 60 to the BR-2 inventory and both used a value of 1.2E-2 for the release fraction for the CRUD chemical element group, as had been done in the Environmental Assessment (see Table 1). The first calculation examined the consequences of an accident that releases only CRUD. Because CRUD is not volatile, this release was assumed to be cold, that is, to be caused only by the mechanical forces generated by the ship collision. The second calculation added the CRUD release to the EA5 release used in the reference calculation. Because this release postulates a severe engulfing fire, the second calculation assumed that the release was hot.

Table 41 shows that the first calculation, the cold release that contained only CRUD, leads to consequences that differ from those produced by the reference calculation as follows: for the $0-1.6 \mathrm{~km}$ distance range, mean values of population dose and cancer fatalities are about 3 times larger and peak values about 2 times smaller; for the $0-80 \mathrm{~km}$ distance range, mean and peak values for these two consequences are both smaller than the reference calculation results by factors of about 2.5 and 5 , respectively. Mean and peak results for the $0-80 \mathrm{~km}$ distance range and peak results for the $0-1.6 \mathrm{~km}$ range are smaller, because the curie content of the CRUD release is smaller than the total curie content of the release used in the reference calculation (the release produced by EA5 release fractions and the BR-2 inventory). Mean results for the $0-1.6 \mathrm{~km}$ distance range are larger because the release is cold and therefore not lofted over nearby populations. Table 41 also shows that adding the CRUD release to the EA5 release used in the reference calculation increases consequence predictions only slightly (by about 20 percent), as would be expected given the small curie content of the CRUD release compared to that of the reference release.

\subsubsection{Workforce Population}

About 7000 people work in the port of Elizabeth in Newark, NJ. Thus, at least for accidents that occur during the workweek, these workers could be exposed to radiation as a result of a ship collision that involves a ship carrying research reactor spent fuel. Inspection of maps showed that these workers should be added to the residential populations in the first two distance intervals of the north sector of the Newark dock population distribution. Since the division of workers between these two distance intervals was not known, 3500 workers were added to each interval for these sensitivity calculations.

Workforce sensitivity calculations were performed first assuming, as was done for the reference calculation, a hot release, the BR- 2 inventory, and EA5 release fractions (calculation $5 a$ in Tables 40 and 41). Then, this calculation was repeated two times assuming a cold 
release. The first of these two cold release calculations (calculation $5 \mathrm{~b}$ ) used the same shielding factors that had been used in the reference calculation. For the second cold release calculation (calculation 5c), larger shielding factors were used during the first 24 hours after the accident over the distance range $0-8 \mathrm{~km}(0-5 \mathrm{mi})$, because the commercial buildings located near the port are likely to provide better shielding than is provided by the general mix of buildings and houses that are located within 50 miles of the port. Next, these two cold release calculations were repeated assuming that the release consists of a puff caused by the collision impact and a tail caused by the ensuing fire (see calculations 5d and 5e). EA4 release fractions were used for the puff, and the release fractions for the tail were obtained by subtracting the EA4 release fractions from the EA5 release fractions. The puff was released when the collision occurred and lasted for 10 minutes; the tail was released one hour later and had a one-hour release duration. Finally, the puff and tail calculation that did not use increased shielding factor values was repeated (see calculation 5f) (1) assuming that an evacuation would be called for if a severe accident caused a fire that engulfed a radioactive material transportation cask, (2) that the evacuation would begin about one hour after the accident took place (i.e., at about the time the tail release begins), and (3) that the average evacuation speed would be slow because of traffic congestion.

Inspection of Table 41 shows that, when a hot release is assumed, adding a workforce population increases mean population dose and cancer fatalities by about a factor of 2 in the 0-1.6 km distance range, but has little effect on peak values in this distance range or on either mean or peak values in the $0-80 \mathrm{~km}$ distance range. When the release is cold, $0-1.6 \mathrm{~km}$ mean population doses and cancer fatalities are increased by factors of about 35 and 2 respectively, and peak doses and cancer fatalities are increased by factors of about 3 . For the $0-80 \mathrm{~km}$ distance range, mean results increase by factors of about 2 and peak results actually decrease by a factor of about 0.7 . Moreover, these results are little changed by using increased shielding factors for commercial buildings, by assuming a puff and tail release, or by assuming a slow, delayed evacuation.

The insensitivity to short-term shielding factor values, to release timing, and to evacuation is easy to understand when one remembers that population dose and cancer fatalities in these calculations are determined almost entirely by long-term groundshine exposures which are little influenced by variation of any of these three short-term effects. Summarizing, elimination of lofting by assuming a cold release increases consequences, especially those that occur at short distances, but little else has much effect because only recovery actions (decontamination, temporary interdiction, condemnation) not examined by these calculations can significantly affect long-term groundshine dose. 


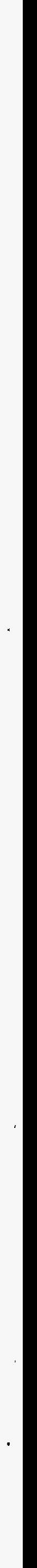




\subsection{ACCIDENT RISKS}

The expected (mean) values of the population dose and cancer fatalities presented in Tables 31 and 35 are conditional on the occurrence of the accident. To convert these values to risks, they must be multiplied by the probability that an accident has occurred that was severe enough to produce the release (source term) used in the consequence calculation that led to the conditional mean results presented in Tables 31 and 35. These source term (accident category) probabilities were presented in Table 17 .

If the conditional mean consequence values for the population dose and cancer fatalities presented in Tables 31 and 35 are multiplied by the accident category probabilities presented in Table 17, mean absolute risk values are obtained. Table 43 presents these values for the three sets of EA release fractions, EA4, EA5, and EA6. Mean absolute risk values are presented in Table 44 for the five sets of EIS release fractions derived for high-temperature fire events, release fractions EIS4, EIS5A, EIS5B, EIS6A, and EIS6B.

Table 43 shows that mean absolute population-dose risk values range from $5.8 \times 10^{-11}$ per port call for the MOTSU dock calculation that used the TRIGA inventory and EA4 release fractions to $3.5 \times 10^{-7}$ per port call for the Newark channel calculation that used the BR-2 inventory and EA5 release fractions. The table also shows that mean absolute cancer-fatality risk values range from $2.5 \times 10^{-12}$ per port call for the MOTSU dock calculation that used the TRIGA inventory and EA4 release fractions to $1.5 \times 10^{-8}$ per port call for the Newark channel calculation that used the BR-2 inventory and EA5 release fractions.

Inspection of Table 43 shows that for each of the four inventories examined, the result obtained using EA5 release fractions is about ten times the result obtained using EA6 release fractions, and the result obtained using EA6 release fractions is about two times the result obtained using EA4 release fractions. Further, the largest mean absolute risk values are obtained for the BR-2 inventory. Thus, the EA5 Accident Category is risk dominant and that category yields the largest risk predictions when a BR-2 inventory is used in the MACCS consequence calculation.

Table 44 shows that mean absolute population-dose risk values range from $2.3 \times 10^{-13}$ per port call for the MOTSU dock and Wilmington channel calculations that used the RHF inventory and EIS6A release fractions to $3.7 \times 10^{-7}$ per port call for the Newark channel calculation that used the BR-2 inventory and EIS5B release fractions. The table also shows that mean absolute cancer fatality risk values range from $9.7 \times 10^{-15}$ per port call for the Wilmington channel calculation that used the RHF inventory and EIS6A release fractions to $1.5 \times 10^{-8}$ per port call for the Newark channel calculation that used the BR-2 inventory and EA5 release fractions.

Inspection of Table 44 shows that, for the three Al-U alloy fuels (BR-2, RHF, and Osiris), the smallest absolute population dose or cancer fatality risk values are obtained using EIS6A release fractions, that the result obtained using EIS5A release fractions is about 7 times larger than the EIS6A result, that the EIS4 result is about 100 times larger than the EIS5A result, and 
Table 43. Absolute Risks for EA Accident Categories

\begin{tabular}{|c|c|c|c|}
\hline & EDE Whol & Body & Populatior \\
\hline & & $B R-2$ & \\
\hline Site/Loc & EA4 & EAS & EA6 6 \\
\hline CHA-D & $1.44 \mathrm{E}-09$ & $2.08 E-08$ & $2.48 \mathrm{E}-09$ \\
\hline $\mathrm{CHA}-\mathrm{C}$ & $2.27 E-09$ & $2.09 E-08$ & $2.53 E-09$ \\
\hline CNC-D & $2.64 E-09$ & 1.03E-07 & $1.33 \mathrm{E}-08$ \\
\hline CNC-C & $5.66 \mathrm{E}-09$ & 1. $65 \mathrm{E}-07$ & $2.04 E-08$ \\
\hline GAI-D & $4.36 \mathrm{E}-09$ & $7.20 \mathrm{E}-08$ & $9.48 E-09$ \\
\hline GAI-C & $1.94 \mathrm{E}-09$ & $7.10 \mathrm{E}-08$ & $9.30 \mathrm{E}-09$ \\
\hline JAC-D & $1.67 \mathrm{E}-09$ & $3.41 E-08$ & $4.06 \mathrm{E}-09$ \\
\hline JAC-C & $1.55 E-09$ & $2.66 \mathrm{E}-08$ & $3.27 E-09$ \\
\hline IOS-D & $1.28 \mathrm{E}-08$ & $2.35 E-07$ & $2.89 E-08$ \\
\hline LOS-C & $4.85 \mathrm{E}-09$ & $2.13 E-07$ & $2.64 E-08$ \\
\hline MOT-D & $4.34 E-10$ & $1.04 E-08$ & $1.33 E-09$ \\
\hline NEW-D & $1.40 E-08$ & $3.28 E-07$ & $3.91 \mathrm{E}-08$ \\
\hline NEW-C & $2.26 \mathrm{E}-08$ & $3.47 \mathrm{E}-07$ & $4.06 E-08$ \\
\hline NOR-D & $3.31 E-09$ & $4.27 E-08$ & $4.99 E-09$ \\
\hline NOR-C & $1.81 \mathrm{E}-09$ & $3.33 E-08$ & $3.98 E-09$ \\
\hline PHI-D & $1.06 \mathrm{E}-08$ & $1.41 E-07$ & $1.67 \mathrm{E}-08$ \\
\hline PHI-C & 5.09E-09 & $1.37 \mathrm{E}-07$ & $1.69 \mathrm{E}-08$ \\
\hline POR-D & $4.62 E-09$ & $5.85 E-08$ & $7.14 E-09$ \\
\hline POR-C & $3.20 E-09$ & $5.60 \mathrm{E}-08$ & $6.90 \mathrm{E}-09$ \\
\hline SAV-D & $3.36 \mathrm{E}-09$ & $2.45 E-08$ & 3.01E-09 \\
\hline SAV-C & $8.04 E-10$ & $1.91 E-08$ & $2.36 E-09$ \\
\hline$S E A-C$ & $7.86 \mathrm{E}-10$ & $3.77 \mathrm{E}-08$ & $4.97 E-09$ \\
\hline TAC-D & $3.33 E-09$ & $8.65 E-08$ & $1.10 \mathrm{E}-08$ \\
\hline TAC-C & $2.32 E-09$ & $7.15 \mathrm{E}-08$ & $9.00 \mathrm{E}-09$ \\
\hline WII-D & $2.28 \mathrm{E}-09$ & $2.41 \mathrm{E-08}$ & 3.01E-09 \\
\hline WIL-C & $5.79 E-10$ & $1.03 E-08$ & 2.32E-09 \\
\hline
\end{tabular}

(SV)

Dose, $0-80 \mathrm{~km}$

$\begin{array}{ccc} & \text { RHF } & \\ \text { EA4 } & \text { EAS } & E A 6 \\ 5.73 E-10 & 7.70 E-09 & 9.18 E-10 \\ 9.06 E-10 & 7.75 E-09 & 9.36 E-10 \\ 1.06 E-09 & 3.98 E-08 & 5.11 E-09 \\ 2.26 E-09 & 6.45 E-08 & 7.92 E-09 \\ 1.74 E-09 & 2.72 E-08 & 3.60 E-09 \\ 7.74 E-10 & 2.68 E-08 & 3.53 E-09 \\ 6.66 E-10 & 1.27 E-08 & 1=51 E-09 \\ 6.18 E-10 & 9.95 E-09 & 1.22 E-09 \\ 5.11 E-09 & 9.25 E-08 & 1.13 E-08 \\ 1.94 E-09 & 8.35 E-08 & 1.04 E-08 \\ 1.73 E-10 & 3.73 E-09 & 4.75 E-10 \\ 5.58 E-09 & 1.29 E-07 & 1.54 E-08 \\ 9.00 E-09 & 1.36 E-07 & 1.60 E-08 \\ 1.32 E-09 & 1.63 E-08 & 1.89 E-09 \\ 7.26 E-10 & 1.26 E-08 & 1.50 E-09 \\ 4.25 E-09 & 5.50 E-08 & 6.48 E-09 \\ 2.03 E-09 & 5.35 E-08 & 6.54 E-09 \\ 1.84 E-09 & 2.22 E-08 & 2.70 E-09 \\ 1.28 E-09 & 2.13 E-08 & 2.62 E-09 \\ 1.34 E-09 & 9.00 E-09 & 1.10 E-09 \\ 3.19 E-10 & 6.90 E-09 & 8.52 E-10 \\ 3.13 E-10 & 1.42 E-08 & 1.87 E-09 \\ 1.33 E-09 & 3.34 E-08 & 4.21 E-09 \\ 9.30 E-10 & 2.75 E-08 & 3.44 E-09 \\ 9.06 E-10 & 8.95 E-09 & 1.12 E-09 \\ 2.30 E-10 & 3.73 E-09 & 4.78 E-10\end{array}$

\begin{tabular}{|c|c|c|c|c|c|c|}
\hline & & OSIRIS & & & TRIGA & \\
\hline Site/Ioc & EA4 & EA5 & EA6 & EA4 & EA5 & EA6 \\
\hline$C H A-D$ & $1.70 E-09$ & 1. $74 E-08$ & $2.06 \mathrm{E}-09$ & $1.78 \mathrm{E}-10$ & $2.66 \mathrm{E}-09$ & $3.16 E-10$ \\
\hline CHA-C & $2.80 E-09$ & $1.75 \mathrm{E}-08$ & $2.10 E-09$ & $2.75 E-10$ & $2.68 \mathrm{E}-09$ & 3. $22 E-10$ \\
\hline CNC-D & $3.17 \mathrm{E}-09$ & $9.45 \mathrm{E}-08$ & $1.21 E-08$ & $3.26 \mathrm{E}-10$ & $1.39 E-08$ & 1. $78 \mathrm{E}-09$ \\
\hline $\mathrm{CNC}-\mathrm{C}$ & $7.14 E-09$ & $1.56 \mathrm{E}-07$ & $1.92 \mathrm{E}-08$ & $6.78 \mathrm{E}-10$ & $2.26 \mathrm{E}-08$ & $2.78 E-09$ \\
\hline GAL-D & $5.27 E-09$ & $6.35 E-08$ & $8.40 E-09$ & $5.36 \mathrm{E}-10$ & $9.50 E-09$ & $1.25 E-09$ \\
\hline GAI-C & $2.21 E-09$ & $6.20 E-08$ & $8.22 E-09$ & $2.48 \mathrm{E}-10$ & $9.30 \mathrm{E}-09$ & $1.22 E-09$ \\
\hline$J A C-D$ & $1.97 \mathrm{E}-09$ & $2.92 \mathrm{E}-08$ & $3.44 E-09$ & $2.09 E-10$ & $4.42 E-09$ & $5.23 E-10$ \\
\hline JAC-C & $1.81 E-09$ & $2.26 E-08$ & $2.75 E-09$ & $1.93 \mathrm{E}-10$ & $3.43 E-09$ & $4.19 \Xi-10$ \\
\hline IOS-D & $1.63 E-08$ & $2.25 E-07$ & $2.75 E-08$ & $1.52 \mathrm{E}-09$ & $3.25 E-08$ & $3.97 E-09$ \\
\hline IOS-C & $6.12 E-09$ & $2.03 E-07$ & $2.51 E-08$ & $5.83 E-10$ & $2.93 E-08$ & $3.63 E-09$ \\
\hline MOT-D & $4.4 I E-10$ & $8.005-09$ & $1.01 E-09$ & $5.83 \mathrm{E}-11$ & $1.27 E-09$ & $1.62 E-10$ \\
\hline NEW-D & $1.78 \mathrm{E}-08$ & $3.15 E-07$ & $3.76 E-08$ & $1.66 \mathrm{E}-09$ & $4.53 E-08$ & $5.40 E-09$ \\
\hline NEW-C & $2.89 E-08$ & $3.33 E-07$ & $3.92 E-08$ & $2.68 \mathrm{E}-09$ & $4.80 E-08$ & $5.62 \mathrm{E}-09$ \\
\hline NOR-D & $4.09 E-09$ & $3.805-08$ & $4.40 E-09$ & 4. $01 E-10$ & $5.65 E-09$ & $6.54 E-10$ \\
\hline NOR-C & $2.21 \mathrm{E}-09$ & $2.91 E-08$ & $3.47 E-09$ & $2.22 \mathrm{E}-10$ & $4.36 \mathrm{E}-09$ & $5.20 \mathrm{E}-10$ \\
\hline PHI-D & $1.35 E-08$ & $1.33 E-07$ & $1.57 \mathrm{E}-08$ & $1.27 E-09$ & $1.92 \mathrm{E}-08$ & $2.27 E-09$ \\
\hline PHI-C & $6.36 \mathrm{E}-09$ & $1.29 E-07$ & 1. 58E-08 & $6.12 E-10$ & $1.87 \mathrm{E}-08$ & $2.30 E-09$ \\
\hline POR-D & $5.73 E-09$ & $5.20 E-08$ & $6.30 \mathrm{E}-09$ & $5.59 \pm-10$ & $7.75 \mathrm{E}-09$ & $9.36 \mathrm{E}-10$ \\
\hline POR-C & $3.89 E-09$ & $4.96 E-08$ & $6.06 E-09$ & $3.91 E-10$ & $7.40 \mathrm{E}-09$ & $9.06 \mathrm{E}-10$ \\
\hline SAV-D & $4.11 E-09$ & I.99E-08 & $2.42 E-09$ & $4.09 E-10$ & 3.09E-09 & $3.77 \mathrm{E}-10$ \\
\hline$S A V-C$ & $8.58 E-10$ & $1.51 E-08$ & $1.85 \mathrm{E}-09$ & $1.05 \mathrm{E}-10$ & $2.37 E-09$ & $2.92 \mathrm{E}-10$ \\
\hline$S E A-C$ & $8.76 E-10$ & $3.28 E-08$ & $4.33 E-09$ & $1.01 E-10$ & $4.93 \mathrm{E}-09$ & $6.48 E-10$ \\
\hline TAC-D & $4.03 E-09$ & $7.90 \mathrm{E}-08$ & $1.00 \mathrm{E}-08$ & $4.09 \mathrm{E}-10$ & $1.16 \mathrm{E}-08$ & $1.47 \mathrm{E}-09$ \\
\hline$T A C-C$ & $2.83 E-09$ & $6.50 E-08$ & $8.20 \mathrm{E}-09$ & $2.85 E-10$ & $9.60 \mathrm{E}-09$ & $1.20 \mathrm{E}-09$ \\
\hline WII-D & $2.76 E-09$ & $2.03 E-08$ & $2.53 E-09$ & $2.80 \mathrm{E}-10$ & $3.10 E-09$ & $3.86 E-10$ \\
\hline WIL-C & $6.42 \mathrm{E}-10$ & $8.15 \mathrm{E}-09$ & $1.04 \mathrm{E}-09$ & $7.44 \mathrm{E}-11$ & $1.28 \mathrm{E}-09$ & $1.63 E-10$ \\
\hline
\end{tabular}


Table 43. Absolute Risks for EA Accident Categories (Continued)

\begin{tabular}{lcccccc}
\hline \multicolumn{7}{c}{ Total Cancer Fatalities, $0-80 \mathrm{~km}$} \\
Site/LOC & EA4 & EA5 & EAE & EA4 & EA5 & EA6 \\
CHA-D & $6.30 E-11$ & $9.45 E-10$ & $1.14 E-10$ & $2.52 E-11$ & $3.49 E-10$ & $4.17 E-11$ \\
CHA-C & $9.96 E-11$ & $9.50 E-10$ & $1.16 E-10$ & $3.99 E-11$ & $3.51 E-10$ & $4.25 E-11$ \\
CNC-D & $1.15 E-10$ & $4.48 E-09$ & $5.74 E-10$ & $4.58 E-11$ & $1.72 E-09$ & $2.20 E-10$ \\
CNC-C & $2.46 E-10$ & $7.05 E-09$ & $8.70 E-10$ & $9.90 E-11$ & $2.74 E-09$ & $3.37 E-10$ \\
GAL-D & $1.90 E-10$ & $3.20 E-09$ & $4.21 E-10$ & $7.62 E-11$ & $1.20 E-09$ & $1.59 E-10$ \\
GAL-C & $8.34 E-11$ & $3.15 E-09$ & $4.15 E-10$ & $3.34 E-11$ & $1.18 E-09$ & $1.56 E-10$ \\
JAC-D & $7.32 E-11$ & $1.54 E-09$ & $1.84 E-10$ & $2.93 E-11$ & $5.70 E-10$ & $6.78 E-11$ \\
JAC-C & $6.78 E-11$ & $1.21 E-09$ & $1.49 E-10$ & $2.71 E-11$ & $4.48 E-10$ & $5.50 E-11$ \\
LOS-D & $5.59 E-10$ & $9.95 E-09$ & $1.22 E-09$ & $2.25 E-10$ & $3.89 E-09$ & $4.78 E-10$ \\
LOS-C & $2.11 E-10$ & $9.00 E-09$ & $1.12 E-09$ & $8.46 E-11$ & $3.52 E-09$ & $4.37 E-10$ \\
MOT-D & $1.90 E-11$ & $4.97 E-10$ & $6.36 E-11$ & $7.50 E-12$ & $1.77 E-10$ & $2.26 E-11$ \\
NEW-D & $6.12 E-10$ & $1.38 E-08$ & $1.64 E-09$ & $2.45 E-10$ & $5.40 E-09$ & $6.42 E-10$ \\
NEW-C & $9.84 E-10$ & $1.45 E-08$ & $1.70 E-09$ & $3.97 E-10$ & $5.70 E-09$ & $6.72 E-10$ \\
NOR-D & $1.45 E-10$ & $1.88 E-09$ & $2.22 E-10$ & $5.83 E-11$ & $7.10 E-10$ & $8.34 E-11$ \\
NOR-C & $7.92 E-11$ & $1.48 E-09$ & $1.78 E-10$ & $3.18 E-11$ & $5.55 E-10$ & $6.66 E-11$ \\
PHI-D & $4.65 E-10$ & $6.00 E-09$ & $7.14 E-10$ & $1.87 E-10$ & $2.33 E-09$ & $2.77 E-10$ \\
PHI-C & $2.22 E-10$ & $5.85 E-09$ & $7.20 E-10$ & $8.94 E-11$ & $2.26 E-09$ & $2.80 E-10$ \\
POR-D & $2.02 E-10$ & $2.59 E-09$ & $3.16 E-10$ & $8.10 E-11$ & $9.75 E-10$ & $1.19 E-10$ \\
POR-C & $1.40 E-10$ & $2.48 E-09$ & $3.07 E-10$ & $5.60 E-11$ & $9.35 E-10$ & $1.15 E-10$ \\
SAV-D & $1.48 E-10$ & $1.14 E-09$ & $1.40 E-10$ & $5.92 E-11$ & $4.14 E-10$ & $5.08 E-11$ \\
SAV-C & $3.53 E-11$ & $8.95 E-10$ & $1.11 E-10$ & $1.39 E-11$ & $3.22 E-10$ & $3.99 E-11$ \\
SEA-C & $3.37 E-11$ & $1.69 E-09$ & $2.22 E-10$ & $1.34 E-11$ & $6.30 E-10$ & $8.34 E-11$ \\
TAC-D & $1.45 E-10$ & $3.77 E-09$ & $4.77 E-10$ & $5.80 E-11$ & $1.44 E-09$ & $1.82 E-10$ \\
TAC-C & $1.01 E-10$ & $3.13 E-09$ & $3.93 E-10$ & $4.05 E-11$ & $1.19 E-09$ & $1.49 E-10$ \\
WIL-D & $9.96 E-11$ & $1.09 E-09$ & $1.37 E-10$ & $4.00 E-11$ & $4.04 E-10$ & $5.06 E-11$ \\
WIL-C & $2.53 E-11$ & $4.88 E-10$ & $6.24 E-11$ & $1.01 E-11$ & $1.75 E-10$ & $2.24 E-11$
\end{tabular}

\begin{tabular}{lccc} 
& \multicolumn{3}{c}{ OSIRIS } \\
Site/LOC & EA4 & EA5 & EA6 \\
CHA-D & $7.32 E-11$ & $7.80 E-10$ & $9.24 E-11$ \\
CHAA-C & $1.20 E-10$ & $7.85 E-10$ & $9.42 E-11$ \\
CNC-D & $1.34 E-10$ & $4.05 E-09$ & $5.20 E-10$ \\
CNC-C & $3.04 E-10$ & $6.55 E-09$ & $8.10 E-10$ \\
GAI-D & $2.25 E-10$ & $2.77 E-09$ & $3.66 E-10$ \\
GAI-C & $9.36 E-11$ & $2.72 E-09$ & $3.59 E-10$ \\
JAC-D & $8.40 E-11$ & $1.29 E-09$ & $1.53 E-10$ \\
JAC-C & $7.74 E-11$ & $1.00 E-09$ & $1.23 E-10$ \\
LOS-D & $6.96 E-10$ & $9.40 E-09$ & $1.16 E-09$ \\
LOS-C & $2.59 E-10$ & $8.50 E-09$ & $1.06 E-09$ \\
MOT-D & $1.88 E-11$ & $3.75 E-10$ & $4.78 E-11$ \\
NEW-D & $7.62 E-10$ & $1.32 E-08$ & $1.57 E-09$ \\
NEW-C & $1.24 E-09$ & $1.39 E-08$ & $1.64 E-09$ \\
NOR-D & $1.75 E-10$ & $1.65 E-09$ & $1.92 E-10$ \\
NOR-C & $9.42 E-11$ & $1.27 E-09$ & $1.52 E-10$ \\
PHI-D & $5.78 E-10$ & $5.60 E-09$ & $6.66 E-10$ \\
PHI-C & $2.72 E-10$ & $5.45 E-09$ & $6.72 E-10$ \\
POR-D & $2.45 E-10$ & $2.26 E-09$ & $2.74 E-10$ \\
POR-C & $1.67 E-10$ & $2.16 E-09$ & $2.66 E-10$ \\
SAV-D & $1.76 E-10$ & $9.05 E-10$ & $1.10 E-10$ \\
SAV-C & $3.67 E-11$ & $6.95 E-10$ & $8.58 E-11$ \\
SEA-C & $3.69 E-11$ & $1.44 E-09$ & $1.90 E-10$ \\
TAC-D & $1.72 E-10$ & $3.39 E-09$ & $4.29 E-10$ \\
TAC-C & $1.21 E-10$ & $2.80 E-09$ & $3.50 E-10$ \\
WIL-D & $1.18 E-10$ & $9.05 E-10$ & $1.13 E-10$ \\
WIL-C & $2.75 E-11$ & $3.76 E-10$ & $4.82 E-11$
\end{tabular}

\begin{tabular}{|c|c|c|}
\hline & TRIGA & \\
\hline EA4 & EA5 & EA6 \\
\hline $7.44 \mathrm{E}-12$ & $1.20 E-10$ & $1.43 \mathrm{E}-11$ \\
\hline $1.14 \mathrm{E}-11$ & $1.20 E-10$ & $1.46 \mathrm{E}-11$ \\
\hline $1.34 \mathrm{E}-11$ & $6.00 \mathrm{E}-10$ & $7.68 \mathrm{E}-11$ \\
\hline $2.78 \mathrm{E}-11$ & $9.60 \mathrm{E}-10$ & $1.18 \mathrm{E}-10$ \\
\hline $2.22 \mathrm{E}-11$ & $4.17 E-10$ & $5.50 E-11$ \\
\hline $1.03 E-11$ & $4.10 \mathrm{E}-10$ & $5.4 I E-11$ \\
\hline $8.70 E-12$ & $1.97 E-10$ & $2.35 \mathrm{E}-11$ \\
\hline $8.04 \mathrm{E}-12$ & $1.54 E-10$ & $1.89 E-11$ \\
\hline $6.24 E-11$ & $1.37 \mathrm{E}-09$ & $1.67 \mathrm{E}-10$ \\
\hline $2.38 \mathrm{E}-11$ & $1.23 \mathrm{E}-09$ & $1.53 \mathrm{E}-10$ \\
\hline $2.48 \mathrm{E}-12$ & $6.00 E-11$ & $7.68 \mathrm{E}-12$ \\
\hline $6.78 E-11$ & $1.90 \mathrm{E}-09$ & $2.26 \mathrm{E}-10$ \\
\hline $1.10 \mathrm{E}-10$ & $2.00 \mathrm{E}-09$ & $2.35 E-10$ \\
\hline $1.66 \mathrm{E}-11$ & $2.47 \mathrm{E}-10$ & $2.89 \mathrm{E}-11$ \\
\hline $9.18 E-12$ & $1.93 E-10$ & $2.30 \mathrm{E}-11$ \\
\hline $5.20 \mathrm{E}-11$ & $8.15 E-10$ & $9.668-11$ \\
\hline $2.51 \mathrm{E}-11$ & $7.95 E-10$ & $9.78 \mathrm{E}-11$ \\
\hline $2.31 E-11$ & $3.39 \mathrm{E}-10$ & $4.12 \mathrm{E}-11$ \\
\hline $1.62 \mathrm{E}-11$ & $3.25 E-10$ & $4.00 \mathrm{E}-11$ \\
\hline $1.70 E-11$ & $1.42 \mathrm{E}-10$ & $1.74 \mathrm{E}-11$ \\
\hline $4.45 E-12$ & $1.10 \mathrm{E}-10$ & $1.36 \mathrm{E}-11$ \\
\hline $4.16 E-12$ & $2.18 E-10$ & $2.87 E-11$ \\
\hline $1.69 \mathrm{E}-11$ & $5.00 \mathrm{E}-10$ & $6.36 E-11$ \\
\hline $.17 E-11$ & $4.15 E-10$ & $5.20 \mathrm{E}-11$ \\
\hline $1.16 \mathrm{E}-11$ & $1.39 E-10$ & $1.74 \mathrm{E}-11$ \\
\hline $3.13 E-12$ & $6.00 \mathrm{E}-11$ & $7.68 E-12$ \\
\hline
\end{tabular}


Table 43. Absolute Risks for EA Accident Categories (Continued)

\begin{tabular}{|c|c|c|c|c|c|c|}
\hline \multirow[b]{3}{*}{ Site/Loc } & \multirow{2}{*}{\multicolumn{2}{|c|}{$\begin{array}{c}\text { Early } \\
\text { BR-2 }\end{array}$}} & \multicolumn{2}{|c|}{ Fatalities, $0-80$} & $\mathrm{~m}$ & \multirow[b]{3}{*}{ EA6 } \\
\hline & & & & & RHF & \\
\hline & EA4 & EA5 & EA6 6 & EA4 & EAS & \\
\hline CHA-D & $0.00 E+00$ & $0.00 \mathrm{E}+00$ & $0.00 E+00$ & $0.00 \mathrm{E}+00$ & $0.00 E+00$ & $0.00 E+00$ \\
\hline $\mathrm{CHA}-\mathrm{C}$ & $0.00 E+00$ & $0.00 \mathrm{E}+00$ & $0.00 \mathrm{E}+00$ & $0.00 \mathrm{E}+00$ & $0.00 E+00$ & $0.00 \mathrm{E}+00$ \\
\hline CNC-D & $0.00 E+00$ & $0.00 E+00$ & $0.00 E+00$ & $0.00 E+00$ & $0.00 E \div 00$ & $0.00 E+00$ \\
\hline $\mathrm{CNC}-\mathrm{C}$ & $0.00 E+00$ & $0.00 E \div 00$ & $0.00 E+00$ & $0.00 \mathrm{E}+00$ & $0.00 E+00$ & $0.00 E+00$ \\
\hline GAL-D & $0.00 \mathrm{E}+00$ & $0.00 E \div 00$ & $0.00 \mathrm{E}+00$ & $0.00 E+00$ & $0.00 E+00$ & $0.00 E+00$ \\
\hline GAI-C & $0.00 E+00$ & $0.00 E+00$ & $0.00 E+00$ & $0.00 \mathrm{E}+00$ & $0.00 E+00$ & $0.00 E+00$ \\
\hline JAC-D & $0.00 E+00$ & $0.00 E+00$ & $0.00 E+00$ & $0.00 E+00$ & $0.00 E \div 00$ & $0.00 E+00$ \\
\hline JAC-C & $0.00 E+00$ & $0.00 E+00$ & $0.00 E+00$ & $.0 .00 E+00$ & $0.00 E+00$ & $0.00 E+00$ \\
\hline LOS-D & $0.00 E+00$ & $0.00 E+00$ & $0.00 E+00$ & $0.00 \mathrm{E}+00$ & $0.00 E+00$ & $0.00 E+00$ \\
\hline LOS-C & $0.00 E+00$ & $0.00 E+00$ & $0.00 E+00$ & $0.00 E+00$ & $0.00 E+00$ & $0.00 E+00$ \\
\hline MOT-D & $0.00 E+00$ & $0.00 E+00$ & $0.00 E+00$ & $0.00 E+00$ & $0.00 E+00$ & $0.00 E+00$ \\
\hline NEW-D & $0.00 \mathrm{E}+00$ & $0.00 E+00$ & $0.00 E+00$ & $0.00 \mathrm{E}+00$ & $0.00 \mathrm{E}+00$ & $0.00 E+00$ \\
\hline NEW-C & $0.00 E+00$ & $0.00 E+00$ & $0.00 E+00$ & $0.00 E+00$ & $0.00 E+00$ & $0.00 E+00$ \\
\hline NOR-D & $0.00 E+00$ & $0.00 \mathrm{E}+00$ & $0.00 E+00$ & $0.00 E+00$ & $0.00 E+00$ & $0.00 E+00$ \\
\hline NOR-C & $0.00 E+00$ & $0.00 E+00$ & $0.00 E+00$ & $0.00 E+00$ & $0.00 E+00$ & $0.00 E+00$ \\
\hline PHI-D & $0.00 E+00$ & $0.00 E+00$ & $0.00 E+00$ & $0.00 E+00$ & $0.00 E+00$ & $0.00 \mathrm{E}+00$ \\
\hline PHI-C & $0.00 E+00$ & $0.00 E+00$ & $0.00 E+00$ & $0.00 \mathrm{E}+00$ & $0.00 E+00$ & $0.00 \mathrm{E}+00$ \\
\hline POR-D & $0.00 E+00$ & $0.00 E \div 00$ & $0.00 E+00$ & $0.00 E+00$ & $0.00 E+00$ & $0.00 E+00$ \\
\hline POR-C & $0.00 \mathrm{E}+00$ & $0.00 E+00$ & $0.00 E+00$ & $0.00 \mathrm{E}+00$ & $0.00 E+00$ & $0.00 E+00$ \\
\hline SAV-D & $0.00 E+00$ & $0.00 E+00$ & $0.00 E+00$ & $0.00 E+00$ & $0.00 E+00$ & $0.00 \mathrm{E}+00$ \\
\hline SAV-C & $0.00 E+00$ & $0.00 E+00$ & $0.00 E+00$ & $0.00 E+00$ & $0.00 E \div 00$ & $0.00 E+00$ \\
\hline SEA-C & $0.00 \mathrm{E}+00$ & $0.00 E+00$ & $0.00 E+00$ & $0.00 E+00$ & $0.00 E+00$ & $0.00 E+00$ \\
\hline TAC-D & $0.00 E+00$ & $0.00 E+00$ & $0.00 E+00$ & $0.00 E+00$ & $0.00 E+00$ & $0.00 \mathrm{E}+00$ \\
\hline TAC-C & $0.00 E+00$ & $0.00 E+00$ & $0.00 E+00$ & $0.00 E+00$ & $0.00 E+00$ & $0.00 E+00$ \\
\hline WII-D & $0.00 E+00$ & $0.00 E+00$ & $0.00 E+00$ & $0.00 E+00$ & $0.00 E+00$ & $0.00 \mathrm{E}+00$ \\
\hline WII-C & $0.00 E+00$ & $0.00 E+00$ & $0.00 E+00$ & $0.00 E+00$ & $0.00 \mathrm{E}+00$ & $0.00 \mathrm{E}+00$ \\
\hline
\end{tabular}

\begin{tabular}{|c|c|c|c|c|c|c|}
\hline \multirow[b]{2}{*}{ Site/Loc } & \multicolumn{3}{|c|}{ OSIRIS } & \multicolumn{3}{|c|}{ TRIGA } \\
\hline & EA4 4 & EAS & EA6 & EA4 & EA5 & EA6 \\
\hline CHA-D & $0.00 \mathrm{E}+00$ & $0.00 \mathrm{E}+00$ & $0.00 E+00$ & $0.00 \mathrm{E}+00$ & $0.00 E+00$ & $0.00 \mathrm{E}+00$ \\
\hline $\mathrm{CHA}-\mathrm{C}$ & $0.00 E \div 00$ & $0.00 \mathrm{E}+00$ & $0.00 E+00$ & $0.00 \mathrm{E}+00$ & $0.00 E+00$ & $0.00 \mathrm{E}+00$ \\
\hline CNC-D & $0.00 E \div 00$ & $0.00 E+00$ & $0.00 \mathrm{E}+00$ & $0.00 \mathrm{E}+00$ & $0.00 \mathrm{E}+00$ & $0.00 \mathrm{E}+00$ \\
\hline CNC-C & $0.00 E+00$ & $0.00 \mathrm{E}+00$ & $0.00 \mathrm{E}+00$ & $0.00 \mathrm{E}+00$ & $0.00 \mathrm{E}+00$ & $0.00 \mathrm{E}+00$ \\
\hline GAI,D & $0.00 E+00$ & $0.00 E+00$ & $0.00 E+00$ & $0.00 E+00$ & $0.00 E+00$ & $0.00 E+00$ \\
\hline GAI-C & $0.00 E+00$ & $0.00 \mathrm{E}+00$ & $0.00 E+00$ & $0.00 \mathrm{E}+00$ & $0.00 \mathrm{E}+00$ & $0.00 \mathrm{E}+00$ \\
\hline JAC-D & $0.00 E+00$ & $0.00 E+00$ & $0.00 E+00$ & $0.00 \mathrm{E}+00$ & $0.00 \mathrm{E}+00$ & $0.00 E+00$ \\
\hline JAC-C & $0.00 E+00$ & $0.00 \mathrm{E}+00$ & $0.00 E+00$ & $0.00 E+00$ & $0.00 E \div 00$ & $0.00 E+00$ \\
\hline LOS-D & $0.00 E+00$ & $0.00 E+00$ & $0.00 E+00$ & $0.00 \mathrm{E}+00$ & $0.00 E+00$ & $0.00 E+00$ \\
\hline LOS-C & $0.00 E+00$ & $0.00 \mathrm{E}+00$ & $0.00 E+00$ & $0.00 \mathrm{E}+00$ & $0.00 E+00$ & $0.00 \mathrm{E}+00$ \\
\hline MOT-D & $0.00 E+00$ & $0.00 E+00$ & $0.00 E+00$ & $0.00 E+00$ & $0.00 \mathrm{E} \div 00$ & $0.00 E+00$ \\
\hline NEW-D & $0.00 E+00$ & $0.00 \mathrm{E}+00$ & $0.00 E+00$ & $0.00 E+00$ & $0.00 E+00$ & $0.00 \mathrm{E}+00$ \\
\hline NEW-C & $0.00 E+00$ & $0.00 \mathrm{E}+00$ & $0.00 E+00$ & $0.00 \mathrm{E}+00$ & $0.00 E+00$ & $0.00 \mathrm{E}+00$ \\
\hline NOR-D & $0.00 E+00$ & $0.00 E+00$ & $0.00 \mathrm{E}+00$ & $0.00 \mathrm{E}+00$ & $0.00 E \div 00$ & $0.00 \mathrm{E}+00$ \\
\hline NOR-C & $0.00 \mathrm{E}+00$ & $0.00 E \div 00$ & $0.00 \mathrm{E}+00$ & $0.00 \mathrm{E}+00$ & $0.00 E+00$ & $0.00 \mathrm{E}+00$ \\
\hline PHI-D & $0.00 \mathrm{E}+00$ & $0.00 E+00$ & $0.00 \mathrm{E}+00$ & $0.00 E+00$ & $0.00 E+00$ & $0.00 \mathrm{E}+00$ \\
\hline PHI-C & $0.00 E+00$ & $0.00 E+00$ & $0.00 E+00$ & $0.00 \mathrm{E}+00$ & $0.00 E+00$ & $0.00 E+00$ \\
\hline POR-D & $0.00 E+00$ & $0.00 E \div 00$ & $0.00 E+00$ & $0.00 \mathrm{E}+00$ & $0.00 E+00$ & $0.00 \mathrm{E}+00$ \\
\hline POR-C & $0.00 E+00$ & $0.00 E+00$ & $0.00 E+00$ & $0.00 E+00$ & $0.00 E+00$ & $0.00 \mathrm{E}+00$ \\
\hline SAV-D & $0.00 E+00$ & $0.00 E+00$ & $0.00 \mathrm{E}+00$ & $0.00 \mathrm{E}+00$ & $0.00 E+00$ & $0.00 \mathrm{E}+00$ \\
\hline$S A V-C$ & $0.00 E+00$ & $0.00 E+00$ & $0.00 E+00$ & $0.00 E+00$ & $0.00 E \div 00$ & $0.00 \mathrm{E}+00$ \\
\hline SEA-C & $0.00 \mathrm{E}+00$ & $0.00 E+00$ & $0.00 \mathrm{E}+00$ & $0.00 \mathrm{E}+00$ & $0.00 E+00$ & $0.00 \mathrm{E}+00$ \\
\hline TAC-D & $0.00 E+00$ & $0.00 E \div 00$ & $0.00 E+00$ & $0.00 \mathrm{E}+00$ & $0.00 \Xi+00$ & $0.00 \mathrm{E}+00$ \\
\hline TAC-C & $0.00 \mathrm{E}+00$ & $0.00 E+00$ & $0.00 \mathrm{E}+00$ & $0.00 \mathrm{E}+00$ & $0.00 E+00$ & $0.00 E+00$ \\
\hline WIL-D & $0.00 E+00$ & $0.00 E+00$ & $0.00 E+00$ & $0.00 E+00$ & $0.00 \mathrm{E}+00$ & $0.00 \mathrm{E}+00$ \\
\hline WIL-C & $0.00 \mathrm{E}+00$ & $0.00 E+00$ & $0.00 \mathrm{E}+00$ & $0.00 \mathrm{E}+00$ & $0.00 E+00$ & $0.00 \mathrm{E}+00$ \\
\hline
\end{tabular}


Table 43. Absolute Risks for EA Accident Categories (Continued)

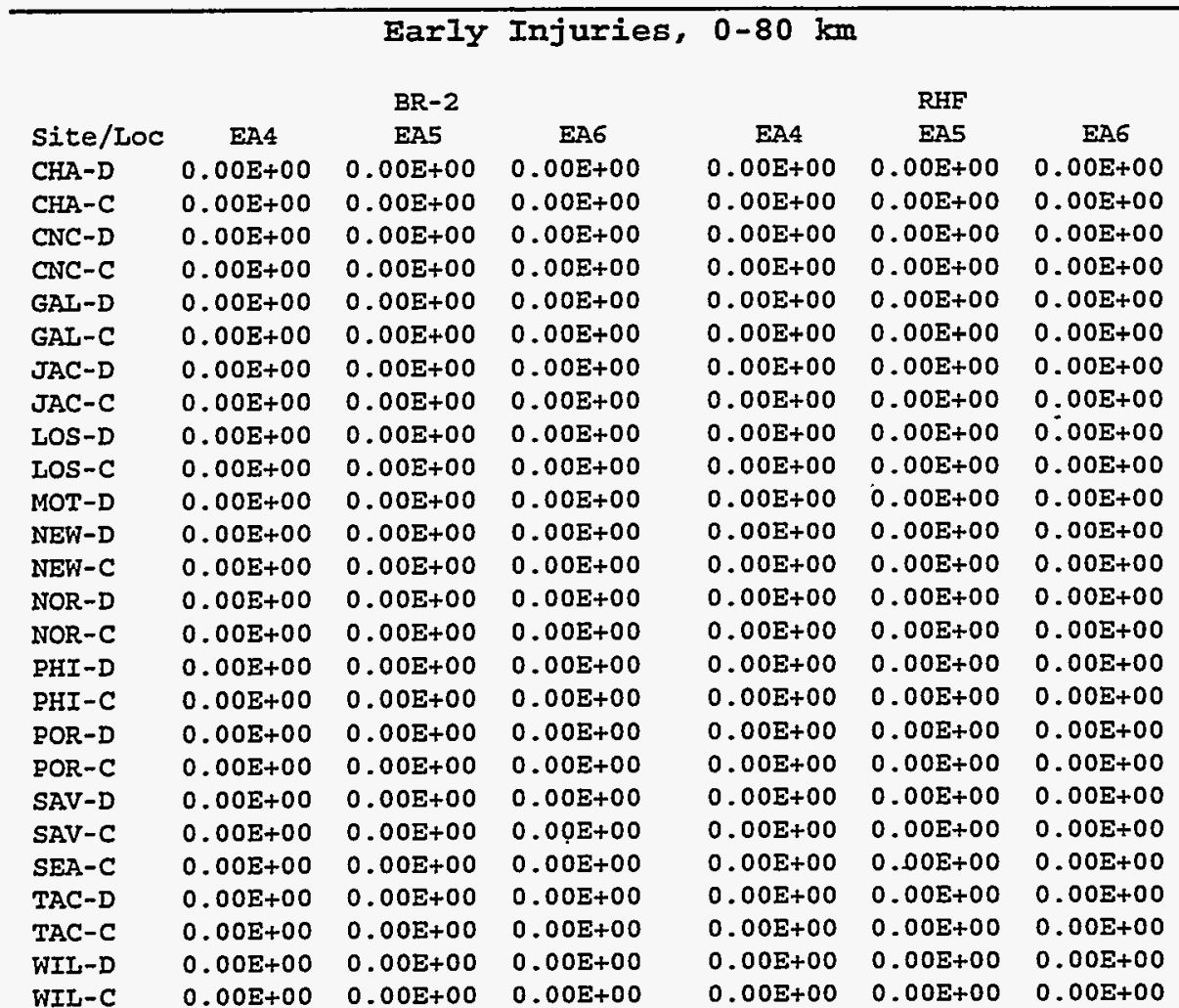

$\begin{array}{lccc} & & \text { OSIRIS } \\ \text { Site/LOC } & E A 4 & \text { EAS } & \text { EAE } \\ \text { CHA-D } & 0.00 E+00 & 0.00 E+00 & 0.00 E+00 \\ \text { CHA-C } & 0.00 E+00 & 0.00 E+00 & 0.00 E+00 \\ \text { CNC-D } & 0.00 E+00 & 0.00 E+00 & 0.00 E+00 \\ \text { CNC-C } & 0.00 E+00 & 0.00 E+00 & 0.00 E+00 \\ \text { GAL-D } & 0.00 E+00 & 0.00 E+00 & 0.00 E+00 \\ \text { GAI-C } & 0.00 E+00 & 0.00 E+00 & 0.00 E+00 \\ \text { JAC-D } & 0.00 E+00 & 0.00 E+00 & 0.00 E+00 \\ \text { JAC-C } & 0.00 E+00 & 0.00 E+00 & 0.00 E+00 \\ \text { LOS-D } & 0.0 .0 E+00 & 0.00 E+00 & 0.00 E+00 \\ \text { LOS-C } & 0.00 E+00 & 0.00 E+00 & 0.00 E+00 \\ \text { MOT-D } & 0.00 E+00 & 0.00 E+00 & 0.00 E+00 \\ \text { NEW-D } & 0.00 E+00 & 0.00 E+00 & 0.00 E+00 \\ \text { NEW-C } & 0.00 E+00 & 0.00 E+00 & 0.00 E+00 \\ \text { NOR-D } & 0.00 E+00 & 0.00 E+00 & 0.00 E+00 \\ \text { NOR-C } & 0.00 E+00 & 0.00 E+00 & 0.00 E+00 \\ \text { RHI-D } & 0.00 E+00 & 0.00 E+00 & 0.00 E+00 \\ \text { PHI-C } & 0.00 E+00 & 0.00 E+00 & 0.00 E+00 \\ \text { POR-D } & 0.00 E+00 & 0.00 E+00 & 0.00 E+00 \\ \text { POR-C } & 0.00 E+00 & 0.00 E+00 & 0.00 E+00 \\ \text { SAV-D } & 0.00 E+00 & 0.00 E+00 & 0.00 E+00 \\ \text { SAV-C } & 0.00 E+00 & 0.00 E+00 & 0.00 E+00 \\ \text { SEA-C } & 0.00 E+00 & 0.00 E+00 & 0.00 E+00 \\ \text { TAC-D } & 0.00 E+00 & 0.00 E+00 & 0.00 E+00 \\ \text { TAC-C } & 0.00 E+00 & 0.00 E+00 & 0.00 E+00 \\ \text { WIL-D } & 0.00 E+00 & 0.00 E+00 & 0.00 E+00 \\ \text { WIL-C } & 0.00 E+00 & 0.00 E+00 & 0.00 E+00\end{array}$

$\begin{array}{ccc}E A 4 & E A 5 & E A G \\ 0.00 E+00 & 0.00 E+00 & 0.00 E+00 \\ 0.00 E+00 & 0.00 E+00 & 0.00 E+00 \\ 0.00 E+00 & 0.00 E+00 & 0.00 E+00 \\ 0.00 E+00 & 0.00 E+00 & 0.00 E+00 \\ 0.00 E+00 & 0.00 E+00 & 0.00 E+00 \\ 0.00 E+00 & 0.00 E+00 & 0.00 E+00 \\ 0.00 E+00 & 0.00 E+00 & 0.00 E+00 \\ 0.00 E+00 & 0.00 E+00 & 0.00 E+00 \\ 0.00 E+00 & 0.00 E+00 & 0.00 E+00 \\ 0.00 E+00 & 0.00 E+00 & 0.00 E+00 \\ 0.00 E+00 & 0.00 E+00 & 0.00 E+00 \\ 0.00 E+00 & 0.00 E+00 & 0.00 E+00 \\ 0.00 E+00 & 0.00 E+00 & 0.00 E+00 \\ 0.00 E+00 & 0.00 E+00 & 0.00 E+00 \\ 0.00 E+00 & 0.00 E+00 & 0.00 E+00 \\ 0.00 E+00 & 0.00 E+00 & 0.00 E+00 \\ 0.00 E+00 & 0.00 E+00 & 0.00 E+00 \\ 0.00 E+00 & 0.00 E+00 & 0.00 E+00 \\ 0.00 E+00 & 0.00 E+00 & 0.00 E+00 \\ 0.00 E+00 & 0.00 E+00 & 0.00 E+00 \\ 0.00 E+00 & 0.00 E+00 & 0.00 E+00 \\ 0.00 E+00 & 0.00 E+00 & 0.00 E+00 \\ 0.00 E+00 & 0.00 E+00 & 0.00 E+00 \\ 0.00 E+00 & 0.00 E+00 & 0.00 E+00 \\ 0.00 E+00 & 0.00 E+00 & 0.00 E+00 \\ 0.00 E+00 & 0.00 E+00 & 0.00 E+00\end{array}$


Table 43. Absolute Risks for EA Accident Categories (Continued)

\begin{tabular}{|c|c|c|c|c|c|c|}
\hline \multicolumn{7}{|c|}{ Total Costs, $0-80 \mathrm{~km}$} \\
\hline & & $\mathrm{BR}-2$ & & & RHF & \\
\hline Site/Loc & EA4 & EA5 & EA6 & EA4 & EA5 & EA6 \\
\hline CHA-D & $0.00 \mathrm{E}+00$ & $9.35 \mathrm{E}-08$ & $1.12 \mathrm{E}-08$ & $0.00 E+00$ & $0.00 E+00$ & $0.00 \mathrm{E}+00$ \\
\hline $\mathrm{CHA}-\mathrm{C}$ & $0.00 \mathrm{E}+00$ & $5.00 E-08$ & $6.00 \mathrm{E}-09$ & $0.00 \mathrm{E}+00$ & $0.00 E+00$ & $0.00 \mathrm{E}+00$ \\
\hline CNC-D & $0.00 E+00$ & $0.00 \mathrm{E}+00$ & $0.00 \mathrm{E}+00$ & $0.00 \mathrm{E}+00$ & $0.00 E+00$ & $0.00 \mathrm{E}+00$ \\
\hline CNC-C & $0.00 E \div 00$ & $0.00 E+00$ & $0.00 \mathrm{E}+00$ & $0.00 \mathrm{E}+00$ & $0.00 E+00$ & $0.00 \mathrm{E}+00$ \\
\hline GAL-D & $0.00 E+00$ & $1.73 \mathrm{E}-07$ & $2.30 \mathrm{E}-08$ & $0.00 \mathrm{E}+00$ & $3.80 \mathrm{E}-08$ & $4.56 \mathrm{E}-09$ \\
\hline GAI-C & $0.00 E+00$ & $6.55 \mathrm{E}-08$ & $9.12 \mathrm{E}-09$ & $0.00 \mathrm{E}+00$ & $1.25 E-08$ & $2.50 \mathrm{E}-09$ \\
\hline JAC-D & $0.00 E \div 00$ & $1.99 \mathrm{E}-07$ & $2.38 \mathrm{E}-08$ & $0.00 \mathrm{E}+00$ & $0.00 E+00$ & $0.00 \mathrm{E}+00$ \\
\hline JAC-C & $0.00 E+00$ & $2.55 \mathrm{E}-07$ & $3.06 \mathrm{E}-08$ & $0.00 \mathrm{E}+00$ & $0.00 \Sigma+00$ & $0.00 E+00$ \\
\hline LOS-D & $0.00 \mathrm{E} \div 00$ & $0.00 \mathrm{E}+00$ & $0.00 \mathrm{E}+00$ & $0.00 \mathrm{E}+00$ & $0.00 E+00$ & $0.00 \mathrm{E}+00$ \\
\hline LOS-C & $0.00 E \div 00$ & $0.00 \mathrm{E}+00$ & $0.00 \mathrm{E}+00$ & $0.00 \mathrm{E}+00$ & $0.00 \mathrm{E}+00$ & $0.00 \mathrm{E}+00$ \\
\hline MOT-D & $0.00 E \div 00$ & $1.61 E-07$ & $1.94 \mathrm{E}-08$ & $0.00 \mathrm{E}+00$ & $6.00 E-08$ & $7.20 \mathrm{E}-09$ \\
\hline$N E W-D$ & $0.00 \mathrm{E}+00$ & $1.79 \mathrm{E}-07$ & $2.15 E-08$ & $0.00 E+00$ & $0.00 E+00$ & $0.00 \mathrm{E}+00$ \\
\hline NEW-C & $0.00 E+00$ & $9.00 \mathrm{E}-08$ & $1.08 \mathrm{E}-08$ & $0.00 E+00$ & $0.00 E+00$ & $0.00 E+00$ \\
\hline NOR-D & $0.00 \mathrm{E} \div 00$ & $4.72 \mathrm{E}-08$ & $5.66 \mathrm{E}-09$ & $0.00 E+00$ & $1.76 \mathrm{E}-08$ & $2.11 E-09$ \\
\hline NOR-C & $0.00 E+00$ & $2.76 E-08$ & $3.31 E-09$ & $0.00 E+00$ & $1.03 \mathrm{E}-08$ & $1.24 \mathrm{E}-09$ \\
\hline PHI-D & $0.00 E+00$ & $1.19 E-07$ & $1.43 E-08$ & $0.00 \mathrm{E}+00$ & $1.70 E-08$ & $2.04 E-09$ \\
\hline PHI-C & $0.00 \mathrm{E}+00$ & $4.21 E-08$ & $5.05 E-09$ & $0.00 E+00$ & $6.00 E-09$ & $7.20 E-10$ \\
\hline POR-D & $0.00 E+00$ & $9.00 \mathrm{E}-09$ & $1.08 \mathrm{E}-09$ & $0.00 \mathrm{E}+00$ & $4.51 E-09$ & $5.41 E-10$ \\
\hline POR-C & $0.00 \mathrm{E}+00$ & $1.00 \mathrm{E}-08$ & $1.20 \mathrm{E}-09$ & $0.00 \mathrm{E}+00$ & $4.99 \mathrm{E}-09$ & $5.99 E-10$ \\
\hline$S A V-D$ & $0.00 E+00$ & $2.32 \mathrm{E}-07$ & $2.79 E-08$ & $0.00 \mathrm{E}+00$ & $0.00 \mathrm{E}+00$ & $0.00 \mathrm{E}+00$ \\
\hline SAV-C & $0.00 \mathrm{E}+00$ & $1.30 \mathrm{E}-07$ & $1.56 \mathrm{E}-08$ & $0.00 \mathrm{E}+00$ & $0.00 E+00$ & $0.00 E+00$ \\
\hline$S E A-C$ & $0.00 E+00$ & $0.00 E+00$ & $0.00 E \div 00$ & $0.00 E+00$ & $0.00 E+00$ & $0.00 \mathrm{E}+00$ \\
\hline TAC-D & $0.00 E+00$ & $2.25 E-08$ & $2.70 \pm-09$ & $0.00 E+00$ & $1.13 \mathrm{E}-08$ & $1.35 E-09$ \\
\hline TAC-C & $0.00 E+00$ & $0.00 \mathrm{E}+00$ & $0.00 E+00$ & $0.00 \mathrm{E}+00$ & $0.00 E+00$ & $0.00 E+00$ \\
\hline WIL-D & $0.00 \mathrm{E}+00$ & $2.26 \mathrm{E}-07$ & $2.71 E-08$ & $0.00 \mathrm{E} \div 00$ & $8.40 \mathrm{E}-08$ & $1.01 E-08$ \\
\hline \multirow[t]{2}{*}{ WIL-C } & $0.00 \mathrm{E}+00$ & $1.30 \mathrm{E}-07$ & $1.56 \mathrm{E}-08$ & $0.00 \mathrm{E}+00$ & $4.83 E-08$ & $5.80 \mathrm{E}-09$ \\
\hline & & OSIRIS & & & TRIGA & \\
\hline Site/Loc & EA4 & EA5 & EA6 & EA4 & EA5 & EA6 \\
\hline CHA-D & $0.00 \mathrm{E}+00$ & $6.35 \mathrm{E}-08$ & $7.62 \mathrm{E}-09$ & $0.00 \mathrm{E}+00$ & $0.00 \mathrm{E}+00$ & $0.00 \mathrm{E}+00$ \\
\hline $\mathrm{CHA}-\mathrm{C}$ & $0.00 \mathrm{E}+00$ & $3.38 \mathrm{E}-08$ & $4.06 \mathrm{E}-09$ & $0.00 \mathrm{E}+00$ & $0.00 \mathrm{E}+00$ & $0.00 \mathrm{E}+00$ \\
\hline CNC-D & $0.00 \mathrm{E}+00$ & $0.00 E+00$ & $0.00 E+00$ & $0.00 \mathrm{E}+00$ & $0.00 \mathrm{E}+00$ & $0.00 \mathrm{E}+00$ \\
\hline CArC-C & $0.00 E+00$ & $0.00 E+00$ & $0.00 \mathrm{E}+00$ & $0.00 \mathrm{E}+00$ & $0.00 \mathrm{E}+00$ & $0.00 E+00$ \\
\hline GAL-D & $0.00 \mathrm{E}+00$ & $8.90 \mathrm{E}-08$ & $1.59 \mathrm{E}-08$ & $0.00 \mathrm{E}+00$ & $0.00 \mathrm{E}+00$ & $0.00 \mathrm{E}+00$ \\
\hline GAL-C & $0.00 \mathrm{E}+00$ & $2.93 E-08$ & $5.75 E-09$ & $0.00 E+00$ & $0.00 \mathrm{E}+00$ & $0.00 E+00$ \\
\hline JAC-D & $0.00 E+00$ & $1.38 \mathrm{E}-07$ & $1.66 \mathrm{E}-08$ & $0.00 \mathrm{E}+00$ & $0.00 E+00$ & $0.00 \mathrm{E}+00$ \\
\hline JAC-C & $0.00 \mathrm{E}+00$ & $1.77 \mathrm{E}-07$ & $2.13 \mathrm{E}-08$ & $0.00 \mathrm{E}+00$ & $0.00 \mathrm{E}+00$ & $0.00 \mathrm{E}+00$ \\
\hline IOS-D & $0.0 .0 \mathrm{E}+00$ & $0.00 \mathrm{E}+00$ & $0.00 \mathrm{E}+00$ & $0.00 \mathrm{E}+00$ & $0.00 E+00$ & $0.00 \mathrm{E}+00$ \\
\hline IOS-C & $0.00 E+00$ & $0.00 \mathrm{E}+00$ & $0.00 \mathrm{E}+00$ & $0.00 \mathrm{E} \div 00$ & $0.00 E+00$ & $0.00 \mathrm{E}+00$ \\
\hline MOT-D & $0.00 E+00$ & $1.01 E-07$ & $1.21 \mathrm{E}-08$ & $0.00 \mathrm{E}+00$ & $0.00 E+00$ & $0.00 \mathrm{E}+00$ \\
\hline NEW-D & $0.00 \mathrm{E}+00$ & $7.80 E-08$ & $9.36 \mathrm{E}-09$ & $0.00 \mathrm{E}+00$ & $0.00 E \div 00$ & $0.00 \mathrm{E}+00$ \\
\hline NEW-C & $0.00 \mathrm{E}+00$ & $3.93 \mathrm{E}-08$ & $4.72 \mathrm{E}-09$ & $0.00 E+00$ & $0.00 \mathrm{E}+00$ & $0.00 \mathrm{E}+00$ \\
\hline NOR-D & $0.00 E+00$ & $2.96 E-08$ & $3.55 \mathrm{E}-09$ & $0.00 \mathrm{E}+00$ & $0.00 \mathrm{E}+00$ & $0.00 \mathrm{E}+00$ \\
\hline NOR-C & $0.00 E+00$ & $1.74 \mathrm{E}-08$ & $2.08 E-09$ & $0.00 \mathrm{E}+00$ & $0.00 E+00$ & $0.00 \mathrm{E}+00$ \\
\hline PHI-D & $0.00 E+00$ & $1.02 \mathrm{E}-07$ & $1.43 \mathrm{E}-08$ & $0.00 E+00$ & $0.00 E+00$ & $0.00 E+00$ \\
\hline PHI-C & $0.00 \mathrm{E}+00$ & $3.61 \mathrm{E}-08$ & $5.05 E-09$ & $0.00 \mathrm{E}+00$ & $0.00 \mathrm{E}+00$ & $0.00 E+00$ \\
\hline POR-D & $0.00 E+00$ & $9.00 \mathrm{E}-09$ & $1.08 \mathrm{E}-09$ & $0.00 \mathrm{E}+00$ & $0.00 \mathrm{E}+00$ & $0.00 \mathrm{E}+00$ \\
\hline POR-C & $0.00 \mathrm{E}+00$ & $1.00 \mathrm{E}-08$ & $1.20 \mathrm{E}-09$ & $0.00 \mathrm{E} \div 00$ & $0.00 E+00$ & $0.00 E+00$ \\
\hline$S A V-D$ & $0.00 \mathrm{E}+00$ & $1.64 \mathrm{E}-07$ & $1.97 E-08$ & $0.00 \mathrm{E}+00$ & $0.00 E+00$ & $0.00 E+00$ \\
\hline$S A V-C$ & $0.00 E+00$ & $8.80 \mathrm{E}-08$ & $1.06 \mathrm{E}-08$ & $0.00 E+00$ & $0.00 \mathrm{E}+00$ & $0.00 \mathrm{E}+00$ \\
\hline$S E A-C$ & $0.00 \mathrm{E}+00$ & $0.00 \mathrm{E}+00$ & $0.00 \mathrm{E}+00$ & $0.00 \mathrm{E}+00$ & $0.00 E+00$ & $0.00 \mathrm{E}+00$ \\
\hline TAC-D & $0.00 \mathrm{E}+00$ & $2.25 \mathrm{E}-08$ & $2.70 \mathrm{E}-09$ & $0.00 \mathrm{E}+00$ & $0.00 \mathrm{E}+00$ & $0.00 \mathrm{E}+00$ \\
\hline TAC-C & $0.00 \mathrm{E}+00$ & $0.00 E+00$ & $0.00 E+00$ & $0.00 \mathrm{E}+00$ & $0.00 \mathrm{E}+00$ & $0.00 \mathrm{E}+00$ \\
\hline WII-D & $0.00 \mathrm{E}+00$ & $1.42 E-07$ & $1.70 \mathrm{E}-08$ & $0.00 E+00$ & $0.00 E+00$ & $0.00 \mathrm{E}+00$ \\
\hline WIL-C & $0.00 \mathrm{E}+00$ & $8.15 E-08$ & $9.78 \mathrm{E}-09$ & $0.00 \mathrm{E}+00$ & $0.00 \mathrm{E}+00$ & $0.00 E+00$ \\
\hline
\end{tabular}


Table 43. Absolute Risks for EA Accident Categories (Continued)

Individual Centerline EDE Whole Body Dose, 0-1.6 $\mathrm{km}$ (SV)

$\begin{array}{lccc} & & & \text { BR-2 } \\ \text { Site/LOC } & \text { EA4 } & \text { EA5 } & \text { EA6 } \\ \text { CHA-D } & 5.16 E-12 & 3.42 E-12 & 4.26 E-13 \\ \text { CHA-C } & 5.16 E-12 & 3.42 E-12 & 4.26 E-13 \\ \text { CNC-D } & 6.42 E-12 & 1.14 E-12 & 1.30 E-13 \\ \text { CNC-C } & 6.42 E-12 & 1.14 E-12 & 1.30 E-13 \\ \text { GAI-D } & 5.57 E-12 & 3.26 E-12 & 4.15 E-13 \\ \text { GAI-C } & 5.57 E-12 & 3.26 E-12 & 4.15 E-13 \\ \text { JAC-D } & 5.16 E-12 & 3.42 E-12 & 4.26 E-13 \\ \text { JAC-C } & 5.16 E-12 & 3.42 E-12 & 4.26 E-13 \\ \text { LOS-D } & 6.42 E-12 & 1.14 E-12 & 1.30 E-13 \\ \text { LOS-C } & 6.42 E-12 & 1.14 E-12 & 1.30 E-13 \\ \text { MOT-D } & 3.19 E-12 & 3.12 E-12 & 3.31 E-13 \\ \text { NEW-D } & 3.59 E-12 & 5.85 E-12 & 5.72 E-13 \\ \text { NEW-C } & 3.59 E-12 & 5.85 E-12 & 5.72 E-13 \\ \text { NOR-D } & 3.19 E-12 & 3.12 E-12 & 3.31 E-13 \\ \text { NOR-C } & 3.19 E-12 & 3.12 E-12 & 3.31 E-13 \\ \text { PHI-D } & 6.06 E-12 & 3.15 E-12 & 3.95 E-13 \\ \text { PHI-C } & 6.06 E-12 & 3.15 E-12 & 3.95 E-13 \\ \text { POR-D } & 4.52 E-12 & 3.78 E-12 & 4.78 E-13 \\ \text { POR-C } & 4.52 E-12 & 3.78 E-12 & 4.78 E-13 \\ \text { SAV-D } & 5.16 E-12 & 3.42 E-12 & 4.26 E-13 \\ \text { SAV-C } & 5.16 E-12 & 3.42 E-12 & 4.26 E-13 \\ \text { SEA-C } & 4.52 E-12 & 3.78 E-12 & 4.78 E-13 \\ \text { TAC-D } & 4.52 E-12 & 3.78 E-12 & 4.78 E-13 \\ \text { TAC-C } & 4.52 E-12 & 3.78 E-12 & 4.78 E-13 \\ \text { WII-D } & 3.19 E-12 & 3.12 E-12 & 3.31 E-13 \\ \text { WIL-C } & 3.19 E-12 & 3.12 E-12 & 3.31 E-13\end{array}$

$\begin{array}{ccc}\text { EA4 } & \text { RHF } & \text { EA5 } \\ 2.06 E-12 & 1.35 E-12 & 1.69 E-13 \\ 2.06 E-12 & 1.35 E-12 & 1.69 E-13 \\ 2.57 E-12 & 4.51 E-13 & 5.15 E-14 \\ 2.57 E-12 & 4.51 E-13 & 5.15 E-14 \\ 2.23 E-12 & 1.29 E-12 & 1.64 E-13 \\ 2.23 E-12 & 1.29 E-12 & 1.64 E-13 \\ 2.06 E-12 & 1.35 E-12 & 1.69 E-13 \\ 2.06 E-12 & 1.35 E-12 & 1.69 E-13 \\ 2.57 E-12 & 4.51 E-13 & 5.15 E-14 \\ 2.57 E-12 & 4.51 E-13 & 5.15 E-14 \\ 1.27 E-12 & 1.23 E-12 & 1.31 E-13 \\ 1.43 E-12 & 2.31 E-12 & 2.26 E-13 \\ 1.43 E-12 & 2.31 E-12 & 2.26 E-13 \\ 1.27 E-12 & 1.23 E-12 & 1.31 E-13 \\ 1.27 E-12 & 1.23 E-12 & 1.31 E-13 \\ 2.41 E-12 & 1.25 E-12 & 1.57 E-13 \\ 2.41 E-12 & 1.25 E-12 & 1.57 E-13 \\ 1.81 E-12 & 1.49 E-12 & 1.89 E-13 \\ 1.81 E-12 & 1.49 E-12 & 1.89 E-13 \\ 2.06 E-12 & 1.35 E-12 & 1.69 E-13 \\ 2.06 E-12 & 1.35 E-12 & 1.69 E-13 \\ 1.81 E-12 & 1.49 E-12 & 1.89 E-13 \\ 1.81 E-12 & 1.49 E-12 & 1.89 E-13 \\ 1.81 E-12 & 1.49 E-12 & 1.89 E-13 \\ 1.27 E-12 & 1.23 E-12 & 1.31 E-13 \\ 1.27 E-12 & 1.23 E-12 & 1.31 E-13\end{array}$

$\begin{array}{lccc} & & \text { OSIRIS } \\ \text { Site/LOC } & \text { EA4 } & \text { EA5 } & \text { EA6 } \\ \text { CHA-D } & 7.02 E-12 & 3.31 E-12 & 4.15 E-13 \\ \text { CHA-C } & 7.02 E-12 & 3.31 E-12 & 4.15 E-13 \\ \text { CNC-D } & 8.76 E-12 & 1.10 E-12 & 1.27 E-13 \\ \text { CNC-C } & 8.76 E-12 & 1.10 E-12 & 1.27 E-13 \\ \text { GAI-D } & 7.56 E-12 & 3.16 E-12 & 4.04 E-13 \\ \text { GAI-C } & 7.56 E-12 & 3.16 E-12 & 4.04 E-13 \\ \text { JAC-D } & 7.02 E-12 & 3.31 E-12 & 4.15 E-13 \\ \text { JAC-C } & 7.02 E-12 & 3.31 E-12 & 4.15 E-13 \\ \text { LOS-D } & 8.7 .6 E-12 & 1.10 E-12 & 1.27 E-13 \\ \text { LOS-C } & 8.76 E-12 & 1.10 E-12 & 1.27 E-13 \\ \text { MOT-D } & 4.30 E-12 & 3.03 E-12 & 3.22 E-13 \\ \text { NEW-D } & 4.82 E-12 & 5.65 E-12 & 5.56 E-13 \\ \text { NEW-C } & 4.82 E-12 & 5.65 E-12 & 5.56 E-13 \\ \text { NOR-D } & 4.30 E-12 & 3.03 E-12 & 3.22 E-13 \\ \text { NOR-C } & 4.30 E-12 & 3.03 E-12 & 3.22 E-13 \\ \text { DHI-D } & 8.22 E-12 & 3.07 E-12 & 3.85 E-13 \\ \text { PHI-C } & 8.22 E-12 & 3.07 E-12 & 3.85 E-13 \\ \text { POR-D } & 6.12 E-12 & 3.67 E-12 & 4.65 E-13 \\ \text { POR-C } & 6.12 E-12 & 3.67 E-12 & 4.65 E-13 \\ \text { SAV-D } & 7.02 E-12 & 3.31 E-12 & 4.15 E-13 \\ \text { SAV-C } & 7.02 E-12 & 3.31 E-12 & 4.15 E-13 \\ \text { SEA-C } & 6.12 E-12 & 3.67 E-12 & 4.65 E-13 \\ \text { TAC-D } & 6.12 E-12 & 3.67 E-12 & 4.65 E-13 \\ \text { TAC-C } & 6.12 E-12 & 3.67 E-12 & 4.65 E-13 \\ \text { WIL-D } & 4.30 E-12 & 3.03 E-12 & 3.22 E-13 \\ \text { WIL-C } & 4.30 E-12 & 3.03 E-12 & 3.22 E-13\end{array}$

\begin{tabular}{|c|c|c|}
\hline & & \\
\hline EA4 & EA5 & EA6 \\
\hline $3 E-13$ & $.75 E-13$ & \\
\hline & $5 E-13$ & 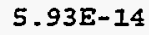 \\
\hline $26 E-13$ & $9 E-13$ & 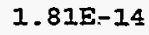 \\
\hline $\mathrm{E}-\mathbf{7}$ & $9 E-13$ & s- \\
\hline $30 E-13$ & $.54 E-13$ & \\
\hline 2 & & \\
\hline & $.75 E-13$ & גת חת \\
\hline .8 & $E-13$ & \\
\hline 3 & $E$ & \\
\hline 2 & $E-$ & -1 \\
\hline 6 & .3 & -1 \\
\hline 0 & 3 & -1 \\
\hline $.09 \mathrm{E}$ & $E-$ & -1 \\
\hline $62 \mathrm{E}-13$ & $E-13$ & -14 \\
\hline $62 \mathrm{E}-13$ & $E-13$ & -14 \\
\hline $.84 \mathrm{E}-$ & $E-13$ & $50 E-14$ \\
\hline .84 & $E-13$ & -14 \\
\hline .1 & $E-$ & $:-14$ \\
\hline 3 & -13 & -14 \\
\hline & $E-13$ & $=-14$ \\
\hline . & $E-13$ & $E-14$ \\
\hline - & $25 E-13$ & $E-14$ \\
\hline $.14 \mathrm{E}-13$ & 13 & -14 \\
\hline & & $\varepsilon-14$ \\
\hline & & $8-1$ \\
\hline$-2+3+2$ & & 50E- \\
\hline
\end{tabular}


Table 43. Absolute Risks for EA Accident Categories (Concluded)

Individual Centerline Cancer Risk, 0-1.6 km

\begin{tabular}{|c|c|c|c|c|c|c|}
\hline \multirow[b]{2}{*}{ :LOC } & \multicolumn{3}{|c|}{ BR-2 } & \multicolumn{3}{|c|}{ RHF } \\
\hline & EA4 & EA5 & EA6 & EA4 & EAS & EA6 \\
\hline$C H A-D$ & $2.46 E-13$ & $1.42 \mathrm{E}-13$ & $1.78 E-14$ & $9.96 \mathrm{E}-14$ & $5.65 E-14$ & $7.02 E-15$ \\
\hline CHA-C & $2.46 \mathrm{E}-13$ & $1.42 \mathrm{E}-13$ & $1.78 \mathrm{E}-14$ & $9.96 E-14$ & $5.65 E-14$ & $7.02 \mathrm{E}-15$ \\
\hline CNC-D & $3.07 E-13$ & $4.75 \mathrm{E}-14$ & $5.44 \mathrm{E}-15$ & $1.25 E-13$ & $1.87 \mathrm{E}-14$ & $2.15 E-15$ \\
\hline CNC-C & $3.07 E-13$ & $4.75 \mathrm{E}-14$ & $5.44 E-15$ & $1.25 \mathrm{E}-13$ & $1.87 \mathrm{E}-14$ & $2.15 E-15$ \\
\hline GAI-D & $2.66 \mathrm{E}-13$ & $1.36 \mathrm{E}-13$ & $1.73 \mathrm{E}-14$ & $1.08 \mathrm{E}-13$ & $5.40 E-14$ & $6.84 E-15$ \\
\hline GAI-C & $2.66 \mathrm{E}-13$ & $1.36 \mathrm{E}-13$ & $1.73 \mathrm{E}-14$ & $1.08 \mathrm{E}-13$ & $5.40 E-14$ & $6.84 \mathrm{E}-15$ \\
\hline JAC-D & $2.46 \mathrm{E}-13$ & $1.42 \mathrm{E}-13$ & $1.78 \mathrm{E}-14$ & $9.96 \mathrm{E}-14$ & $5.65 E-14$ & $7.02 \mathrm{E}-15$ \\
\hline JAC-C & $2.46 \mathrm{E}-13$ & $1.42 \mathrm{E}-13$ & $1.78 E-14$ & $9.96 \mathrm{E}-14$ & $5.65 E-14$ & $7.02 E-15$ \\
\hline LOS-D & $3.07 E-13$ & $4.75 \mathrm{E}-14$ & $5.44 \mathrm{E}-15$ & $1.25 \mathrm{E}-13$ & $1.87 \mathrm{E}-14$ & $2.15 E-15$ \\
\hline LOS-C & $3.07 E-13$ & $4.75 E-14$ & $5.44 E-15$ & $1.25 \mathrm{E}-13$ & $1.87 E-14$ & $2.15 \mathrm{E}-15$ \\
\hline MOT-D & $1.51 \mathrm{E}-13$ & $1.30 \mathrm{E}-13$ & $1.38 E-14$ & $6.12 E-14$ & $5.15 \mathrm{E}-14$ & $5.45 E-15$ \\
\hline NEW-D & $1.68 \mathrm{E}-13$ & $2.44 \mathrm{E}-13$ & $2.38 E-14$ & $6.84 \mathrm{E}-14$ & $9.65 E-14$ & $9.42 E-15$ \\
\hline NEW-C & $1.68 \mathrm{E}-13$ & $2.44 \mathrm{E}-13$ & $2.38 \mathrm{E}-14$ & $6.84 E-14$ & $9.65 E-14$ & $9.42 \mathrm{E}-15$ \\
\hline NOR-D & $1.51 E-13$ & $1.30 \mathrm{E}-13$ & $1.38 \mathrm{E}-14$ & $6.12 \mathrm{E}-14$ & $5.15 \mathrm{E}-14$ & $5.45 E-15$ \\
\hline NOR-C & 1. $51 E-13$ & $1.30 \mathrm{E}-13$ & $1.38 \mathrm{E}-14$ & $6.12 \mathrm{E}-14$ & $5.15 \mathrm{E}-14$ & $5.45 E-15$ \\
\hline PHI-D & $2.88 E-13$ & $1.31 \mathrm{E}-13$ & $1.65 \mathrm{E}-14$ & $1.17 E-13$ & $5.20 \mathrm{E}-14$ & $6.54 E-15$ \\
\hline PHI-C & $2.88 E-13$ & $1.31 \mathrm{E}-13$ & $1.65 E-14$ & $1.17 \mathrm{E}-13$ & $5.20 \mathrm{E}-14$ & $6.54 E-15$ \\
\hline POR-D & $2.13 E-13$ & $1.58 \mathrm{E}-13$ & $1.99 \mathrm{E}-14$ & $8.64 \mathrm{E}-14$ & $6.25 \mathrm{E}-14$ & $7.86 \mathrm{E}-15$ \\
\hline POR-C & $2.13 E-13$ & $1.58 \mathrm{E}-13$ & $1.99 \mathrm{E}-14$ & $8.64 E-14$ & $6.25 E-14$ & $7.86 \mathrm{E}-15$ \\
\hline$S A V-D$ & $2.46 E-13$ & $1.42 \mathrm{E}-13$ & $1.78 E-14$ & $9.96 \mathrm{E}-14$ & $5.65 E-14$ & $7.02 E-15$ \\
\hline$S A V-C$ & $2.46 E-13$ & $1.42 \mathrm{E}-13$ & $1.7 .8 \mathrm{E}-14$ & $9.96 \mathrm{E}-14$ & $5.65 E-14$ & $7.02 \mathrm{E}-15$ \\
\hline SEA-C & $2.13 E-13$ & $1.58 \mathrm{E}-13$ & $1.99 \mathrm{E}-14$ & $8.64 \mathrm{E}-14$ & $6.25 E-14$ & $7.86 E-15$ \\
\hline TAC-D & $2.13 E-13$ & $1.58 \mathrm{E}-13$ & $1.99 \mathrm{E}-14$ & $8.64 \mathrm{E}-14$ & $6.25 E-14$ & $7.86 \mathrm{E}-15$ \\
\hline TAC-C & $2.13 E-13$ & $1.58 \mathrm{E}-13$ & $1.99 \mathrm{E}-14$ & $8.64 \mathrm{E}-14$ & $25 E-14$ & $86 E-15$ \\
\hline WIL-D & $1.51 E-13$ & $1.30 \mathrm{E}-13$ & $1.38 \mathrm{E}-14$ & $.12 \mathrm{E}-14$ & $15 E-14$ & $E-15$ \\
\hline IL-C & $1.51 E-13$ & $.30 E-13$ & $38 E-14$ & $12 \mathrm{E}-14$ & 5. $15 E-14$ & $5.45 E-15$ \\
\hline
\end{tabular}

\begin{tabular}{|c|c|c|c|c|c|c|}
\hline \multirow[b]{2}{*}{ Site/Loc } & \multicolumn{3}{|c|}{ OSIRIS } & \multicolumn{3}{|c|}{ TRIGA } \\
\hline & EA4 & EA5 & EAG & EA4 & EA.5 & EA6 \\
\hline$C H A-D$ & $3.23 \mathrm{E}-13$ & $1.38 \mathrm{E}-13$ & $1.72 \mathrm{E}-14$ & $2.57 E-14$ & $\cdot 1.98 \mathrm{E}-14$ & $2.47 E-15$ \\
\hline $\mathrm{CHA}-\mathrm{C}$ & $3.23 \mathrm{E}-13$ & $1.38 \mathrm{E}-13$ & $1.72 \mathrm{E}-14$ & $2.57 E-14$ & $1.98 \mathrm{E}-14$ & $2.47 \mathrm{E}-15$ \\
\hline CNC-D & $4.04 E-13$ & $4.59 E-14$ & $5.27 E-15$ & $3.22 \mathrm{E}-14$ & $6.60 \mathrm{E}-15$ & $7.56 \mathrm{E}-16$ \\
\hline CNC-C & $4.04 \mathrm{E}-13$ & $4.59 E-14$ & $5.27 \mathrm{E}-15$ & $3.22 \mathrm{E}-14$ & $6.60 \mathrm{E}-15$ & $7.56 \mathrm{E}-16$ \\
\hline GAL-D & $3.49 E-13$ & $1.31 E-13$ & $1.68 \mathrm{E}-14$ & $2.78 E-14$ & $1.89 E-14$ & $2.41 E-15$ \\
\hline GAI-C & $3.49 \mathrm{E}-13$ & $1.318-13$ & $1.68 \mathrm{E}-14$ & $2.78 \mathrm{E}-14$ & $1.89 E-14$ & $2.41 E-15$ \\
\hline$J A C-D$ & $3.23 \mathrm{E}-13$ & $1.38 \mathrm{E}-13$ & $1.72 \mathrm{E}-14$ & $2.57 \mathrm{E}-14$ & $1.98 \mathrm{E}-14$ & $2.47 E-15$ \\
\hline JAC-C & $3.23 E-13$ & $1.38 E-13$ & $1.72 \mathrm{E}-14$ & $2.57 E-14$ & $1.98 \mathrm{E}-14$ & $2.47 E-15$ \\
\hline LOS-D & $4.04 E-13$ & $4.59 E-14$ & $5.27 E-15$ & $3.22 E-14$ & $6.60 E-15$ & $7.56 E-16$ \\
\hline LOS-C & $4.04 \mathrm{E}-13$ & $4.59 \mathrm{E}-14$ & $5.27 \mathrm{E}-15$ & $3.22 E-14$ & $6.60 E-15$ & $7.56 \mathrm{E}-16$ \\
\hline MOT-D & $1.97 E-13$ & $1.26 \mathrm{E}-13$ & $1.34 \mathrm{E}-14$ & $1.58 \mathrm{E}-14$ & $1.81 \mathrm{E}-14$ & $1.91 \mathrm{E}-15$ \\
\hline NEW-D & $2.20 E-13$ & $2.36 \mathrm{E}-13$ & $2.32 \mathrm{E}-14$ & $1.78 \mathrm{E}-14$ & $3.39 E-14$ & $3.31 \mathrm{E}-15$ \\
\hline NEW-C & $2.20 E-13$ & $2.36 E-13$ & $2.32 \mathrm{E}-14$ & $1.78 \mathrm{E}-14$ & $3.39 \mathrm{E}-14$ & $3.31 E-15$ \\
\hline NOR-D & $1.97 \mathrm{E}-13$ & $1.26 \mathrm{E}-13$ & $1.34 \mathrm{E}-14$ & $1.58 \mathrm{E}-14$ & $1.81 E-14$ & $1.91 E-15$ \\
\hline NOR-C & $1.97 \mathrm{E}-13$ & $1.26 \mathrm{E}-13$ & $1.34 \mathrm{E}-14$ & $1.58 \mathrm{E}-14$ & $1.81 E-14$ & $1.91 E-15$ \\
\hline PHI-D & $3.78 E-13$ & $1.27 E-13$ & $1.60 \mathrm{E}-14$ & $3.01 E-14$ & $1.83 \mathrm{E}-14$ & $2.29 \mathrm{E}-15$ \\
\hline PHI-C & $3.78 E-13$ & $1.27 \mathrm{E}-13$ & $1.60 \mathrm{E}-14$ & $3.01 E-14$ & $1.83 \mathrm{E}-14$ & $2.29 \mathrm{E}-15$ \\
\hline QOR-D & $2.78 E-13$ & $1.53 \mathrm{E}-13$ & $1.94 \mathrm{E}-14$ & $2.24 \mathrm{E}-14$ & $2.19 E-14$ & 2.77E-15 \\
\hline POR-C & $2.78 E-13$ & $1.53 \mathrm{E}-13$ & $1.94 E-14$ & $2.24 \mathrm{E}-14$ & $2.19 \mathrm{E}-14$ & $2.77 E-15$ \\
\hline SAV-D & $3.23 E-13$ & $1.38 \mathrm{E}-13$ & $1.72 \mathrm{E}-14$ & $2.57 E-14$ & $1.98 E-14$ & $2.47 E-15$ \\
\hline SAV-C & $3.23 \mathrm{E}-13$ & $1.38 \mathrm{E}-13$ & $1.72 E-14$ & $2.57 \mathrm{E}-14$ & $1.98 \mathrm{E}-14$ & $2.47 E-15$ \\
\hline$S E A-C$ & $2.78 E-13$ & $1.53 E-13$ & $1.94 \mathrm{E}-14$ & $2.24 E-14$ & $2.19 \mathrm{E}-14$ & $2.77 E-1.5$ \\
\hline TAC-D & $2.78 \mathrm{E}-13$ & $1.53 \mathrm{E}-13$ & $1.94 \mathrm{E}-14$ & $2.24 E-14$ & $2.19 \mathrm{E}-14$ & $2.77 E-15$ \\
\hline TAC-C & $2.78 E-13$ & $1.53 E-13$ & $1.94 \mathrm{E}-14$ & $2.24 \mathrm{E}-14$ & $2.19 E-14$ & $2.77 E-15$ \\
\hline WII-D & $1.97 E-13$ & $1.26 E-13$ & $1.34 \mathrm{E}-14$ & $1.58 \mathrm{E}-14$ & $1.81 E-14$ & $1.91 E-15$ \\
\hline WIL-C & $1.97 \mathrm{E}-13$ & $1.26 \mathrm{E}-13$ & $1.34 \mathrm{E}-14$ & $1.58 \mathrm{E}-14$ & $1.81 \mathrm{E}-14$ & $1.91 E-15$ \\
\hline
\end{tabular}


Table 44. Absolute Risks for EIS Accident Categories

EDE Whole Body Population Dose, $0-80 \mathrm{~km}$ (Sv)

$\begin{array}{lccccc}\text { Site/LOC } & \text { EIS4 } & \text { EIS5A } & \begin{array}{c}\text { BR-2 } \\ \text { EIS5B }\end{array} & \text { EIS6A } & \text { EIS6B } \\ \text { CHA-D } & 1.43 E-09 & 6.75 E-12 & 2.24 \mathrm{E}-08 & 9.55 \mathrm{E}-13 & 2.30 \mathrm{E}-08 \\ \text { CHA-C } & 2.26 \mathrm{E}-09 & 6.75 \mathrm{E}-12 & 2.24 \mathrm{E}-08 & 9.65 \mathrm{E}-13 & 2.24 \mathrm{E}-08 \\ \text { CNC-D } & 2.62 \mathrm{E}-09 & 3.03 \mathrm{E}-11 & 1.12 \mathrm{E}-07 & 4.56 \mathrm{E}-12 & 1.34 \mathrm{E}-07 \\ \text { CNC-C } & 5.60 \mathrm{E}-09 & 4.77 \mathrm{E}-11 & 1.80 \mathrm{E}-07 & 6.90 \mathrm{E}-12 & 2.07 \mathrm{E}-07 \\ \text { GAL-D } & 4.34 \mathrm{E}-09 & 2.28 \mathrm{E}-11 & 7.75 \mathrm{E}-08 & 3.54 \mathrm{E}-12 & 9.30 \mathrm{E}-08 \\ \text { GAL-C } & 1.93 \mathrm{E}-09 & 2.26 \mathrm{E}-11 & 7.70 \mathrm{E}-08 & 3.50 \mathrm{E}-12 & 9.36 \mathrm{E}-08 \\ \text { JAC-D } & 1.67 \mathrm{E}-09 & 1.09 \mathrm{E}-11 & 3.69 \mathrm{E}-08 & 1.54 \mathrm{E}-12 & 3.89 \mathrm{E}-08 \\ \text { JAC-C } & 1.54 \mathrm{E}-09 & 8.70 \mathrm{E}-12 & 2.88 \mathrm{E}-08 & 1.26 \mathrm{E}-12 & 3.12 \mathrm{E}-08 \\ \text { LOS-D } & 1.27 \mathrm{E}-08 & 6.75 \mathrm{E}-11 & 2.56 \mathrm{E}-07 & 9.70 \mathrm{E}-12 & 2.92 \mathrm{E}-07 \\ \text { LOS-C } & 4.79 \mathrm{E}-09 & 6.10 \mathrm{E}-11 & 2.32 \mathrm{E}-07 & 8.85 \mathrm{E}-12 & 2.68 \mathrm{E}-07 \\ \text { MOT-D } & 4.34 \mathrm{E}-10 & 3.86 \mathrm{E}-12 & 1.13 \mathrm{E}-08 & 5.80 \mathrm{E}-13 & 1.28 \mathrm{E}-08 \\ \text { NEW-D } & 1.39 \mathrm{E}-08 & 9.15 \mathrm{E}-11 & 3.56 \mathrm{E}-07 & 1.27 \mathrm{E}-11 & 3.86 \mathrm{E}-07 \\ \text { NEW-C } & 2.24 \mathrm{E}-08 & 9.65 \mathrm{E}-11 & 3.74 \mathrm{E}-07 & 1.32 \mathrm{E}-11 & 3.83 \mathrm{E}-07 \\ \text { NOR-D } & 3.29 \mathrm{E}-09 & 1.35 \mathrm{E}-11 & 4.62 \mathrm{E}-08 & 1.86 \mathrm{E}-12 & 4.71 \mathrm{E}-08 \\ \text { NOR-C } & 1.81 \mathrm{E}-09 & 1.07 \mathrm{E}-11 & 3.60 \mathrm{E}-08 & 1.52 \mathrm{E}-12 & 3.88 \mathrm{E}-08 \\ \text { PHI-D } & 1.06 \mathrm{E}-08 & 4.05 \mathrm{E}-11 & 1.52 \mathrm{E}-07 & 5.65 \mathrm{E}-12 & 1.58 \mathrm{E}-07 \\ \text { PHI-C } & 5.04 \mathrm{E}-09 & 3.97 \mathrm{E}-11 & 1.49 \mathrm{E}-07 & 5.75 \mathrm{E}-12 & 1.65 \mathrm{E}-07 \\ \text { POR-D } & 4.59 \mathrm{E}-09 & 1.84 \mathrm{E}-11 & 6.35 \mathrm{E}-08 & 2.64 \mathrm{E}-12 & 6.90 \mathrm{E}-08 \\ \text { POR-C } & 3.18 \mathrm{E}-09 & 1.77 \mathrm{E}-11 & 6.10 \mathrm{E}-08 & 2.56 \mathrm{E}-12 & 6.84 \mathrm{E}-08 \\ \text { SAV-D } & 3.35 \mathrm{E}-09 & 8.15 \mathrm{E}-12 & 2.61 \mathrm{E}-08 & 1.18 \mathrm{E}-12 & 2.57 \mathrm{E}-08 \\ \text { SAV-C } & 8.04 \mathrm{E}-10 & 6.55 \mathrm{E}-12 & 2.06 \mathrm{E}-08 & 9.60 \mathrm{E}-13 & 2.25 \mathrm{E}-08 \\ \text { SEA-C } & 7.80 \mathrm{E}-10 & 1.17 \mathrm{E}-11 & 4.10 \mathrm{E}-08 & 1.82 \mathrm{E}-12 & 5.02 \mathrm{E}-08 \\ \text { TAC-D } & 3.31 \mathrm{E}-09 & 2.59 \mathrm{E}-11 & 9.45 \mathrm{E}-08 & 3.85 \mathrm{E}-12 & 1.10 \mathrm{E}-07 \\ \text { TAC-C } & 2.31 \mathrm{E}-09 & 2.17 \mathrm{E}-11 & 7.80 \mathrm{E}-08 & 3.20 \mathrm{E}-12 & 9.06 \mathrm{E}-08 \\ \text { WIL-D } & 2.27 \mathrm{E}-09 & 7.95 \mathrm{E}-12 & 2.57 \mathrm{E}-08 & 1.17 \mathrm{E}-12 & 2.77 \mathrm{E}-08 \\ \text { WIL-C } & 5.78 \mathrm{E}-10 & 3.74 \mathrm{E}-12 & 1.11 \mathrm{E}-08 & 5.65 \mathrm{E}-13 & 1.27 \mathrm{E}-08\end{array}$

$\begin{array}{ccccc}\text { EIS4 } & \text { EIS5A } & \begin{array}{c}\text { RIS } \\ \text { EISB }\end{array} & \text { EIS6A } & \text { EIS6B } \\ 5.70 \mathrm{E}-10 & 2.68 \mathrm{E}-12 & 8.35 \mathrm{E}-09 & 3.79 \mathrm{E}-13 & 9.06 \mathrm{E}-09 \\ 9.00 \mathrm{E}-10 & 2.69 \mathrm{E}-12 & 8.40 \mathrm{E}-09 & 3.84 \mathrm{E}-13 & 8.94 \mathrm{E}-09 \\ 1.04 \mathrm{E}-09 & 1.21 \mathrm{E}-11 & 4.34 \mathrm{E}-08 & 1.81 \mathrm{E}-12 & 5.20 \mathrm{E}-08 \\ 2.23 \mathrm{E}-09 & 1.90 \mathrm{E}-11 & 7.05 \mathrm{E}-08 & 2.74 \mathrm{E}-12 & 8.10 \mathrm{E}-08 \\ 1.73 \mathrm{E}-09 & 9.15 \mathrm{E}-12 & 2.95 \mathrm{E}-08 & 1.41 \mathrm{E}-12 & 3.56 \mathrm{E}-08 \\ 7.74 \mathrm{E}-10 & 9.00 \mathrm{E}-12 & 2.91 \mathrm{E}-08 & 1.40 \mathrm{E}-12 & 3.57 \mathrm{E}-08 \\ 6.60 \mathrm{E}-10 & 4.35 \mathrm{E}-12 & 1.39 \mathrm{E}-08 & 6.10 \mathrm{E}-13 & 1.52 \mathrm{E}-08 \\ 6.12 \mathrm{E}-10 & 3.46 \mathrm{E}-12 & 1.08 \mathrm{E}-08 & 5.00 \mathrm{E}-13 & 1.21 \mathrm{E}-08 \\ 5.05 \mathrm{E}-09 & 2.69 \mathrm{E}-11 & 1.00 \mathrm{E}-07 & 3.87 \mathrm{E}-12 & 1.15 \mathrm{E}-07 \\ 1.91 \mathrm{E}-09 & 2.44 \mathrm{E}-11 & 9.10 \mathrm{E}-08 & 3.54 \mathrm{E}-12 & 1.06 \mathrm{E}-07 \\ 1.72 \mathrm{E}-10 & 1.54 \mathrm{E}-12 & 4.04 \mathrm{E}-09 & 2.31 \mathrm{E}-13 & 4.73 \mathrm{E}-09 \\ 5.54 \mathrm{E}-09 & 3.66 \mathrm{E}-11 & 1.40 \mathrm{E}-07 & 5.10 \mathrm{E}-12 & 1.55 \mathrm{E}-07 \\ 8.94 \mathrm{E}-09 & 3.85 \mathrm{E}-11 & 1.48 \mathrm{E}-07 & 5.25 \mathrm{E}-12 & 1.59 \mathrm{E}-07 \\ 1.31 \mathrm{E}-09 & 5.40 \mathrm{E}-12 & 1.76 \mathrm{E}-08 & 7.45 \mathrm{E}-13 & 1.88 \mathrm{E}-08 \\ 7.20 \mathrm{E}-10 & 4.28 \mathrm{E}-12 & 1.37 \mathrm{E}-08 & 6.05 \mathrm{E}-13 & 1.51 \mathrm{E}-08 \\ 4.21 \mathrm{E}-09 & 1.61 \mathrm{E}-11 & 5.95 \mathrm{E}-08 & 2.25 \mathrm{E}-12 & 6.48 \mathrm{E}-08 \\ 2.01 \mathrm{E}-09 & 1.58 \mathrm{E}-11 & 5.80 \mathrm{E}-08 & 2.28 \mathrm{E}-12 & 6.66 \mathrm{E}-08 \\ 1.83 \mathrm{E}-09 & 7.30 \mathrm{E}-12 & 2.42 \mathrm{E}-08 & 1.05 \mathrm{E}-12 & 2.71 \mathrm{E}-08 \\ 1.27 \mathrm{E}-09 & 7.05 \mathrm{E}-12 & 2.32 \mathrm{E}-08 & 1.02 \mathrm{E}-12 & 2.63 \mathrm{E}-08 \\ 1.33 \mathrm{E}-09 & 3.24 \mathrm{E}-12 & 9.70 \mathrm{E}-09 & 4.70 \mathrm{E}-13 & 1.03 \mathrm{E}-08 \\ 3.18 \mathrm{E}-10 & 2.60 \mathrm{E}-12 & 7.50 \mathrm{E}-09 & 3.80 \mathrm{E}-13 & 8.52 \mathrm{E}-09 \\ 3.12 \mathrm{E}-10 & 4.69 \mathrm{E}-12 & 1.54 \mathrm{E}-08 & 7.25 \mathrm{E}-13 & 1.91 \mathrm{E}-08 \\ 1.32 \mathrm{E}-09 & 1.03 \mathrm{E}-11 & 3.63 \mathrm{E}-08 & 1.53 \mathrm{E}-12 & 4.28 \mathrm{E}-08 \\ 9.18 \mathrm{E}-10 & 8.65 \mathrm{E}-12 & 2.99 \mathrm{E}-08 & 1.27 \mathrm{E}-12 & 3.50 \mathrm{E}-08 \\ 9.06 \mathrm{E}-10 & 3.17 \mathrm{E}-12 & 9.70 \mathrm{E}-09 & 4.66 \mathrm{E}-13 & 1.08 \mathrm{E}-08 \\ 2.30 \mathrm{E}-10 & 1.49 \mathrm{E}-12 & 4.05 \mathrm{E}-09 & 2.25 \mathrm{E}-13 & 4.73 \mathrm{E}-09\end{array}$


Table 44. Absolute Risks for EIS Accident Categories (Continued)

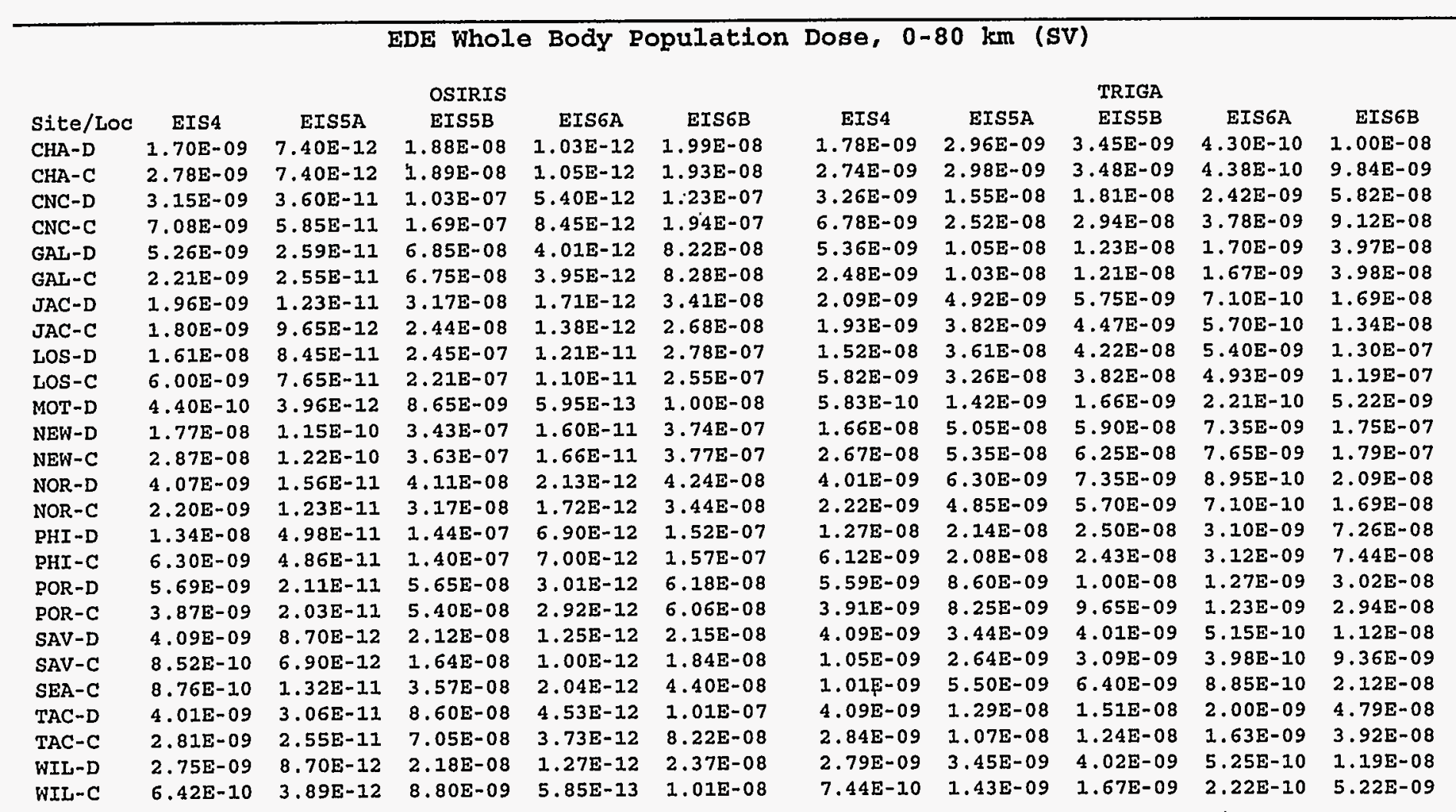


Table 44. Absolute Risks for EIS Accident Categories (Continued)

\section{Total Cancer Fatalities, $0-80 \mathrm{~km}$}

\begin{tabular}{|c|c|c|c|c|c|}
\hline & & & BR-2 & & \\
\hline Site/Loc & EIS4 & $\begin{array}{l}\text { EIS5A } \\
94 \mathrm{~F}-73\end{array}$ & - EIS5B & $\begin{array}{c}\text { EIS6A } \\
4.16 E-14\end{array}$ & $\begin{array}{c}\text { EIS6B } \\
1.06 \mathrm{E}-09\end{array}$ \\
\hline CHA-D & $6.30 \mathrm{E}-11$ & $2.94 \mathrm{E}-13$ & $1.02 \mathrm{E}-09$ & & $1.06 \mathrm{E}-09$ \\
\hline $\mathrm{CHA}-\mathrm{C}$ & $9.90 \mathrm{E}-11$ & $2.94 \mathrm{E}-13$ & $1.02 \mathrm{E}-09$ & $4.21 E-14$ & $.03 E-09$ \\
\hline CNC-D & $1.14 \mathrm{E}-10$ & $.31 E-12$ & $4.88 \mathrm{E}-09$ & $1.96 \mathrm{E}-13$ & $.83 E-09$ \\
\hline NC-C & $2.45 \mathrm{E}-10$ & $.07 E-12$ & $7.65 \mathrm{E}-09$ & $2.97 E-13$ & $8.82 \mathrm{E}-09$ \\
\hline GAL-D & $1.90 \mathrm{E}-10$ & $9.80 \mathrm{E}-13$ & $3.43 E-09$ & $1.52 \mathrm{E}-13$ & $.13 E-09$ \\
\hline GAL-C & $4 E-11$ & $5 E-13$ & E-09 & $1.50 E-13$ & $16 \mathrm{E}-09$ \\
\hline JAC-D & $7.32 \mathrm{E}-11$ & $4.78 E-13$ & E-09 & $6.70 \mathrm{E}-14$ & $1.76 \mathrm{E}-09$ \\
\hline$-C$ & $6.78 E-11$ & $3.80 E-13$ & $1.31 E-09$ & $5.50 \mathrm{E}-14$ & $1.42 \mathrm{E}-09$ \\
\hline LOS-D & $5.56 \mathrm{E}-10$ & $2.93 \mathrm{E}-12$ & $1.09 \mathrm{E}-08$ & $4.21 E-13$ & $1.24 \mathrm{E}-08$ \\
\hline os-C & $2.09 \mathrm{E}-10$ & $2.66 \mathrm{E}-12$ & $9.80 \mathrm{E}-09$ & $3.85 \mathrm{E}-13$ & $3.13 \mathrm{E}-08$ \\
\hline OT-D & $1.90 E-11$ & $1.68 \mathrm{E}-13$ & $5.35 \mathrm{E}-10$ & $2.53 \mathrm{E}-14$ & $.12 \mathrm{E}-10$ \\
\hline$E W-D$ & $6.06 E-10$ & $3.95 \mathrm{E}-12$ & $1.49 \mathrm{E}-08$ & $5.50 \mathrm{E}-13$ & 08 \\
\hline EW-C & $9.84 E-10$ & $4.15 \mathrm{E}-12$ & $1.57 \mathrm{E}-08$ & 3 & $E-08$ \\
\hline$O R-D$ & $5 E-10$ & $5.85 \mathrm{E}-13$ & $2.04 E-09$ & $8.10 \mathrm{E}-14$ & $2.09 E-09$ \\
\hline NOR-C & $7.92 \mathrm{E}-11$ & $4.65 \mathrm{E}-13$ & $1.61 \mathrm{E}-09$ & $6.60 \mathrm{E}-14$ & $1.73 \mathrm{E}-09$ \\
\hline PHI-D & $4.63 \mathrm{E}-10$ & $1.75 \mathrm{E}-12$ & $6.50 \mathrm{E}-09$ & $2.43 E-13$ & $6.72 \mathrm{E}-09$ \\
\hline PHI -C & $2.21 E-10$ & $1.71 \mathrm{E}-12$ & $6.35 \mathrm{E}-09$ & $2.47 \mathrm{E}-13$ & $7.02 \mathrm{E}-09$ \\
\hline POR-D & 2.02E-10 & $7.95 \mathrm{E}-13$ & $2.82 \mathrm{E}-09$ & $1.14 \mathrm{E}-13$ & $3.06 \mathrm{E}-09$ \\
\hline POR-C & $1.39 \mathrm{E}-10$ & $7.65 \mathrm{E}-13$ & $2.70 \mathrm{E}-09$ & 3 & \\
\hline SAV-D & $1.48 \mathrm{E}-10$ & $3.56 \mathrm{E}$ & 9 & $15 E-14$ & $1.21 \mathrm{E}-09$ \\
\hline SAV-C & $3.52 \mathrm{E}-$ & 13 & $9.70 \mathrm{E}-10$ & $4.19 \mathrm{E}-14$ & $1.06 \mathrm{E}-09$ \\
\hline$A-C$ & $3.36 \mathrm{E}-11$ & $5.05 E-13$ & $1.84 \mathrm{E}-09$ & $7.80 \mathrm{E}-14$ & $2.24 \mathrm{E}-09$ \\
\hline TAC-D & $1.44 \mathrm{E}-10$ & $1.12 \mathrm{E}-12$ & $4.10 \mathrm{E}-09$ & $1.65 \mathrm{E}-13$ & $4.78 \mathrm{E}-09$ \\
\hline TAC-C & $1.01 \mathrm{E}-10$ & $9.35 E-13$ & $3.40 \mathrm{E}-09$ & $1.38 \mathrm{E}-13$ & $3.95 E-09$ \\
\hline WIL-D & $9.96 \mathrm{E}-11$ & $3.44 \mathrm{E}-13$ & $1.17 \mathrm{E}-09$ & $5.05 E-14$ & $1.27 E-09$ \\
\hline IL-C & $.53 \mathrm{E}-11$ & $.63 E-13$ & $5.25 \mathrm{E}-10$ & $2.45 \mathrm{E}-14$ & $6.00 \mathrm{E}-10$ \\
\hline
\end{tabular}

$\begin{array}{ccccc}\text { EIS4 } & \text { EIS5A } & \text { RHF } \\ 2.51 E-11 & 1.16 \mathrm{E}-13 & 3.77 \mathrm{E}-10 & 1.64 \mathrm{E}-14 & 4.12 \mathrm{E}-10 \\ 3.98 \mathrm{E}-11 & 1.16 \mathrm{E}-13 & 3.80 \mathrm{E}-10 & 1.66 \mathrm{E}-14 & 4.09 \mathrm{E}-10 \\ 4.56 \mathrm{E}-11 & 5.25 \mathrm{E}-13 & 1.87 \mathrm{E}-09 & 7.85 \mathrm{E}-14 & 2.24 \mathrm{E}-09 \\ 9.84 \mathrm{E}-11 & 8.30 \mathrm{E}-13 & 2.98 \mathrm{E}-09 & 1.19 \mathrm{E}-13 & 3.43 \mathrm{E}-09 \\ 7.62 \mathrm{E}-11 & 3.90 \mathrm{E}-13 & 1.30 \mathrm{E}-09 & 6.05 \mathrm{E}-14 & 1.57 \mathrm{E}-09 \\ 3.34 \mathrm{E}-11 & 3.85 \mathrm{E}-13 & 1.28 \mathrm{E}-09 & 5.95 \mathrm{E}-14 & 1.58 \mathrm{E}-09 \\ 2.92 \mathrm{E}-11 & 1.89 \mathrm{E}-13 & 6.20 \mathrm{E}-10 & 2.66 \mathrm{E}-14 & 6.84 \mathrm{E}-10 \\ 2.69 \mathrm{E}-11 & 1.51 \mathrm{E}-13 & 4.85 \mathrm{E}-10 & 2.18 \mathrm{E}-14 & 5.45 \mathrm{E}-10 \\ 2.24 \mathrm{E}-10 & 1.18 \mathrm{E}-12 & 4.24 \mathrm{E}-09 & 1.69 \mathrm{E}-13 & 4.85 \mathrm{E}-09 \\ 8.40 \mathrm{E}-11 & 1.06 \mathrm{E}-12 & 3.83 \mathrm{E}-09 & 1.54 \mathrm{E}-13 & 4.44 \mathrm{E}-09 \\ 7.44 \mathrm{E}-12 & 6.65 \mathrm{E}-14 & 1.91 \mathrm{E}-10 & 1.00 \mathrm{E}-14 & 2.24 \mathrm{E}-10 \\ 2.45 \mathrm{E}-10 & 1.59 \mathrm{E}-12 & 5.90 \mathrm{E}-09 & 2.21 \mathrm{E}-13 & 6.48 \mathrm{E}-09 \\ 3.96 \mathrm{E}-10 & 1.67 \mathrm{E}-12 & 6.20 \mathrm{E}-09 & 2.28 \mathrm{E}-13 & 6.66 \mathrm{E}-09 \\ 5.81 \mathrm{E}-11 & 2.34 \mathrm{E}-13 & 7.75 \mathrm{E}-10 & 3.23 \mathrm{E}-14 & 8.28 \mathrm{E}-10 \\ 3.17 \mathrm{E}-11 & 1.85 \mathrm{E}-13 & 6.05 \mathrm{E}-10 & 2.63 \mathrm{E}-14 & 6.72 \mathrm{E}-10 \\ 1.87 \mathrm{E}-10 & 7.05 \mathrm{E}-13 & 2.53 \mathrm{E}-09 & 9.75 \mathrm{E}-14 & 2.76 \mathrm{E}-09 \\ 8.88 \mathrm{E}-11 & 6.90 \mathrm{E}-13 & 2.46 \mathrm{E}-09 & 9.90 \mathrm{E}-14 & 2.83 \mathrm{E}-09 \\ 8.10 \mathrm{E}-11 & 3.17 \mathrm{E}-13 & 1.06 \mathrm{E}-09 & 4.53 \mathrm{E}-14 & 1.19 \mathrm{E}-09 \\ 5.59 \mathrm{E}-11 & 3.05 \mathrm{E}-13 & 1.02 \mathrm{E}-09 & 4.42 \mathrm{E}-14 & 1.16 \mathrm{E}-09 \\ 5.90 \mathrm{E}-11 & 1.40 \mathrm{E}-13 & 4.46 \mathrm{E}-10 & 2.04 \mathrm{E}-14 & 4.77 \mathrm{E}-10 \\ 1.39 \mathrm{E}-11 & 1.13 \mathrm{E}-13 & 3.50 \mathrm{E}-10 & 1.65 \mathrm{E}-14 & 3.98 \mathrm{E}-10 \\ 1.34 \mathrm{E}-11 & 2.01 \mathrm{E}-13 & 6.85 \mathrm{E}-10 & 3.10 \mathrm{E}-14 & 8.46 \mathrm{E}-10 \\ 5.78 \mathrm{E}-11 & 4.47 \mathrm{E}-13 & 1.57 \mathrm{E}-09 & 6.60 \mathrm{E}-14 & 1.85 \mathrm{E}-09 \\ 4.03 \mathrm{E}-11 & 3.74 \mathrm{E}-13 & 1.30 \mathrm{E}-09 & 5.50 \mathrm{E}-14 & 1.52 \mathrm{E}-09 \\ 3.99 \mathrm{E}-11 & 1.36 \mathrm{E}-13 & 4.38 \mathrm{E}-10 & 2.00 \mathrm{E}-14 & 4.91 \mathrm{E}-10 \\ 1.01 \mathrm{E}-11 & 6.45 \mathrm{E}-14 & 1.89 \mathrm{E}-10 & 9.70 \mathrm{E}-15 & 2.22 \mathrm{E}-10 \\ & & & & \end{array}$


Table 44. Absolute Risks for EIS Accident Categories (Continued)

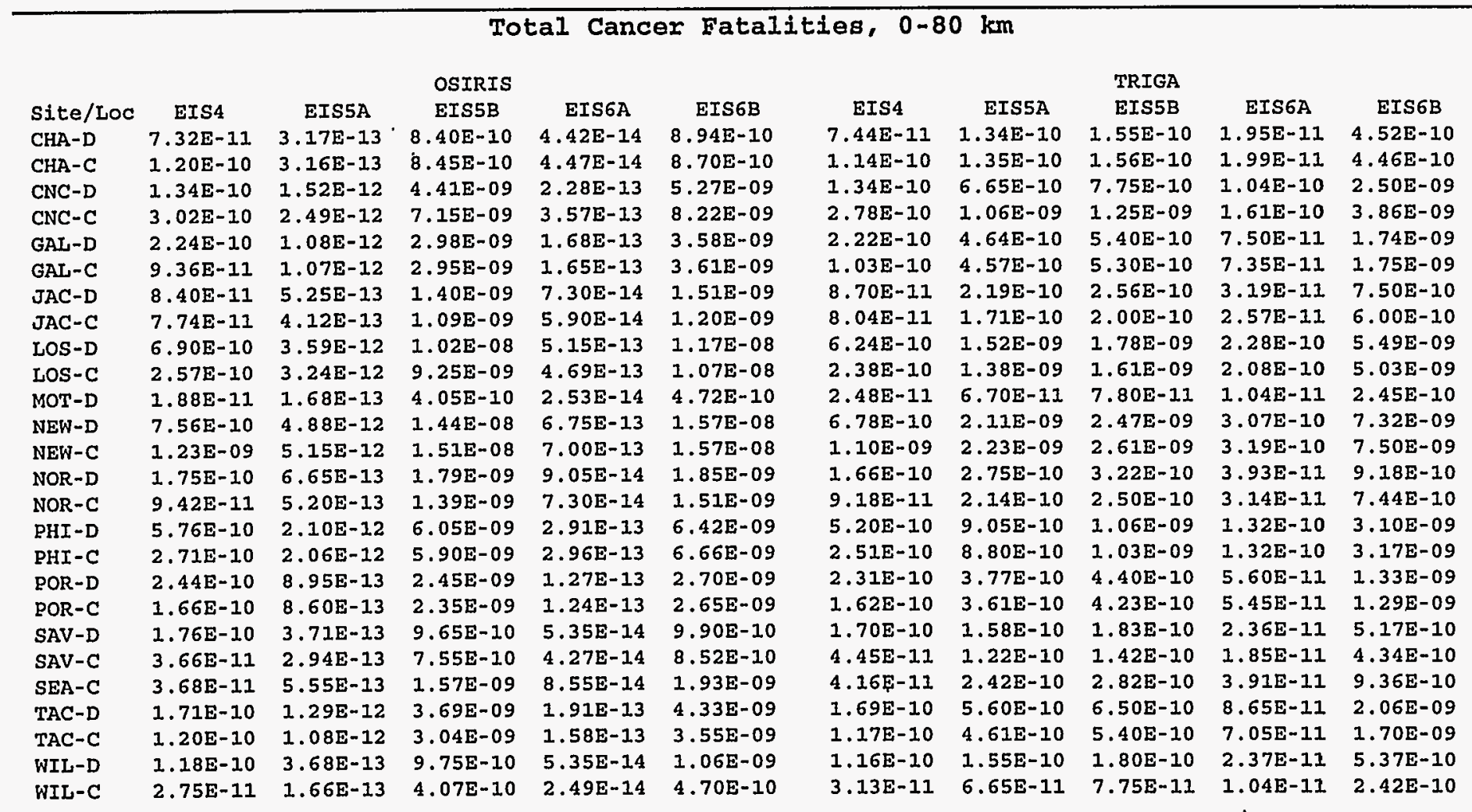


Table 44. Absolute Risks for EIS Accident Categories (Continued)

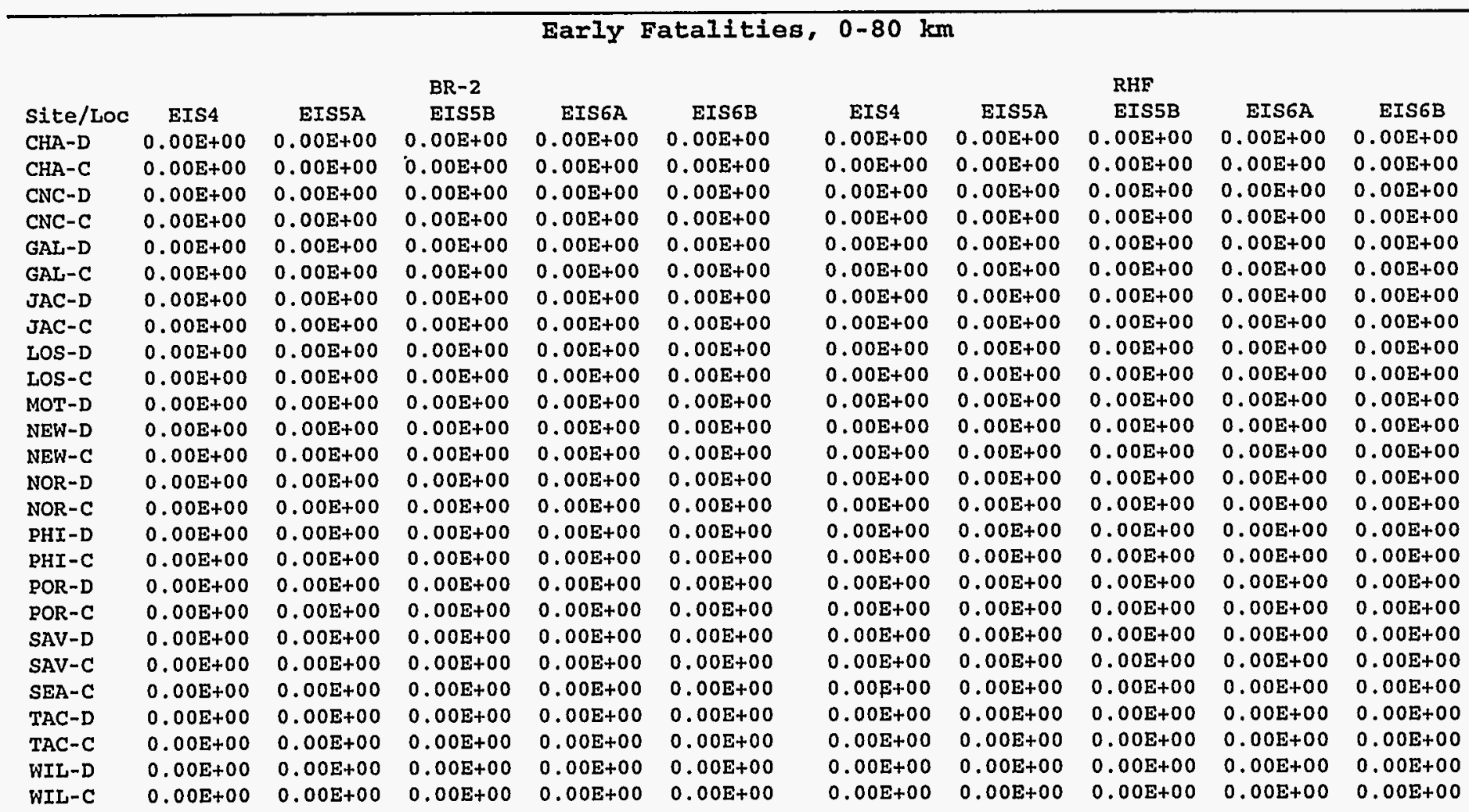


Table 44. Absolute Risks for EIS Accident Categories (Continued)

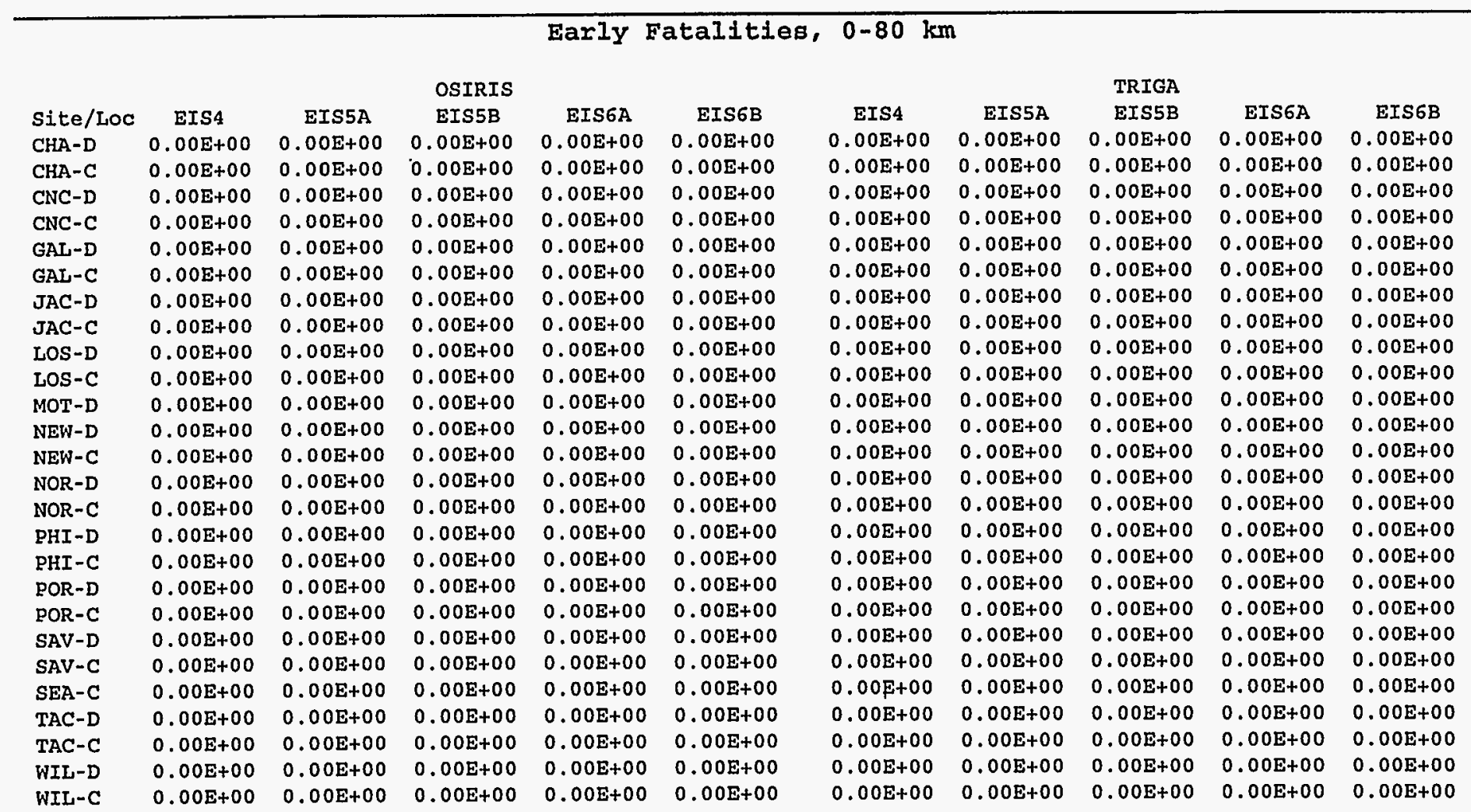


Table 44. Absolute Risks for EIS Accident Categories (Continued)

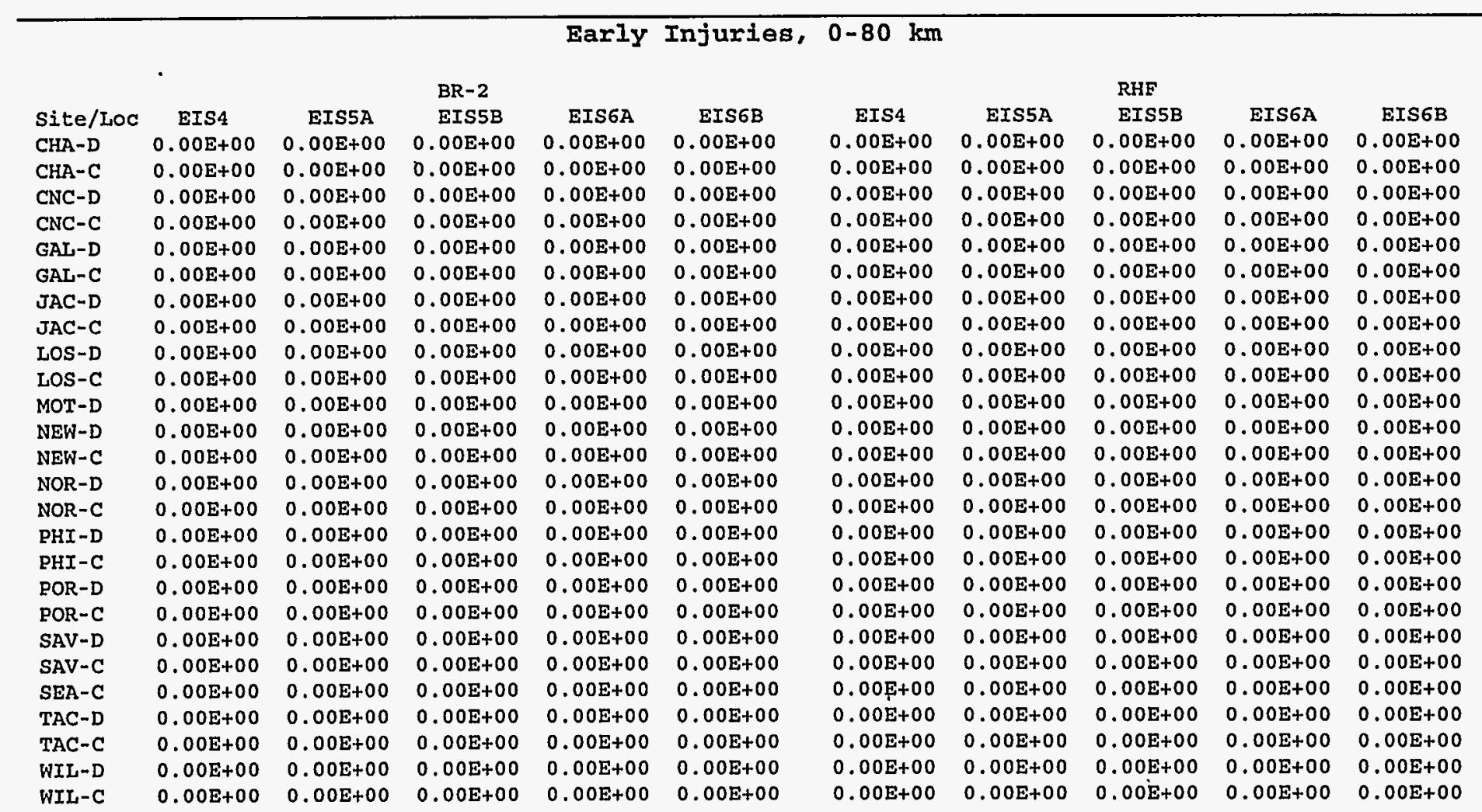


Table 44. Absolute Risks for EIS Accident Categories (Continued)

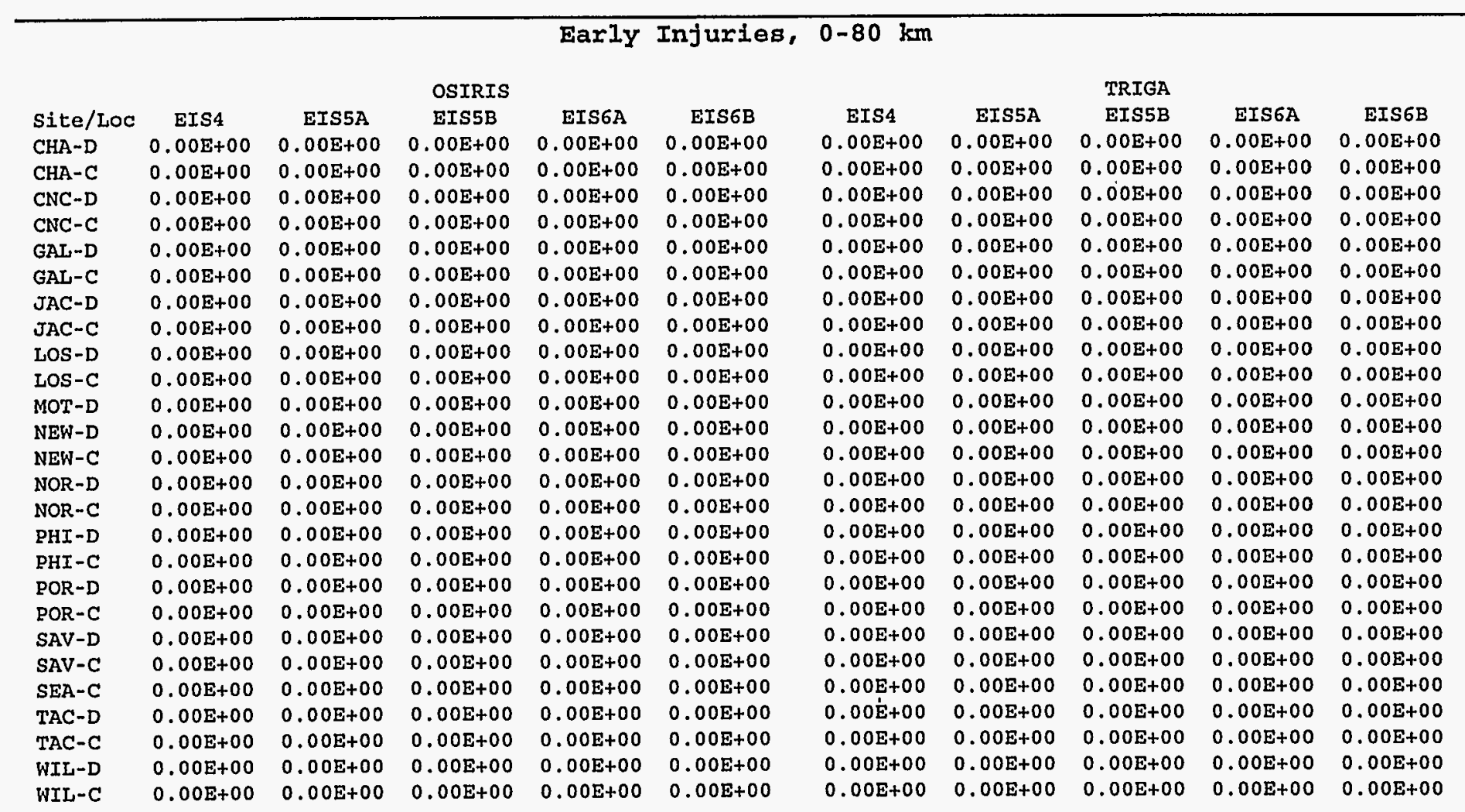


Table 44. Absolute Risks for EIS Accident Categories (Continued)

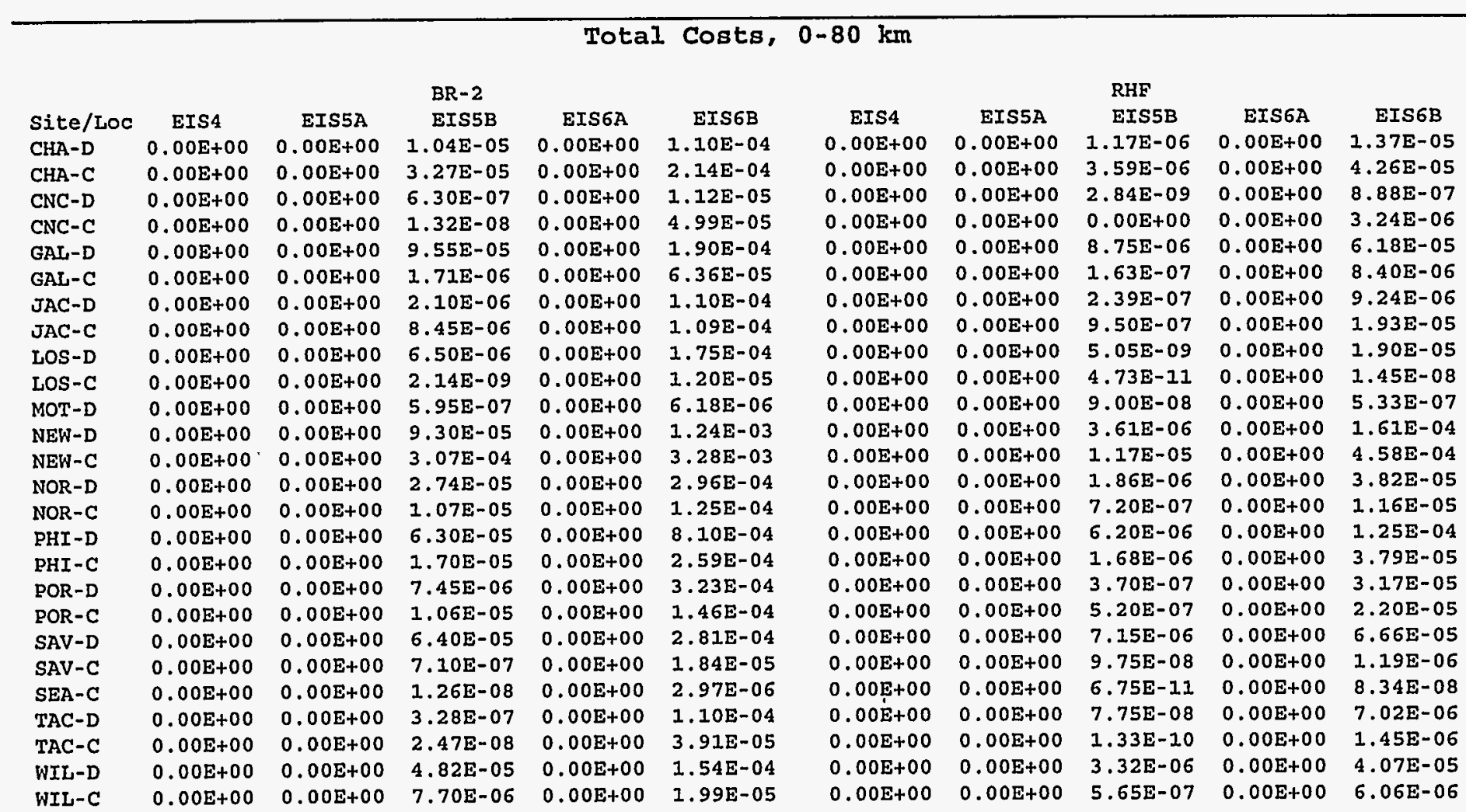


Table 44. Absolute Risks for EIS Accident Categories (Continued)

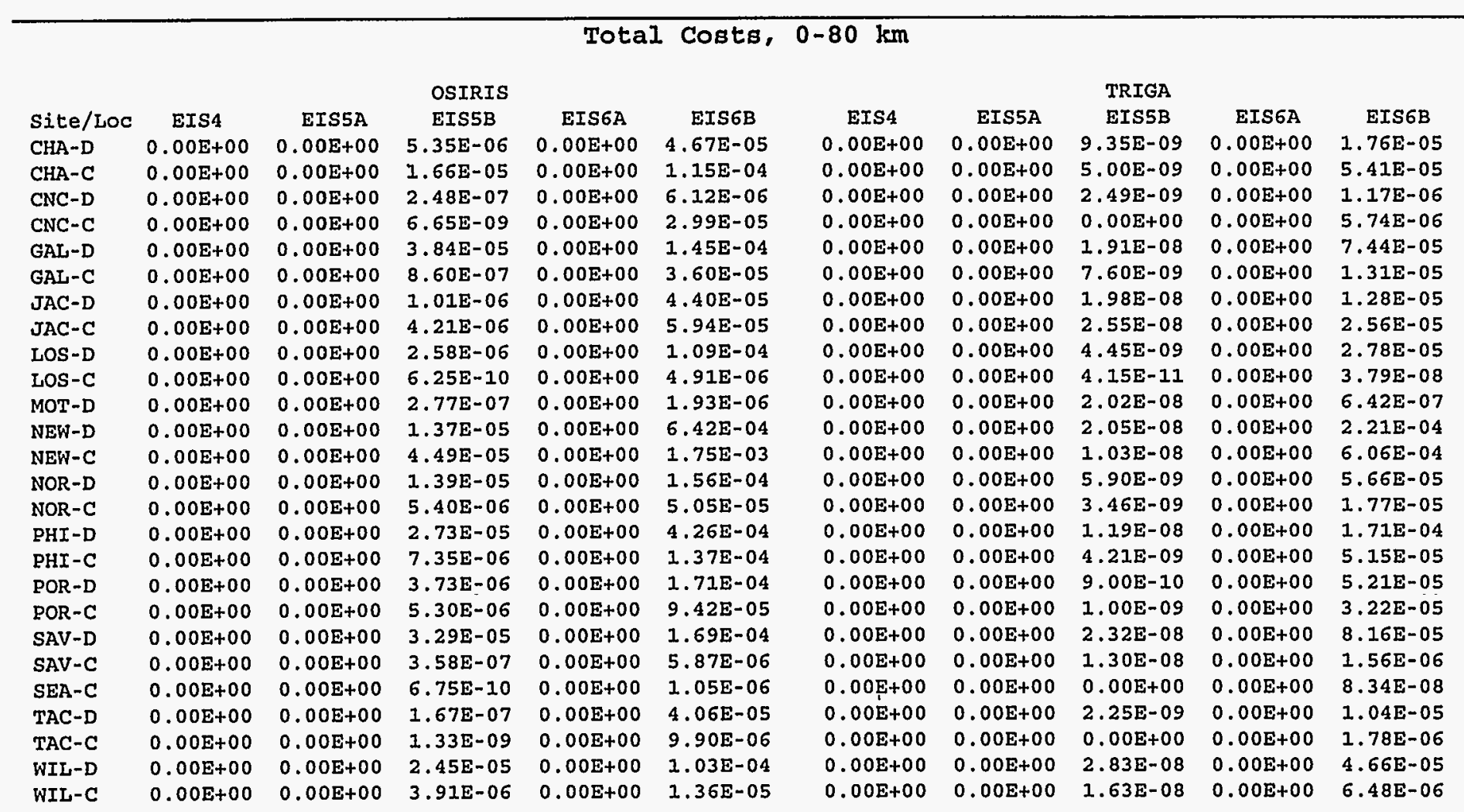


Table 44. Absolute Risks for EIS Accident Categories (Continued)

\begin{tabular}{|c|c|c|c|c|c|c|c|c|c|c|}
\hline \multirow[b]{3}{*}{ site/Loc } & \multirow[b]{3}{*}{ EIS4 } & \multicolumn{3}{|c|}{ Individual Centerline } & \multirow{3}{*}{$\begin{array}{c}\text { EDE Whole } \\
\text { EIS6B }\end{array}$} & \multicolumn{2}{|c|}{ Body Dose, 0-1.6 } & \multicolumn{2}{|l|}{$\mathrm{km}$ (sv) } & \multirow[b]{3}{*}{ EIS6B } \\
\hline & & & $\mathrm{BR}-2$ & & & & & RHF & & \\
\hline & & EIS5A & EIS5B & EIS6A & & EIS4 & EIS5A & EIS5B & EIS6A & \\
\hline CHA-D & $5.12 \mathrm{E}-12$ & $9.10 \mathrm{E}-16$ & $2.50 E-12$ & $1.32 \mathrm{E}-16$ & $6.84 \mathrm{E}-13$ & $2.05 E-12$ & $3.63 E-16$ & $1.29 \mathrm{E}-12$ & $5.30 \mathrm{E}-17$ & $4.91 E-13$ \\
\hline CHA-C & $5.12 \mathrm{E}-12$ & $9.10 \mathrm{E}-16$ & $2.50 \mathrm{E}-12$ & $1.32 \mathrm{E}-16$ & $6.84 \mathrm{E}-13$ & $2.05 \mathrm{E}-12$ & $3.63 E-16$ & $1.29 \mathrm{E}-12$ & $5.30 \mathrm{E}-17$ & $4.91 E-13$ \\
\hline CNC-D & $6.42 \mathrm{E}-12$ & $3.14 \mathrm{E}-16$ & $1.07 \mathrm{E}-12$ & $4.15 \mathrm{E}-17$ & $4.52 \mathrm{E}-13$ & $2.55 E-12$ & $1.26 \mathrm{E}-16$ & $4.91 \mathrm{E}-13$ & $1.66 \mathrm{E}-17$ & $3.14 \mathrm{E}-13$ \\
\hline CNC-C & $6.42 \mathrm{E}-12$ & $3.14 \mathrm{E}-16$ & $1.07 \mathrm{E}-12$ & $4.15 \mathrm{E}-17$ & $4.52 \mathrm{E}-13$ & $2.55 \mathrm{E}-12$ & $1.26 \mathrm{E}-16$ & $4.91 E-13$ & $1.66 \mathrm{E}-17$ & $3.14 \mathrm{E}-13$ \\
\hline GAL-D & $5.53 \mathrm{E}-12$ & $8.65 E-16$ & $2.13 \mathrm{E}-12$ & $1.29 \mathrm{E}-16$ & $4.01 \mathrm{E}-13$ & $21 E-12$ & $3.47 E-16$ & $1.23 \mathrm{E}-12$ & $5.15 \mathrm{E}-17$ & $4.39 \mathrm{E}-13$ \\
\hline GAL-C & $5.53 \mathrm{E}-12$ & $8.65 E-16$ & $2.13 \mathrm{E}-12$ & $1.29 \mathrm{E}-16$ & $4.01 \mathrm{E}-13$ & $2.21 \mathrm{E}-12$ & $3.47 \mathrm{E}-16$ & $1.23 \mathrm{E}-12$ & $5.15 \mathrm{E}-17$ & $4.39 \mathrm{E}-13$ \\
\hline JAC-D & $5.12 \mathrm{E}-12$ & $9.10 \mathrm{E}-16$ & $2.50 \mathrm{E}-12$ & $1.32 E-16$ & $6.84 \mathrm{E}-13$ & $2.05 \mathrm{E}-12$ & $3.63 \mathrm{E}-16$ & $1.29 \mathrm{E}-12$ & $5.30 \mathrm{E}-17$ & $4.91 \mathrm{E}-13$ \\
\hline JAC-C & $5.12 \mathrm{E}-12$ & $9.10 \mathrm{E}-16$ & $2.50 \mathrm{E}-12$ & $1.32 \mathrm{E}-16$ & $6.84 E-13$ & $2.05 E-12$ & $3.63 \mathrm{E}-16$ & $1.29 \mathrm{E}-32$ & $5.30 \mathrm{E}-17$ & $4.91 E-33$ \\
\hline LOS-D & $6.42 \mathrm{E}-12$ & $3.14 \mathrm{E}-16$ & $1.07 \mathrm{E}-12$ & $4.15 \mathrm{E}-17$ & $4.52 \mathrm{E}-13$ & $2.55 \mathrm{E}-12$ & $1.26 \mathrm{E}-16$ & $4.91 \mathrm{E}-13$ & $1.66 \mathrm{E}-17$ & -13 \\
\hline LOS-C & $6.42 \mathrm{E}-12$ & 3.14E-16 & $1.07 \mathrm{E}-12$ & $4.15 E-17$ & $4.52 \mathrm{E}-13$ & $2.55 E-12$ & $1.26 \mathrm{E}-16$ & $4.91 E-13$ & $1.66 \mathrm{E}-17$ & -13 \\
\hline MOT-D & $3.17 E-12$ & $8.60 \mathrm{E}-16$ & $2.41 \mathrm{E}-12$ & $1.03 E-16$ & $6.84 E-13$ & .27E-12 & $3.42 \mathrm{E}-16$ & $1.25 \mathrm{E}-12$ & 4.13 & $6.06 \mathrm{E}-13$ \\
\hline NEW-D & $3.56 \mathrm{E}-12$ & $1.62 \mathrm{E}-15$ & $5.15 \mathrm{E}-12$ & $1.79 \mathrm{E}-16$ & $8.34 \mathrm{E}-13$ & $.42 E-12$ & $6.50 \mathrm{E}-16$ & $2.47 \mathrm{E}-12$ & $7.15 \mathrm{E}-17$ & $1.00 \mathrm{E}-12$ \\
\hline NEW-C & $3.56 \mathrm{E}-12$ & $1.62 \mathrm{E}-15$ & $5.15 \mathrm{E}-12$ & $1.79 \mathrm{E}-16$ & $8.34 \mathrm{E}-13$ & $1.42 \mathrm{E}-12$ & $6.50 \mathrm{E}-16$ & $2.47 \mathrm{E}-12$ & $7.15 \mathrm{E}-17$ & $1.00 \mathrm{E}-12$ \\
\hline NOR-D & $3.17 \mathrm{E}-12$ & $8.60 \mathrm{E}-16$ & $2.41 E-12$ & $1.03 \mathrm{E}-16$ & $6.84 \mathrm{E}-13$ & $1.27 \mathrm{E}-12$ & $3.42 \mathrm{E}-16$ & $1.25 \mathrm{E}-12$ & $4.13 \mathrm{E}-17$ & $6.06 \mathrm{E}-13$ \\
\hline NOR-C & $3.17 \mathrm{E}-12$ & $8.60 \mathrm{E}-16$ & $2.41 \mathrm{E}-12$ & $1.03 \mathrm{E}-16$ & $6.84 \mathrm{E}-13$ & $1.27 \mathrm{E}-12$ & $3.42 \mathrm{E}-16$ & $1.25 \mathrm{E}-12$ & $4.13 \mathrm{E}-17$ & $6.06 \mathrm{E}-13$ \\
\hline PHI-D & $5.99 E-12$ & $8.40 \mathrm{E}-16$ & $2.76 \mathrm{E}-12$ & $1.22 \mathrm{E}-16$ & $6.90 \mathrm{E}-13$ & $2.39 \mathrm{E}-12$ & $3.35 E-16$ & $1.27 \mathrm{E}-12$ & $4.89 E-17$ & $6.36 \mathrm{E}-13$ \\
\hline PHI-C & $5.99 \mathrm{E}-12$ & $8.40 \mathrm{E}-16$ & $2.76 \pm-12$ & $1.22 \mathrm{E}-16$ & $6.90 \mathrm{E}-13$ & $2.39 \mathrm{E}-12$ & $3.35 E-16$ & $1.27 \mathrm{E}-12$ & $4.89 \mathrm{E}-17$ & $6.36 \mathrm{E}$ \\
\hline POR-D & $4.49 \mathrm{E}-12$ & $1.03 E-15$ & $3.73 E-12$ & $1.52 \mathrm{E}-16$ & 1.45 & $1.79 \mathrm{E}-12$ & $4.12 \mathrm{E}-16$ & $1.60 \mathrm{E}-12$ & $6.10 \mathrm{E}-17$ & $9.96 \mathrm{E}-13$ \\
\hline POR-C & $4.49 \mathrm{E}-12$ & $1.03 \mathrm{E}-15$ & $3.73 E-12$ & $1.52 \mathrm{E}-16$ & $1.45 \mathrm{E}-12$ & $1.79 \mathrm{E}-12$ & $4.12 \mathrm{E}-16$ & $1.60 \mathrm{E}-12$ & $6.10 \mathrm{E}-17$ & $9.96 \mathrm{E}-13$ \\
\hline SAV-D & $5.12 \mathrm{E}-12$ & $9.10 \mathrm{E}-16$ & $2.50 \mathrm{E}-12$ & $1.32 \mathrm{E}-16$ & $6.84 \mathrm{E}-13$ & $2.05 \mathrm{E}-12$ & $3.63 \mathrm{E}-16$ & $1.29 \mathrm{E}-12$ & $5.30 \mathrm{E}-17$ & $4.91 E-13$ \\
\hline SAV-C & $5.12 \mathrm{E}-12$ & $9.10 \mathrm{E}-16$ & $2.50 E-12$ & 1. $32 \mathrm{E}-16$ & $6.84 \mathrm{E}-13$ & $2.05 \mathrm{E}-12$ & $3.63 \mathrm{E}-16$ & $1.29 \mathrm{E}-12$ & $5.30 \mathrm{E}-17$ & $4.91 E-13$ \\
\hline SEA-C & $4.49 \mathrm{E}-12$ & $1.03 \mathrm{E}-15$ & $3.73 \mathrm{E}-12$ & $1.52 \mathrm{E}-16$ & $1.45 \mathrm{E}-12$ & $1.79 \mathrm{~F}-12$ & $4.12 E-16$ & $1.60 \mathrm{E}-12$ & $6.10 \mathrm{E}-17$ & $9.96 \mathrm{E}-13$ \\
\hline TAC-D & $4.49 \mathrm{E}-12$ & $1.03 \mathrm{E}-15$ & $3.73 E-12$ & $1.52 \mathrm{E}-16$ & $1.45 \mathrm{E}-12$ & $1.79 \mathrm{E}-12$ & $4.12 \mathrm{E}-16$ & $1.60 \mathrm{E}-12$ & $6.10 \mathrm{E}-17$ & $9.96 \mathrm{E}-13$ \\
\hline TAC-C & $4.49 E-12$ & $1.03 \mathrm{E}-15$ & $3.73 E-12$ & $1.52 \mathrm{E}-16$ & $1.45 \mathrm{E}-12$ & $1.79 \mathrm{E}-12$ & $4.12 \mathrm{E}-16$ & $1.60 \mathrm{E}-12$ & $6.10 \mathrm{E}-17$ & $9.96 \mathrm{E}-13$ \\
\hline WIL-D & $3.17 E-12$ & $8.60 \mathrm{E}-16$ & $2.41 \mathrm{E}-12$ & $1.03 \mathrm{E}-16$ & $6.84 E-13$ & $1.27 \mathrm{E}-12$ & $3.42 \mathrm{E}-16$ & $1.25 \mathrm{E}-12$ & $4.13 \mathrm{E}-17$ & $6.06 \mathrm{E}-13$ \\
\hline WIL-C & $3.17 \mathrm{E}-12$ & $8.60 E-16$ & $2.41 \mathrm{E}-12$ & $1.03 \mathrm{E}-16$ & $6.84 \mathrm{E}-1.3$ & $1.27 \mathrm{E}-12$ & $3.42 \mathrm{E}-16$ & $1.25 \mathrm{E}-12$ & $4.13 \mathrm{E}-17$ & $6.06 \mathrm{E}-13$ \\
\hline
\end{tabular}


Table 44. Absolute Risks for EIS Accident Categories (Continued)

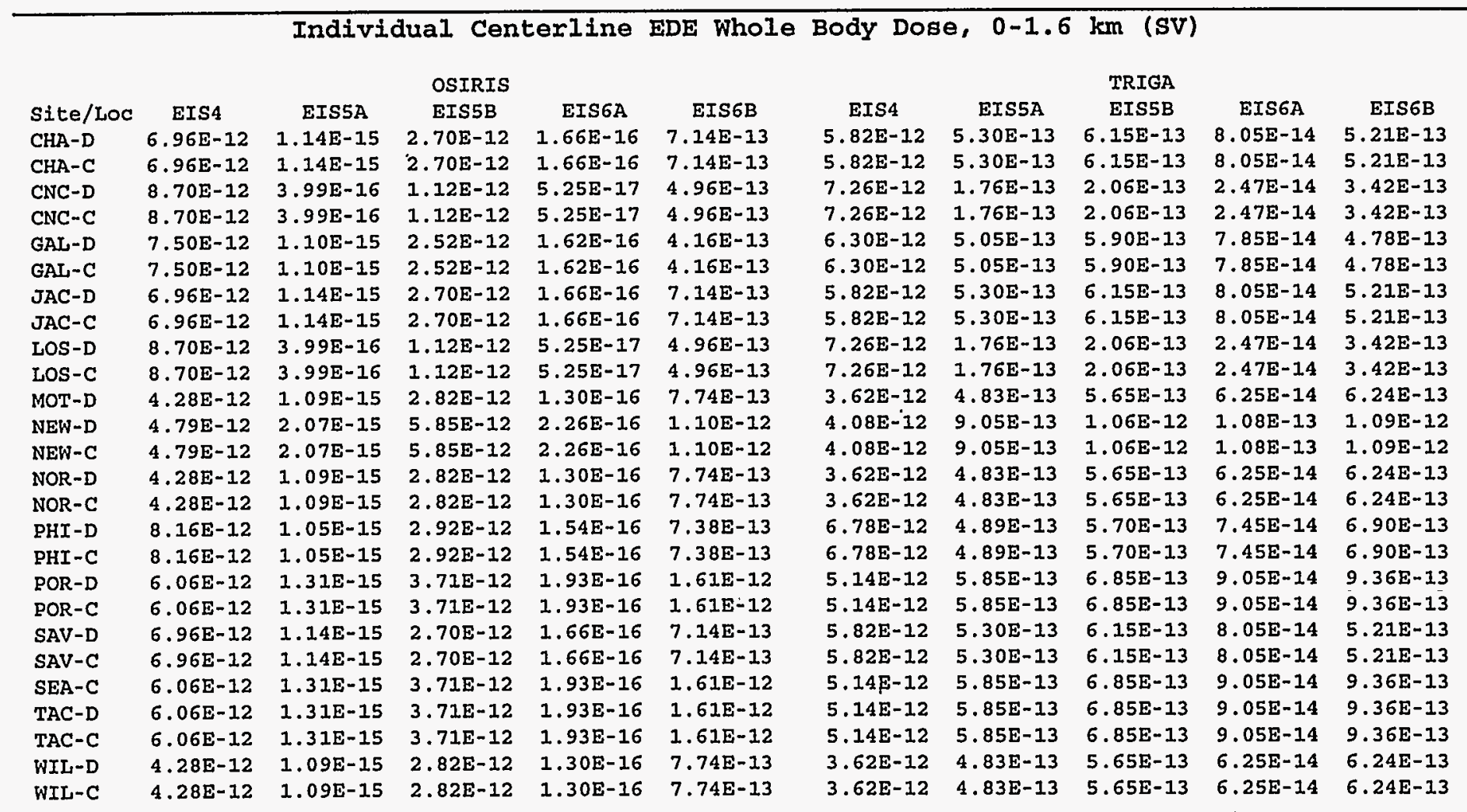


Table 44. Absolute Risks for EIS Accident Categories (Continued)

Individual Centerline Cancer Risk, 0-1.6 km

$\begin{array}{lccccc}\text { Site/LOC } & \text { EIS4 } & \text { EIS5A } & \begin{array}{c}\text { BR-2 } \\ \text { EIS5B }\end{array} & \text { EIS6A } & \text { EIS6B } \\ \text { CHA-D } & 2.45 E-13 & 3.85 E-17 & 1.04 \mathrm{E}-13 & 5.60 \mathrm{E}-18 & 2.86 \mathrm{E}-14 \\ \text { CHA-C } & 2.45 \mathrm{E}-13 & 3.85 \mathrm{E}-17 & 1.04 \mathrm{E}-13 & 5.60 \mathrm{E}-18 & 2.86 \mathrm{E}-14 \\ \text { CNC-D } & 3.06 \mathrm{E}-13 & 1.35 \mathrm{E}-17 & 4.47 \mathrm{E}-14 & 1.77 \mathrm{E}-18 & 1.88 \mathrm{E}-14 \\ \text { CNC-C } & 3.06 \mathrm{E}-13 & 1.35 \mathrm{E}-17 & 4.47 \mathrm{E}-14 & 1.77 \mathrm{E}-18 & 1.88 \mathrm{E}-14 \\ \text { GAL-D } & 2.64 \mathrm{E}-13 & 3.68 \mathrm{E}-17 & 8.85 \mathrm{E}-14 & 5.45 \mathrm{E}-18 & 1.67 \mathrm{E}-14 \\ \text { GAL-C } & 2.64 \mathrm{E}-13 & 3.68 \mathrm{E}-17 & 8.85 \mathrm{E}-14 & 5.45 \mathrm{E}-18 & 1.67 \mathrm{E}-14 \\ \text { JAC-D } & 2.45 \mathrm{E}-13 & 3.85 \mathrm{E}-17 & 1.04 \mathrm{E}-13 & 5.60 \mathrm{E}-18 & 2.86 \mathrm{E}-14 \\ \text { JAC-C } & 2.45 \mathrm{E}-13 & 3.85 \mathrm{E}-17 & 1.04 \mathrm{E}-13 & 5.60 \mathrm{E}-18 & 2.86 \mathrm{E}-14 \\ \text { LOS-D } & 3.06 \mathrm{E}-13 & 1.35 \mathrm{E}-17 & 4.47 \mathrm{E}-14 & 1.77 \mathrm{E}-18 & 1.88 \mathrm{E}-14 \\ \text { LOS-C } & 3.06 \mathrm{E}-13 & 1.35 \mathrm{E}-17 & 4.47 \mathrm{E}-14 & 1.77 \mathrm{E}-18 & 1.88 \mathrm{E}-14 \\ \text { MOT-D } & 1.50 \mathrm{E}-13 & 3.69 \mathrm{E}-17 & 1.01 \mathrm{E}-13 & 4.39 \mathrm{E}-18 & 2.84 \mathrm{E}-14 \\ \text { NEW-D } & 1.67 \mathrm{E}-13 & 7.05 \mathrm{E}-17 & 2.15 \mathrm{E}-13 & 7.60 \mathrm{E}-18 & 3.47 \mathrm{E}-14 \\ \text { NEW-C } & 1.67 \mathrm{E}-13 & 7.05 \mathrm{E}-17 & 2.15 \mathrm{E}-13 & 7.60 \mathrm{E}-18 & 3.47 \mathrm{E}-14 \\ \text { NOR-D } & 1.50 \mathrm{E}-13 & 3.69 \mathrm{E}-17 & 1.01 \mathrm{E}-13 & 4.39 \mathrm{E}-18 & 2.84 \mathrm{E}-14 \\ \text { NOR-C } & 1.50 \mathrm{E}-13 & 3.69 \mathrm{E}-17 & 1.01 \mathrm{E}-13 & 4.39 \mathrm{E}-18 & 2.84 \mathrm{E}-14 \\ \text { PHI-D } & 2.86 \mathrm{E}-13 & 3.55 \mathrm{E}-17 & 1.15 \mathrm{E}-13 & 5.20 \mathrm{E}-18 & 2.87 \mathrm{E}-14 \\ \text { PHI-C } & 2.86 \mathrm{E}-13 & 3.55 \mathrm{E}-17 & 1.15 \mathrm{E}-13 & 5.20 \mathrm{E}-18 & 2.87 \mathrm{E}-14 \\ \text { POR-D } & 2.12 \mathrm{E}-13 & 4.43 \mathrm{E}-17 & 1.56 \mathrm{E}-13 & 6.55 \mathrm{E}-18 & 6.06 \mathrm{E}-14 \\ \text { POR-C } & 2.12 \mathrm{E}-13 & 4.43 \mathrm{E}-17 & 1.56 \mathrm{E}-13 & 6.55 \mathrm{E}-18 & 6.06 \mathrm{E}-14 \\ \text { SAV-D } & 2.45 \mathrm{E}-13 & 3.85 \mathrm{E}-17 & 1.04 \mathrm{E}-13 & 5.60 \mathrm{E}-18 & 2.86 \mathrm{E}-14 \\ \text { SAV-C } & 2.45 \mathrm{E}-13 & 3.85 \mathrm{E}-17 & 1.04 \mathrm{E}-13 & 5.60 \mathrm{E}-18 & 2.86 \mathrm{E}-14 \\ \text { SEA-C } & 2.12 \mathrm{E}-13 & 4.43 \mathrm{E}-17 & 1.56 \mathrm{E}-13 & 6.55 \mathrm{E}-18 & 6.06 \mathrm{E}-14 \\ \text { TAC-D } & 2.12 \mathrm{E}-13 & 4.43 \mathrm{E}-17 & 1.56 \mathrm{E}-13 & 6.55 \mathrm{E}-18 & 6.06 \mathrm{E}-14 \\ \text { TAC-C } & 2.12 \mathrm{E}-13 & 4.43 \mathrm{E}-17 & 1.56 \mathrm{E}-13 & 6.55 \mathrm{E}-18 & 6.06 \mathrm{E}-14 \\ \text { WIL-D } & 1.50 \mathrm{E}-13 & 3.69 \mathrm{E}-17 & 1.01 \mathrm{E}-13 & 4.39 \mathrm{E}-18 & 2.84 \mathrm{E}-14 \\ \text { WIL-C } & 1.50 \mathrm{E}-13 & 3.69 \mathrm{E}-17 & 1.01 \mathrm{E}-13 & 4.39 \mathrm{E}-18 & 2.84 \mathrm{E}-14\end{array}$

$\begin{array}{ccccc}\text { EIS4 } & \text { EIS5A } & \text { EIS5B } & \text { EIS6A } & \text { EIS6B } \\ 9.90 \mathrm{E}-14 & 1.55 \mathrm{E}-17 & 5.40 \mathrm{E}-14 & 2.24 \mathrm{E}-18 & 2.05 \mathrm{E}-14 \\ 9.90 \mathrm{E}-14 & 1.55 \mathrm{E}-17 & 5.40 \mathrm{E}-14 & 2.24 \mathrm{E}-18 & 2.05 \mathrm{E}-14 \\ 1.24 \mathrm{E}-13 & 5.45 \mathrm{E}-18 & 2.04 \mathrm{E}-14 & 7.15 \mathrm{E}-19 & 1.31 \mathrm{E}-14 \\ 1.24 \mathrm{E}-13 & 5.45 \mathrm{E}-18 & 2.04 \mathrm{E}-14 & 7.15 \mathrm{E}-19 & 1.31 \mathrm{E}-14 \\ 1.07 \mathrm{E}-13 & 1.48 \mathrm{E}-17 & 5.15 \mathrm{E}-14 & 2.19 \mathrm{E}-18 & 1.83 \mathrm{E}-14 \\ 1.07 \mathrm{E}-13 & 1.48 \mathrm{E}-17 & 5.15 \mathrm{E}-14 & 2.19 \mathrm{E}-18 & 1.83 \mathrm{E}-14 \\ 9.90 \mathrm{E}-14 & 1.55 \mathrm{E}-17 & 5.40 \mathrm{E}-14 & 2.24 \mathrm{E}-18 & 2.05 \mathrm{E}-14 \\ 9.90 \mathrm{E}-14 & 1.55 \mathrm{E}-17 & 5.40 \mathrm{E}-14 & 2.24 \mathrm{E}-18 & 2.05 \mathrm{E}-14 \\ 1.24 \mathrm{E}-13 & 5.45 \mathrm{E}-18 & 2.04 \mathrm{E}-14 & 7.15 \mathrm{E}-19 & 1.31 \mathrm{E}-14 \\ 1.24 \mathrm{E}-13 & 5.45 \mathrm{E}-18 & 2.04 \mathrm{E}-14 & 7.15 \mathrm{E}-19 & 1.31 \mathrm{E}-14 \\ 6.06 \mathrm{E}-14 & 1.48 \mathrm{E}-17 & 5.20 \mathrm{E}-14 & 1.76 \mathrm{E}-18 & 2.52 \mathrm{E}-14 \\ 6.78 \mathrm{E}-14 & 2.83 \mathrm{E}-17 & 1.03 \mathrm{E}-13 & 3.06 \mathrm{E}-18 & 4.18 \mathrm{E}-14 \\ 6.78 \mathrm{E}-14 & 2.83 \mathrm{E}-17 & 1.03 \mathrm{E}-13 & 3.06 \mathrm{E}-18 & 4.18 \mathrm{E}-14 \\ 6.06 \mathrm{E}-14 & 1.48 \mathrm{E}-17 & 5.20 \mathrm{E}-14 & 1.76 \mathrm{E}-18 & 2.52 \mathrm{E}-14 \\ 6.06 \mathrm{E}-14 & 1.48 \mathrm{E}-17 & 5.20 \mathrm{E}-14 & 1.76 \mathrm{E}-18 & 2.52 \mathrm{E}-14 \\ 1.16 \mathrm{E}-13 & 1.43 \mathrm{E}-17 & 5.30 \mathrm{E}-14 & 2.08 \mathrm{E}-18 & 2.64 \mathrm{E}-14 \\ 1.16 \mathrm{E}-13 & 1.43 \mathrm{E}-17 & 5.30 \mathrm{E}-14 & 2.08 \mathrm{E}-18 & 2.64 \mathrm{E}-14 \\ 8.58 \mathrm{E}-14 & 1.78 \mathrm{E}-17 & 6.70 \mathrm{E}-14 & 2.63 \mathrm{E}-18 & 4.15 \mathrm{E}-14 \\ 8.58 \mathrm{E}-14 & 1.78 \mathrm{E}-17 & 6.70 \mathrm{E}-14 & 2.63 \mathrm{E}-18 & 4.15 \mathrm{E}-14 \\ 9.90 \mathrm{E}-14 & 1.55 \mathrm{E}-17 & 5.40 \mathrm{E}-14 & 2.24 \mathrm{E}-18 & 2.05 \mathrm{E}-14 \\ 9.90 \mathrm{E}-14 & 1.55 \mathrm{E}-17 & 5.40 \mathrm{E}-14 & 2.24 \mathrm{E}-18 & 2.05 \mathrm{E}-14 \\ 8.58 \mathrm{E}-14 & 1.78 \mathrm{E}-17 & 6.70 \mathrm{E}-14 & 2.63 \mathrm{E}-18 & 4.15 \mathrm{E}-14 \\ 8.58 \mathrm{E}-14 & 1.78 \mathrm{E}-17 & 6.70 \mathrm{E}-14 & 2.63 \mathrm{E}-18 & 4.15 \mathrm{E}-14 \\ 8.58 \mathrm{E}-14 & 1.78 \mathrm{E}-17 & 6.70 \mathrm{E}-14 & 2.63 \mathrm{E}-18 & 4.15 \mathrm{E}-14 \\ 6.06 \mathrm{E}-14 & 1.48 \mathrm{E}-17 & 5.20 \mathrm{E}-14 & 1.76 \mathrm{E}-18 & 2.52 \mathrm{E}-14 \\ 6.06 \mathrm{E}-14 & 1.48 \mathrm{E}-17 & 5.20 \mathrm{E}-14 & 1.76 \mathrm{E}-18 & 2.52 \mathrm{E}-14\end{array}$


Table 44. Absolute Risks for EIS Accident Categories (Concluded)

\begin{tabular}{|c|c|c|c|c|c|c|c|c|c|c|}
\hline \multirow[b]{3}{*}{ Site/Loc } & \multirow[b]{3}{*}{ EIS4 } & & \multirow{3}{*}{$\begin{array}{c}\text { Individu } \\
\text { OSIRIS } \\
\text { EIS5B }\end{array}$} & \multicolumn{3}{|c|}{ al Centerline Cancer Risk, } & \multicolumn{2}{|c|}{$0-1.6 \mathrm{~km}$} & \multirow[b]{3}{*}{ EIS6A } & \multirow[b]{3}{*}{ EIS6B } \\
\hline & & & & & & & & TRIGA & & \\
\hline & & EIS5A & & EIS6A & EIS6B & EIS4 & EIS5A & EIS5B & & \\
\hline CHA-D & $3.22 \mathrm{E}-13$ & $4.77 \mathrm{E}-17$ & $1.12 \mathrm{E}-13$ & $6.90 \mathrm{E}-18$ & $2.98 \mathrm{E}-14$ & $2.57 \mathrm{E}-13$ & $2.20 \mathrm{E}-14$ & $2.57 E-14$ & $3.35 \mathrm{E}-15$ & $2.17 \mathrm{E}-14$ \\
\hline $\mathrm{CHA}-\mathrm{C}$ & $3.22 E-13$ & $4.77 \mathrm{E}-17$ & $1.12 \mathrm{E}-13$ & $6.90 \mathrm{E}-18$ & $2.98 \mathrm{E}-14$ & $2.57 E-13$ & $2.20 \mathrm{E}-14$ & $2.57 \mathrm{E}-14$ & $3.35 E-1.5$ & $2.17 \mathrm{E}-14$ \\
\hline CNC-D & $4.02 \mathrm{E}-13$ & $1.68 \mathrm{E}-17$ & $4.66 \mathrm{E}-14$ & $2.20 \mathrm{E}-1.8$ & $2.06 \mathrm{E}-14$ & $3.21 E-13$ & $7.35 \mathrm{E}-15$ & $8.60 \mathrm{E}-15$ & $1.02 \mathrm{E}-15$ & $1.43 \mathrm{E}-14$ \\
\hline CNC-C & $4.02 E-13$ & $1.68 \mathrm{E}-1.7$ & $4.66 \mathrm{E}-14$ & $2.20 \mathrm{E}-18$ & $2.06 \mathrm{E}-14$ & $3.21 \mathrm{E}-13$ & $7.35 \mathrm{E}-15$ & $8.60 E-15$ & $1.02 \mathrm{E}-15$ & $1.43 \mathrm{E}-14$ \\
\hline GAL-D & $3.47 \mathrm{E}-13$ & $4.54 \mathrm{E}-17$ & $1.05 E-13$ & $6.75 \mathrm{E}-18$ & $1.73 E-14$ & $2.78 \mathrm{E}-13$ & $2.10 \mathrm{E}-14$ & $2.45 E-14$ & $3.26 \mathrm{E}-1.5$ & $1.99 \mathrm{E}-14$ \\
\hline GAL-C & $3.47 \mathrm{E}-13$ & $4.54 \mathrm{E}-17$ & $1.05 \mathrm{E}-13$ & $6.75 \mathrm{E}-18$ & $1.73 E-14$ & $2.78 \mathrm{E}-13$ & $2.10 \mathrm{E}-14$ & $2.45 \mathrm{E}-14$ & $3.26 \mathrm{E}-15$ & $1.99 \mathrm{E}-14$ \\
\hline$J A C-D$ & $3.22 \mathrm{E}-13$ & $4.77 \mathrm{E}-17$ & $1.12 \mathrm{E}-13$ & $6.90 \mathrm{E}-18$ & $2.98 E-14$ & $2.57 E-13$ & $2.20 \mathrm{E}-14$ & $2.57 \mathrm{E}-14$ & $3.35 \mathrm{E}-15$ & $2.17 \mathrm{E}-14$ \\
\hline JAC-C & $3.22 \mathrm{E}-13$ & $4.77 \mathrm{E}-17$ & $1.12 \mathrm{E}-13$ & $6.90 \mathrm{E}-18$ & $2.98 \mathrm{E}-14$ & $2.57 \mathrm{E}-13$ & $2.20 \mathrm{E}-14$ & $2.57 \mathrm{E}-14$ & $3.35 \mathrm{E}-15$ & $2.17 E-14$ \\
\hline LOS-D & $4.02 \mathrm{E}-13$ & $1.68 \mathrm{E}-17$ & $4.66 \mathrm{E}-14$ & $2.20 \mathrm{E}-18$ & $2.06 \mathrm{E}-14$ & $3.21 \mathrm{E}-13$ & $7.35 \mathrm{E}-15$ & $8.60 E-15$ & $1.02 \mathrm{E}-15$ & 1. $43 \mathrm{E}-14$ \\
\hline LOS-C & $4.02 \mathrm{E}-13$ & $1.68 \mathrm{E}-17$ & $4.66 \mathrm{E}-14$ & $2.20 \mathrm{E}-18$ & $2.06 \mathrm{E}-14$ & $3.21 \mathrm{E}-13$ & $7.35 \mathrm{E}-15$ & $8.60 \mathrm{E}-15$ & $1.02 \mathrm{E}-15$ & $1.43 E-14$ \\
\hline MOT-D & $1.96 \mathrm{E}-13$ & $4.59 \mathrm{E}-17$ & $1.17 \mathrm{E}-13$ & $5.40 \mathrm{E}-18$ & $3.23 E-14$ & $1.58 \mathrm{E}-13$ & $2.01 \mathrm{E}-14$ & $2.35 \mathrm{E}-14$ & $2.60 \mathrm{E}-15$ & $2.60 \mathrm{E}-14$ \\
\hline NEW-D & $2.18 E-13$ & $8.80 \mathrm{E}-17$ & $2.43 \mathrm{E}-13$ & $9.40 \mathrm{E}-18$ & $4.57 E-14$ & $1.78 \mathrm{E}-13$ & $3.76 \mathrm{E}-14$ & $4.42 \mathrm{E}-14$ & $4.50 \mathrm{E}-15$ & $4.55 E-14$ \\
\hline NEW-C & $2.18 \mathrm{E}-13$ & $8.80 \mathrm{E}-17$ & $2.43 \mathrm{E}-13$ & $9.40 \mathrm{E}-18$ & $4.57 \mathrm{E}-14$ & $1.78 \mathrm{E}-13$ & $3.76 \mathrm{E}-14$ & $4.42 \mathrm{E}-14$ & $4.50 \mathrm{E}-15$ & $4.55 \mathrm{E}-14$ \\
\hline NOR-D & $1.96 \mathrm{E}-13$ & $4.59 \mathrm{E}-17$ & $1.17 \mathrm{E}-13$ & $5.40 \mathrm{E}-18$ & $3.23 \mathrm{E}-14$ & $1.58 \mathrm{E}-13$ & $2.01 E-14$ & $2.35 \mathrm{E}-14$ & $2.60 \mathrm{E}-15$ & $2.60 \mathrm{E}-14$ \\
\hline NOR-C & $1.96 \mathrm{E}-13$ & $4.59 \mathrm{E}-17$ & $1.17 \mathrm{E}-13$ & $5.40 \mathrm{E}-18$ & $3.23 \mathrm{E}-14$ & $1.58 \mathrm{E}-13$ & $2.01 E-14$ & $2.35 \mathrm{E}-14$ & $2.60 \mathrm{E}-15$ & $2.60 \mathrm{E}-14$ \\
\hline PHI -D & $3.77 \mathrm{E}-13$ & $4.39 \mathrm{E}-17$ & $1.21 \mathrm{E}-13$ & $6.40 \mathrm{E}-18$ & $3.07 E-14$ & $3.01 \mathrm{E}-13$ & $2.04 \mathrm{E}-14$ & $2.37 \mathrm{E}-14$ & $3.11 \mathrm{E}-15$ & $2.87 \mathrm{E}-14$ \\
\hline PHI-C & $3.77 \mathrm{E}-13$ & $4.39 \mathrm{E}-17$ & $1.21 E-13$ & $6.40 \mathrm{E}-18$ & $3.07 E-14$ & $3.01 E-13$ & $2.04 \mathrm{E}-14$ & $2.37 \mathrm{E}-14$ & $3.11 E-15$ & $2.87 \mathrm{E}-14$ \\
\hline POR-D & $2.77 \mathrm{E}-13$ & $5.50 \mathrm{E}-17$ & $1.54 \mathrm{E}-13$ & $8.10 \mathrm{E}-18$ & $6.66 \mathrm{E}-14$ & $2.24 \mathrm{E}-13$ & $2.44 \mathrm{E}-14$ & $2.85 E-14$ & $3.76 \mathrm{E}-15$ & $3.92 \mathrm{E}-14$ \\
\hline POR-C & $2.77 \mathrm{E}-13$ & $5.50 \mathrm{E}-17$ & $1.54 \mathrm{E}-13$ & $8.10 \mathrm{E}-18$ & $6.66 \mathrm{E}-14$ & $2.24 \mathrm{E}-13$ & $2.44 \mathrm{E}-14$ & $2.85 \mathrm{E}-14$ & $3.76 \mathrm{E}-15$ & $3.92 \mathrm{E}-14$ \\
\hline SAV-D & $3.22 \mathrm{E}-13$ & $4.77 E-17$ & $1.12 \mathrm{E}-13$ & $6.90 \mathrm{E}-18$ & $2.98 \mathrm{E}-14$ & $2.57 \mathrm{E}-13$ & $2.20 \mathrm{E}-14$ & $2.57 \mathrm{E}-14$ & $3.35 E-15$ & $2.17 \mathrm{E}-14$ \\
\hline SAV-C & $3.22 \mathrm{E}-13$ & $4.77 \mathrm{E}-17$ & $1.12 \mathrm{E}-13$ & $6.90 \mathrm{E}-18$ & $2.98 E-14$ & $2.57 E-13$ & $2.20 \mathrm{E}-14$ & $2.57 \mathrm{E}-14$ & $3.35 \mathrm{E}-15$ & $2.17 \mathrm{E}-14$ \\
\hline SEA-C & $2.77 E-13$ & $5.50 E-17$ & $1.54 \mathrm{E}-13$ & $8.10 \mathrm{E}-18$ & $6.66 \mathrm{E}-14$ & $2.24 \mathrm{E}-13$ & $2.44 \mathrm{E}-14$ & $2.85 \mathrm{E}-14$ & $3.76 \mathrm{E}-15$ & $3.92 \mathrm{E}-14$ \\
\hline TAC-D & $2.77 E-13$ & $5.50 E-17$ & $1.54 \mathrm{E}-13$ & $8.10 \mathrm{E}-18$ & $6.66 \mathrm{E}-14$ & $2.24 \mathrm{E}-13$ & $2.44 \mathrm{E}-14$ & $2.85 \mathrm{E}-14$ & $3.76 E-15$ & $3.92 \mathrm{E}-14$ \\
\hline TAC-C & $2.77 E-13$ & $5.50 \mathrm{E}-17$ & $1.54 \mathrm{E}-13$ & $8.10 \mathrm{E}-18$ & $6.66 \mathrm{E}-14$ & $2.24 \mathrm{E}-13$ & $2.44 \mathrm{E}-14$ & $2.85 \mathrm{E}-14$ & $3.76 \mathrm{E}-15$ & $3.92 \mathrm{E}-14$ \\
\hline WIL-D & $1.96 \mathrm{E}-13$ & $4.59 \mathrm{E}-17$ & $1.17 \mathrm{E}-13$ & $5.40 \mathrm{E}-18$ & $3.23 \mathrm{E}-14$ & $1.58 \mathrm{E}-13$ & $2.01 \mathrm{E}-14$ & $2.35 E-14$ & $2.60 \mathrm{E}-15$ & $2.60 \mathrm{E}-14$ \\
\hline WIL-C & $1.96 E-13$ & $4.59 \mathrm{E}-17$ & $1.17 \mathrm{E}-13$ & $5.40 \mathrm{E}-18$ & $3.23 \mathrm{E}-14$ & $1.58 \mathrm{E}-13$ & $2.01 \mathrm{E}-14$ & $2.35 \mathrm{E}-14$ & $2.60 \mathrm{E}-15$ & $2.60 \mathrm{E}-14$ \\
\hline
\end{tabular}


that the EIS5B and EIS6B results are similar and each is about 10 times larger than the EIS4 result. For TRIGA fuel, EIS4, EIS5A, and EIS5B release fractions yield similar mean population-dose and cancer-fatality risk values, while EIS6A and EIS6B results are about ten times smaller and ten times larger, respectively. As was the case for the EA release fractions, the largest risk values for any set of release fractions are obtained for EIS release fractions using the BR-2 inventory.

Figures 61 through 66 present CCDFs for population dose and cancer fatalities. These CCDFs were calculated using the BR-2 inventory for the dock locations at three ports: MOTSU, the port with the lowest population to 50 miles of the 13 ports examined by this study; Tacoma, a medium population port; and Newark, the high-population port. All of the CCDFs are conditional on the occurrence of the accident. Each figure presents eight CCDFs, one CCDF for each of the three sets of EA release fractions (EA4, EA5, and EA6), and one CCDF for each of the five sets of EIS release fractions (EIS4, EIS5A, EIS5B, EIS6A, and EIS6B). Thus, the figures depict the range of the BR-2 population dose and cancer fatality estimates.

Inspection of the figures shows that each graph presents seven rather than eight CCDFs. Only seven CCDFs are presented because the EA4 and EIS4 results for the BR-2 inventory are essentially identical. Thus, these two CCDFs lie one on top of the other.

The EA4 and EIS4 results for the BR-2 inventory are essentially identical because the EA4 and EIS4 sets of release fractions have identical values for $\mathrm{Cs}, \mathrm{Ru}$, and Particulate and differ only in that the EA4 release fraction for $\mathrm{Kr}$ is one million times larger than the EIS4 value. However, since $\mathrm{Kr}$ radiation exposures contribute negligibly to both total dose and to cancer induction, the very large difference between the $\mathrm{Kr}$ release fractions does not affect either the population dose or the cancer fatality CCDFs obtained using the EA4 and EIS4 sets of release fractions.

Because all of the CCDFs fall off steeply after the 99th quantile has been reached, consequence values for all quantiles smaller than the 99th quantile have quite similar ranges. Figures 61 through 63 show that for population dose these ranges are approximately $3 \times 10^{-4}$ to $3 \times 10^{3} \mathrm{~Sv}$ for MOTSU, $1 \times 10^{-3}$ to $1 \times 10^{4} \mathrm{~Sv}$ for Tacoma, and $1 \times 10^{-2}$ to $1 \times 10^{5} \mathrm{~Sv}$ for Newark. For cancer fatalities, Figures 64 through 66 show that these ranges are approximately $3 \times 10^{-4}$ to $1 \times 10^{2}$ cancer fatalities for MOTSU, $3 \times 10^{-4}$ to $3 \times 10^{2}$ cancer fatalities for Tacoma, and $3 \times 10^{-4}$ to $3 \times 10^{3}$ cancer fatalities for Newark.

Inspection of the figures also shows (1) that the CCDFs for EIS source terms $5 \mathrm{~A}$ and $6 \mathrm{~A}$ lie lower and substantially to the left of the CCDFs for EA source terms 5 and 6 , and (2) that the CCDFs for EIS source terms $5 \mathrm{~B}$ and $6 \mathrm{~B}$ lie higher and to the right of the CCDFs for EA source terms 5 and 6 . This occurs because fission product release from Al-U alloy fuels, such as the BR-2 fuel, is not significant until the fuel melts. Thus, because source terms EIS5A and EIS6A represent fire events that do not heat Al-U alloy fuels to their melting points, release fractions for these source terms are much less than was assumed in the EA for source 


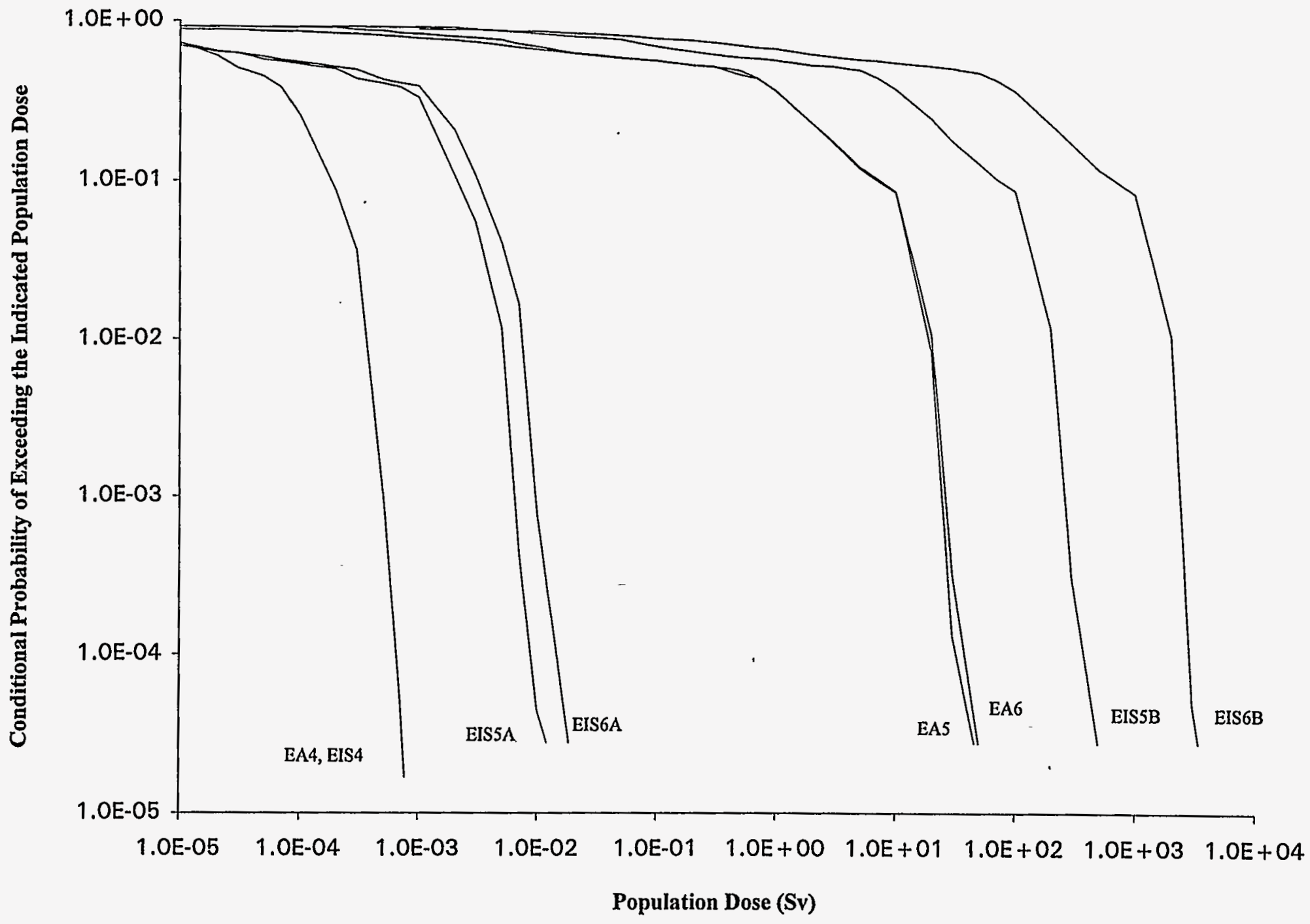

Figure 61. EDE Whole Body Population Dose, 0-80 km, MOTSU Dock, BR-2 Inventory, All EA and EIS Source Terms, Variable Meteorology 
Conditional Probability of Exceeding the Indicated Population Dose

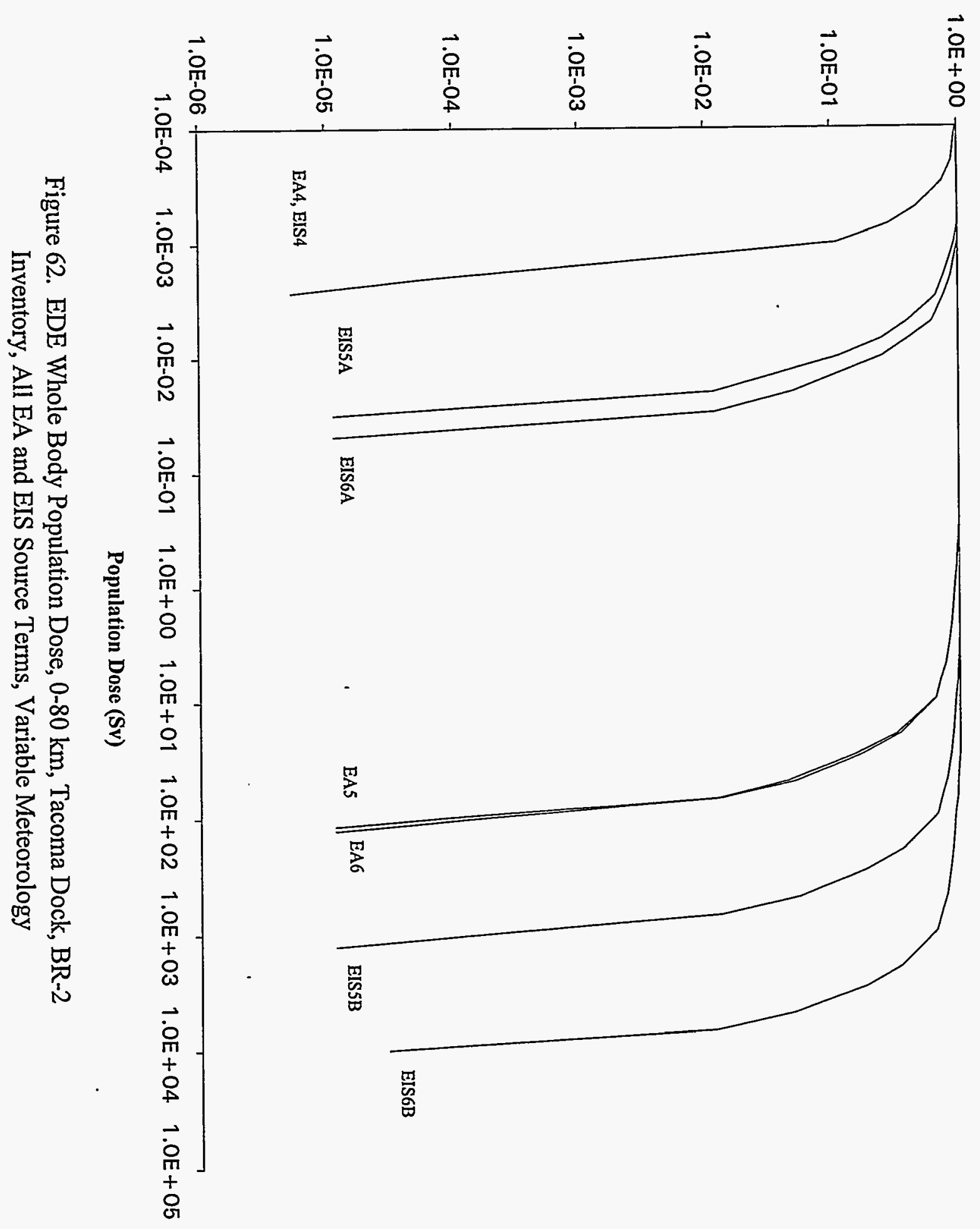




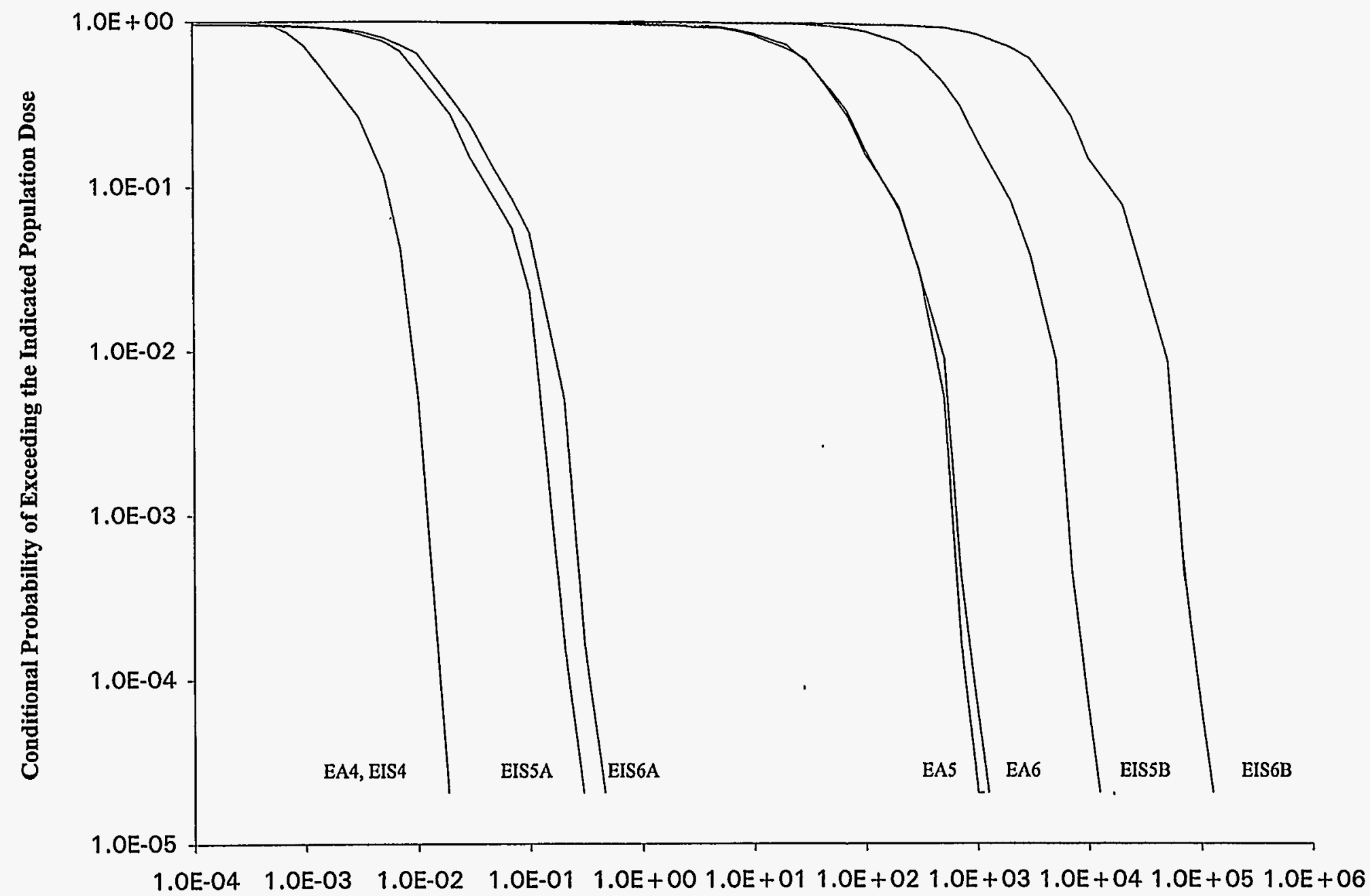

Population Dose (Sv)

Figure 63. EDE Whole Body Population Dose, 0-80 km, Newark Dock, BR-2 Inventory, All EA and EIS Source Terms, Variable Meteorology 
Conditional Probability of Exceeding the Indicated Number of

Total Cancer Fatalities

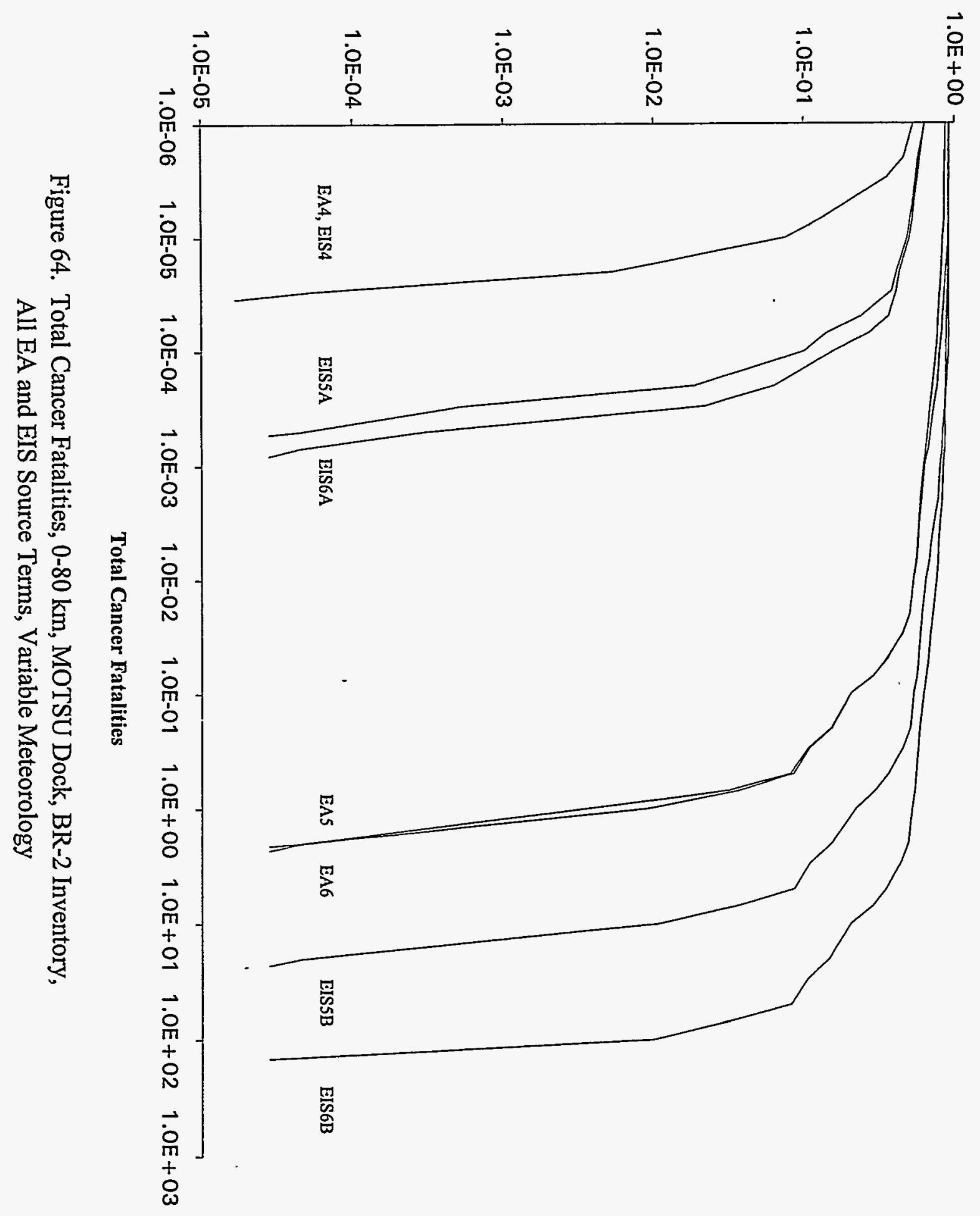




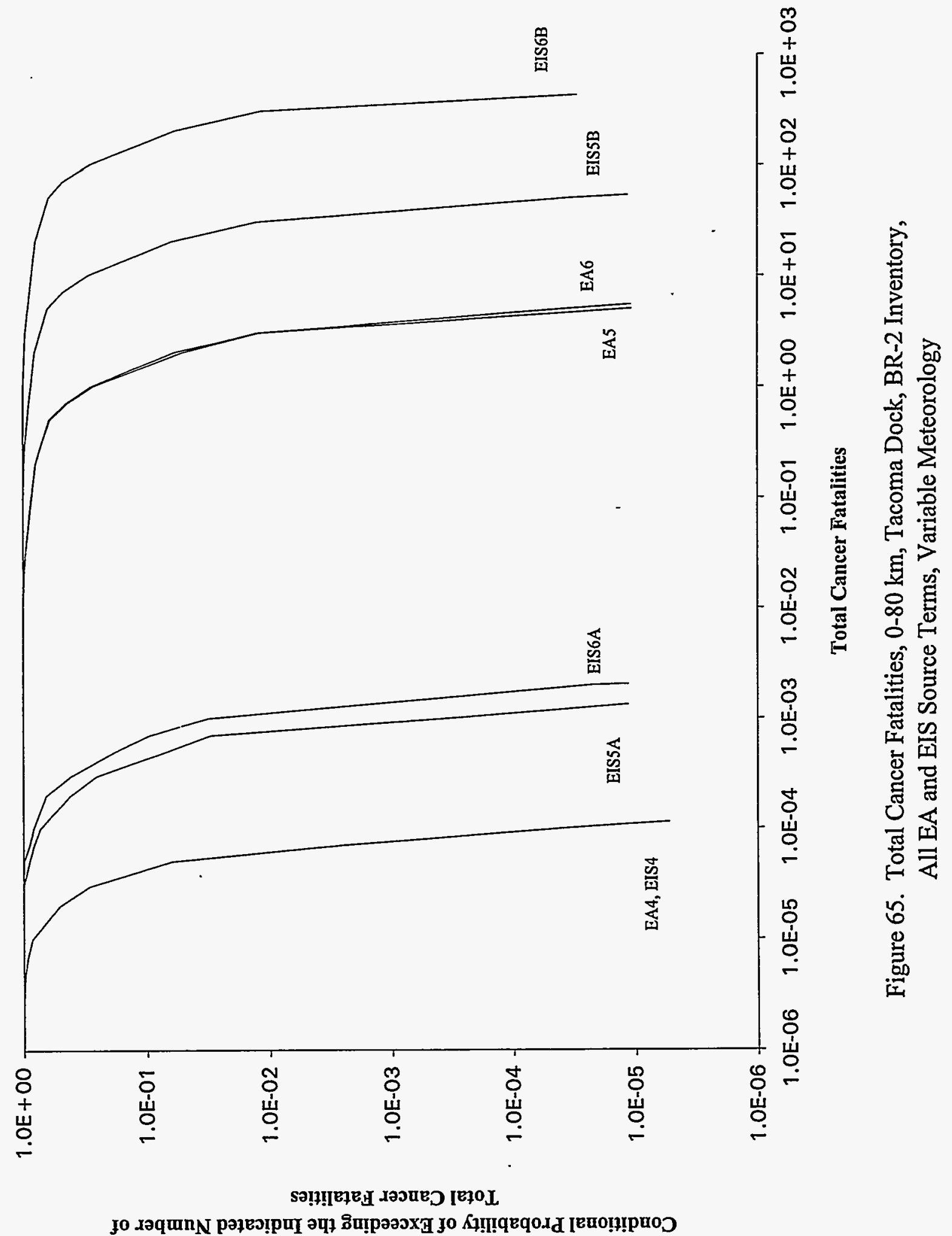




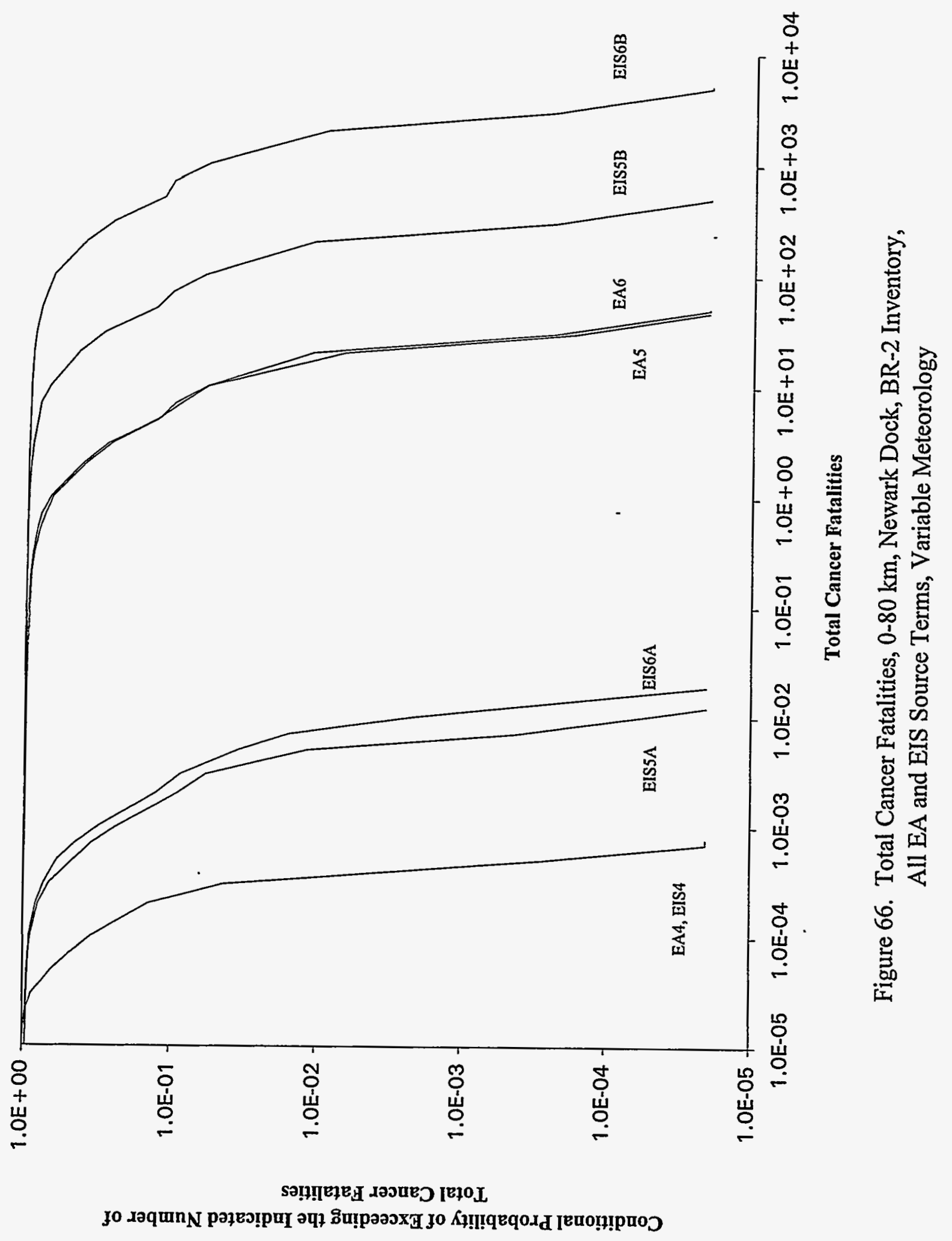


terms EA5 and EA6. Conversely, source terms EIS5B and EIS6B represent accidents during which fuel melting temperatures are exceeded which greatly increases fission product release. Thus, the release fractions assumed for these events are substantially larger than those assumed in the EA for source terms EA5 and EA6.

Table 17 shows that the probability of occurrence per port call for source term EA.5 is about ten times that for source term EA6, which is about the same as that for source term EIS5B, which is about ten times that for source term EIS6B. But the magnitude of the consequences produced by source term EIS6B are about ten times those produced by source term EIS5B, which in turn are about ten times those produced by source term EA6 or EA5 which produce similar CCDFs. Thus, the risks posed by source terms EIS6B, EIS5B, and EA5 have similar magnitudes that are all about ten times the risks predicted for source term EA6. 


\subsection{DISCUSSION}

This study has examined the radiological consequences that might be caused by ship collisions in U.S. ports where the struck ship is transporting spent research reactor fuel in a certified transportation cask. Release fractions have been developed for these hypothetical accidents that reflect the fact that, at temperatures above $900 \mathrm{~K}$, Al-U alloy research reactor fuels melt and, if exposed to air, TRIGA research reactor fuel burns.

The many consequence calculations performed show that consequence magnitudes (expected values, quantile values, largest result calculated) are primarily determined by source term magnitude and by the size of the exposed population, and are only secondarily influenced by the meteorological conditions characteristic of the port region. Thus, consequence estimates were largest for the hypothetical accidents that were assumed to lead to fires able (1) to heat the transportation cask and its spent fuel contents to temperatures greater than $900 \mathrm{~K}$ and (2) to maintain these temperatures for at least an hour or more. When such an accident is assumed to occur at a high population port (Newark) under the least favorable meteorological conditions (those that lead to the largest result calculated), the cancer death rate attributable to the accident $\left(3 \times 10^{-4}\right.$ per year) is still almost ten times smaller than the normal cancer death rate $\left(2 \times 10^{-3}\right.$ per year) among the exposed population. Since the probability of this accident is approximately $6 \times 10^{-11}$ per port call and the chance of the least favorable weather conditions occurring at the time of the accident is approximately $1.5 \times 10^{-4}$, the probability that this result will occur is vanishingly small, only $9 \times 10^{-14}$ per port call.

Of course, when the largest result calculated leads to predicted numbers of cancer deaths 20 to 40 years in the future among the exposed population that are small compared to the normal death rate due to cancer among this population, then, were these predictions to actually occur, the expected results would be so small as to be wholly undetectable in the exposed population by the best of epidemiological studies. Moreover, for accidents that lead to smaller source terms or occur in ports with smaller surrounding populations, consequences are further decreased. Thus, the principal conclusion of this study is that port accidents that involve ships transporting spent research reactor fuel are extremely unlikely to lead to radiological consequences or risks of concern.

This conclusion is strengthened by the fact that the calculations performed are probably conservative for the following reasons:

- The highest consequence accident examined, the EIS6B accident, assumes that gas flow through the damaged cask will be large because the cask has suffered at least two significant failures (a seal failure and a puncture or shear failure). The chance that such multiple failures would occur was conservatively assumed to be one in ten given that cask integrity has been lost. Because failure of the cask by puncture or shearing can only be caused by a most unlikely configuration of collapsing ship structures, the assumed probability of one in ten is probably an order of magnitude conservative. 
Thus, the risks estimated for these accidents are also likely to be conservative by an order of magnitude.

- All of the calculations used a distribution of ship speeds that is appropriate for open waters (top speeds of $25 \mathrm{mph}$ ). Since speeds in port channels are unlikely to exceed $15 \mathrm{mph}$ and are more likely to be around $10 \mathrm{mph}$, and speeds dockside would likely be 3 to $5 \mathrm{mph}$, the chance of a ship collision leading to penetration of the RAM hold sufficient to damage the spent fuel cask has been significantly overestimated. This is particularly true because the method used to estimate penetration distances, Minorsky's method, neglects the resistance to deep penetration posed by the keel structures of the struck ship, an effect expressed by the empirical $\mathrm{B} / 5$ rule that states that ship collisions rarely lead to penetrations greater than one fifth of the beam of the struck ship [ORI80]. Since a cask stowed at the midline of the RAM hold would be undamaged by collisions that lead to penetration depths less than one fifth the beam of the struck ship, neglect of keel structure mass and the use of striking speeds that are substantially conservative means that the chance of cask damage has been significantly overestimated.

- Deposition of radioactive vapors and aerosols on cargo surfaces or hold walls was neglected, even though such deposition is likely to constitute a significant removal mechanism for radioactivity released from the failed cask to the RAM hold. Therefore, the release fractions used in all of the accident calculations are at least somewhat conservative.

- Finally, no credit has been taken for port firefighting capabilities. Since all of the predicted larger releases are caused by accidents that are assumed to lead to long duration fires, the fact that ship fires in ports will seldom be allowed to burn freely means that both the magnitude and the chance of fire-driven releases of radioactivity have been overestimated. 


\subsection{REFERENCES}

Ab85 M. Abkowitz and J. Galarraga, "Tanker Accident Rates and Expected Consequences in U.S. Ports and High Seas Regions," Conference on Recent Advances in Hazardous Materials Transportation Research: An International Exchange, Transportation Research Council, November 10-13, 1985.

Al82 D. C. Aldrich et al., "Technical Guidance for Siting Criteria Development," NUREG/CR-2239, SAND81-1549, Sandia National Laboratories, Albuquerque NM, December 1982.

Am95 D. J. Ammerman and J. G. Bobbe, "Testing of the Structural Evaluation Test Unit,” Proceed. PATRAM ‘95, Las Vegas, NV, December 1995.

Ba86a V. Babrauskas, "Pool Fires: Burning Rates and Heat Fluxes," Fire Protection Handbook, 16th Edition, A. E. Cote and J. L. Linville, Editors, National Fire Protection Association, Quincy, MA, 1986.

Ba86b V. Babrauskas, "Room Fire Temperature Computations," Fire Protection Handbook, 16th Edition, A. E. Cote and J. L. Linville, Editors, National Fire Protection Association, Quincy, MA, 1986.

Be81 M. Benedict et a1., Nuclear Chemical Engineering, McGraw-Hill, New York, NY, p. $325,1981$.

BIER90 Health Effects of Exposure to Low Levels of Ionizing Radiation, BEIR V, National Academy Press, Washington, DC, p. 18, 1990.

Ch90 D. I. Chanin et al., "MELCOR Accident Consequence Code System (MACCS)," Vol. 1, User's Guide, NUREG/CR-4691, SAND86-1562, Sandia National Laboratories, Albuquerque, NM, February 1990.

Co90 E. H. P. Cordfunke and R. J. M. Konings, Thermochemical Data for Reactor Materials and Fission Products, North-Holland, Amsterdam, Holland, p. 105, 1990.

Cr80 A. G. Croff, "ORIGEN2 - A Revised and Updated Version of the Oak Ridge Isotope Generation and Depletion Code," ORNL-5621, Oak Ridge National Laboratory, Oak Ridge, TN, July 1980.

Cu84 D. Cubicoitti and B. R. Sehgal, Nuclear Technol., 65, 266 (1984).

DOE86 "Environmental Assessment on Shipment of Taiwanese Research Reactor Spent Fuel," DOE/EA-0321, U.S. Department of Energy, Washington, DC, December 1986. 
DOE88a "Environmental Assessment on Shipment of Taiwanese Research Reactor Spent Fuel (Phase II)," DOE/EA-0363, U.S. Department of Energy, Washington, DC, June 1988.

DOE88b "External Dose-Rate Conversion Factors for Calculation of Dose to the Public," DOE/EH-0070, U.S. Department of Energy, Washington, DC, July 1988.

DOE88c "Internal Dose-Rate Conversion Factors for Calculation of Dose to the Public," DOE/EH-0071, U.S. Department of Energy, Washington, DC, July 1988.

DOE91 "Environmental Assessment of the Risks of the Taiwan Research Reactor Spent Fuel Project," DOE/EA-0515, U.S. Department of Energy, Washington, DC, June 1991.

DOE94a "Environmental Assessment of Urgent-Relief Acceptance of Foreign Research Reactor Spent Nuclear Fuel," DOE/EA-0912, U.S. Department of Energy, Washington, DC, April 1994.

DOE94b "Department of Energy Programmatic Spent Nuclear Fuel Management and Idaho National Engineering Laboratory Environmental Restoration and Waste Management Programs Draft Environmental Impact Statement," DOE/EIS-0203-D, U.S. Department of Energy, Idaho Falls, ID, June 1994.

DOE95 "Draft Environmental Impact Statement on a Proposed Nuclear Weapons Nonproliferation Policy Concerning Foreign Research Reactor Spent Nuclear Fuel," Appendix B, "Foreign Research Reactor Spent Nuclear Fuel Characteristics and Transportation Casks," DOE/EIS-0218D, March 1995.

E193 P. G. Ellison et al., Nuclear Safety, 34, 196 (1993).

Fi87 L. E. Fischer et al., "Shipping Container Response to Severe Highway and Railway Accident Conditions," NUREG/CR-4829, UCID-20733, Lawrence Livermore National Laboratory, Livermore, CA, 1987.

FR88 "Certificate of Approval of Package Design," F/007/B(U)-F D00, Ministry of Public Facilities, Housing, Territorial Development and Transportation, Paris, French Republic, May 6, 1988.

GNS93 "Safety Analysis Report, Vitrified High Level Waste Type B Shipping Cask," General Nuclear Systems, Inc., Columbia, SC, August 1993.

Gr87 J. J. Gregory et al., "Thermal Measurements in a Series of Large Pool Fires," SAND85-0196, Sandia National Laboratories, Albuquerque, NM, August 1987.

Gr89 J. J. Gregory et al., J. Heat Transfer, 111, 446 (1989). 
Hu94 S. L. Humphreys et al., "Sector Population, Land Fraction, and Economic Estimation Program (SECPOP90)," SAND93-4032, Sandia National Laboratories, Albuquerque, NM, July 1994 (draft report, available upon request).

IAEA61 "Regulation for the Safe Transport of Radioactive Materials, Notes on Certain Aspects of the Regulations," Safety Series No. 7, International Atomic Energy Agency, Vienna, Austria, 1961.

IAEA85 "Regulation for the Safe Transport of Radioactive Materials," Safety Series No. 7, International Atomic Energy Agency, Vienna, Austria, 1961.

IMO92 "Analysis of Fire Casualty Records," FP 37/5, Sub-Committee on Fire Protection, 37th Session, Agenda Item 5, International Maritime Organization, 20 February 1992.

Jo90 H.-N. Jow et al., "MELCOR Accident Consequence Code System (MACCS)," Vol. 2, "Model Description," NUREG/CR-4691, SAND86-1562, Sandia National Laboratories, Albuquerque, NM, February 1990.

Ke94 N. R. Keltner et al., "Simulating Fuel Spill Fires Under the Wing of an Aircraft," 4th International Symposium on Fire Safety Science, Ottawa, Canada, June 1994.

LMIS91 Casualty File Manual, Lloyd's Maritime Information Services, London, England, November 1991.

Mi59 V. U. Minorsky, J. Ship Research, 3, 1 (1959).

Mo71 S. Motora, J. Japanese Soc. Naval Architec., I, 138 (1971).

Mu88 K. S. Mudan and P. A. Croce, "Fire Hazard Calculations for Large Open Hydrocarbon Fires," SPFE Handbook of Fire Protection Engineering, P. J. DiNenno, Ed., National Fire Protection Association, Quincy, MA, 1988.

Ne86 J. M. Nelson, "Determination of Net Heat Fluxes and Assessment of Test-to-Test Thermal Input Variation for Three Large Engulfing Open Pool Fire/Calorimeter Tests," SAND85-1821, Sandia National Laboratories, Albuquerque, NM, November 1986.

NRC90 "Severe Accident Risks: An Assessment for Five U.S. Nuclear Power Plants," Appendices A, B, and C, Final Report, Vol. 2, NUREG-1150, U.S. Nuclear Regulatory Commission, Washington, DC, December 1990. 
ORI80 P. King, J. Kirkland, and B. Paramore, "Hazardous Environments Experienced by Radioactive Material Packages Transported by Water," ORI Inc., Silver Spring, MD, November 1981 (draft report, available on request from Sandia National Laboratories).

ORI81 J. Kirkland and T. Baranano, "Accident Severities Experienced by Radioactive Material Packages Transported by Water," ORI Inc., Silver Spring, MD, November 1981 (draft report, available on request from Sandia National Laboratories).

Pe82 M. J. Petersen, Ocean Engineer, 2, 295 (1982).

Po94 D. A. Powers et al., "A Review of the Technical Issues of Air Ingression During Severe Reactor Accidents," NUREG/CR-6218, SAND94-0731, Sandia National Laboratories, Albuquerque, NM, September 1994.

Sa88 R. P. Sandoval et al., "Estimate of CRUD Contribution to Shipping Cask Containment Requirements," SAND88-1358, Sandia National Laboratories, Albuquerque, NM, January 1991.

Sa92 T. L. Sanders et al., "A Method for Determining the Spent-Fuel Contribution to Transport Cask Containment Requirements," SAND90-2406, Sandia National Laboratories, Albuquerque, NM, November 1992.

Sc89 M. E. Schneider et al., "Thermal Measurements in the Nuclear Winter Fire Test," SAND88-2839, Sandia National Laboratories, Albuquerque, NM, November 1986.

Sh94 C. S. Shaffer, SEA, Inc., Albuquerque NM, seminar presentation (MELCOR calculations indicate that only large engulfing pool fires with durations of about an hour that involve high quality fuels such as gasoline, jet fuel, or diesel fuel can raise transportation cask temperatures to $1000 \mathrm{~K}$ ), November 1994 (to be published).

SNL89 "Beneficial U̇ses Shipping Cask, BUSS, Safety Analysis Report for Packaging (SARP)," SAND83-0698, Sandia National Laboratories, Albuquerque, NM, March 1989.

Sp90 J. L. Sprung et al., "Evaluation of Severe Accident Risks: Quantification of Major Input Parameters," Vol. 2, Rev. 1, Part 7, "MACCS Input," NUREG/CR-4551, SAND86-1309, Sandia National Laboratories, Albuquerque, NM, December 1990.

SRI78 "Cost-Effectiveness of Marine Fire Protection Programs," SRI International (prepared for the U.S. Department of Commerce, Maritime Administration, and the National Bureau of Standards), November 1978. 
US88 Code of Federal Regulations, Part 71, "Packaging and Transportation of Radioactive Materials," Subpart F, "Packaging and Special Form Tests," Section 71.73, "Hypothetical Accident Conditions."

US90 "Packaging and Transportation of Radioactive Material," U.S. Code of Federal Regulations, Title 10, Part 71, revised January 1990.

Wa76 J. E. Warick and A. L. Anderson, "The Nature of Ship Collisions within Ports," Todd Shipyard Corp., Galveston, TX (prepared for the U.S. Maritime Administration), April 1976.

WA92 World Almanac and Book of Facts, Pharos Books, New York, NY, p. 940, 1992.

Wi81 E. L. Wilmot et al., "Report on a Workshop on Spent Fuel Accident Scenarios," SAND80-2012, Sandia National Laboratories, Albuquerque, NM, February 1981.

Wi84 E. L. Wilmot, "Transportation Accident Scenarios for Commercial Spent Fuel," SAND80-2012, Sandia National Laboratories, Albuquerque, NM, July 1984. 
. 


\section{APPENDIX}

This appendix presents the input files used in the MACCS calculations performed for this study and the archival tables that summarize the output of these MACCS calculations. The appendix is structured as follows:

Part A: Input Files

1. ATMOS, EARLY, CHRONC, and SITE files for the Newark channel (NEW-C) MACCS calculation that used EA5 release fractions and the BR-2 inventory.

2. 26 site population tables.

3. 26 sets of land fraction, region index, and watershed index tables.

4. 1 crop and economic data file.

Part B: Archival tables for MACCS calculations that used EA release fractions (release fractions EA4, EA5, and EA6).

Part C: Archival tables for MACCS calculations that used EIS release fractions (release fractions EIS4, EIS5A, EIS5B, EIS6A, and EIS6B).

Part D: Input and archival tables for MACCS calculations for nine military ports (Bremerton, Everett, and Port Hadlock, WA; Port Hueneme, CA; Pensacola and Mayport, FL; Kings Bay, GA; Yorktown, VA; and Charleston Naval Reservation, SC) that were examined after the original study was completed. For each military port, calculations were performed for all combinations of four cask inventories (BR-2, RHF, Osiris, TRIGA) and eight sets of release fractions (EA4, EA5, EA6; EIS4, EIS5A, EIS5B, EIS6A, EIS6B).

Because of the large size of this appendix, these tables have been archived on microfiche. The microfiche packet is attached to the inside of the back cover of this report.

Consequence Probabilities. All of the consequence probabilities presented in the archival tables are conditional probabilities, that is, they assume that the accident has occurred and has led to the source term that produced the result given in the table. To obtain the absolute probability of any archival table result (the probability per port call of that result), the conditional probability must be multiplied by the probability of occurrence per port call of the source term that produced the specific result. These source term probabilities of occurrence per port call are given in Table 17. Note that multiplication of a conditional consequence probability by the accident probability per port call, rather than the source term probability per port call, is not correct, as many ship collisions will not lead to releases of radioactivity. Thus, the probability of occurrence per port call of any mean consequence is simply the source term probability per port call. For non-zero results, for consequence quantiles, and for the 
largest consequence found for any single weather trail (the peak result), the absolute probability of occurrence per port call of the listed result is the product of the source term probability per port call and either the probability of the non-zero result, the quantile probability, or the probability of the peak result.

Abbreviations. All of the archival tables use the following abbreviations.

\begin{tabular}{|l|c|}
\hline \multicolumn{1}{|c|}{ Original 14 Ports } & Abbreviation \\
\hline Charleston, SC & CHA \\
Concord (San Francisco, CA) & CNC \\
Galveston, TX & GAL \\
Jacksonville, FL & JAC \\
Long Beach, CA & LOS \\
MOTSU (Wilmington, NC) & MOT \\
Newark, NJ & NEW \\
Norfolk, VA & NOR \\
Philadelphia, PA & PHI \\
Portland, OR & POR \\
Savannah, GA & SAV \\
Seattle, WA & SEA \\
Tacoma, WA & TAC \\
Wilmington, NC & WIL \\
\hline \multicolumn{1}{|c|}{ Additional 9 Military Ports } & Abbreviation \\
\hline Bremerton, WA & BRE \\
Everett, WA & EVE \\
Port Hadlock, WA & HAD \\
Port Hueneme, CA & HUE \\
Mayport, FL & MAY \\
Pensacola, FL & PEN \\
Kings Bay, GA & KIN \\
Charleston Naval Reservation, SC & CHN \\
Yorktown, VA & YOR \\
\hline \multicolumn{1}{|c|}{ Variable Meteorology File } & Abbreviation \\
\hline Apalachicola, FL & APA \\
Cape Hatteras, NC & CAP \\
Charleston, SC & CHA \\
Lake Charles, LA & LAK \\
New York, NY & NYC \\
Santa Maria, CA & SAN \\
Seattle, WA & SEA \\
Washington, DC & WAS \\
\hline
\end{tabular}




\section{UNLIMITED RELEASE DISTRIBUTION}

1 United States Department of Energy Office of Scientific \& Technical Information

Attn: DOE/OSTI-4500-R74 UC722

Oak Ridge, TN 37830

1 United States Department of Energy Routing GC-11

Attn: J. Sweeney 1000 Independence $S W$

Washington, DC 20585

1 United States Department of Energy Routing EM-37

Attn: C. Head 1000 Independence SW

Washington, DC 20585

1 United States Department of Energy

Routing EM-60

Attn: D. Huizenga

1000 Independence SW

Washington, DC 20585

8 United States Department of Energy Routing EM-76

Attn: R. Brancato

M. Carter

M. Conroy

A. Kapoor

M. Keane

J. Holm

E. McNeil

M. Wangler

19901 Germantown Road

Germantown, MD 20874-1290

3 United States Department of Energy

Attn: J. Williams, RW-321

W. Lake, RW-323

C. Kouts, RW-323

Washington, DC 20545
1 United States Department of Energy

Albuquerque Operations Office

Albuquerque Headquarters

Attn: Porter Grace

P.O. Box 5400

Albuquerque, NM 87115

1 United States Department of Transportation

Attn: R. Boyle

Hazardous Materials Safety

400 7th St. NW

Washington, DC 20590

1 United States Nuclear Regulatory

Commission

Nuclear Material Safety \& Safeguards

Attn: E. Easton

11545 Rockville Pike

Rockville, MD 20852

1 A. J. Cappeto

Environmental Protection Specialist

Military Sealift Command, Atlantic

Military Ocean Terminal, Bldg. 42-4

Bayonne, NJ 07002

1 Dr. S. Y. Chen

Environmental Assessment Division

Building 900

Argonne National Laboratory

9700 South Cass Avenue

Argonne, IL 60439-4832

1 S. M. Dalton

Senior Marine Underwriter

Atlantic Mutual Companies

195 Broadway

New York, NY 10007

1 CDR C. R. Dempsey, USNR

Officer-in-Charge

Department of Naval Science

U.S. Merchant Marine Academy

Kings Point, NY 11024-1699 
1 M. Ebert

SAIC

20201 Century Blvd.

Germantown, MD 20874

1 D. Gallagher

SAIC

1151 Roger Bacon Dr.

Reston, VA 22090

1 B. Hall

Damage Control Officer

Military Sealift Command, Atlantic

Military Ocean Terminal, Bldg. 42-4

Bayonne, NJ 07002

1 J. D. Johnson

GRAM Incorporated

8500 Menaul Blvd. NE

Albuquerque, NM 87111

1 LCDR P. Mucciarone, USN

Assistant Officer-in-Charge

Department of Naval Science

U.S. Merchant Marine Academy

Kings Point, NY 11024-1699

1 E. P. Pfersich

Chief, Packaged Cargo Section

Hazardous Materials Branch

United States Coast Guard

2100 Second St. SW

Washington, DC 20593

1 P. C. Reardon

PCR Technologies

8416 Yeager Dr. NE

Albuquerque, NM 87109

1 CDR T. Rice, USCG

Department of Marine Transportation

U.S. Merchant Marine Academy

Kings Point, NY 11024-1699

1 Capt. R. Stewart, USMS

Head, Department of Transportation

U.S. Merchant Marine Academy

Kings Point, NY 11024-1699
1 Capt. P. Walter, USMS

Head, Department of Shipboard Training and Director of Continuing Education

U.S. Merchant Marine Academy

Kings Point, NY 11024-1699

SANDIA NATIONAL LABORATORIES, INTERNAL DISTRIBUTION

1 MS0724 J. B. Woodard, 6000

$1 \mathrm{MS0724}$ J. A. Rice, 6600

$1 \mathrm{MS} 0720$

$1 \mathrm{MS0720}$

C. D. Massey, 6624

T. A. Wheeler, 6624

1 MS0718

1 MSO718

1 MS0718

S. B. Bespalko, 6641

G. S. Mills, 6641

S. K. Neuhauser, 6641

10 MS0718

$1 \mathrm{MS0718}$

$1 \mathrm{MS} 0717$

1 MS0717

J. L. Sprung, 6641

H. R. Yoshimura, 6641

D. J. Ammerman, 6642

1 MS0717

G. F. Hohnstreiter, 6642

1 MS0717

1 MS0717

1 MS9018

5 MS0899

J. A. Koski, 6642

K. B. Sorenson, 6643

P. E. McConnell, 6643

Central Technical Files, 8523-2

2 MS0619
Technical Library, 4414

Review and Approval Desk, 12630, For DOE/OSTI 